\title{
EXPERIMENT DATA REPORT FOR SEMISCALE MOD-1 TEST S-06-6 (LOFT COUNTERPART TEST)
}

VICENTE ESPARZA

September 1977

MASTER

\section{EGгG Idaho, Inc.}




\section{DISCLAIMER}

This report was prepared as an account of work sponsored by an agency of the United States Government. Neither the United States Government nor any agency Thereof, nor any of their employees, makes any warranty, express or implied, or assumes any legal liability or responsibility for the accuracy, completeness, or usefulness of any information, apparatus, product, or process disclosed, or represents that its use would not infringe privately owned rights. Reference herein to any specific commercial product, process, or service by trade name, trademark, manufacturer, or otherwise does not necessarily constitute or imply its endorsement, recommendation, or favoring by the United States Government or any agency thereof. The views and opinions of authors expressed herein do not necessarily state or reflect those of the United States Government or any agency thereof. 


\section{DISCLAIMER}

Portions of this document may be illegible in electronic image products. Images are produced from the best available original document. 


\section{Printed in the United States of America} Available from

National Technical Information Service

U.S. Department of Commerce

5285 Port Royal Road

Springfield, Virginia 22161

Price: Printed Copy $\$ 8.00$; Microfiche $\$ 3.00$

$$
\text { \$ } 1 /, 00
$$

"The NRC will make available data tapes and operational computer codes on research programs dealing with postulated loss-of-coolant accidents in light water reactors. Persons requesting this information must reimburse the NRC contractors for their expenses in preparing copies of the data tapes and the operational computer codes. Requests should be submitted to the Research Applications Branch, Office of Nuclear Regulatory Research, Nuclear Regulatory Commission, Washington, D.C. 20555."

\section{NOTICE}

This report was prepared as an account of work sponsored by the United States Government. Neither the United States nor the Energy Research and Development Administration, nor the Nuclear Regulatory Commission, nor any of their employees, nor any of their contractors, subcontractors, or their employees, makes any warranty, express or implied, or assumes any legal liability or responsibility for the accuracy, completeness or usefulness of any information, apparatus, product or process disclosed, or represents that its use would not infringe privately owned rights. 
TREE-NUREG-1126

EXPERIMENT DATA REPORT FOR SEMISCALE MOD-1

TEST S-06-6

(LOFT COUNTERPART TEST)

Approved:
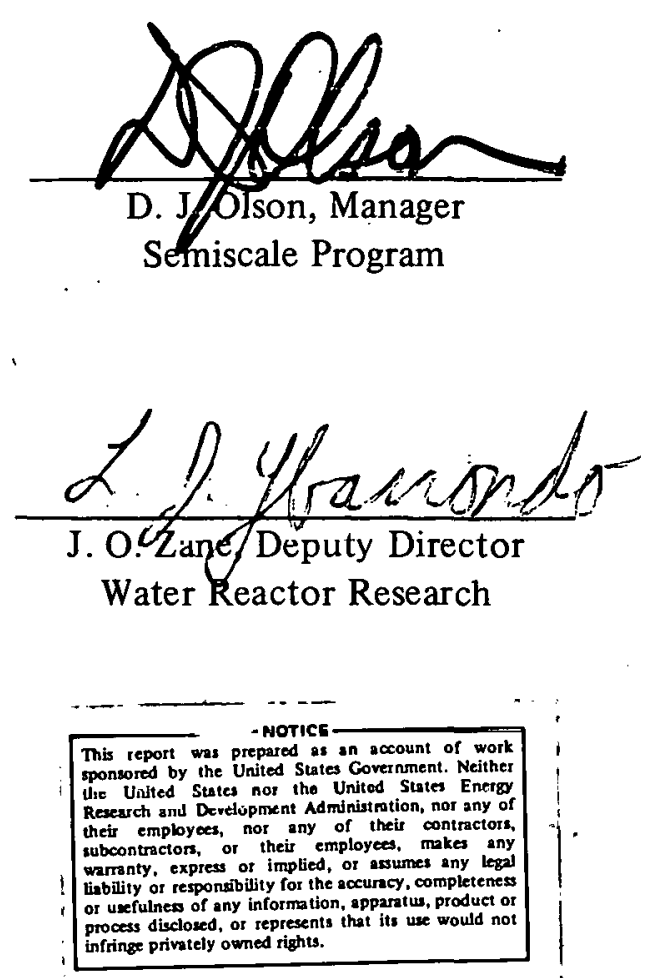


\title{
EXPERIMENT DATA REPORT FOR SEMISCALE MOD-1 \\ TEST S-06-6 \\ (LOFT COUNTERPART TEST)
}

\author{
By \\ Vicente Esparza \\ Kenneth E. Sackett
}

EG\&G IDAHO, INC.

September 1977

PREPARED FOR THE

U. S. NUCLEAR REGULATORY COMMISSION

AND

ENERGY RESEARCH AND DEVELOPMENT ADMINISTRATION

IDAHO OPERATIONS OFFICE

UNDER CONTRACT NO. EY-76-C-07-1570 


\begin{abstract}
Recorded test data are presented for Test S-06-6 of the Semiscale Mod-1 LOFT counterpart test serfes. These lests are among scveral Semiscale Mod-1 experiments conducted to investigate the thermal and hydraulic phenomena accompanying a hypothesized loss-of-coolant accident in a pressurized water reactor ( $\mathrm{PWR}$ ) system.

Test 3-06-6 was conducted from initial conditions of $1.5792 \mathrm{kPa}$ and $563 \mathrm{~K}$ to investigate 'the response of the Semiscale Mod-1 system to a depressurization and reflood transient following a simulated double-ended offset shear of the broken loop cold leg piping. During the test, cooling water was injected into the cold leg of the intact loop to simulate emergency core coolant injection in a PWR. The heater rods in the electrically heated core were operated at an axial peak power density which was $75 \%$ of the maximum peak power density $(52.5 \mathrm{~kW} / \mathrm{m})$. Test S-06-6 also evaluated the effect of special hardware assumptions on the core response.
\end{abstract}

The purpose of this report is to make available the uninterpreted data from Test S-06-6 for future data analysis and test results reporting activities. The data, presented in the form of graphs in engineering units, have been analyzed only to the extent necessary to ensure that they are reasonable and consistent. 


\section{SUMMARY}

Test S-06-6 was performed as part of the Semiscale Mod-1 portion of the Semiscale Program conducted by EG\&G Idaho, Inc. for the United States Government. This test is part of the LOFT counterpart test series (Test Series 6) performed to investigate the response of the Mod-1 system to specific variations in the peak power densities of the heater rods to assist the LOFT Program in the planning of the first LOFT nuclear test series. The test objective specific to Test S-06-6 was to determine the maximum cladding temperature associated with a high powered rod peak power density of $39.4 \mathrm{~kW} / \mathrm{m}$, or $75 \%$ of the maximum high powered rod peak power density of $52.5 \mathrm{~kW} / \mathrm{m}$. Test S-06-6 had the additional objective of evaluating the effect of special hardware assumptions on the core response. Hardware configuration and test parameters were selected to yield a system response that simulates the response of the LOFT nuclear facility during the first nuclear test series.

Test S-06-6 utilized the Semiscale Mod-1 system equipped with a pressure vessel with a 40-rod electrically heated core; an intact loop with pump, steam generator, and pressurizer; a broken loop with simulated pump, simulated steam generator, simulated reflood bypass lines, LOFT counterpart nozzles, and rupture assemblies; and a pressure suppression system with header, pressure suppression tank, and heated steam supply system. High and low pressure coolant injection pumps and a coolant injection accumulator were provided for the intact loop. For Test S-06-6, four heater rods were intentionally unpowered to simulate LOFT passive rod locations and the power in four heater rods was increased by $5 \%$ over the surrounding rods to produce a peaked power profile.

The test was conducted from initial conditions of $15792 \mathrm{kPa}$ and $563 \mathrm{~K}$ (at the intact loop cold leg vessel inlet) with a simulated full size (200\%) double-ended offset shear of the broken loop cold leg piping at an initial core power level of $1002 \mathrm{~kW}$, and an initial core inlet flow rate of $6.62 \mathrm{l} / \mathrm{s}$. The instantaneous offset shear of the broken loop cold leg piping was simulated by simultaneous (within $10 \mathrm{~ms}$ ) actuation of the rupture assemblies. After initiation of blowdown, power to the heated core was reduced to simulate the predicted heat flux response of nuclear fuel rods during a loss-of-coolant accident. Blowdown was accompanied by simulated emergency core coolant injection into the cold leg piping of the intact loop.

Test S-06-6 was generally conducted as specified. Conditions which did not conform to the specified test configuration were considered acceptable for analysis purposes within the test objectives. The instrumentation used generally functioned as intended. Of 229 measurements taken, 224 produced usable data. 


\section{CONTENTS}

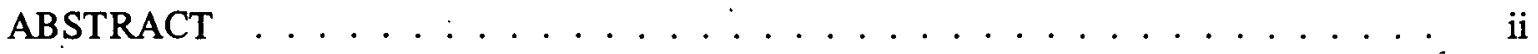

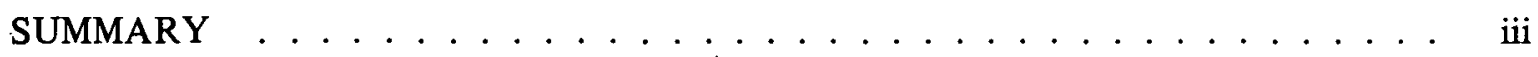

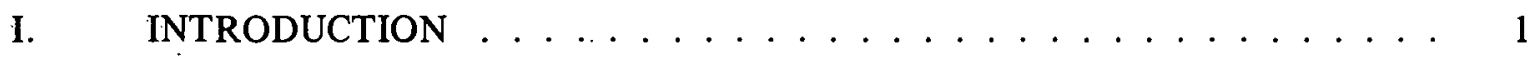

II. SYSTEM, PROCEDURES, CONDITIONS, AND

EVENTS FOR TEST S-06-6 . . . . . . . . . . . . . . . . 2

1. SYSTEM CONFIGURATION AND

TEST PROCEDURES . . . . . . . . . . . . . . . . 2

2. INIIIAL IESII CUNUITIONNS AND

SEQUENCE OF EVENTS . . . . . . . . . . . . . . 5

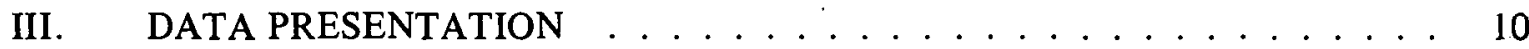

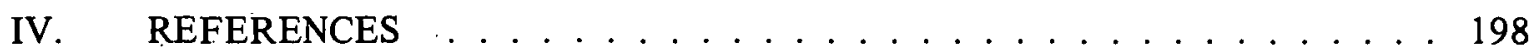

APPENDIX A - POSTTEST ADJUSTMENTS TO DATA FROM

SEMISCALE MOD-1 TEST S-06-6 . . . . . . . . . . . . . . . 199

1. PRESSURE MEASUREMENTS . . . . . . . . . . . . . . 201

2. DIFFERENTIAL PRESSURE MEASUREMENTS . . . . . . . 202

3. MOMENTUM FLUX MEASUREMENT . . . . . . . . . . . . 204

4. DENSITYMEASUREMENTS . . . . . . . . . . . 207

APPENDIX B - SELECTED DATA WITH ESTIMATED TOTAL

ERROR BANDS FROM SEMISCALE MOD-1 TEST S-06-6 . . . . . . . . 211

\section{FIGURES}

1. Semiscale Mod-1 system for cold leg break

configuration - isometric $\ldots \ldots \ldots \ldots$. . . . . . . . . . 3

2. Semiscale Mod-1 system for cold leg break

configuration - schematic . . . . . . . . . . . . . . . . . 4 
3. Semiscale Mod-1 system and instrumentation for cold leg break configuration - isometric

4. Semiscale Mod-1 system and instrumentation for

cold leg break configuration - schematic

5. Semiscale Mod-1 pressure vessel - cross

section showing instrumentation

6. Semiscale Mod-1 pressure vessel - isometric

showing instrumentation

7. Semiscale Mod-1 pressure vessel - penetrations

and instrumentation .................... 15

8. Semiscale Mod-1 heated core - plan view . . . . . . . . . . . 16

9. Fluid temperature in intact loop hot leg

(TFU-1 and RBU-2), from -20 to $200 \mathrm{~s}$

10. Fluid temperature in intact loop hot leg

(TFU-1 and RBU-2), from -6 to $42 \mathrm{~s}$

11: Fluid temperature in intact loop cold leg

(TFU-7 and TFU-10), from -20 to $200 \mathrm{~s} \ldots \ldots . . \ldots 28$

12. Fluid temperature in in tact loop cold leg

(TFU-7 and TFU-10), from -6 to $42 \mathrm{~s}$

13. Fluid temperature in intact loop cold leg

(RBU-14A, TFU-14B, and TFU-15), from -20 to $200 \mathrm{~s} \ldots \ldots 29$

14. Fluid temperature in intact loop cold leg

(RBU-14A, TFU-14B, and TFU-15), from -6 to $42 \mathrm{~s} \ldots \ldots . . . . . . .29$

15. Fluid temperature in broken loop, vessel side

(TFB-20, TFB-23, and TFB-24), from -20 to $200 \mathrm{~s} \ldots \ldots 30$

16. Fluid temperature in broken loop, vessel side

(TFB-20, TFB-23, and TFB-24), from -6 to $42 \mathrm{~s}$

17. Fluid temperature in broken loop, pump side

(TFB-30, TFB-37, TFB-42, and TFB-43), from -20 to $200 \mathrm{~s}$

18. Fluid temperature in broken loop, pump side

(TFB-30, TFB-37, TFB-42, and TFB-43), from -6 to $42 \mathrm{~s}$ 
19. Fluid temperature in broken loop, reflood bypass simulators

(TFB-RFB-C and TFB-RFB-H), from -20 to $200 \mathrm{~s} \ldots \ldots \ldots \ldots . \ldots 32$

20. Fluid temperature in broken loop, reflood bypass simulators

(TFB-RFB-C and TFB-RFB-H), from -6 to $42 \mathrm{~s} \ldots \ldots \ldots \ldots \ldots$

21. Fluid temperature in inlet annulus (TFV-ANN-4A and TFV-ANN-4M), from -20 to $200 \mathrm{~s} \ldots \ldots \ldots \ldots \ldots$

22. Fluid temperature in inlet annulus (TFV-ANN-4A and TFV-ANN-4M), from -6 to $42 \mathrm{~s} \ldots \ldots \ldots \ldots \ldots$

23. Fluid temperature in downcomer annulus (TFV-ANN-15T, TFV-ANN-35A, TFV-ANN-35T, and TFV-ANN-70A), from -20 to $200 \mathrm{~s} \ldots \ldots \ldots \ldots \ldots \ldots \ldots$

24. Fluid temperature in downcomer annulus (TFV-ANN-15T, TFV-ANN-35A, TFV-ANN-35T, and TFV-ANN-70A), from -6 to $42 \mathrm{~s} \ldots \ldots \ldots \ldots \ldots \ldots \ldots \ldots \ldots$

25. Fluid temperature in downcomer annulus (TFV-ANN-115A, TFV-ANN-115M, and TFV-ANN-156A), from -20 to $200 \mathrm{~s}$

26. Fluid temperature in downcomer annulus (TFV-ANN-115A, TFY-ANN-1 15M, and TFV-ANN-156A), from -6 to $42 \mathrm{~s}$

27. Fluid temperature in upper plenum (TFV-UP+13),

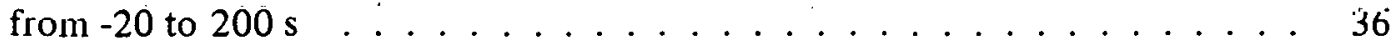

28. Fluid temperature in upper plenum (TFV-UP+13), from -6 to $42 \mathrm{~s} \ldots \ldots \ldots \ldots \ldots \ldots \ldots \ldots \ldots$

29. Fluid temperature in lower plenum (TFV-LP-8, TFV-L_P-15, and TFV-I.P-2.?), frnm -20 to $200 \mathrm{~s}$

30. Fluid temperature in lower plenum (TFV-LP-8, TFV-LP-15, and TFV-I.P-2,2), from 6 to $42 \mathrm{~s} \ldots \ldots \ldots, \ldots \ldots, \ldots, \ldots$

31. Fluid temperature in core inlet (TFV-CORE-IN), from -20 to $200 \mathrm{~s} \ldots \ldots \ldots \ldots \ldots \ldots \ldots$

32. Fluid temperature in çore inlet (TFV-CORE-IN), from -6 to $42 \mathrm{~s} \ldots \ldots \ldots \ldots \ldots \ldots \ldots \ldots \ldots$

33. Fluid temperature in core, Grid Spacer 5 (TFG-5CD-45), from -20 to $200 \mathrm{~s} \ldots \ldots \ldots \ldots \ldots$ 
34. Fluid temperature in core, Grid Spacer 5 (TFG-5CD-45), from -6 to $42 \mathrm{~s}$

35. Fluid temperature in core, Grid Spacer 6 (TFG-6CD-45

and TFG-6DE-67), from -20 to $200 \mathrm{~s} \ldots \ldots \ldots \ldots$. . . . . . 40

36. Fluid temperature in core, Grid Spacer 6 (TFG-6CD-45

and TFG-6DE-67), from -6 to $42 \mathrm{~s} \ldots \ldots \ldots \ldots$

37. Fluid temperature in core, Grid Spacer 10 (TFG-10AB-45

and TFG-10GH-45), from -20 to $200 \mathrm{~s} \ldots \ldots \ldots \ldots$. . . . . . 41

38: Fluid temperature in corc, Grid Spacer 10 (TFG-10AB-45

and TFG-10GH-45), from -6 to $42 \mathrm{~s} \ldots \ldots \ldots \ldots . \ldots . \ldots 41$

39. Fluid temperature in intact loop coolant injection

line (TFU-ECC-14), from -20 to $200 \mathrm{~s} \ldots \ldots \ldots \ldots$. . . . . . 42

40. Fluid temperature in intact loop coolant injection

line (TFU-ECC-14), from -6 to $42 \mathrm{~s} \ldots \ldots \ldots \ldots . \ldots \ldots 42$

41. Fluid temperature in steam generator, feedwater

line (TFU-SGFW), from -20 to $200 \mathrm{~s} \ldots \ldots \ldots \ldots$

42. Fluid temperature in steam generator, feedwater

line (TFU-SGFW), from -6 to $42 \mathrm{~s} \ldots \ldots \ldots \ldots \ldots$

43. Fluid temperature in steam generator, secondary

side (TFU-SGSD), from -20 to $200 \mathrm{~s} \ldots \ldots \ldots \ldots \ldots$. . . . . . 44

44. Fluid temperature in steam generator, secondary

side (TFU-SGSD), from -6 to $42 \mathrm{~s} \ldots \ldots \ldots \ldots$. . . . . . . . . . 44

45. Fluid temperature in steam generator, secondary side

(TFU-SG1, TFU-SG3, and TFU-SG4), from -20 to $200 \mathrm{~s}$

46. Fluid temperature in steam generator, secondary side

(TFU-SG 1, TFU-SG3, and TFU-SG4), from -6 to $42 \mathrm{~s}$

47. Fluid temperature in pressurizer surge line (TFU-PRIZE),

from -20 to $200 \mathrm{~s} \ldots \ldots \ldots \ldots \ldots \ldots$. . . . . . . . . . .

48. Fluid temperature in pressurizer surge line (TFU-PRIZE),

from -6 to $42 \mathrm{~s} \ldots \ldots \ldots \ldots \ldots \ldots \ldots \ldots \ldots \ldots$ 
49. Fluid temperature in pressure suppression tank.

(TF-PSS-33, TF-PSS-63, and TF-PSS-130),

from -20 to $200 \mathrm{~s}$

50: $\quad$ Fluid temperature in pressure suppression tank

(TF-PSS-33, TF-PSS-63, and TF-PSS-130),

from -6 to $42 \mathrm{~s} \ldots \ldots \ldots \ldots . \ldots \ldots$. . . . . . . . . . . . . 47

51. Material temperature in intact loop (TMU-1T16

and TMU-15T 16), from -20 to $200 \mathrm{~s} \ldots \ldots . \ldots 48$

52. Material temperature in intact loop (TMU-1'1'16

and TMU-15T16), from -6 to $42 \mathrm{~s} \ldots \ldots$. . . . . . . . . . . . 48

53. Material temperature in broken loop (TMB-20B 16

and TMB-30B 16), from -20 to $200 \mathrm{~s}$. . . . . . . . . . . . . . . . 49

54. Material temperature in broken loop (TMB-20B16

and TMB-30B 16), from -6 to $42 \mathrm{~s} \ldots \ldots . \ldots . \ldots . . \ldots 49$

55. Material temperature in vessel filler

(TMV-FI-115A), from -20 to $200 \mathrm{~s} \quad \ldots \ldots \ldots \ldots$. . . . . . . 50

56. Material temperature in vessel filler

(TMV-FI-1 15A), from -6 to $42 \mathrm{~s} \ldots \ldots \ldots 50$

57. Material temperature in core barrel inner diameter

(TMV-CI-35A), from -20 to $200 \mathrm{~s} \ldots \ldots . \ldots 51$

58. Material temperature in core barrel inner diameter

(TMV-CI-35A), from -6 to $42 \mathrm{~s} \ldots \ldots \ldots . \ldots . \ldots 51$

59. Core heater temperature, Rod D-4 (TH-D4-14

and TH-D4-29), from -20 to $200 \mathrm{~s} \ldots \ldots . \ldots 52$

60. Core heater temperature, Rod D-4 (TH-D4-14

and TH-D4-29), from $=6$ to $42 \mathrm{~s} \ldots \ldots \ldots \ldots$

61. Core heater temperature, Rod D-5 (TH-D5-09,

TH-D5-29, and TH-D5-39), from -20 to $200 \mathrm{~s} \ldots \ldots \ldots$. . . . . . 53

62. Core heater temperature, Rod D-5 (TH-D5-09,

TH-D5-29, and TH-D5-39), from -6 to $42 \mathrm{~s}$

63. Core heater temperature, Rod E-4 (TH-E4-09,

TH-E4-27, and TH-E4-55), from -20 to $200 \mathrm{~s}$ 
64. Core heater temperature, Rod E-4 (TH-E4-09, TH-E4-27, and TH-E4-55), from -6 to $42 \mathrm{~s} \ldots \ldots \ldots \ldots$. . . . . . 54

65. Core heater temperature, Rod E-5 (TH-E5-21), from -20 to $200 \mathrm{~s}$. . . . . . . . . . . . . . . . . 55

66. Core heater temperature, Rod E-5 (TH-E5-21), from -6 to $42 \mathrm{~s} \ldots \ldots \ldots \ldots \ldots \ldots \ldots \ldots \ldots$

67. Core heater temperature, Rod A-4 (TH-A4-09 and TH-A4-29), from -20 to $200 \mathrm{~s} \ldots \ldots \ldots \ldots 56$

68. Core heater temperature, Rod A-4 (TH-A4-09 , and TH-A4-29), from -6 to $42 \mathrm{~s} \ldots \ldots \ldots \ldots \ldots$

69. Core heater temperature, Rod A-5 (TH-A5-29 and TH-A5-45), from -20 to $200 \mathrm{~s} \ldots \ldots \ldots \ldots$. . . . . . . . 57

70. Core heater temperature, Rod A-5 (TH-A5-29 and TH-A5-45), from -6 to $42 \mathrm{~s}$

71. Core heater temperature, Rod B-3 (TH-B3-32), from -20 to $200 \mathrm{~s} \ldots \ldots \ldots \ldots \ldots$. . . . . . . . 58

72. Core heater temperature, Rod B-3 (TH-B3-32), from -6 to $42 \mathrm{~s}$

73. Core heater temperature, Rod B-5 (TH-B5-29 and TH-B5-33), from -20 to $200 \mathrm{~s}$

74. Core heater temperature, Rod B-5 (TH-B5-29 and TH-B5-33), frum -6 lo $42 \mathrm{~s}$

75. Core heater temperature, Rod B-6 (TH-B6-14 and TH-B6-29), from -20 to $200 \mathrm{~s}$

76. Core heater temperature, Rod B-6 (TH-B6-14 and TH-B5-29), from -6 to $42 \mathrm{~s}$ 60

77. Core heater temperature, Rod C-2 (TH-C2-28 and TH-C2-38), from -20 to $200 \mathrm{~s}$

78. Core heater temperature, Rod C-2

(TH-C2-28 and TH-C2-38), from -6 to $42 \mathrm{~s}$ 
79. Core heater temperaturc, Rod C-3

(TH-C3-60), from -20 to $200 \mathrm{~s}$

80. Core heater temperature, Rod C-3

(TH-C3-60), from -6 to $42 \mathrm{~s} \ldots \ldots \ldots 2$

81. Core heater temperature, Rod $\mathrm{C}-4$

(TH-C4-20 and TH-C4-26), from -20 to $200 \mathrm{~s} \ldots \ldots 63$

82. Core heater temperature, Rod C-4

(TH-C4-20 and TH-C4-26), from -6 to $42 \mathrm{~s} \ldots \ldots$. . . . . . . . . . 63

83. Core heater temperature, Rod C-5

(TH-C5-28), from -20 to $200 \mathrm{~s} \ldots \ldots$. . . . . . . . . . 64

84. Core heater temperature, Rod C-5

(TH-C5-28), from -6 to $42 \mathrm{~s} \ldots \ldots . \ldots$. . . . . . . . . . 64

85. Core heater temperature, Rod C-6 (TH-C6-32

and TH-C6-53), from -20 to $200 \mathrm{~s} \ldots \ldots \ldots 5$

86. Core heater temperature, Rod C-6 (TH-C6-32

and TH-C6-53), from -6 to $42 \mathrm{~s} \ldots \ldots$. . . . . . . . . . . 65

87. Core heater temperature, Rod C-7 (TH-C7-07

and $\mathrm{TH}-\mathrm{C} 7-15)$, from -20 to $200 \mathrm{~s} \ldots \ldots 66$

88. Core heater temperature, Rod C-7 (TH-C7-07

and TH-C7-15), from -6 to $42 \mathrm{~s} \ldots \ldots \ldots 6$

89. Core heater temperature, Rod D-1

(TH-D 1-21), from -20 to $200 \mathrm{~s} \ldots \ldots$. . . . . . . . . . 67

90. Corre heater temperature, Rod D-1

-(TH-D1-21), from -6 to $42 \mathrm{~s} \ldots \ldots \ldots$. . . . . . . . . 67

91. Corc heatcr temperature, Rod D-2.(TH D2 14

and TH-D2-61), from -20 to $200 \mathrm{~s} \ldots \ldots$. . . . . . . . . 68

92. Core heater temperature, Rod D-2 (TH-D2-14

and TH-D2 61), from -6 to $42 \mathrm{~s} \ldots \ldots 68$

93. Core heater temperature, Rod D-3 (TH-D3-29, TH-D3-33, and TH-D3-39), from -20 to $200 \mathrm{~s} \ldots \ldots \ldots$. . . . . . . . 
94. Core heater temperature, Rod D-3 (TH-D3-29, TH-D3-33,

and TH-D3-39), from -6 to $42 \mathrm{~s} \ldots \ldots$. . . . . . . . . . . 69

95. Core heater temperature, Rod D-7

(TH-D7-20), from -20 to $200 \mathrm{~s}$

96. Core heater temperature, Rod D-7

(TH-D7-20), from -6 to $42 \mathrm{~s} \ldots \ldots \ldots \ldots$. . . . . . . . . . 70

97. Core heater temperature, Rod D-8

(TH-D8-57), from -20 to $200 \mathrm{~s} \ldots \ldots \ldots 71$

98. Core heater temperature, Rod D-8

(TH-D8-57), from -6 to $42 \mathrm{~s} \ldots \ldots \ldots 71$

99. Core heater temperature, Rod E-1

(TH-E1-33), from -20 to $200 \mathrm{~s} \ldots \ldots \ldots 72$

100. Core heater temperature, Rod E-1

(TH-E1-33), from -6 to $42 \mathrm{~s} \ldots \ldots \ldots \ldots$. . . . . . . . . . . . . . .

101. Core heater temperature, Rod E-2 (TH-E2-20

and TH-E2-33), from -20 to $200 \mathrm{~s} \ldots \ldots \ldots 73$

102. Core heater temperature, Rod E-2 (TH-E2-20

and TH-E2-33), from -6 to $42 \mathrm{~s} \ldots \ldots . \ldots 73$

103. Core heater tempcrature, Rod E-3

(TH-E3-24), from -20 to $200 \mathrm{~s} \ldots \ldots \ldots$. . . . . . . . . . 74

104. Core heater temperature, Rod E-3

(TH-E3-21), from -6 to $42 \mathrm{~s} \ldots \ldots \ldots$. . . . . . . . . . 74

105. Core heater temperature, Rod E-6 (TH-E6-08,

TH-E6-28, and TH-E6-37), from -20 to $200 \mathrm{~s} \ldots \ldots . \ldots 75$

106. Core heater temperature, Rod E-6 (TH-E6-08,

TH-E6-28, and TH-E6-37), from -6 to $42 \mathrm{~s} \ldots \ldots \ldots$. . . . . . . 75

107. Core heater temperature, Rod E-7 (TH-E7-13

and TH-E7-44), from -20 to $200 \mathrm{~s} \ldots \ldots \ldots$. . . . . . . . 76

108. Core heater temperature, Rod E-7 (TH-E7-13

and TH-E7-44), from -6 to $42 \mathrm{~s}$ 
109. Core heater temperature, Rod E-8 (TH-E8-14, TH-E8-29, and TH-E8-45), from -20 to $200 \mathrm{~s}$

110. Core heater temperature, Rod E-8 (TH-E8-14, TH-E8-29, and TH-E8-45), from -6 to $42 \mathrm{~s}$

111. Core heater temperature, Rod F-2 (TH-F2-07, TH-F2-22, and TH-F2-25), from -20 to 200 s

112. Core heater temperature, Rod F-2 (TH-F2-07, TH-F2-22, and TH-F2-25), from -6 to $42 \mathrm{~s}$

113. Core heater temperaturc, Rod F-3 (TH-F3-06, TH-F3-22, and TH-F3-25), from -20 to $200 \mathrm{~s}$

114. Core heater temperature, Rod F-3 (TH-F3-06, TH-F3-22, and TH-F3-25), from -6 to $42 \mathrm{~s}$

115. Core heater temperature, Rod F-4 (TH-F4-14, TH-F4-29, and TH-F4-44), from -20 to $200 \mathrm{~s}$

116. Core heater temperature, Rod F-4 (TH-F4-14, TH-F4-29, and TH-F4-44), from -6 to $42 \mathrm{~s}$

117. Core heater temperature, Rod F-5 (TH-F5-20 and TH-F5-26), from -20 to $200 \mathrm{~s} \ldots \ldots \ldots 1$

118. Core heater temperature, Rod F-5 (TH-F5-20 and TH-F5-26), from -6 to $42 \mathrm{~s}$

119. Core heater temperature, Rod F-6 (TH-F6-08 and TH-F6-28), from -20 to $200 \mathrm{~s} \ldots \ldots . \ldots 82$

120. Core heater temperature, Rod F-6 (TH-F6-08 and TH-F6-28), from -6 to $42 \mathrm{~s}$

121. Core heater temperaturc, Rod G-3

(TH-G3-13), from -20 to $200 \mathrm{~s}$

122. Core heater temperature, Rod G-3 (TII-G3-13), from -6 to $42 \mathrm{~s}$

123. Core heater temperature, Rod G-4 (TH-G4-29, TH-G4-33, and TH-G4-38), from -20 to $200 \mathrm{~s}$ 
124. Core heater temperature, Rod G-4 (TH-G4-29, TH-G4-33, and TH-G4-38), from -6 to $42 \mathrm{~s}$

125. Core heater temperature, Rod G-5 (TH-G5-14 and TH-G5-24), from -20 to $200 \mathrm{~s}$

126. Core heater temperature, Rod G-5 (TH-G5-14 and TH-G5-24), from -6 to $42 \mathrm{~s}$

127. Core heater temperature, Rod H-5, (TH-H5-32), from -20 to $200 \mathrm{~s}$

128. Core heater temperature, Rod H-5, (TH-H5-32), from -6 to $42 \mathrm{~s}$

129. Pressure in intact loop (PU-13 and PU-15L), from -20 to $200 \mathrm{~s}$

130. Pressure in intact loop (PU-13 and PU-15L), from -6 to $42 \mathrm{~s}$

131. Pressure in broken loop, vessel side (PB-21, PB-23, and PB-24), from -20 to $200 \mathrm{~s}$

132. Pressure in broken loop, vessel side (PB-21, PB-23, and PB-24), from -6 to $42 \mathrm{~s}$

133. Pressure in broken loop, pump side (PB-30, $\mathrm{PB}-42$, and PB-43), from -20 to $200 \mathrm{~s}$

134. Pressure in broken loop, pump side (PB-30, PB-42, and PB-43), fromi -6 lu $42 \mathrm{~s}$

135. Pressure in broken loop, vessel side (PB-CN1), from -20 to $200 \mathrm{~s}$

136. Pressure in broken loop, vessel side (PB-CN1), frum -6 lo 42 s

137. Pressure in vessel (PV-UP+1U and PV-LP-180), from -20 to $200 \mathrm{~s}$

138. Pressure in vessel (PV-UP+10 and PV-LP-180), from -6 to $42 \mathrm{~s}$ 
139. Pressure in intact loop accumulator (PU-ACC), from -20 to $200 \mathrm{~s}$

140. Pressure in intact loop accumulator

(PU-ACC), from -6 to $42 \mathrm{~s} \ldots \ldots \ldots \ldots \ldots$

141. Pressure in steam generator, secondary side

(PU-SGSD), from -20 to $200 \mathrm{~s} \ldots \ldots . \ldots . \ldots 93$

142. Pressure in steam generator, secondary side

(PU-SGSD), from -6 to $42 \mathrm{~s} \ldots \ldots \ldots \ldots . \ldots \ldots$

143. Pressure in pressurizer (PU-PRIZE),

from -20 to $200 \mathrm{~s}$

144. Pressure in pressurizer (PU-PRIZE),

from -6 to $42 \mathrm{~s} \ldots \ldots \ldots \ldots$. . . . . . . . . . . . . . 94

145. Pressure in pressure suppression tank (P-PSS), from -20 to $200 \mathrm{~s} \ldots \ldots \ldots \ldots$

146. Pressure in pressure suppression tank

(P-PSS), from -6 to $42 \mathrm{~s} \ldots \ldots \ldots 95$

147. Differential pressure in intact loop

(DPU-UP-3), from -20 to $200 \mathrm{~s} \ldots \ldots . \ldots . \ldots 96$

148. Differential pressure in intact loop

(DPU-UP-3), from -6 to $42 \mathrm{~s} \ldots \ldots \ldots$. . . . . . . . . . 96

149. Differential pressure in in tact loop

(DPU-3-6), from -20 to $200 \mathrm{~s} \ldots \ldots . \ldots 97$

150. Differential pressure in intact loop

(DPU-3-6), from -6 to $42 \mathrm{~s} \ldots \ldots \ldots 97$

151. Differential pressure in intact loop

(DPU-6-SGIP), from -20 to $200 \mathrm{~s} \ldots \ldots \ldots \ldots$

152. Differential pressure in intact loop

(DPU-6-SGIP), from -6 to $42 \mathrm{~s} \ldots \ldots \ldots$. . . . . . . . . . 98

153. Differential pressure in intact loop

(DPU-6-7), from -20 to $200 \mathrm{~s} \ldots \ldots . \ldots . \ldots . \ldots 99$ 
154. Differential pressure in intact loop

(DPU-6-7), from -6 to $42 \mathrm{~s} \ldots \ldots \ldots . \ldots . \ldots 99$

155. Differential pressure in intact loop

(DPU-SGOP-7), from -20 to $200 \mathrm{~s}$. . . . . . . . . . . . . 100

156. Differential pressure in intact loop

(DPU-SGOP-7), from -6 to $42 \mathrm{~s} \ldots \ldots . \ldots 100$

157. Differential pressure in intact loop

(DPU-7-10), from -20 to $200 \mathrm{~s} \ldots \ldots \ldots 10 . \ldots \ldots$

158. Differential pressure in intact loop

(DPU-7-10), from -6 to $42 \mathrm{~s} \ldots \ldots \ldots 10 . \ldots \ldots 1$

159. Differential pressure in intact loop

(DPU-12-10), from -20 to $200 \mathrm{~s} \ldots \ldots . . \ldots 102$

160. Differential pressure in intact loop

(DPU-12-10), from -6 to $42 \mathrm{~s} \ldots \ldots \ldots \ldots . \ldots \ldots 2$

161. Differential pressure in intact loop, low

range (DPU-12-10L), from -20 to $200 \mathrm{~s} \ldots \ldots . . \ldots 103$

162. Differential pressure in in tact loop, low

range (DPU-12-10L), from -6 to $42 \mathrm{~s} \ldots \ldots . \ldots 103$

163. Differential pressure in intact loop

(DPU-12-15), from -20 to $200 \mathrm{~s} \ldots \ldots$. . . . . . . . . . . 104

164. Differential pressure in in tact loop

(DPU-1 2-15), from -6 to $42 \mathrm{~s} \ldots \ldots . \ldots 104$

165. Differential pressure in intact loop

(DPU-15-3), from -20 to $200 \mathrm{~s} \ldots \ldots \ldots$. . . . . . . . . . 105

166. Differential pressure in intact loop

(DPU-15-3), from -6 to $42 \mathrm{~s} \ldots \ldots \ldots$. . . . . . . . . . . 105

167. Differential pressure in intact loop, low range (DPU-15-3L), from -20 to $200 \mathrm{~s} \ldots \ldots \ldots 106$

168. Differential pressure in intact loop, low range (DPU-15-3L), from -6 to $42 \mathrm{~s} \ldots \ldots . \ldots 106$ 
169. Differential pressure in in tact loop

(DPU-15-IANN), from -20 to $200 \mathrm{~s}$

170. Differential pressure in in tact loop

(DPU-1 5-IANN), from -6 to $42 \mathrm{~s}$

171. Differential pressure in intact loop

(DPU-PRESLL), from -20 to $200 \mathrm{~s}$

172. Differential pressure in intact loop

(DPU-PRESLL), from -6 to $42 \mathrm{~s} \ldots \ldots . \ldots$. . . . . . . . 108

173. Differential prescure in intact loop

(DPU-PR-4), from -20 to $200 \mathrm{~s}$

174. Differential pressure in intact loop

(DPU-PR-4), from -6 to $42 \mathrm{~s} \ldots \ldots . . \ldots$. . . . . . . . . 109

175. Differential pressure in broken loop

(DPB-21-IANN), from -20 to $200 \mathrm{~s}$

176. Differential pressure in broken loop

(DPB-21-IANN), from -6 to $42 \mathrm{~s} \ldots \ldots \ldots 110$

177. Differential pressure in broken loop

(DPB-21-23), from -20 to $200 \mathrm{~s}$

178. Differential pressure in broken loop

(DPB-21-23), from -6 to $42 \mathrm{~s}$

179. Differential pressure in broken loop

(DPB-23-CN1), from -20 to $200 \mathrm{~s}$

180. Differential pressure in broken loop

(DPB-23-CN1), from -6 to $42 \mathrm{~s}$

181. Differential preseure in broken loop

(DPB-23-24), from -20 to $200 \mathrm{~s}$

182. Differential pressure in broken loop

(DPB-23-24), from -6 to $42 \mathrm{~s}$

183. Differential pressure in broken loop

(DPB-30-36L), from -20 to $200 \mathrm{~s}$ 
184. Differential pressure in broken loop (DPB-30-36L), from -6 to $42 \mathrm{~s} \ldots \ldots \ldots \ldots 114$

185. Differential pressure in broken loop (DPB-30-38), from -20 to $200 \mathrm{~s}$

186. Differential pressure in broken loop

(DPB-30-38), from -6 to $42 \mathrm{~s}$

187. Differential pressure in broken loop

(DPB-32U-36L), from -20 to $200 \mathrm{~s}$

188. Differential pressure in broken loop

(DPB-32U-36L), from -6 to $42 \mathrm{~s}$

189. Differential pressure in broken loop

(DPB-38-40), from -20 to $200 \mathrm{~s}$

190. Differential pressure in broken loop

(DPB-38-40), from -6 to $42 \mathrm{~s}$

191. Differential pressure in broken loop

(DPB-40-42), from -20 to $200 \mathrm{~s}$

192. Differential pressure in broken loop

(DPB-40-42), from -6 to $42 \mathrm{~s}$

193. Differential pressure in broken loop

(DPB-42-43), from -20 to $200 \mathrm{~s}$

194. Differential pressure in broken loop

(DPB-42-43), from -6 to 42 s

195. Differential pressure in vessel

(DPV-UP-IANN), from -20 to $200 \mathrm{~s} \ldots \ldots$. . . . . . . . . 120

196. Differential pressure in vessel

(DPV-UP-IANN), from -6 to $42 \mathrm{~s} \ldots \ldots \ldots \ldots$

197. Differential pressure in vessel

(DPV-0-9GQ), from -20 to $200 \mathrm{~s}$

198. Differential pressure in vessel

(DPV-0-9GQ), from -6 to $42 \mathrm{~s}$.

xvii 
199. Differential pressure in vessel

(DPV-9-26QQ), from -20 to $200 \mathrm{~s} \ldots \ldots . \ldots . \ldots . \ldots 122$

200. Differential pressure in vessel

(DPV-9-26QQ), from -6 to $42 \mathrm{~s} \ldots \ldots \ldots \ldots . \ldots \ldots$

201. Differential pressure in vessel

(DPV-9-180QQ), from -20 to $200 \mathrm{~s} \ldots \ldots \ldots \ldots . \ldots \ldots$

202. Differential pressure in vessel

(DPV-9-180QQ), from -6 to $42 \mathrm{~s} \ldots \ldots \ldots \ldots$

203. Differential pressure in vessel

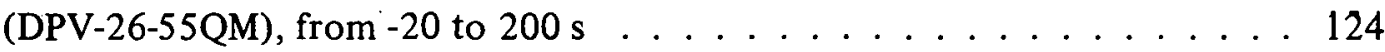

204. Differential pressure in vẹssel

(DPV-26-55QM), from -6 to $42 \mathrm{~s} \ldots \ldots \ldots \ldots . \ldots \ldots$

205. Differential pressure in vessel

(DPV-55-1 10MM), from -20 to $200 \mathrm{~s} \ldots \ldots \ldots . \ldots . \ldots . \ldots . \ldots 125$

206. Differential pressure in vessel

(DPV-55-110MM), from -6 to $42 \mathrm{~s} \ldots \ldots \ldots . \ldots 125$

207. Differential pressure in vessel

(DPV-110-156MQ), from -20 to $200 \mathrm{~s} \ldots \ldots \ldots 126$

208. Differential pressure in vessel

(DPV-1 10-156MQ), from -6 to $42 \mathrm{~s} \ldots \ldots \ldots 126$

209. Diffęrential pressure in vessel

(DPV-156-173QQ), from -20 to $200 \mathrm{~s} \ldots \ldots \ldots 127$

210. Differential pressure in vessel

(DPV-156-173QQ), from -6 to $42 \mathrm{~s} \ldots \ldots \ldots \ldots$. . . . . . . . . 127

211. Diffcrential pressüurc in vesscl

(DPV-166-192QT), from -20 to $200 \mathrm{~s} \ldots \ldots \ldots$. . . . . . . . . 128

212. Differential pressure in vessel

(DPV-166 192QT), from -6 to $42 \mathrm{~s} \ldots \ldots . \ldots \ldots$

213. Differential pressure in vessel

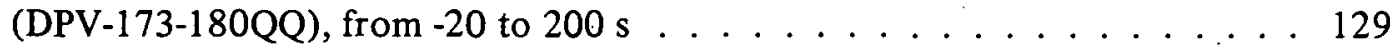


214. Differential pressure in vessel

(DPV-173-180QQ), from -6 to $42 \mathrm{~s}$. . . . . . . . . . . . . 129

215. Differential pressure in vessel

(DPV-LP-UP), from -20 to $200 \mathrm{~s} \ldots \ldots \ldots$. . . . . . . . . . 130

216. Differential pressure in vessel

(DPV-LP-UP), from -6 to $42 \mathrm{~s} \ldots \ldots \ldots$. . . . . . . . . . 130

217. Differential pressure in intact loop

accumulator (DPU-ACC-TB), from -20 to $200 \mathrm{~s} \ldots \ldots \ldots \ldots$. . . . . . 131

218. Differential pressure in intact loop

accumulator (DPU-ACC-TB), from -6 to $42 \mathrm{~s} \ldots \ldots \ldots 131$

219. Differential pressure across steam generator

feedwater orifice (DPU-SGFW), from -20 to $200 \mathrm{~s} \ldots \ldots$. . . . . . . 132

220. Differential pressure across steam generator

feedwater orifice (DPU-SGFW), from -6 to $42 \mathrm{~s} \ldots \ldots . . . \ldots 132$

221. Differential pressure in steam generator

secondary (DPU-SG-SEC), from -20 to $200 \mathrm{~s} \ldots \ldots . . . . . . . . .133$

222. Differential pressure in steam generator

secondary (DPU-SG-SEC), from -6 to $42 \mathrm{~s} \ldots \ldots \ldots$. . . . . . . . . 133

223. Differential pressure across steam generator outlet

orifice (DPU-SG-DISC), from -20 to $200 \mathrm{~s} \ldots \ldots$. . . . . . . . . . 134

224. Differential pressure across steam generator outlet .

orifice (DPU-SG DISC), from -6 to $42 \mathrm{~s} \ldots \ldots$. . . . . . . . . 134

225. Differential pressure in pressure suppression tank

(DP-PSS-TB), from -20 to $200 \mathrm{~s} \ldots \ldots \ldots . \ldots \ldots$

226. Differential pressure in pressure suppression tank

(DP-PSS-TB), from -6 to $42 \mathrm{~s} \ldots \ldots \ldots \ldots . \ldots \ldots$

227. Volumetric flow in intact loop (F"IU-1

and FTU-9), from -20 to $200 \mathrm{~s} \ldots \ldots . \ldots 136$

228. Volumetric flow in intact loop (FTU-1

and FTU-9), from -6 to $42 \mathrm{~s} \ldots \ldots \ldots \ldots$. . . . . . . . . . 136 
229. Volumetric flow in intact loop (FTU-13

and FTU-15), from -20 to $200 \mathrm{~s} \ldots \ldots \ldots$. . . . . . . . . . . . . .

230. Volumetric flow in intact loop (FTU-13

and FTU-15), from -6 to $42 \mathrm{~s} \ldots \ldots \ldots$. . . . . . . . . . 137

231. Volumetric flow in broken loop (FTB-21),

from -20 to $200 \mathrm{~s}$

232. Volumetric flow in broken loop (FTB-21),

from -6 to $42 \mathrm{~s}$

233. Volumetric flow in broken loop (FTB-30

and FTB-37), from -20 to $200 \mathrm{~s} \ldots \ldots \ldots$. . . . . . . . . . . . . . . .

234. Volumetric flow in broken loop (FTB-30

and FTB-37), from -6 to $42 \mathrm{~s} \ldots \ldots \ldots \ldots$

235. V.olumetric flow in core entrance

(FTV-CORE-IN), from -20 to $200 \mathrm{~s} \ldots \ldots \ldots$. . . . . . . . . . . . . . .

236. Volumetric flow in core entrance

(FTV-CORE-IN), from ' 6 to $42 \mathrm{~s}$

237. Volumetric flow in intact loop high pressure

injection line (FTU-HPIS), from -20 to $200 \mathrm{~s} \ldots \ldots \ldots 141$

238. Volumetric flow in intact loop high pressure

injection line (FTU-HPIS), from -6 to $42 \mathrm{~s}$

239. Volumetric flow in intact loop low pressure

injection line (FTU-LPIS), from -20 to $200 \mathrm{~s}$

240. Volumetric flow in intact loop low pressure

injection line (FTU-LPIS), from -6 to $42 \mathrm{~s}$

241. Volumetric flow in intact loop accumulator discharge

line (FTU-ACC), from -20 to $200 \mathrm{~s}$

242. Volumetric flow in intact loop accumulator discharge

line (FTU-ACC), from -6 to 42 s

243. Volumetric flow from pressurizer

(FTU-P.RIZE), from -20 tọ $200 \mathrm{~s}$ 
244. Volumetric flow from pressurizer

(FTU-PRIZE), from -6 to $42 \mathrm{~s} \ldots \ldots \ldots$. . . . . . . . . . . . 144

245. Fluid velocity in vessel (FTV-40A

and FTV-40M), from -20 to $200 \mathrm{~s} \ldots \ldots \ldots \ldots \ldots . \ldots \ldots$

246. Fluid velocity in vessel (FTV-40A and FTV-40M), from -6 to $42 \mathrm{~s} \ldots \ldots \ldots \ldots \ldots \ldots$

247. Momentum flux in intact loop (FDU-1), from -20 to $200 \mathrm{~s} \ldots \ldots \ldots \ldots \ldots \ldots \ldots$. . . . . . . . . . . . . . . . .

248. Momentum flux in intact loop (FDU-1), from -6 to $42 \mathrm{~s} \ldots \ldots \ldots \ldots \ldots \ldots \ldots$. . . . . . . . . . . . . . . . . .

249. Momentum flux in intact loop (FDU-5), from -20 to $200 \mathrm{~s} \ldots \ldots \ldots \ldots \ldots$. . . . . . . . . . 147

250. Momentum flux in intact loop (FDU-5), from -6 to $42 \mathrm{~s} \ldots \ldots \ldots \ldots \ldots \ldots \ldots . \ldots \ldots 147$

251. Momentum flux in intact loop (FDU-10), from -20 to $200 \mathrm{~s} \ldots \ldots \ldots \ldots \ldots \ldots \ldots$. . . . . . . . . . . . . . . .

252. Momentum flux in intact loop (FDU-10), from -6 to $42 \mathrm{~s} \ldots \ldots \ldots \ldots \ldots \ldots \ldots \ldots \ldots$

253. Momentum flux in intact loop (FDU-13), from -20 to $200 \mathrm{~s}$

254. Momentum flux in intact loop (FDU-13),

from -6 to $42 \mathrm{~s} \ldots \ldots \ldots$. . . . . . . . . . . . . . . . . . . 149

255. Momentum flux in intact loop (FDU-15), from -20 to $200 \mathrm{~s}$

256. Momentum flux in intact loop (FDU-15), from -6 to $42 \mathrm{~s} \ldots \ldots \ldots \ldots \ldots \ldots \ldots \ldots \ldots \ldots$

257. Momentum flux in broken loop (FDB-21),

258. Momentum flux in broken loop (FDB-21), from -6 to $42 \mathrm{~s} \ldots \ldots \ldots \ldots \ldots \ldots \ldots \ldots \ldots \ldots$ 
259. Momentum flux in broken loop (FDB-23),

from -20 to $200 \mathrm{~s} \ldots \ldots \ldots . \ldots \ldots 152$

260. Momentum flux in broken loop (FDB-23),

from -6 to $42 \mathrm{~s} \ldots \ldots \ldots \ldots \ldots$. . . . . . . . . . . . . . . . . . 52

261. Momentum flux in broken loop (FDB-30),

from -20 to $200 \mathrm{~s} \ldots \ldots \ldots \ldots$. . . . . . . . . . . . . . . . . . . . . .

262. Momentum flux in broken loop (FDB-30),

from -6 to $42 \mathrm{~s} \ldots \ldots \ldots \ldots \ldots \ldots$

263. Momentum flux in broken loop (FDB-37),

from -20 to $200 \mathrm{~s} \ldots \ldots \ldots \ldots$. . . . . . . . . . . . . . . . . . . . . .

264. Momentum flux in broken loop (FDB-37),

from -6 to $42 \mathrm{~s} \ldots \ldots \ldots \ldots . \ldots \ldots$

265. Momentum flux in broken loop (FDB-42),

from -20 to $200 \mathrm{~s} \ldots \ldots \ldots \ldots \ldots \ldots \ldots$

266. Momentum flux in broken loop (FDB-42),

from -6 to $42 \mathrm{~s} \ldots \ldots \ldots \ldots \ldots \ldots$

267. Momentum flux in core entrance (FDV-CORE-IN),

from -20 to $200 \mathrm{~s} \ldots \ldots \ldots \ldots$. . . . . . . . . . . . . . . . . . . . . .

268. Momentum flux in core entrance (FDV-CORE-IN),

from -6 to $42 \mathrm{~s} \ldots \ldots \ldots \ldots . \ldots \ldots 156$

269. Density in intact loop (GU-1T

and $\mathrm{GU}-1 \mathrm{~B})$, from -20 to $200 \mathrm{~s} \ldots \ldots \ldots \ldots$. . . . . . . . . . . . . . .

270. Donsity in intact loop (GU-1T

and GU-1B), from -6 to $42 \mathrm{~s} \ldots \ldots \ldots$. . . . . . . . . . . . . . . . . . . . . . .

271. Density in in tact loop (GU-1C), from -20 to $200 \mathrm{~s} \ldots \ldots \ldots$

272. Density in intact loop (GU-1C), from -6 to $42 \mathrm{~s} \ldots \ldots \ldots$

273. Density in intact loop (GU-5VR

and GU-10V:R), from -20 to 200 s. . . . . . . . . . . . . . . . . . . . 159

274. Density: in intact loop (GU-5VR

and GU-lOV.R), from -6 to $42 \mathrm{~s}: \ldots \ldots \ldots \ldots$ 
275. Density in intact loop (GU-13VR), from -20 to $200 \mathrm{~s} \ldots \ldots 160$

276. Density in in tact loop (GU-13VR), from -6 to $42 \mathrm{~s} \ldots \ldots$. . . . . . . 160

277. Density in intact loop (GU-15T

and GU-15B), from -20 to $200 \mathrm{~s} \ldots \ldots \ldots 1$

278. Density in intact loop (GU-15T

and GU-15B); from -6 to $42 \mathrm{~s} \ldots \ldots \ldots 161$

279. Density in intact loop (GU-15C), from -20 to $200 \mathrm{~s} \ldots \ldots$. . . . . . . 162

280. Density in intact loop (GU-15C), from -6 to $42 \mathrm{~s} \ldots \ldots \ldots 2$

281. Density in broken loop (GB-21T

and $\mathrm{GB}-21 \mathrm{~B})$, from -20 to $200 \mathrm{~s} \ldots \ldots \ldots 3$

282. Density in broken loop (GB-21T

and GB-21B), from -6 to $42 \mathrm{~s} \ldots \ldots \ldots \ldots$

283. Density in broken loop (GB-21C), from -20 to $200 \mathrm{~s} \ldots \ldots 4$

284. Density in broken loop (GB-21C), from -6 to $42 \mathrm{~s} \ldots \ldots \ldots 4$

285. Density in broken loop (GB-23VR), from -20 to $200 \mathrm{~s} \ldots \ldots \ldots$

286. Density in broken loop (GB-23VR), from -6 to $42 \mathrm{~s} \ldots \ldots \ldots 5$

287. Density in broken loop (GB-30T

and GB-30B), from -20 to $200 \mathrm{~s} \ldots \ldots \ldots$. . . . . . . . . 166

288. Density in broken loop (GB-30T

and GB-30B), from -6 to $42 \mathrm{~s} \ldots \ldots \ldots$

289. Density in broken loop (GB-30C), from -20 to $200 \mathrm{~s} \ldots \ldots \ldots 7$

290. Density in broken loop (GB-30C), from -6 to $42 \mathrm{~s} \ldots \ldots \ldots 7$

291. Density in broken loop (GB-37 and GB-42VR), from -20 to $200 \mathrm{~s} \ldots \ldots 8$

292. Density in broken loop (GB-37 and GB-42VR), from -6 to $42 \mathrm{~s} \ldots \ldots$. . . . 168

293. Density in vessel (GV-COR-150HZ), from -20 to $200 \mathrm{~s} \ldots \ldots$. . . . . . 169

294. Density in vessel (GV-COR-150HZ), from -6 to $42 \mathrm{~s} \ldots \ldots$. . . . . . . 169 
295. Density in vessel (GV-162/192D), from -20 to $200 \mathrm{~s} \ldots \ldots$. . . . . 170

296. Density in vessel (GV-162/192D), from -6 to $42 \mathrm{~s} \ldots \ldots \ldots$

297. Density in vessel (GVLP-165HZ and

GVLP-172HZ), from -20 to $200 \mathrm{~s} \ldots \ldots \ldots 171$

298. Density in vessel (GVLP-165HZ and

GVLP-172HZ), from -6 to $42 \mathrm{~s} \ldots \ldots \ldots \ldots$. . . . . . . . . . . . 171

299. Density in pressurizer (GU-PRIZE), from -20 to $200 \mathrm{~s} \ldots \ldots \ldots$

300. Density in pressurizer (GU-PRIZE), from -6 to $42 \mathrm{~s} \ldots \ldots \ldots 172$

301. Mass flow in intact loop (FDU-1,

GU-1C), from -20 to $200 \mathrm{~s} \ldots \ldots \ldots \ldots$

302. Mass flow in intact loop (FDU-1, GU-1C), from -6 to $42 \mathrm{~s} \ldots \ldots \ldots \ldots . \ldots \ldots$

303.: Mass flow in intact loop (FTU-1, GU-1C), from -20 to $200 \mathrm{~s} \ldots \ldots \ldots$. . . . . . . . . . . . 174

304. Mass flow in intact loop (FTU-1,

GU-1C), from -6 to $42 \mathrm{~s} \ldots \ldots \ldots \ldots$. . . . . . . . . . . 174

305. Mass flow in intact loop (FDU-5, GU-5VR), from -20 to $200 \mathrm{~s} \ldots \ldots \ldots$. . . . . . . . . . 175

306. Mass flow in in tact loop (FDU-5, GU-5VR), from -6 to $42 \mathrm{~s} \ldots \ldots \ldots \ldots . \ldots \ldots$

307. Mass flow in intact loop (FTU-9, (rTT-1nVR), from -20 to $200 \mathrm{~s} \ldots \ldots \ldots 176$

308. Mass flow in intact loop (FTU-9, (itJ-10VR), from -6 to $42.8 \ldots \ldots \ldots \ldots$

309. Mass flow in intact loop (FDU-10, GU-10VR), from -20 to $200 \mathrm{~s}$

310. Mass flow in intact loop (FDU-10, GU-10VR), from -6 to $42 \cdot \mathrm{s} \ldots \ldots \ldots \ldots$. . . . . . . . . . . . . . . .

311. Mass flow in intact loop (FDU-13, GU-13VR), from -20 to $200 \mathrm{~s} \ldots \ldots \ldots$. . . . . . . . . . . 178 
312. Mass flow in intact loop (FDU-13,

GU-13VR), from -6 to $42 \mathrm{~s} \ldots \ldots \ldots . \ldots 178$

313. Mass flow in intact loop (FTU-13,

GU-13VR), from -20 to $200 \mathrm{~s} \ldots \ldots \ldots 179$

314. Mass flow in intact loop (FTU-13,

GU-13VR), from -6 to $42 \mathrm{~s} \ldots \ldots \ldots 179$

315. Mass flow in intact loop (FDU-15,

GU-15C), from -20 to $200 \mathrm{~s} \ldots \ldots \ldots \ldots$

316. Mass flow in intact loop (FDU-15,

GU-15C), from -6 to $42 \mathrm{~s} \ldots \ldots . \ldots 180 . \ldots \ldots$

317. Mass flow in intact loop (FTU-15,

GU-15C), from -20 to $200 \mathrm{~s} \ldots \ldots \ldots 18 \ldots \ldots \ldots$

318. Mass flow in intact loop (FTU-15,

GU-15C), from -6 to $42 \mathrm{~s} \ldots \ldots \ldots 181$

319. Mass flow in intact loop (FDB-21,

GB-21C), from -20 to $200 \mathrm{~s} \ldots \ldots \ldots 182$

320. Mass flow in intact loop (FDB-21,

GB-21C), from -6 to $42 \mathrm{~s} \ldots \ldots \ldots 182$

321. Mass flow in broken loop (FTB-21,

GB-21C), from -20 to $200 \mathrm{~s} \ldots \ldots \ldots 183$

322. Mass flow in broken loop (FTB-21,

GB-21C), fron $=6$ to $42 \mathrm{~s} \ldots \ldots \ldots \ldots . \ldots \ldots$

323. Mass flow in broken loop (FDB-23,

GB-23VR), from -20 to $200 \mathrm{~s} \ldots \ldots \ldots$. . . . . . . . . . 184

324. Mass Flow in broken loop (FDB-23,

GB-23VR), from -6 to $42 \mathrm{~s} \ldots \ldots \ldots \ldots$. . . . . . . . . . . 184

325. Mass tlow in broken loop (FDB-30,

GB-30C), from -20 to $200 \mathrm{~s} \ldots \ldots \ldots$. . . . . . . . . . 185

326. Mass flow in broken loop (FDB-30,

GB-30C), from -6 to $42 \mathrm{~s} \ldots \ldots \ldots \ldots$ 
327. Mass flow in broken loop (FTB-30, GB-30C), from -20 to $200 \mathrm{~s} \ldots \ldots \ldots$. . . . . . . . . . 186

328. Mass flow in broken loop (FTB-30,

GB-30C), from -6 to $42 \mathrm{~s} \ldots \ldots \ldots$. . . . . . . . . . . . . . . . . .

329. Mass flow in broken loop (FDB-37,

GB-37), from -20 to $200 \mathrm{~s} \ldots \ldots \ldots$. . . . . . . . . . . 187

330. Mass flow in broken loop (FDB-37,

GB-37), from -6 to $42 \mathrm{~s} \ldots \ldots \ldots \ldots \ldots$

331. Mass flow in broken loop (FTB-37,

GB-37), from -20 to $200 \mathrm{~s} \ldots \ldots \ldots$. . . . . . . . . . 188

332. Mass flow in broken loop (FTB-37,

GB-37), from -6 to $42 \mathrm{~s} \ldots \ldots \ldots$. . . . . . . . . . . . . . . . . . .

333. Mass flow in broken loop (FDB-42,

GB-42VR), from -20 to 200 s . . . . . . . . . . . . . . 189

334. Mass flow in broken loop (FDB-42,

GB-42VR), from -6 to $42 \mathrm{~s} \ldots \ldots . \ldots . . \ldots 189$

335. Mass flow in vessel (FDV-CORE-IN,

GV-COR-150HZ), from -20 to $200 \mathrm{~s} \ldots \ldots$. . . . . . . . . . . . 190

336. Mass flow in vessel (FDV-CORE-IN,

GV-COR-150HZ), from -6 to $42 \mathrm{~s} \ldots \ldots \ldots$. . . . . . . . . . 190

337. Mass flow in vessel (FTV-CORE-IN,

GV-COR-1 50HZ), from -20 to $200 \mathrm{~s} \ldots \ldots \ldots 1$

338. Mass flow in vessel (FTV-CORE-IN,

GV-COR-150HZ), from -6 to $42 \mathrm{~s} \ldots \ldots \ldots 191$

339. Mass flow in pressurizer (FTU-PRIZE,

GU-PRIZE), from -20 to $200 \mathrm{~s} \ldots \ldots . \ldots . . \ldots . . \ldots 192$

340. Mass flow in pressurizer (FTU-PRIZE,

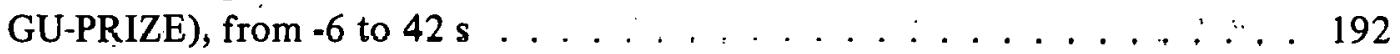

341. Core heater rod total power (PWRCOR T-1 and

PWRCOR T-2), from -20 to $200 \mathrm{~s} \ldots \ldots \ldots 3$ 
342. Core heater rod total power (PWRCOR T-1 and

PWRCOR T-2), from -6 to $42 \mathrm{~s} \ldots \ldots \ldots$

343. Core heater voltage (VOLTCOR-T), from -20 to $200 \mathrm{~s} \ldots \ldots$. . . . . 194

344. Core heater voltage (VOLTCOR-T), from -6 to 42 s . . . . . . . . . . 194

345. Core heater total current (AMPCOR-T), from -20 to $200 \mathrm{~s} \ldots \ldots \ldots$

346. Core heater total current (AMPCOR-T), from -6 to $42 \mathrm{~s} \ldots \ldots \ldots$

347. Primary pump current (PUMPU-CUR), from -20 to $200 \mathrm{~s} \ldots \ldots \ldots$

348. Primary pump current (PUMPU-CUR), from -6 to $42 \mathrm{~s} \ldots \ldots \ldots$

349. Primary pump speed (PUMPU-RPM), from -20 to $200 \mathrm{~s} \ldots \ldots \ldots$

350. Primary pump speed (PUMPU-RPM), from -6 to $42 \mathrm{~s} \ldots \ldots \ldots \ldots$

A-1. Geometry used for processing of density data obtaincd from two-beam gamma densitometers . . . . . . . . 209

B-1. Fluid temperature in broken loop (TFB-23) $\ldots \ldots \ldots 22$

B-2. Fluid temperature in downcomer annulus (TFV-ANN-35A) $\ldots \ldots \ldots 221$

B-3. Fluid temperature in lower plenum (TFV-LP-15) $\ldots \ldots \ldots 22$

B-4. Fluid temperature in core, Grid Spacer 6 (TFG-6DE-67) . . . . . . . 222

B-5. Fluid temperature in steam generator (TFU-SG4) $\ldots \ldots \ldots \ldots 223$

B-6. Fluid temperature in pressurizer surge line (TFU-PRIZE) $\ldots \ldots \ldots \ldots$

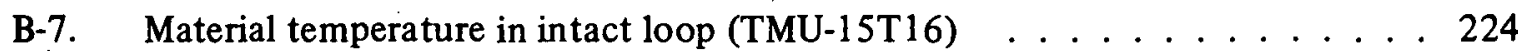

B-8. Material temperature in vessel filler (TMV-CI-35A) . . . . . . . . . . . 224

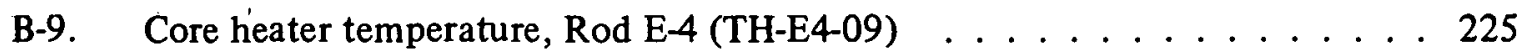

B-10. Core heater temperature, Rod E-4 (TH-E4-27) . . . . . . . . . . 225

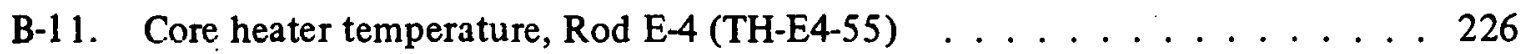

B-12. Pressure in intact loop, Spool 13 (PU-13) $\ldots \ldots \ldots \ldots . \ldots \ldots$ 
B-13. Pressure in broken loop, Spool 23 (PB-23) . . . . . . . . . . . . 227

B-14. Differential pressure in intact loop (DPU-6-7) . . . . . . . . . . . 227

B-15. Differential pressure in intact loop (DPU-7-10) . . . . . . . . . 228

B-16. Differential pressure in in tact loop (DPU-12-10) . . . . . . . . 228

B-17. Differential pressure in intact loop (DPU-12-15) . . . . . . . . . 229

B-18. Differential pressure in vessel (DPV-LP-UP) . . . . . . . . . . . . . 229

B-1 9. Volumetric tlow in intact loop (FTU-1) . . . . . . . . . . . 230

B-20. Volumetric flow in intact loop (FTU-15) . . . . . . . . . . 230

B-21. Volumetric flow in intact loop high pressure injection line (FTU-HPIS) . . . . . . . . . . . . . . . . . 231

B-22. Volumetric flow in intact loop low pressure injection

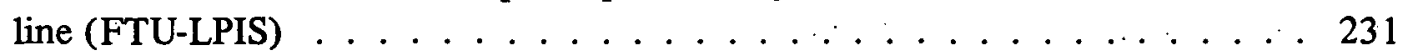

B-23. Volumetric flow in intact loop accumulator discharge line (FTU-ACC1) . . . . . . . . . . . . . . . . . 232

B-24. Fluid velocity in vessel (FTV-40A) . . . . . . . . . . . . 232

B-25. Fluid velocity in vessel (FTV-40M) . . . . . . . . . . 233

B-26. Density in intact loop (GU-1T) . . . . . . . . . . . 233

B-27. Density in intact loop $(\mathrm{GU}-1 \mathrm{~B}) \ldots \ldots \ldots \ldots$

B-28 Density in intact loop $(G U-1 C) \ldots \ldots \ldots 234$

B-29. Density in intact loop (GU-10VR) . . . . . . . . . . . 235

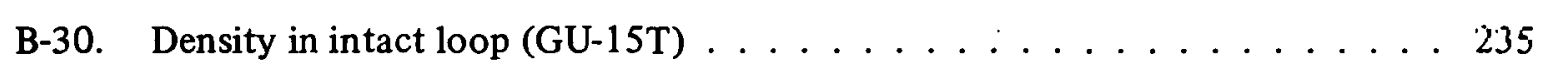

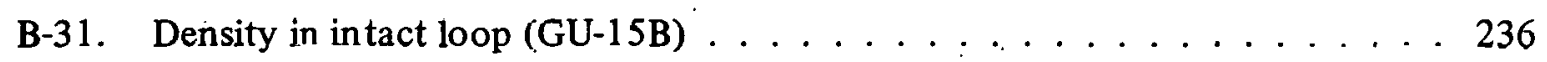

B-32. Density in intact loop (GU-15C) . . . . . . . . . . . 236

B-33. Density in broken loop (GB-23VR) . . . . . . . . . . . . 237

B-34. Density in vessel (GV-COR-150HZ) . . . . . . . . . . . . 237 
B-35. Density in vessel (GVLP-165HZ) . . . . . . . . . . 238

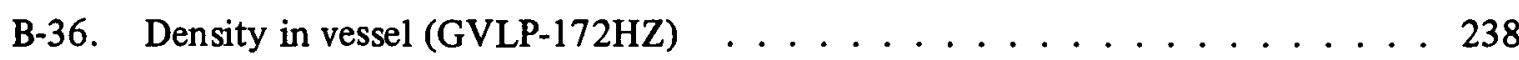

B-37. Mass flow in intact loop (FDU-1, GU-1C) . . . . . . . . . . . 239

B-38. Mass flow in intact loop (FTU-1, GU-1C) $\ldots \ldots \ldots \ldots . \ldots 239$

B-39. Mass flow in intact loop (FDU-5, GU-5VR) $\ldots \ldots \ldots \ldots \ldots$

B-40. Mass flow in intact loop (FTU-13, GU-13VR) $\ldots \ldots \ldots . \ldots . . . .240$

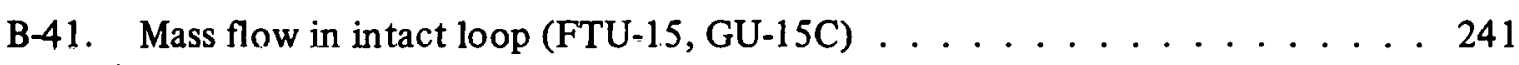

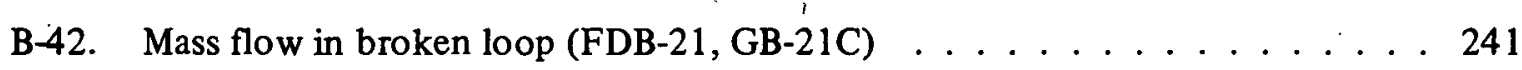

B-43. Mass flow in broken loop (FTB-21, GB-21C) $\ldots \ldots \ldots \ldots \ldots 242$

B-44. Mass Flow in vessel (FTV-CORE-IN, GV-COR-150HZ) . . . . . . . . 242

\section{TABLES}

I. Conditions at Blowdown Initiation $\ldots \ldots \ldots \ldots$

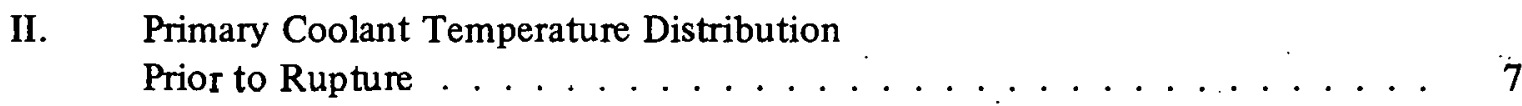

III. Water Chemistry Prior to Blowdown $\ldots \ldots \ldots \ldots \ldots$

IV. Sequence of Events During Test $\mathrm{S}-06=6 \ldots \ldots \ldots \ldots$

V. Data Presentation for Semiscale Mod-1 Test S-06-6 . . . . . . . . 17

A-I. Constants for Pressure Measurement

Corrections (Test S-06-6) . . . . . . . . . . . . . . . . 202

A-II. Constants for Differential Pressure

Measurement Corrections (Test S-0G-G) . . . . . . . . . . . 204

A-III. Constants for Momentum Flux

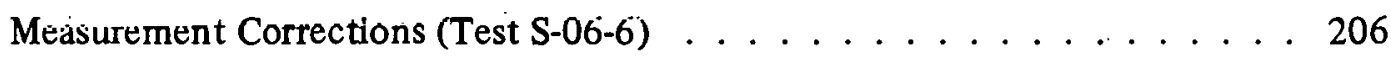

A-IV. Constants for Density Measurement Conversions

to Engineering Units (Test $\mathrm{S}-06-6) \ldots \ldots \ldots \ldots 20 . \ldots \ldots$ 


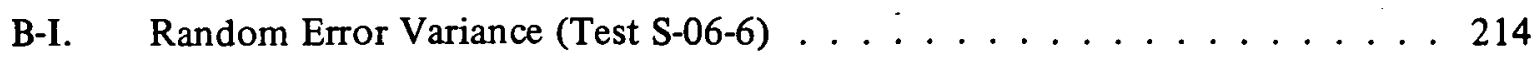

B-II. General Measurement Engineering Error

Sources and Error Values (Test S-06-6) $\ldots \ldots \ldots \ldots$. . . . . . . 243

B-III. Time Periods when Flow Regime Errors

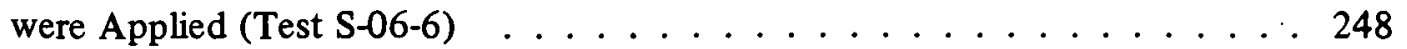




\title{
EXPERIMENT DATA REPORT FOR SEMISCALE MOD-1
}

\author{
TEST S-06-6
}

\section{(LOFT COUNTERPART TEST)}

\section{INTRODUCTION}

The Semiscale Mod-1 experiments represent the current phase of the Semiscale Program conducted by EG\&G Idaho, Inc. for the United States Government. The program, which is sponsored by the Nuclear Regulatory Commission through the Energy Research and Development Administration, is part of the overall program designed to investigate the response of a pressurized water reactor system to a hypothesized loss-of-coolant accident (LOCA). The underlying objectives of the Semiscale Program are to quantify the physical processes controlling system behavior during a LOCA and to provide an experimental data base for assessing reactor safety evaluation models. The Semiscale Mod-1 Program has the further objective of providing support to other experimental programs in the form of instrumentation assessment, optimization of test series, selection of test parameters, and evaluation of test results.

Test S-06-6 was conducted May 17, 1977, in the Semiscale Mod-1 system as part of the LOFT counterpart test series (Test Series 6). This series was designed to obtain thermal-hydraulic response data from blowdown, refill, and reflood transients in a simulated reactor system with a heated core to assist the Loss-of-Fluid Test (LOFT) Program in the planning of the first LOFT nuclear test series. The test objective specific to Test S-06-6 was to determine the maximum cladding temperature associated with a high powered rod peak power density of $39.4 \mathrm{~kW} / \mathrm{m}$, or $75 \%$ of the maximum peak power density of $52.5 \mathrm{~kW} / \mathrm{m}$. Test S-06-6 had the additional objective of evaluating the effect of special hardware assumptions on the core response.

The purpose of this report is to present the test data in an uninterpreted but readily usable form for use by the nuclear community in advance of detailed analysis and interpretation. Section II briefly describes the system configuration, procedures, initial test conditions, and events that are applicable to Test S-06-6; Section III presents the data graphs and provides comments and supporting information necessary for interpretation of the data. A description of the overall Semiscale Program and test series, a more detailed description of the Semiscale Mod-1 system, and a description of the measurement and data processing techniques and uncertainties can be found in Reference 1. 


\section{SYSTEM, PROCEDURES, CONDITIONS, AND EVENTS FOR TEST S-06-6}

The following system configuration, procedures, initial test conditions, and events are specific to Test S-06-6 as indicated.

\section{SYSTEM CONFIGURATION AND TEST PROCEDURES}

The Semiscale Mod-1 system used for this test consisted of a pressure vessel with internals, including a 40-rod core with 36 electrically heated rods; an intact loop with steam generator, pump, and pressurizer; a broken loop with simulated steam generator, simulated pump, simulated reflood bypass lines, LOFT counterpart nozzles ${ }^{[a]}$, and two rupture assemblies; a coolant injection accumulator for the intact loop; high and low pressure coolant injection pumps for the intact loop; and a pressure suppression system with a suppression tank, header, and heated steam supply systcm. Semiscale Mod-1 experimental system configuration information is provided in Reference 1. Figures 1 and 2 show the system configuration for Test S-06-6.

For Test S-06-6, the 40-rod electrically heated core was operated at an axial peak power density which was $75 \%$ of the maximum peak power density $(52.5 \mathrm{~kW} / \mathrm{m})$. Four rods (Rods D-4, D-5, E-4, and E-5) were operated at approximately $39.4 \mathrm{~kW} / \mathrm{m}, 32$ rods were operated at approximately $24.9 \mathrm{~kW} / \mathrm{m}$, and four rods (Rods C-4, D-6, E-3, and F-5) were unpowered to simulate LOFT passive rod locations. This configuration yielded a peaked power profile which simulates that of LOFT and provides a total core power of approximatcly $1002 \mathrm{~kW}$.

Test S-06-6 was conducted using 10 CFR-50 Appendix $\mathrm{K}^{[3]}$ hardware assumptions to evaluate their effect on the core response. The assumptions investigated are summarized as follows: (a) a loss of power to the in tact loop pump occurred at the break, (b) the broken loop pump simulated the resistance of a locked rotor rather than a free-wheeling rotor, (c) the steam generator feedwater and steam controls were ramped lo close $15 \mathrm{~s}$ atter rupturc and (d) the low pressure injection system (LPIS) and the high pressure injection system (HPIS) flow rates simulated flow from one HPIS and one LPIS pump with injection times delayed to 25 and $35 \mathrm{~s}$, respectively.

In preparation for the test, the intact loop accumulator was filled with treated demineralized water, drained to the specified initial level, and pressurized with nitrogen to $4223 \mathrm{kPa}$. The system was filled with treated demineralized water and vented at strategic points to ensure a liquid full system. Prior to warmup the system was pressurized to check for leakage, system instrumentation was checked, and transducer readings were initialized.

[a] The Semiscale Mod-1 system normally utilizes a break nozzle of the convergingdiverging type referred to as a Henry nozzle. Reference 2 provides an illustration of the LOFT counterpart break nozzle. 
Simulated

steam generator

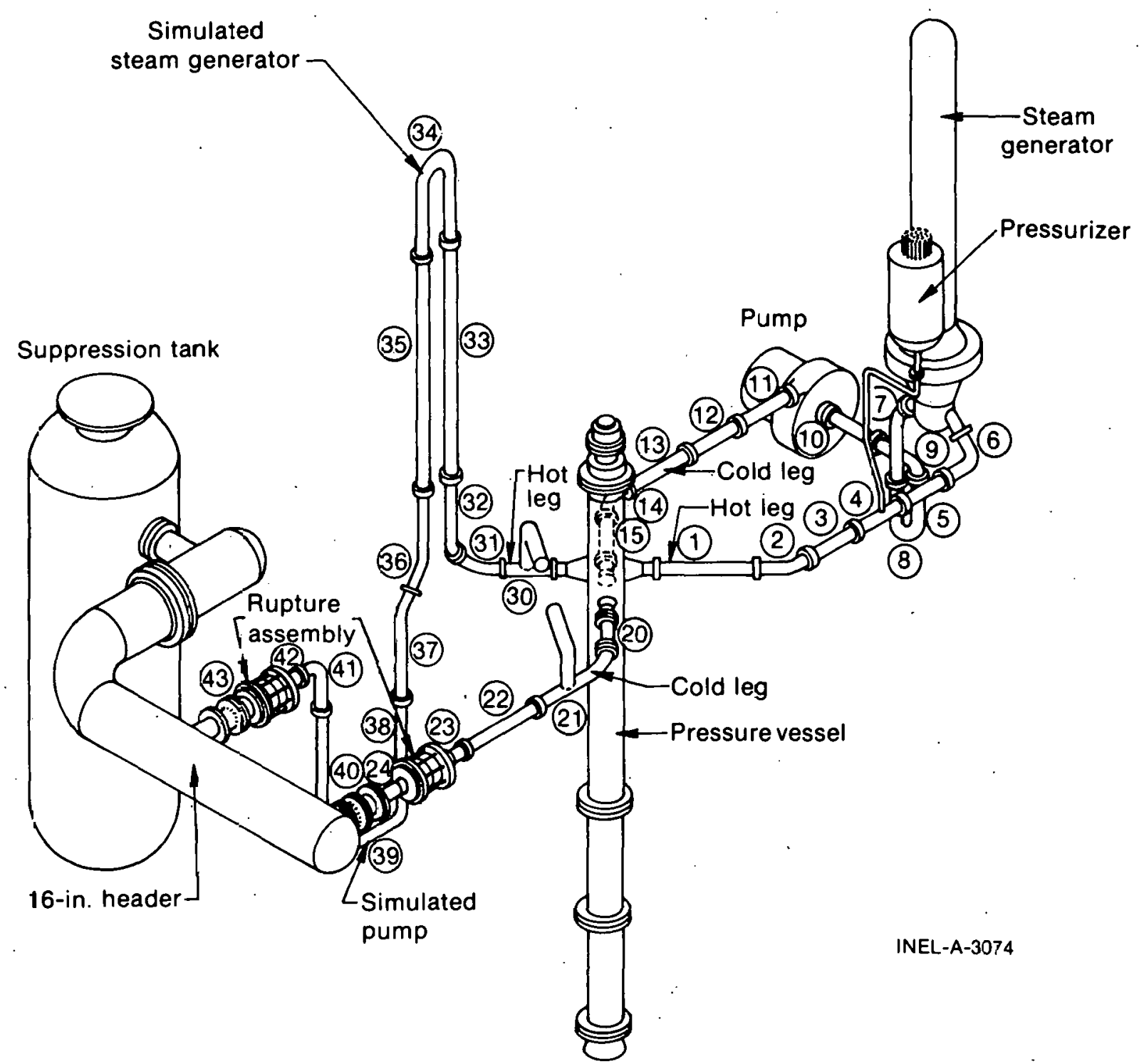

Fig. 1 Semiscale Mod-1 system for cold leg break configuration -isometric. 


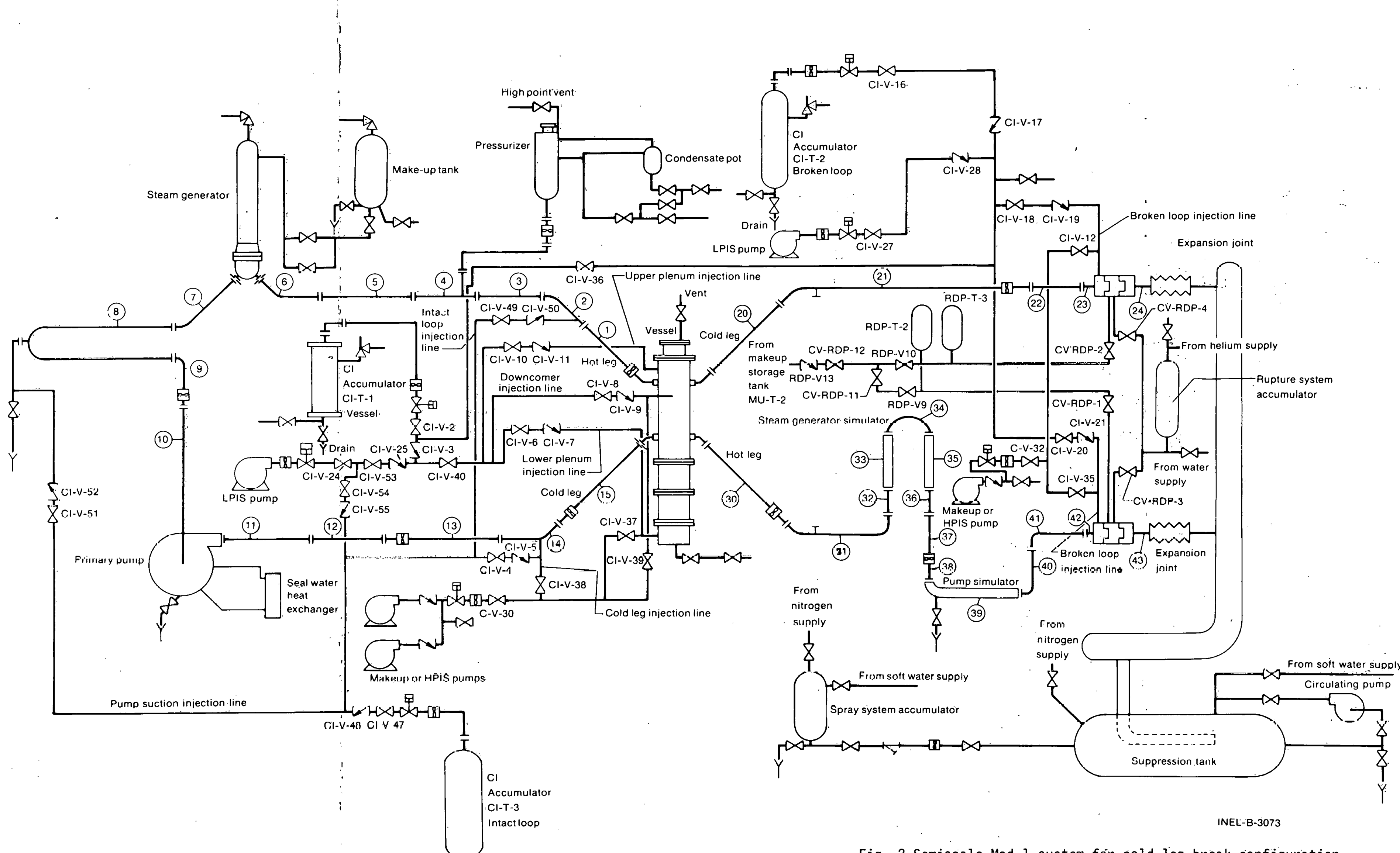

Fig. 2 Semiscale Mod-1 system for cold leg break configuration -schematic. 
Warmup to initial test conditions was accomplished with the heaters in the vessel core. Heatup of the broken loop piping was accomplished with bypass lines which served to allow circulation through the broken loop. During warmup, the purification and sampling systems were valved into the primary system to maintain water chemistry requirements and to provide a water sample at system conditions for subsequent analysis. At 55.56-K-temperature intervals during warmup, detector readings were sampled to allow the integrity of the measurement instrumentation and the operability of the data acquisition system to be checked.

Prior to the initial core power level being established, the pressure suppression system was pressurized to $241 \mathrm{kPa}$ with saturated steam from the steam supply system. After the core power was increased to $1002 \mathrm{~kW}$, initial test conditions were held for $1440 \mathrm{~s}$ to establish equilibrium in the system. At the end of this period all auxiliary systems including the bypass lines were isolated to prevent blowdown through those systems.

The system was successfully subjected to a simulated double-ended cold leg break through two rupture assemblies and two LOFT counterpart nozzles, each having a break area of $0.000243 \mathrm{~m}^{2}$. Pressure to operate the rupture assemblies and initiate blowdown was taken from an accumulator system filled with water and pressurized to $15600 \mathrm{kPa}$ with gaseous nitrogen. Immediately (within $0.02 \mathrm{~s}$ ) after initiation of blowdown, the lines to the accumulator were again isolated. The effluent from the primary system was ejected into the pressure suppression system which was vented to maintain a constant pressure of $241 \mathrm{kPa}$. During the blowdown transient, power to the electrically heated core was automatically controlled to aid in the LOFT simulation. The primary coolant circulation pump speed was controlled by a predetermined coastdown.

For Test S-06-6 all coolant injection systems were arranged to discharge into the intact loop cold leg injection point (Spool 14). Coolant injection from the high pressure injection system pump began at blowdown and continued until test termination $(300 \mathrm{~s})$. Coolant injection from the accumulator started approximately $19 \mathrm{~s}$ after rupture at a system pressure of $5190 \mathrm{kPa}$ and continued to depletion at $66 \mathrm{~s}$ after blowdown. Low pressure coolant injection began $35 \mathrm{~s}$ after rupture at a system pressure of $1165 \mathrm{kPa}$ and continued until test termination ( $300 \mathrm{~s}$ ).

\section{INITIAL TEST CONDITIONS AND SEQUENCE OF EVENTS}

Conditions in the Semiscale Mod-1 system at initiation of blowdown are given in Tables I and II, the primary system water chemistry prior to blowdown is given in Table III, and the sequence of events relative to rupture is given in Table IV. 
TABLE I

CONDITIONS AT BLOWDOWN INITIATION

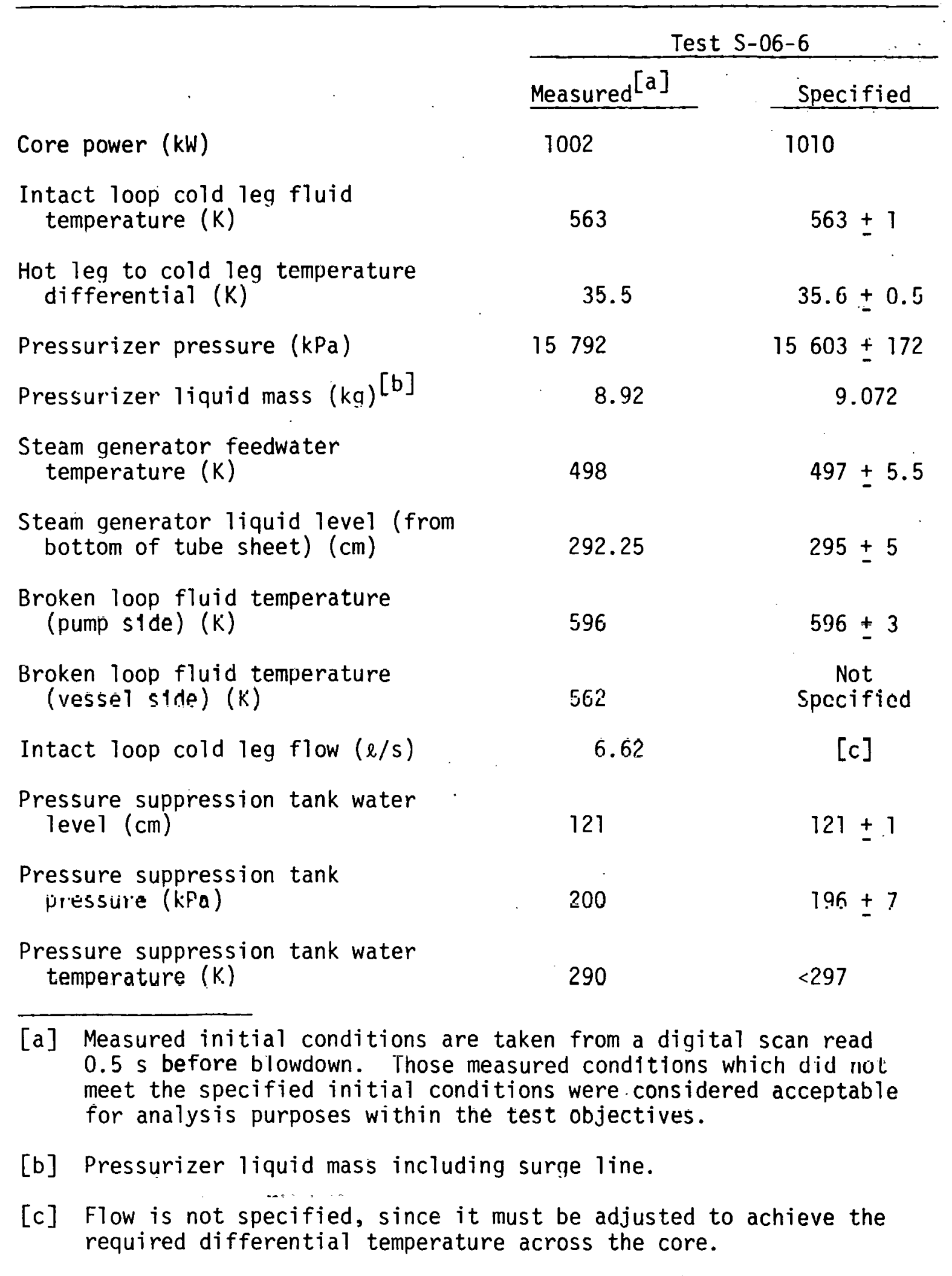




\section{TABLE II}

PRIMARY COOLANT TEMPERATURE DISTRIBUTION PRIOR TO RUPTURE[a]

\begin{tabular}{|c|c|c|}
\hline \multirow[t]{2}{*}{ V } & \multicolumn{2}{|c|}{ Test S-06-6 } \\
\hline & Detector & Temperature (K) \\
\hline Vessel lower plenum & TFV-LP-22 & 563 \\
\hline Intact loop hot leg (near vessel) & RBU-2 & 599 \\
\hline Intact loop cold leg (near pump inlet) & TFU-10 & 564 \\
\hline Intact loop cold leg (near vessel) & RBU-14A & 563 \\
\hline Broken loop cold leg (near nozzle) & TFB-23 & 562 \\
\hline Broken loop hot leg (near vessel) & TFB-30 & 596 \\
\hline Broken loop cold leg (near nozzle) & TFB-42 & 590 \\
\hline $\begin{array}{l}\text { Reflood bypass line hot leg (near } \\
\text { end cap) }\end{array}$ & TFB-RFB-H & 590 \\
\hline $\begin{array}{l}\text { Reflood bypass line cold leg (near } \\
\text { end cap) }\end{array}$ & TFB-RFB-C & 562 \\
\hline
\end{tabular}


TABLE III

WATER CHEMISTRY PRIOR TO BLOWDOWN [a]

\section{Test S-06-6}

$\mathrm{pH}$

10.20

Conductivity $(\mu \mathrm{mho} / \mathrm{cm})$.

463

Lithium $(\mu \mathrm{g} / \mathrm{ml})$

1.2

Chlorides (ppm)

$<0.1$

Fluorides $(\mathrm{ppm})^{[\mathrm{b}]}(\mu \mathrm{g} / \mathrm{ml})$

$<0.4$

Oxygen (cc/l)

0.04

Total gas $(\mathrm{cc} / \mathrm{l})$

160.9

Suspended solids $(\mu \mathrm{g} / \mathrm{m} \ell)$

1.20

[a] Water sample taken at a system pressure of approximately $15603 \mathrm{kPa}$ and a system temperature of approximately $555 \mathrm{~K}$ (cold leg).

[b] Present analytical methods prevent accurate determination of fluorides at concentrations of less than $0.4 \mu \mathrm{g} / \mathrm{ml}$. 
TABLE IV

SEQUENCE OF EVENTS DURING TEST $S-06-6^{[a]}$

\section{Event}

Core power level established

Bypass lines valved out of system

Blowdown initiated

Pump power reduced $[\mathrm{d}]$

ECC accumulators valved in

Steam generator feedwater and discharge valves

closed

Core power decay transient started

High pressure injection system pumps started $[\mathrm{b}]$

Low pressure injection system pumps started $[b]$.

Core power tripped off $[\mathrm{c}]$
Time Relative

To Rupture (s)

1440

$-2.5$

0

0

0

1

1.0

[a] A time-controlled sequencer was used to control critical events during the test.

[b] Injection from ECC accumulators and high and low pressure injection system pumps does not start until system pressure drops below accumulator or pump pressure, respectively.

[c] Core power tripped manually at termination of test.

[d] Pump power was reduced on a predetermined decay curve. 


\section{DATA PRESENTATION}

The data from Semiscale Mod-1 Test S-06-6 are presented with brief comment. Processing analysis has been performed only to the extent necessary to obtain appropriate engineering units and to ensure that the data are reasonable and consistent. In all cases, in converting transducer output to engineering units, a homogeneous fluid was assumed. Further interpretation and analysis should consider that sudden decompression processes such as those occurring during blowdown may have subjected the measurement devices to nonhomogeneous fluid conditions.

The performance of the system during Test S-06-6 was monitored by 224 detectors. The data obtained were recorded on both digital and analog data acquisition systems. The digital system was used to process the data presented in this report. The digital data were recorded at a sample rate of 57.5 points per second. Long term data ( -20 to $300 \mathrm{~s}$ ) were compressed at a 20 to 1 ratio giving an effective sample rate of 2.875 points per second. Long term plots are given for -20 to $200 \mathrm{~s}$ to provide better resolution of the plots. Short term data and plots ( -6 to $42 \mathrm{~s}$ ) were compressed at a 3 to 1 ratio giving an effective sample rate of 19.17 points per second. The analog system was used to provide better resolution capability (needed as input to various data analysis codes).

The data are presented in some instances in the form of composite graphs to facilitate comparison of the values of given variables at several locations. The scales selected for the graphs do not reflect the obtainable resolution of the data. (The data processing techniques are described further in Reference 1).

Figures 3 through 8 and Table V provide supporting information for interpretation of the data graphs shown in Figures 9 through 350, and provide relative locations of all detectors used during Test S-06-6. Table V groups the measurements according to measurement type, identifies the specific measurement location and range of the detector and actual recording range of the data acquisition system, provides brief comments regarding the data, and references the measurements and comments to the corresponding tigure. Figures 9 through 350 present all the blowdown and rellood data obtained. lime zero on the graphs is the time of rupture initiation. Appendix A provides information explaining posttest data processing for data conversion into engineering units and data adjustments. Presented in Appendix B is an analysis of selected data which provide a guide to the uncertainty associated with data measurements in the Semiscale Mod-1 system. 


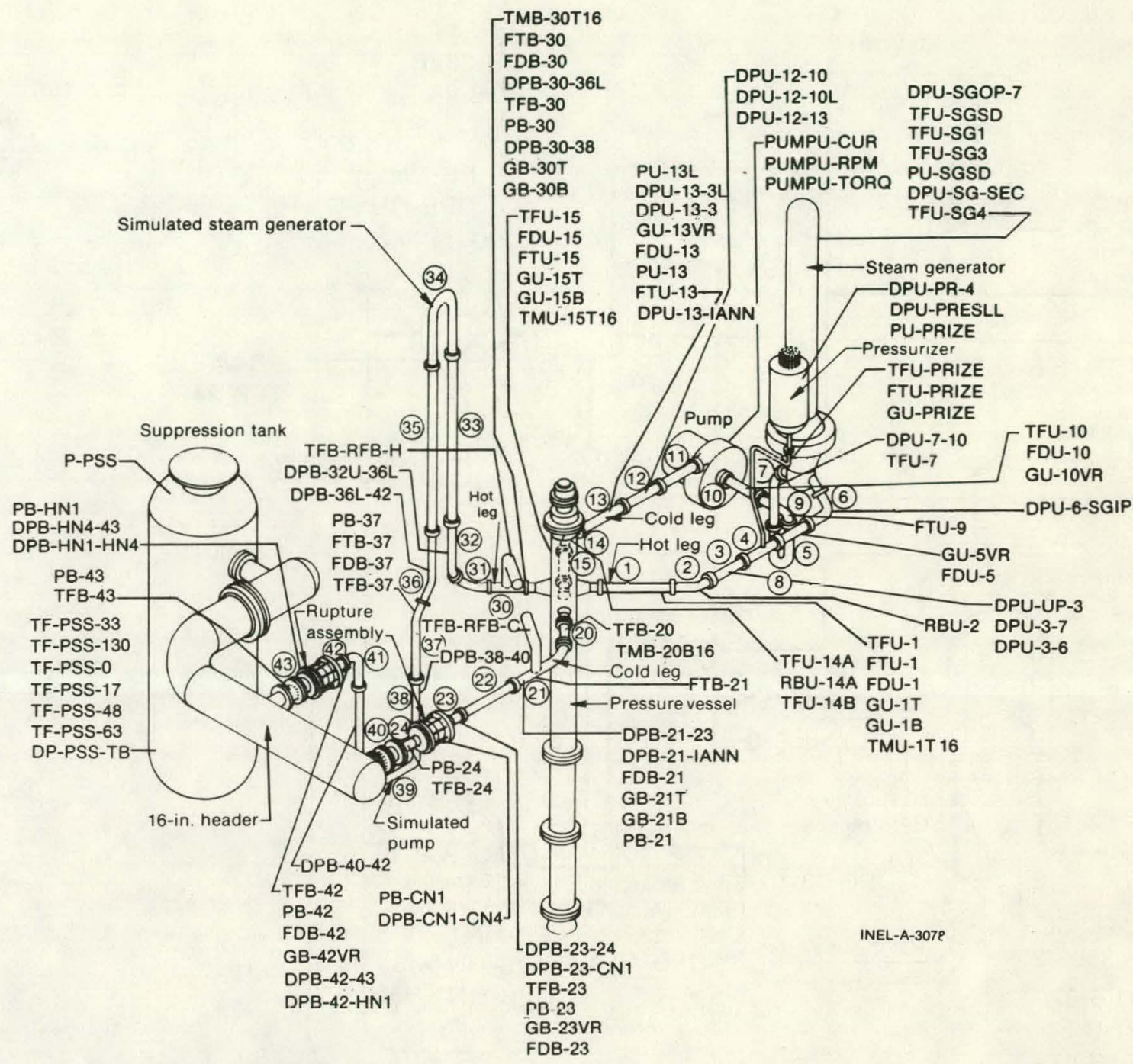

Fig. 3 Semiscale Mod-1 system and instrumentation for cold leg break configuration -- isometric. 


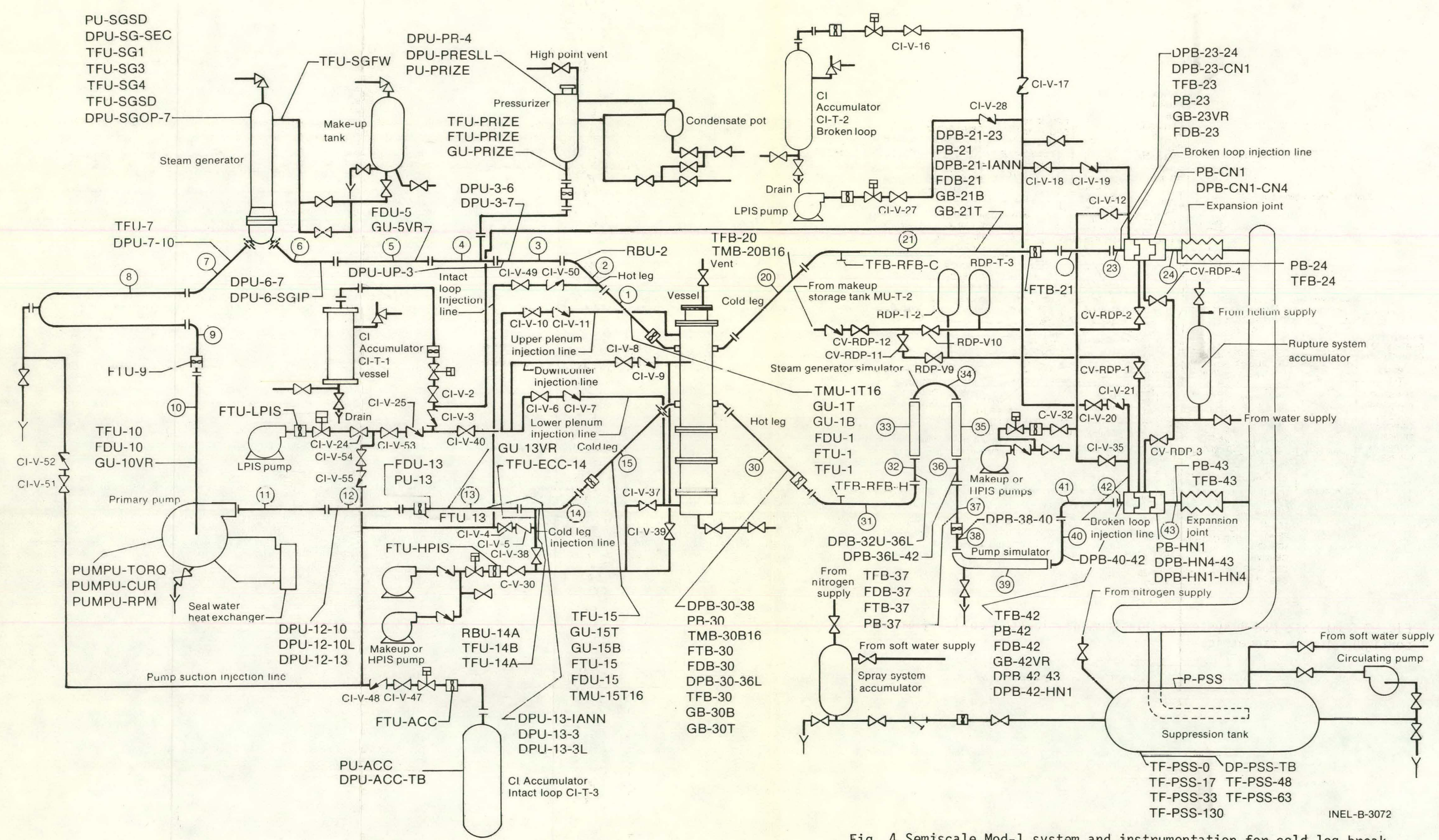

Fig. 4 Semiscale Mod-1 system and instrumentation for cold leg break configuration -- schematic. 


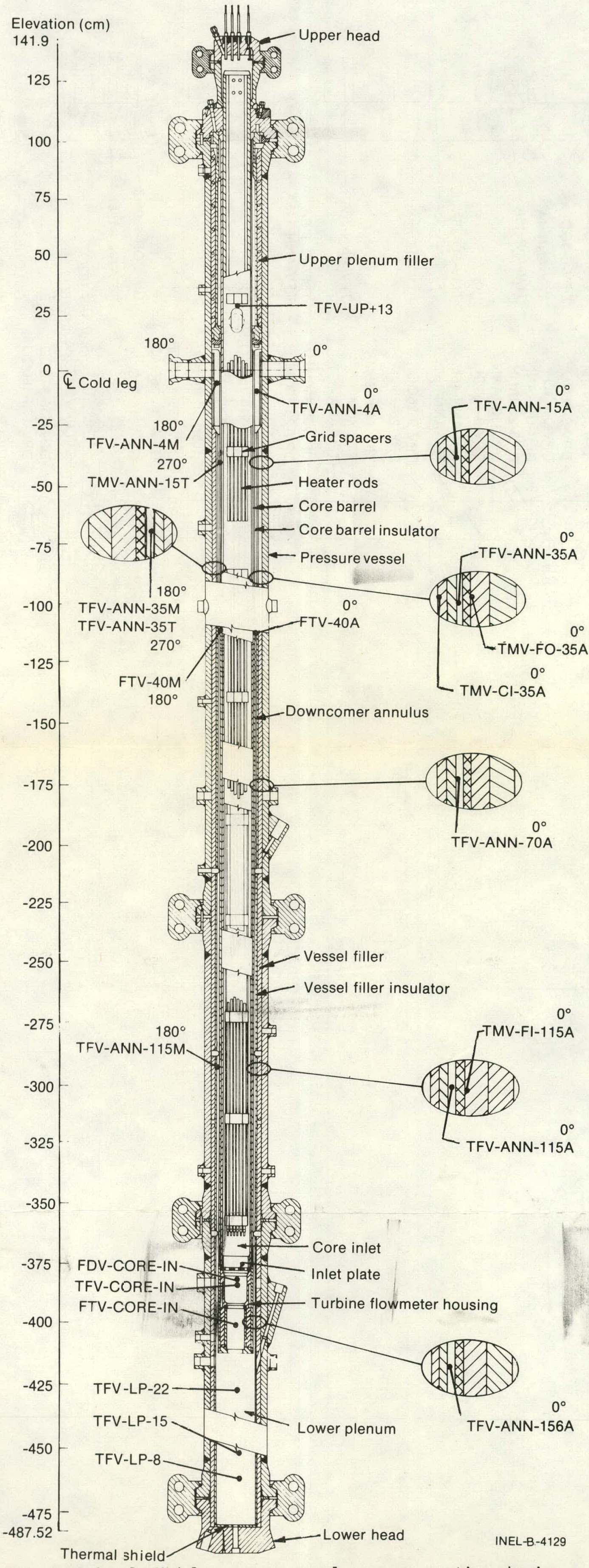

Fig. 5 Semiscale Mod-1 pressure vessel -- cross section showing instrumentation. 
Distance from

cold leg $\varepsilon(\mathrm{cm})$

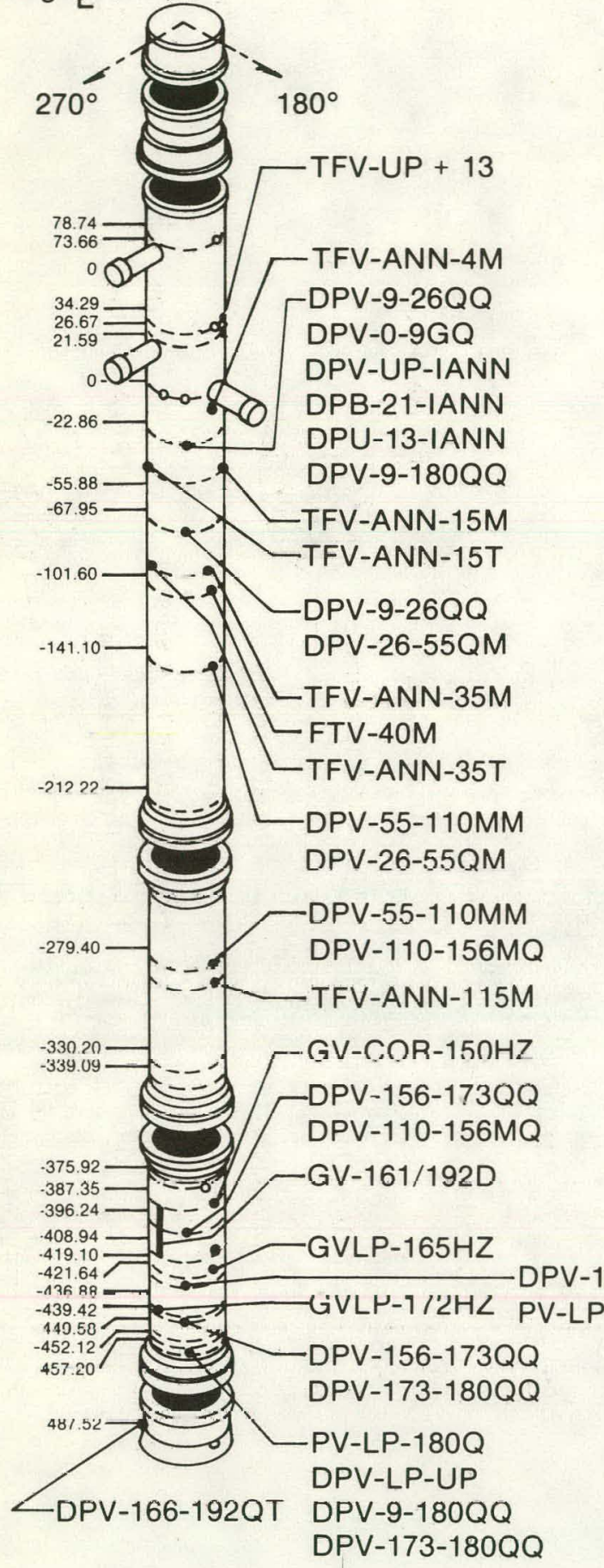

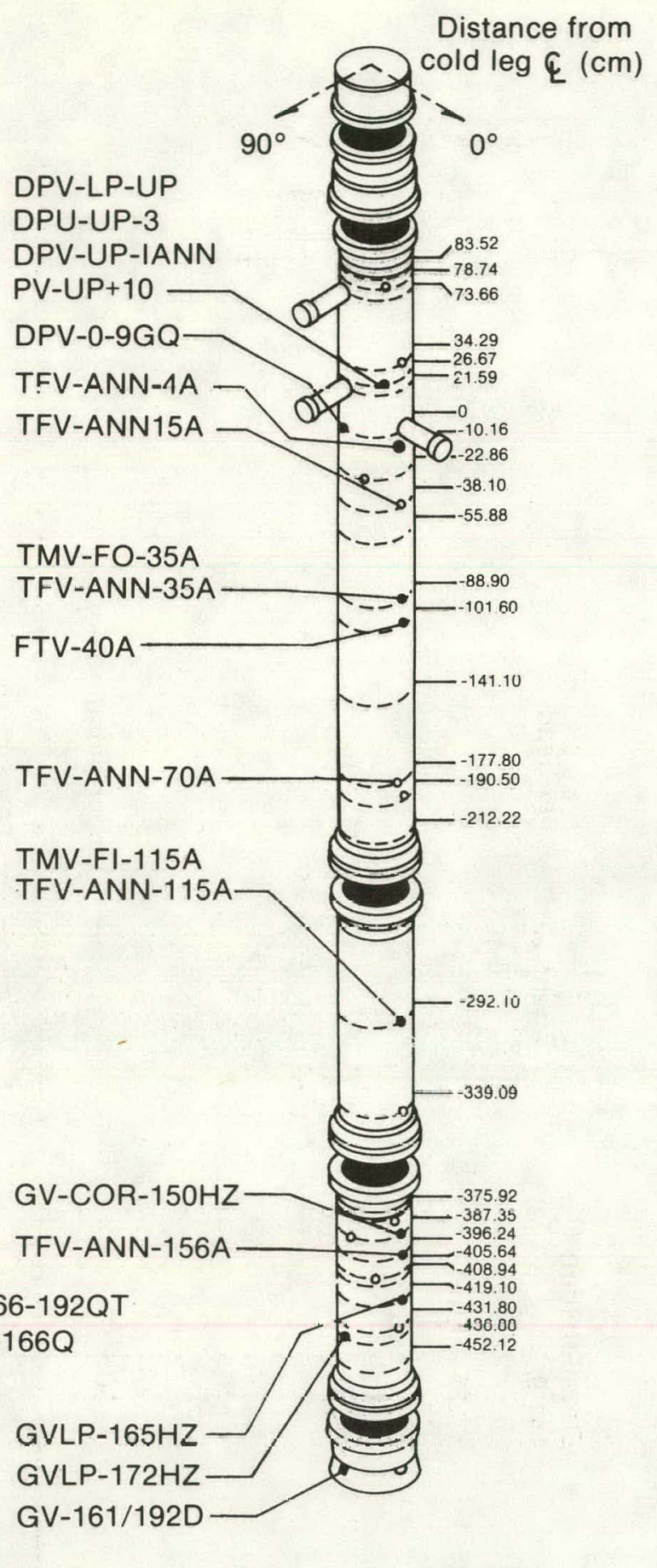

INEL-A-3076

Fig. 6 Semiscale Mod-1 pressure vessel -- isometric showing instrumentation. 


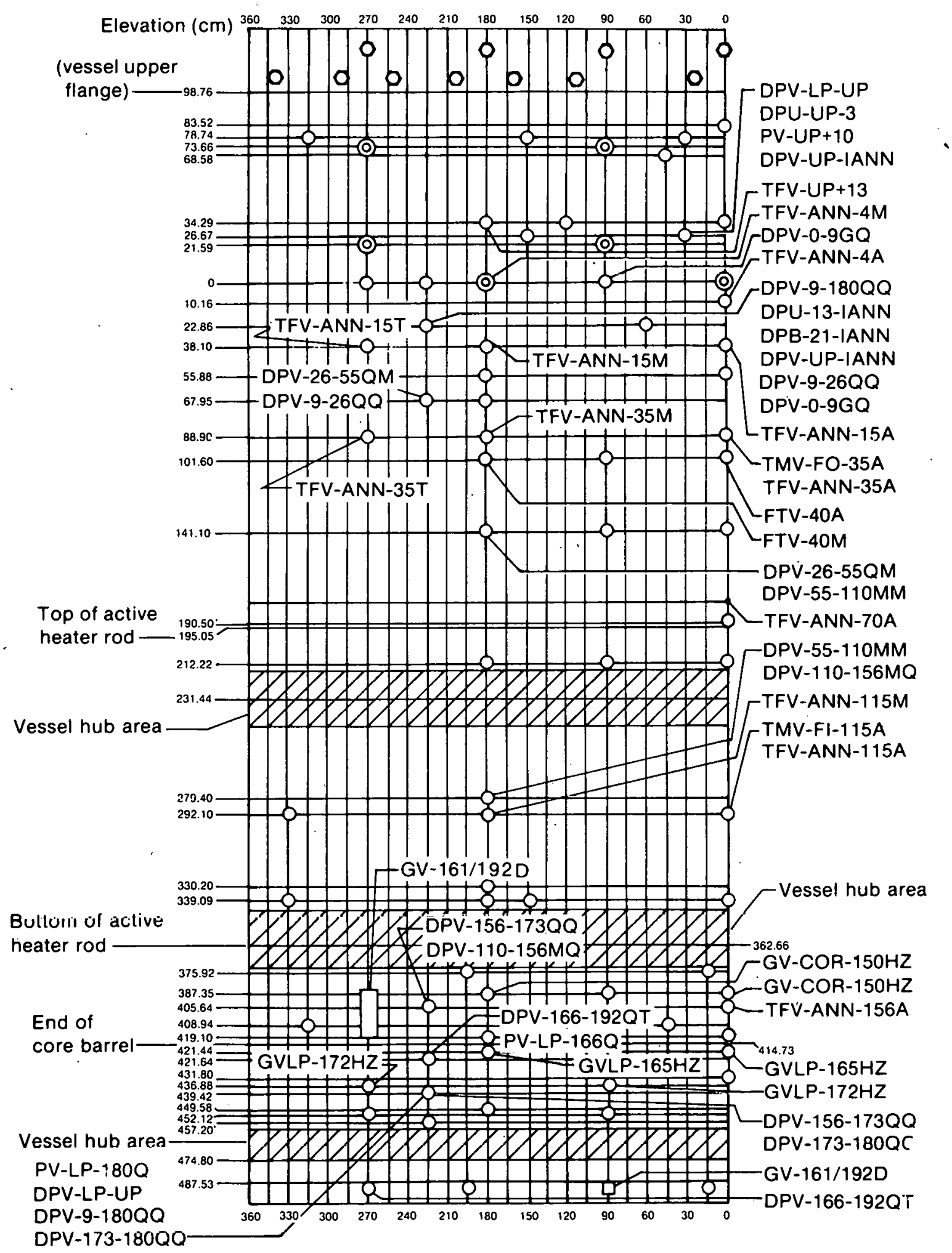

INEL-A-3077

Fig. 7 Semiscale Mod-1 pressure vessel -- penetrations and instrumentation. 
$\begin{array}{llllllll}A & B & C & D & E & F & G & H\end{array}$

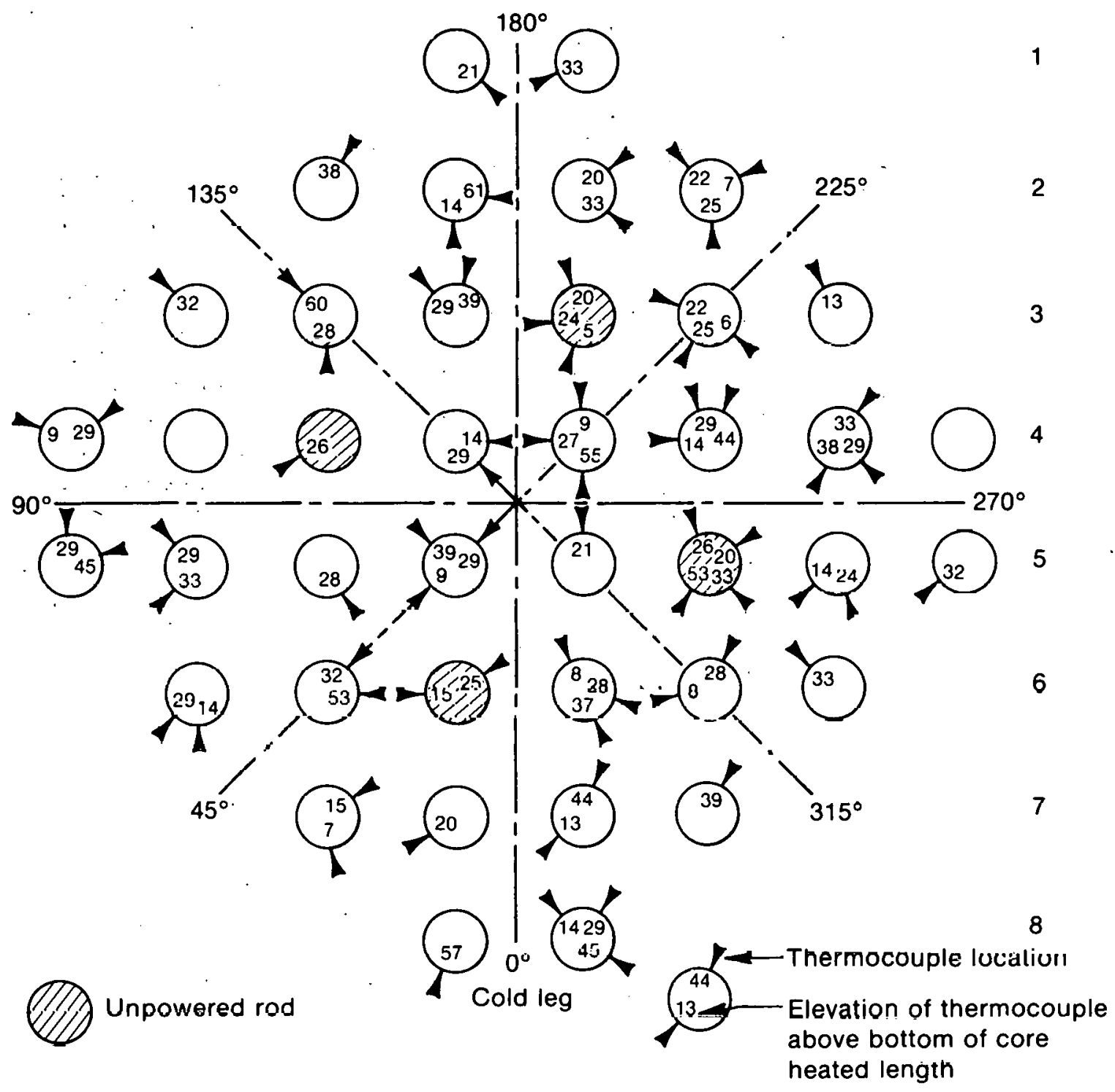

INEL-A-3075

Fig. 8 Semiscale Mod-1 heated core -- plan view. 
TABLE V

DATA PRESENTATION FOR SEMISCALE MOD-1 TEST S-06-6

\begin{tabular}{|c|c|c|c|c|c|}
\hline \multirow[b]{2}{*}{ Measurement } & \multirow[b]{2}{*}{ Location and Coments $^{[\mathrm{a}]}$} & \multicolumn{2}{|c|}{ Range $^{[a]}$} & \multirow{3}{*}{ Eigure ${ }^{[a]}$} & \multirow[b]{2}{*}{ Measuremer.t Comments ${ }^{[b]}$} \\
\hline & & Detector & $\begin{array}{c}\text { Data Acquissition } \\
\text { System }\end{array}$ & & \\
\hline FLUID TEMPERATURE & $\begin{array}{l}\text { Chromel-Alumel thermocouples unless } \\
\text { specified otherwise. }\end{array}$ & & & & \\
\hline Intact Loop & & 0 to $1533 \mathrm{~K}$ & 0 to $584 \mathrm{~K}$ & & $\cdot$ \\
\hline TFU-1 & $\begin{array}{l}\text { Hot leg, Spool } 1,54 \mathrm{~cm} \text { from vessel } \\
\text { center. }\end{array}$ & & 0 to $220 \mathrm{~K}$ & 9,10 & \\
\hline RBU-2 & $\begin{array}{l}\text { Hot leg, Spool } 2,117 \mathrm{~cm} \text { from vessel } \\
\text { center (platinum resistance bulb). }\end{array}$ & 0 to $811 \mathrm{~K}$ & 0 to $811 \mathrm{~K}$ & 9,10 & \\
\hline TFU-7 & $\begin{array}{l}\text { Cold leg, Spool 7, } 624 \mathrm{~cm} \text { from vessel } \\
\text { cérileit. }\end{array}$ & . & . & 11,12 & \\
\hline TFU-10 & $\begin{array}{l}\text { Cold leg, Spool } 10,367 \mathrm{~cm} \text { from } \\
\text { vessel center. }\end{array}$ & & - & 11,12 & \\
\hline RBU-14A & $\begin{array}{l}\text { Cold leg, Spool } 14,109 \mathrm{~cm} \text { from } \\
\text { vescel center, upstream of cold leg } \\
\text { injection port (platinum resistance } \\
\text { bulb). }\end{array}$ & 0 to $811 \mathrm{~K}$ & 0 to $811 \mathrm{~K}$ & 13,14 & \\
\hline TFU-14B & $\begin{array}{l}\text { Cold leg, Spool } 14,99 \mathrm{~cm} \text { from } \\
\text { vessel center. downstream of cold } \\
\text { leg injection port. }\end{array}$ & & & 13,14 & - \\
\hline TFU-15 & $\begin{array}{l}\text { Cold leg, Spool } 15,54 \mathrm{~cm} \text { from } \\
\text { vessel center. }\end{array}$ & & & 13,14 & \\
\hline Broken Loop & $\cdot$ & 0 to $1533 \mathrm{~K}$ & 0 to $820 \mathrm{~K}$ & & $\therefore$ \\
\hline TFB-20 & $\begin{array}{l}\text { Cold leg, Spool } 20,52 \mathrm{~cm} \text { from } \\
\text { vessel center. }\end{array}$ & & & 15,16 & \\
\hline TFB-23 & $\begin{array}{l}\text { Cold leg, Spool } 23,232 \mathrm{~cm} \text { from } \\
\text { vessel center, upstream of vessel- } \\
\text { side nozzle. }\end{array}$ & & & 15,16 & " \\
\hline TFB-24 & $\begin{array}{l}\text { Cold leg, Spool } 24,264 \mathrm{~cm} \text { from } \\
\text { vessel center, downstream from } \\
\text { vessel-side nozzle. }\end{array}$ & & & 15,16 & • \\
\hline TFB-30 & $\begin{array}{l}\text { Hot leg, Spool } 30,40 \mathrm{~cm} \text { from } \\
\text { vessel center. }\end{array}$ & & & 17,18 & \\
\hline TFB-37 & $\begin{array}{l}\text { Cold leg, Spool } 37,703 \mathrm{~cm} \text { from } \\
\text { vessel center along hot leg, dis- } \\
\text { charge of simulated steam generator. }\end{array}$ & & & 17,18 & \\
\hline TFB-42 & $\begin{array}{l}\text { Cold leg, Spool } 42,1054 \mathrm{~cm} \text { from } \\
\text { vessel center along trot leg, upstream } \\
\text { of pump-side nozzle. }\end{array}$ & · & . & 17,18 & \\
\hline TFB-43 & $\begin{array}{l}\text { Cold leg, Spool } 43.1086 \mathrm{~cm} \text { from } \\
\text { vessel center a long hot leg. }\end{array}$ & . & & 17,18 & \\
\hline$T F B-R F B-C$ & $\begin{array}{l}\text { Reflood bypass, near end cap, cold } \\
\text { leg side. }\end{array}$ & & & 19,20 & \\
\hline TFB-RFB-H & $\begin{array}{l}\text { Reflood bypass, near end cap, hot } \\
\text { lepp side. }\end{array}$ & & & 19,20 & \\
\hline Inlet Annulus & $\begin{array}{l}10 \mathrm{~cm} \text { below cold leg centerline, } \\
0.5 \mathrm{~cm} \text { from vesscl wall, Type } \\
\text { iron-constantan thermocouples. }\end{array}$ & 0 to $1033 \mathrm{~K}$ & 0 to $701 \mathrm{~K}$ & & \\
\hline TFV-ANN-4A & $0^{\circ}$. & & & 21,22 & \\
\hline TFV-ANN-4M & $180^{\circ}$. & & & 21,22 & \\
\hline Downcomer Annulus & $\begin{array}{l}\text { Centered in annulus, Type J iron- } \\
\text { constantan thermocouples. }\end{array}$ & 0 to $1033 \mathrm{~K}$ & 0 to $701 \mathrm{~K}$ & & \\
\hline TFV-ANN-15T & $\begin{array}{l}38 \mathrm{~cm} \text { below cold leg centerline, } \\
270^{\circ} \text {. }\end{array}$ & & & 23,24 & $\begin{array}{l}\text { Questionable data, possibly } \\
\text { rcading material temperatuif'e } \\
\text { of vessel filler insulator. }\end{array}$ \\
\hline TFV-ANN-35A & $\begin{array}{l}89 \mathrm{~cm} \text { below'cold leg centerline, } \\
n^{\circ} .\end{array}$ & & & 23,24 & \\
\hline TFV-ANN-35T & $\begin{array}{l}89 \mathrm{~cm} \text { below cold leg centerline, } \\
270^{\circ} \text {. }\end{array}$ & & & 23,24 & \\
\hline TFV-ANN-7OA & $\begin{array}{l}178 \mathrm{~cm} \text { below cold leg centerline, } \\
0^{\circ} \text {. }\end{array}$ & & & 23,24 & \\
\hline TFV-ANH-115A & $\begin{array}{l}292 \mathrm{~cm} \text { below cold leg centerline, } \\
0^{\circ} \text {. }\end{array}$ & & & 25,26 & \\
\hline TFV-ANM- $115 M$ & $\begin{array}{l}292 \mathrm{~cm} \text { below cold leg centerline, } \\
180^{\circ} .\end{array}$ & & $\cdot$ & 25,26 & \\
\hline TFV-ANN-156A & $\begin{array}{l}396 \mathrm{~cm} \text { below cold leg centerline, } \\
0^{\circ} \text {. }\end{array}$ & & . & 25,26 & \\
\hline
\end{tabular}


TABLE V (continued)

\begin{tabular}{|c|c|c|c|c|c|}
\hline \multirow[b]{2}{*}{ Measurement } & \multirow[b]{2}{*}{ Location and Corments $[a]$} & \multicolumn{2}{|c|}{ Range $^{[a]}$} & \multirow{3}{*}{ Figure $^{[a]}$} & \multirow[b]{2}{*}{ Measurement Comments ${ }^{[\mathrm{b}]}$} \\
\hline & & Detector & $\begin{array}{l}\text { Data Acquisition } \\
\text { System }\end{array}$ & & \\
\hline Upper Plenum & & 0 to $1533 \mathrm{~K}$ & 0 to $820 \mathrm{~K}$ & & \\
\hline$T F V-U P+13$ & $\begin{array}{l}\text { In upper plenum, } 34 \mathrm{~cm} \text { above } \\
\text { cold leg centeri ine at } 180^{\circ} .\end{array}$ & & & 27,28 & \\
\hline Lower Plenum & $\begin{array}{l}\text { On fluid thermocouple rack, } 2.54 \mathrm{~cm} \\
\text { from vessel center, } 45^{\circ} \text {. }\end{array}$ & $\mathrm{O}$ to $1533 \mathrm{~K}$ & 0 to $820 \mathrm{~K}$ & & \\
\hline TFV-LP-8 & $19 \mathrm{~cm}$ from bottom of vessel. & & & 29,30 & \\
\hline TFV-LP-15 & $37 \mathrm{~cm}$ from bottom of vessel. & & & 29,30 & \\
\hline$T F V-L P-22$ & $55 \mathrm{~cm}$ from bottom of vessel. & $\because$ & & 29,30 & \\
\hline \multicolumn{6}{|l|}{ Core } \\
\hline TFV-CORE-IN & $\begin{array}{l}\text { In core flow mixer box, } 381 \mathrm{~cm} \\
\text { below cold leg centerline } \\
\text { part of } F D V-C O R E-1 N) \text {. }\end{array}$ & 0 to $1533 \mathrm{~K}$ & 0 to $820 \mathrm{~K}$ & 31,32 & \\
\hline \multicolumn{6}{|l|}{ Core Grid Spacers } \\
\hline Grid Spacer 5 & $\begin{array}{l}140 \mathrm{~cm} \text { below cold leg centerline, } \\
54.6 \mathrm{~cm} \text { above top of heated length. }\end{array}$ & 0 to $1533 \mathrm{~K}$ & 0 to $1579 \mathrm{~K}$ & & \\
\hline TFG- 5 CD- 45 & $\begin{array}{l}\text { Thermocouple in space defined by } \\
\text { Columns } C \text { and } D \text {, Rows } 4 \text { and } 5 \text {. }\end{array}$ & & & 33,34 & \\
\hline Grid Spacer 6 & $\begin{array}{l}193 \mathrm{~cm} \text { below cold leq centerline, } \\
1.3 \mathrm{~cm} \text { above top of heated length. }\end{array}$ & & & & \\
\hline TFG-6CD-45 & $\begin{array}{l}\text { Thermocouple in space defined by } \\
\text { Columns } C \text { and } 0 \text {, Rows } 4 \text { and } 5 .\end{array}$ & & . & 35,36 & \\
\hline TFG-6DE-67 & $\begin{array}{l}\text { Thermocouple in space defined by } \\
\text { Columns } E \text { and } E \text {, Rows } 6 \text { and } 7 \text {. }\end{array}$ & & & 35,36 & \\
\hline Grid Spacer 10 & $\begin{array}{l}363 \mathrm{~cm} \text { below cold leg centerline } \\
\text { at bottom of heated length. }\end{array}$ & & & & \\
\hline TFG-10AB-45 & $\begin{array}{l}\text { Thermocouple in space defined by } \\
\text { Columins } A \text { and } B \text {, Rows } 4 \text { and } 5 \text {. }\end{array}$ & & & 37,38 & \\
\hline TFG-10GH-45 & $\begin{array}{l}\text { Thermocouple in space defined by } \\
\text { Columns } G \text { and } H \text {, Rows } 4 \text { and } 5 \text {. }\end{array}$ & & & 37,38 & \\
\hline [cc 5ystem & - & 0 to $1533 \mathrm{~K}$ & 0 to $584 \mathrm{~K}$ & : & \\
\hline TF̈U-ÊCC-14 & $\begin{array}{l}\text { In ECC line leading to intact } \\
\text { loop Spool } 14 .\end{array}$ & & & $3 y, 40$ & \\
\hline Steam Generator & & 0 to $1533 \mathrm{~K}$ & 0 to $584 \mathrm{~K}$ & & \\
\hline TFU-SG̈F̂H & $\begin{array}{l}\text { in feedwater line leading to steam } \\
\text { generator. }\end{array}$ & & & 11,12 & \\
\hline TFII-SGSO & $\begin{array}{l}\text { In steam dome, } 329 \mathrm{~cm} \text { above } \\
\text { Dot tom tif tubi shecel. }\end{array}$ & & & 43,44 & \\
\hline IFU-SGI & $\begin{array}{l}\text { Secondary side, } 30 \mathrm{~cm} \text { above bottom } \\
\text { of tube sheet. }\end{array}$ & & & 45,46 & \\
\hline TFU-SG3 & $\begin{array}{l}\text { Secondary side, } 122 \mathrm{~cm} \text { above bottom } \\
\text { of tube sheet. }\end{array}$ & & & 45,46 & . \\
\hline TFU-SG4 & $\begin{array}{l}\text { Secondary side, } 244 \mathrm{~cm} \text { above bottom } \\
\text { of tube sheet. }\end{array}$ & & & 45,46 & \\
\hline \multicolumn{6}{|l|}{ Pressurizer } \\
\hline TFU-PRIZE & $\begin{array}{l}\text { In surge line, near pressurizer } \\
\text { exit, between turbine flowmeter } \\
\text { alld pr'tssuri<tr. }\end{array}$ & 0 to $1533 \mathrm{~K}$ & 0 to $820 \mathrm{~K}$ & 47,48 & \\
\hline$\frac{\text { Riessure Suppreggion }}{\text { System }}$ & & $\theta$ te $1532 \%$ & 0 to $584 \mathrm{~K}$ & & \\
\hline $15-r s s-1 j$ & 84 cill fruil bultum uf Laink. & & & 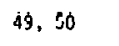 & \\
\hline TF-PSS-63 & $160 \mathrm{~cm}$ from bottom of tank. & & & 49,50 & \\
\hline TF-PSS-130 & $330 \mathrm{~cm}$ from bottom of tank. & & & 49,50 & \\
\hline
\end{tabular}


TABLE V (continued)

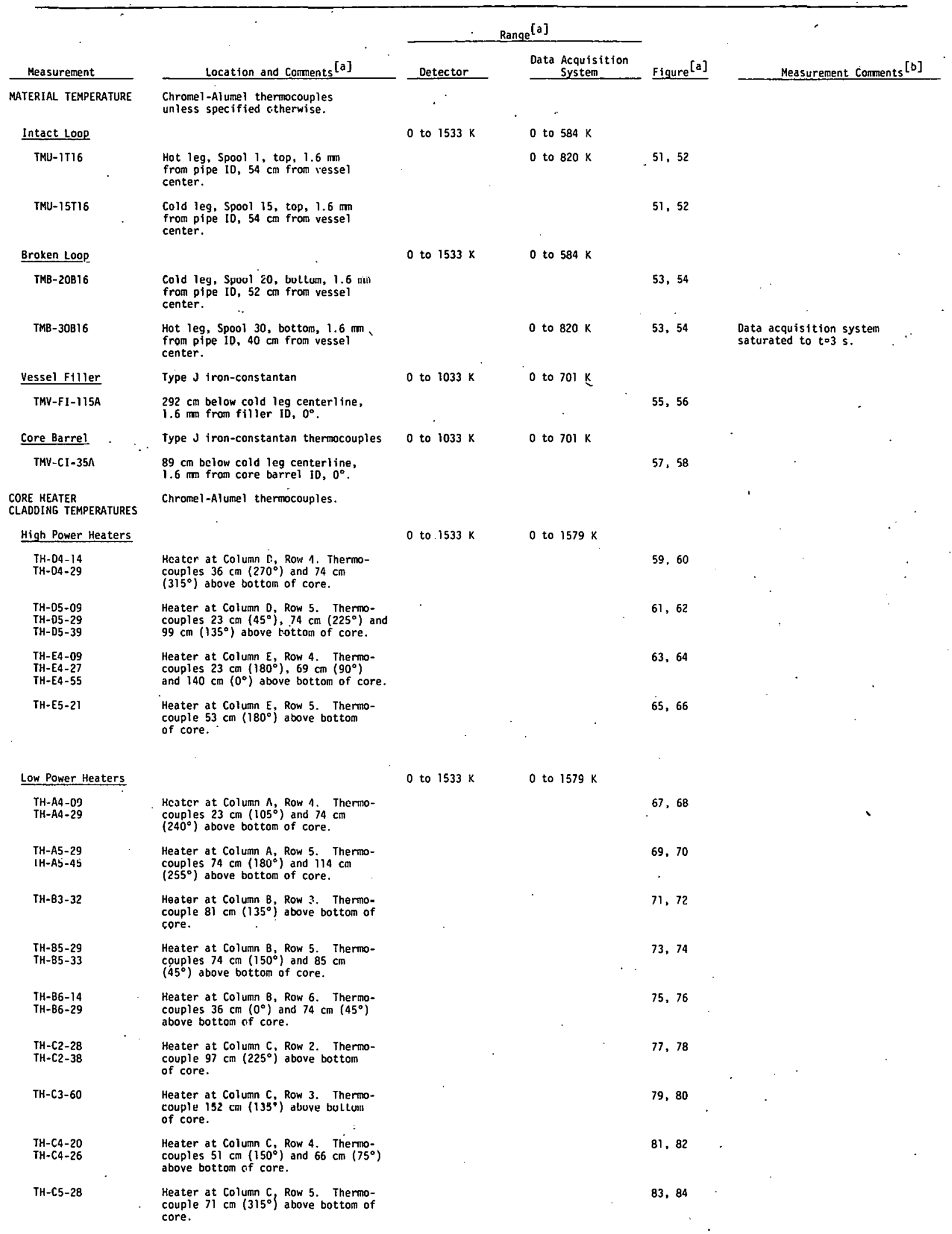




\section{TABLE V (continued)}

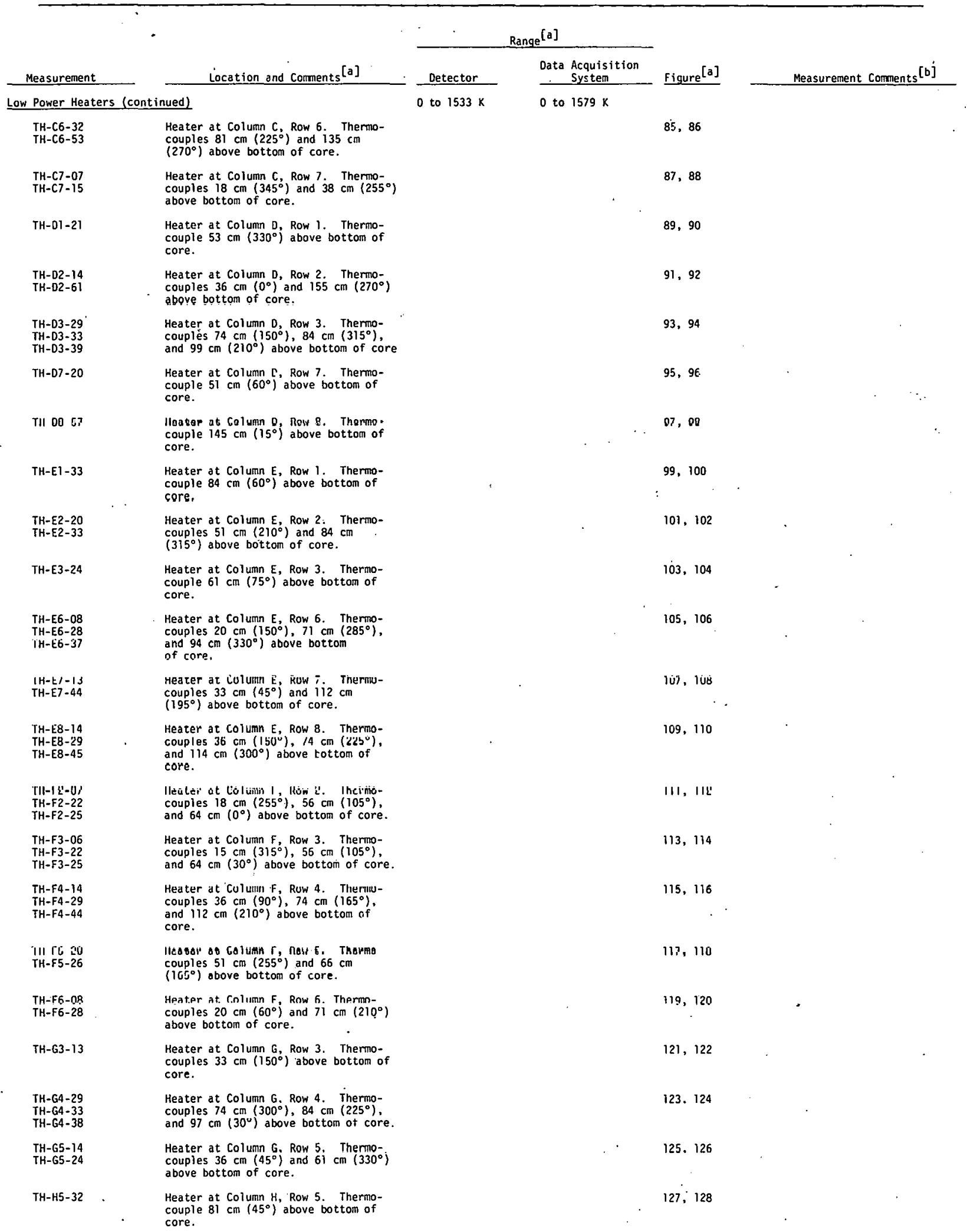


TABLE V (continued)

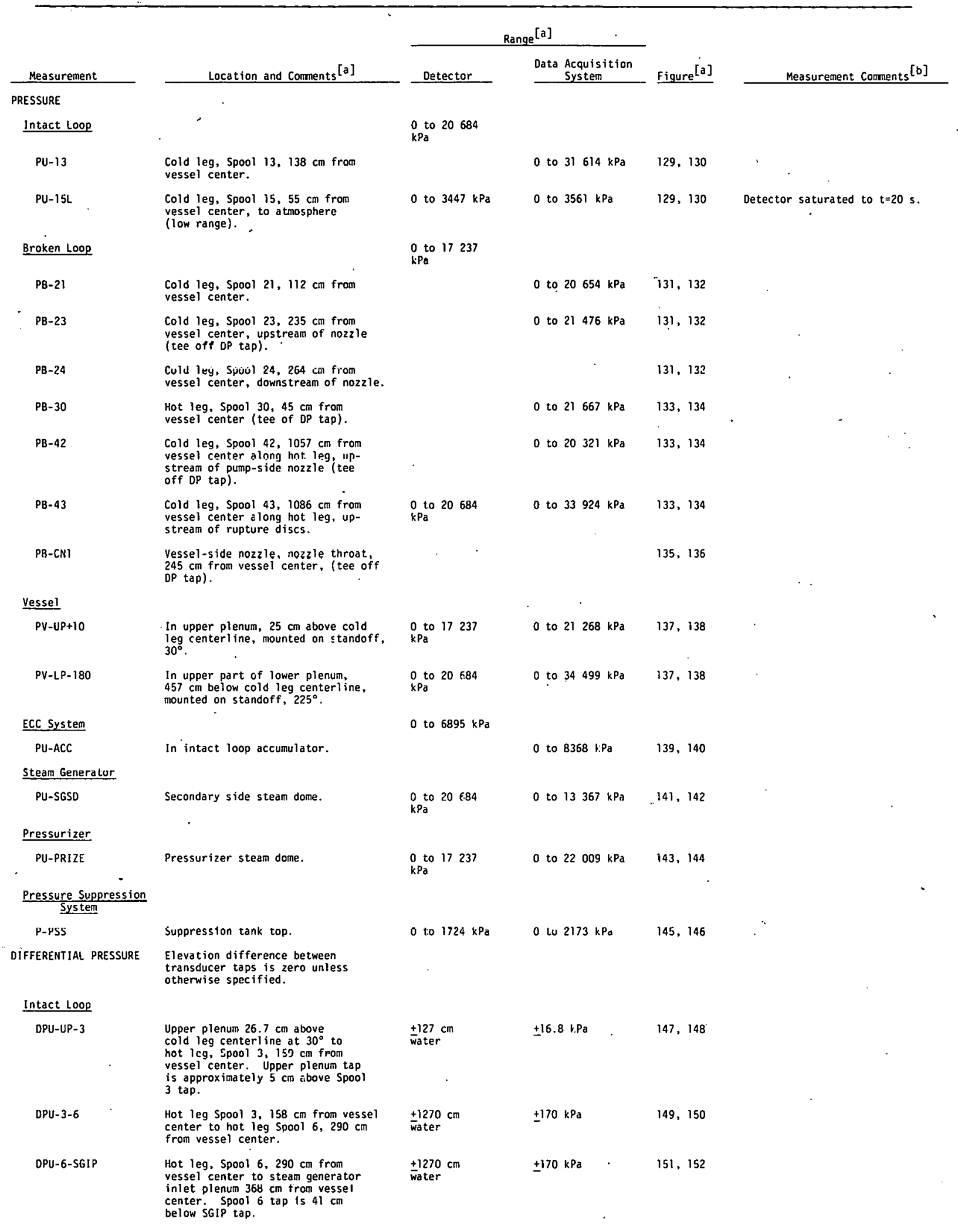




\section{TABLE $V$ (continued)}

\begin{tabular}{|c|c|c|c|c|c|c|}
\hline \multirow[b]{2}{*}{ Measurement } & \multirow{2}{*}{ Location and Comments ${ }^{[a]}$} & \multicolumn{2}{|c|}{$\operatorname{Range}^{[a]}$} & \multirow{3}{*}{ Figure $^{[a]}$} & \multirow{2}{*}{\multicolumn{2}{|c|}{ Measurement Coriments ${ }^{[\mathrm{b}]}$}} \\
\hline & & \multirow[t]{2}{*}{ Detector } & $\begin{array}{l}\text { Data Acquisition } \\
\text { System }\end{array}$ & & & \\
\hline \multicolumn{5}{|c|}{ Intact Loop (continued) } & & \\
\hline DPU-6-7 & $\begin{array}{l}\text { Across steam generator, hot leg } \\
\text { Spool } 6 \text {, 290 com from vessel center } \\
\text { to cold leg. Spool, } 587 \text { cm from } \\
\text { vessel center. Spool } 68 \text { tap is } 48 \\
\mathrm{~cm} \text { above Spool } 7 \text { tap. }\end{array}$ & $\frac{\$ 1270 \mathrm{~cm}}{\text { water }}$ & $\pm 167 \mathrm{kPa}$ & 153,154 & & \\
\hline $\begin{array}{c}\text { DPU-SGOP-7 } \\
-\end{array}$ & $\begin{array}{l}\text { From steam generator outlet plenum } \\
683 \mathrm{~cm} \text { from vessel center along } \\
\text { cold leg to cold leg Spool } 7,587 \mathrm{~cm} \\
\text { from vessel center, including crifice. } \\
\text { Spool } 7 \text { tap is } 89 \mathrm{~cm} \text { below S60P tap. }\end{array}$ & $\frac{\$ 1270 \mathrm{~cm}}{\text { water }}$ & $\pm 169 \mathrm{kPa}$ & 155,156 & $\because$ & $:$ \\
\hline DPU-7-10 & $\begin{array}{l}\text { Steam generator outlet to pump } \\
\text { inlet, cold leg } 5 \text { pool } 7,587 \mathrm{~cm} \\
\text { from vessel center, to cold leg } \\
\text { Spool } 10,359 \mathrm{~cm} \text { from vessel } \\
\text { center. }\end{array}$ & $\underset{\text { water }}{+127 \mathrm{~cm}}$ & $\pm 17.2 \mathrm{kPa}$ & $157, .158$ & . & . \\
\hline DPU-12-10 & $\begin{array}{l}\text { Pump outlet to pump inlet, cold } \\
\text { leg spool 12, 192 cm trom vessel } \\
\text { center, to cold leg spool } 10,359 \\
\text { cm fram vessel center. Spool } 10 \\
\text { tap is } 25 \mathrm{~cm} \text { below Spool } 12 \text { tap. }\end{array}$ & $\pm 345 \mathrm{kPa}$ & $\pm 343 \mathrm{kPa}$ & 159,160 & . & \\
\hline 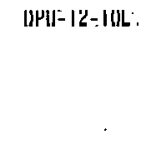 & 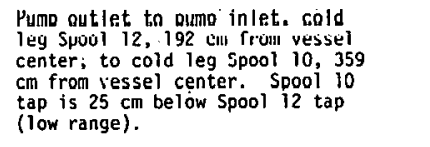 & 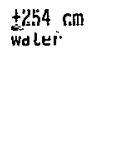 & $\pm 33.8 \mathrm{kPa}$ & |6i. 16? & $\begin{array}{l}\text { hath arnuisitinn systam } \\
\text { saturated to } t=6 \mathrm{~s} \text {. }\end{array}$ & \\
\hline DPU $=12-15$ & $\begin{array}{l}\text { Cold leg Spool } 12,192 \mathrm{~cm} \text { from } \\
\text { vessel center, to cold leg. Spool } \\
13,55 \mathrm{~cm} \text { from vessel center. }\end{array}$ & $\frac{1254 \mathrm{~cm}}{\text { water }}$ & $\pm 34.5 \mathrm{kPa}$ & $163: 154$ & & \\
\hline DPU-15-3 & $\begin{array}{l}\text { cold leg to hot leg; cold leg Spool } \\
15,55 \mathrm{~cm} \text { from vessel center, to } \\
\text { hot leg Spool } 3,158 \mathrm{~cm} \text { from vessel } \\
\text { center. Spool is tap is } 22 \mathrm{~cm} \\
\text { below Spool } 3 \text { tap. }\end{array}$ & $\begin{array}{l} \pm 1270 . c m \\
\text { water. }\end{array}$ & $\pm 169 \mathrm{kPa}$ & 165. 166 & & \\
\hline DPU-15-3L. & 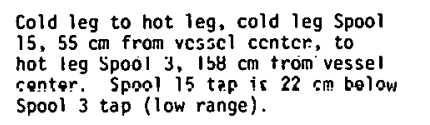 & $\frac{+254 \mathrm{~cm}}{\text { water }}$ & $\pm 33.5 \mathrm{kPa}$ & 167,168 & $\begin{array}{l}\text { Data acquisition system } \\
\text { saturated lio } 1-0 \mathrm{s.}\end{array}$ & \\
\hline OPU-15-IANN & 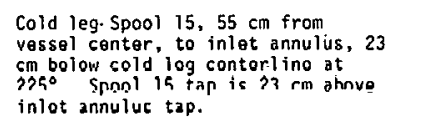 & $\frac{+254 \mathrm{~cm}}{\text { water }}$ & $\pm 33.6 \mathrm{kPa}$ & 169,170 & & \\
\hline DrU PRCSLL & $\begin{array}{l}\text { Pressurizer water level. Lleva- } \\
\text { tion difference between taps is } \\
\text { lis5 cm. Lower tap is } 9 \mathrm{~cm} \text { above } \\
\text { pressurizer exit. }\end{array}$ & $\frac{1137 \text { cin }}{\text { water }}$ & $117.1 \mathrm{kPa}$ & 171,178 & & \\
\hline DPU-PR-4 & 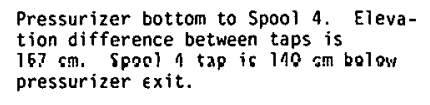 & $\pm 3447 \mathrm{kPa}$ & $\pm 3456 \mathrm{kPa}$ & 173,174 & $\begin{array}{l}\text { Data acquisition system } \\
\text { saturated from } t=0 \text { s to } \\
t=10 \text { s. }\end{array}$ & \\
\hline \multicolumn{7}{|l|}{ Broken Loop } \\
\hline DPB-21-IANN & $\begin{array}{l}\text { Cold leg Spool } 21,112 \mathrm{~cm} \text { from } \\
\text { vessef center, to vesseg, inlet } \\
\text { annulus, } 23 \mathrm{~cm} \text { below cold leg } \\
\text { centerline at } 225^{\circ} \text {. Inlet annulus } \\
\text { tap. is } 23 \mathrm{~cm} \text { below Spool } 21 \text { tap. }\end{array}$ & $\underset{\text { water }}{+254 \mathrm{~cm}}$ & $\pm 33.2 \mathrm{kPa}$ & $175,176^{\prime}$ & & - \\
\hline OPB-21-23 & $\begin{array}{l}\text { Cold leg, spool } 21,112 \mathrm{~cm} \text { from vessel } \\
\text { center, to cold leg 23, } 235 \mathrm{~cm} \text { from } \\
\text { ressel ceittei". }\end{array}$ & $\frac{+2032 \mathrm{~cm}}{\text { water }}$ & $\pm 267 \mathrm{kPa}$ & 177,178 & . & \\
\hline DPB-23-CNI & $\begin{array}{l}\text { Cold leg, Spool } 23,235 \mathrm{~cm} \text { from } \\
\text { vessel center to vessel-side } \\
\text { nozzile throat, } 245 \mathrm{~cm} \text { from vessel } \\
\text { center. }\end{array}$ & $\pm 10342 \mathrm{kPa}$ & $\pm 13843 \mathrm{kPa}$ & 179,180 & & \\
\hline DPB-23-21 & $\begin{array}{l}\text { Across vesscl-side nozzlc, Spool } 23, \\
235 \mathrm{~cm} \text { from vessel center to } \mathrm{Spooi} \\
24,264 \mathrm{~cm} \text { from vessel center. }\end{array}$ & $\pm 10342 \mathrm{kPu}$ & $113043 \mathrm{kPa}$ & $181,18 \hat{\imath}$ & & \\
\hline OP8-30-36L & $\begin{array}{l}\text { Across entire simulated steam gen- } \\
\text { erator assembly, hot leg Spool } 30 \text {, } \\
45 \mathrm{~cm} \text { from vessel center, to cold } \\
\text { leg Spool } 36 \text { lower. tap, } 617 \mathrm{~cm} \\
\text { from vessel center. Spool } 30 \text { tap is } \\
48 \mathrm{~cm} \text { below Spool } 36 \text { lower tap. }\end{array}$ & $\pm 3447 \mathrm{kPa}$ & $\pm 3487 \mathrm{kPa}$ & 183,184 & . & \\
\hline
\end{tabular}




\section{TABLE V (continued)}

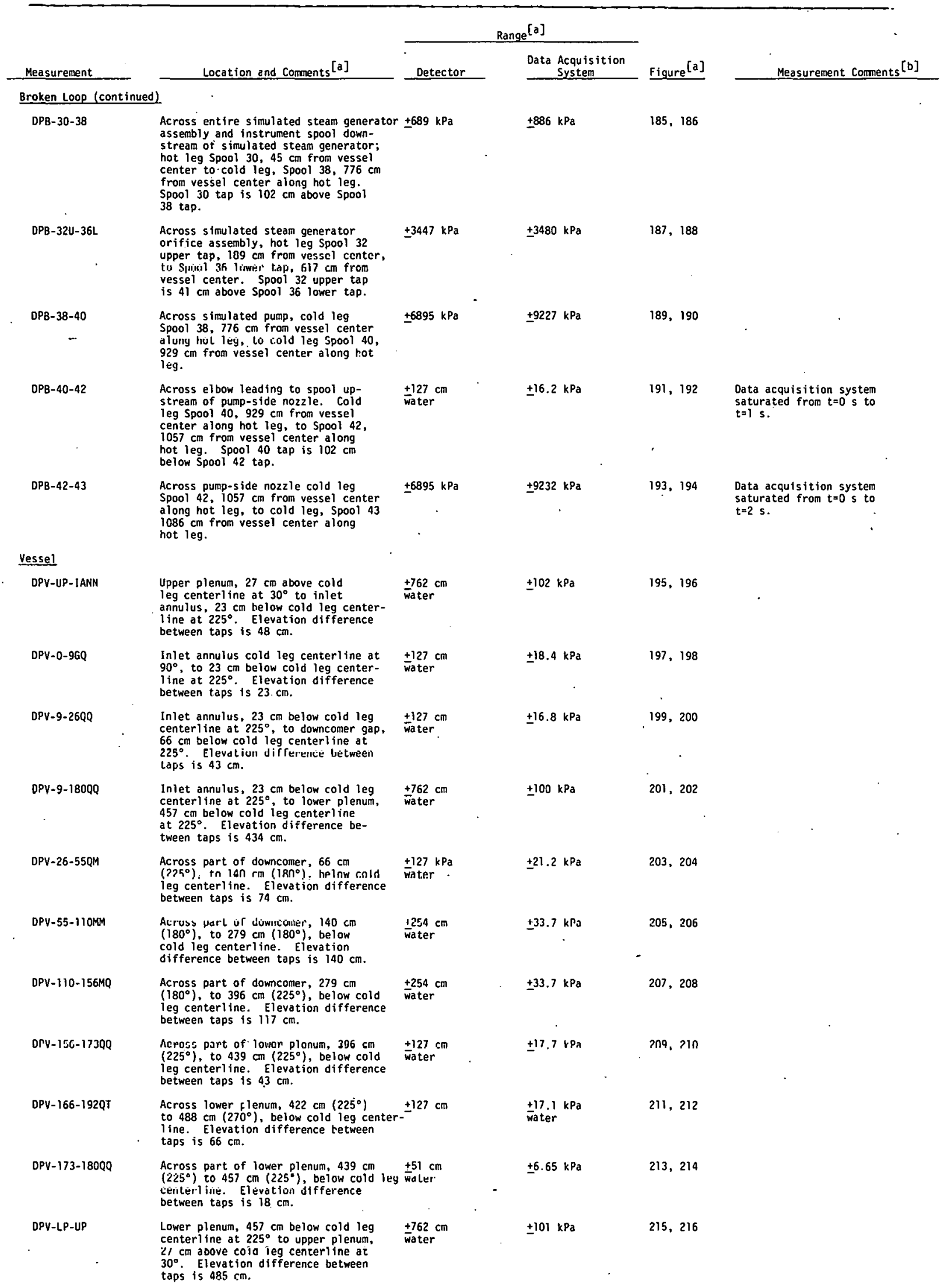




\section{TABLE V (continued)}

\begin{tabular}{|c|c|c|c|c|c|}
\hline \multirow[b]{2}{*}{ Measurement } & \multirow[b]{2}{*}{ Location and Comments ${ }^{[a] .}$} & \multicolumn{2}{|c|}{ Range $^{[\mathrm{a}]}$} & \multirow{3}{*}{ Figure $^{[a]}$} & \multirow[b]{2}{*}{ Measurement Corments ${ }^{[b]}$} \\
\hline & & Detector & $\begin{array}{c}\text { Data Acquisition } \\
\text { System } \\
\end{array}$ & & \\
\hline \multicolumn{5}{|l|}{ ECC SYSTEM } & \\
\hline DPU-ACC-TB & $\begin{array}{l}\text { Top to bottom of intact loop } \\
\text { accumulator. Elevation difference. } \\
\text { between taps is } 274 \mathrm{~cm} \text {. }\end{array}$ & $\frac{+1270 \mathrm{~cm}}{\text { water }}$ & $\pm 108 \mathrm{kPa}$ & 217,218 & $\cdot$ \\
\hline \multicolumn{6}{|l|}{ Steam Generator. } \\
\hline DPU-SGFW & $\begin{array}{l}\text { In. steam generator feedwater } \\
\text { line. }\end{array}$ & $\frac{+762 \mathrm{~cm}}{\text { water }}$ & $\begin{array}{l}+762 \cdot \mathrm{cm}: \\
\text { water. }\end{array}$ & 219,220 & \\
\hline OPU-SG-SEC & $\begin{array}{l}\text { Secondary side, differential pressure } \\
\text { taps at } 114 \mathrm{~cm} \text { and } 320 \mathrm{~cm} \text { above } \\
\text { bottom of tube sheet. Elevation } \\
\text { difference between taps is } 206 \mathrm{~cm} \text {. }\end{array}$ & $\frac{+254 \mathrm{~cm}}{\text { water }}$ & $\pm 33.7 \mathrm{kPa}$ & 221,222 & . \\
\hline DPU-SG-DIISC & $\begin{array}{l}\text { Across venturi tube, } 168 \mathrm{~cm} \text { down- } \\
\text { stream from steam generator dis- } \\
\text { charge. }\end{array}$ & $\begin{array}{l}+1270 \mathrm{~cm} \\
\text { water }\end{array}$ & $\pm 170: \mathrm{kPa}$ & 223.224 & \\
\hline$\frac{\text { Pressure Suppression }}{\text { System }}$ & & & & & \\
\hline DP-PSS-TB & $\begin{array}{l}\text { Top to bottom of pressure } \\
\text { suppression tank. Elevation } \\
\text { difference between taps } \\
\text { is } 338 \mathrm{~cm} \text {. }\end{array}$ & $\frac{ \pm 762 \mathrm{~cm}}{\text { water }}$ & $\pm 103 \mathrm{kPa}$ & 225,226 & . \\
\hline VULUMEIKIC HLUW RAIE & Iurbine flowmeter, bidirectional. & & . & $\cdot$ & 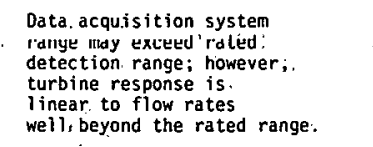 \\
\hline Intact Loop & 3-in. Schedule, 160 pipe. & & & & \\
\hline FTU-1 & $\begin{array}{l}\text { Hot leg, Spool l, } 42 \mathrm{~cm} \text { from } \\
\text { vessel center. }\end{array}$ & $\begin{array}{l} \pm 1.26 \mathrm{to} \\
\pm 25.24 \mathrm{l} / \mathrm{s}\end{array}$ & $\pm 75.71 \mathrm{l} / \mathrm{s}$ & $227, .228$ & $\begin{array}{l}\text { The detector is a unidirectional } \\
\text { flow device and the electronics. } \\
\text { only registered positive values. }\end{array}$ \\
\hline FTU-9 & $\begin{array}{l}\text { Cold leg, Spool 9, } 393 \mathrm{~cm} \text { from } \\
\text { vessel center. }\end{array}$ & $\begin{array}{l}+5.05 \text { to } \\
\pm 50.47 \mathrm{l} / \mathrm{s}\end{array}$ & $\pm 75.71 \mathrm{\ell} / \mathrm{s}$ & $227 ; 228^{\circ}$ & \\
\hline FTU-13 & $\begin{array}{l}\text { Cold leg, Spool 13, } 163 \mathrm{~cm} \text { from } \\
\text { vessel center. }\end{array}$ & $\begin{array}{l}+1.26 \mathrm{to} \\
\pm 50.47 \mathrm{R} / \mathrm{s}\end{array}$ & $+/ 5.11: \ell / s$ & $229, .230$ & \\
\hline FIU-i5 & $\begin{array}{l}\text { Culd leg, spooi is, } 42 \mathrm{~cm} \text { rrom } \\
\text { vessel center. }\end{array}$ & $\frac{ \pm 1.26 \mathrm{to}}{150.47 \mathrm{k} / \mathrm{s}}$ & \pm to's.uy. $l / \bar{s}$ & $22 y, 230$ & \\
\hline Broken Loop & Schedule 160 pipe. & & & . & \\
\hline FTB-21 & $\begin{array}{l}\text { Cold leg, Spool } 21,146 \mathrm{~cm} \text { from } \\
\text { vessel cenier; 3-lil. pipe. }\end{array}$ & $\begin{array}{l}+1.26 \text { to } \\
\pm 25.24 \times 15\end{array}$ & $\pm 75.711 \mathrm{\ell} / \dot{\mathrm{s}}$ & $231 ; 232$ & - \\
\hline FTB-30 & $\begin{array}{l}\text { Hot leg, Spool } 30,63 \mathrm{~cm} \text { from } \\
\text { vessel center; } 3-\text { in. pipe. }\end{array}$ & $\begin{array}{l}+1.26 \text { to } \\
\pm 25.24 \mathrm{x} / \mathrm{s}\end{array}$ & $+50.47 \mathrm{l} / \mathrm{s}$ & 233,234 & \\
\hline FTB-37 & $\begin{array}{l}\text { Cold leg, spool } 37,739 \mathrm{~cm} \text { from } \\
\text { vessel center along hot leg; } 2 \text {-in. } \\
\text { pipe. }\end{array}$ & $\begin{array}{l} \pm 1.26 \text { to } \\
\pm 50.47 \mathrm{l} / \mathrm{s}\end{array}$ & $\pm 50: 47 \mathrm{l} / \mathrm{s}$. & $233, .234$ & \\
\hline Core & & . & & & . \\
\hline FTV-CORE-IN & $\begin{array}{l}\text { Entrance tu core, } 401 \mathrm{~cm} \text { telow } \\
\text { cold leg centerline. }\end{array}$ & $\begin{array}{l} \pm 1.26 \mathrm{to} \\
\pm 12.62 \mathrm{l} / \mathrm{s}\end{array}$ & $\pm 56.78 \mathrm{l} / \mathrm{s}$ & 235,236 & \\
\hline \multicolumn{6}{|l|}{ ECC System } \\
\hline rTU IITIE & 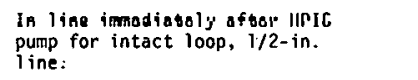 & $\begin{array}{l}10.017 \mathrm{to} \\
\pm 0.47 \mathrm{R} / \mathrm{s}\end{array}$ & $10.315 \mathrm{l} / \mathrm{s}$ & 297,290 & \\
\hline FTU-LP.IS & $\begin{array}{l}\text { In line leading from LPIS pump. } \\
\text { for intact loop, } 1 / 2 \text {-in. line. }\end{array}$ & $\begin{array}{l}+0.047 \text { to } \\
\pm 0.47 \mathrm{2} / \mathrm{s}\end{array}$ & $\pm 0.631 \mathrm{l} / \mathrm{s}$ & 239,240 & . \\
\hline PTU ACC & $\begin{array}{l}\text { In line leading from intact loop } \\
\text { accumulator, } 1-\text {-in. line. }\end{array}$ & $\begin{array}{l}10.315 \mathrm{tu} \\
\pm 3.15 \mathrm{R} / \mathrm{s}\end{array}$ & $14.4 \varepsilon \mathrm{t} / \mathrm{s}$ & 241,242 & $\begin{array}{l}\text { Dd ta diqu / I I ifor sys cem saturated } \\
\text { from } t=68 \text { to } t=86 \mathrm{~s} \text {. }\end{array}$ \\
\hline Pressurizer & $1-1 / 2-$ in. turbine & & & & \\
\hline FTU-PRIZE & Surge line. & $\begin{array}{l}+0.315 \mathrm{t} . \mathrm{n} \\
\pm 3.15 \mathrm{l} / \mathrm{s}\end{array}$ & $\pm \kappa .318 / \mathrm{s}$ & $243,2.44$ & . \\
\hline FLUID VELOCITY & Turbine flowmeter, bidirectional. & & & & \\
\hline \multicolumn{6}{|l|}{ Downcomer } \\
\hline FTV-40A & $\begin{array}{l}102 \mathrm{~cm} \text { below cold leg centerline, } \\
0^{\circ} .\end{array}$ & $\begin{array}{l}+0.762 \text { to } \\
\pm 15.24 \mathrm{~m} / \mathrm{s}\end{array}$ & $\pm 15.24 \pi / \mathrm{s}$ & 245,246 & \\
\hline FTV-40M. & $\begin{array}{l}102 \mathrm{~cm} \text { telow cold leg centerline, } \\
180^{\circ} .\end{array}$ & $\begin{array}{l}+0.762 \text { to } \\
\pm 15.24 / \mathrm{ms}\end{array}$ & $\pm 15.24 \mathrm{~m} / \mathrm{s}$ & 245,246 & \\
\hline MOMENTUM FLUX & Drdy dise, bidirectiunal. & & & & $\begin{array}{l}\text { Drag disc data may exhibit } \\
\text { significant temperature } \\
\text { dependence. Drag disc cata } \\
\text { should be used cnly for short- } \\
\text { term transient response. }\end{array}$ \\
\hline
\end{tabular}


TABLE V (continued)

\begin{tabular}{|c|c|c|c|c|c|}
\hline \multirow[b]{2}{*}{ Measurement } & \multirow[b]{2}{*}{ Location and Comments ${ }^{[\mathrm{a}]}$} & \multicolumn{2}{|c|}{ Range $^{[a]}$} & \multirow[b]{2}{*}{$\underline{F i g u r e}^{[a]}$} & \multirow[b]{2}{*}{ Measurement Corments ${ }^{[b]}$} \\
\hline & & Detector & $\begin{array}{l}\text { Data Acquisition } \\
\text { System }\end{array}$ & & \\
\hline Intact Loop & 3-in. pipe. & & & & \\
\hline $\begin{array}{c}\text { FDU-1 } \\
-\end{array}$ & $\begin{array}{l}\text { Hot leg, Spool } 1,60 \mathrm{~cm} \text { from } \\
\text { vessel center; target size } \\
2.22 \mathrm{~cm} \text {. }\end{array}$ & $\underset{\mathrm{kg} / \mathrm{m}-\mathrm{s}^{2}}{ \pm 298 \text { to }} \pm 17113$ & $\begin{array}{l} \pm 76 \quad 090 \\
\mathrm{~kg} / \mathrm{m}-\mathrm{s}^{2}\end{array}$ & 247,248 & \\
\hline FOU-5 & $\begin{array}{l}\text { Hot leg, Spool } 5,256 \mathrm{~cm} \text { from } \\
\text { vessel center; target size } \\
2.54 \mathrm{~cm} \text {. }\end{array}$ & $\frac{ \pm 1.49 \cdot \text { to }+2976}{\mathrm{~kg} / \mathrm{m}-\mathrm{s}^{2}}$ & $\frac{ \pm 6994}{\mathrm{~kg} / \mathrm{m}-\mathrm{s}^{2}}$ & 249,250 & \\
\hline FDU-10 & $\begin{array}{l}\text { Cold leg, Spool } 10,349 \mathrm{~cm} \text { from } \\
\text { vessel center; target size } 2.22 \mathrm{~cm} .\end{array}$ & $\begin{array}{l} \pm 298 \text { to } \\
\mathrm{kg} / \mathrm{m}-\mathrm{s}^{2}\end{array}$ & $\begin{array}{l} \pm 35344 \\
\mathrm{~kg} / \mathrm{m}-\mathrm{s}^{2}\end{array}$ & 251,252 & . \\
\hline FOU-13 & $\begin{array}{l}\text { Cold leg, Spool } 13,138 \mathrm{~cm} \text { from } \\
\text { vessel center; target size } 2.22 \mathrm{~cm} \text {. }\end{array}$ & $\begin{array}{l} \pm 298 \text { to } \\
\mathrm{kg} / \mathrm{m}-\mathrm{s}^{2}\end{array}$ & $\begin{array}{l} \pm 28528 \\
\mathrm{~kg} / \mathrm{m}-\mathrm{s}^{2}\end{array}$ & 253,254 & \\
\hline FDU -15 & $\begin{array}{l}\text { Cold leg, spool } 15,60 \mathrm{~cm} \text { from } \\
\text { vessel center; target size } 2.22 \mathrm{~cm} .\end{array}$ & $\underset{\mathrm{kg} / \mathrm{m}-\mathrm{s}^{2}}{ \pm 298 \text { to }} \pm 21578$ & $\begin{array}{l} \pm 39124 \\
\mathrm{~kg} / \mathrm{m}-\mathrm{s}^{2}\end{array}$ & 255,256 & : \\
\hline \multicolumn{6}{|l|}{ Broken Loop } \\
\hline FDB-21 & $\begin{array}{l}\text { Cold leg, Spool } 21,134 \mathrm{~cm} \text { from } \\
\text { vessel center, } 3 \text {-in. pipe; target } \\
\text { size } 2.22 \mathrm{~cm} \text {. }\end{array}$ & $\begin{array}{l} \pm 298 \text { to } \pm 104915 \\
\mathrm{~kg} / \mathrm{m}-\mathrm{s}^{2}\end{array}$ & $\begin{array}{l} \pm 66774 \\
\mathrm{~kg} / \mathrm{m}-\mathrm{s}^{2}\end{array}$ & 257,258 & - \\
\hline FOB -23 & $\begin{array}{l}\text { Cold leg, Spool } 23,238 \mathrm{cml} \text { from } \\
\text { vessel center, upstream of vessel- } \\
\text { side nuzzle, 2-in. pipe; torget } \\
\text { size } 1.03 \mathrm{~cm} \text {. }\end{array}$ & $\begin{array}{l} \pm 298 \text { to } \\
\mathrm{kg} / \mathrm{m}-\mathrm{s}^{2}\end{array}$ & $\begin{array}{l} \pm 228730 \\
\mathrm{~kg} / \mathrm{m}-\mathrm{s}^{2}\end{array}$ & 259,260 & \\
\hline FD8-30 & $\begin{array}{l}\text { Hot leg, Spool } 30,52 \mathrm{~cm} \text { from } \\
\text { vessel center, 3-in. pipe; target } \\
\text { size } 1.67 \mathrm{~cm} \text {. }\end{array}$ & $\begin{array}{l} \pm 298 \text { to } \pm 89290 \\
\mathrm{~kg} / \mathrm{m}-\mathrm{s}^{2}\end{array}$ & $\begin{array}{l} \pm 67280 \\
\mathrm{~kg} / \mathrm{m}-\mathrm{s}^{2}\end{array}$ & 261,262 & $\begin{array}{l}\text { Questionable data, drag disc } \\
\text { mounted horizontally and filled } \\
\text { with cold water. }\end{array}$ \\
\hline FDB-37 & $\begin{array}{l}\text { Cold leg, Spool } 37,725 \mathrm{~cm} \text { from } \\
\text { vessel center along hot leg, sleálin } \\
\text { generator outlet, vertical pipe. } \\
\text { 2-in. pipe; target size } 1.03 \mathrm{~cm} \text {. }\end{array}$ & $\begin{array}{l} \pm 298 \text { to } \pm 180067 \\
\mathrm{~kg} / \mathrm{m}-\mathrm{s}^{2}\end{array}$ & $\begin{array}{l} \pm 374272 \\
\mathrm{~kg} / \mathrm{m}-\mathrm{s}^{2}\end{array}$ & 263,264 & $\begin{array}{l}\text { Questionable data, drag disc } \\
\text { mounted horizontally and filled } \\
\text { with cold water. }\end{array}$ \\
\hline FDB- 42 & $\begin{array}{l}\text { Cold leg, Spool } 42,1057 \mathrm{~cm} \text { from } \\
\text { vessel center along hot leg, up- } \\
\text { stream of pump-side nozzle, down- } \\
\text { stream of injection point, 2-in. } \\
\text { pipe; target size } 1.03 \mathrm{~cm} \text {. }\end{array}$ & $\begin{array}{l} \pm 298 \text { to } \\
\mathrm{kg} / \mathrm{m}-\mathrm{s}^{2}\end{array}$ & $\begin{array}{l} \pm 219191 \\
\mathrm{~kg} / \mathrm{m}-\mathrm{s}^{2}\end{array}$ & 265,266 & \\
\hline \multicolumn{6}{|l|}{ Vessel } \\
\hline FOV-CORE-IN & $\begin{array}{l}\text { In core flow mixer box, } 381 \mathrm{~cm} \\
\text { below cold leg centerline; target } \\
\text { size } 2.54 \mathrm{~cm} \text {. }\end{array}$ & $\frac{ \pm 1.44 \text { to }}{\mathrm{kg} / \mathrm{m}-\mathrm{s}^{2}} \pm 2977$ & $\frac{+1725}{\mathrm{~kg} / \mathrm{m}-\mathrm{s}^{2}}$ & 267,268 & \\
\hline DENSITY & & & & & \\
\hline Intact Loop & & $\begin{array}{l}1.6 \text { to } 1600 \\
\mathrm{~kg} / \mathrm{m}^{3}\end{array}$ & $\begin{array}{l}0 \text { to } 1600 \\
\mathrm{~kg} / \mathrm{m}^{3}\end{array}$ & & \\
\hline $\begin{array}{l}\text { GU-1T } \\
\text { GU-1B } \\
\text { GU-1C }\end{array}$ & $\begin{array}{l}\text { Hot leg. Spool } 1,77 \mathrm{~cm} \text { from } \\
\text { vessel center. T (top) ranges } \\
270 \text { to } 360^{\circ} \text {. B (bottom) ranges } \\
30 \text { to } 330^{\circ} \text {. C, mathematical } \\
\text { somposite cf T and } 8 \text {. }\end{array}$ & & : & $\begin{array}{l}269,270 \\
271,272\end{array}$ & \\
\hline GU-5VR & $\begin{array}{l}\text { Hot leg, Spool } 5,246 \mathrm{~cm} \text { from } \\
\text { vessel center, verticral. }\end{array}$ & & ' & 273,274 & \\
\hline GU-10VR & $\begin{array}{l}\text { Cold leg, Spool } 10,35 \mathrm{sm} \text { from } \\
\text { vessel center, vertical. }\end{array}$ & & & 273,274 & \\
\hline GU-13VR & $\begin{array}{l}\text { Cold leg, 5pool } 13,142 \mathrm{~cm} \text { from } \\
\text { vessel center, vertical. }\end{array}$ & & & 275,276 & \\
\hline $\begin{array}{l}\text { GU-15T } \\
\text { GU-15B } \\
\text { GU- } 15 C\end{array}$ & $\begin{array}{l}\text { Cold leg, Spool } 15,77 \mathrm{~cm} \text { from vessel } \\
\text { center. T (top) ranges } 270 \text { to } 360^{\circ} \text {. } \\
B \text { (bottom) ranges } 30 \text { to } 330^{\circ} \text {. } C \text {, } \\
\text { mathematical composite of } T \text { and } B \text {. }\end{array}$ & & & $\begin{array}{l}277,278 \\
279,280\end{array}$ & \\
\hline Broken Loop & & $\begin{array}{l}1.6 \text { to } 1600 \\
\mathrm{~kg} / \mathrm{m}^{3}\end{array}$ & $\begin{array}{l}0 \text { to } 1600 \\
\mathrm{~kg} / \mathrm{m}^{3}\end{array}$ & & \\
\hline $\begin{array}{l}\mathrm{GB}-21 \mathrm{TT} \\
\mathrm{GB}-21 \mathrm{~B} \\
\mathrm{~GB}-21 \mathrm{C}\end{array}$ & $\begin{array}{l}\text { Cold leg, Spool } 21,123 \mathrm{~cm} \text { from } \\
\text { vessel center. T (top) ranges } \\
270 \text { to } 360^{\circ} \text {. B (bottom) ranges } \\
30 \text { to } 330^{\circ} \text {. C, mathematical } \\
\text { composite of T and } 8 \text {. }\end{array}$ & . & & $\begin{array}{l}281,282 \\
283,284\end{array}$ & \\
\hline GD-23VR & $\begin{array}{l}\text { Cold leg, Spool } 23,235 \mathrm{~cm} \text { from } \\
\text { vessel center, vertical. }\end{array}$ & & & 285,286 & \\
\hline $\begin{array}{l}G B-30 T \\
G B-30 B \\
\dot{G} \bar{B}-3 \dot{3} \bar{C}^{\circ}\end{array}$ & 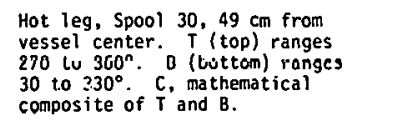 & r. & . & $\begin{array}{l}287,288 \\
289,290\end{array}$ & $\sim$ \\
\hline${ }_{\mathrm{GB}-42 \mathrm{VR}}^{\mathrm{GB}-37}$ & $\begin{array}{l}\text { Cold leg, Spool } 42,1057 \mathrm{~cm} \text { from } \\
\text { vessel center along hot leg, } \\
\text { vertical. }\end{array}$ & & & 291,292 & $\because$ \\
\hline 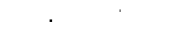 & & 25 & & & \\
\hline
\end{tabular}




\section{TABLE V (continued)}

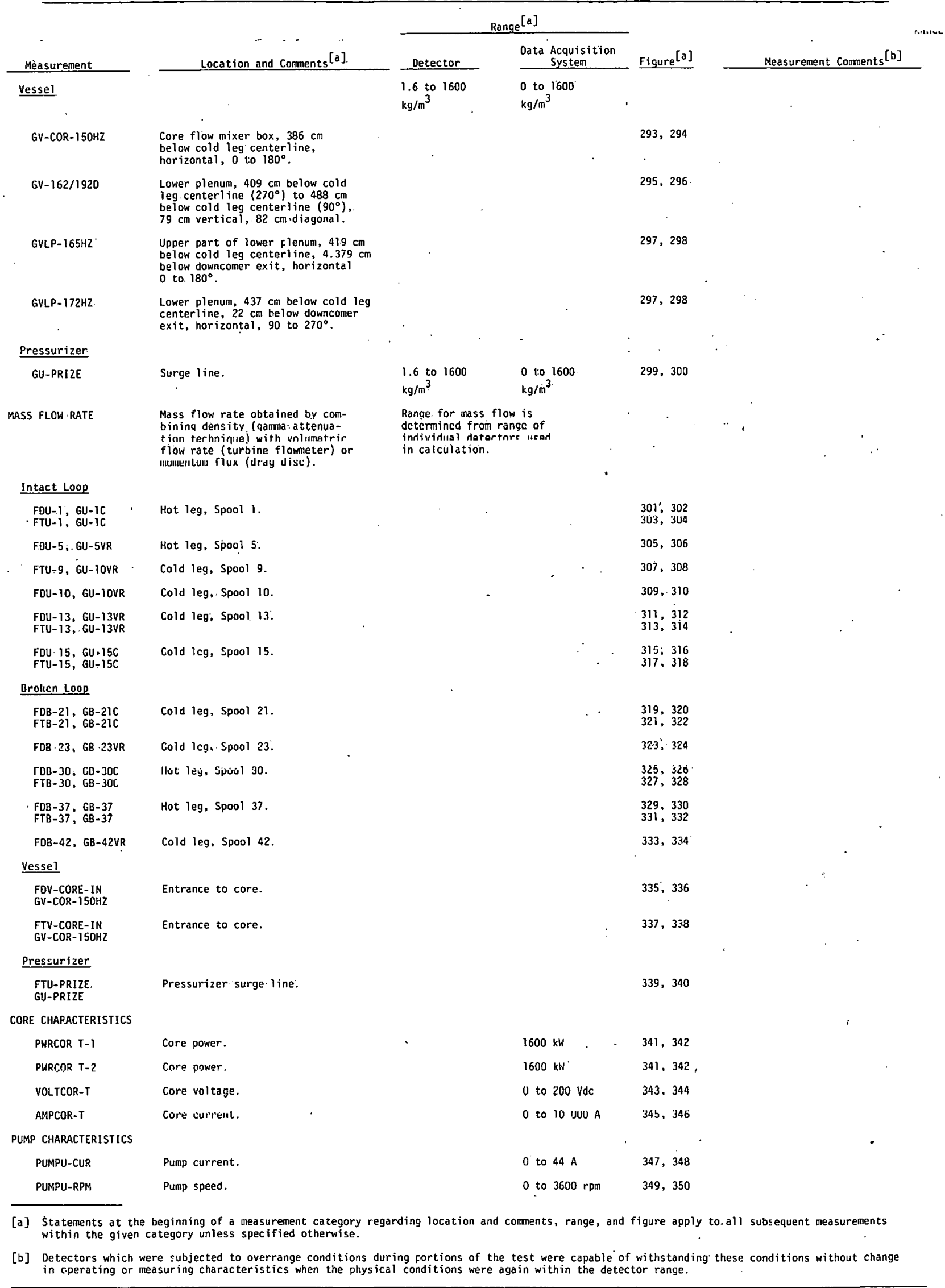




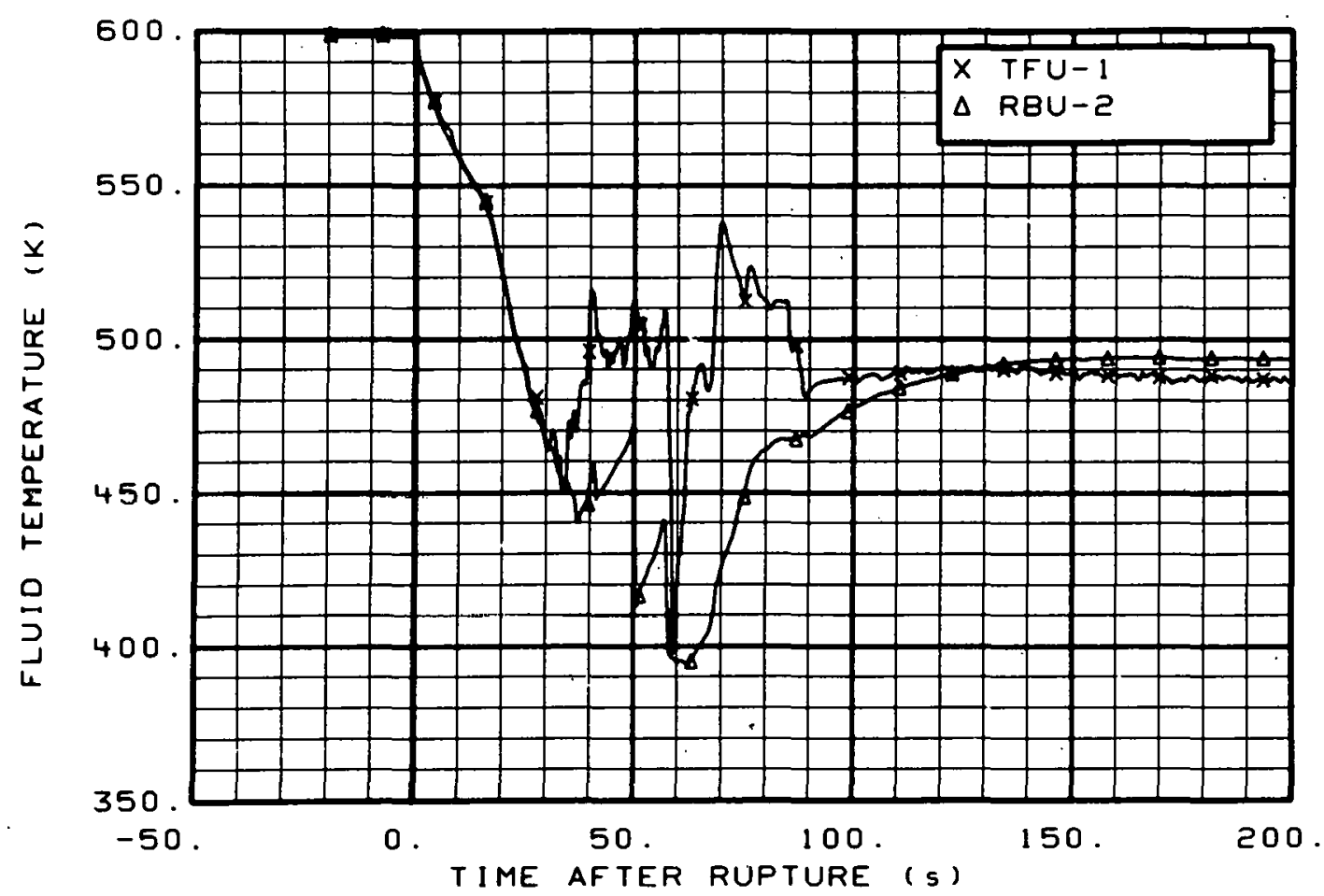

Fig. 9 Fluid temperature in intact loop hot leg (TFU-1 and RBU-2), from -20 to $200 \mathrm{~s}$.

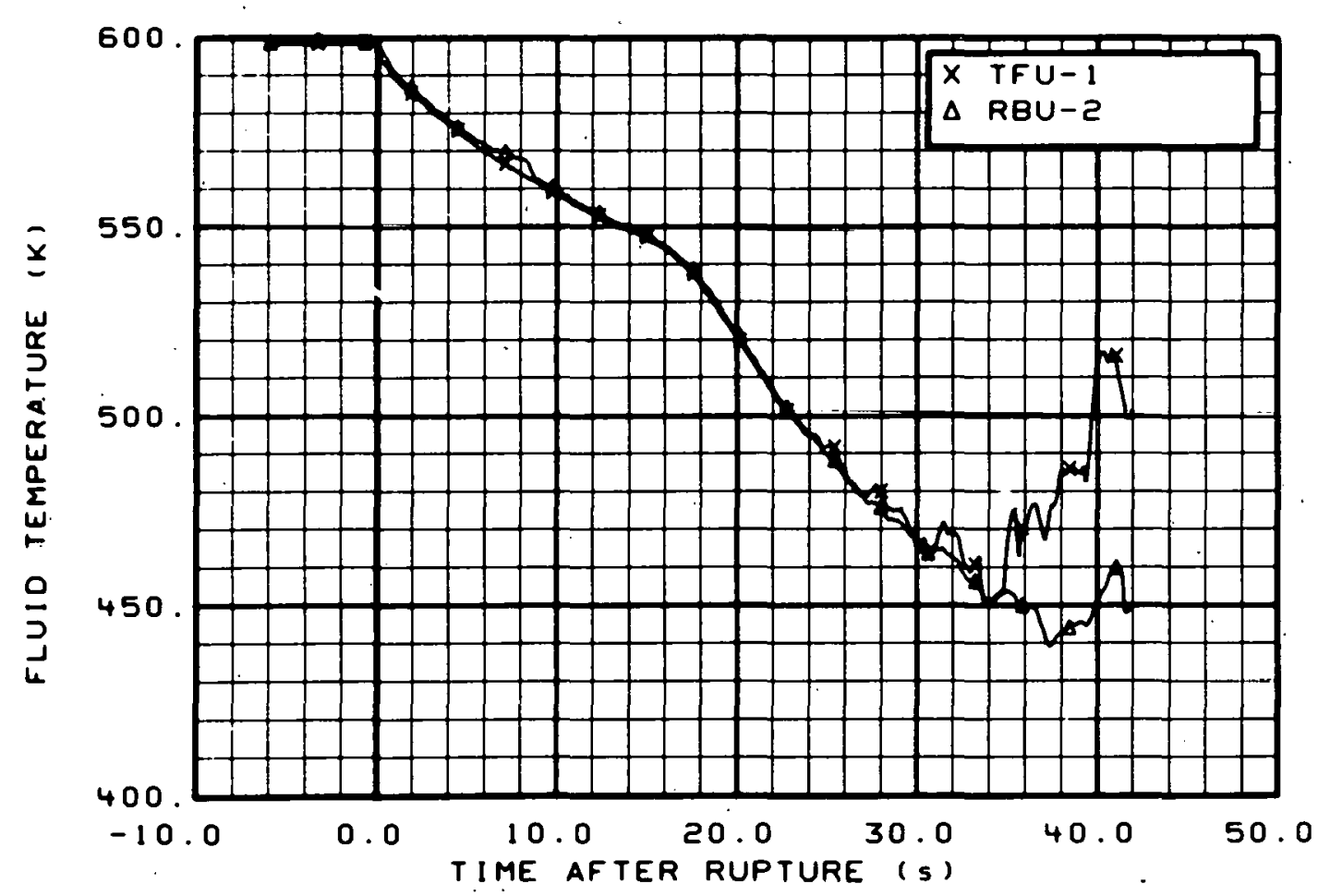

Fig. 10 Fluid temperature in intact loop hot leg (TFU-1 and RBU-2), from -6 to $42 \mathrm{~s}$. 


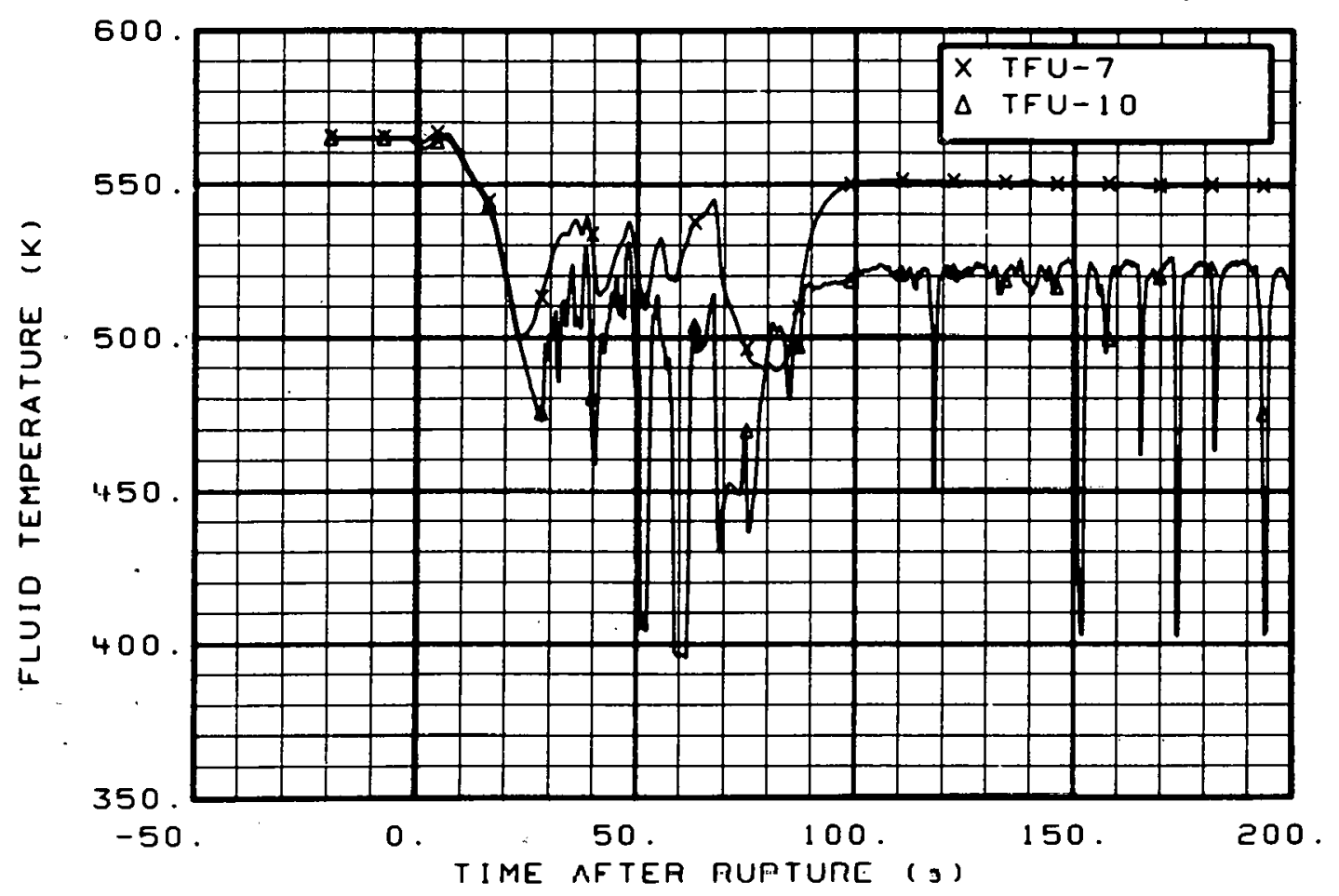

Fig. 11 Fluid temperature in intact loop cold leg (TFU-7 and TFU-10), from -20 to $200 \mathrm{~s}$.

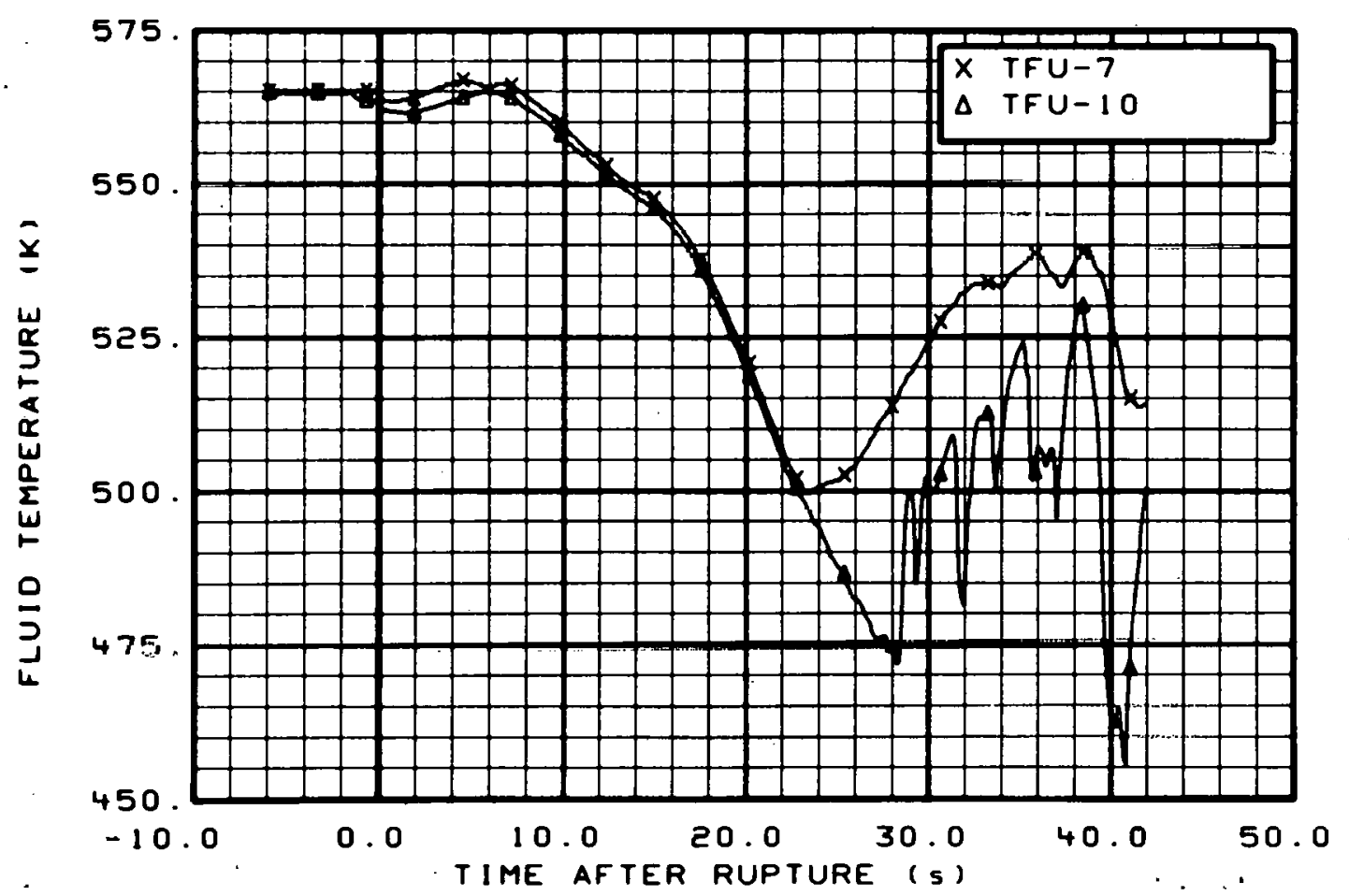

Fig. 12 Fluid temperature in intact loop cold leg (TFU-7 and TFU-10), from -6 to $42 \mathrm{~s}$. 


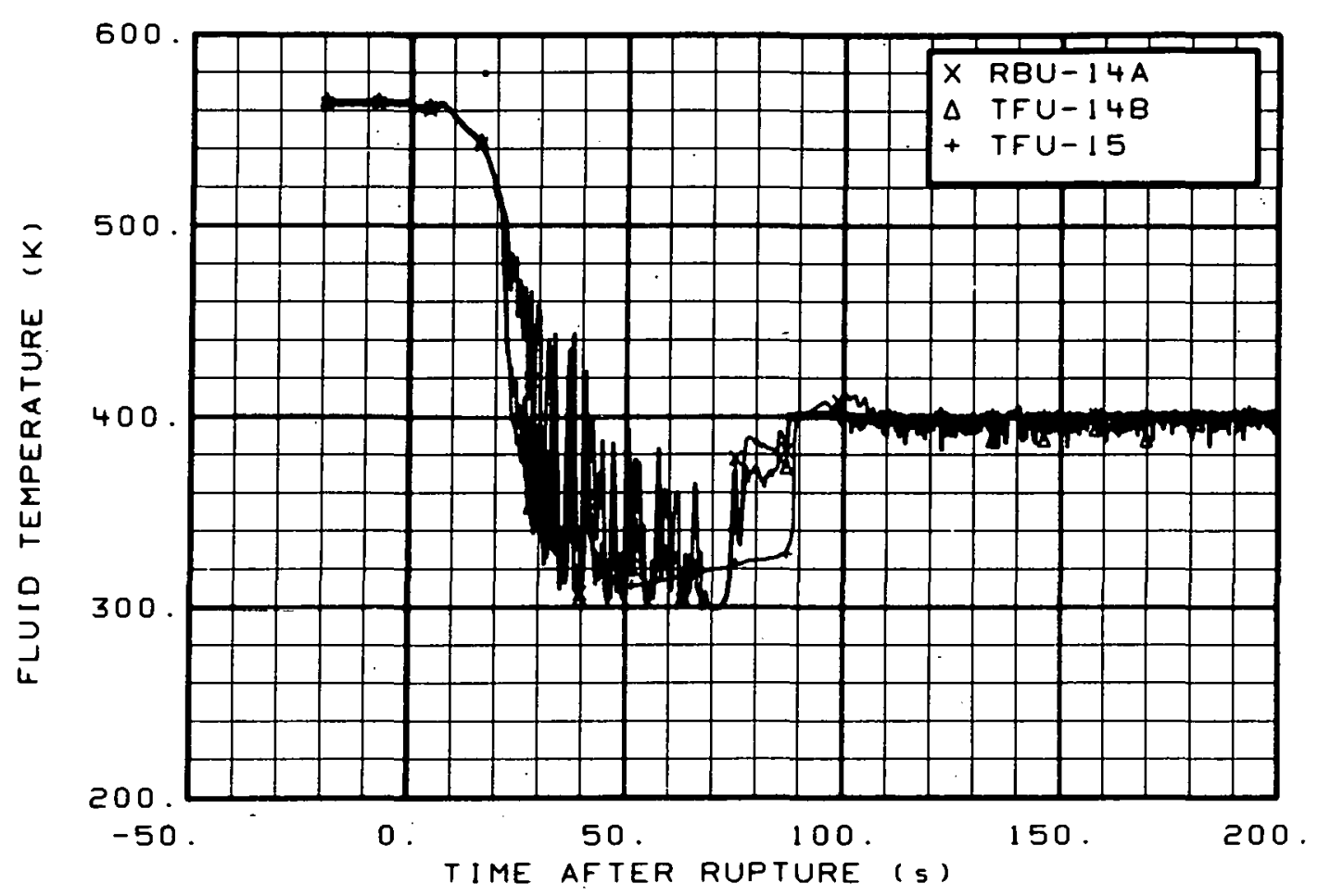

Fig. 13 Fluid temperature in intact 10op cold leg (RBU-14A, TFU-14B, and TFU-15), from -20 to $200 \mathrm{~s}$.

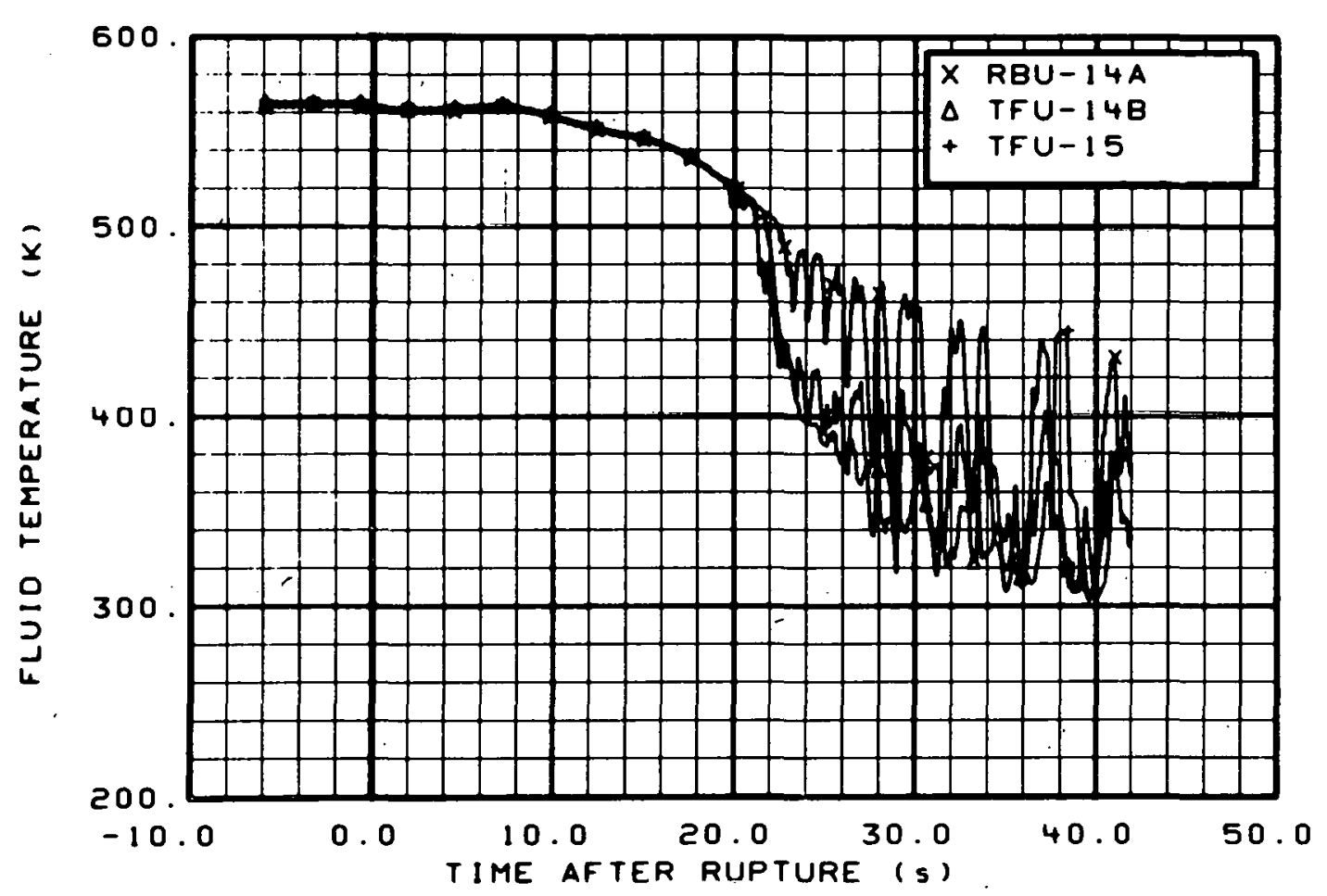

Fig. 14 Fluid temperature in intact loop cold leg (RBU-14A, TFU-14B, and TFU-15), from 6 to $42 \mathrm{~s}$. 


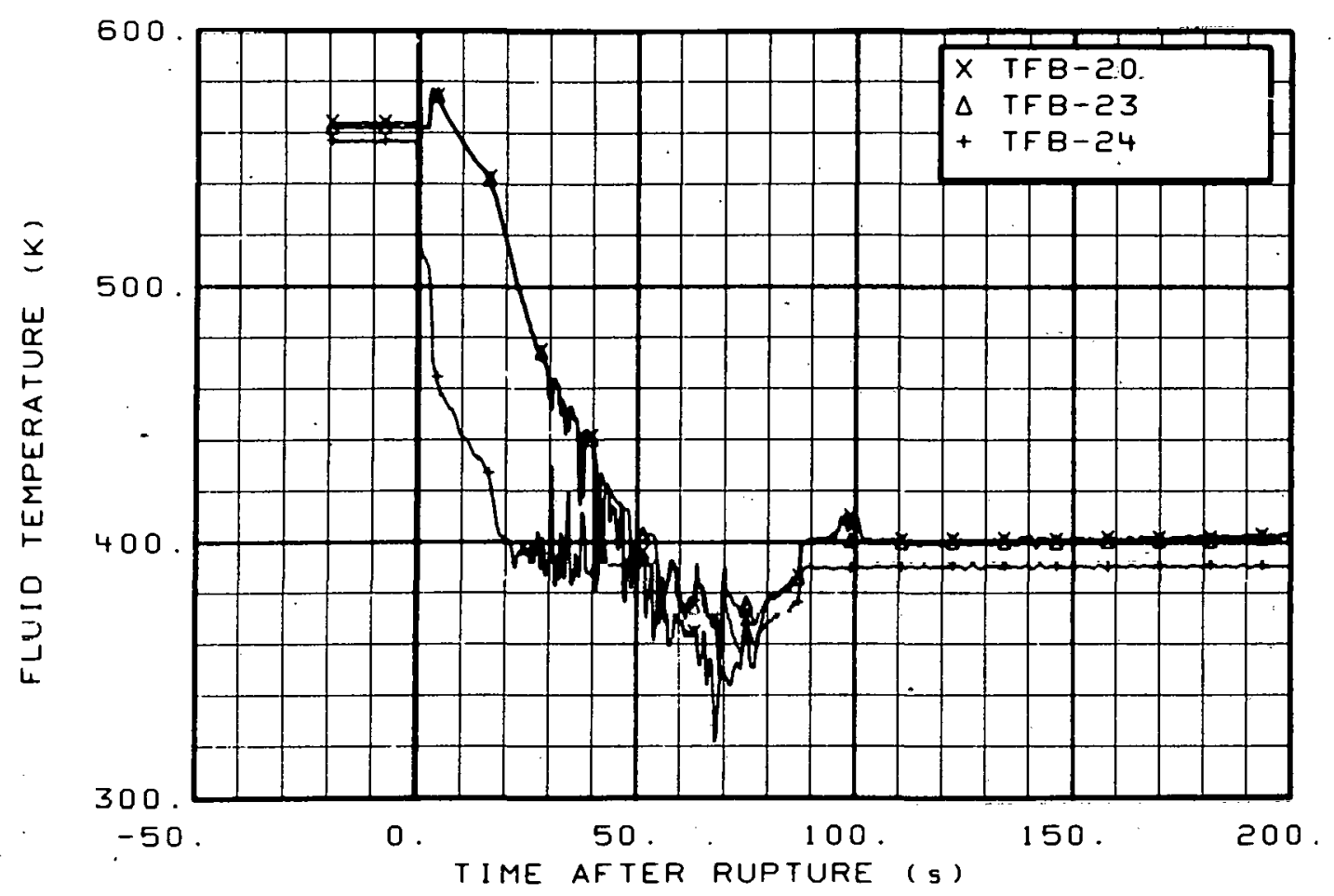

Fig, 15 Fluid temperature in broken loop, vessel side (TFB-20, TFB-23, and TFB-24), from -20 to $200 \mathrm{~s}$.

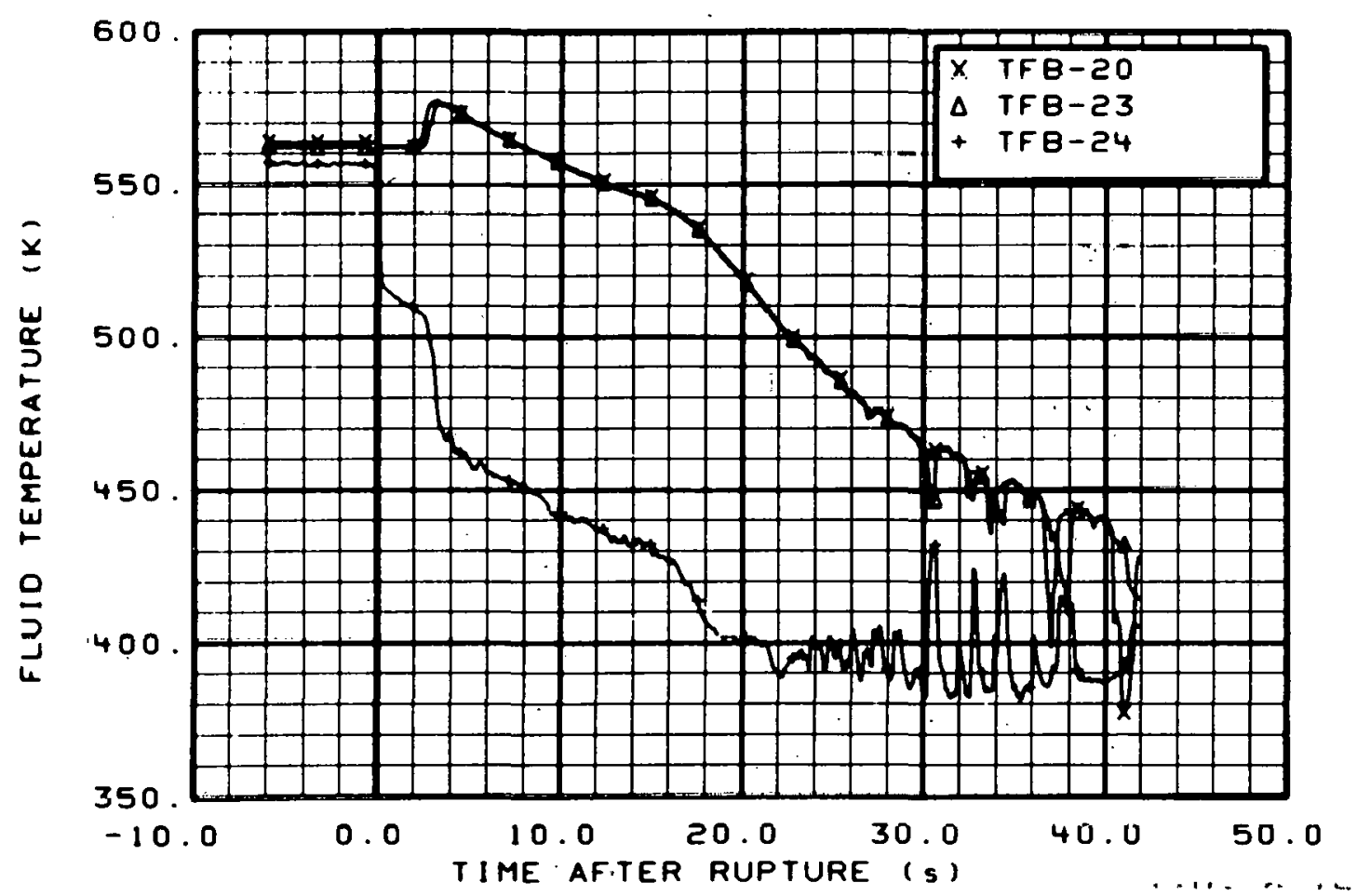

Fig. 16 Fluid temperature in broken loop, vessel side (TFB-20, TFB-23, and TFB-24), from -6 to $42 \mathrm{~s}$. 


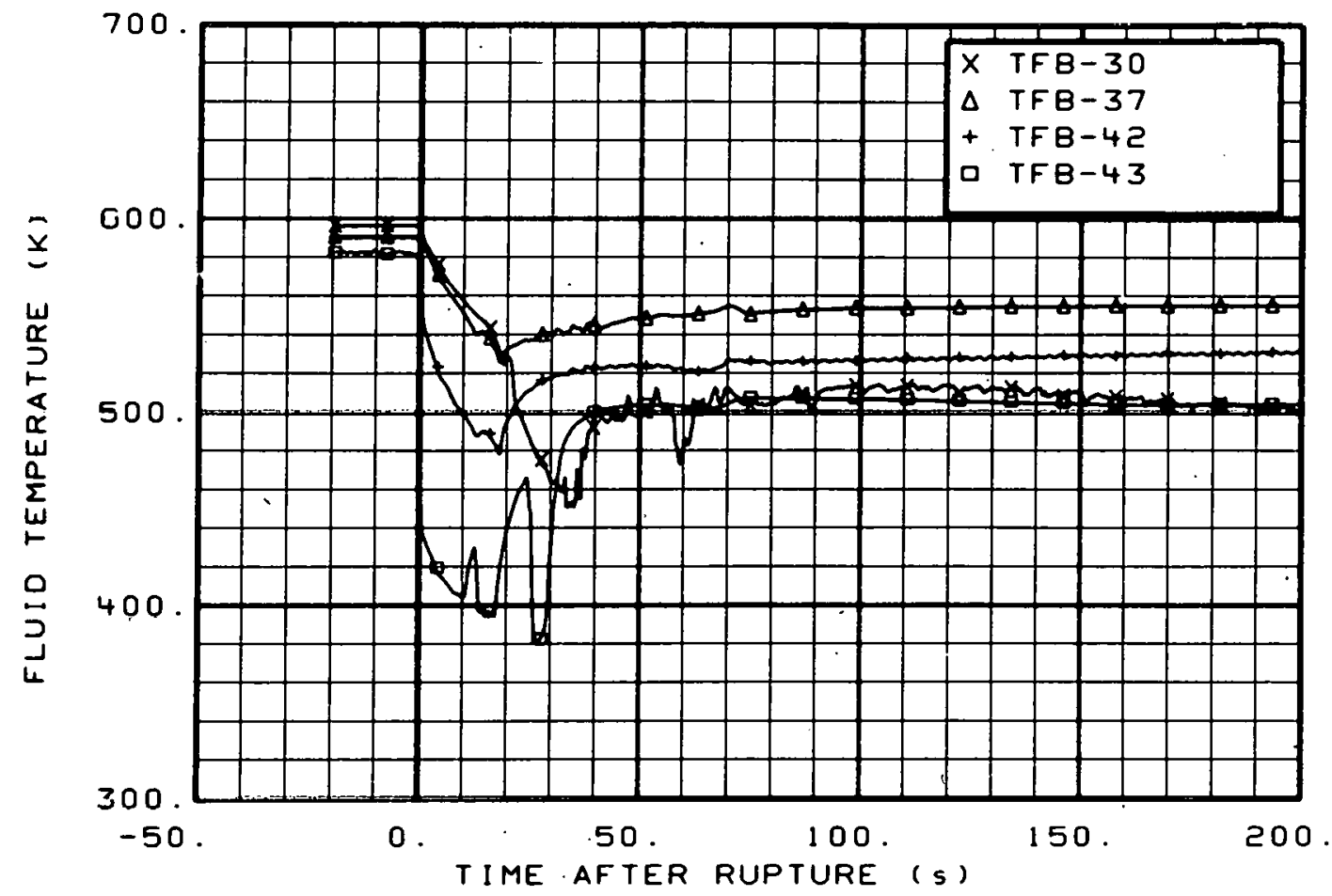

Fig. 17 Fluid temperature in broken loop, pump side (TFB-30, TFB-37, $T F B-42$, and TFB-43), from -20 to $200 \mathrm{~s}$.

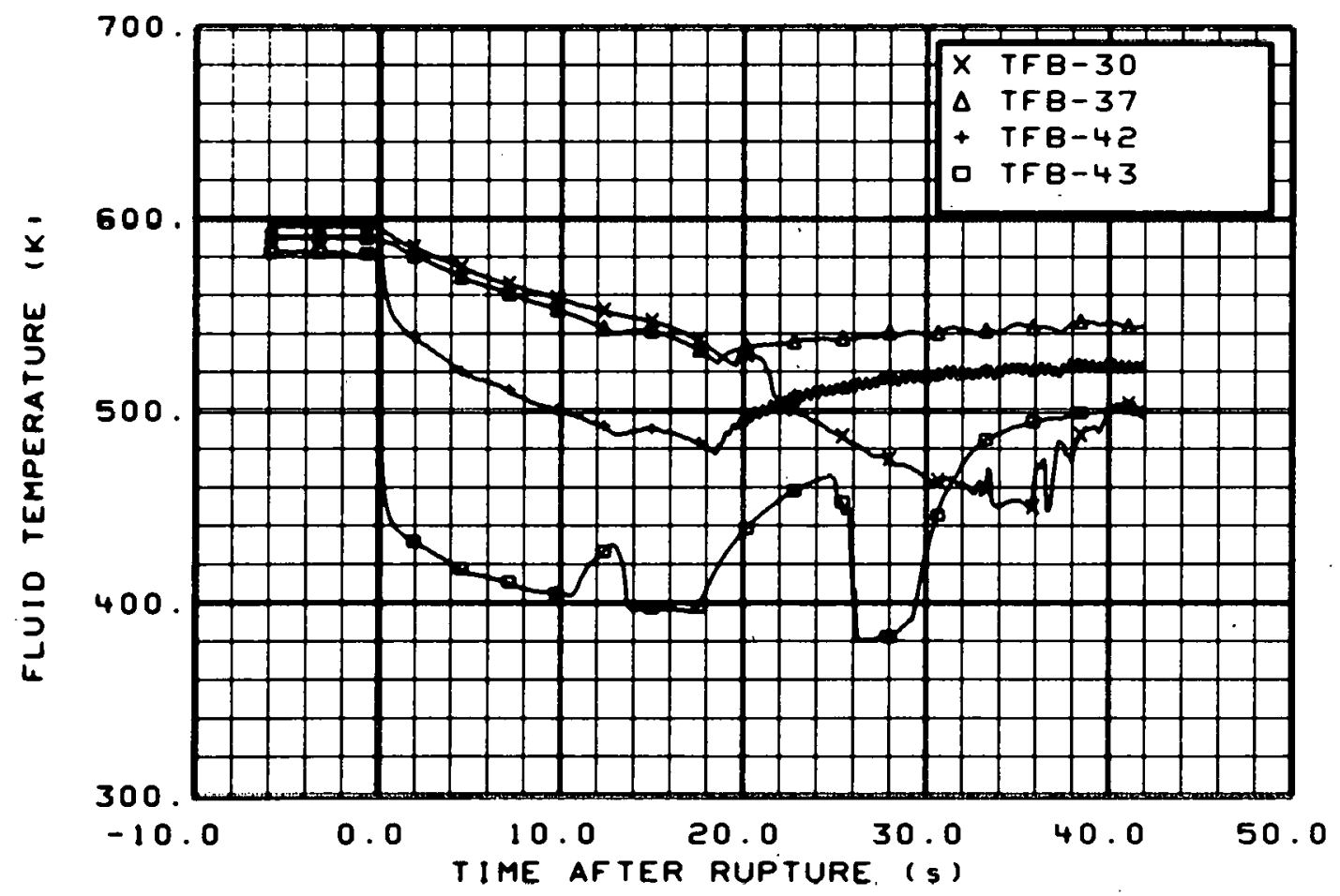

Fig. 18 Fluid temperature in broken loop, pump side (TFB=30, TFB-37, TFB-42, and TFB-43), from -6 to $42 \mathrm{~s}$. 


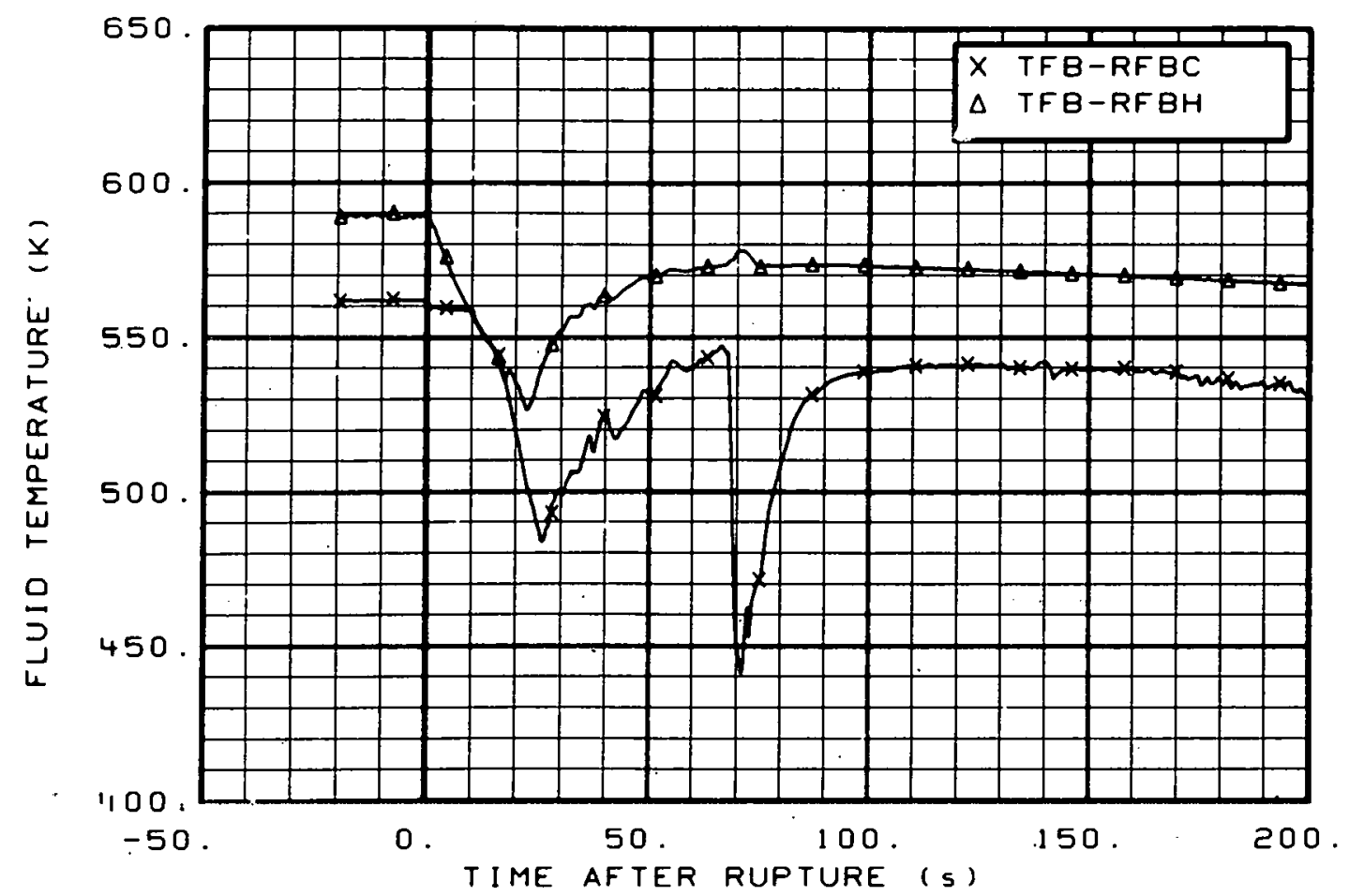

Fig. 19 Fluid temperature in broken loop, reflood bypass simulators (TFB-RFB-C and TFB-RFB-H), from -20 to $200 \mathrm{~s}$.

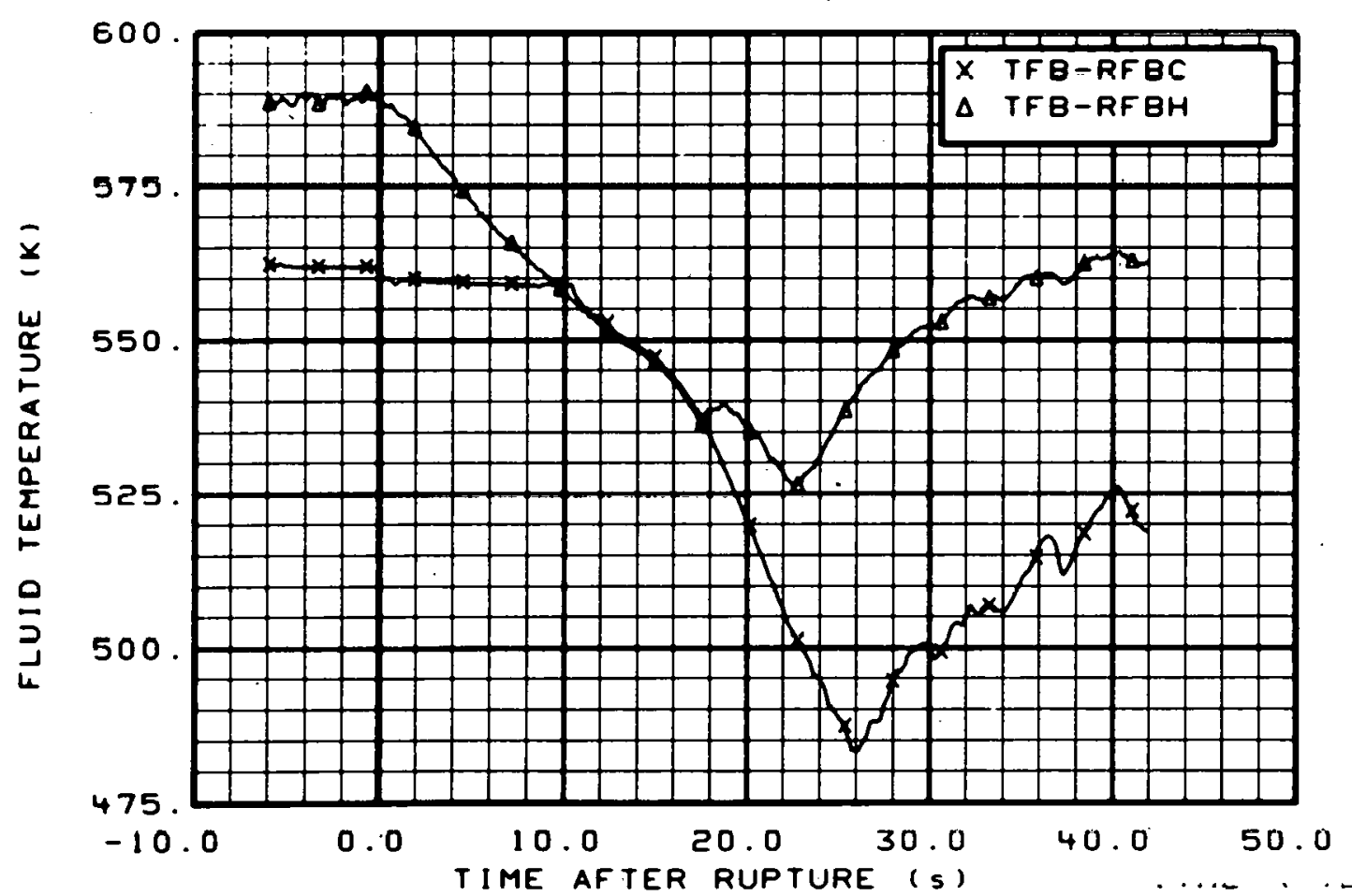

Fig. 20 Flưid temperature in broken loop, reflood bypass simulators (TFB-RFB-C and TFB-RFB-H), from -6 to $42 \mathrm{~s}$. 


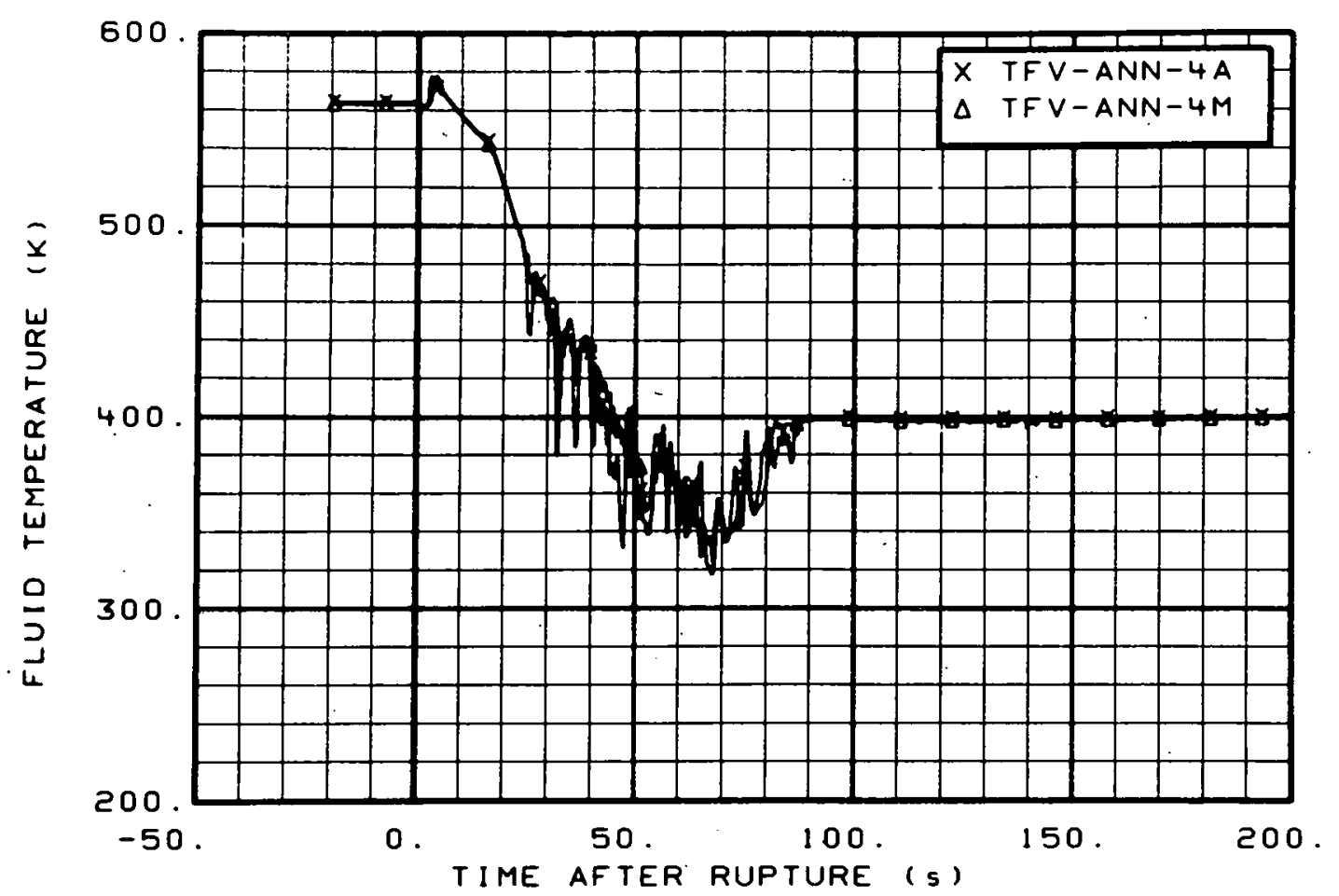

Fig. 21 Fluid temperature in inlet annulus (TFV-ANN-4A and TFV-ANN-4M), from -20 to $200 \mathrm{~s}$.

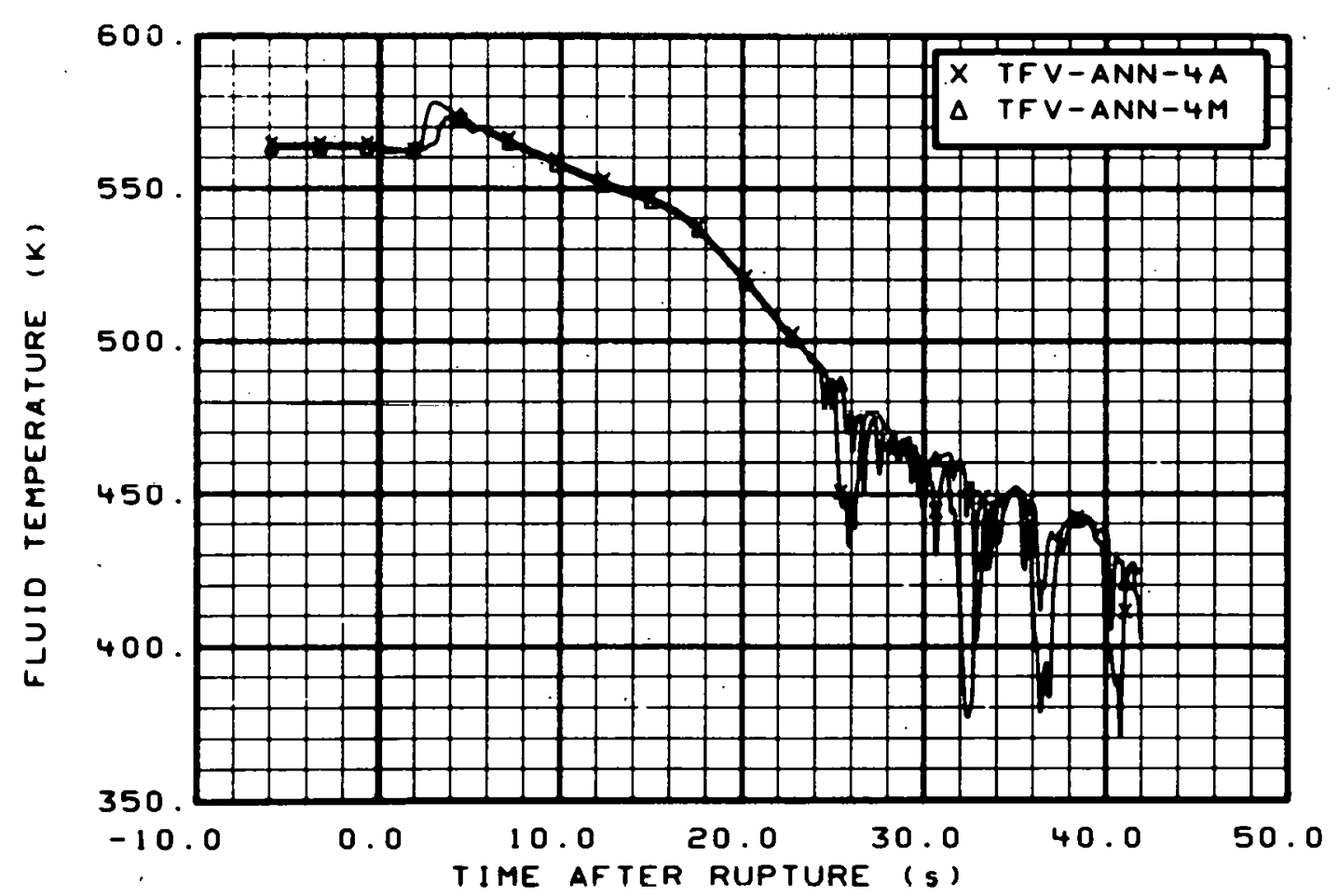

Fig. 22 Fluid temperature in inlet annulus (TFV-ANN-4A and TFV-ANN-4M), from -6 to $42 \mathrm{~s}$. 


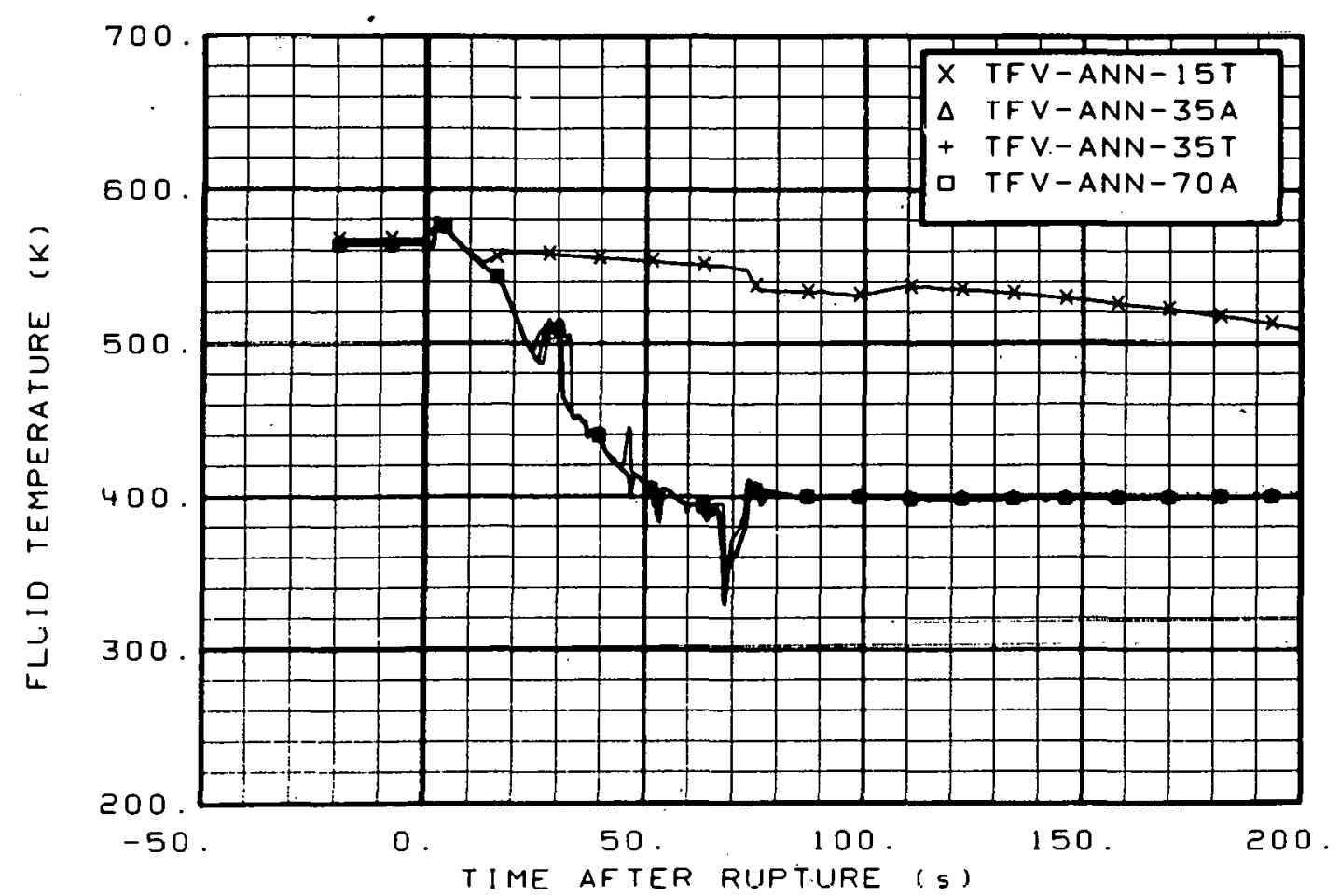

Fig. 23 Fluid temperature in downcomer annulus (TFV-ANN-15T, TFV-ANN-35A, TFV-ANN-35T and TFV-ANN-70A), from -20 to $200 \mathrm{~s}$.

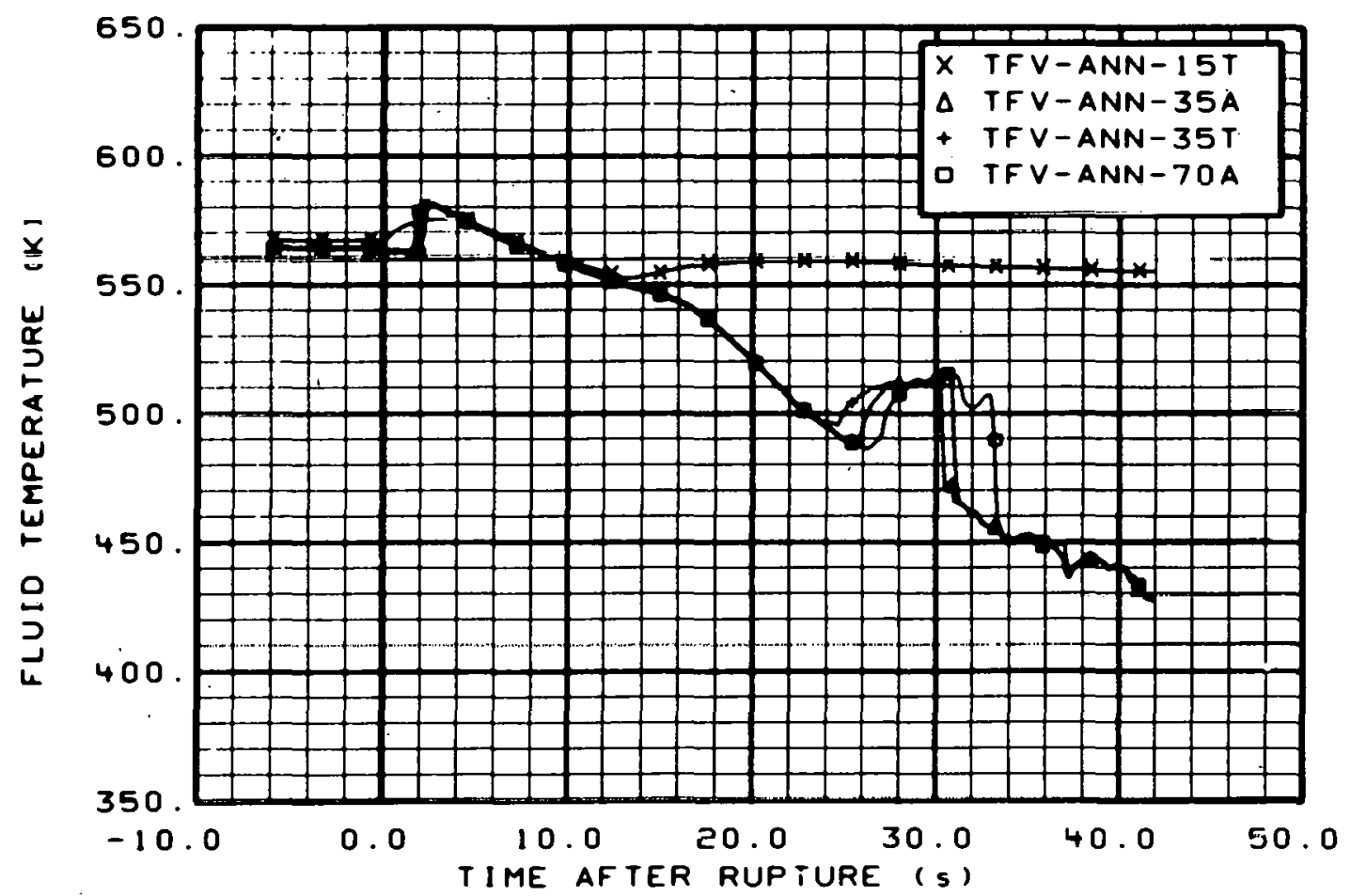

Fig. 24 Fluid temperature in downcomer annulus (TFV-ANN-15T, TFV-ANN-35A, TFV-ANN-35T, and TFV-ANN-70A), from -6 to $42 \mathrm{~s}$. 


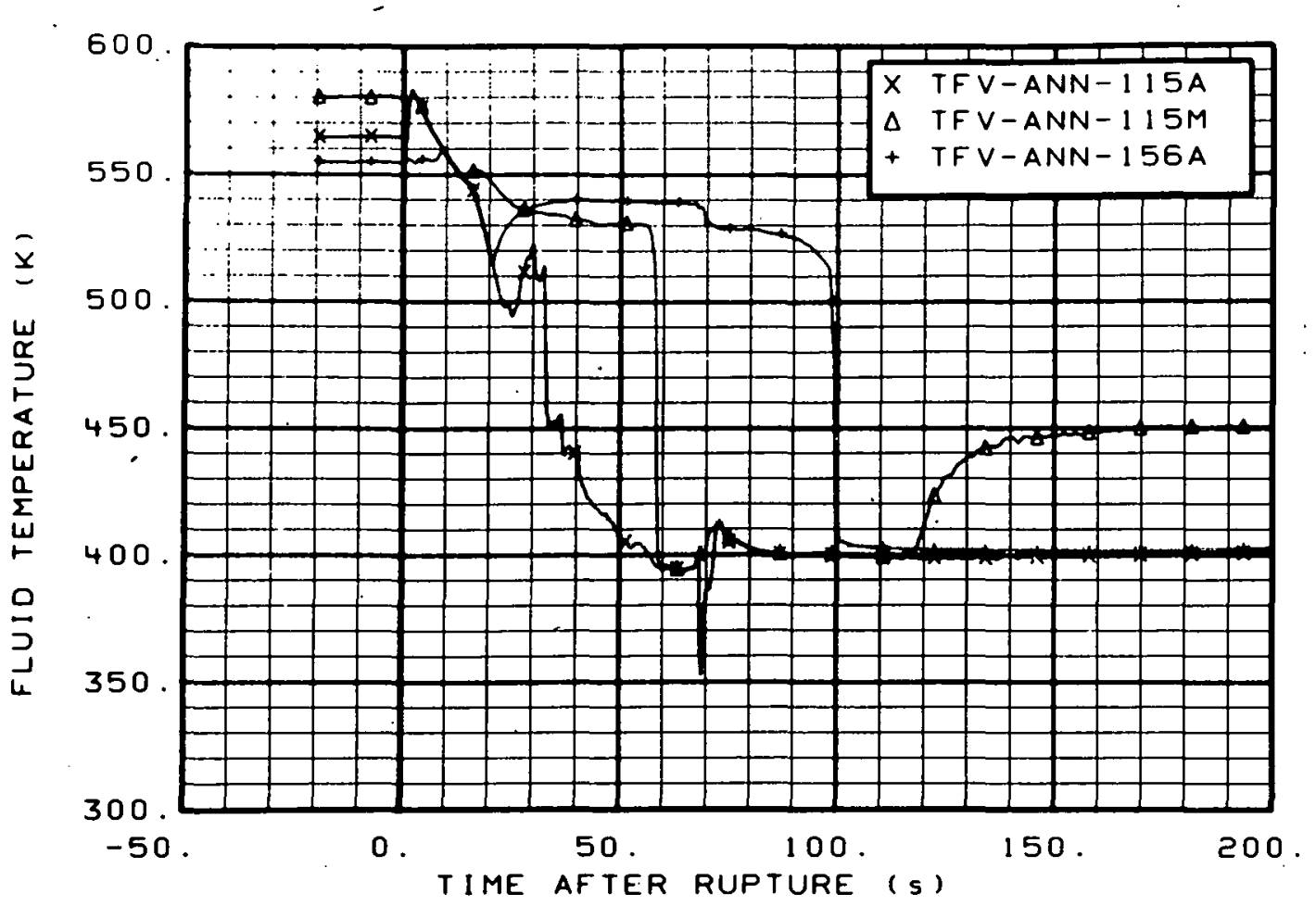

Fig. 25 Fluid temperature in downcomer annulus (TFV-ANN-115A, TFV-ANN-115M, and TFV-ANN-156A), from -20 to $200 \mathrm{~s}$.

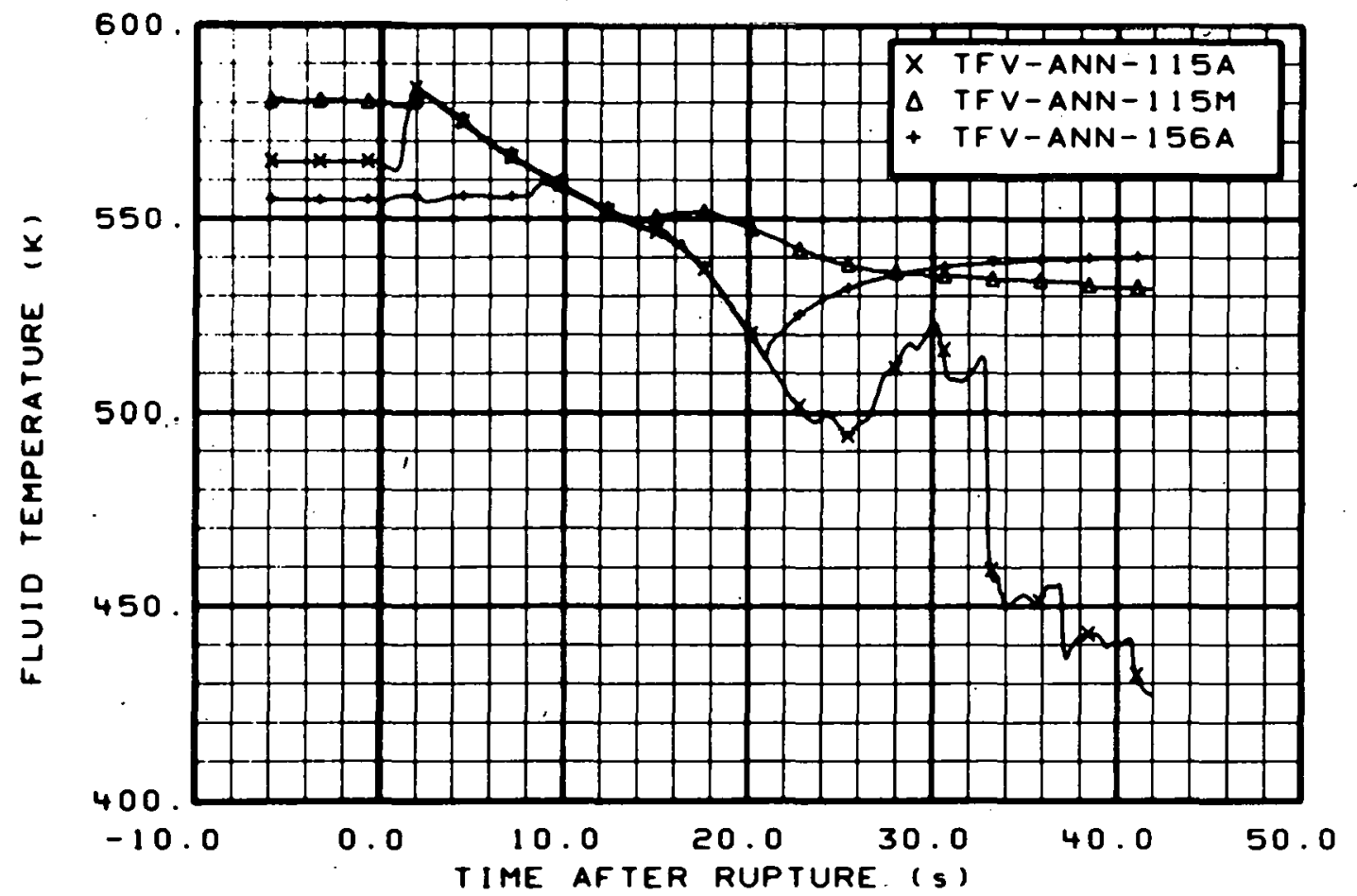

Fig. 26 Fluid temperature in downcomer annulus (TFV-ANN-115A, TFV-ANN-115M, and TFV-ANN-156A), from -6 to $42 \mathrm{~s}$. 


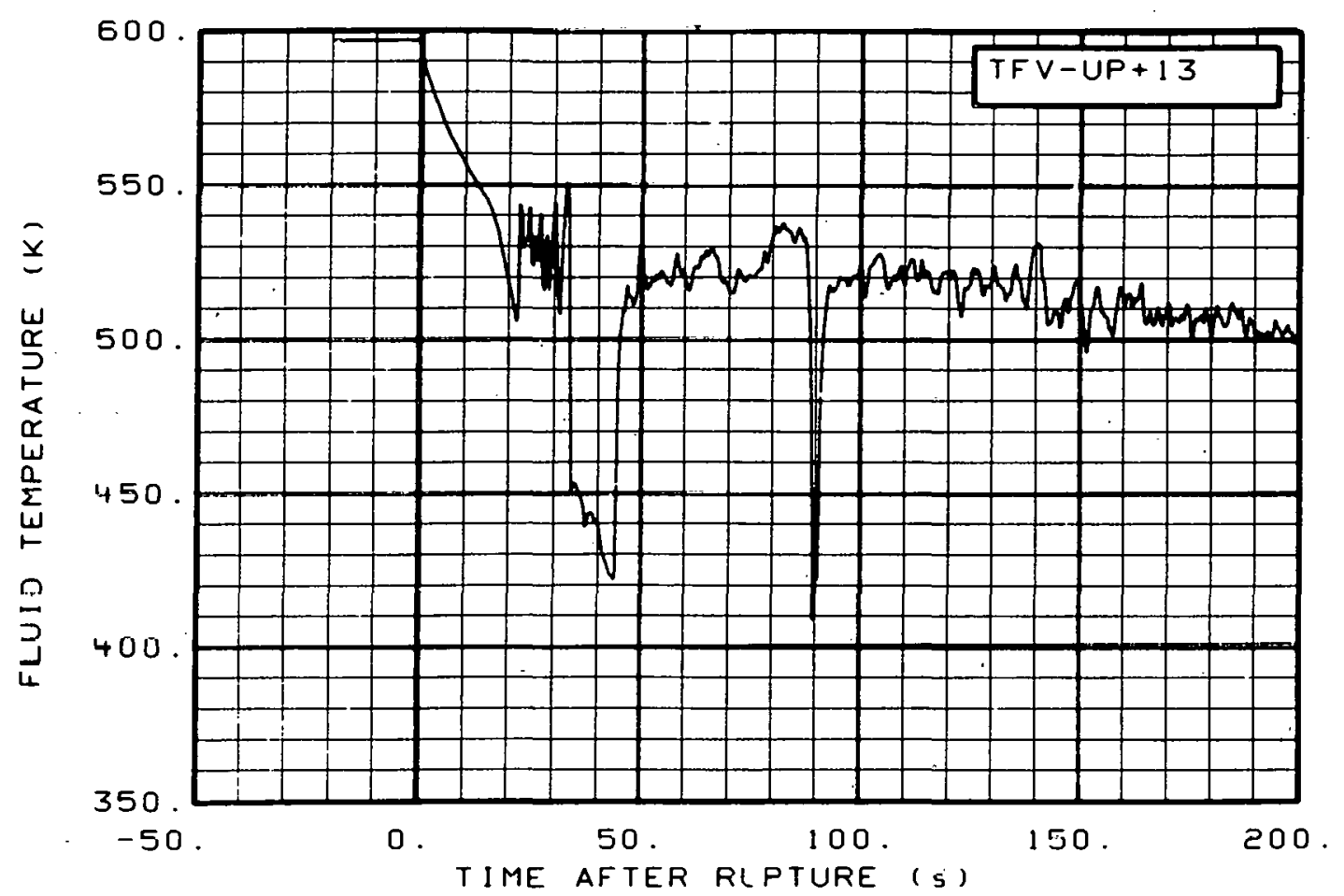

Fig. 27. Fluid temperature in upper plenum $(T F V-U P+13)$, from -20 to $200 \mathrm{~s}$.

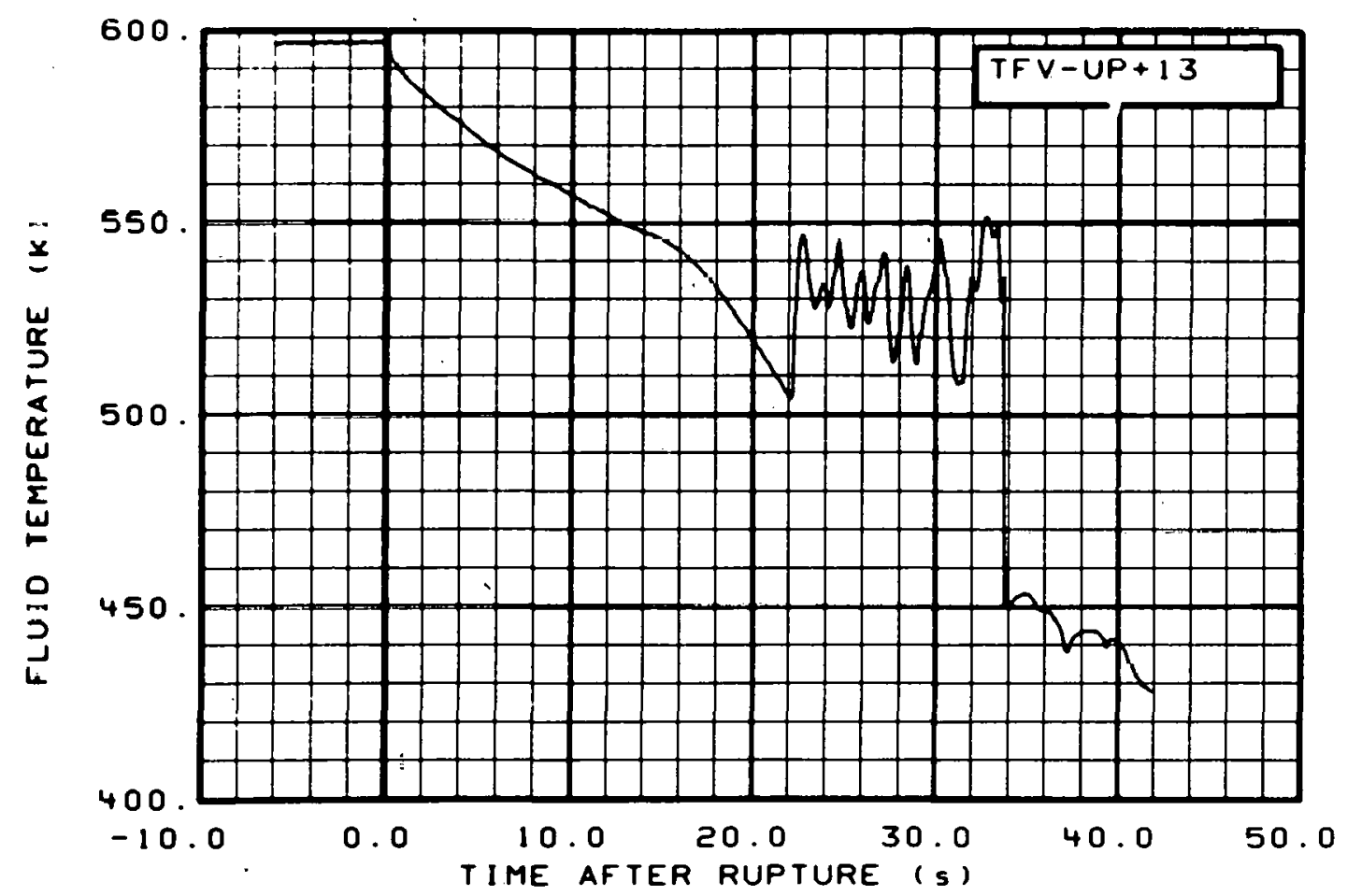

Fig. 28 Fluid temperature in upper plenum (TFV-UP+13), from -6 to $42 \mathrm{~s}$. 


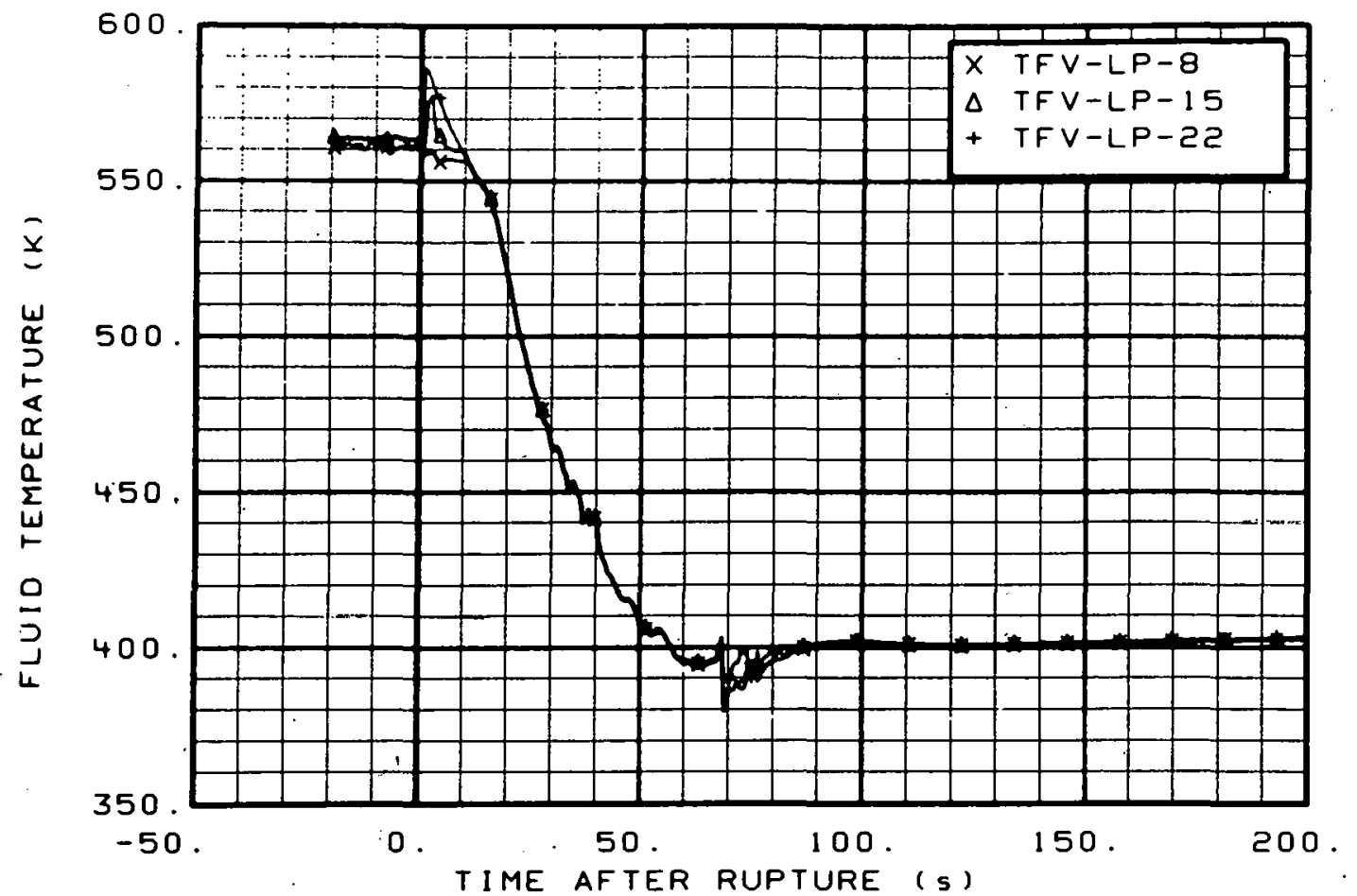

Fig. 29 Fluid temperature in lower plenum (TFV-LP-8, TFV-LP-15, and $\%$ TFV-LP-22), from -20 to $200 \mathrm{~s}$.

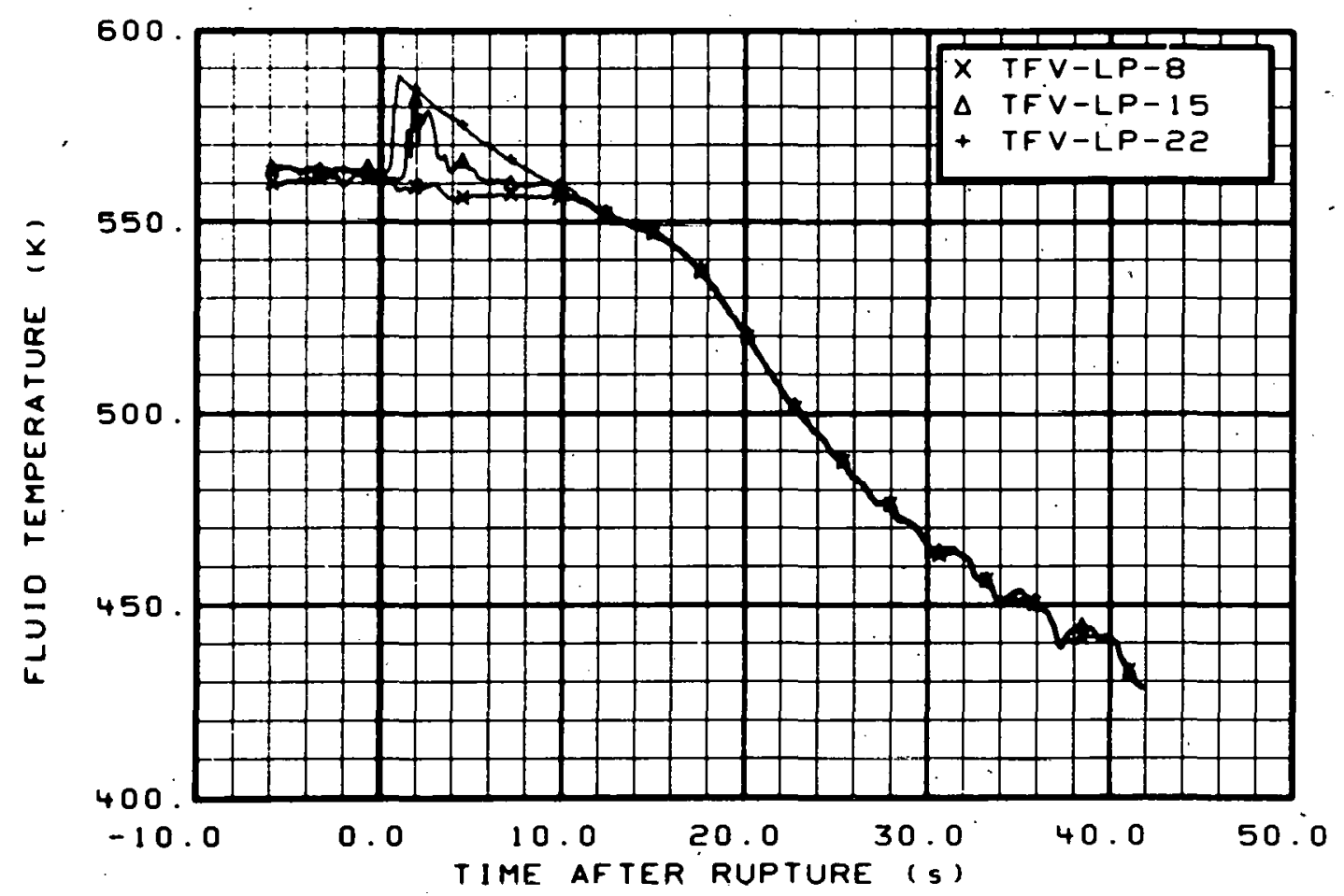

Fig. 30 Fluid temperature in lower plenum (TFV-LP-8, TFV-LP-15, and, TFV-LP-22), from -6 to $42 \mathrm{~s}$. 


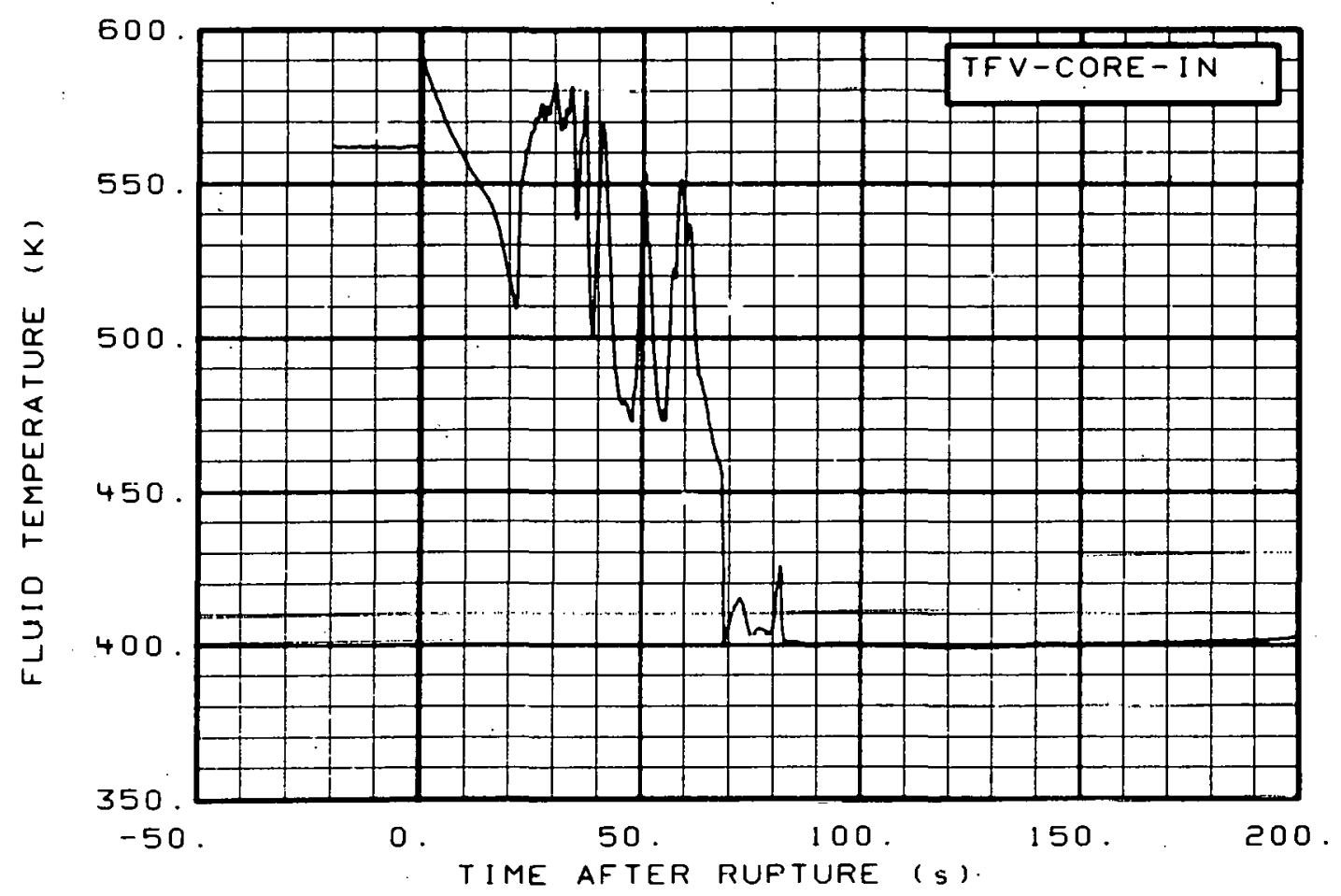

Fig. 31 Fluid temperature in core inlet (TFV-CORE-IN), from -20 to $200 \mathrm{~s}$.

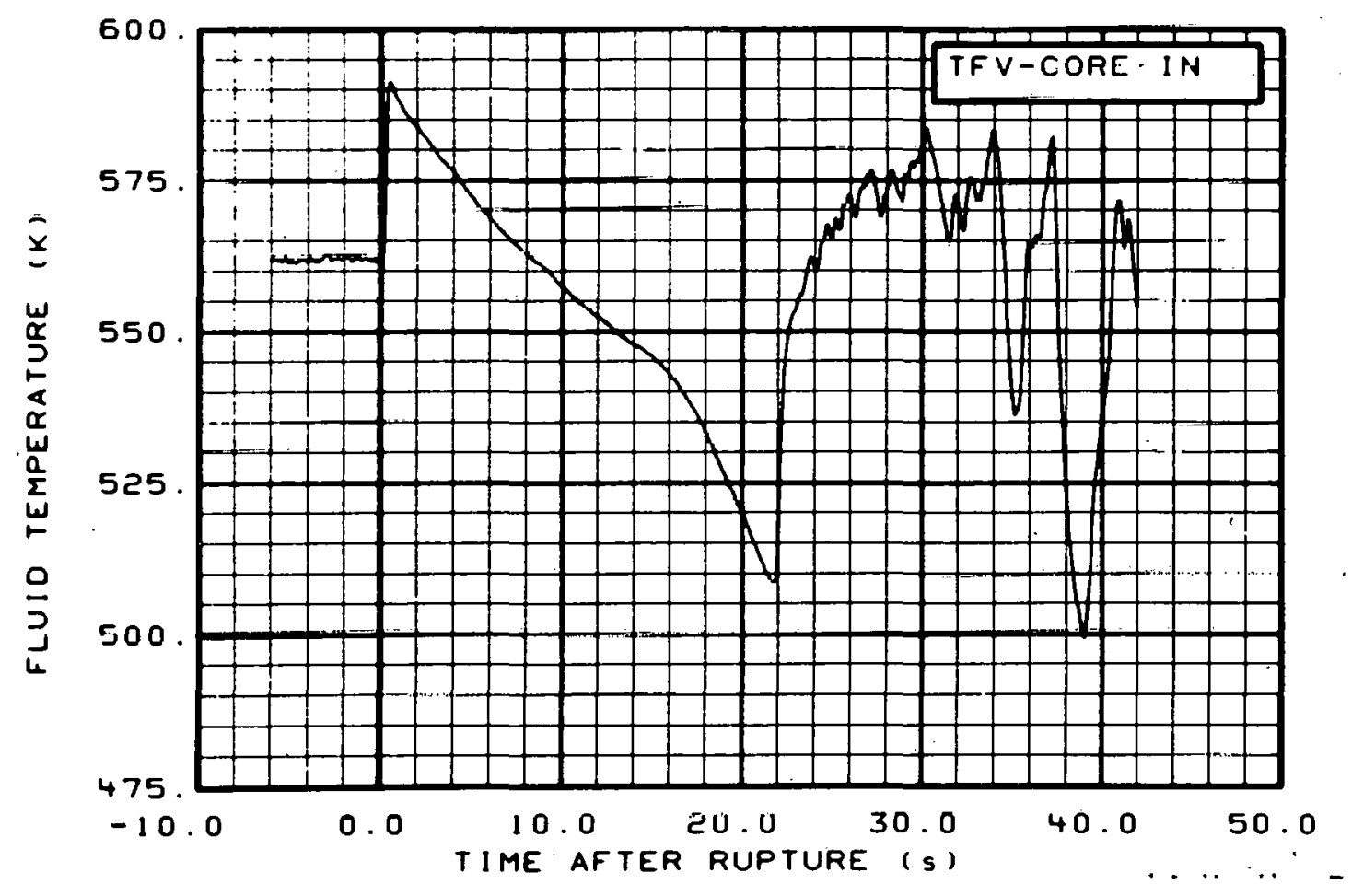

Fig. 32 Fluid temperature in core inlet (TFV-CORE-IN), from -6 to $42 \mathrm{~s}$. 


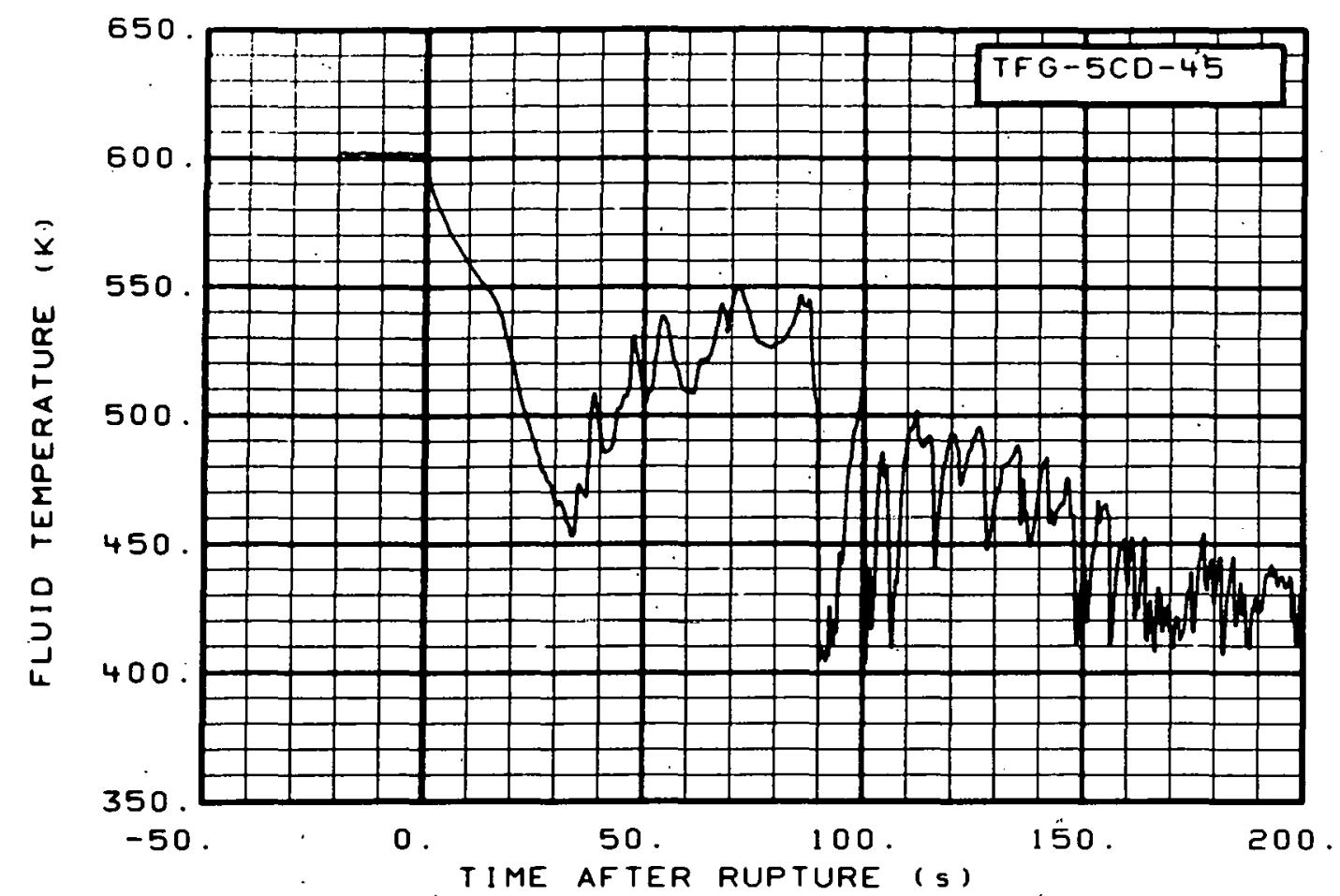

Fig. 33 Fluid temperature in core, Grid Spacer 5 (TFG-5CD-45), from -20 to $200 \mathrm{~s}$.

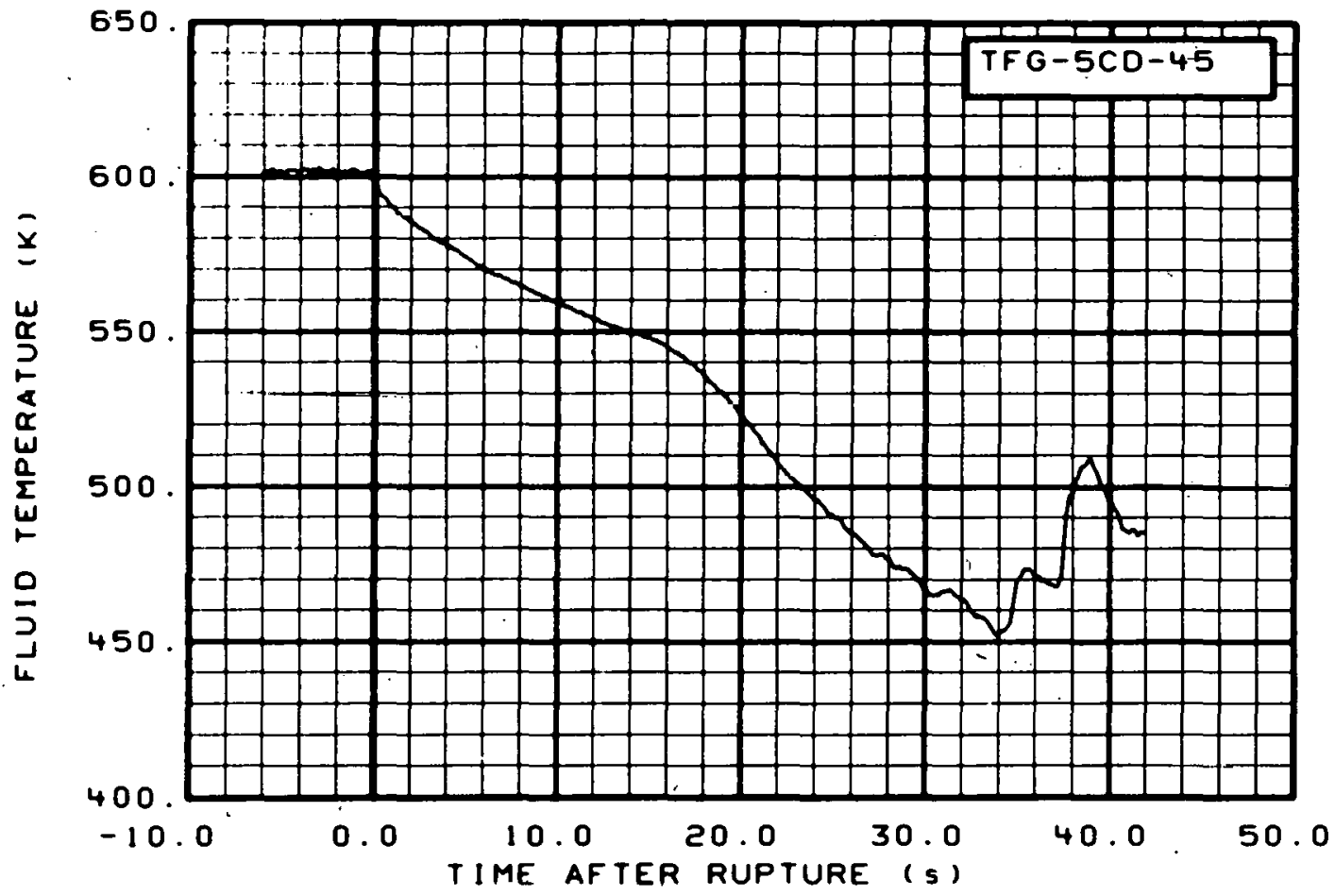

Fig. 34 Fluid temperature in core, Grid Spacer 5 (TFG-5CD-45), from -6 to $42 \mathrm{~s}$. 


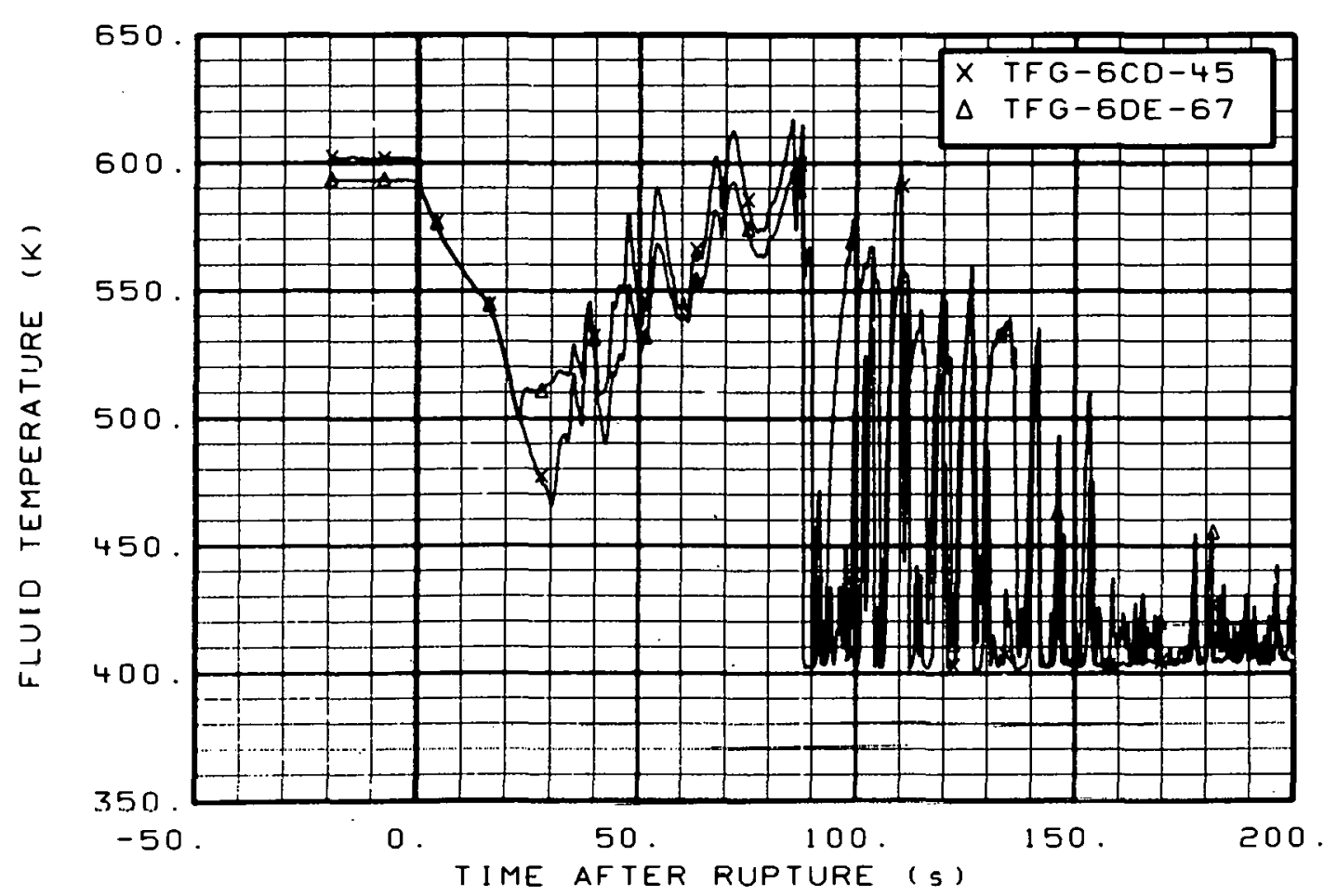

Fig. 35 Fluid temperature in core, Grid Spacer 6 (TFG-6CD-45 and TFG-6DE-67), from -20 to $200 \mathrm{~s}$.

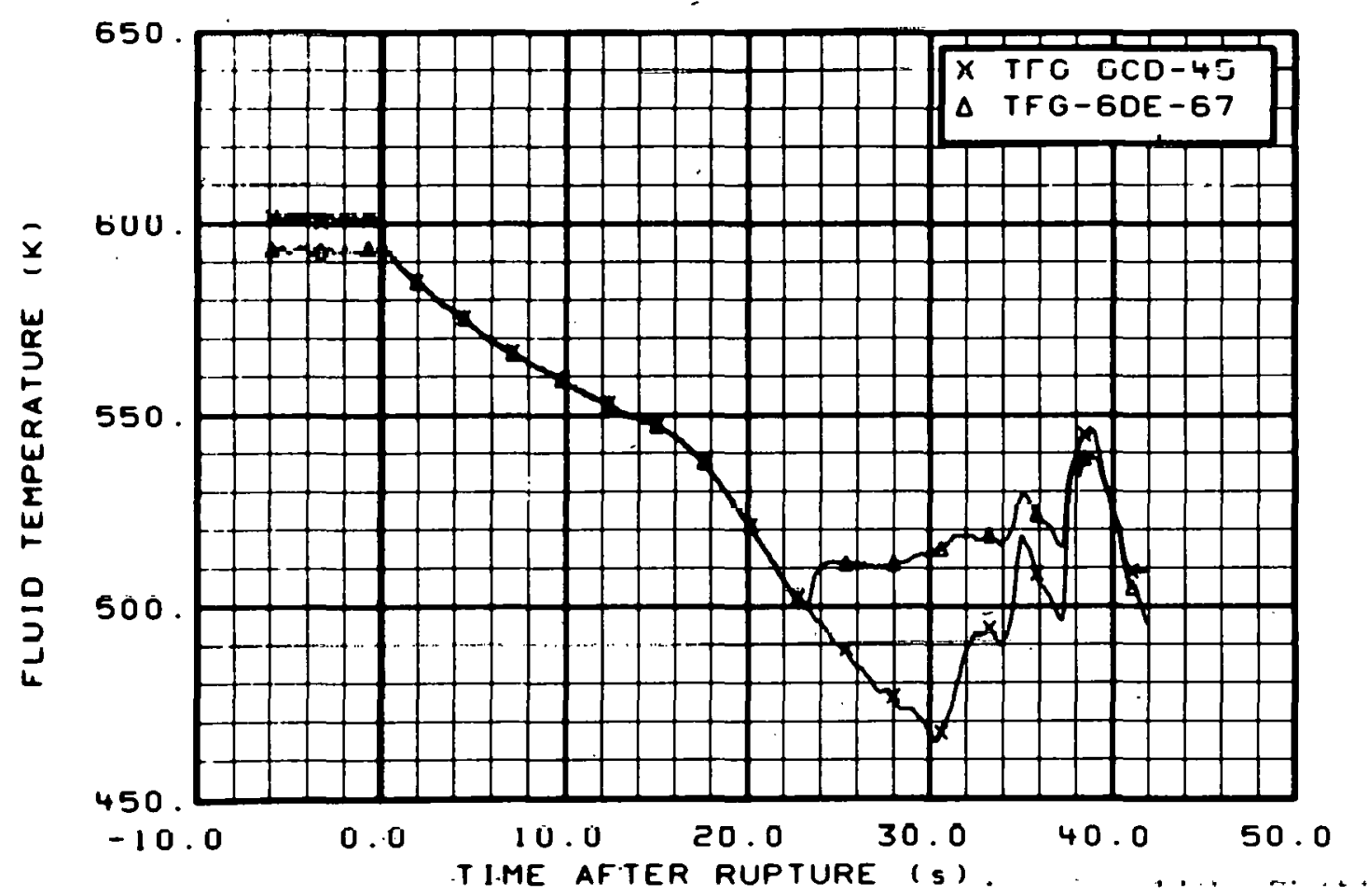

Fig. 36 Fluid temperature in core, Grid Spacer 6 (TFG-6CD-45 and TFG-6DE-67), from -6 to $42 \mathrm{~s}$. 


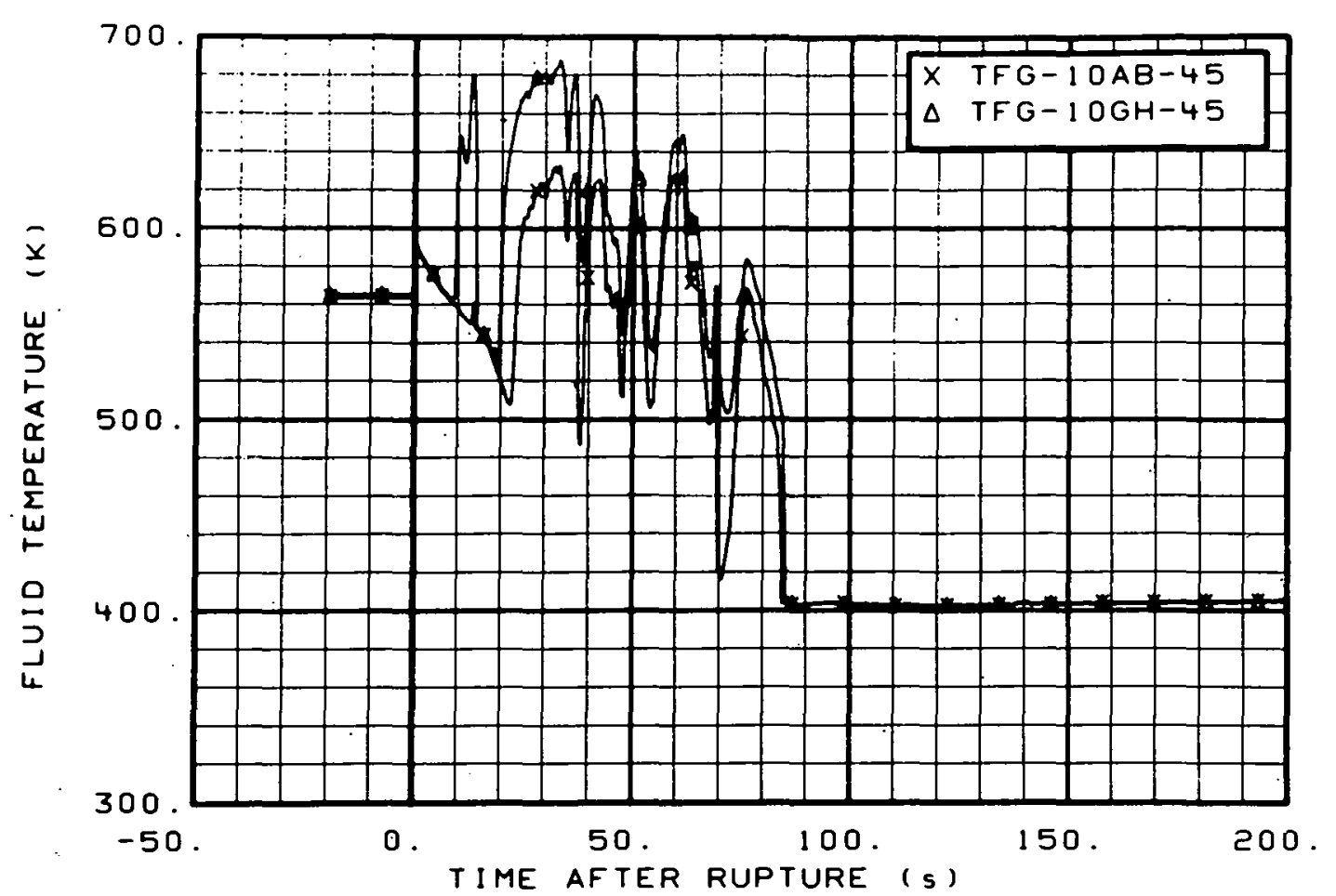

Fig. 37 Fluid temperature in core, Grid Spacer 10 (TFG-10AB-45 and TFG-10GH-45), from -20 to $200 \mathrm{~s}$.

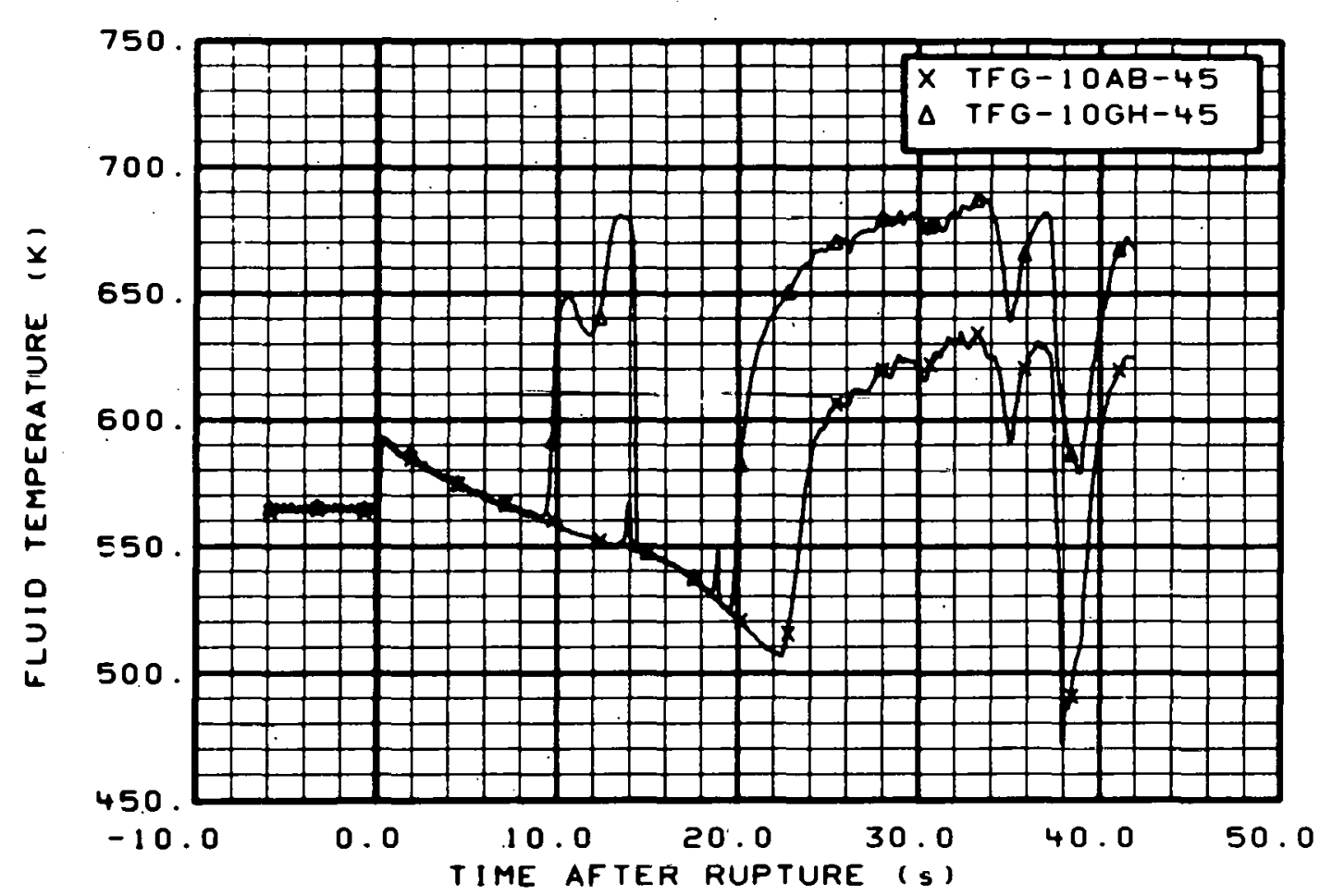

Fig. 38 Fluid temperature in core, Grid Spacer 10 (TFG-10AB-45 and TFG-10GH-45), from -6 to $42 \mathrm{~s}$. 


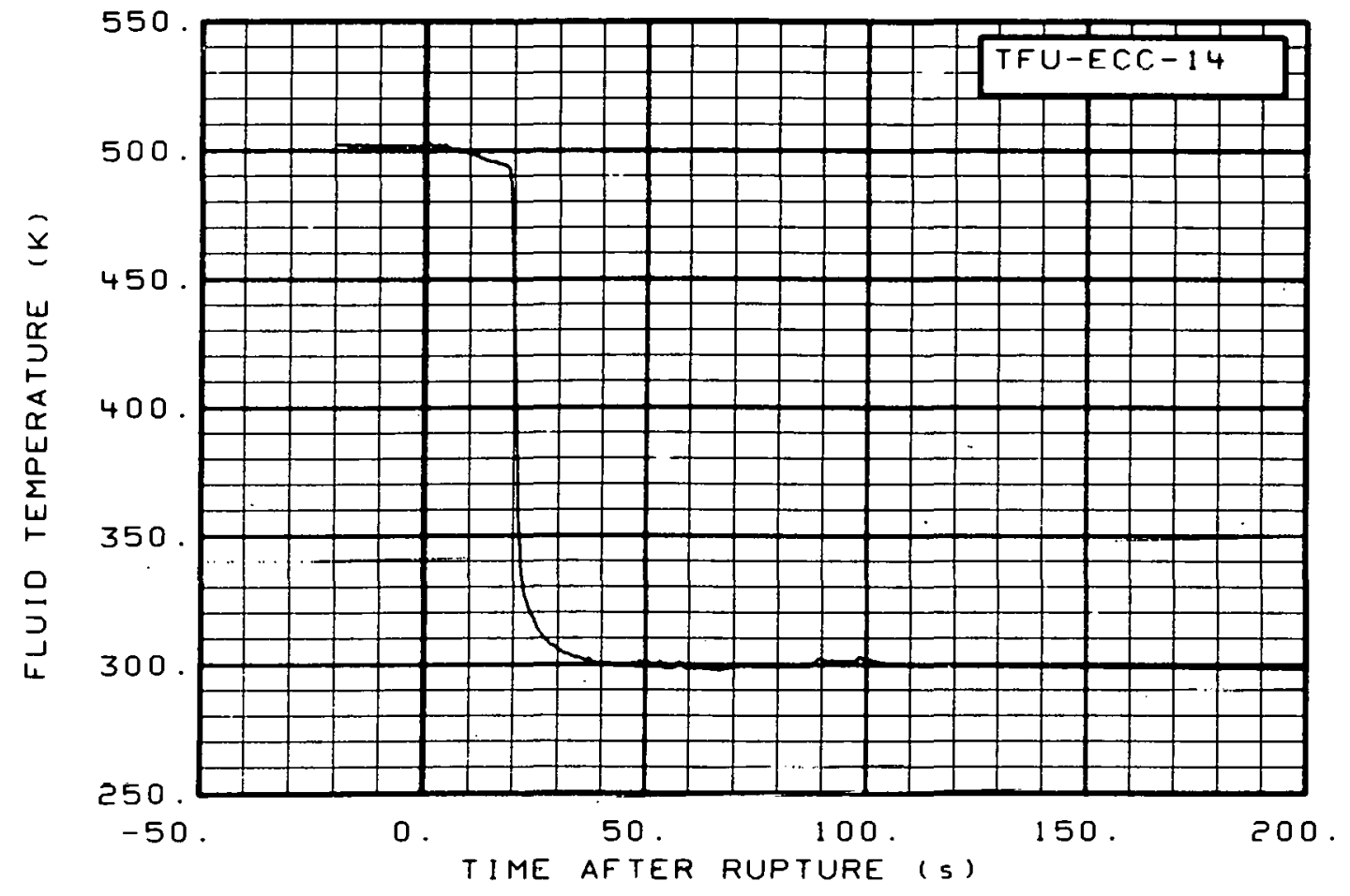

Fig. 39 Fluid temperature in intact loop coolant injection line (TFU-ECC-14), from -20 to $200 \mathrm{~s}$.

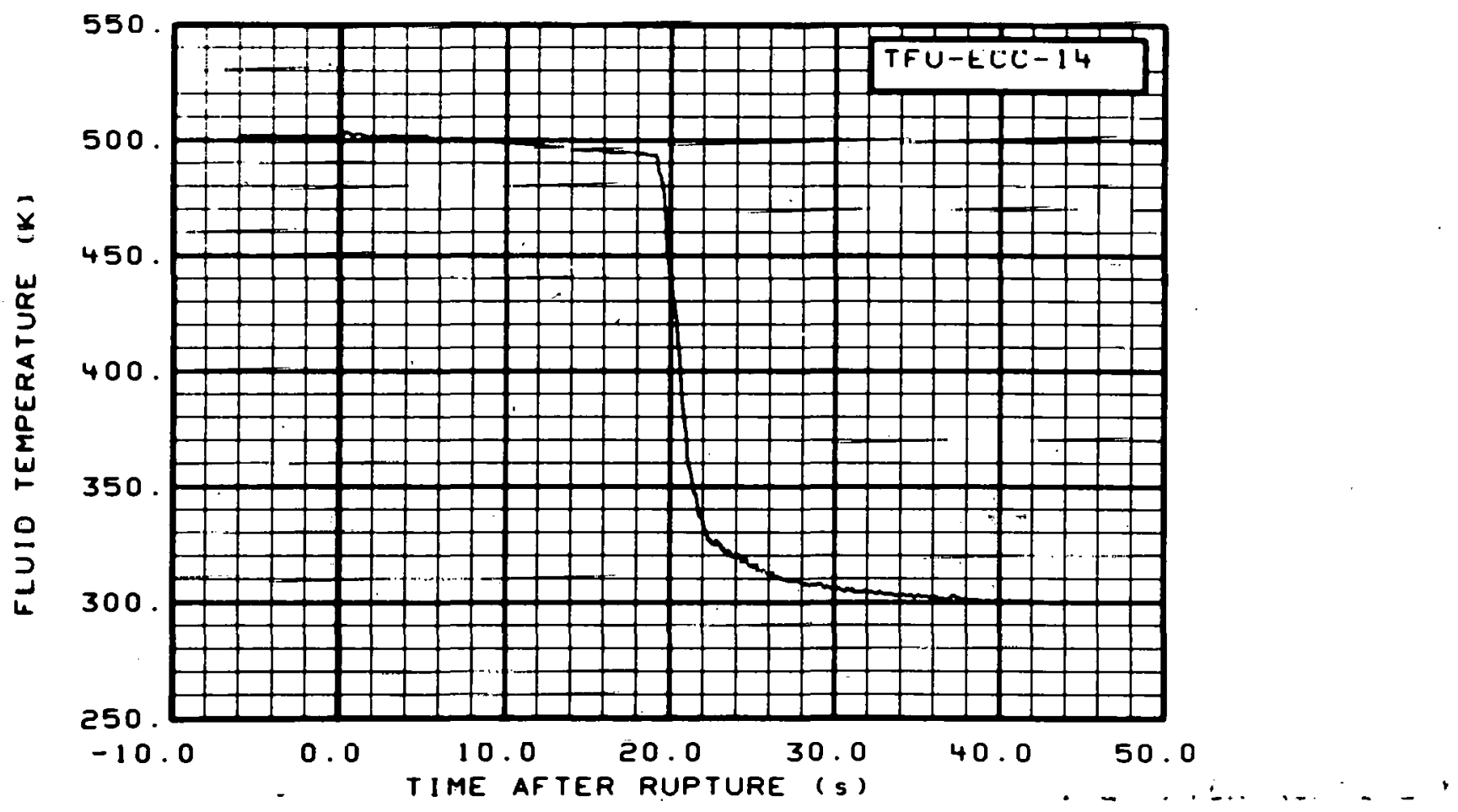

Fig. 40 Fluid temperature in intact loop coolant injection line (TFU-ECC-14), from -6 to $42 \mathrm{~s}$. 


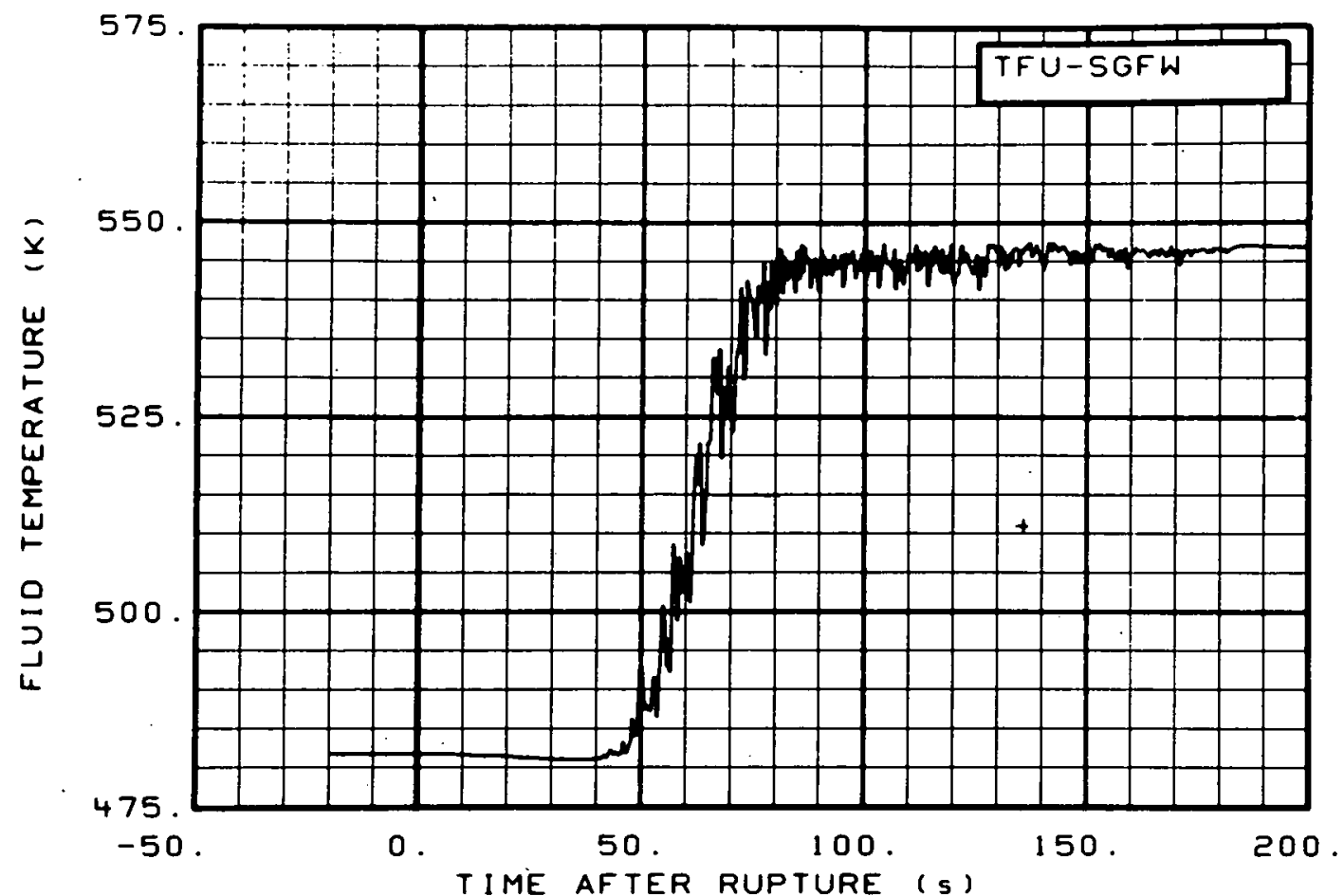

Fig. 41 Fluid temperature in steam generator, feedwater line (TFU-SGFW), from -20 to $200 \mathrm{~s}$.

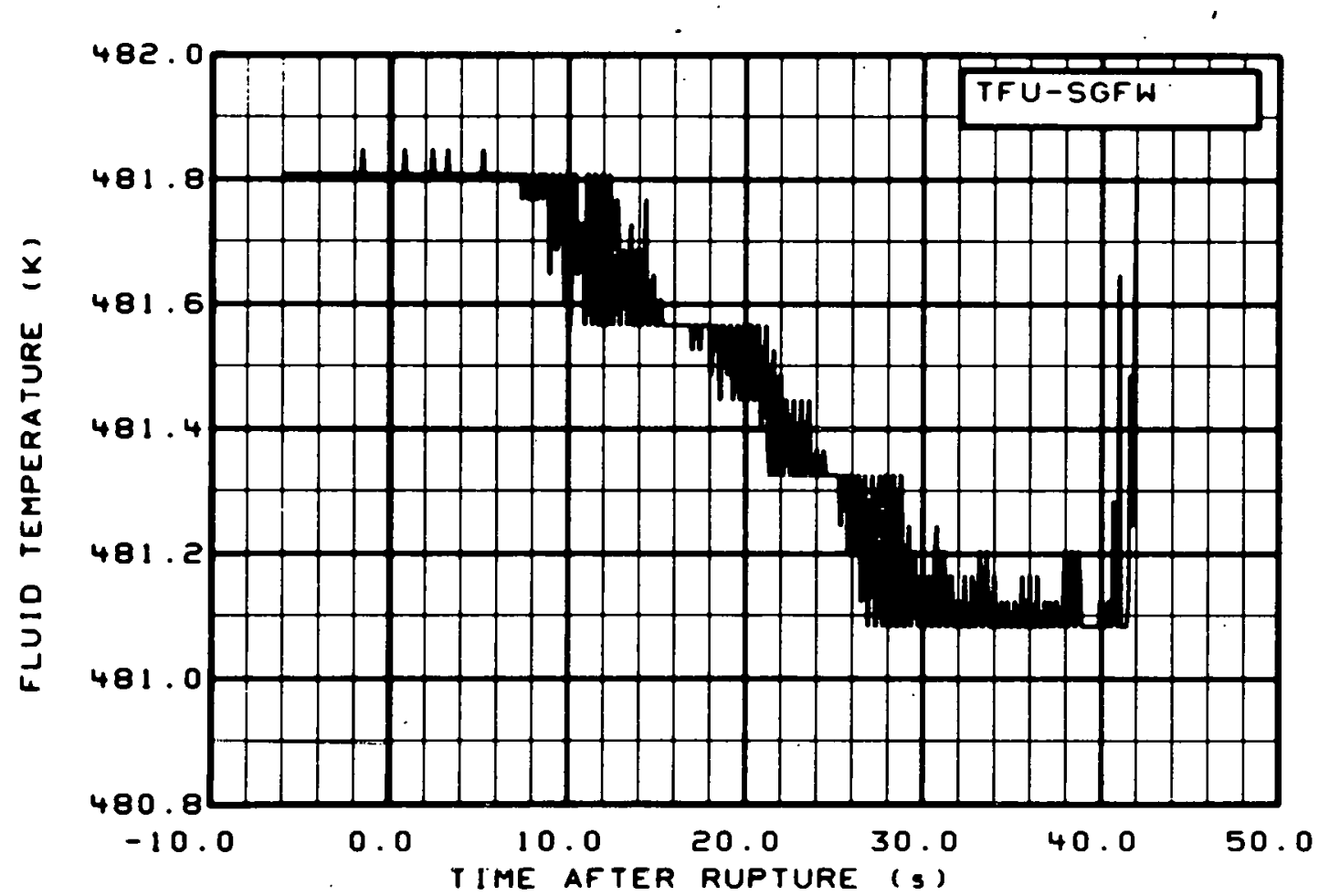

Fig. 42 Fluid temperature in steam generator, feedwater line (TFU-SGFW), from -6 to $42 \mathrm{~s}$. 


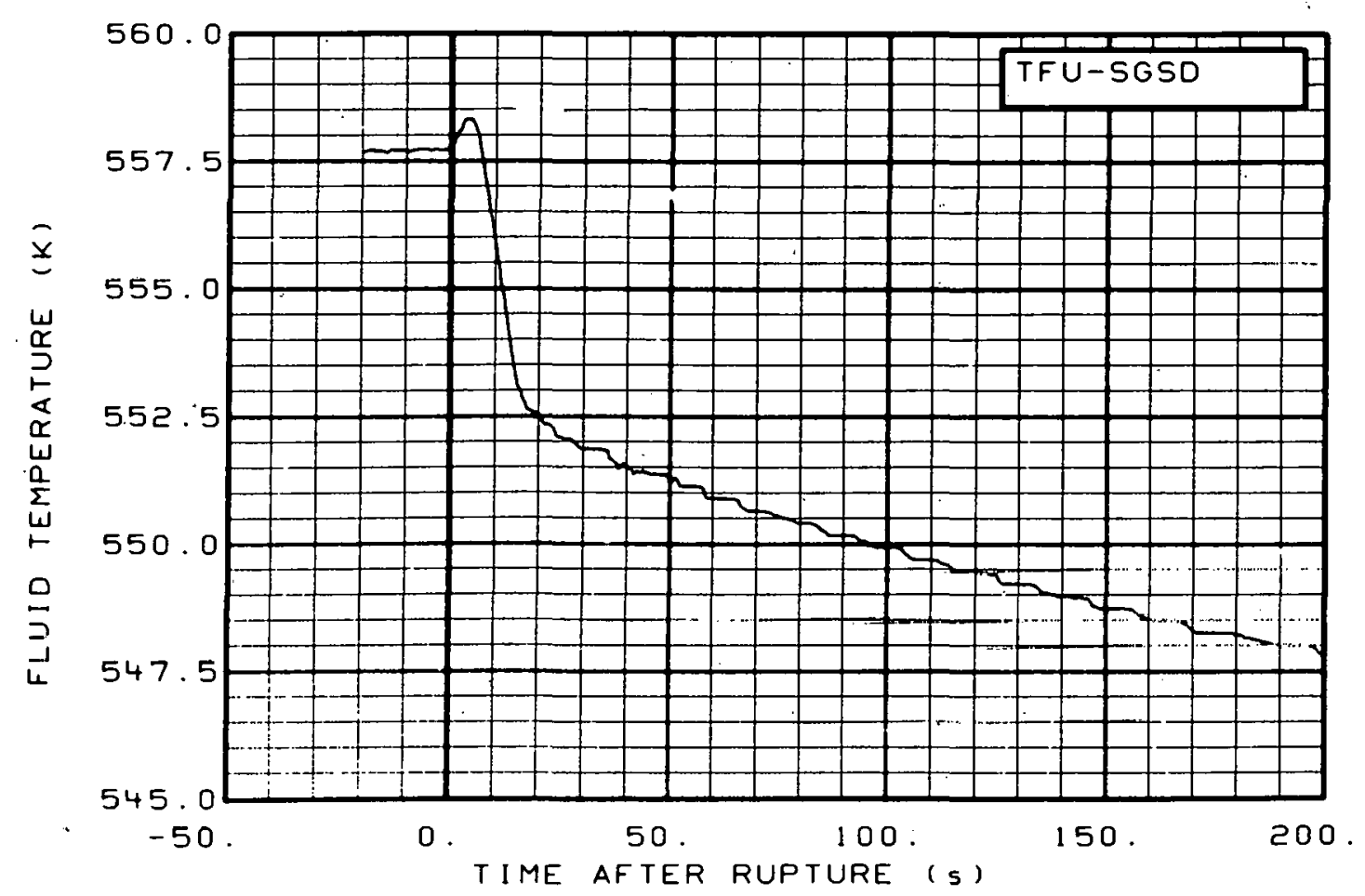

Fig. 43 Fluid temperature in steam generator, secondary side (TFU-SGSD), from -20 to $200 \mathrm{~s}$.

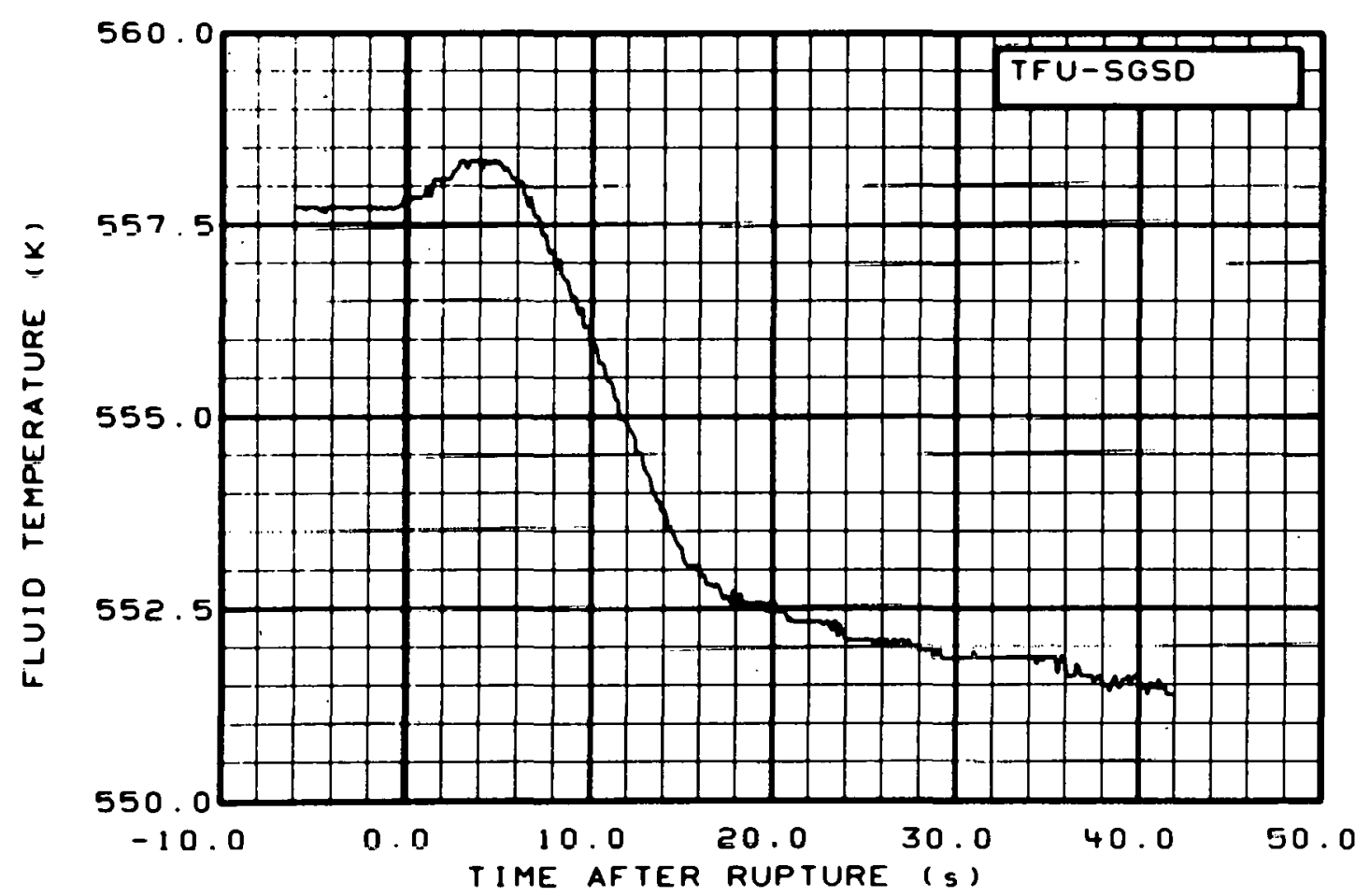

Fig. 44 Fluid temperature in steam generator, secondary side (TFU-SGSD), from -6 to $42 \mathrm{~s}$. 


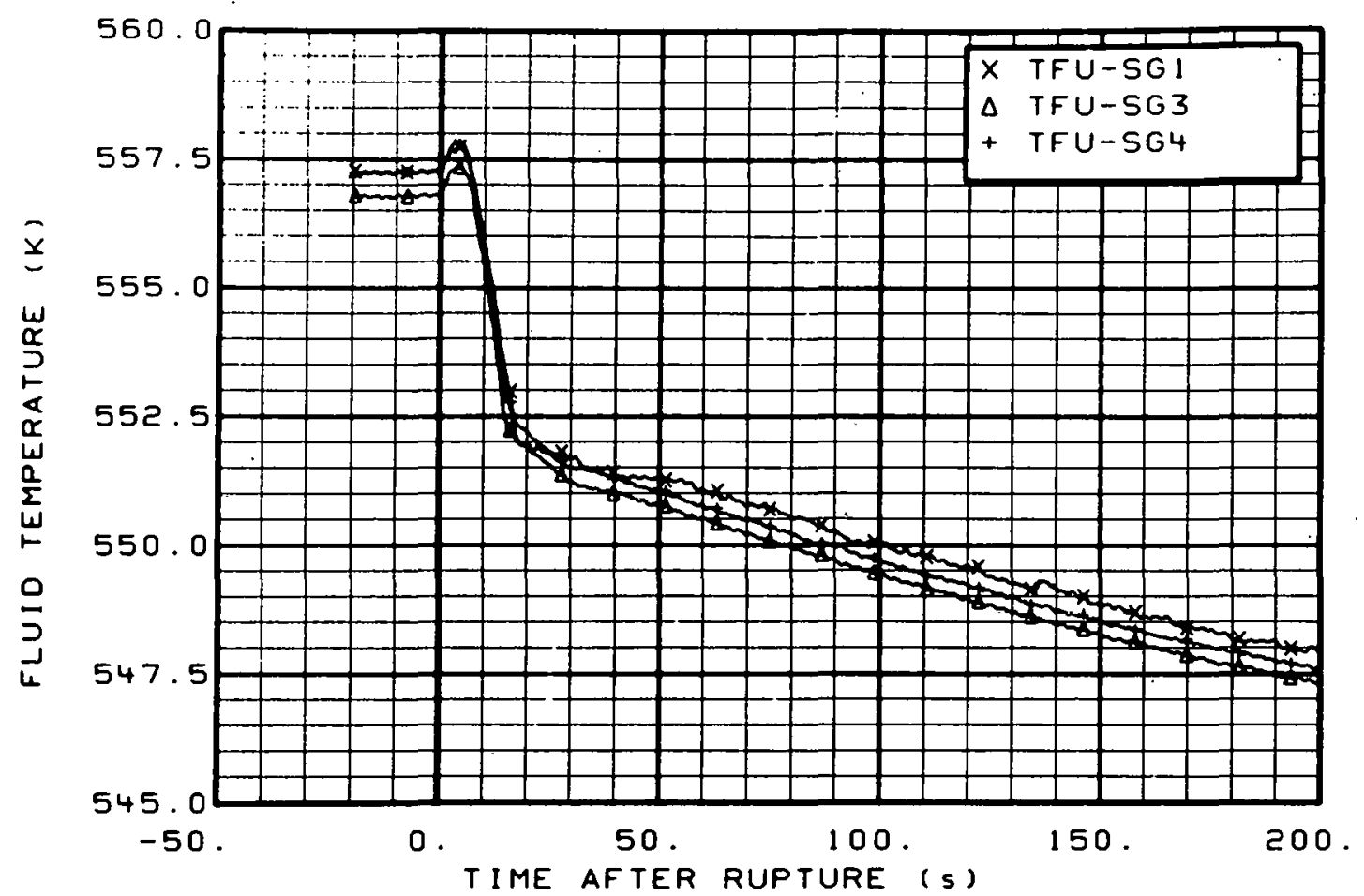

Fig. 45 Fluid temperature in steam generator, secondary side (TFU-SGT, TFU-SG3, and TFU-SG4), -20 to $200 \mathrm{~s}$.

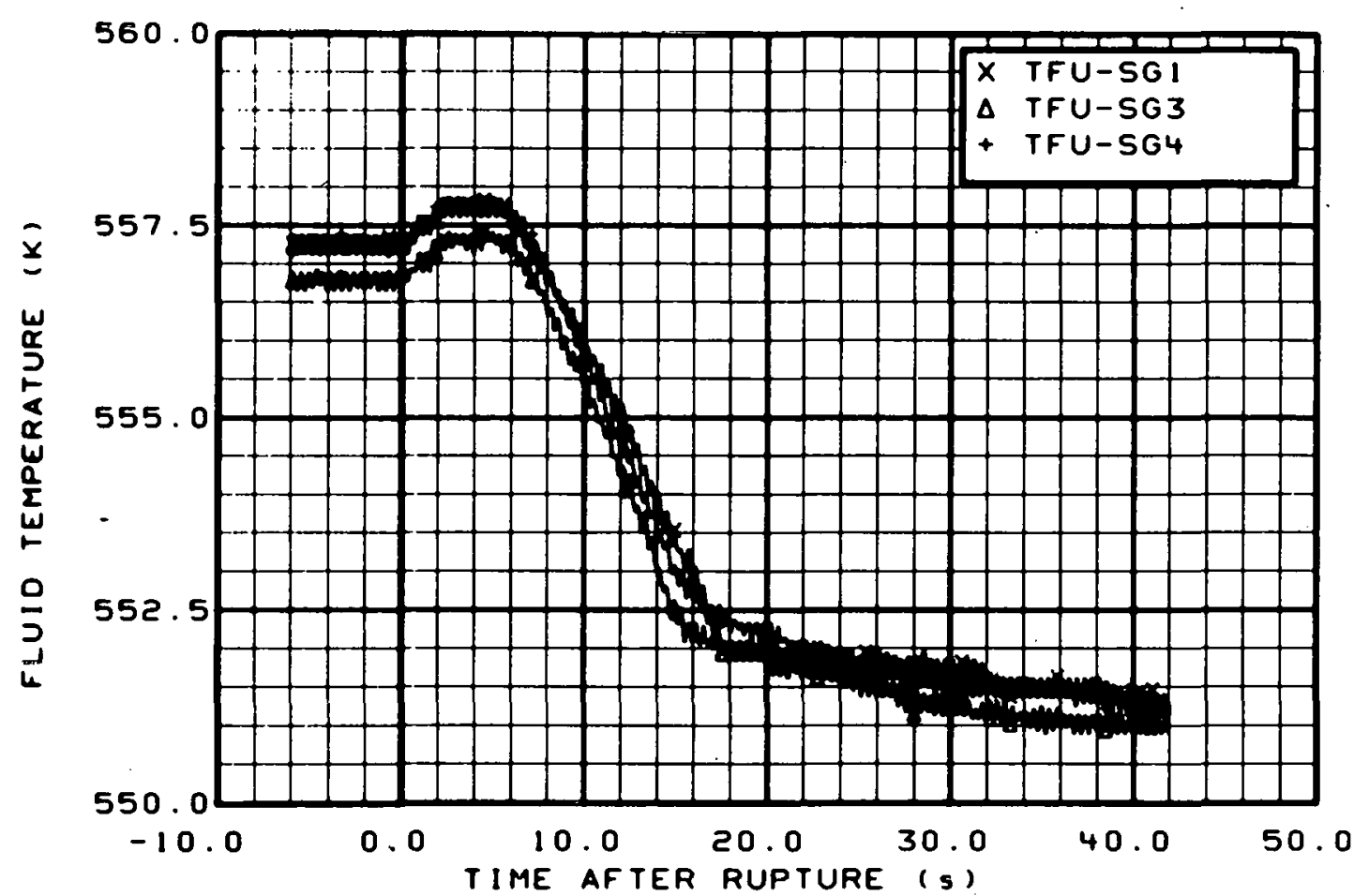

Fig. 46 Fluid temperature in steam generator, secondary side (TFU-SGT, TFU-SG3, and TFU-SG4), from -6 to $42 \mathrm{~s}$. 


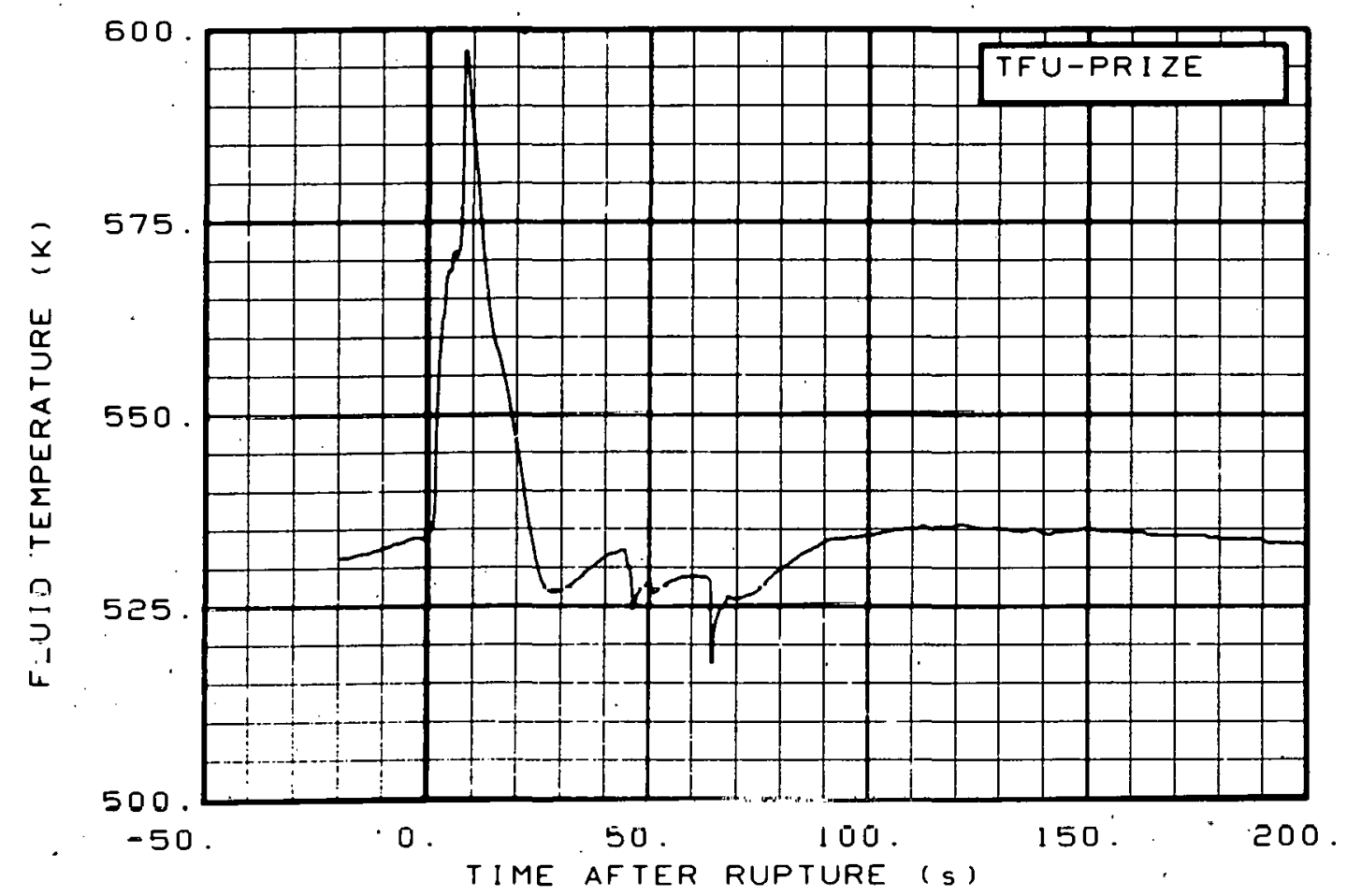

Fig. 47 Fluid temperature in pressurizer surge line (TFU-PRIZE), from -20 to $200 \mathrm{~s}$.

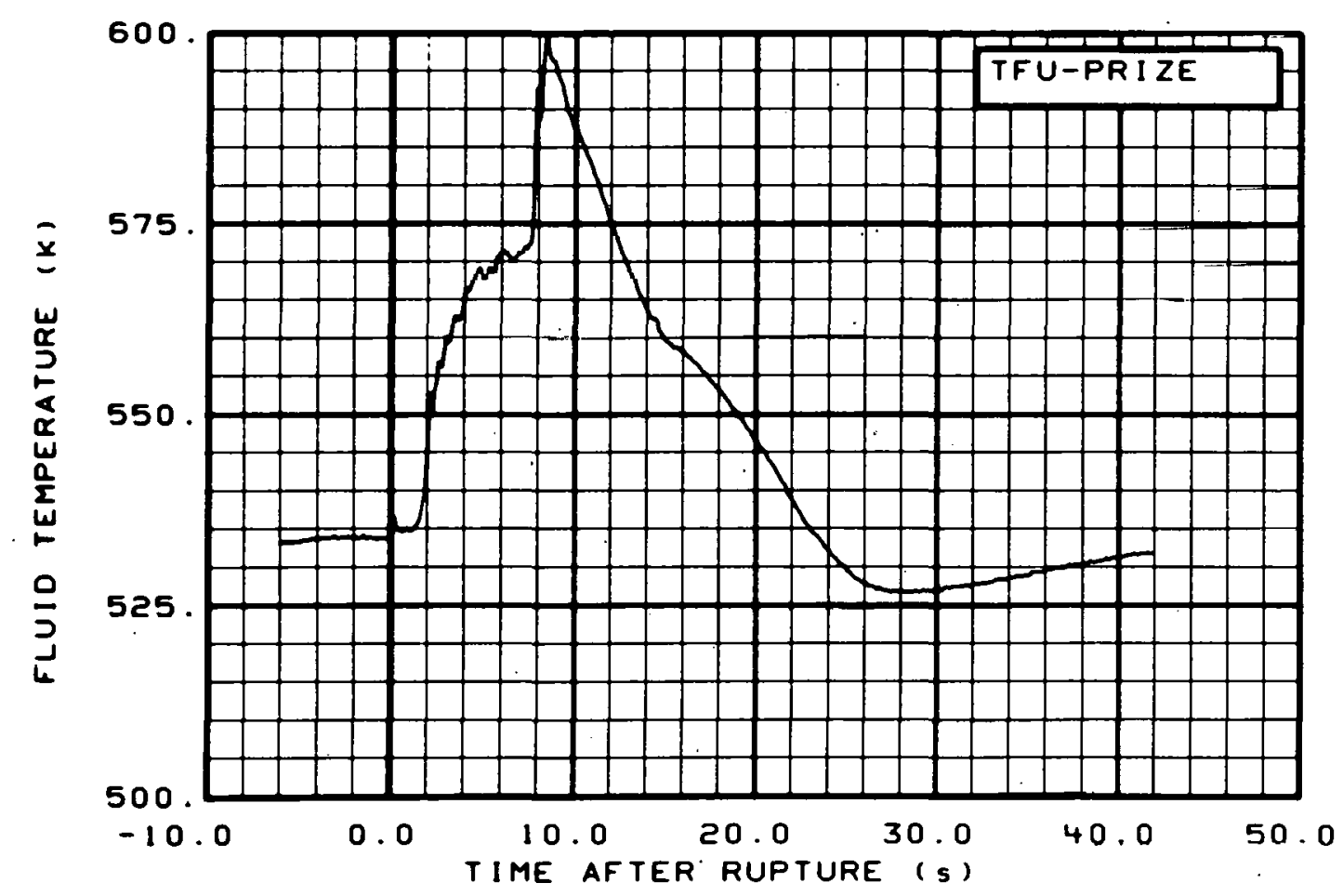

Fig. 48 Fluid temperature in pressurizer surge line (TFU-PRIZE), from -6 to $42 \mathrm{~s}$. 


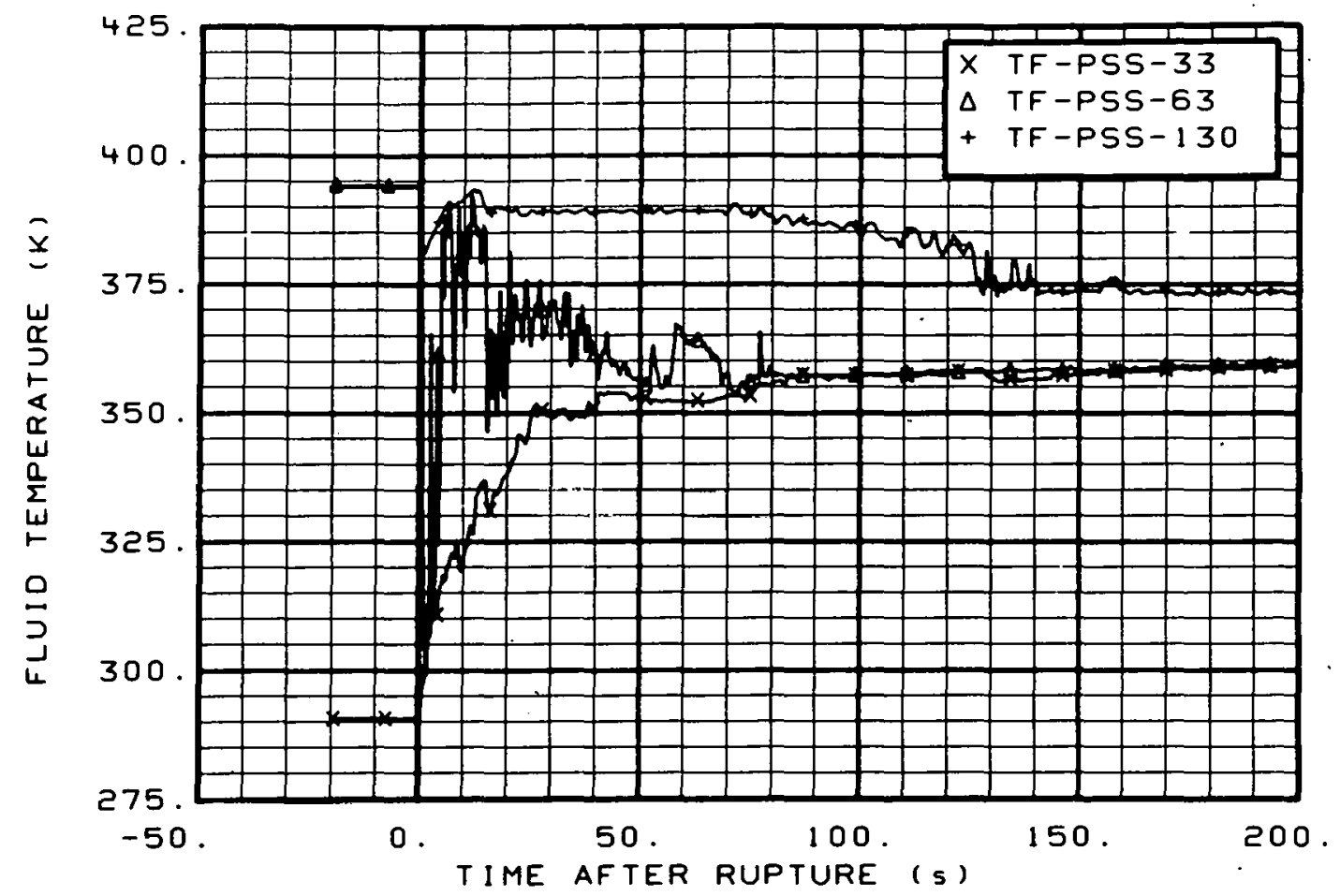

Fig. 49 Fluid temperature in pressure suppression tank (TF-PSS-33,: TF-PSS-63, and TF-PSS-130), from -20 to $200 \mathrm{~s}$.

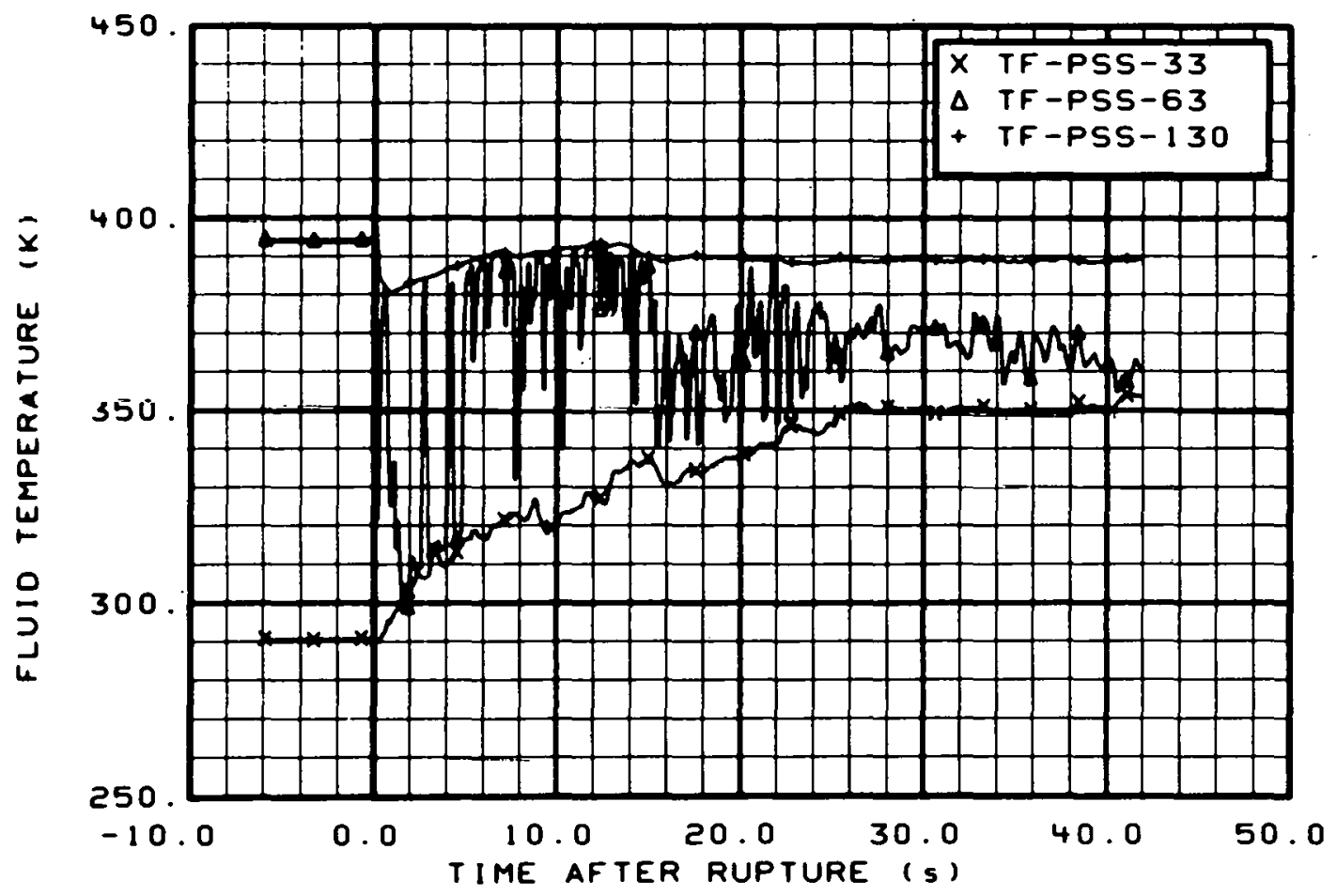

Fig. 50 Fluid temperature in pressure suppression tank (TF-PSS-33, TF-PSS-63, and TF-PSS-130), from -6 to $42 \mathrm{~s}$. 


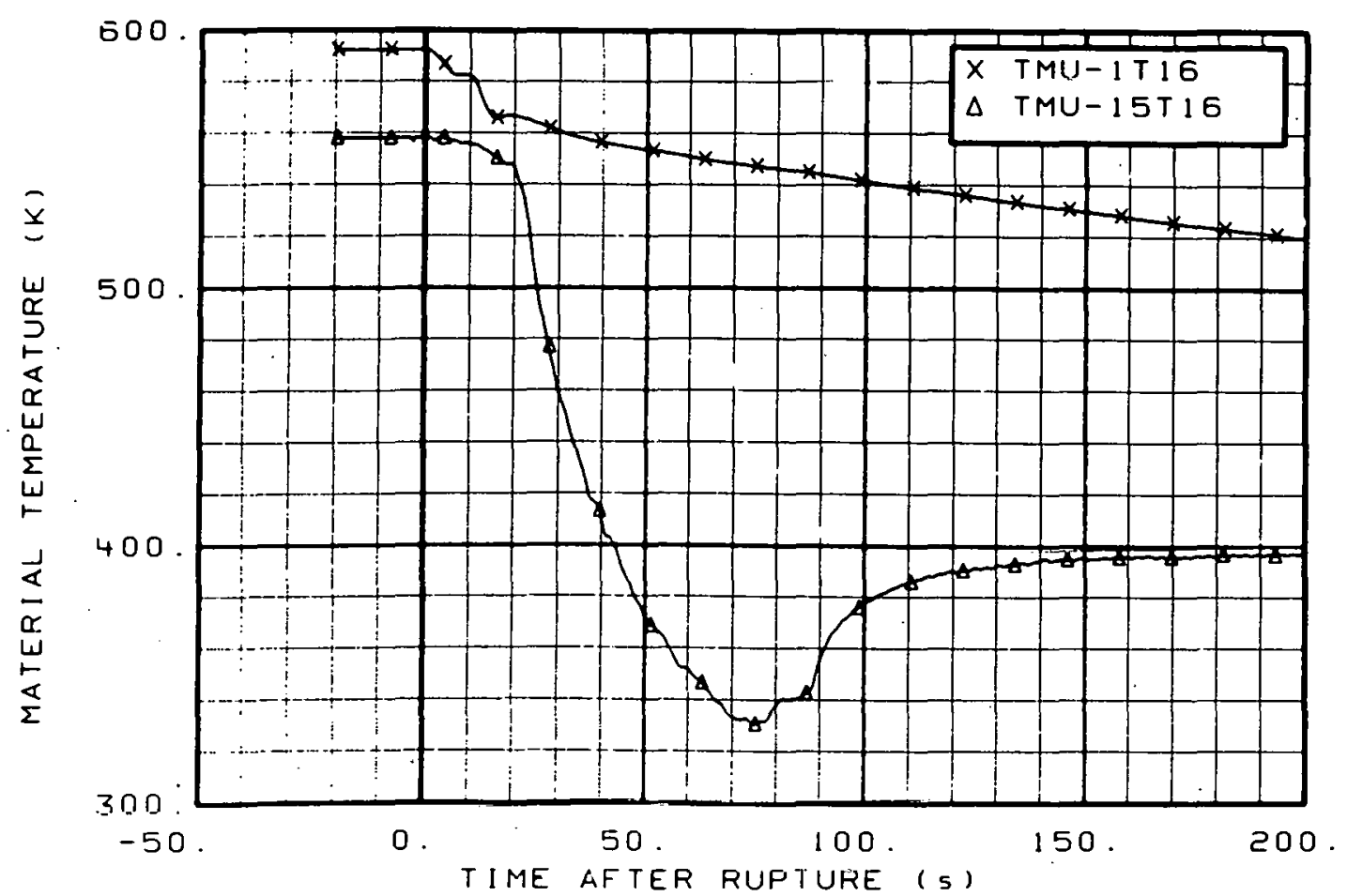

Fig. 51 Material temperature in intact loop (TMU-1T16 and TMU-15T16), from -20 to $200 \mathrm{~s}$.

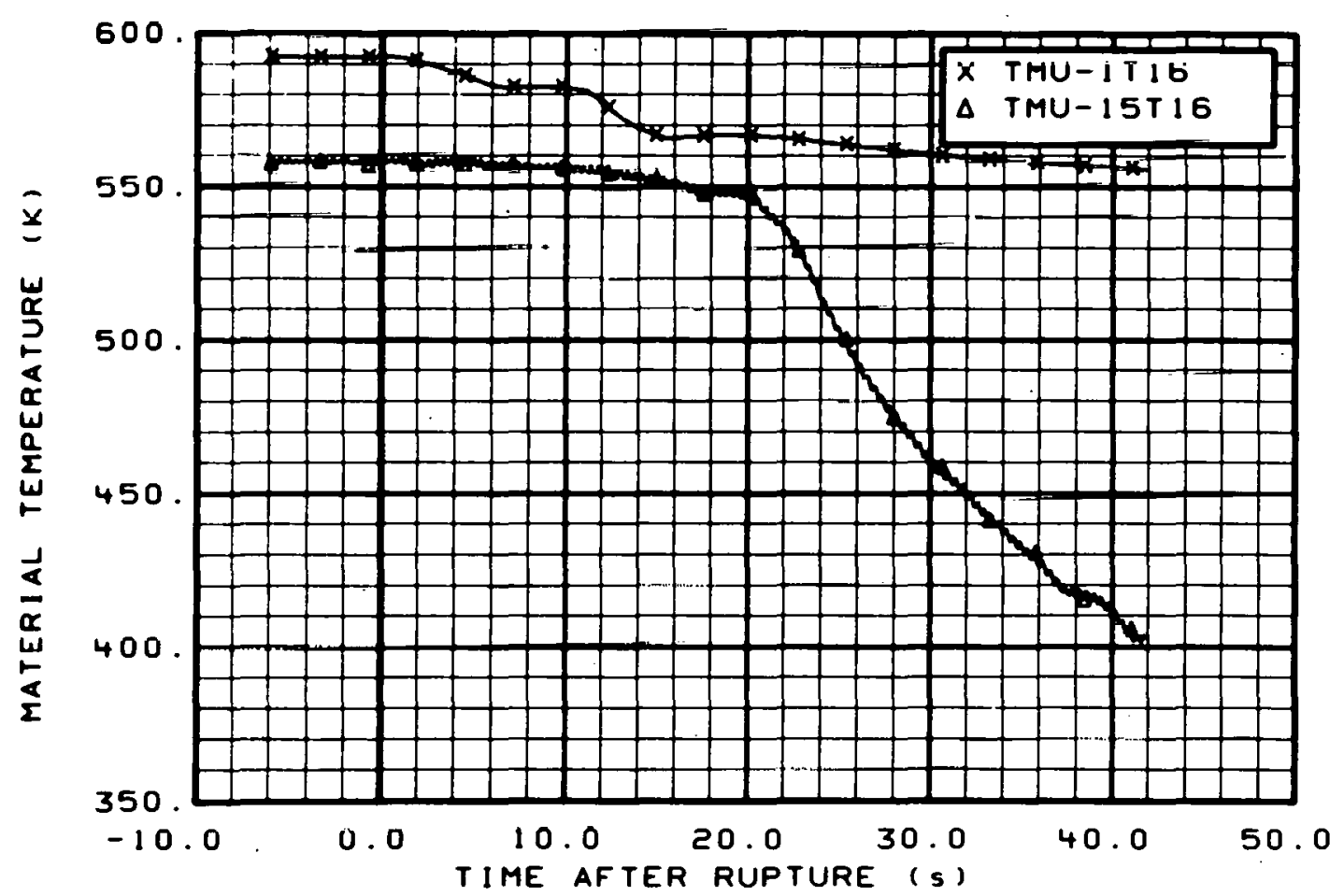

Fig. 52 Material temperature in intact loop (TMU-1T16 and TMU-15T16), from -6 to $42 \mathrm{~s}$. 


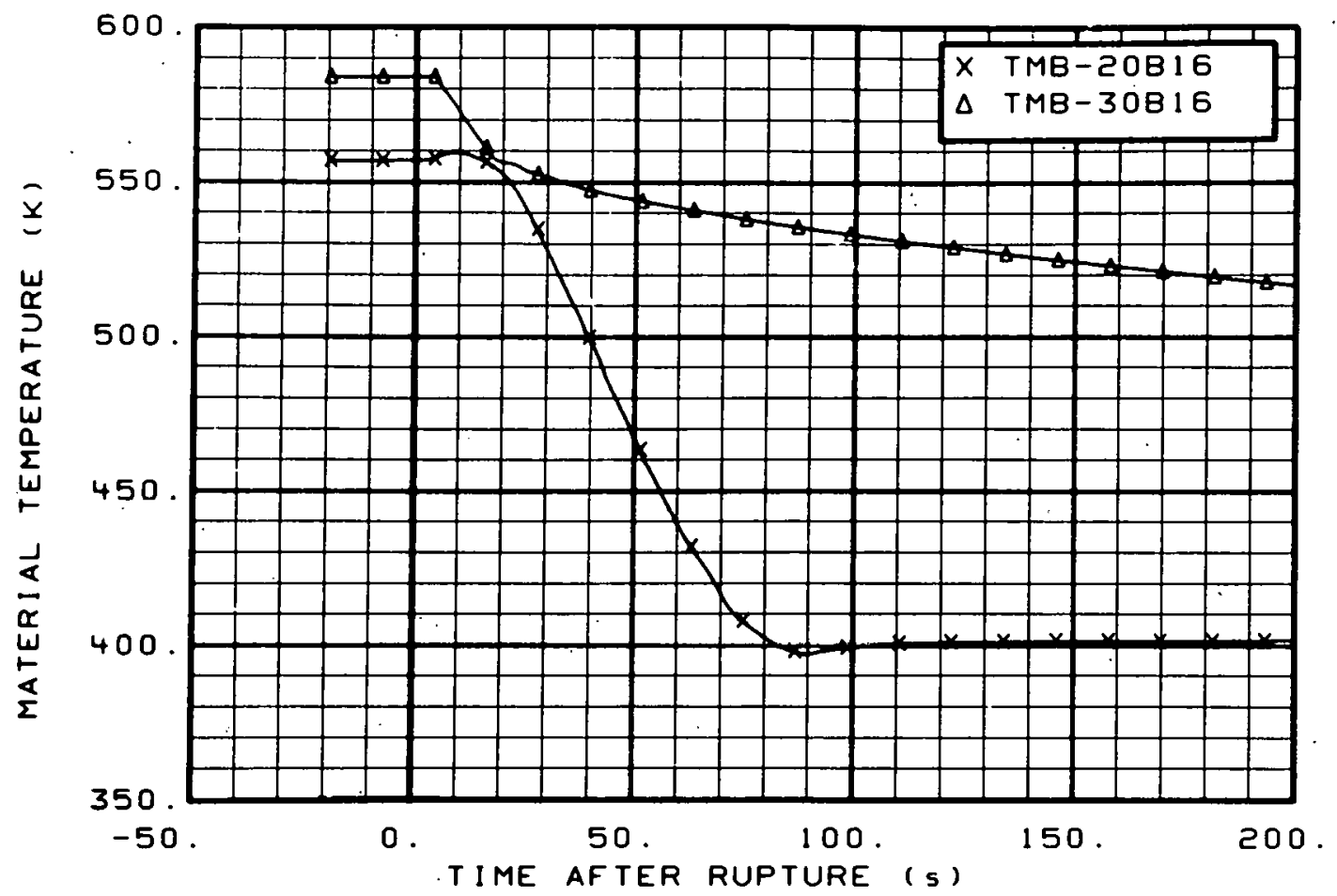

Fig. 53 Material temperature in broken loop (TMB-20B16 and TMB-30B 16), from -20 to $200 \mathrm{~s}$.

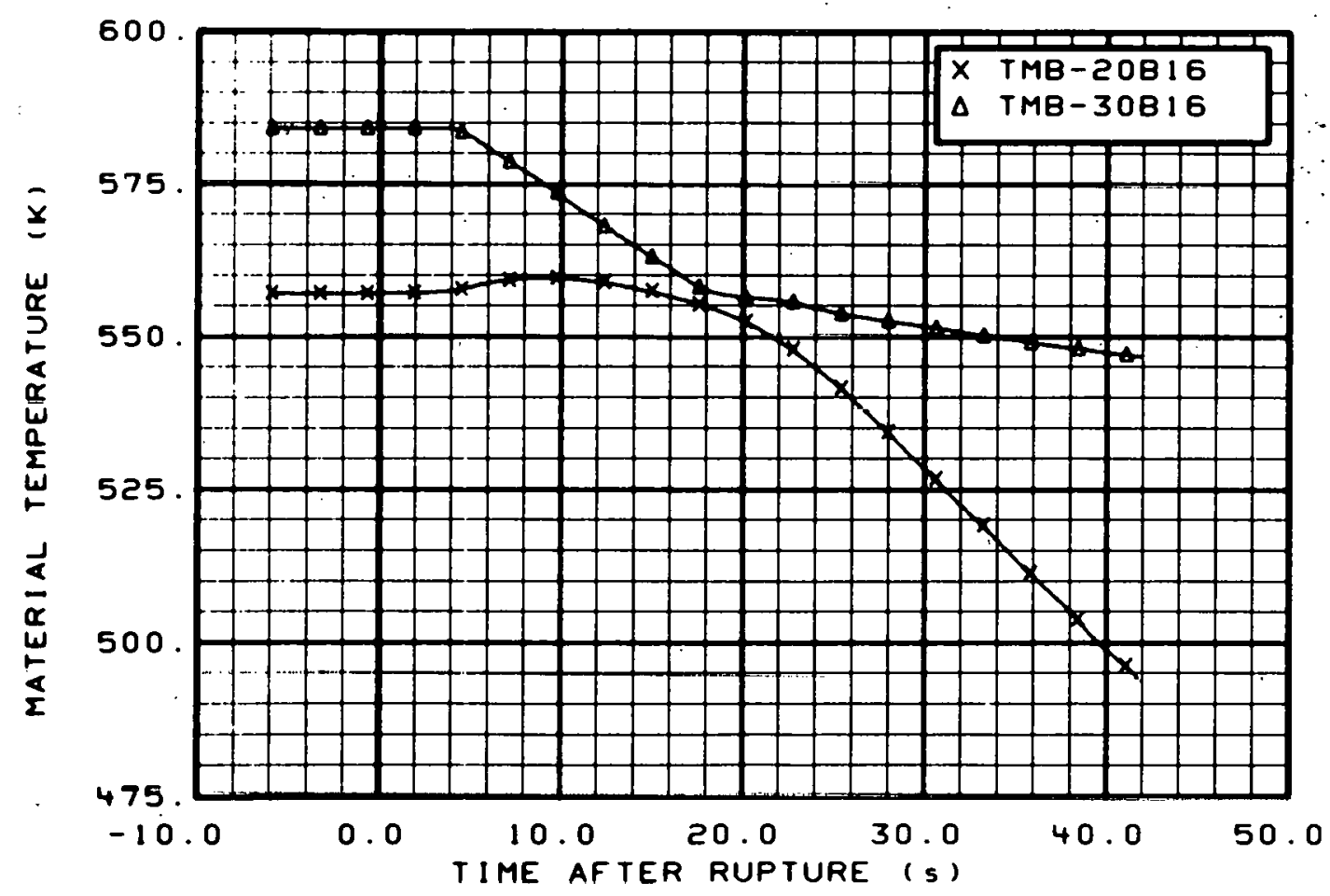

Fig. 54 Material temperature in broken loop (TMB-20B16 and TMB-30B16), from -6 to $42 \mathrm{~s}$. 


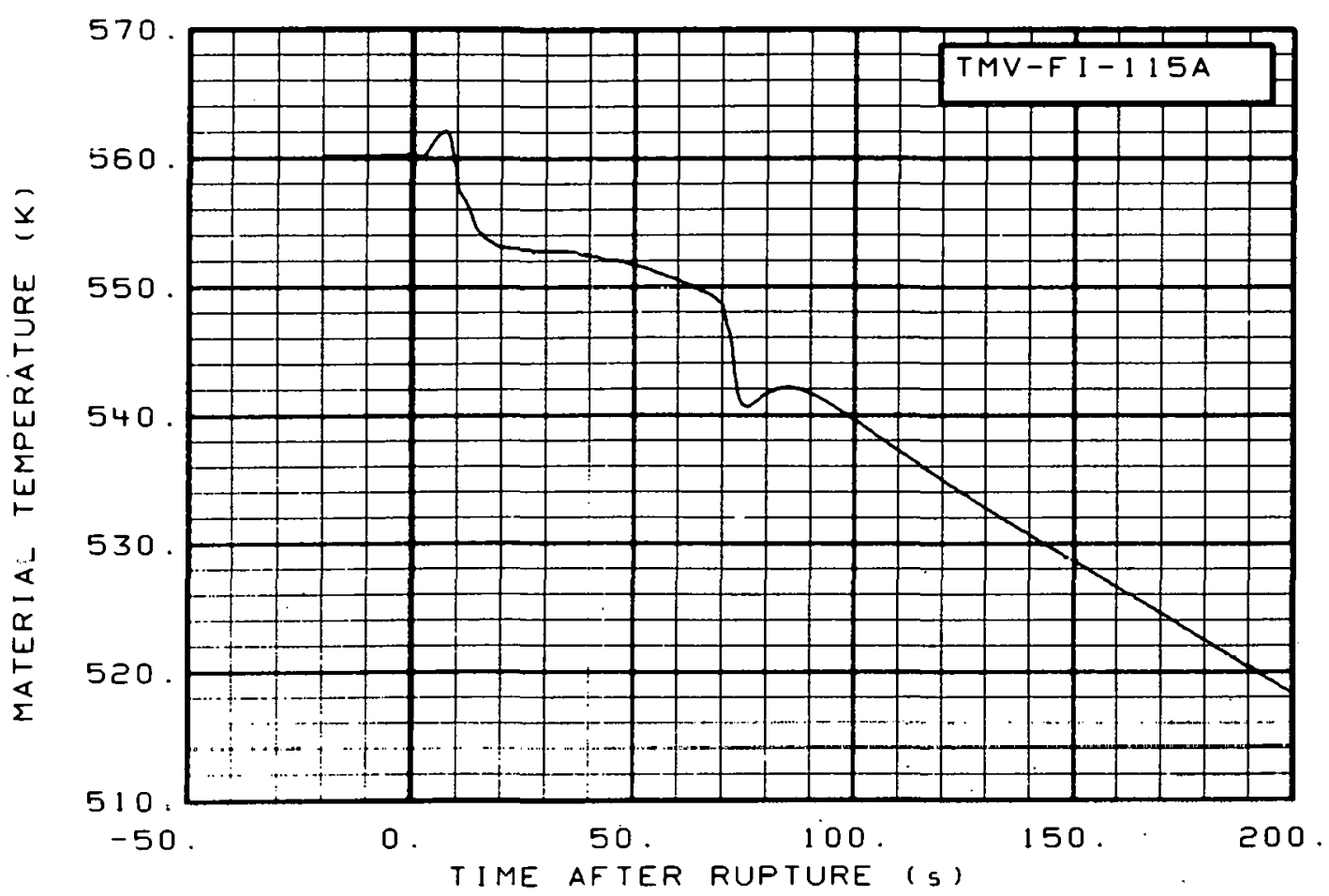

Fig. 55 Material temperature in vessel filler. (TMV-FI-115A), from -20 to $200 \mathrm{~s}$.

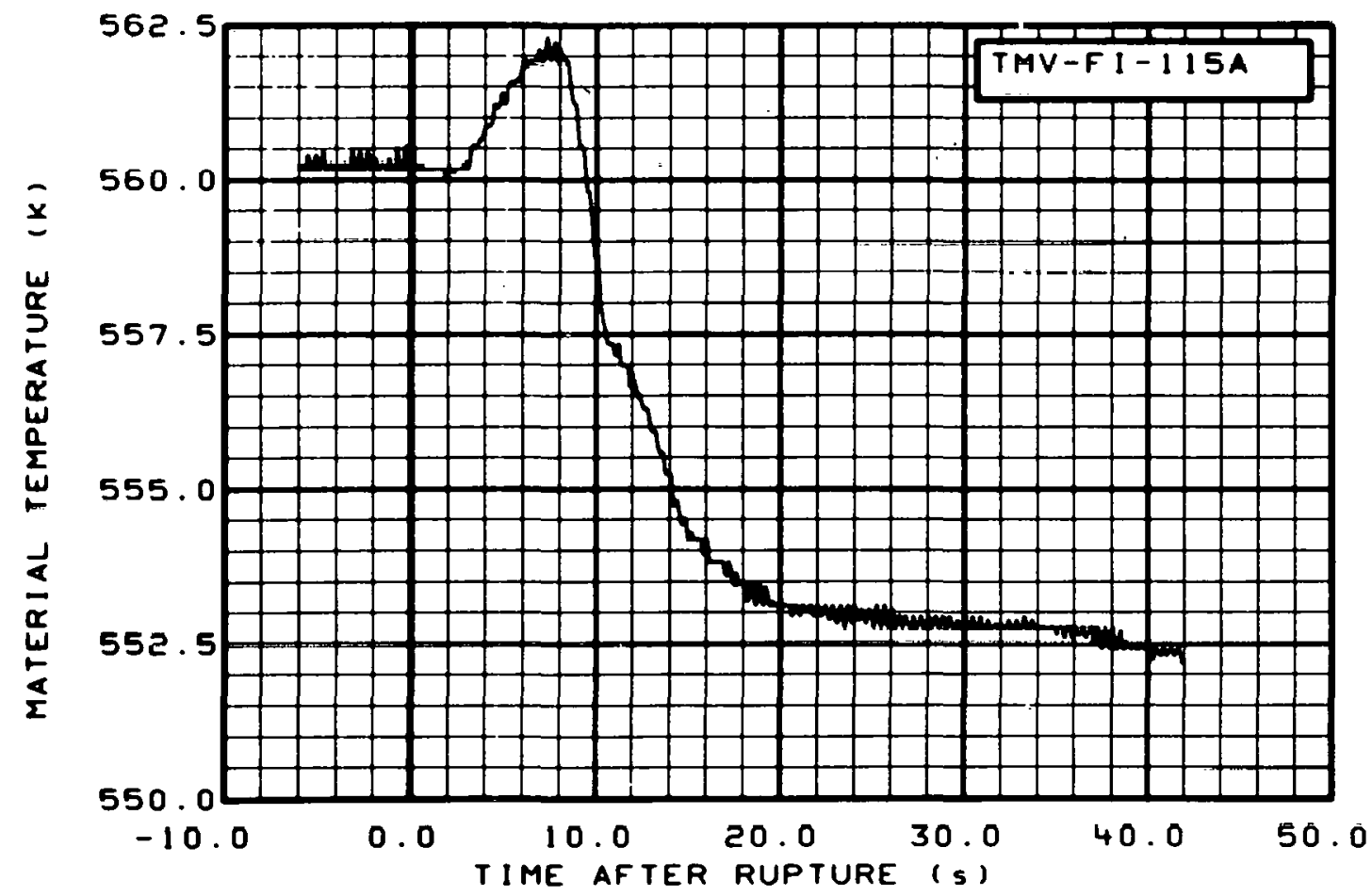

Fig. 56 Material temperature in vessel filler (TMV-FI-115A), from -6 to $42 \mathrm{~s}$. 


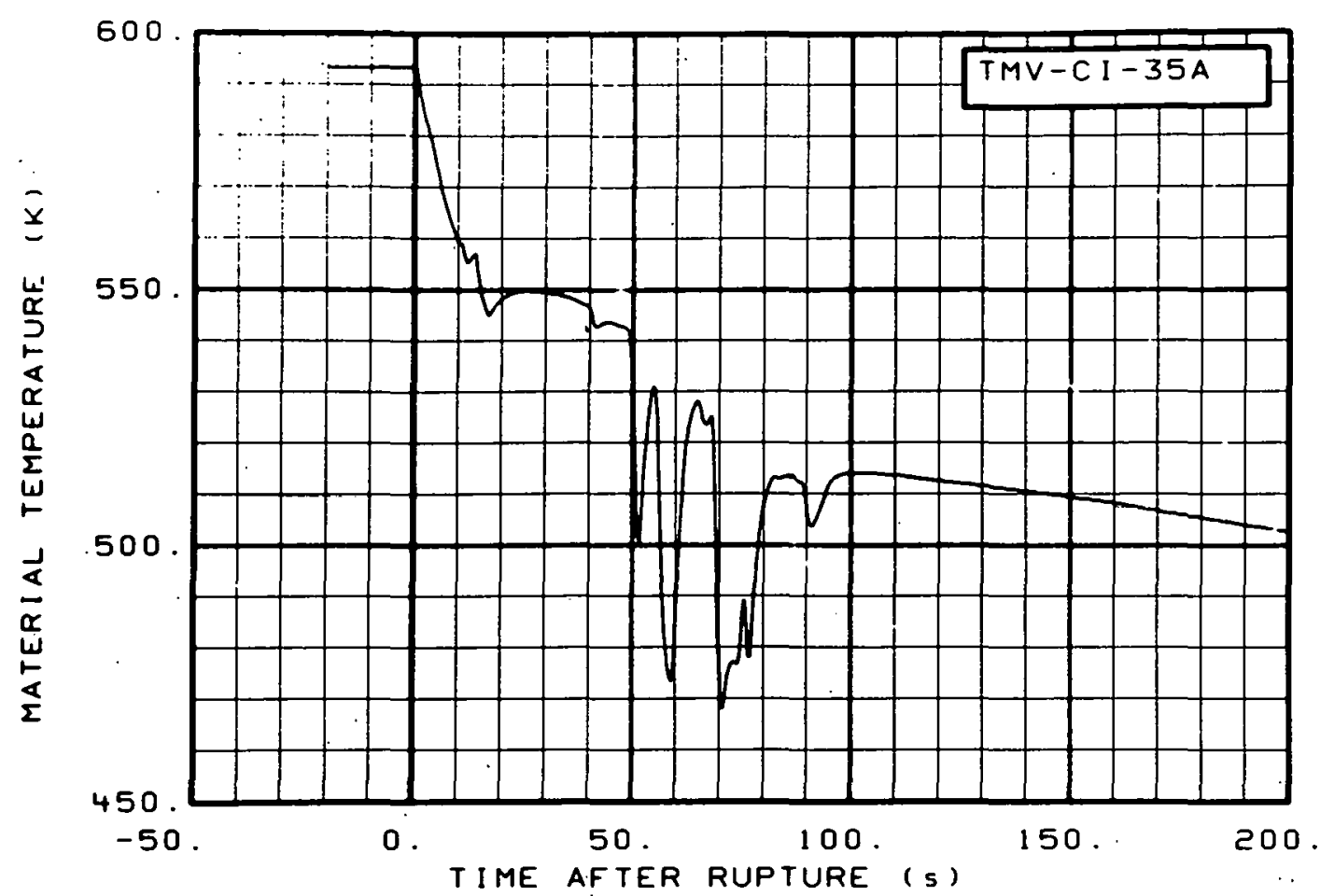

Fig. 57 Material temperature in core barrel inner diameter (TMV-CI-35A), from -20 to $200 \mathrm{~s}$.

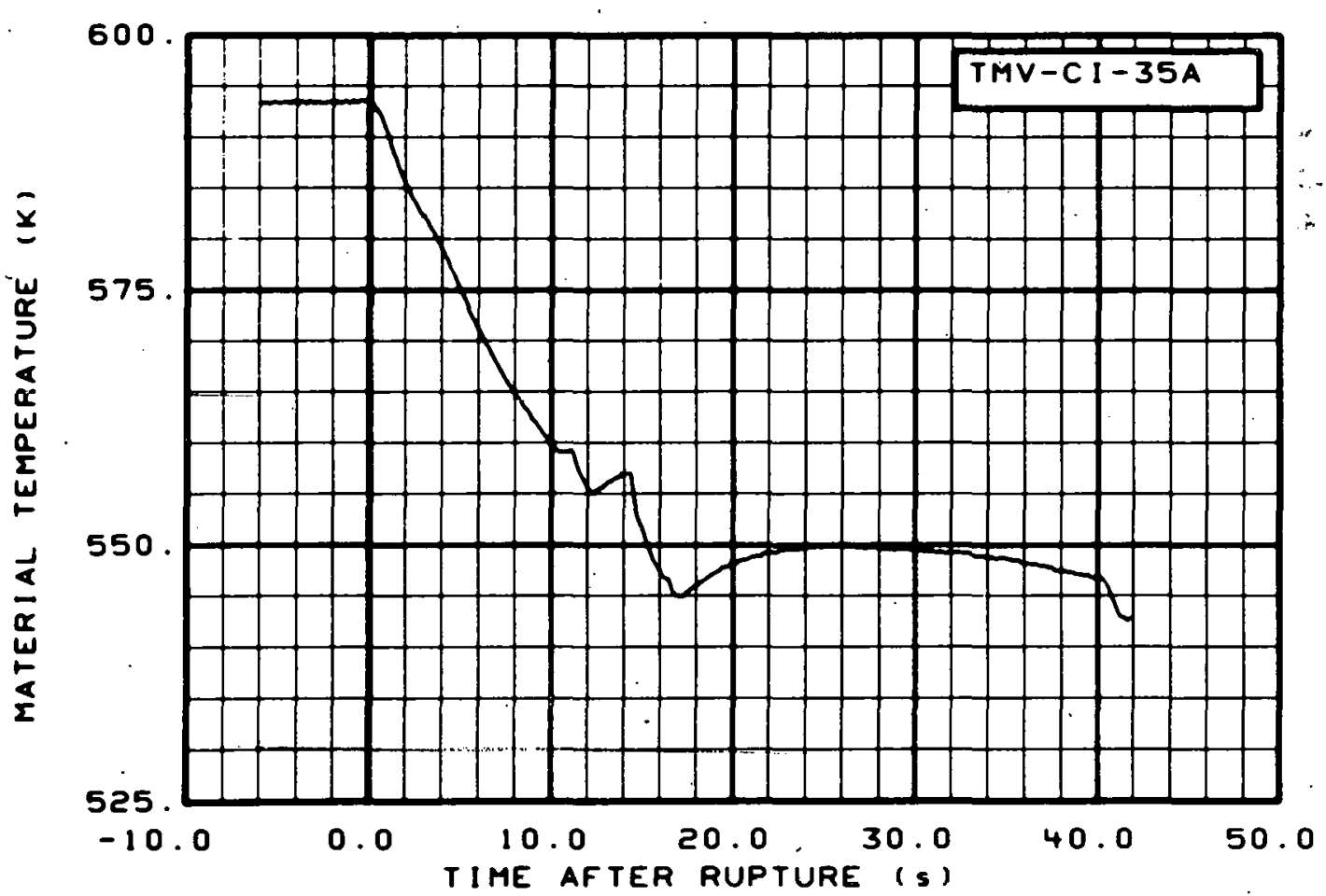

Fig. 58 Material temperature in core barrel inner diameter (TMV-CI-35A), from -6 to $42 \mathrm{~s}$. 


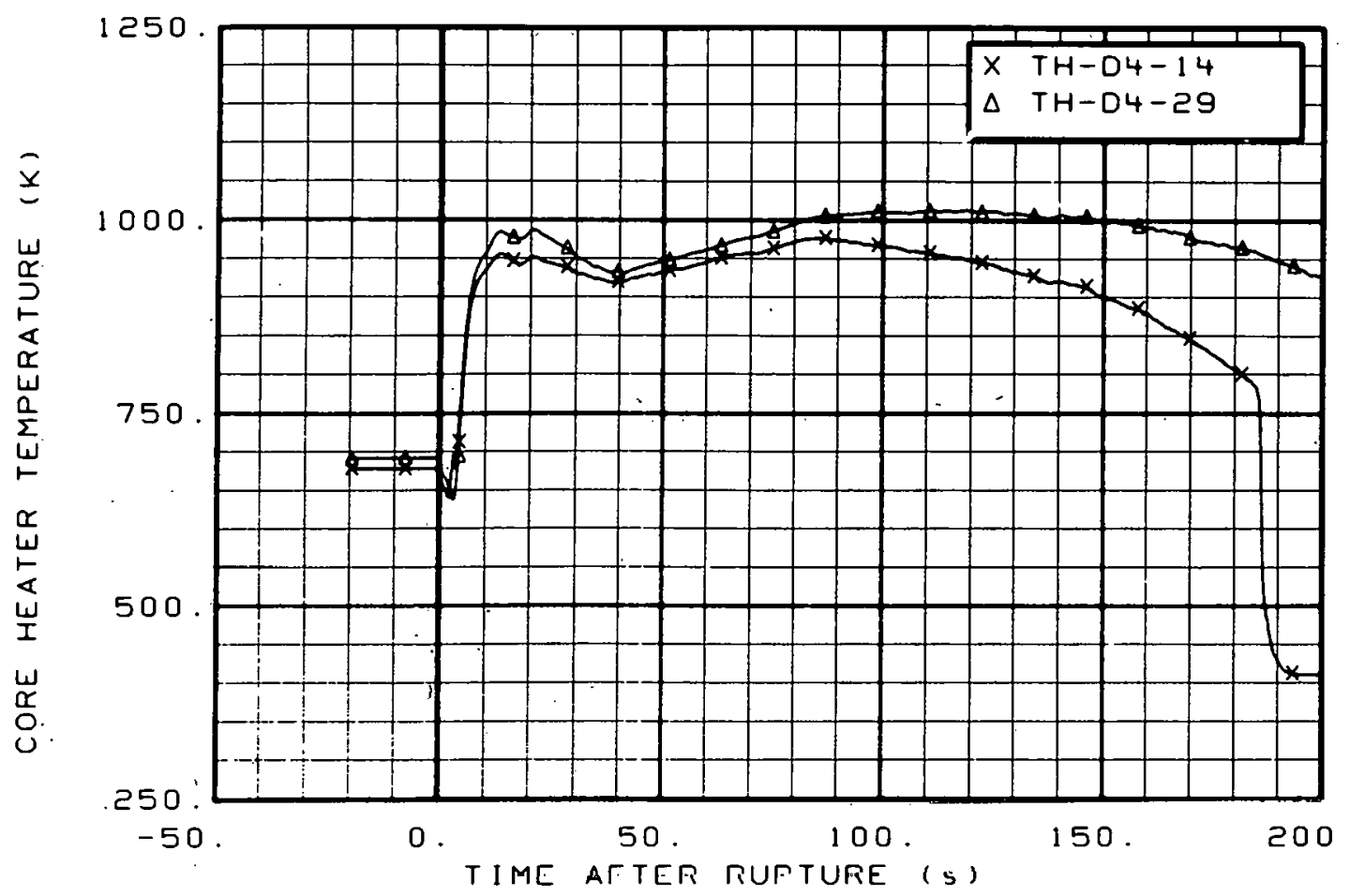

Fig. 59 Core heater temperature, Rod D-4 (TH-D4-1.4 and TH-D4-29), from -20 to $200 \mathrm{~s}$.

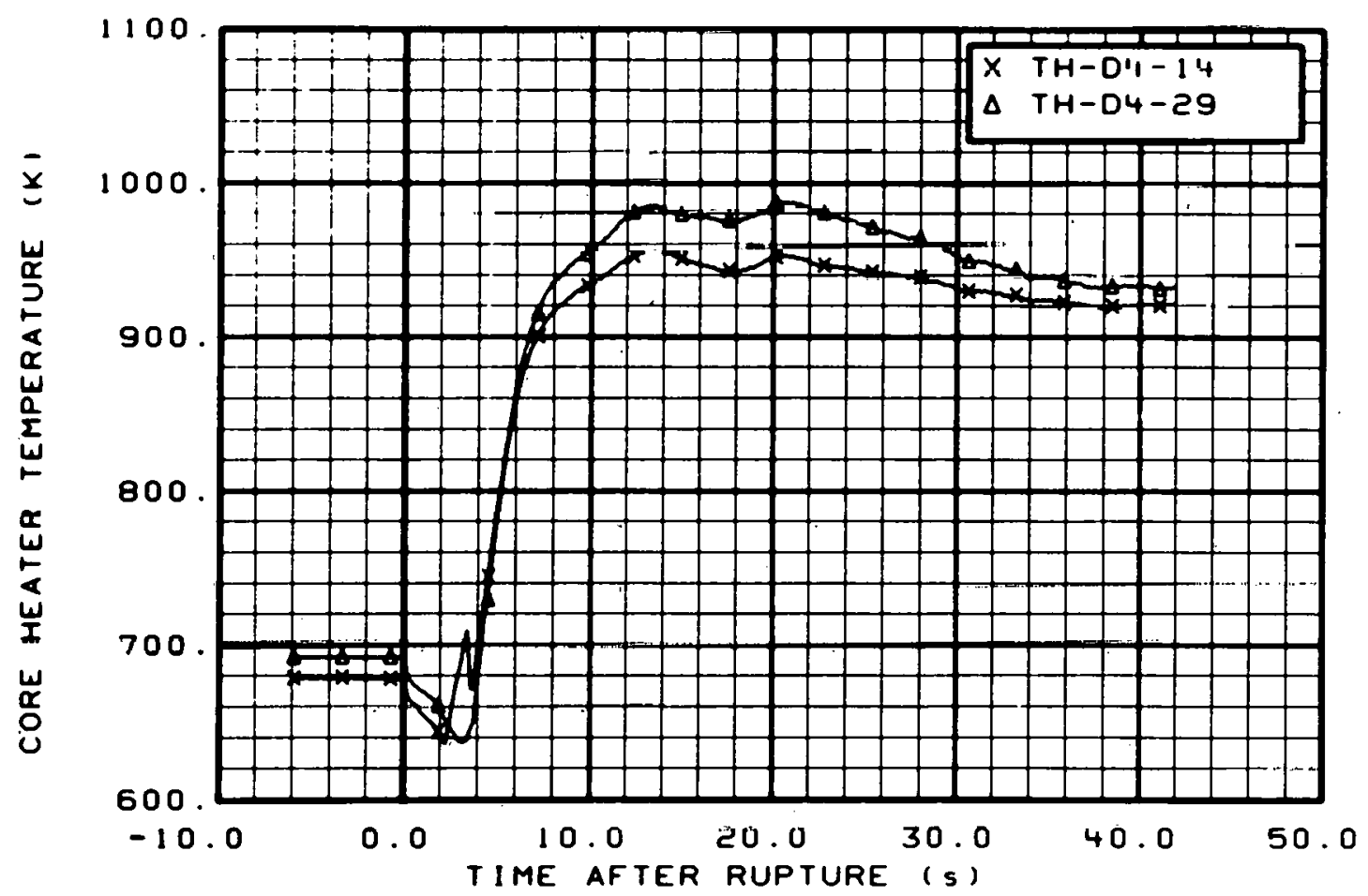

Fig. 60 Core heater temperature, Rod D-4. (TH-D4-14 and TH-D4-29), from -6 to $42 \mathrm{~s}$. 


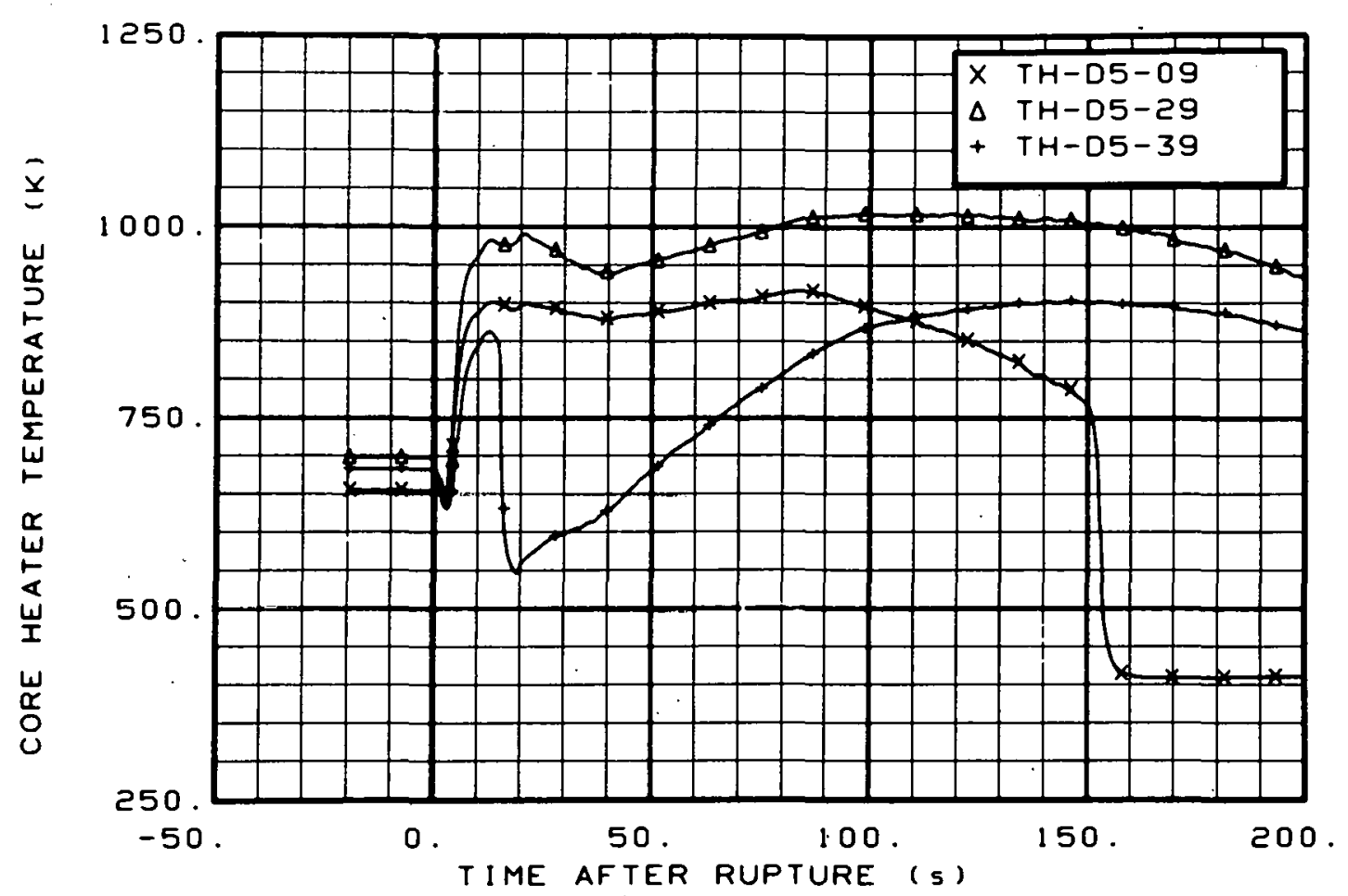

Fig. 61 Core heater temperature, Rod D-5 (TH-D5-09, TH-D5-29, and TH-D5-39), from -20 to $200 \mathrm{~s}$.

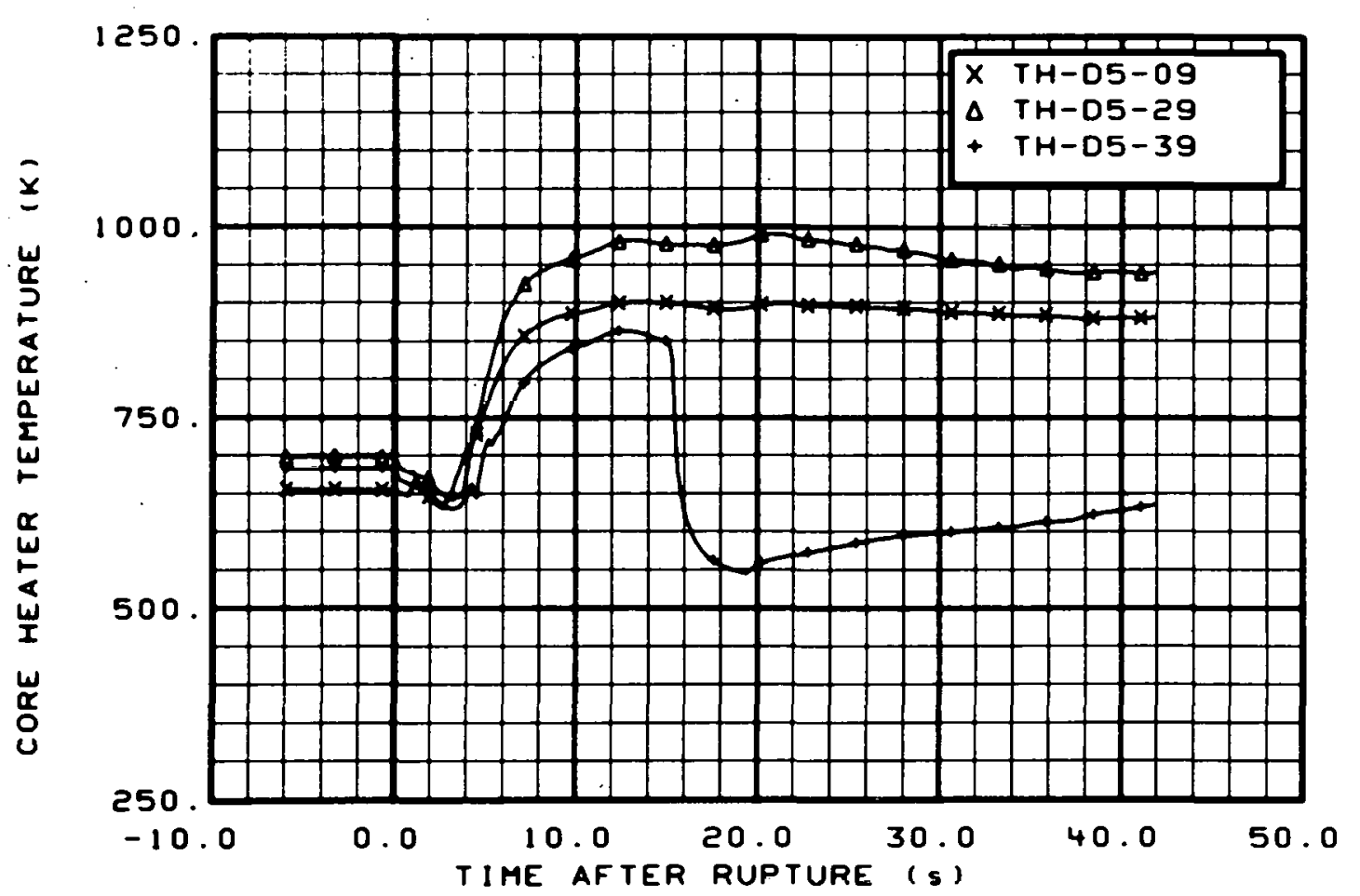

Fig. 62 Core heater temperature, Rod D-5 (TH-D5-09, TH-D5-29, and TH-D5-39), from -6 to $42 \mathrm{~s}$. 


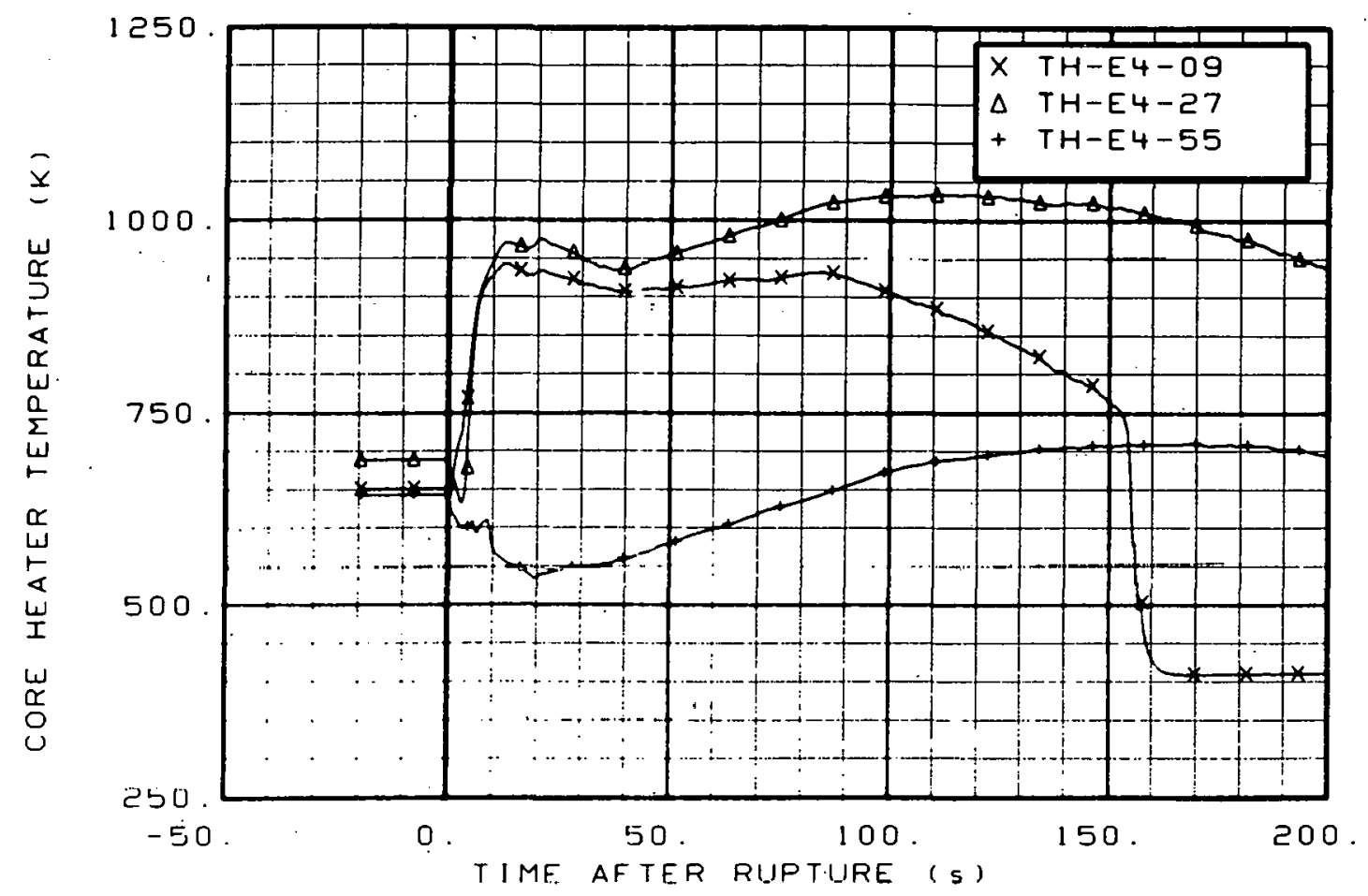

Fig. 63 Core heater temperature, Rod E-4 (TH-E4-09, TH-E4-27, and TH-E4-55), from -20 to $200 \mathrm{~s}$.

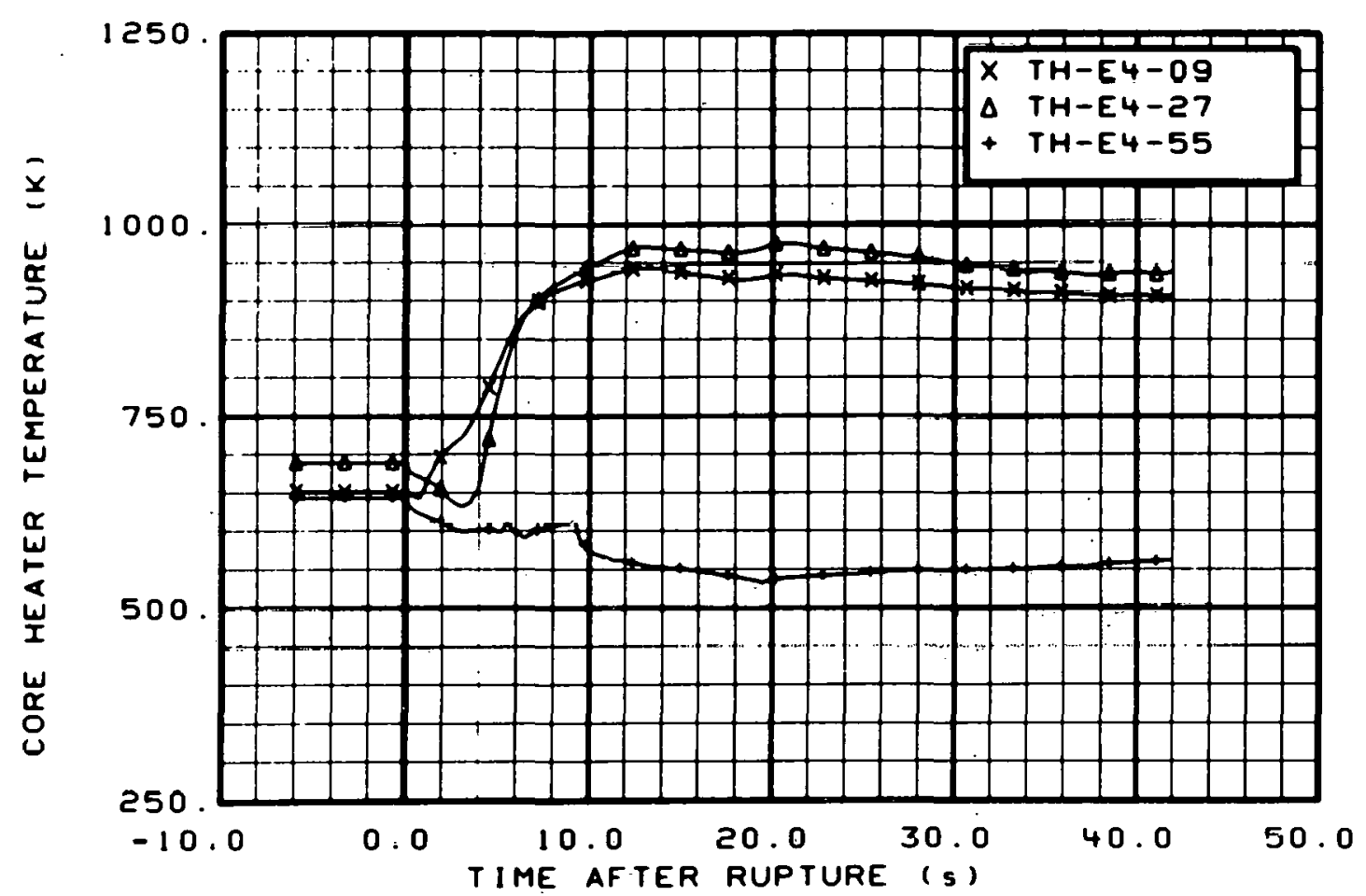

Fig. 64 Core heater temperature, Rod E-4 (TH-E4-09, TH-E4-27, and TH-E4-55), from -6 to $42 \mathrm{~s}$. 


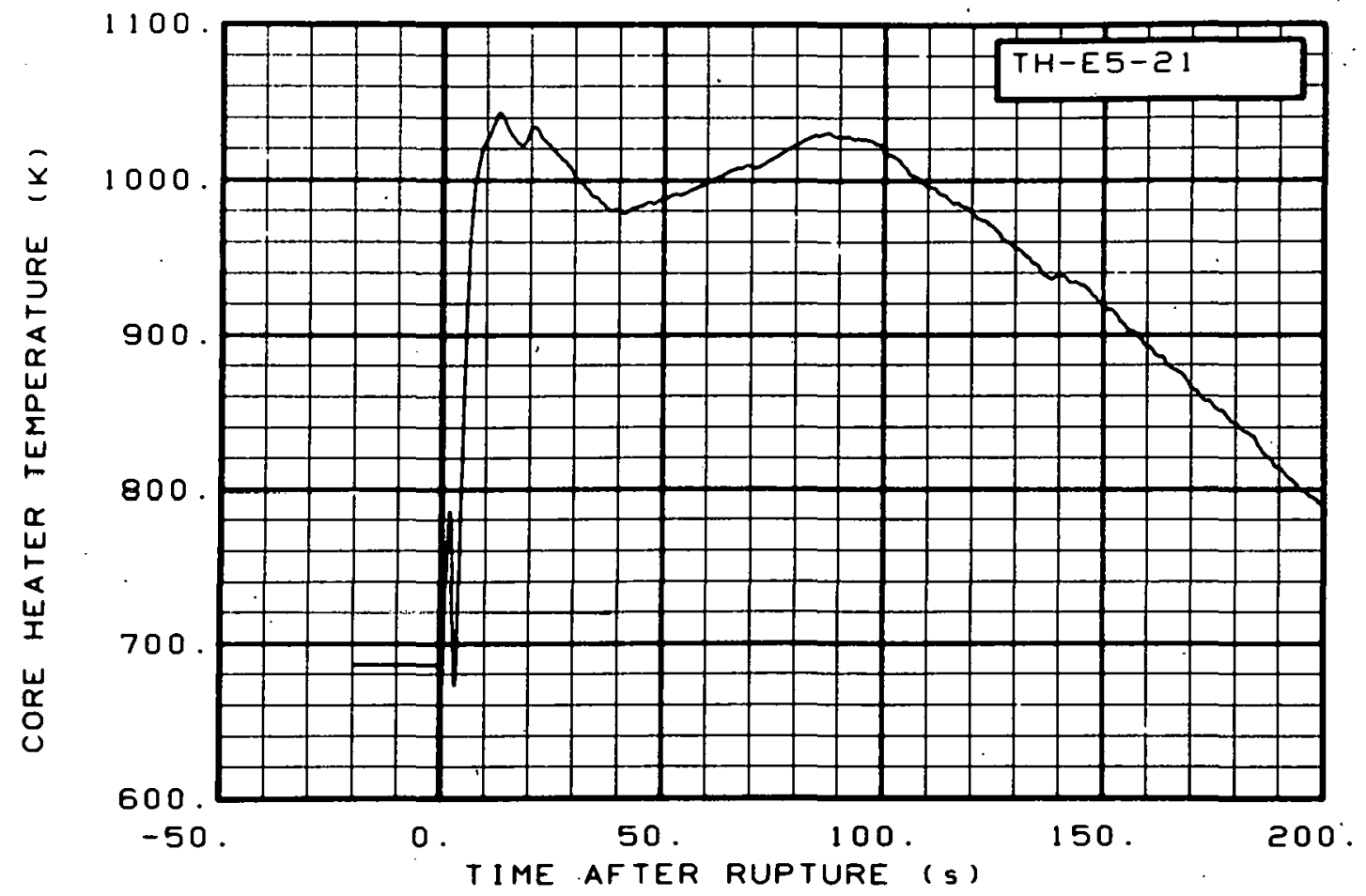

Fig. 65 Core heater temperature, Rod E-5 (TH-E5-21), from -20 to 200 s.

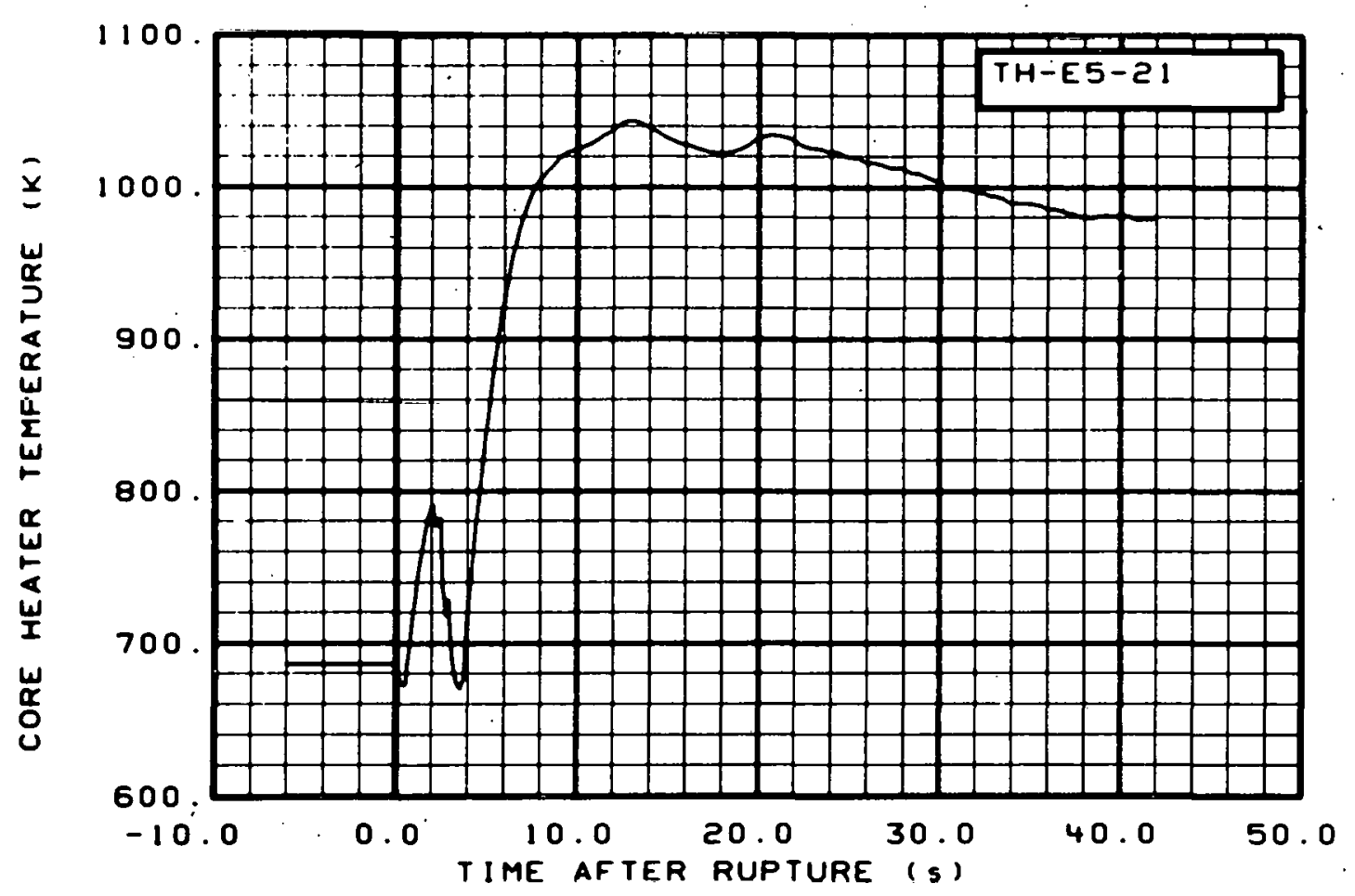

Fig. 66 Core heater temperature, Rod E-5 (TH-E5-21), from -6 to $42 \mathrm{~s}$. 


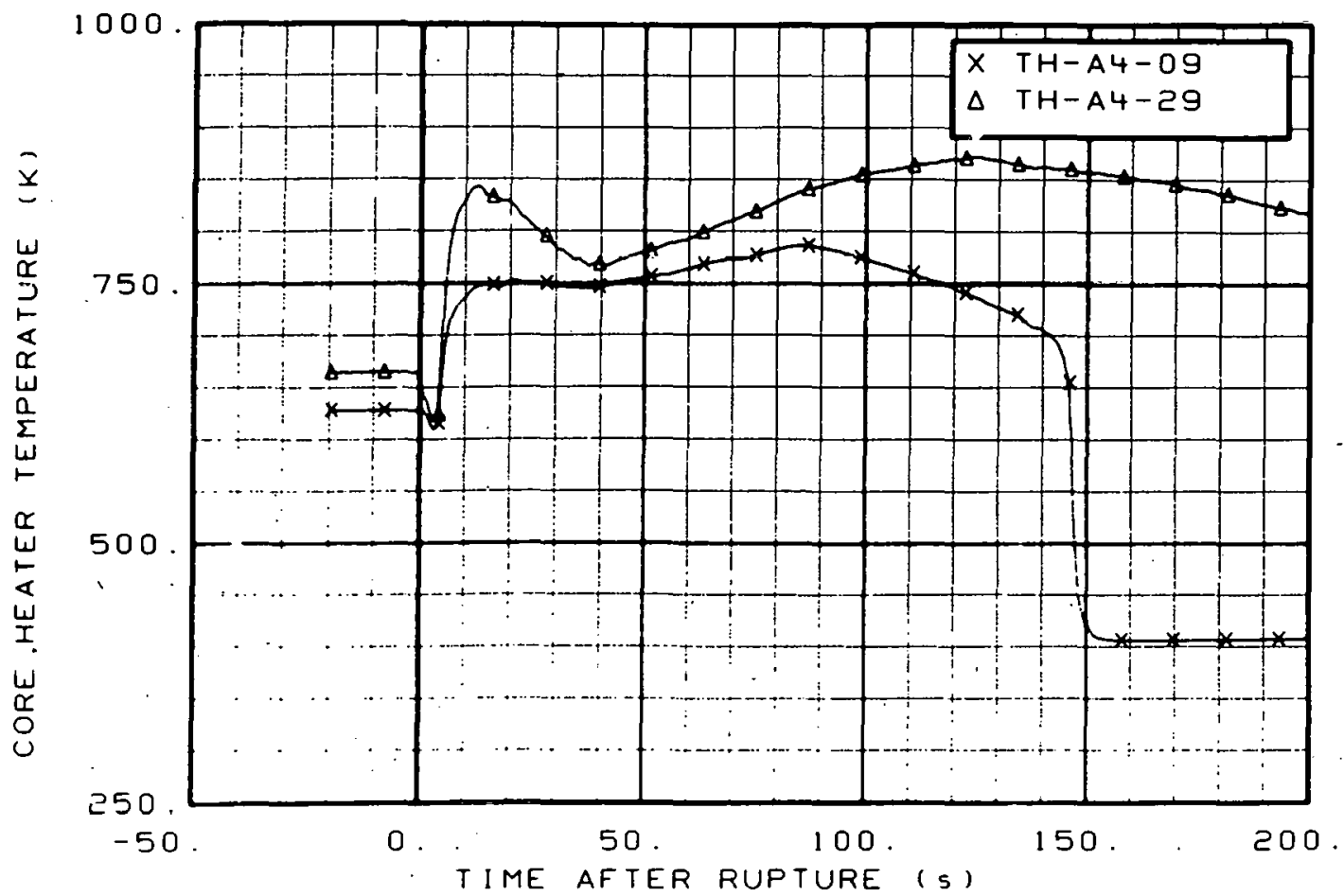

Fig. 67 Core heater temperature, Rod A-4 (TH-A4-09 and TH-A4-29), from -20 to $200 \mathrm{~s}$.

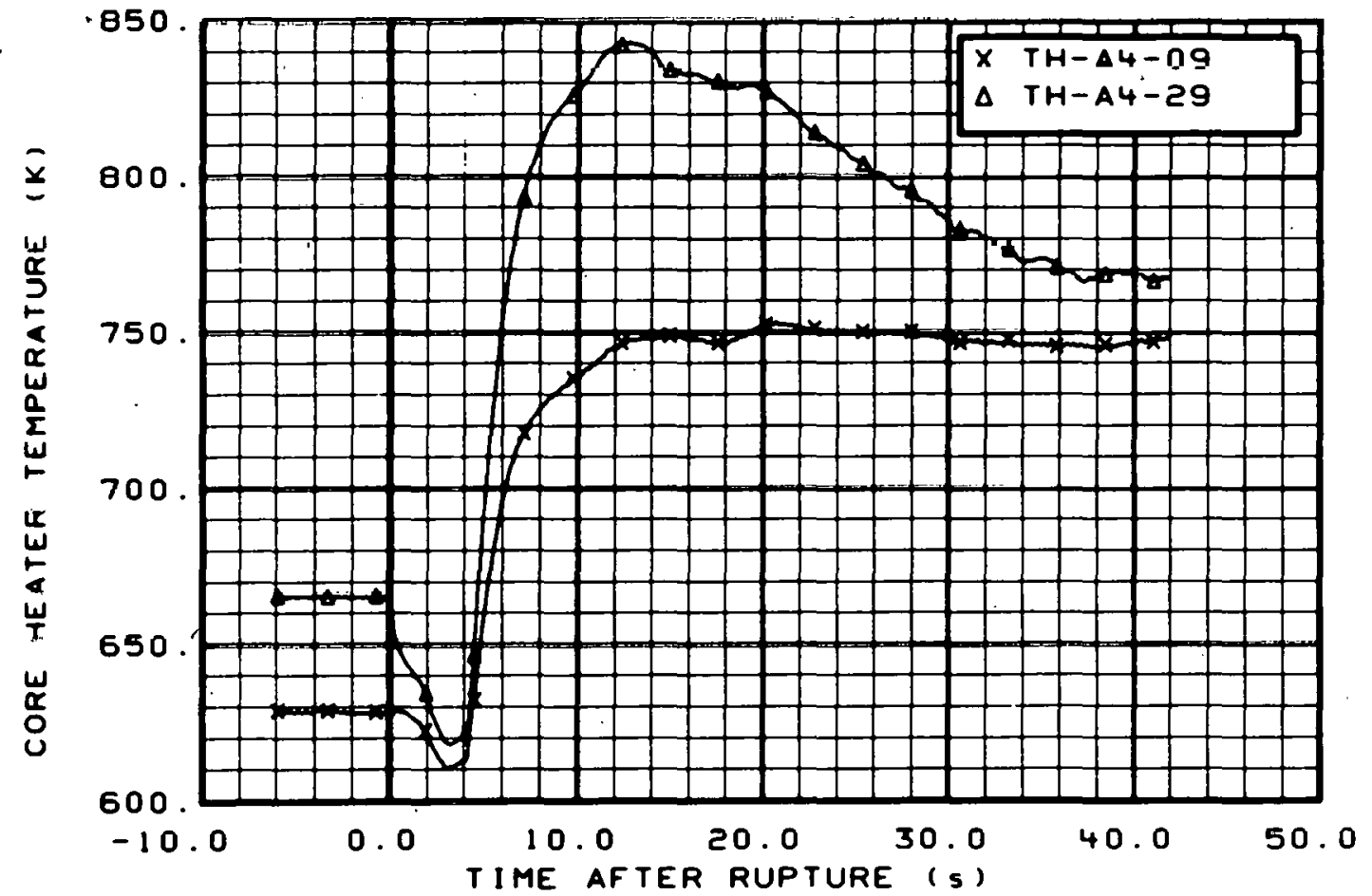

Fig. 68 Core heater temperature, Rod A-4 (TH-A4-09 and TH-A4-29), from -6 to $42 \mathrm{~s}$. 


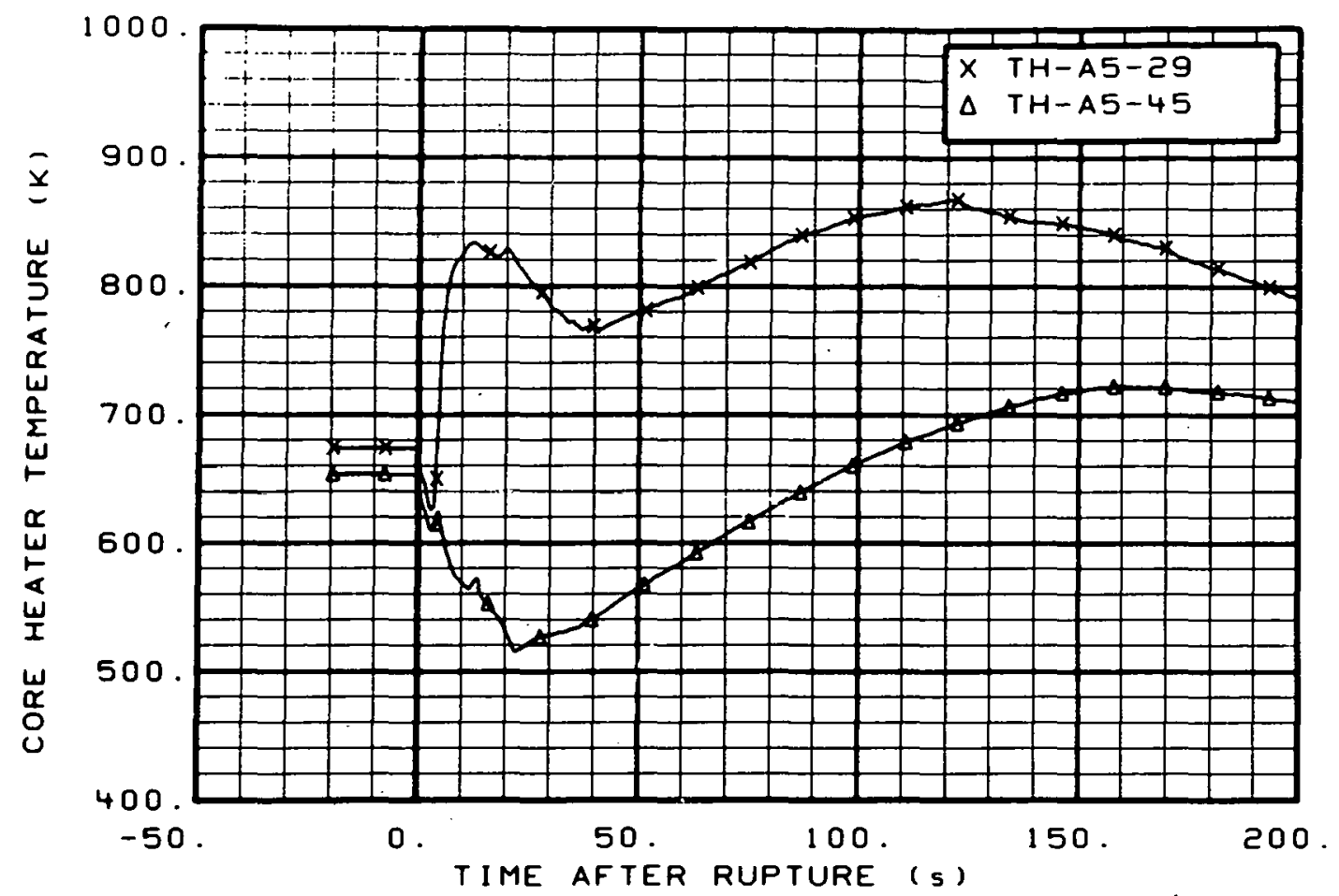

Fig. 69 Core heater temperature, Rod A-5 (TH-A5-29 and TH-A5-45), from -20 to $200 \mathrm{~s}$.

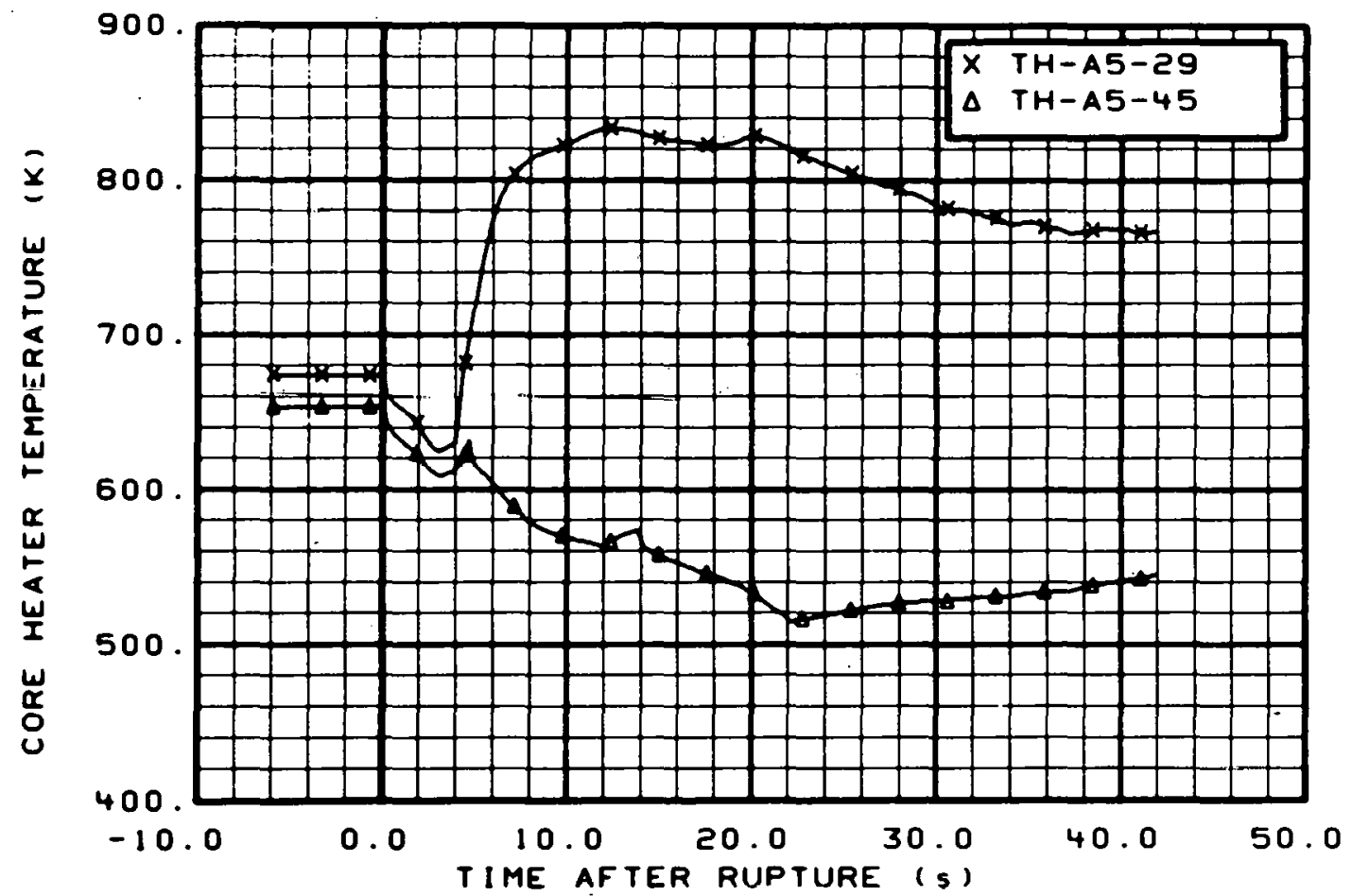

Fig. 70 Core heater temperature, Rod A-5 (TH-A5-29 and TH-A5-45), from -6 to $42 \mathrm{~s}$. 


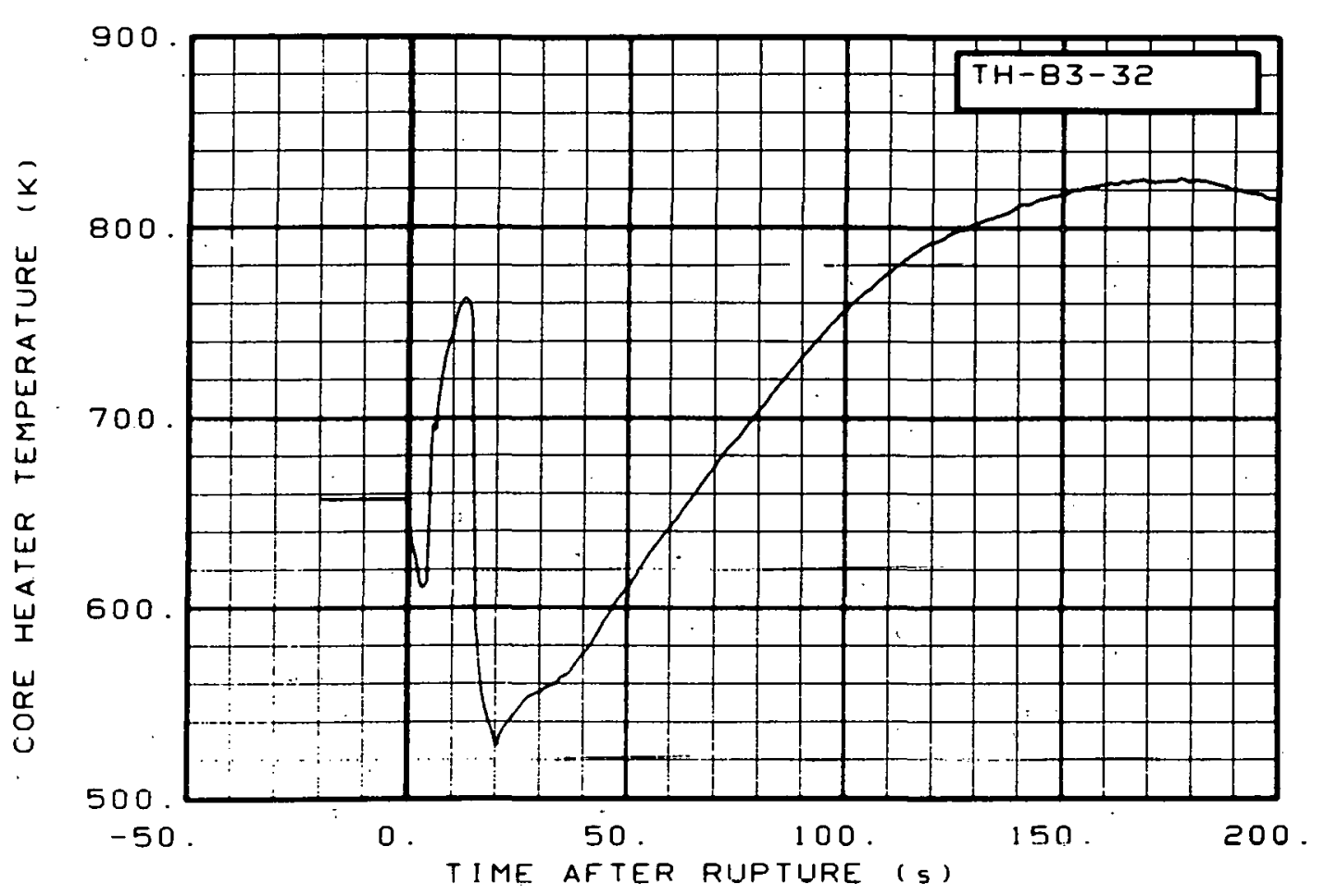

Fig. 71 Core heater temperature, Rod B-3 (TH-B3-32), from -20 to $200 \mathrm{~s}$.

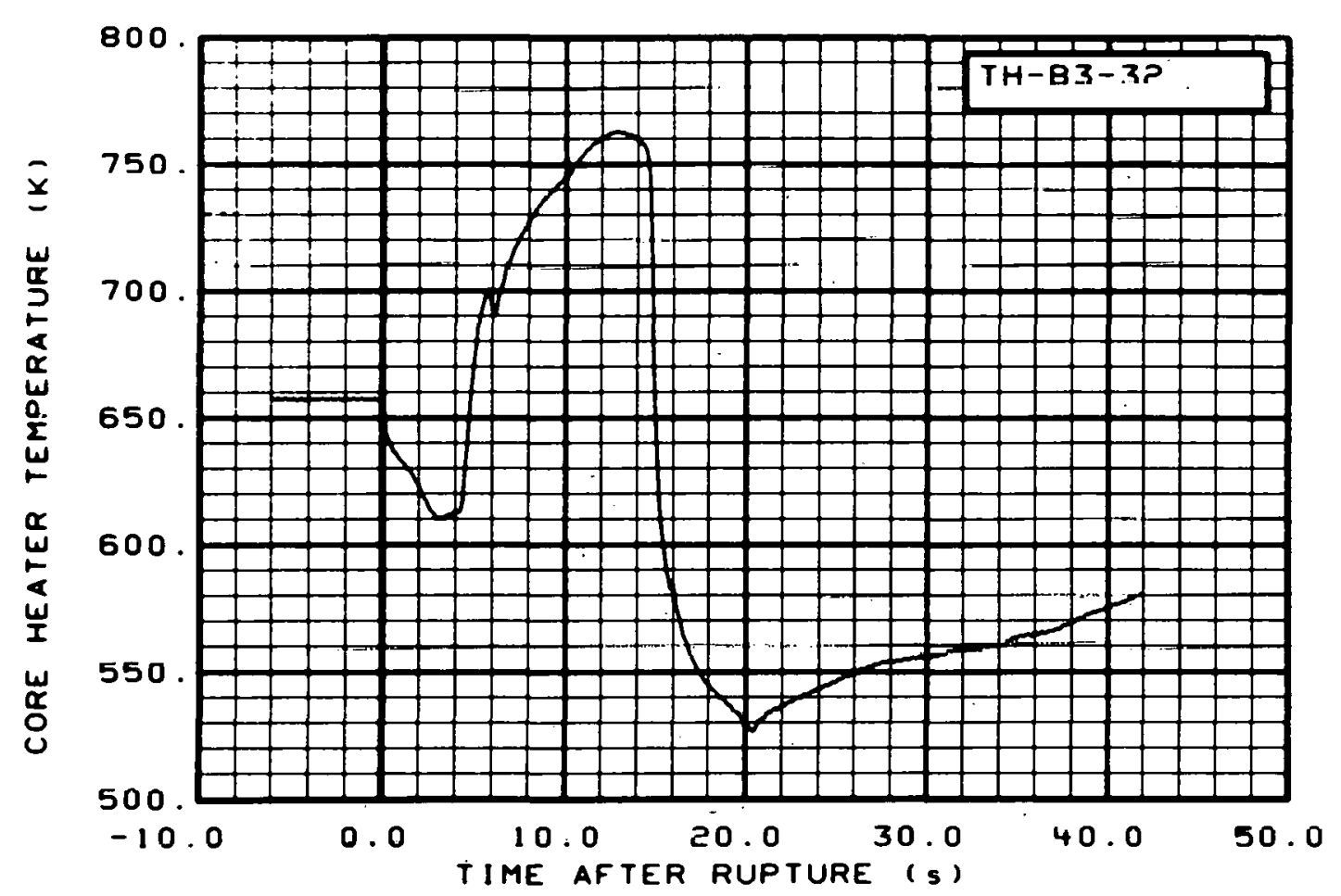

Fig. 72 Core heater temperature, Rod B-3 (TH-B3-32), from -6 to $42 \mathrm{~s}$. 


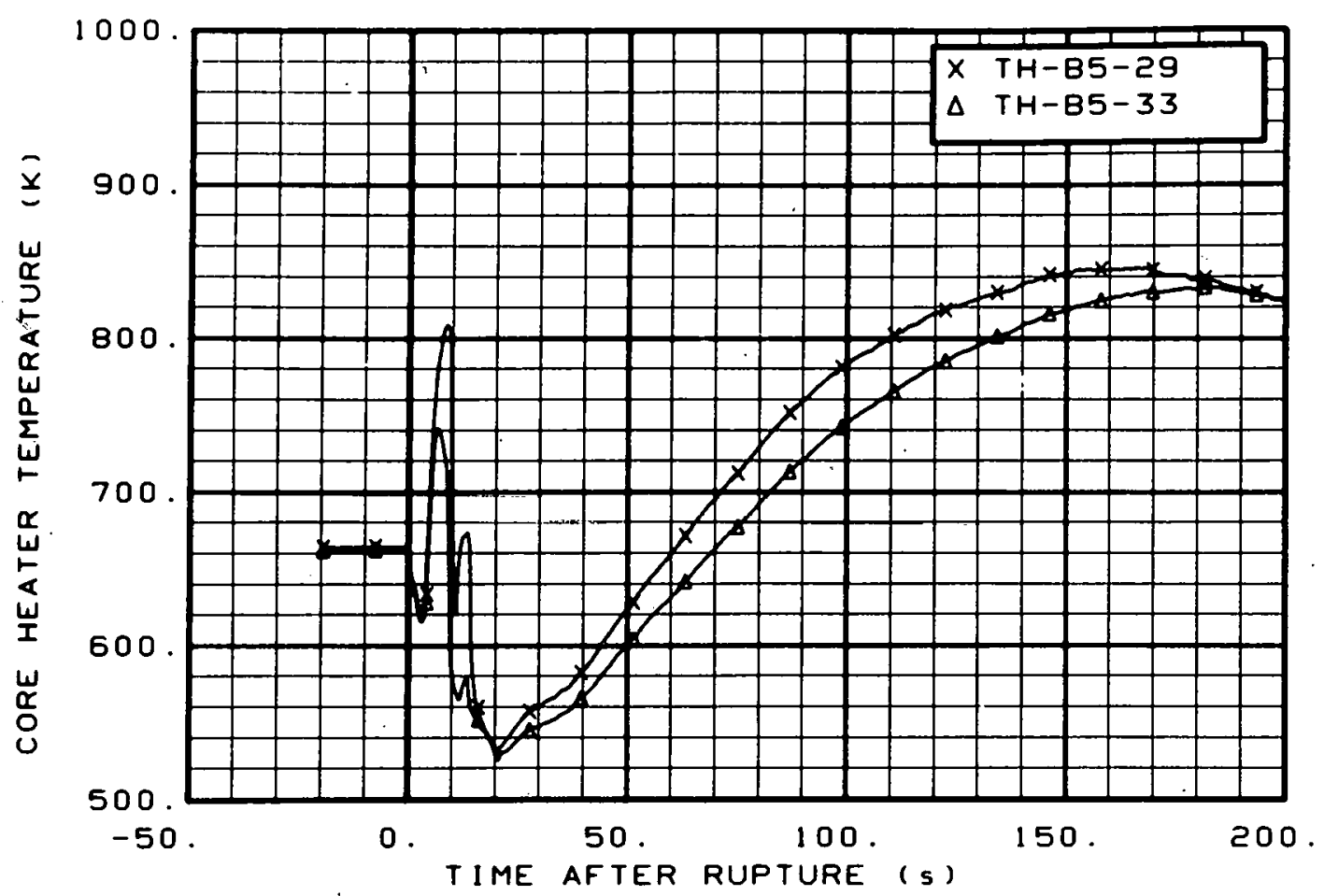

Fig. 73 Core heater temperature, Rod B-5 (TH-B5-29 and TH-B5-33), from -20 to $200 \mathrm{~s}$.

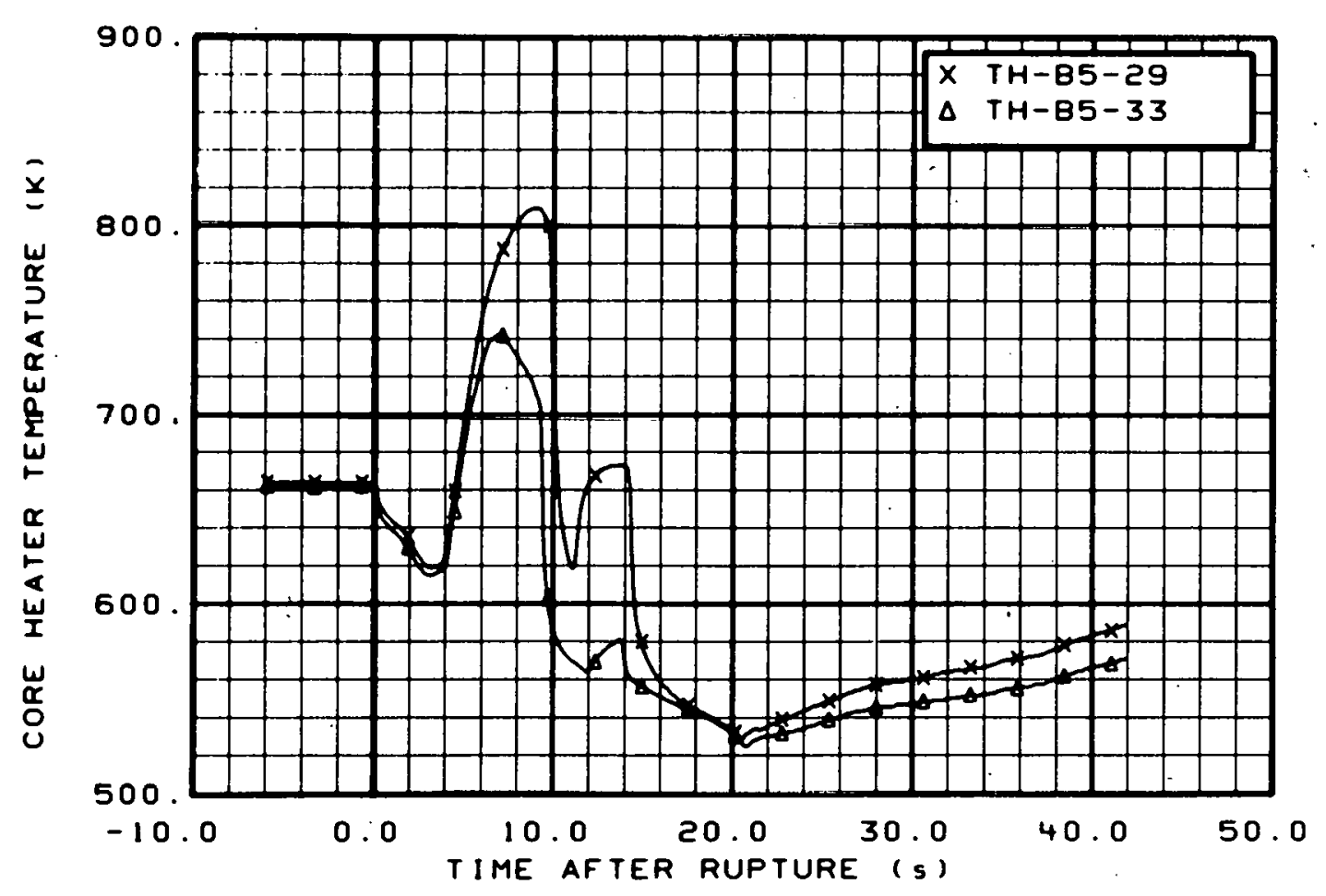

Fig. 74 Core hea.ter temperature, Rod B-5 (TH-B5-29 and TH-B5-33), from -6 to $42 \mathrm{~s}$. 


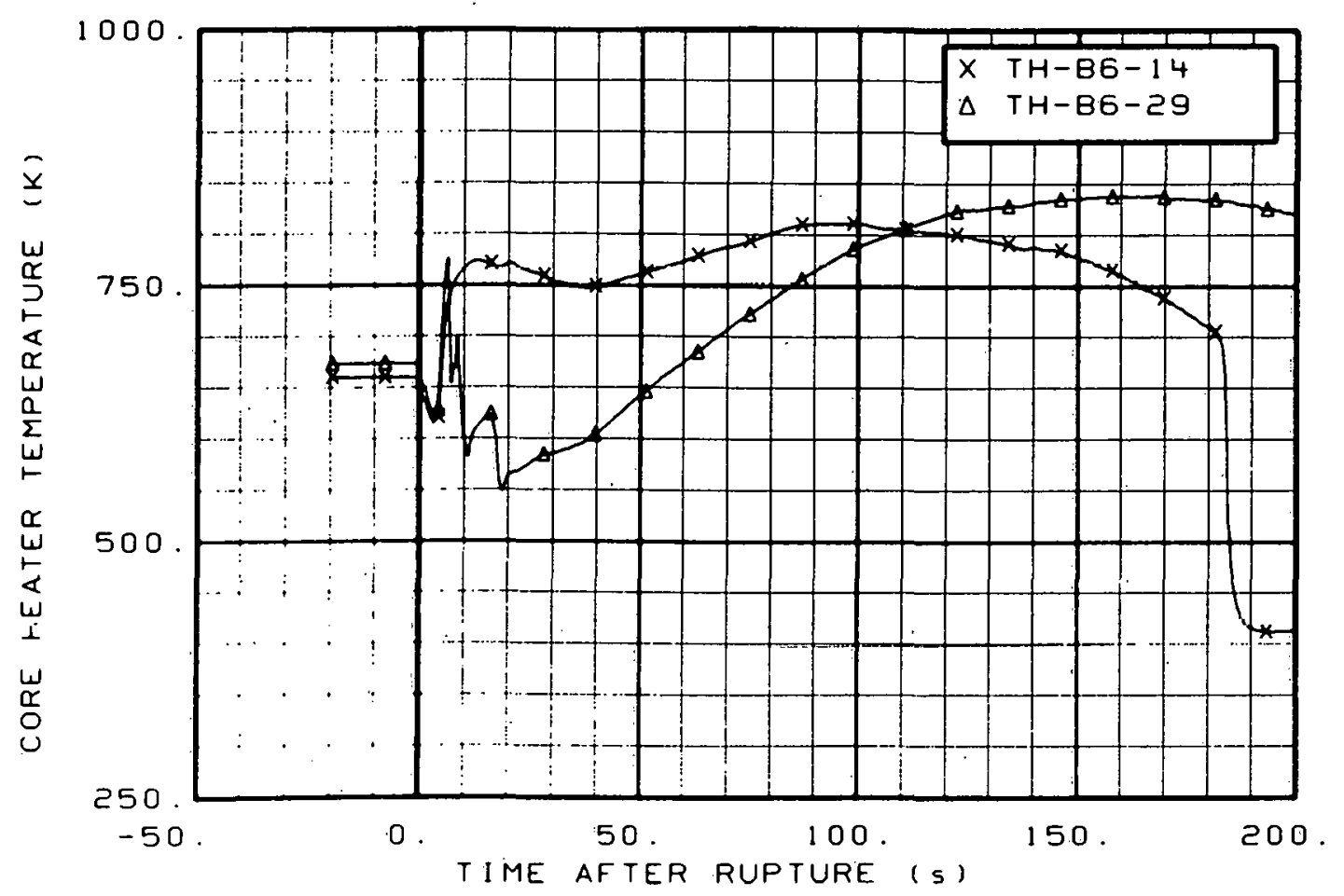

Fig. 75 Core heater temperature, Rod B-6 (TH-B6-i4 and TH-B6-29), from -20 to $200 \mathrm{~s}$.

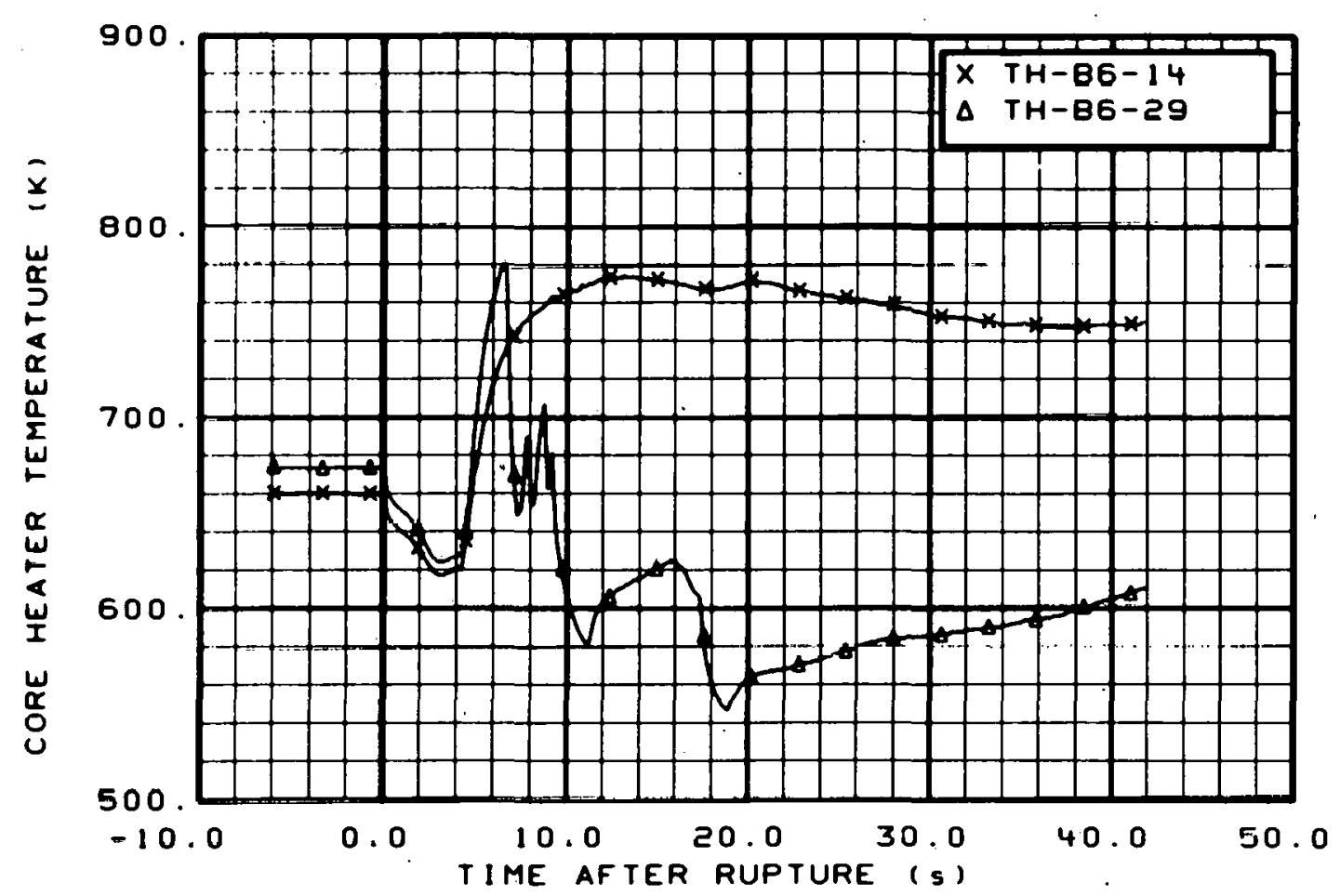

Fig. 76 Core heater temperature, Rod B-6 (TH-B6-14 and TH-B6-29), from -6 to $42 \mathrm{~s}$. 


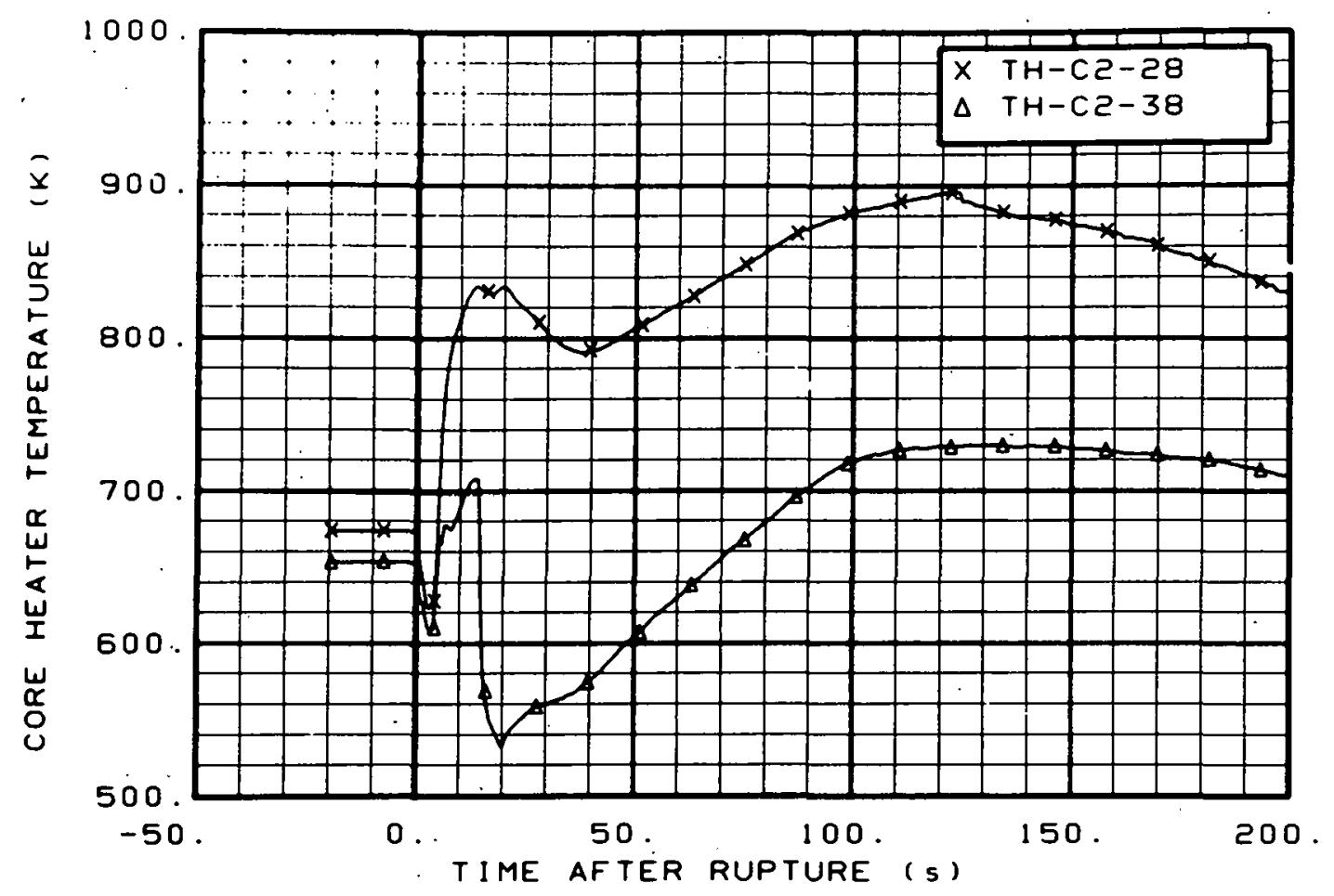

Fig. 77 Core heater temperature, Rod C-2 (TH-C2-28 and TH-C2-38), from -20 to $200 \mathrm{~s}$.

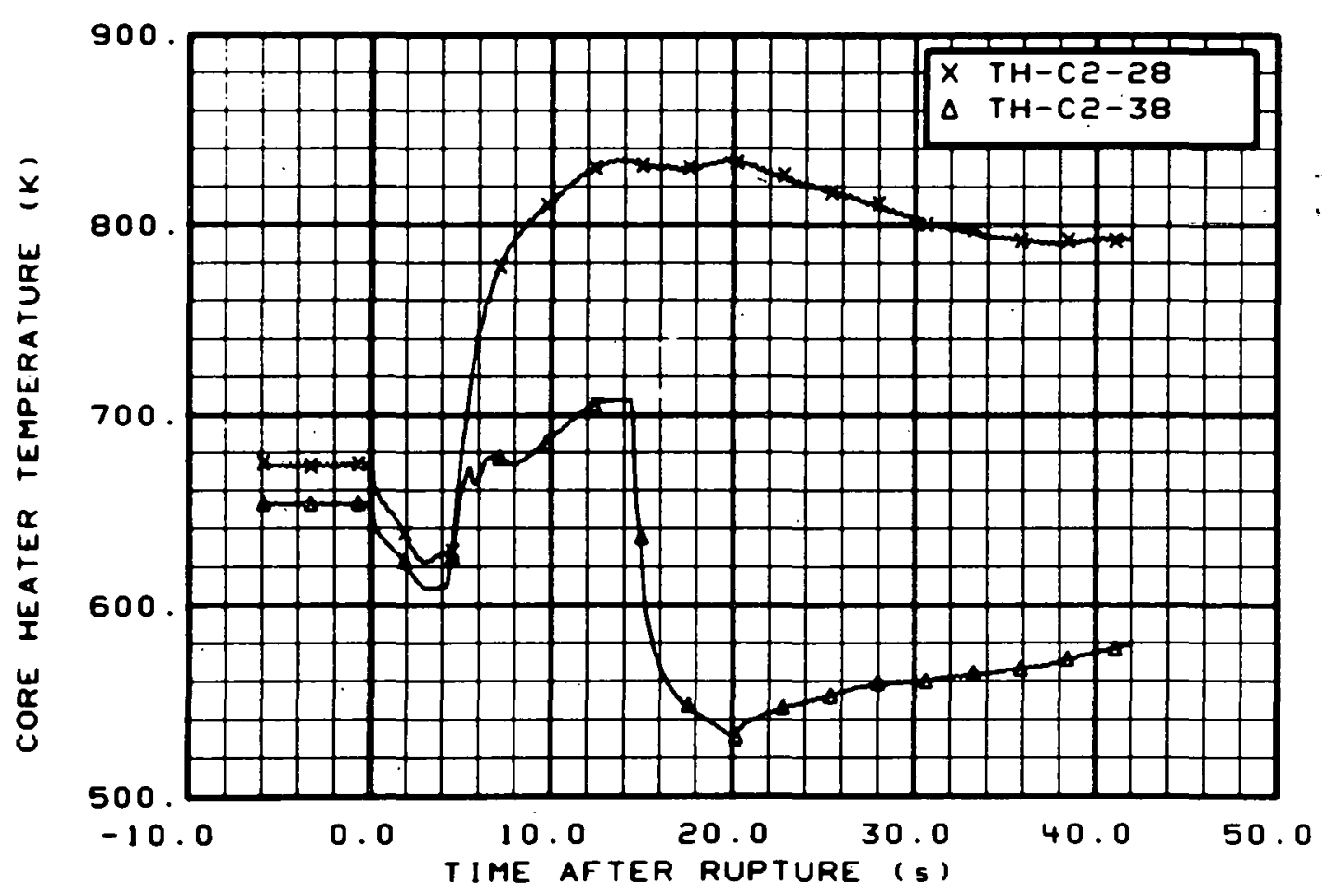

Fig. 78 Core heater temperature, Rod $\mathrm{C}-2$ (TH-C2-28 and TH-C2-38), from -6 to $42 \mathrm{~s}$. 


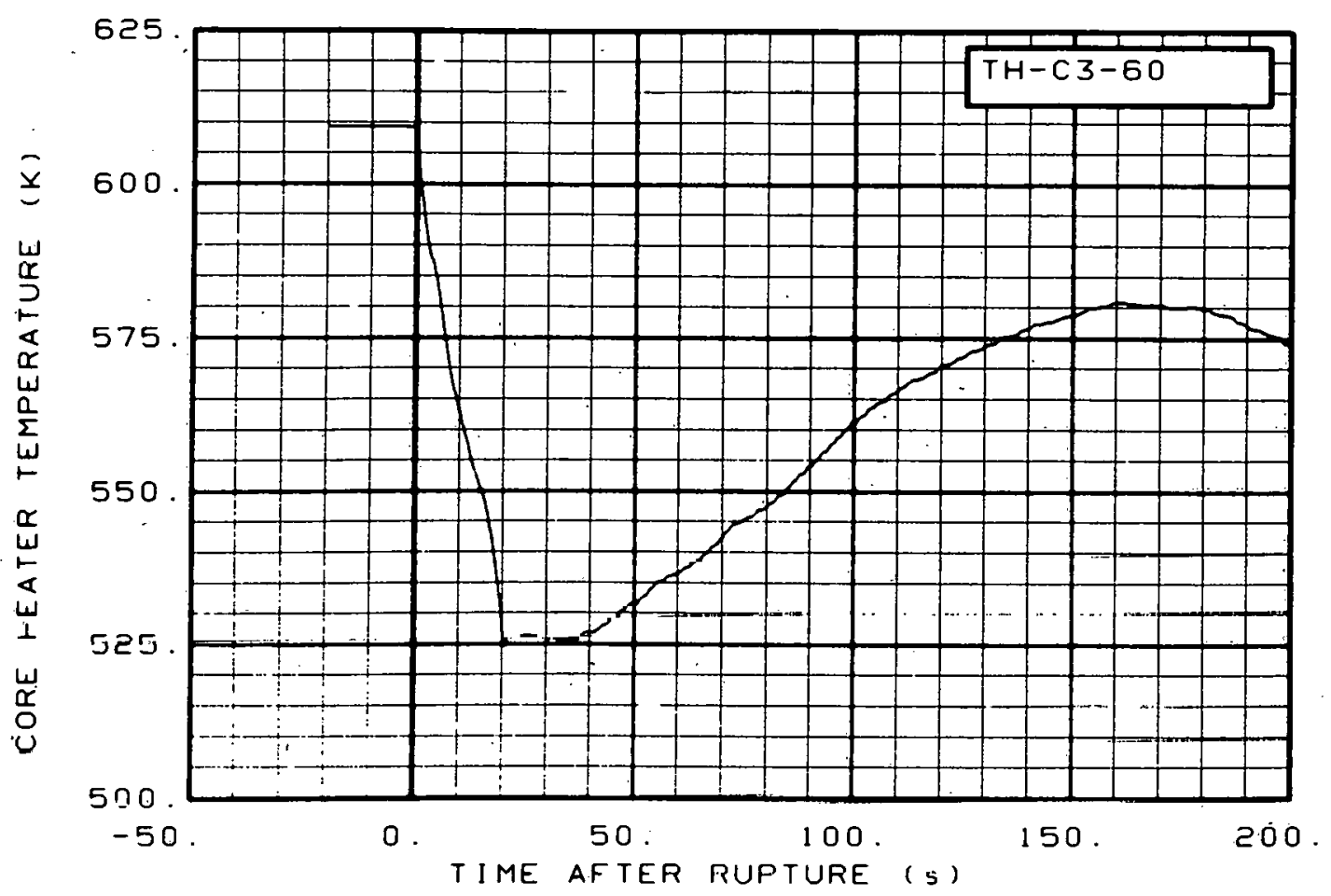

Fig. 79. Core heater temperature, Rod C-3 (TH-C3-60), from -20 to $200 \mathrm{~s}$.

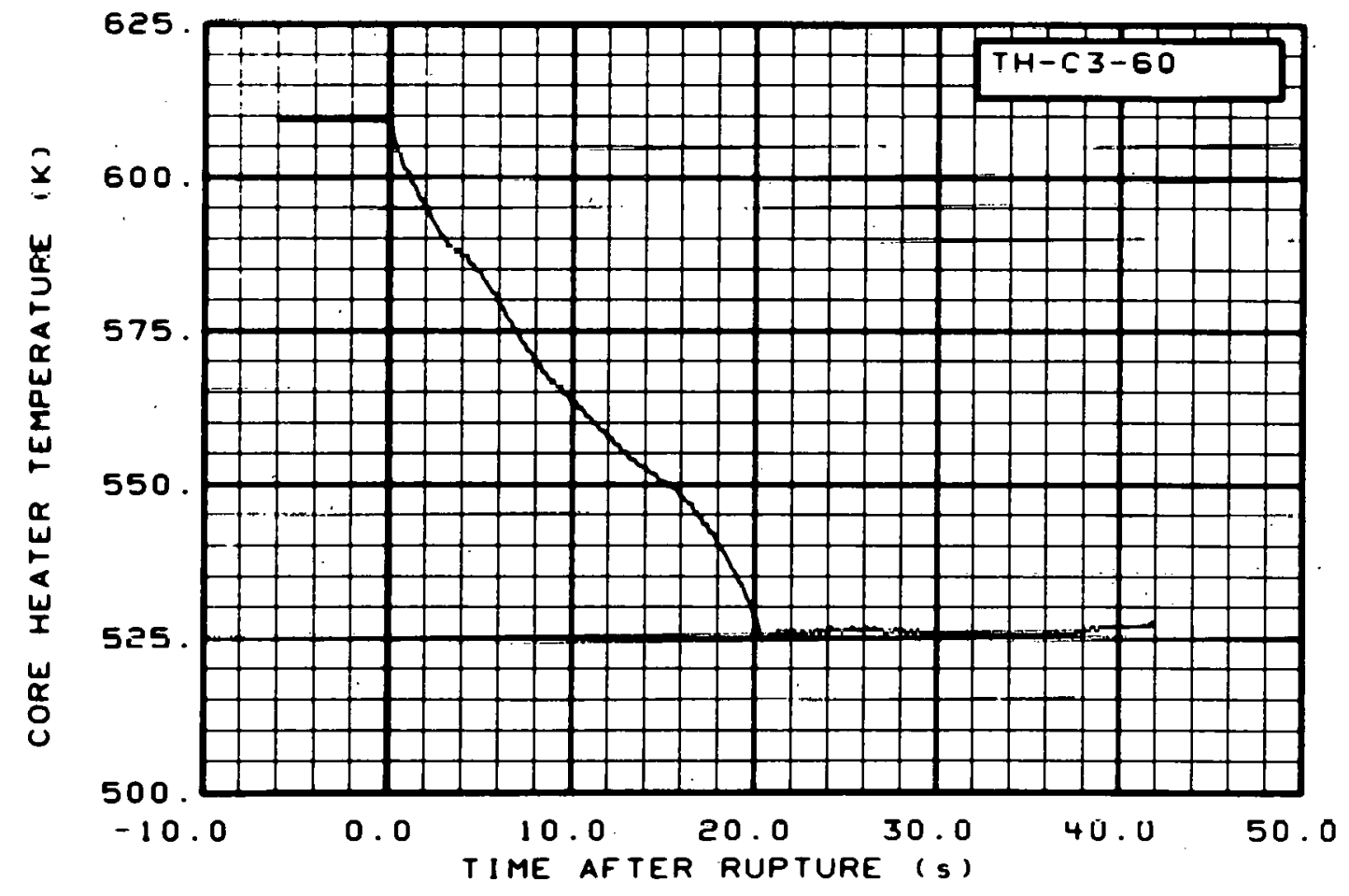

Fig. 80 Core heater temperature, Rod C-3 (TH-C3-60), from -6 to $42 \mathrm{~s}$. 


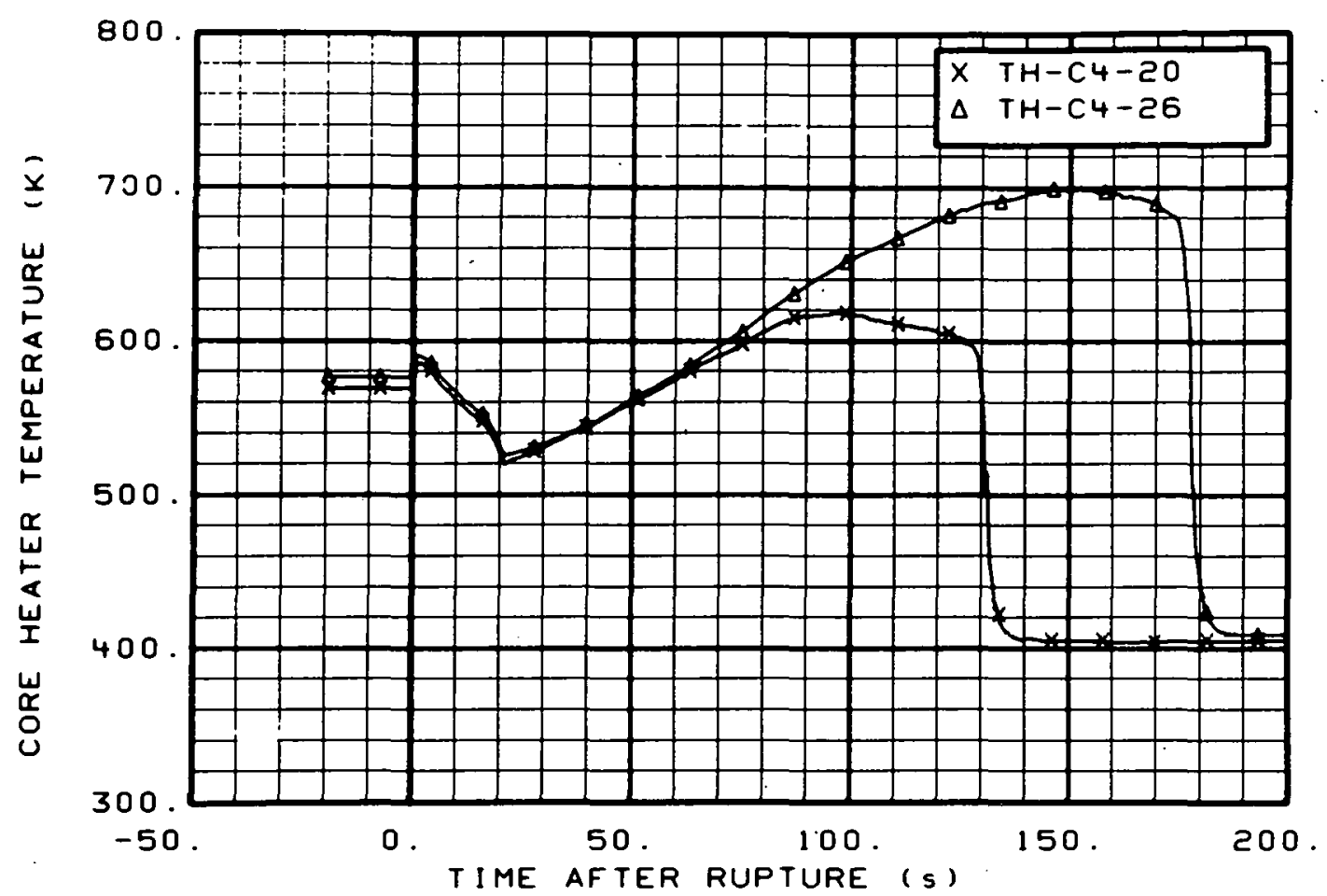

Fig. 81 Core heater temperature, Rod C-4 (TH-C4-20 and TH-C4-26), from -20 to $200 \mathrm{~s}$.

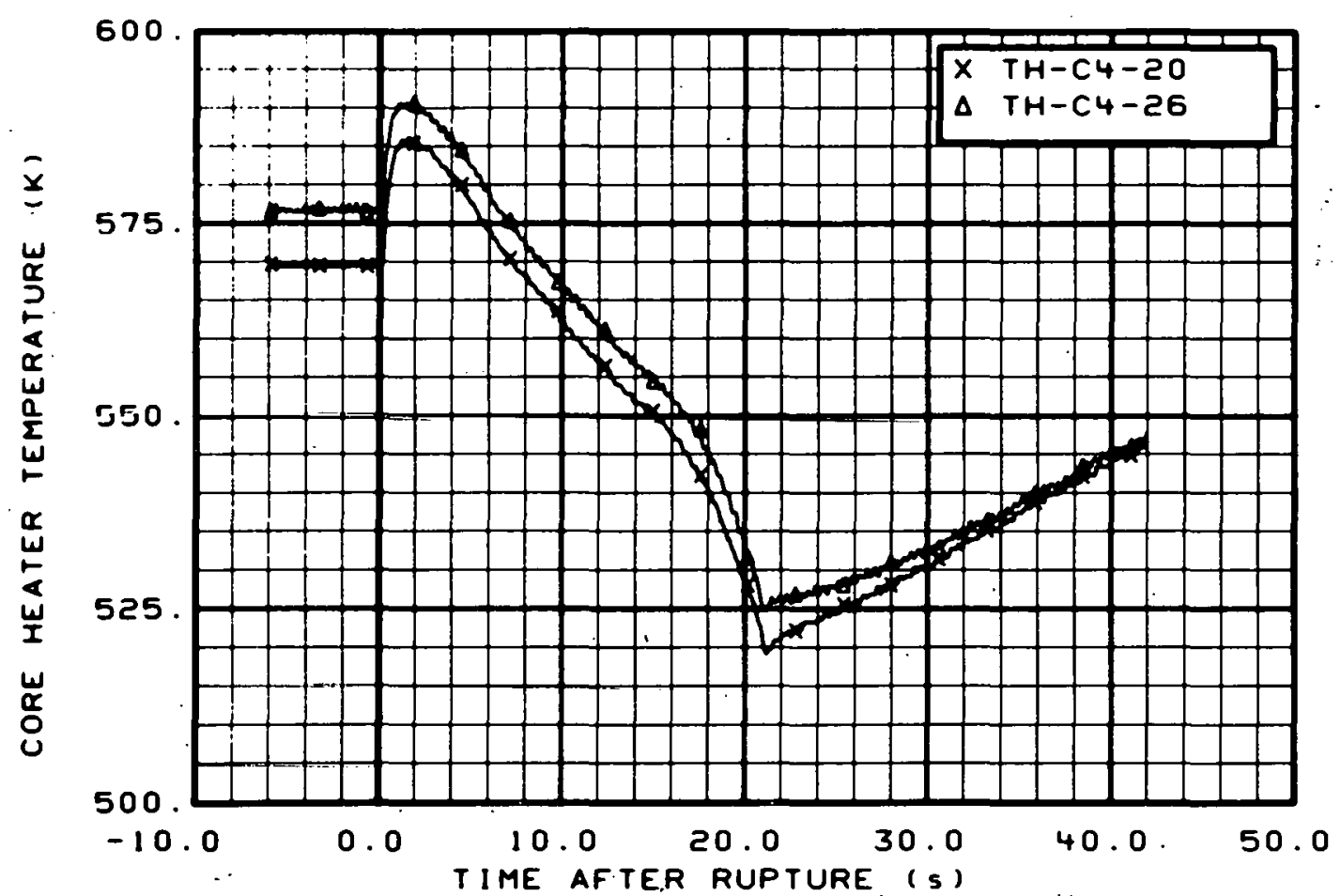

Fig. 82 Core heater temperature, Rod C-4 (TH-C4-20 and TH-C4-26), from -6 to $42 \mathrm{~s}$. 


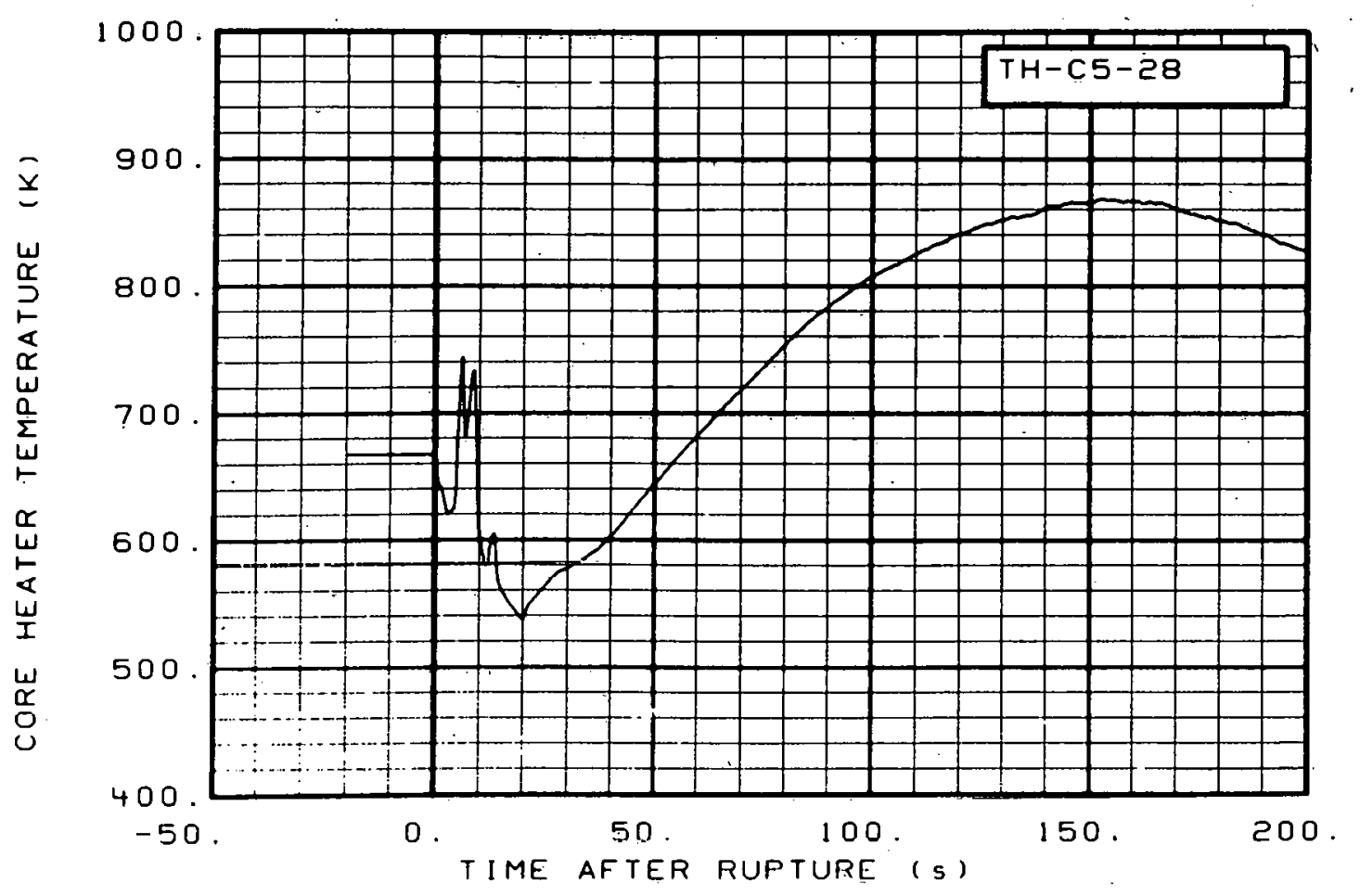

Fig. 83 Core heater temperature, Rod $\mathrm{C}-5$ ( TH-C5-28), from -20 to $200 \mathrm{~s}$.

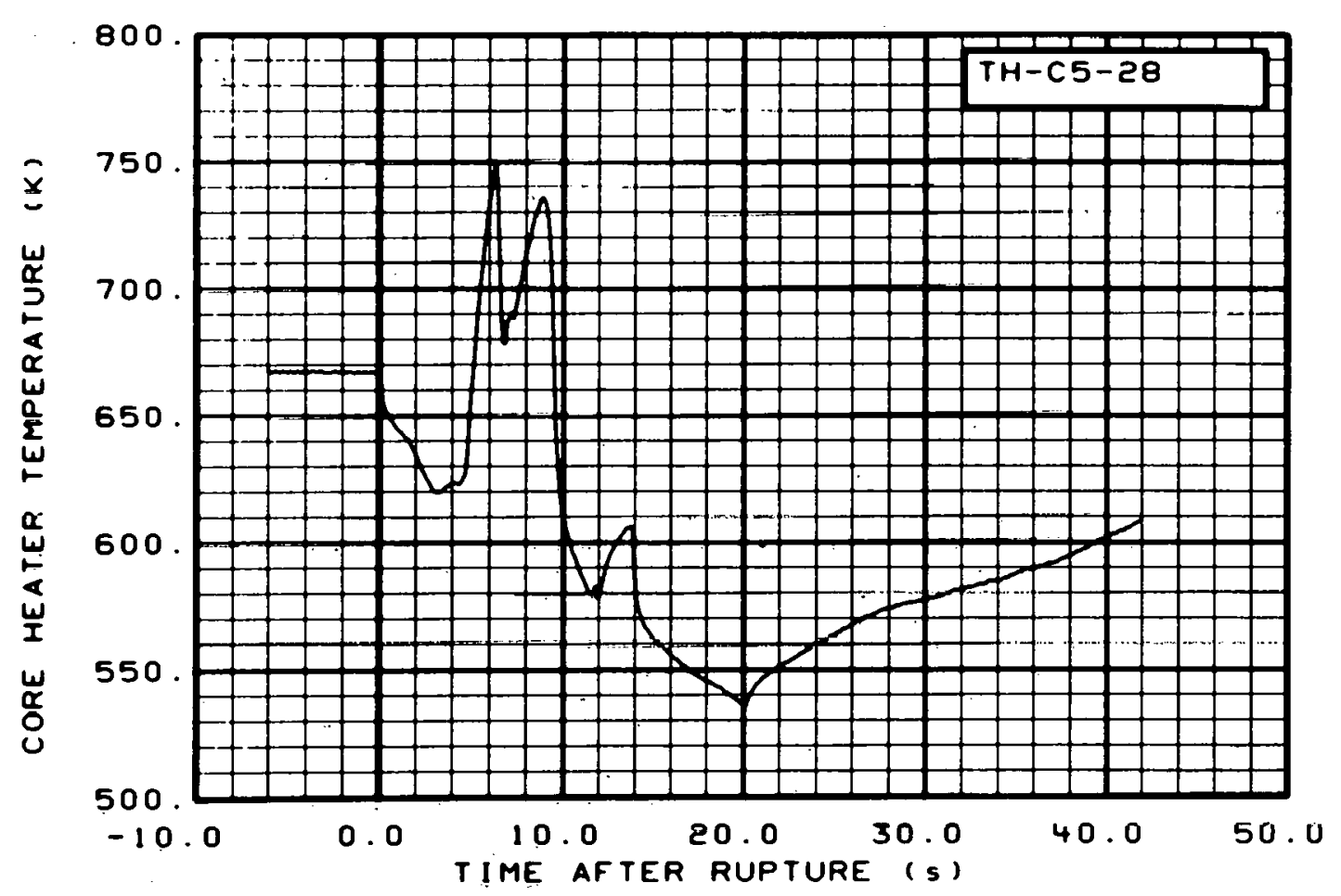

Fig. 84 Core heater temperature, Rod $\mathrm{C}-5$ (TH-C5-28), from -6 to $42 \mathrm{~s}$. 


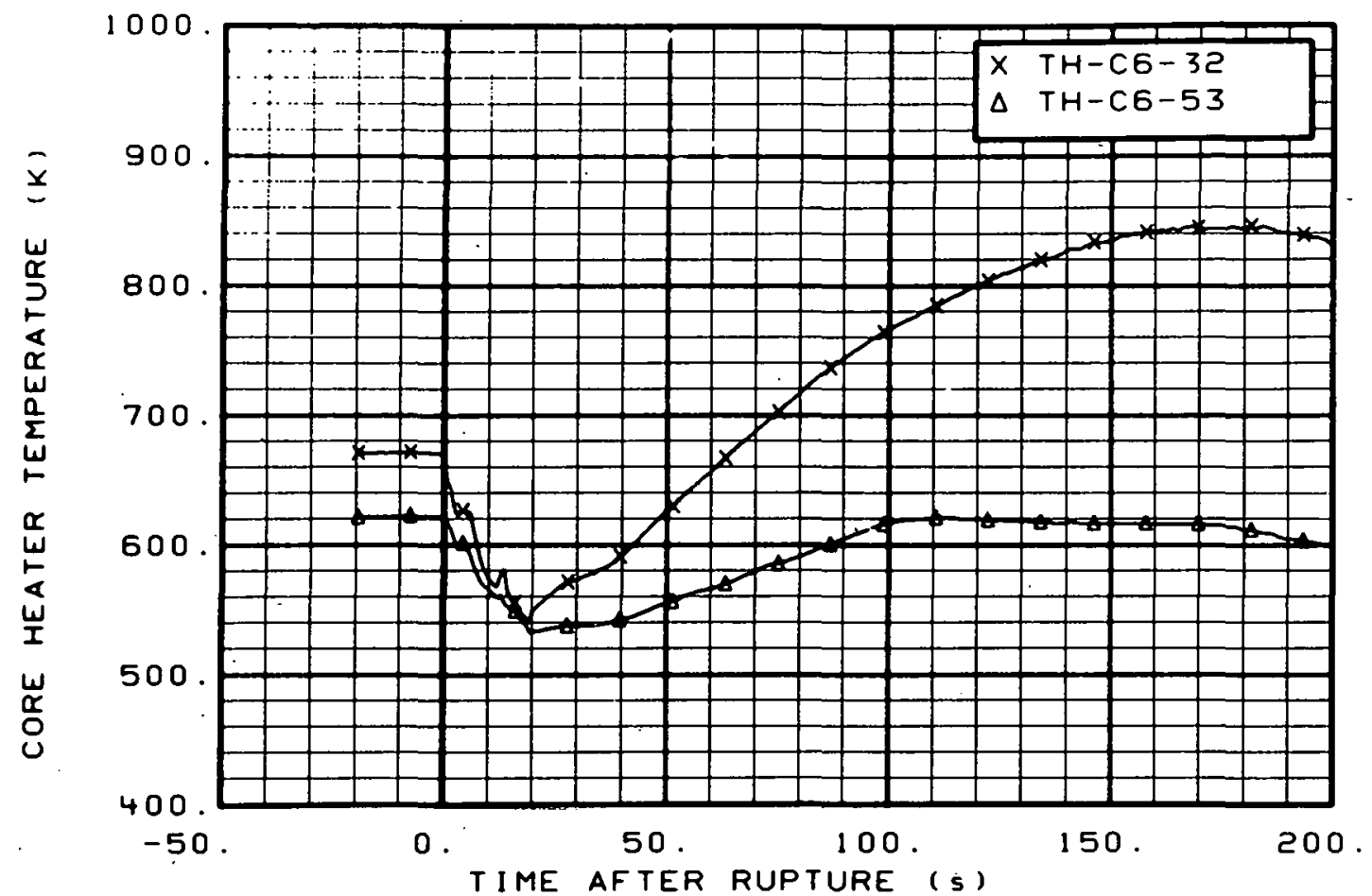

Fig. 85 Core heater temperature, Rod C-6 (TH-C6-32 and TH-C6-53), from -20 to $200 \mathrm{~s}$.

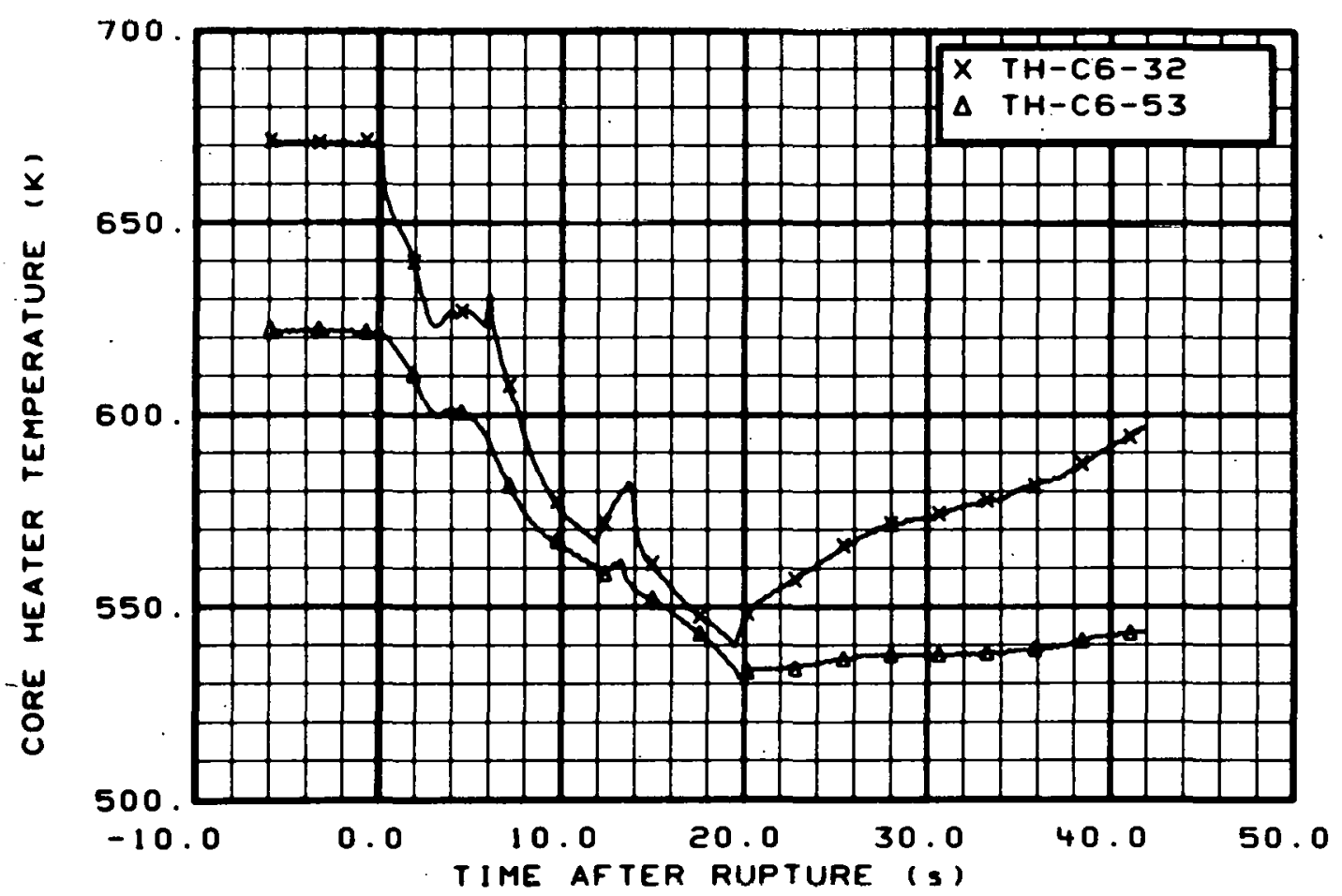

Fig. 86 Core heater temperature, Rod C-6 (TH-C6-32 and TH-C6-53), from -6 to $42 \mathrm{~s}$. 


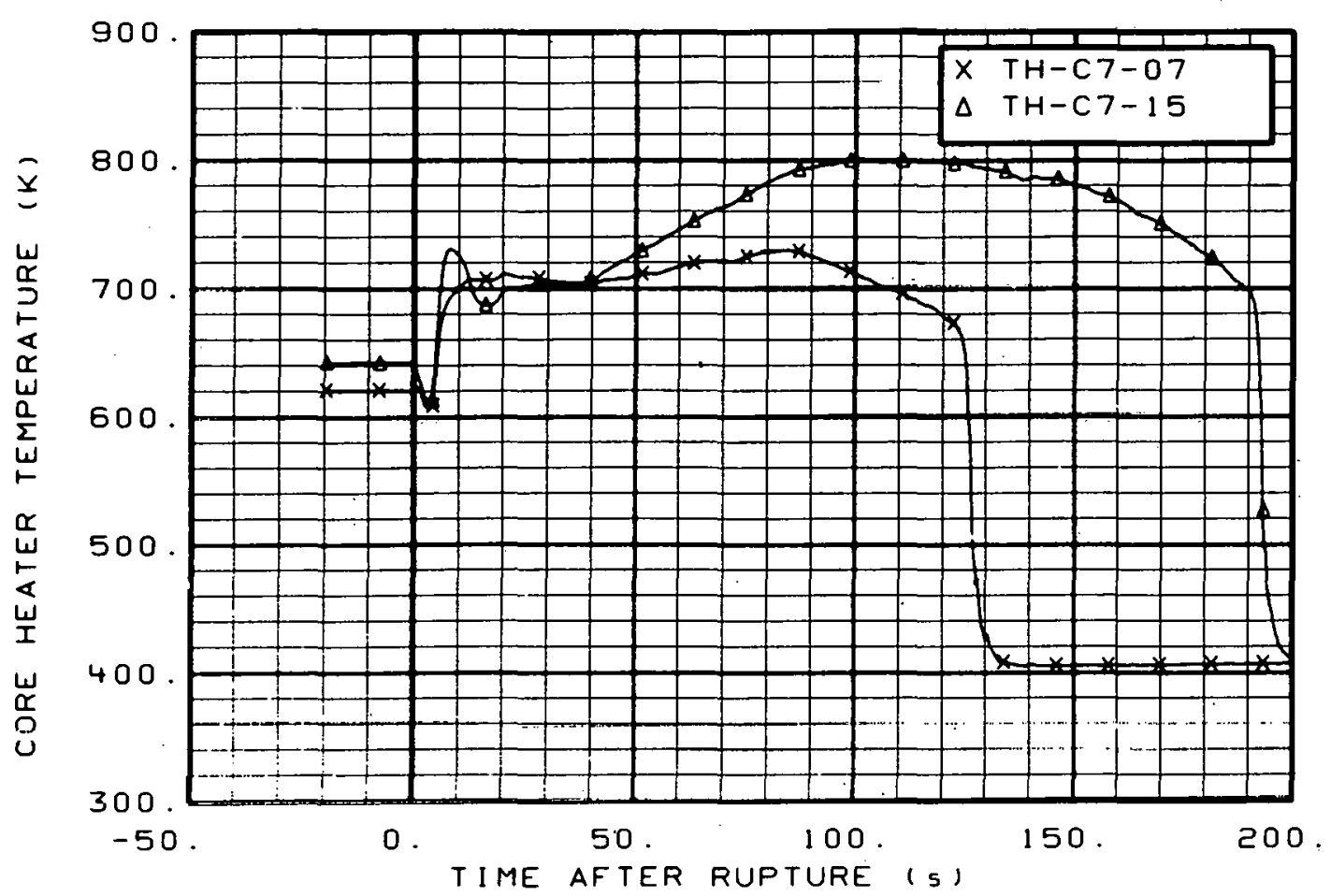

Fig. 87 Core heater temperature, Rod $\mathrm{C}-7$ ( $\mathrm{TH}-\mathrm{C} 7-07$ and $\mathrm{TH}-\mathrm{C} 7-15)$, from -20 to $200 \mathrm{~s}$.

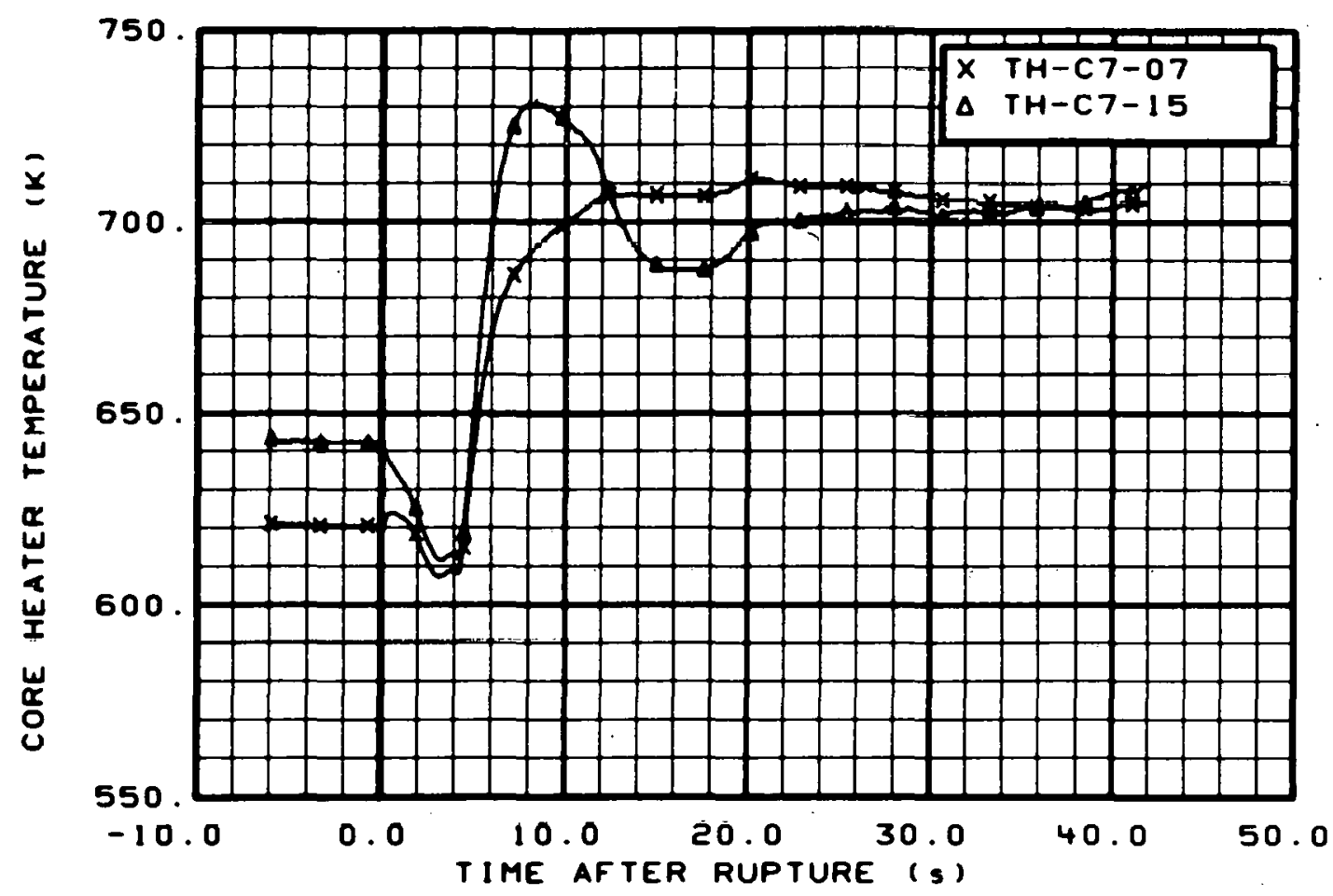

Fig. 88 Core heater temperature, Rod $\mathrm{C}-7$ (TH-C7-07 and TH-C7-15), from -6 to $42 \mathrm{~s}$. 


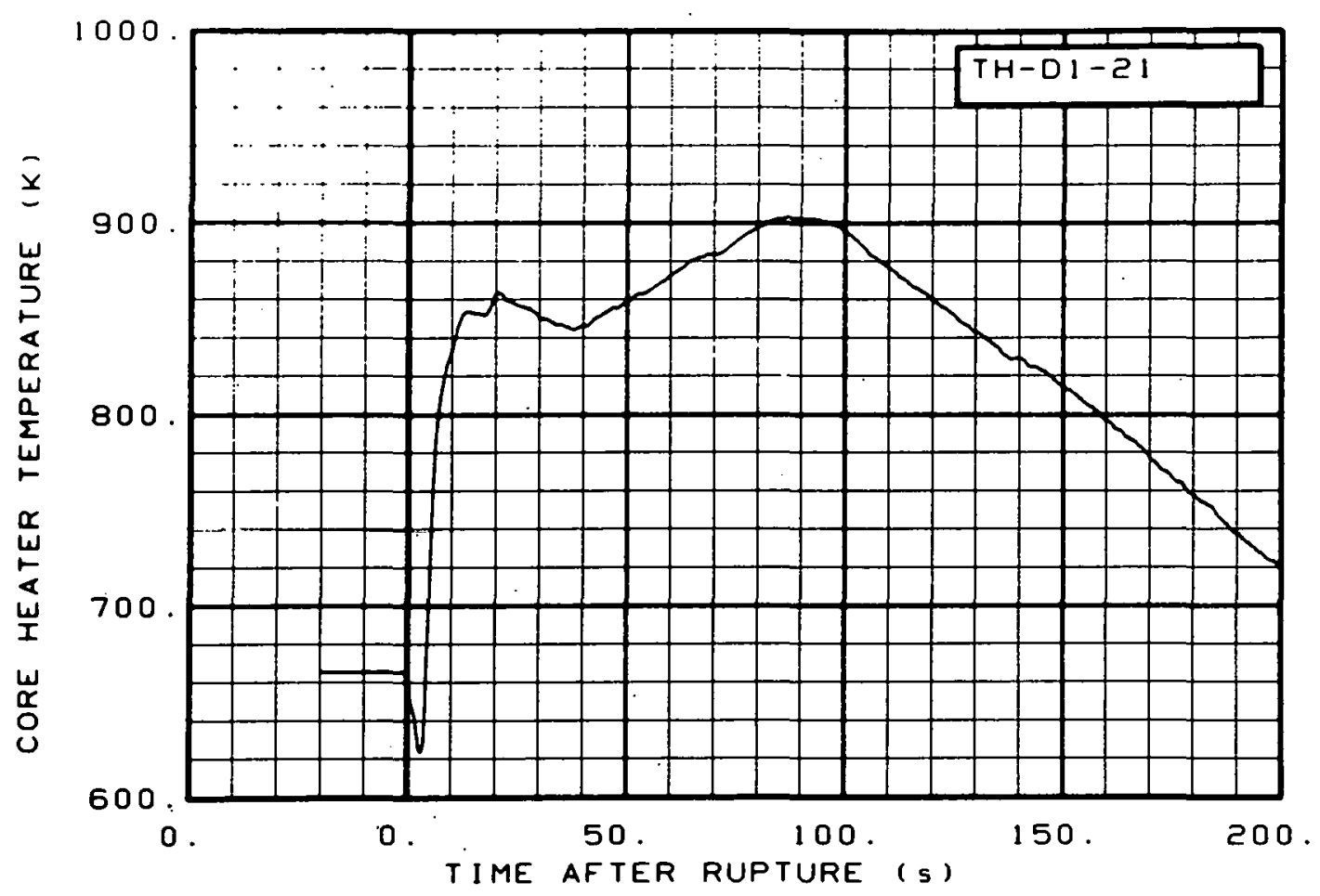

Fig. 89 Core heater temperature, Rod D-1 (TH-D1-21), from -20 to $200 \mathrm{~s}$.

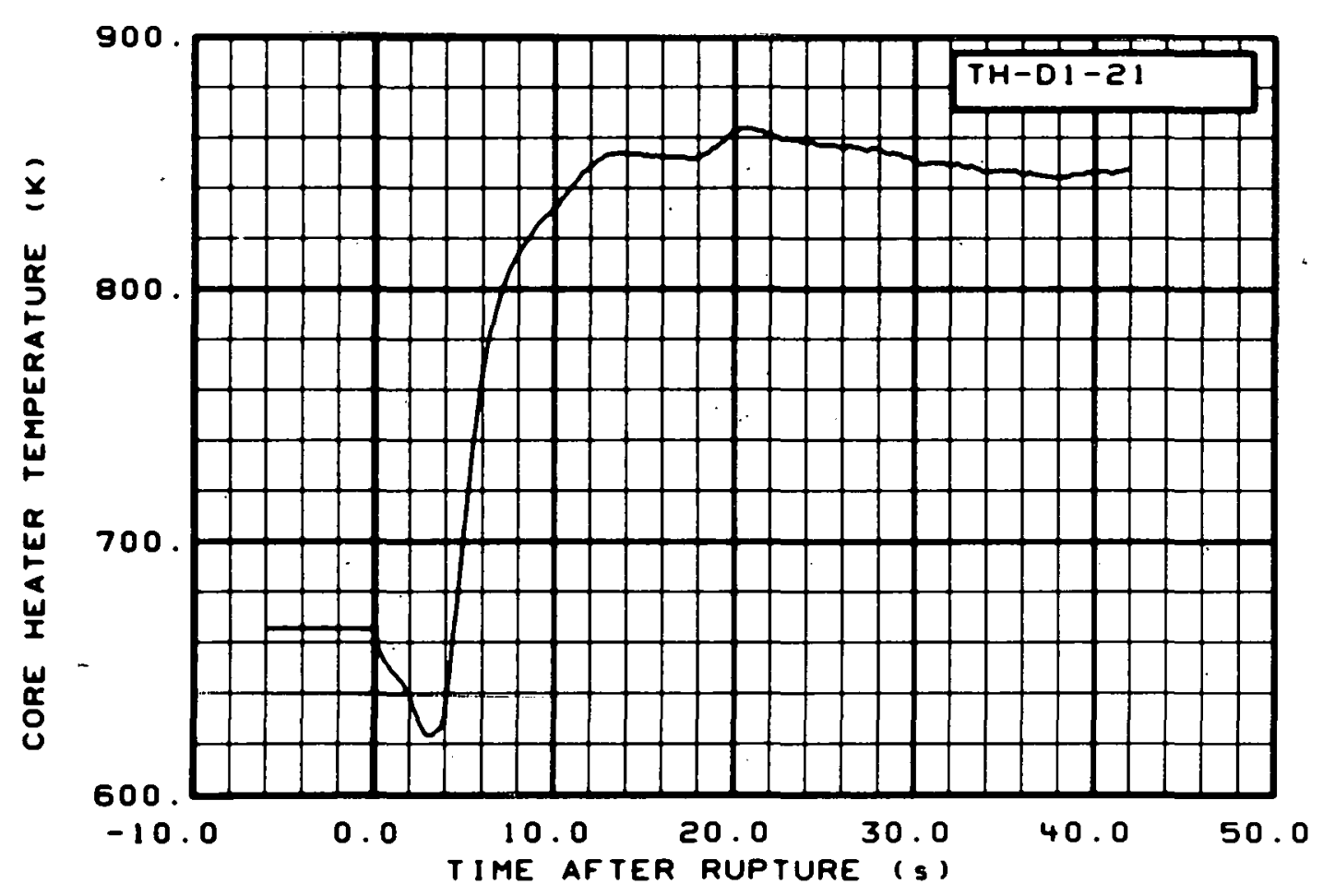

Fig. 90 Core heater temperature, Rod D-1 (TH-DI-21), from -6 to $42 \mathrm{~s}$. 


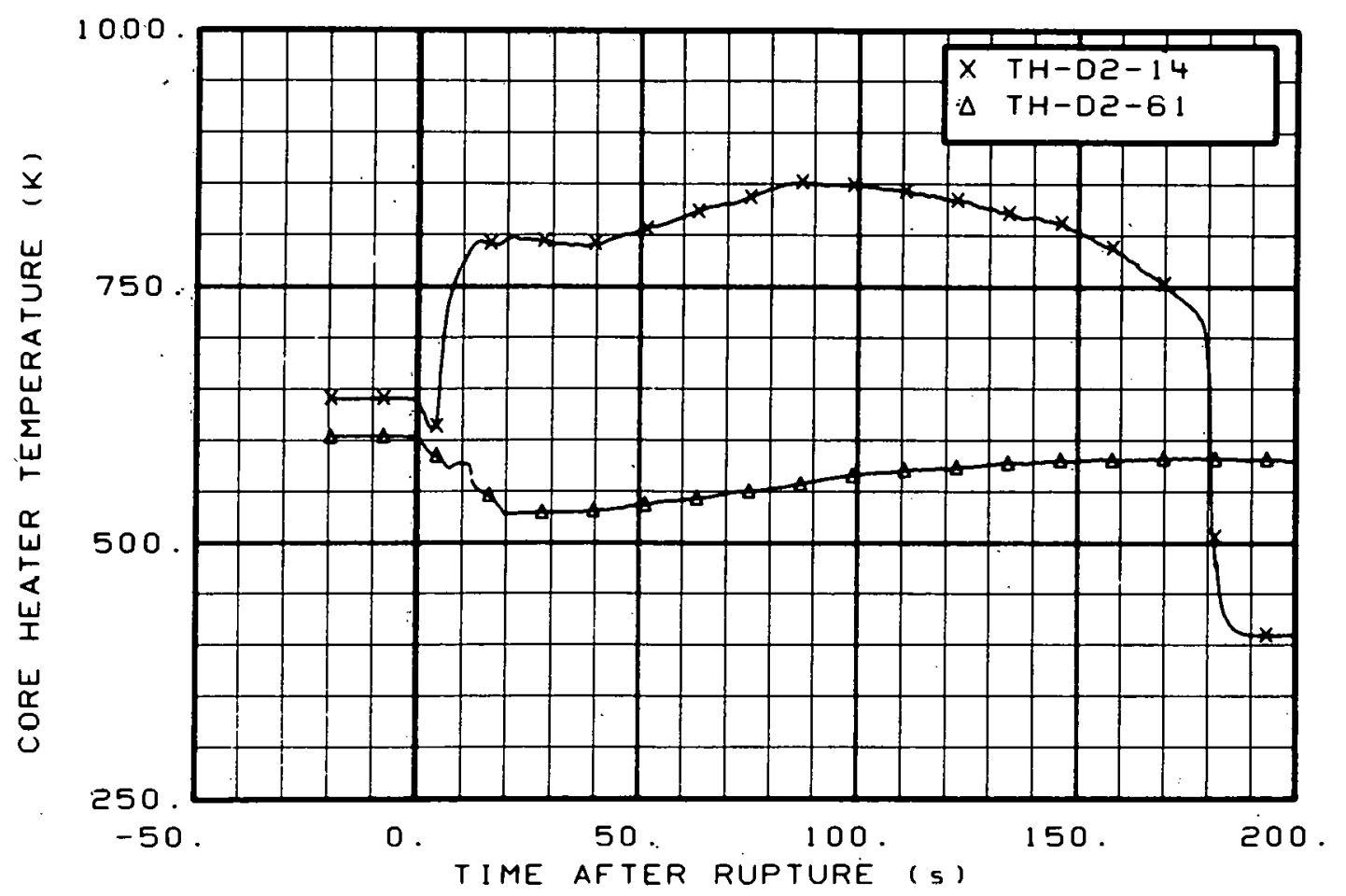

Fig. 91 Core heater temperature, Rod D-2 (TH-D2-14 and TH-D2-61), from -20 to $200 \mathrm{~s}$.

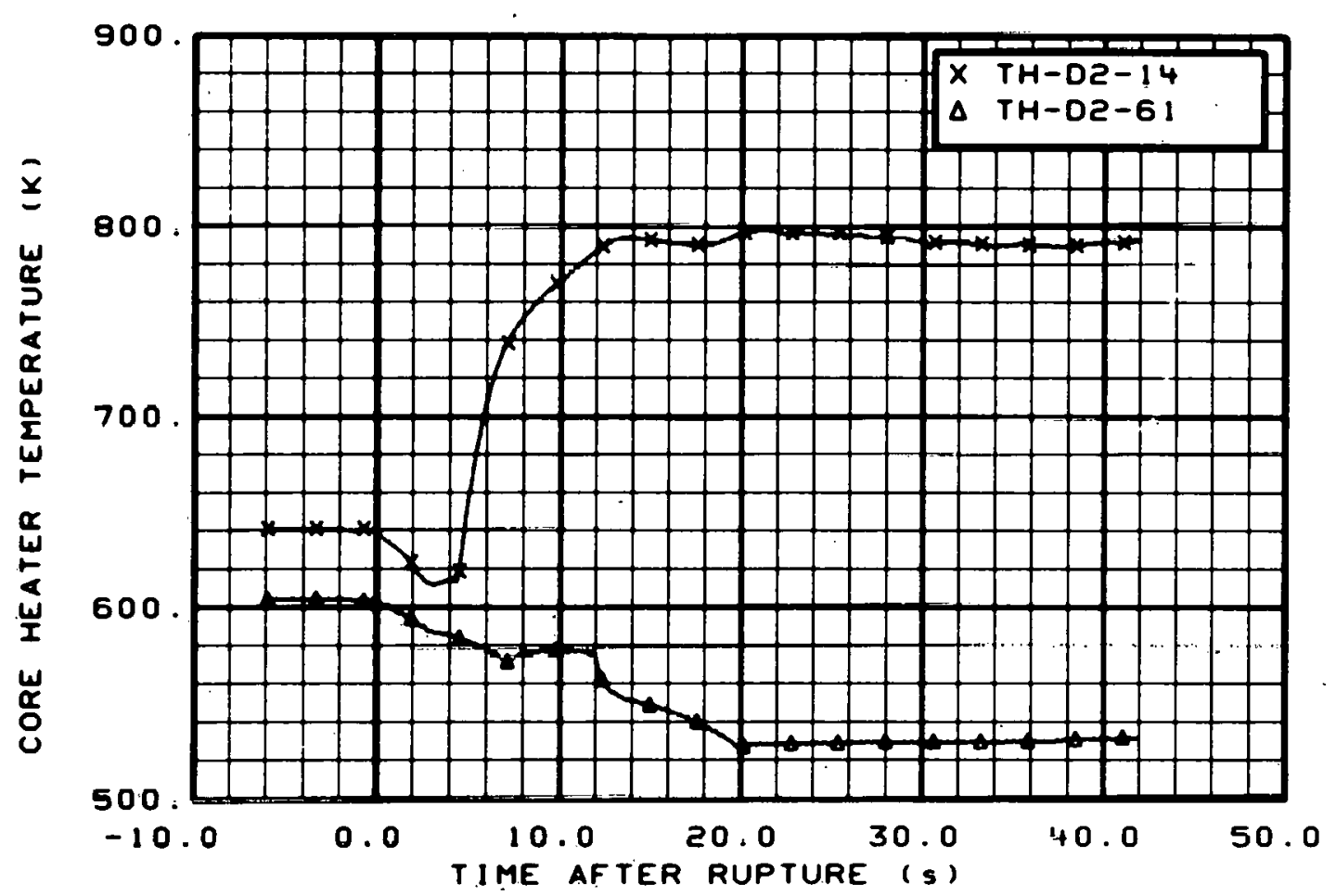

Fig. 92 Core heater temperature, Rod D-2 (TH-D2-14 and TH-D2-61), from -6 to $42 \mathrm{~s}$. 


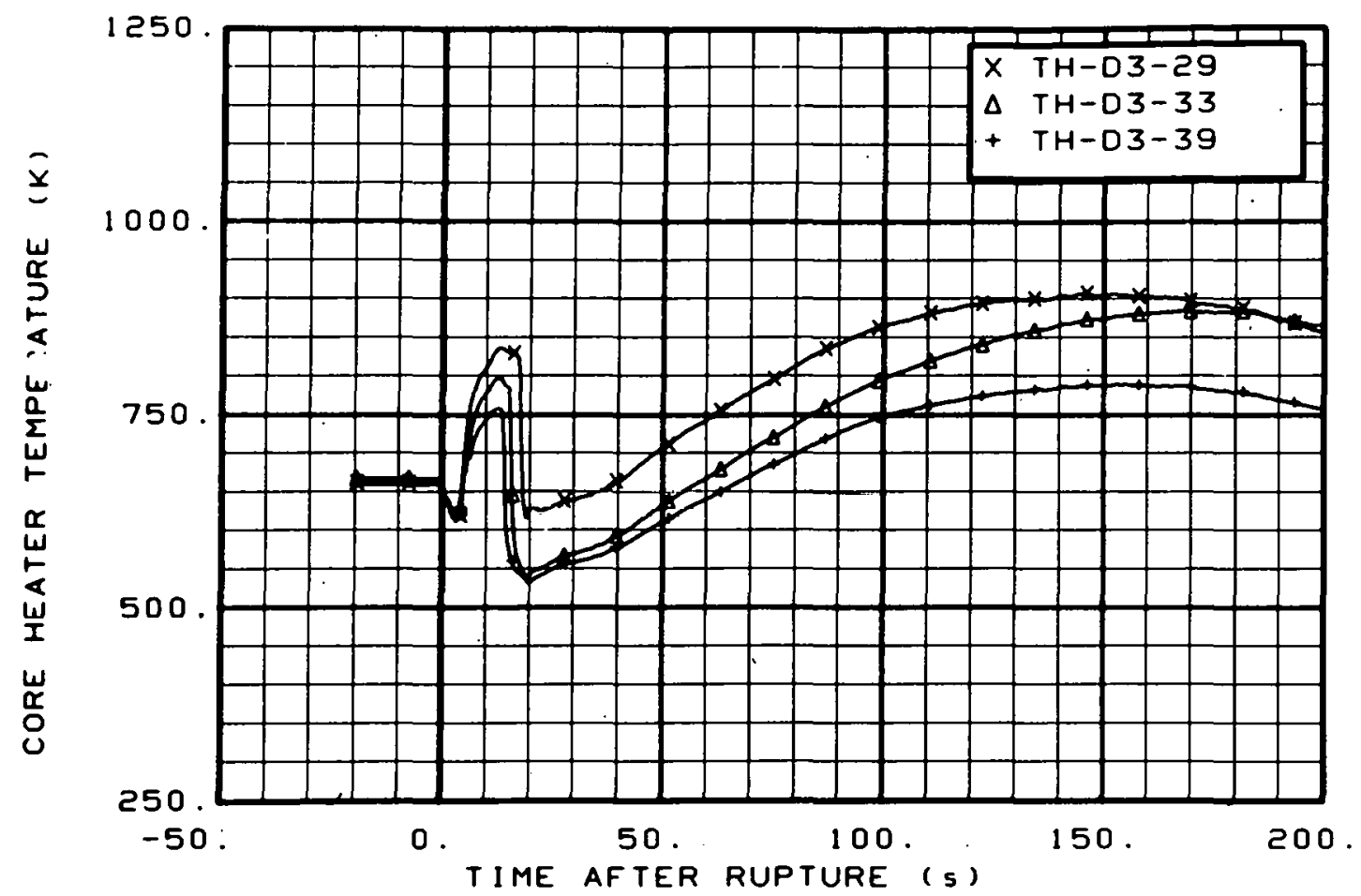

Fig. 93 Core heater temperature, Rod D-3 (TH-D3-29, TH-D3-33, and TH-D3-39), from -20 to $200 \mathrm{~s}$.

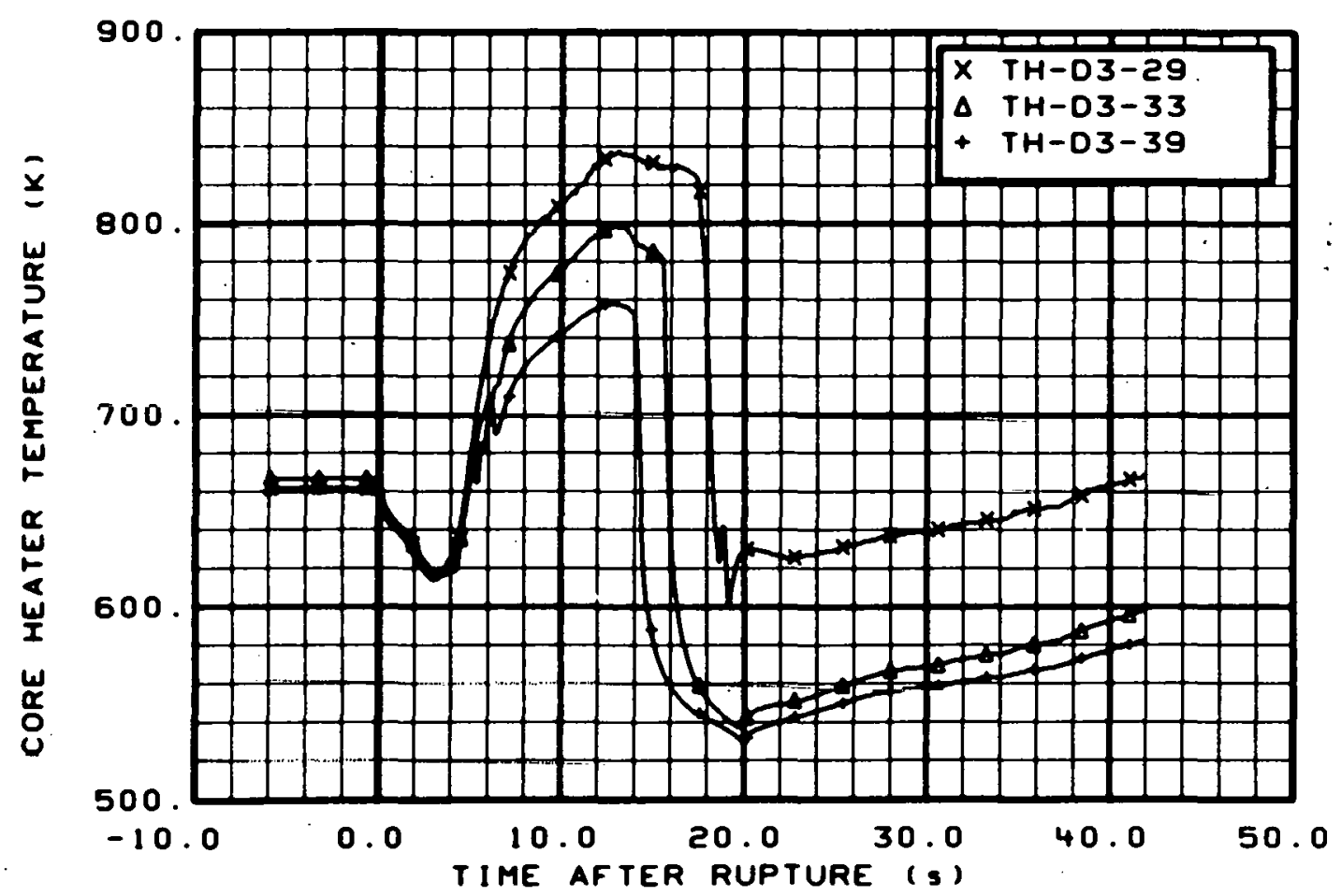

Fig. 94 Core heater temperature, Rod D-3 (TH-D3-29, TH-D3-33, and TH-D3-39), from -6 to $42 \mathrm{~s}$. 


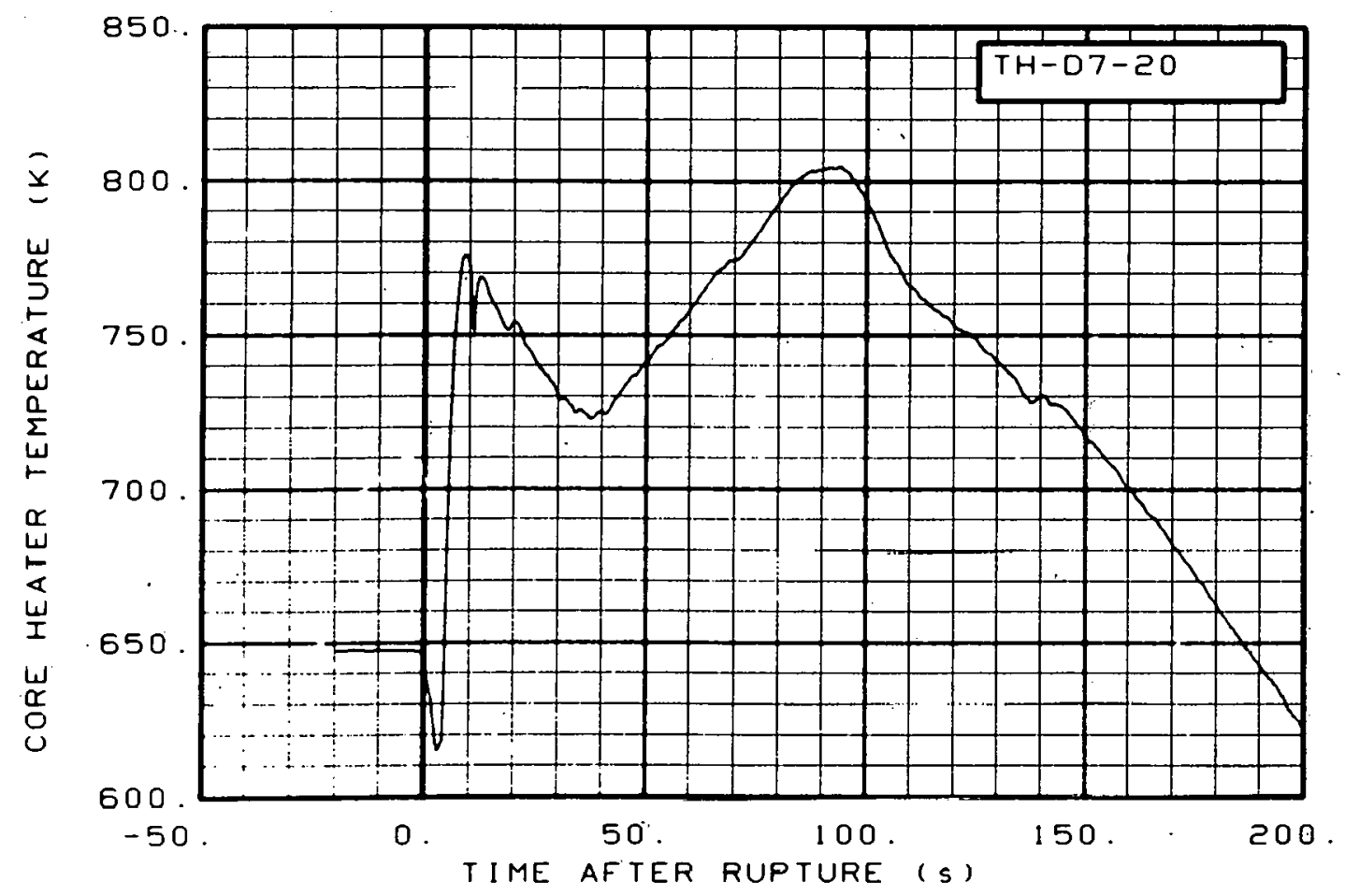

Fig. 95 Core heater temperature, Rod D-7 (TH-D7-20), from -20 to $200 \mathrm{~s}$.

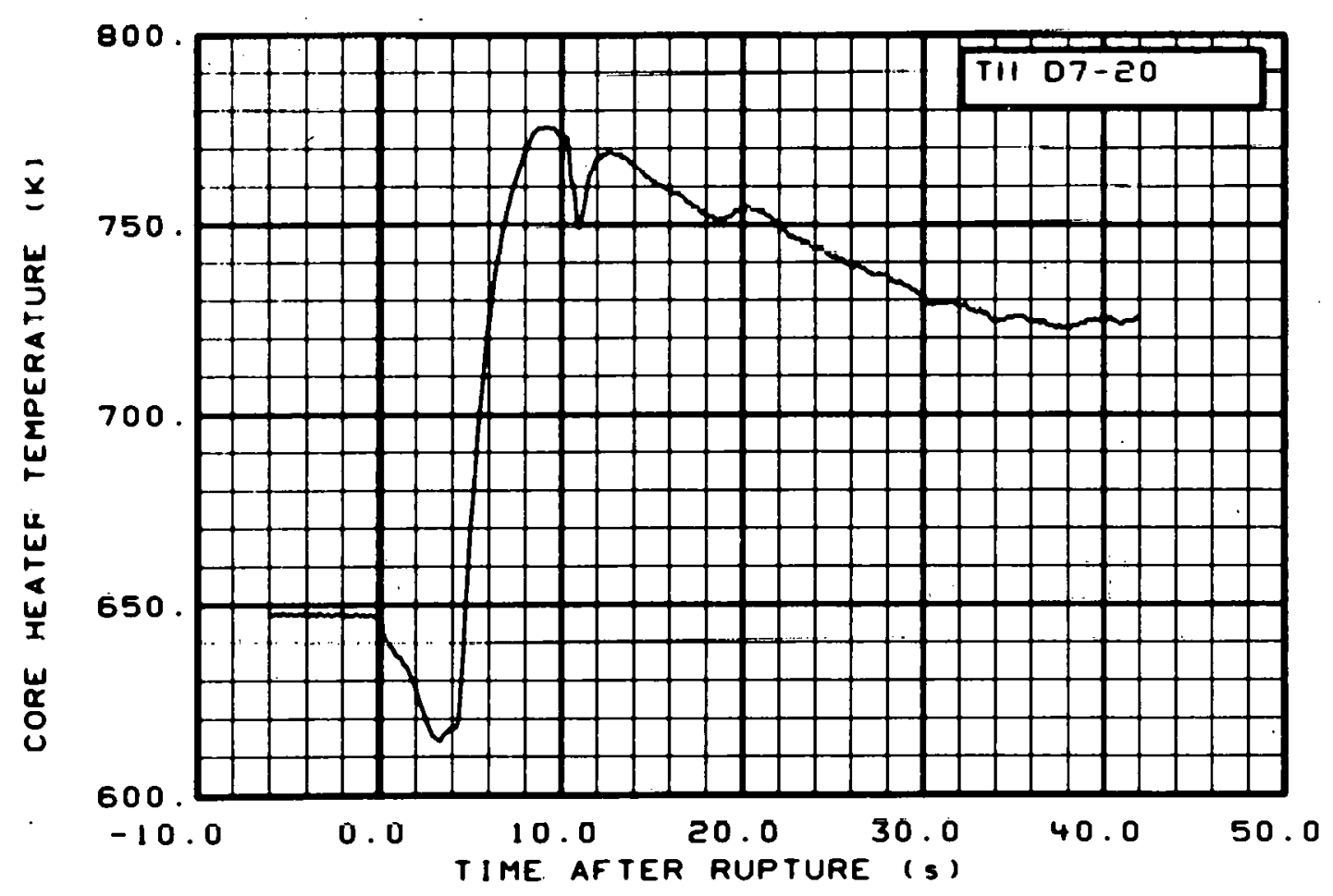

Fig. 96 Core heater temperature, Rod D-7 (TH-D7-20), from -6 to $42 \mathrm{~s}$. 


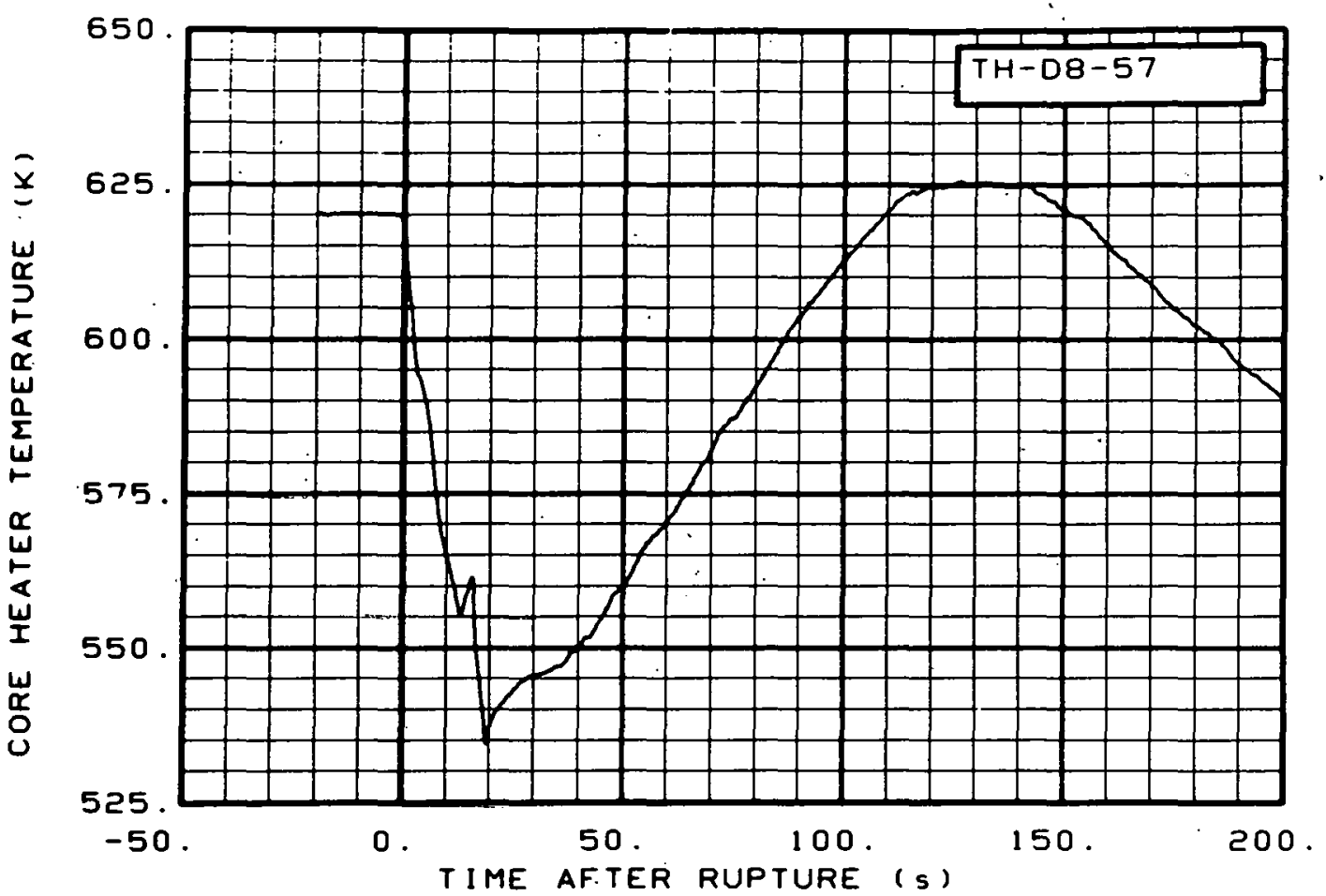

Fig. 97 Core heater temperature, Rod D-8 (TH-D8-57), from -20 to $200 \mathrm{~s}$.

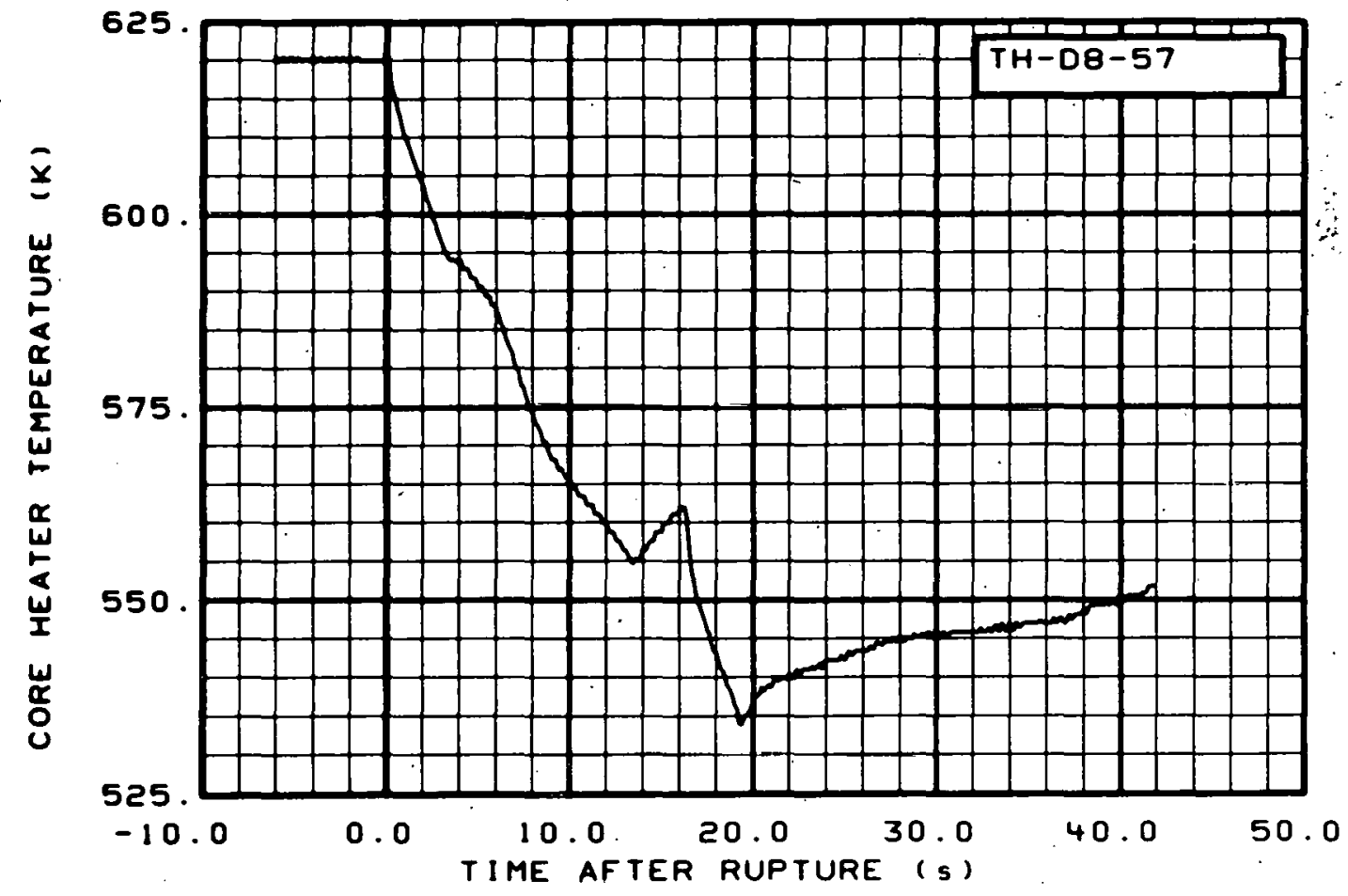

Fig. 98 Core heater temperature, Rod D-8 (TH-D8-57), from -6 to $42 \mathrm{~s}$. 


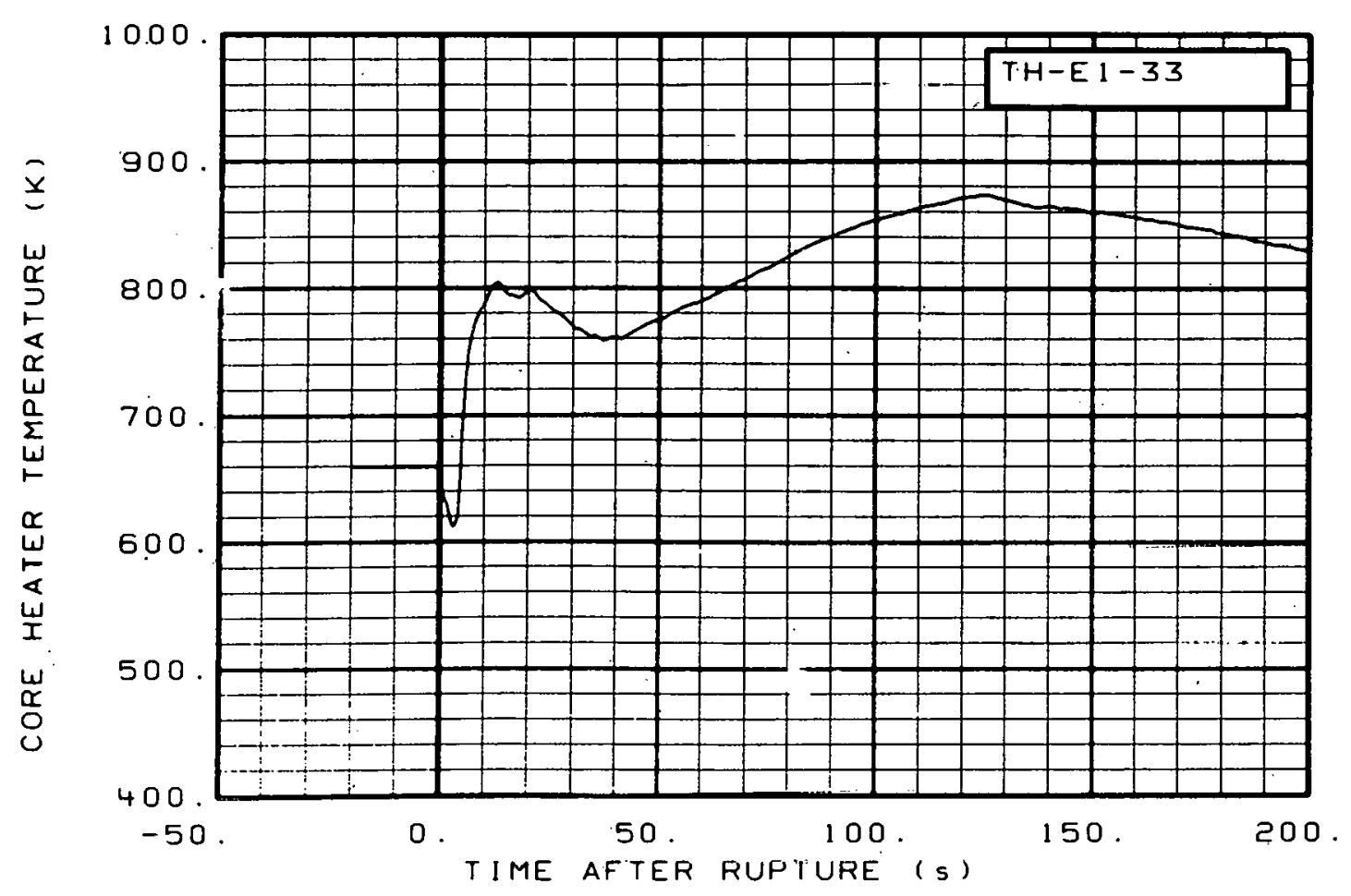

Fig. 99 Core heater temperature, Rod $E-1$ (TH-El-33), from -20 to $200 \mathrm{~s}$.

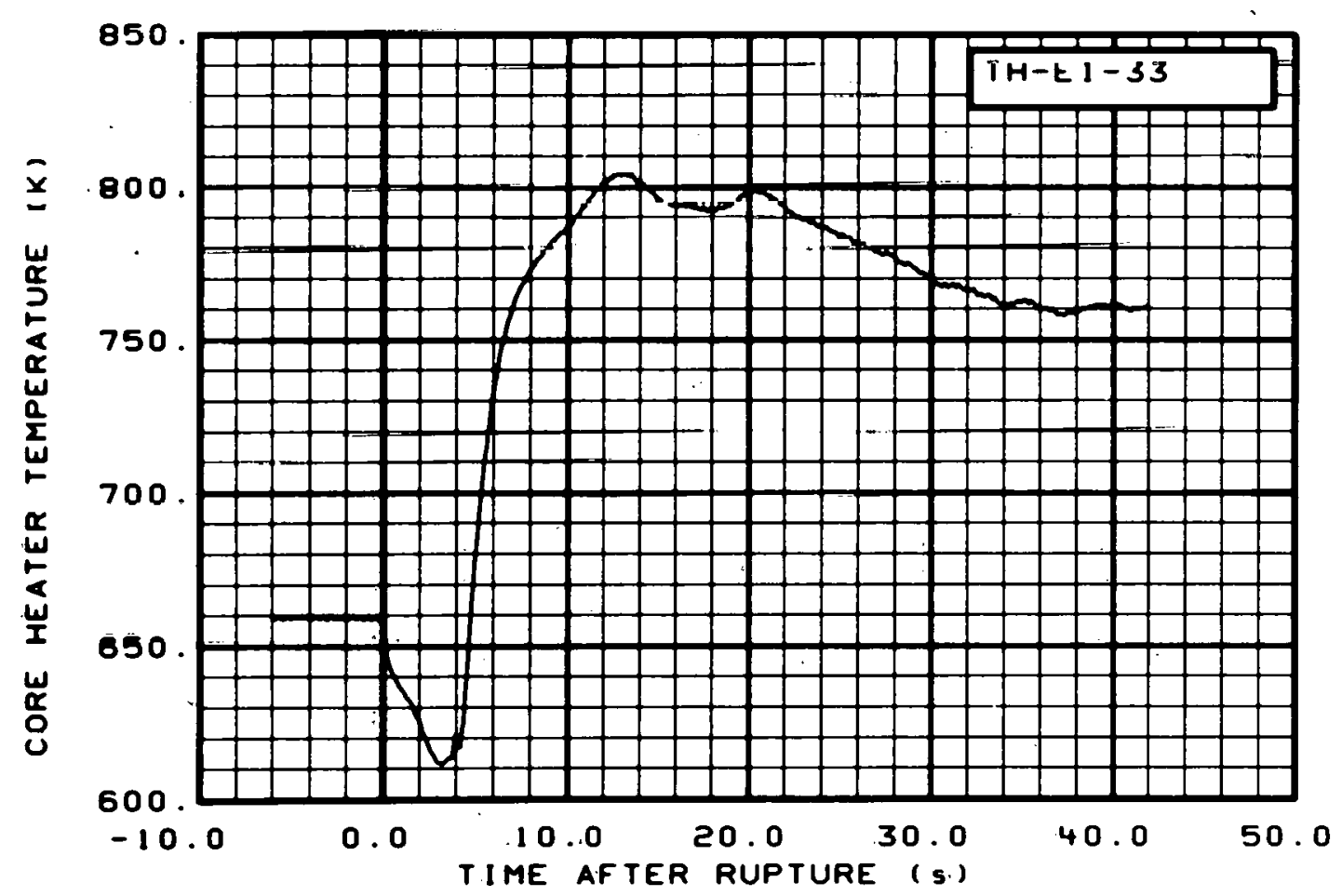

Fig. 100 Core heater temperature, Rod E-1 (TH-El-33), from -6 to $42 \mathrm{~s}$. 


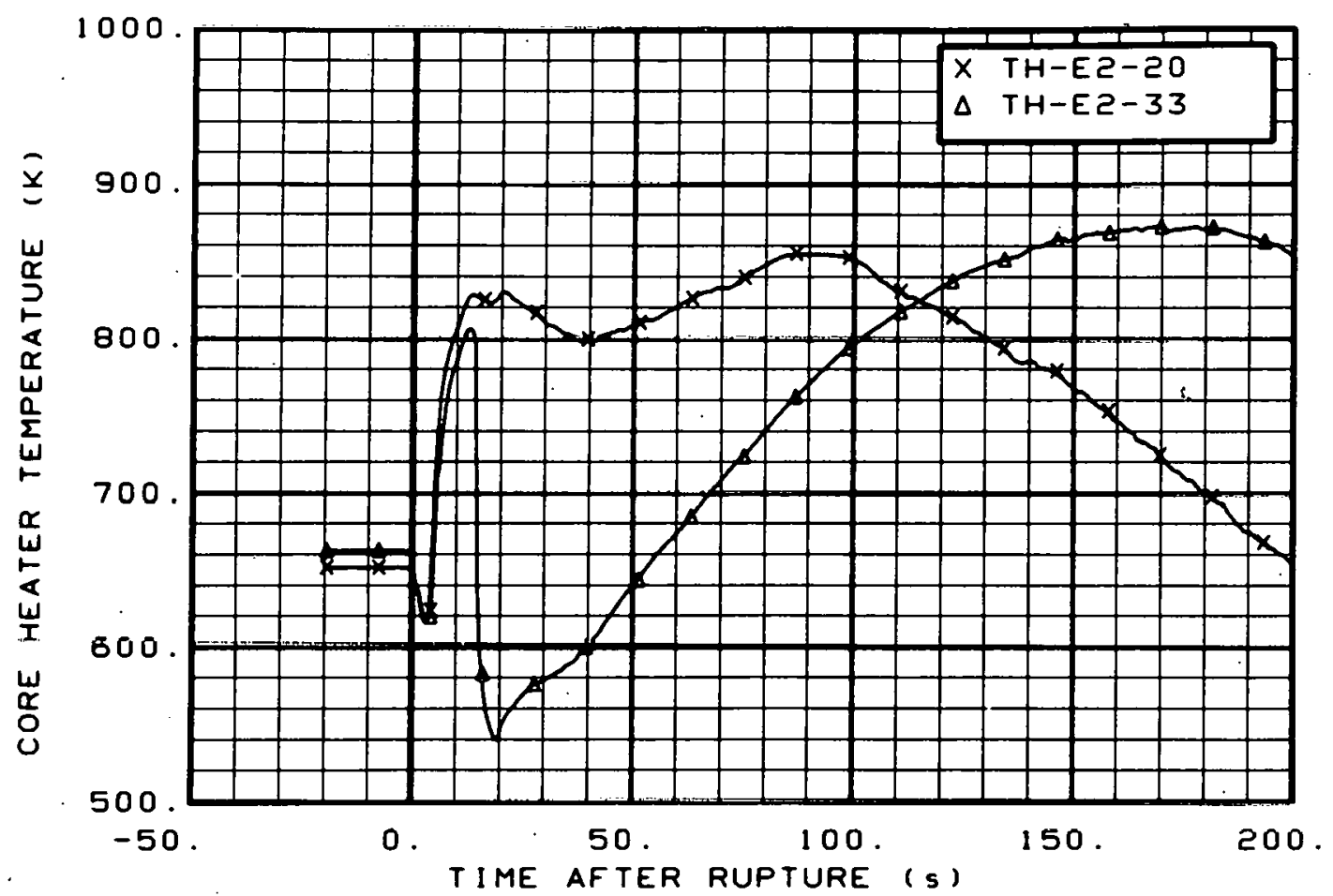

Fig. 101 Core heater temperature, Rod E-2 (TH-E2-20 and TH-E2-33), from -20 to $200 \mathrm{~s}$.

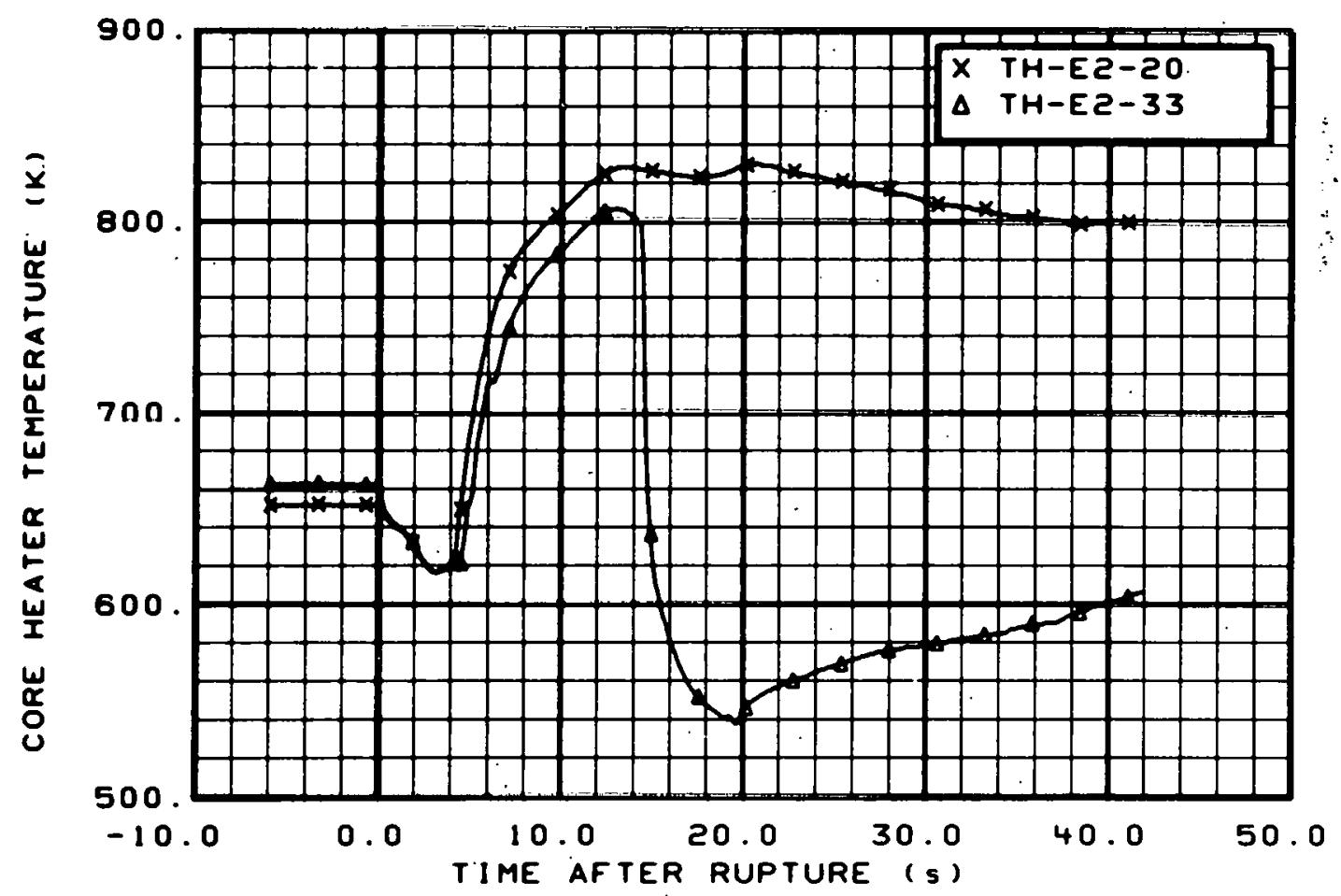

Fig. 102 Core heater temperature, Rod E-2 (TH-E2-20 and TH-E2-33), from -6 to $42 \mathrm{~s}$. 


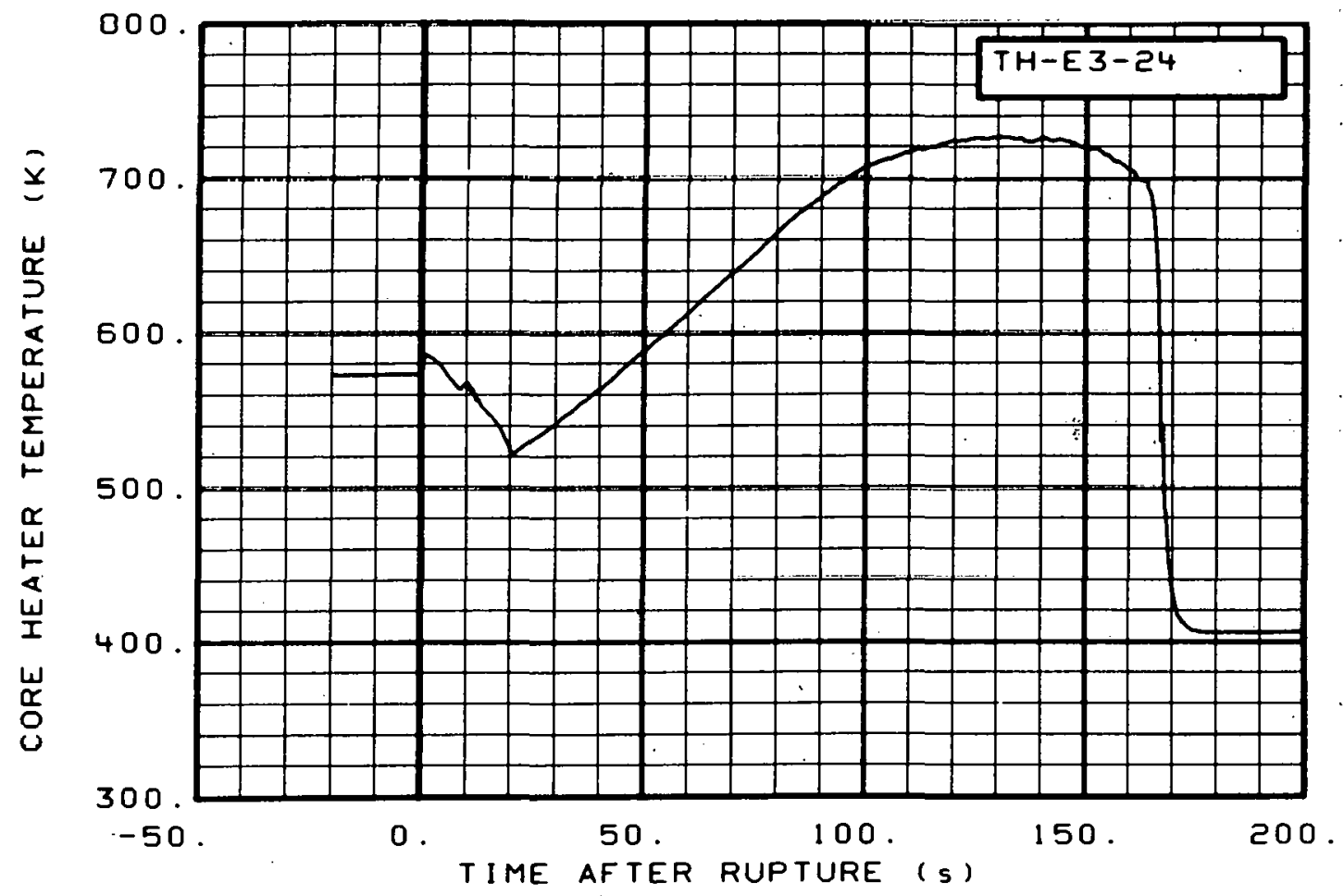

Fig. 103 Core heater temperature, Rod E-3 (TH-E3-24), from -20 to $200 \mathrm{~s}$.

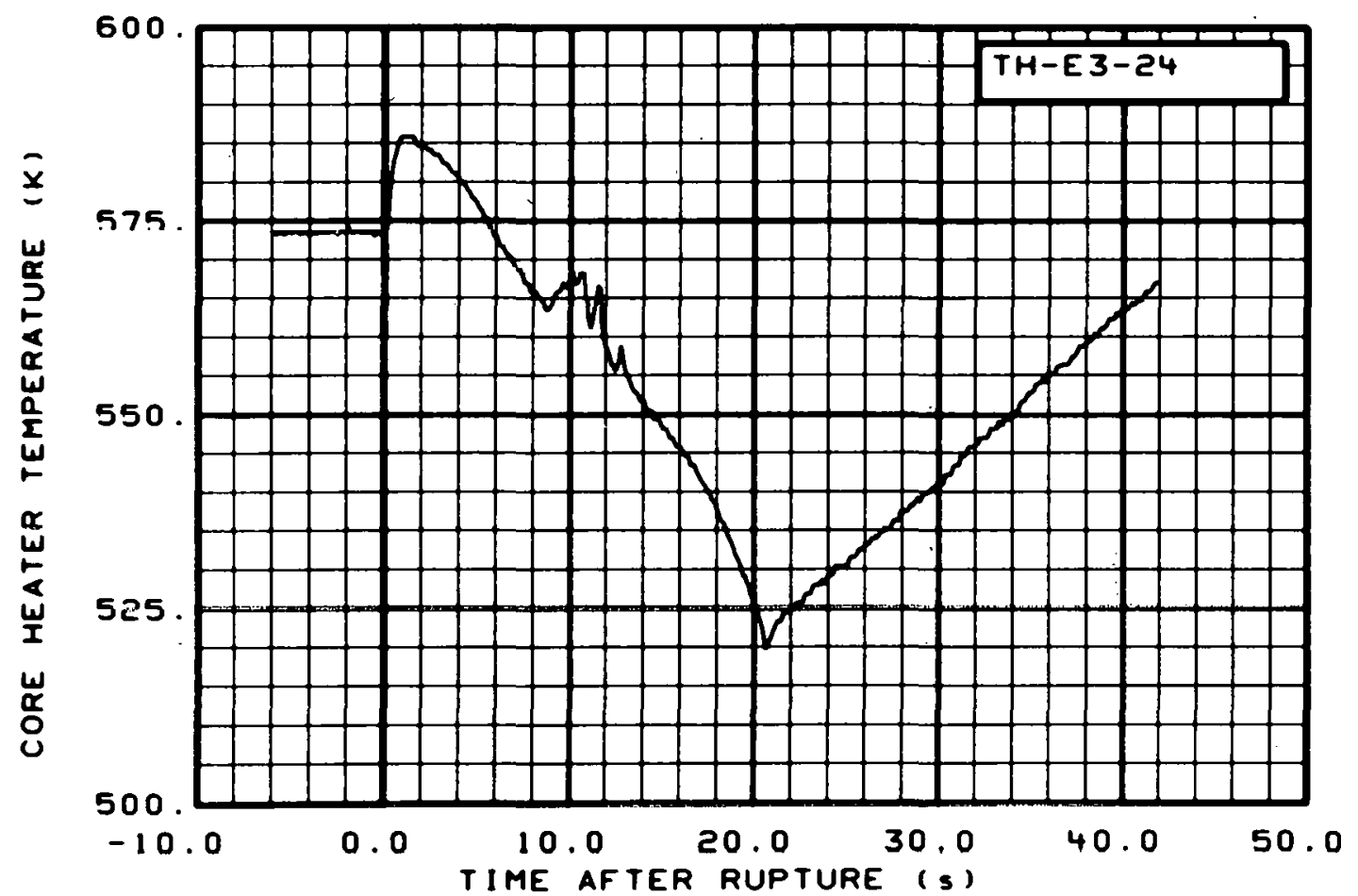

Fig. 104 Core heater temperature, Rod E-3 (TH-E3-24), from -6 to $42 \mathrm{~s}$. 


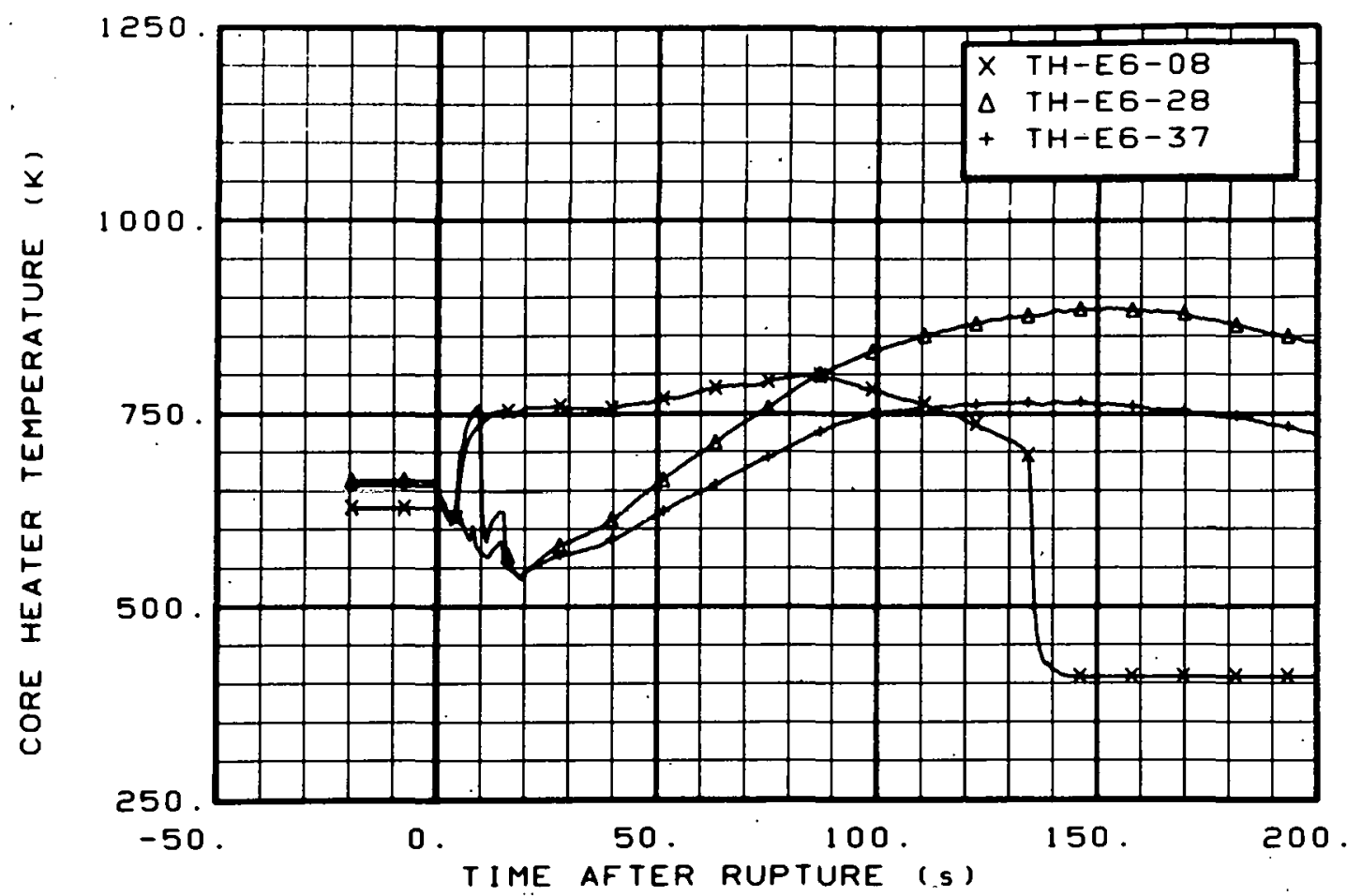

Fig. 105 Core heater temperature, Rod E-6 (TH-E6-08, TH-E6-28, and TH-E6-37), from -20 to $200 \mathrm{~s}$.

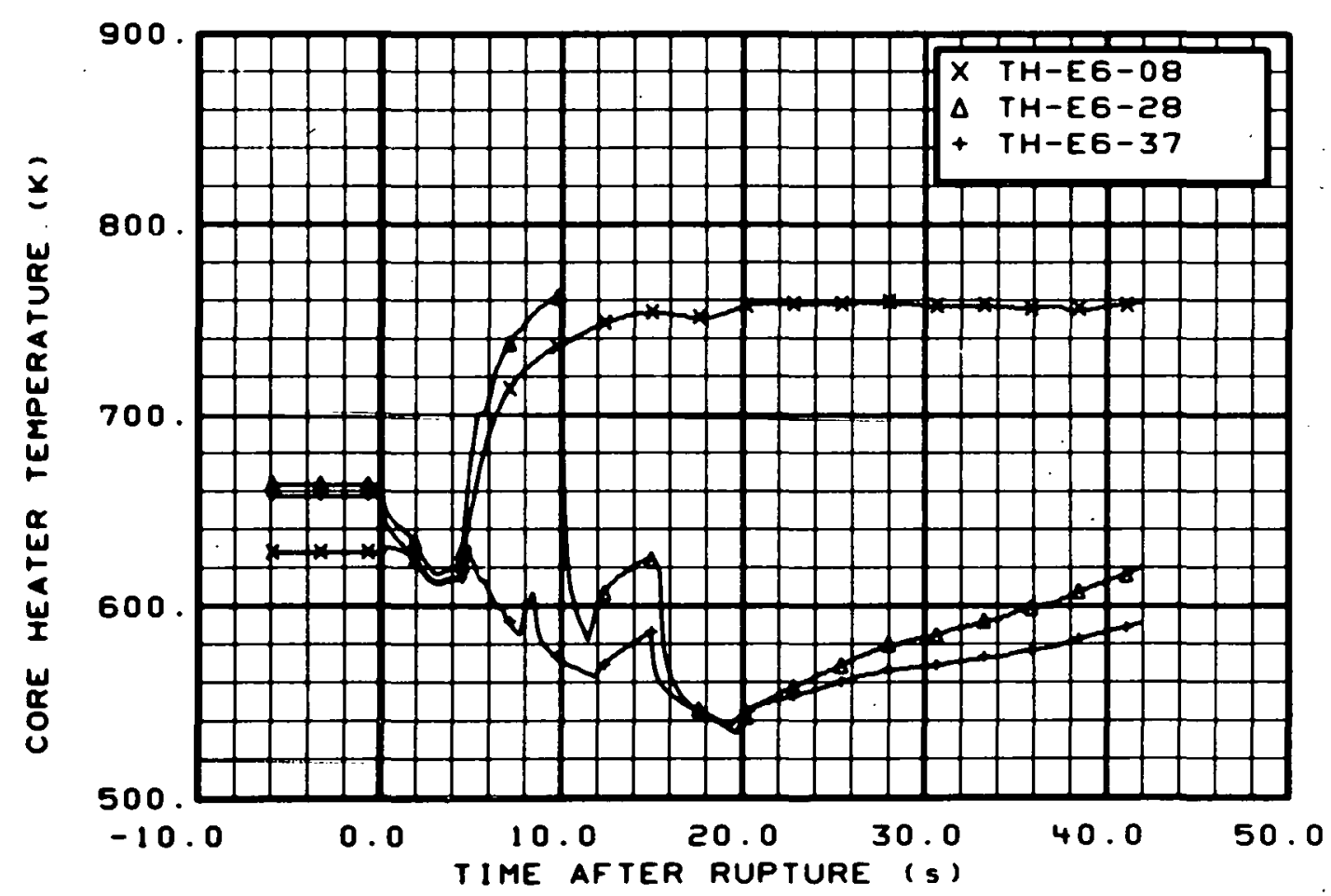

Fig. 106 Core heater temperature, Rod E-6 (TH-E6-08, TH-E6-28, and TH-E6-37), from -6 to $42 \mathrm{~s}$. 


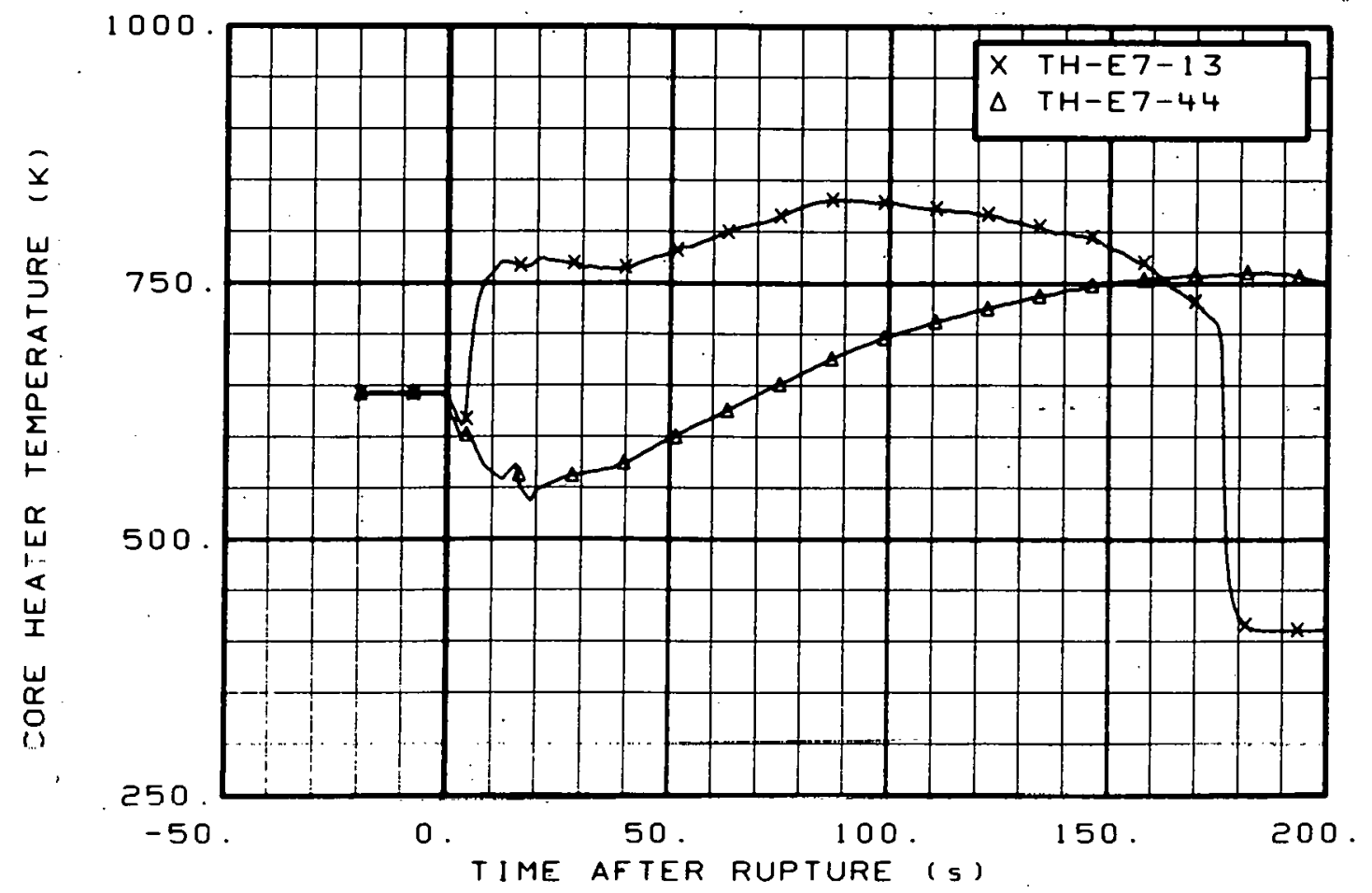

Fig. 107 Core heater temperature, Rod E-7 (TH-E7-13 and TH-E7-44), from -20 to $200 \mathrm{~s}$.

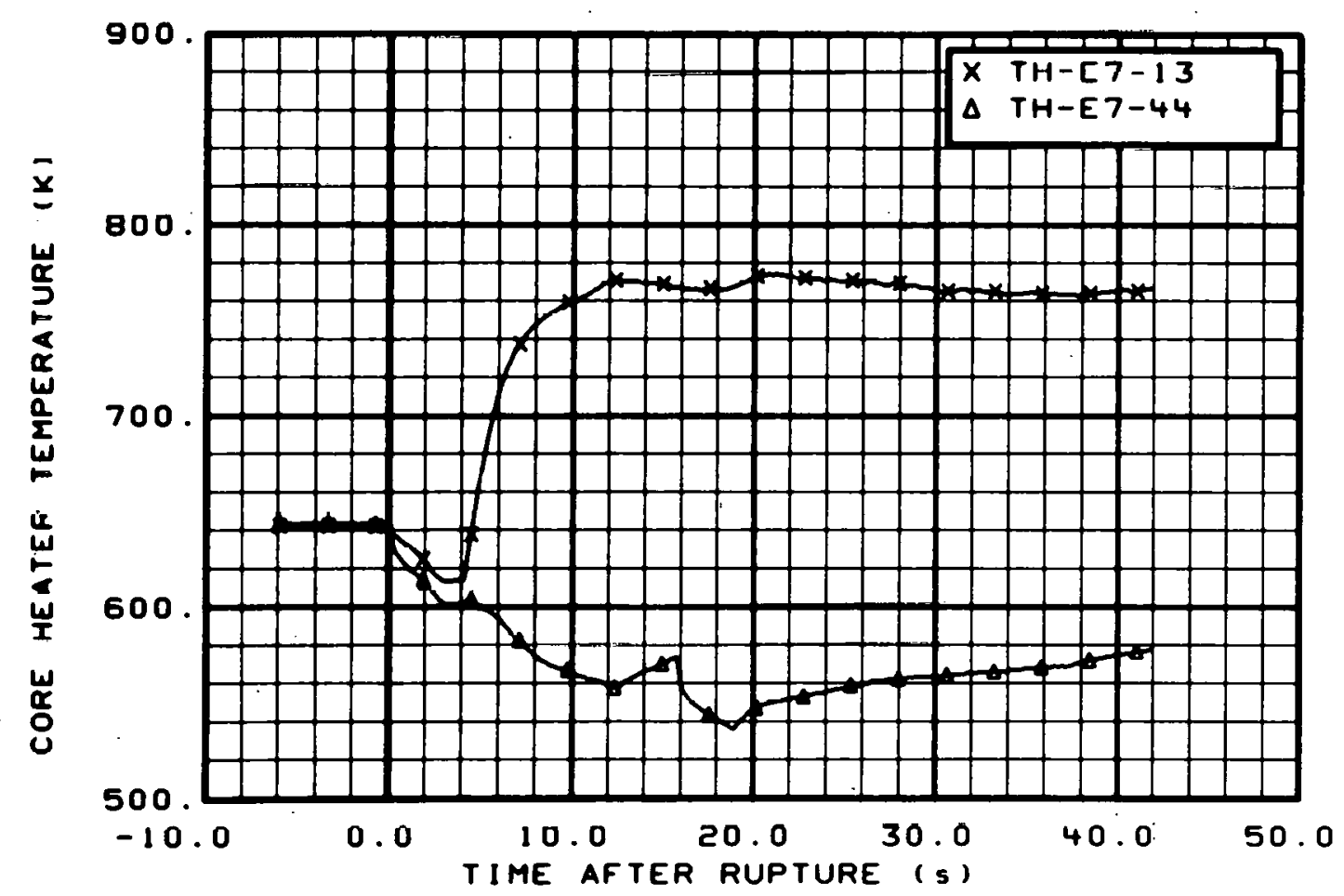

Fig. 108 Core heater temperature, Rod E-7 (TH-E7-13 and TH-E7.-44), from -6 to $42 \mathrm{~s}$. 


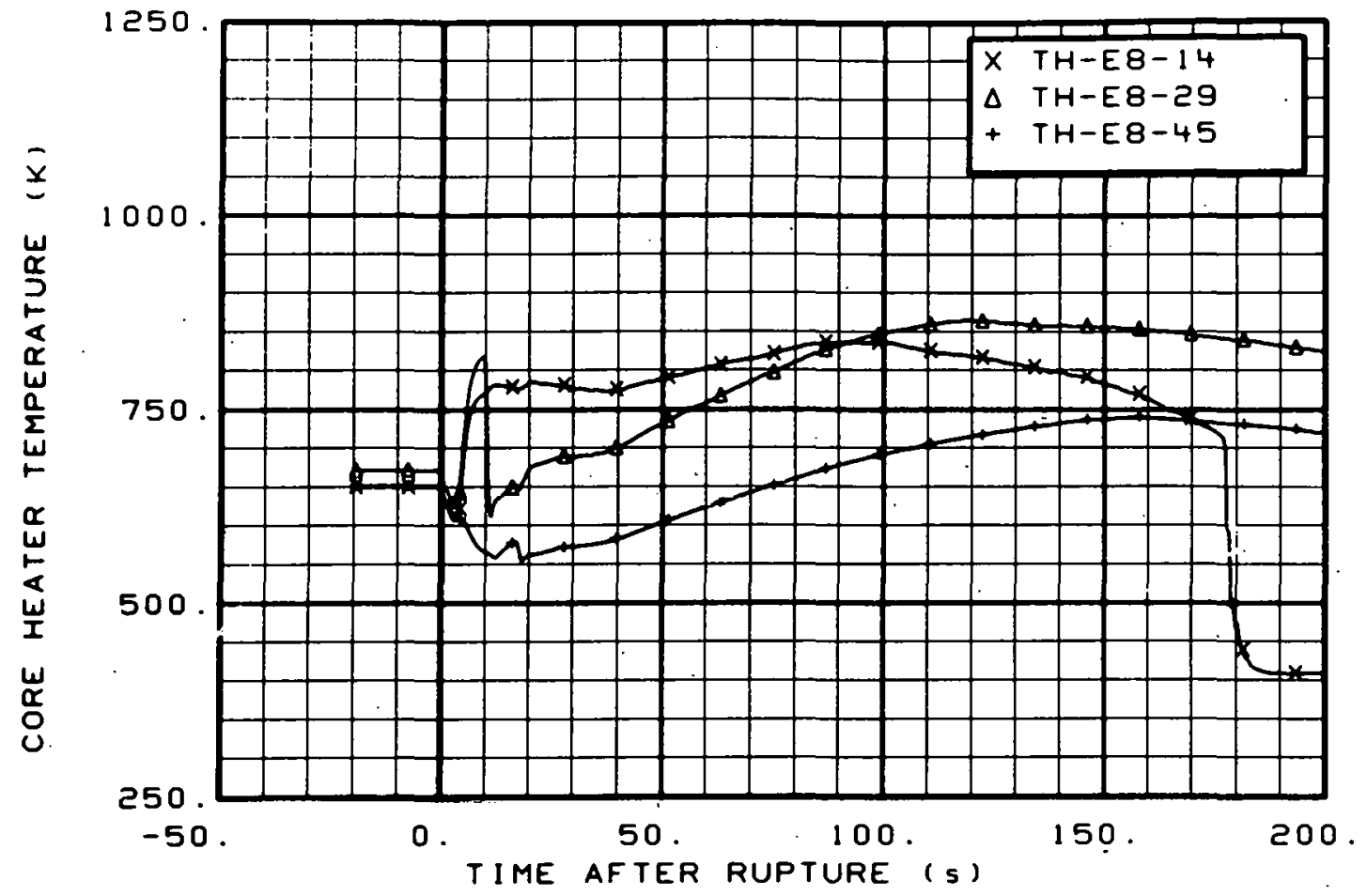

Fig. 109 Core heater temperature, Rod E-8 (TH-E8-14, TH-E8-29, and. $\mathrm{TH}-\mathrm{E} 8-45$ ), from -20 to $200 \mathrm{~s}$.

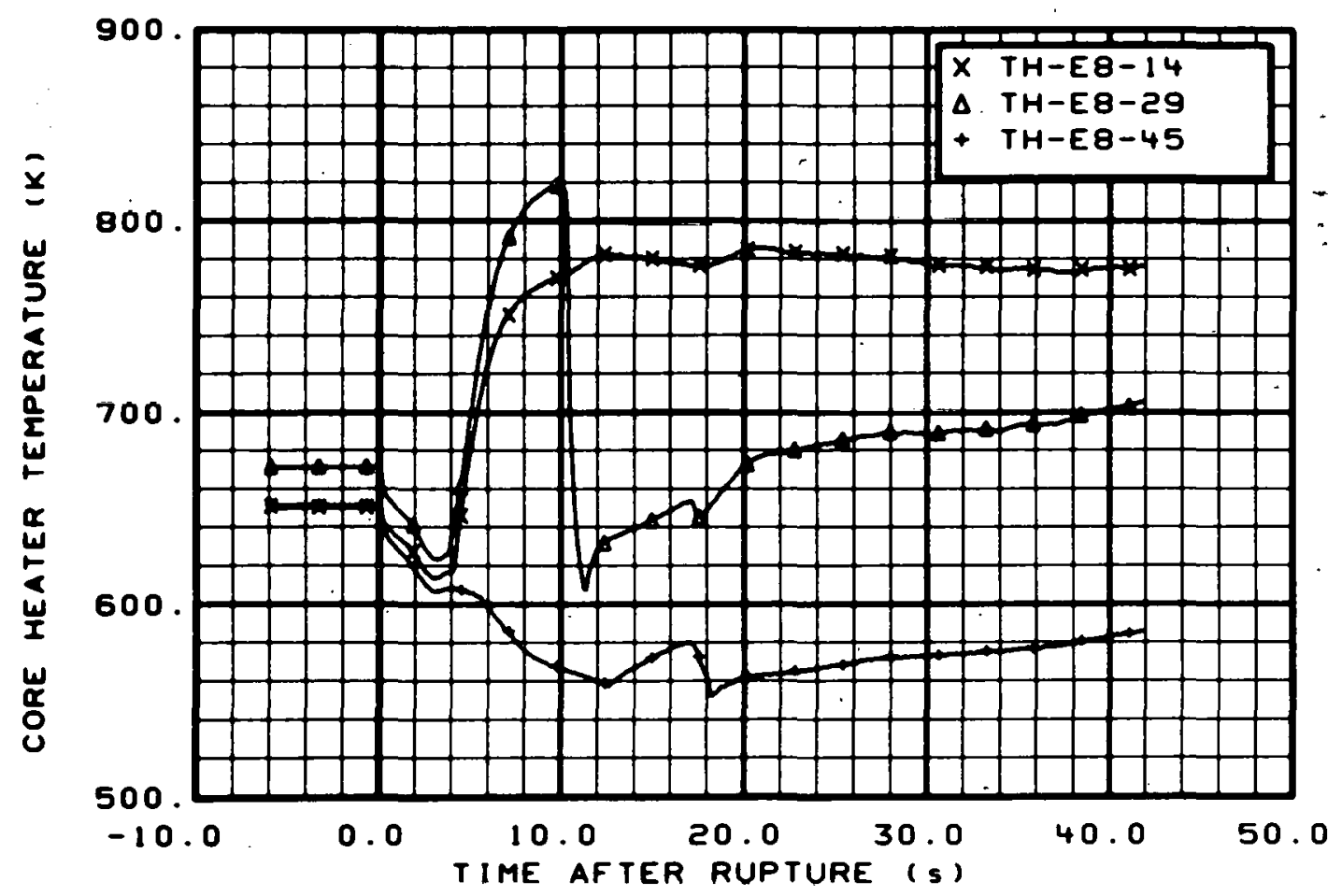

Fig. 110 Core heater temperature, Rod E-8 (TH-E8-14, TH-E8-29, and TH-E8-45), from -6 to $42 \mathrm{~s}$. 


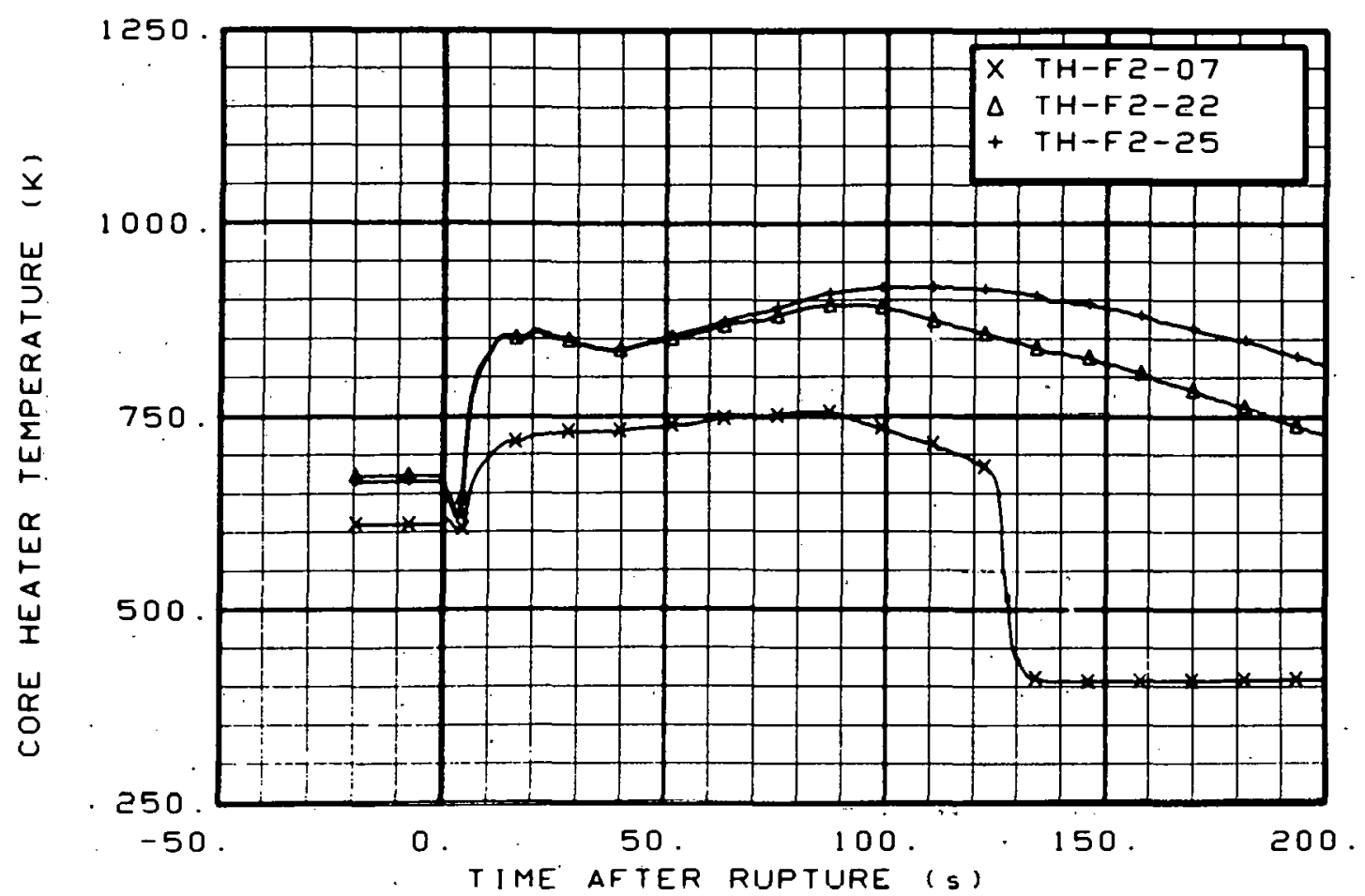

Fig. 111 Core heater temperature, Rod F-2 (TH-F2-07, TH-F2-22, and TH-F2-25), from -20 to $200 \mathrm{~s}$.

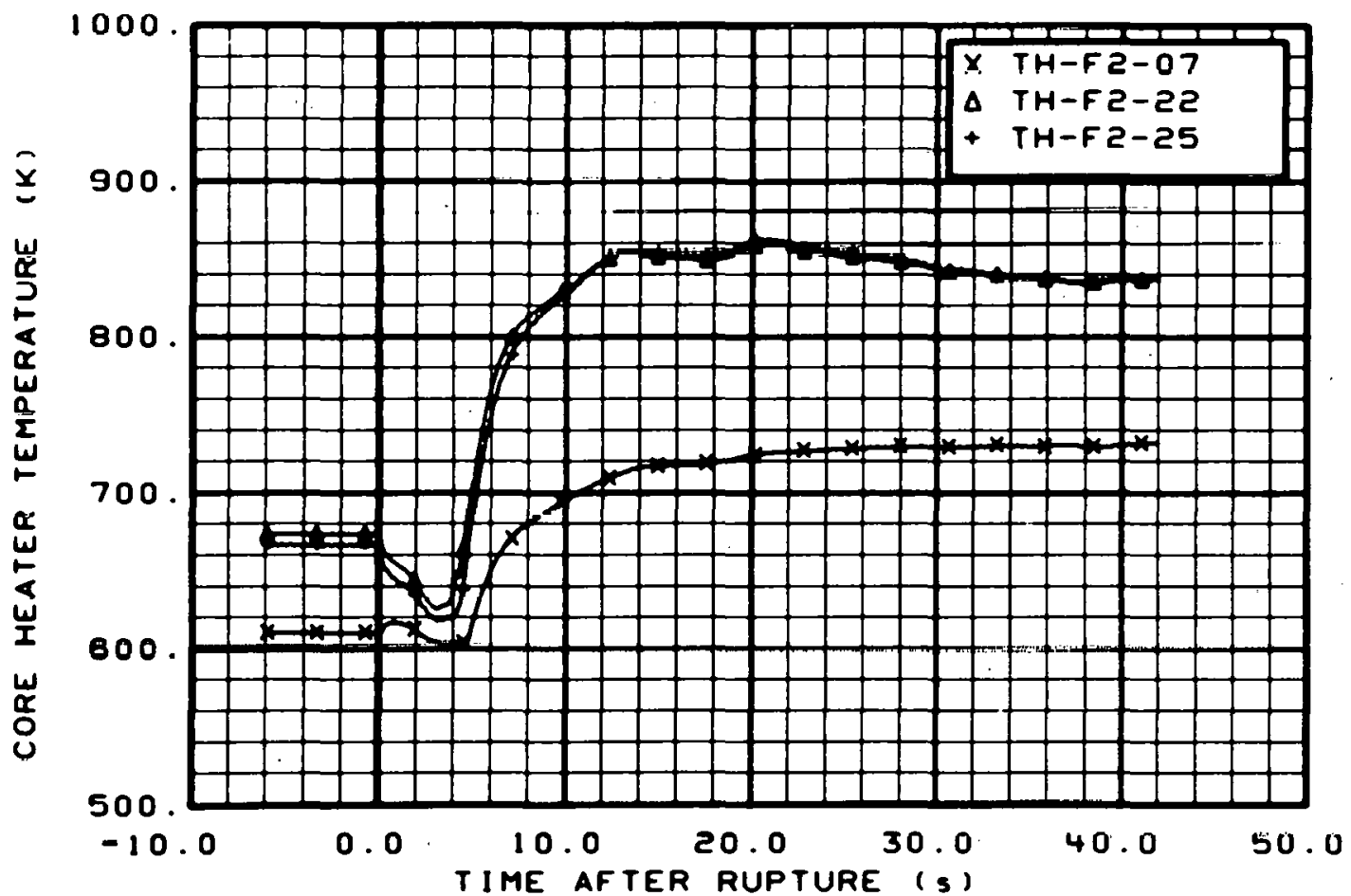

Fig. 112 Core heater temperature, Rod F-2 (TH-F2-07, TH-F2-22, and TH-F2-25), from -6 to $42 \mathrm{~s}$. 


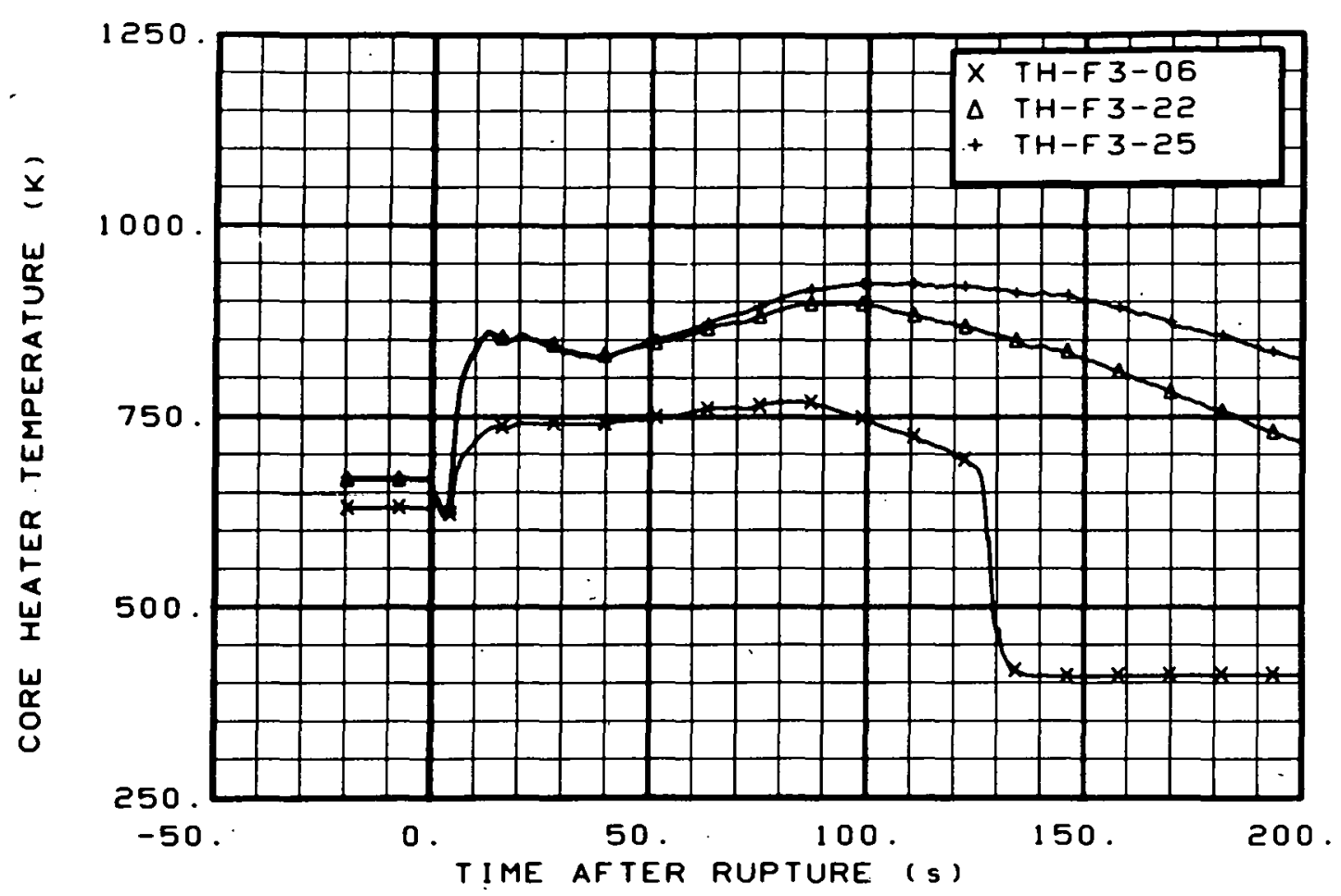

Fig. 113 Core heater temperature, Rod F-3 (TH-F3-06, TH-F3-22, and $\mathrm{TH}-\mathrm{F} 3-25$ ), from -20 to $200 \mathrm{~s}$.

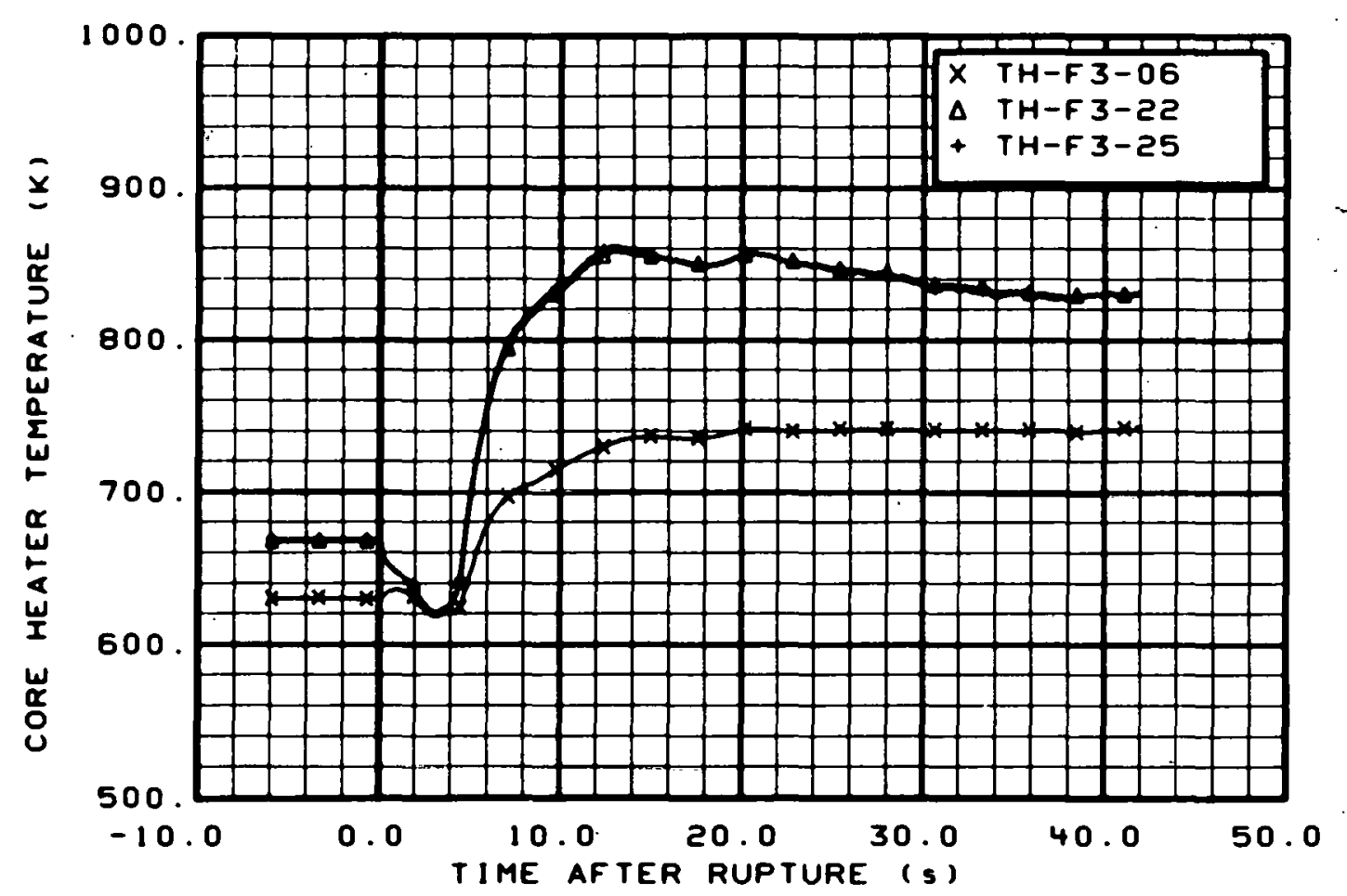

Fig. 114 Core heater temperature, Rod F-3 (TH-F3-06, TH-F3-22, and TH-F3-25), from -6 to $42 \mathrm{~s}$. 


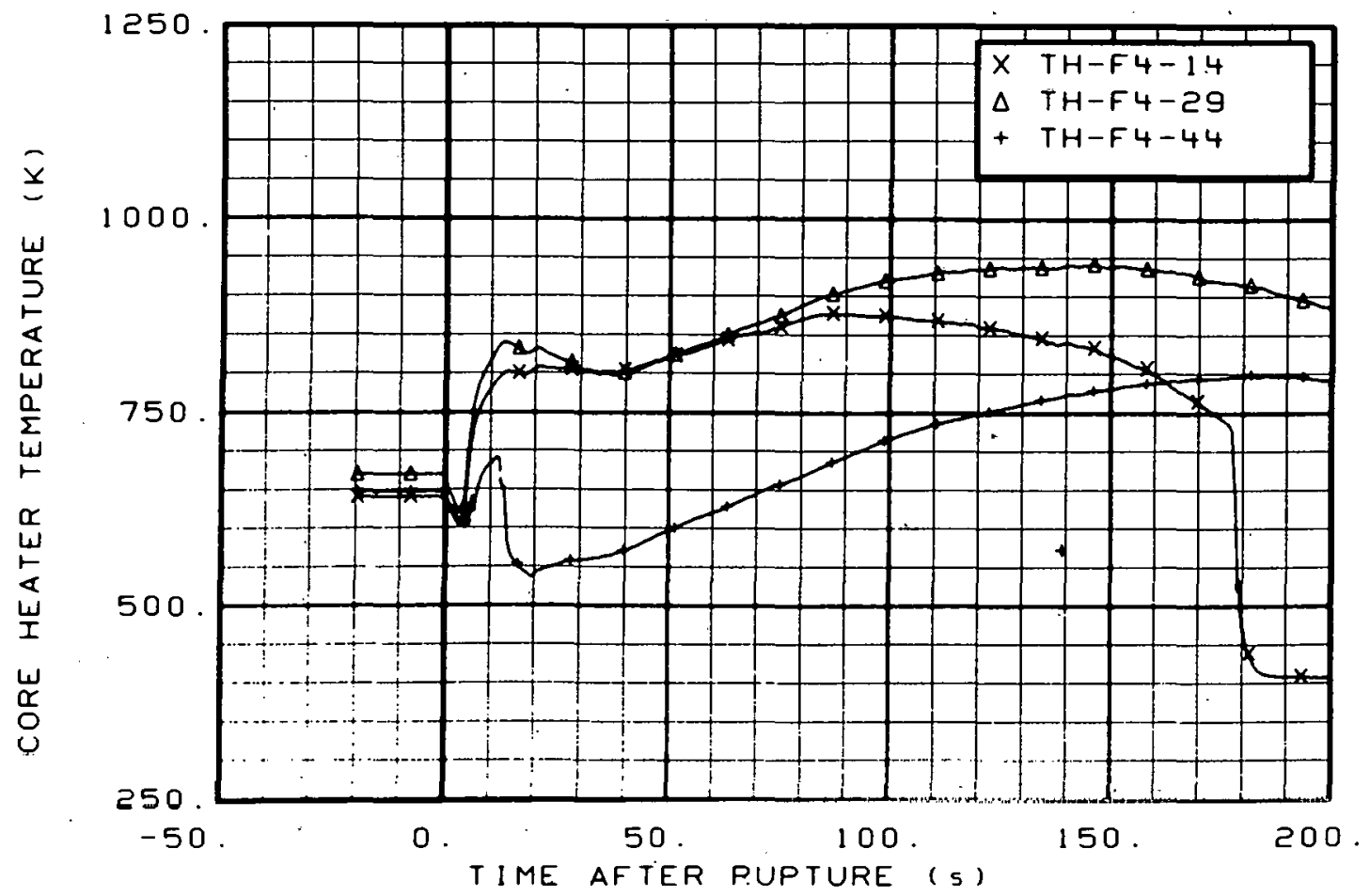

Fig. 115 Core heater temperature, Rod F-4 (TH-F4-14, TH-F4-29, and TH-F4-44), from -20 to $200 \mathrm{~s}$.

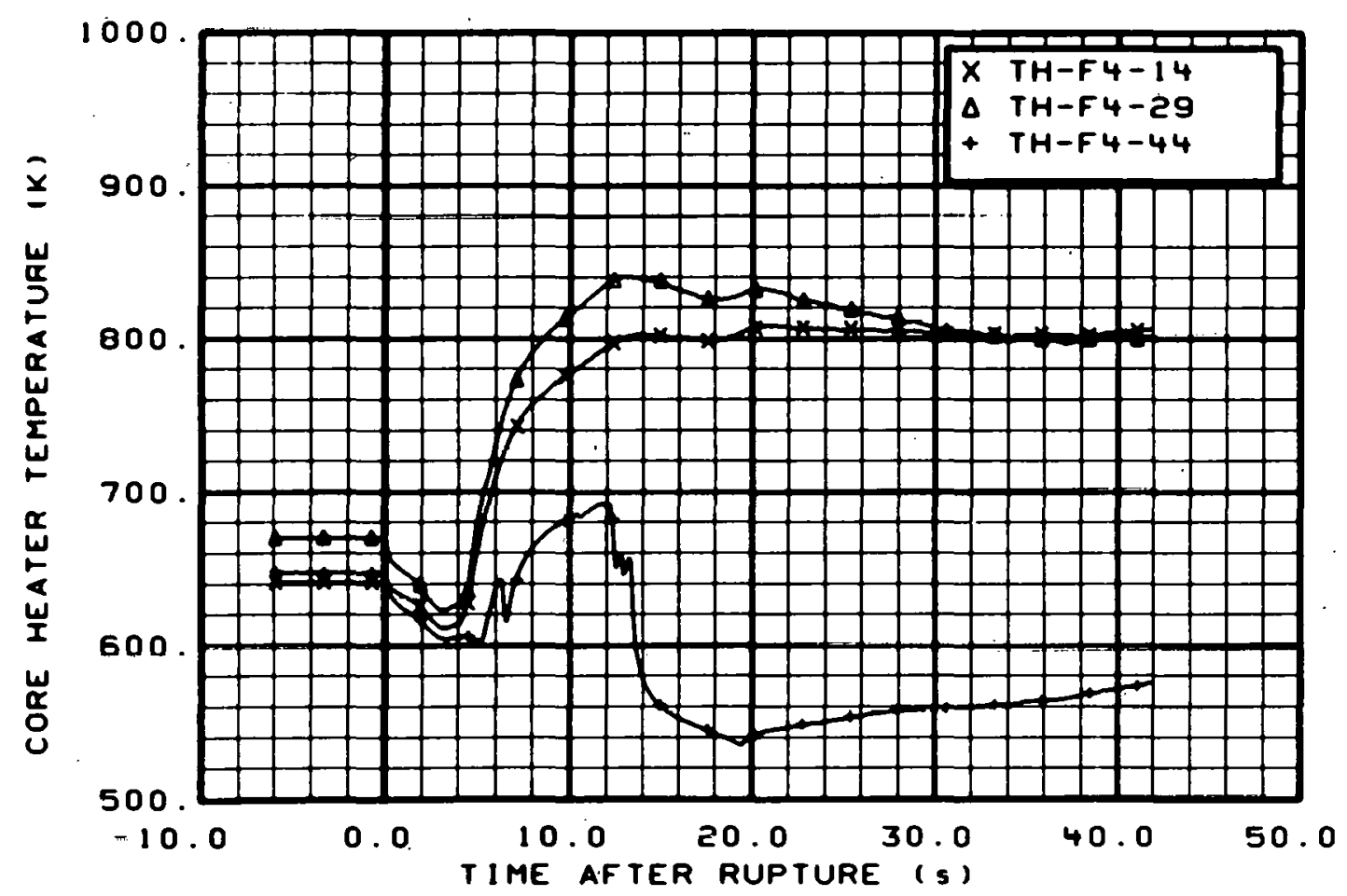

Fig. 116 Core heater temperäture, Rod F-4 (TH-F4-14, TH-F4-29, and TH-F 4-44), from -6 to $42 \mathrm{~s}$. 


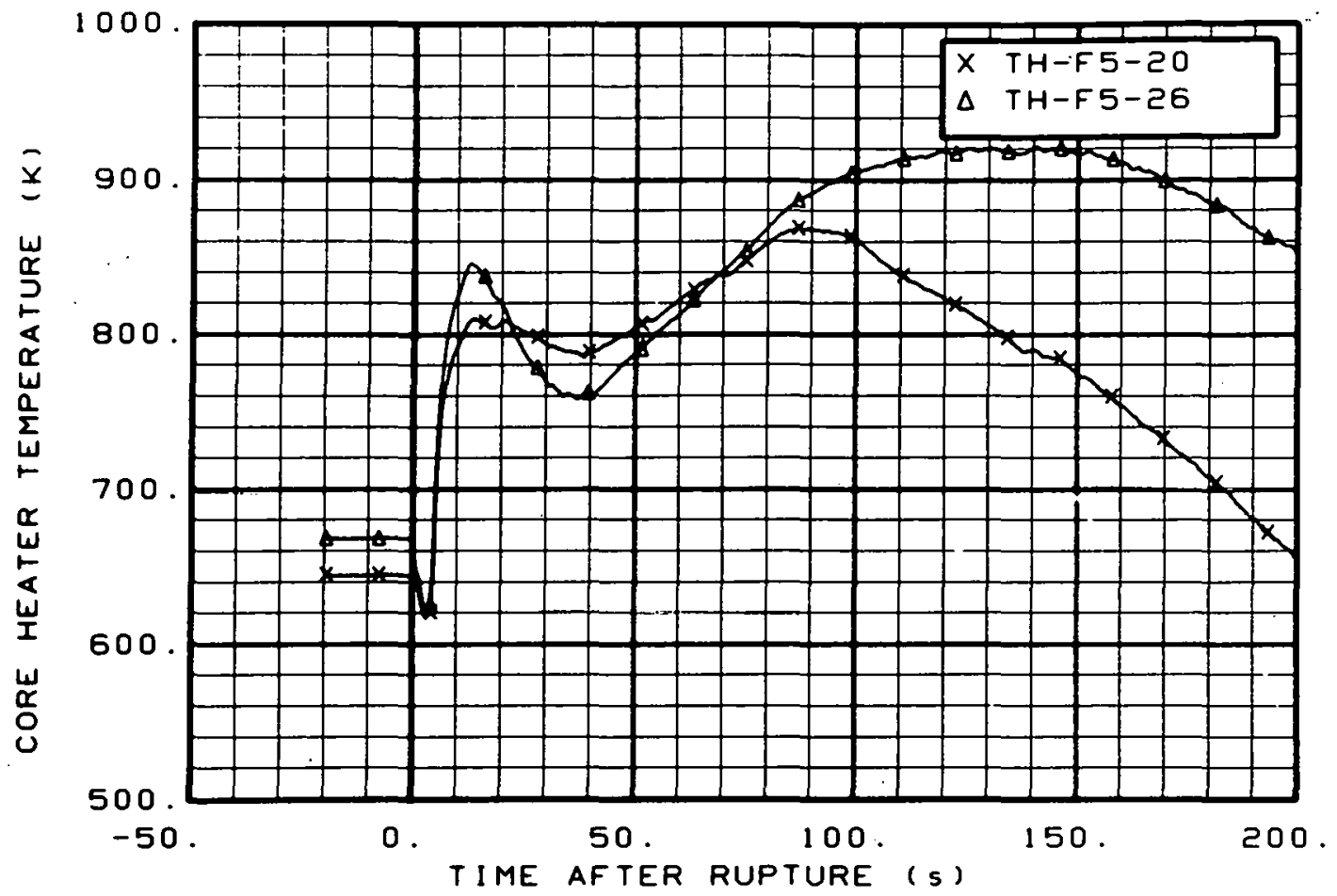

Fig. 117 Core heater temperature, Rod F-5 (TH-F5-20 and TH-F5-26), from -20 to $200 \mathrm{~s}$.

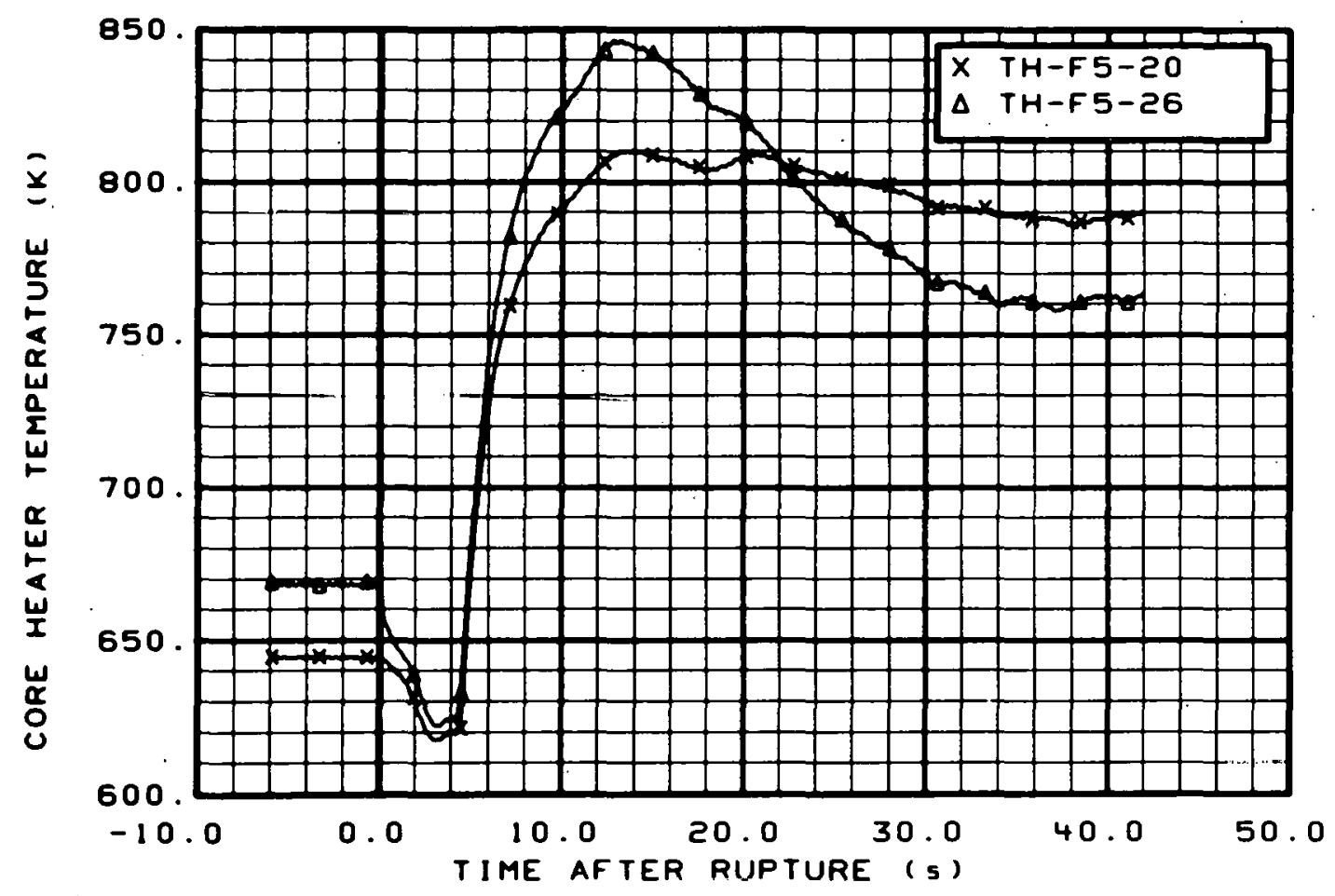

Fig. 118 Core heater temperature, Rod F-5 (TH-F5-20 and TH-F5-26), from $=6$ to $42 \mathrm{~s}$. 


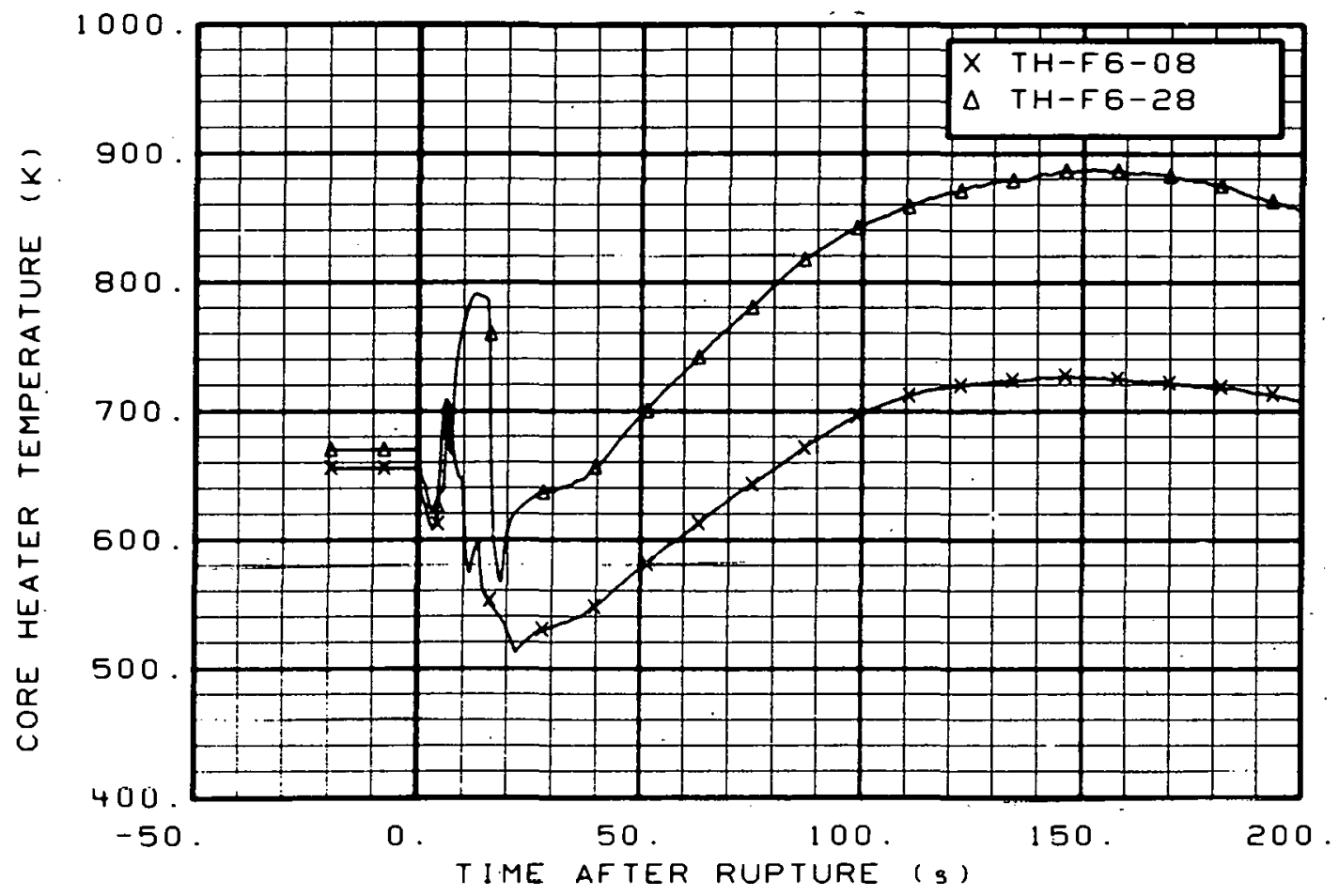

Fig. 119 Core heater temperature, Rod F-6 (TH-F6-08 and TH-F6-28), from -20 to $200 \mathrm{~s}$.

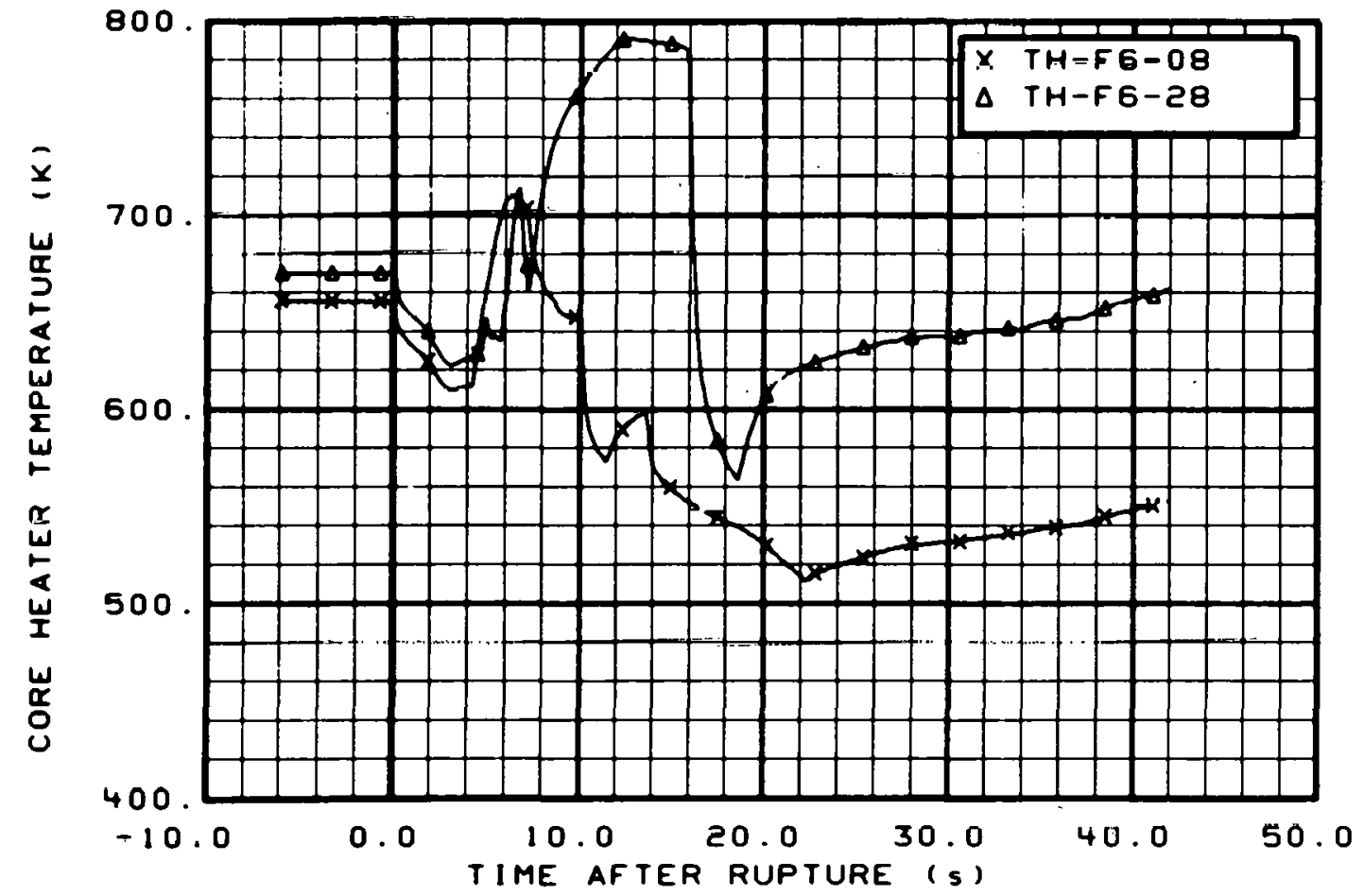

Fig. 120 Core heater temperature, Rod F-6 (TH-F6-08 and TH-F6-28), from -6 to $42 \mathrm{~s}$. 


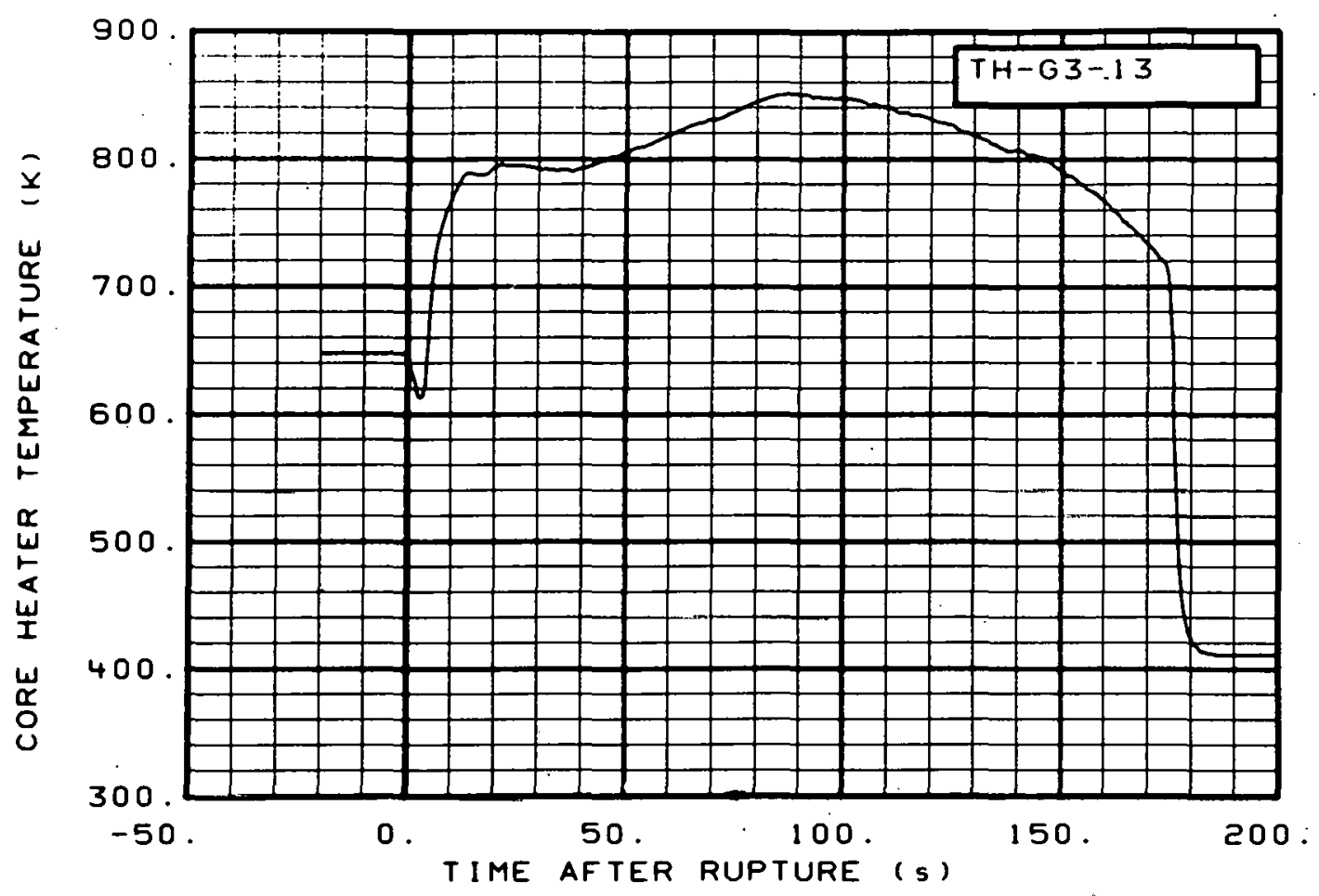

Fig. 121 Core heater temperature, Rod G-3 (TH-G3-13), from -20 to 200. s.

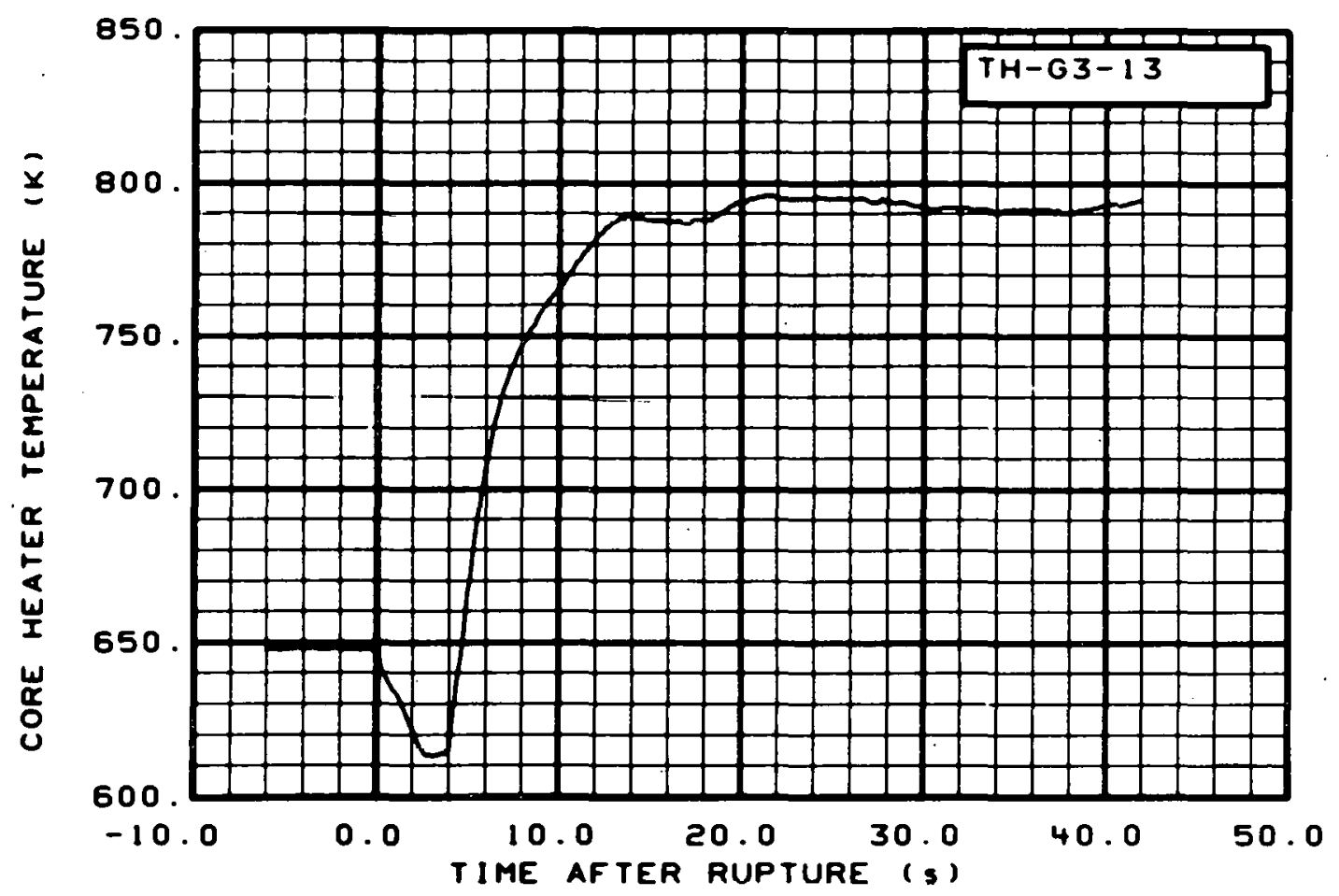

Fig. 122 Core heater temperature, Rod G-3 (TH-G3-13), from -6 to $42 \mathrm{~s}$. 


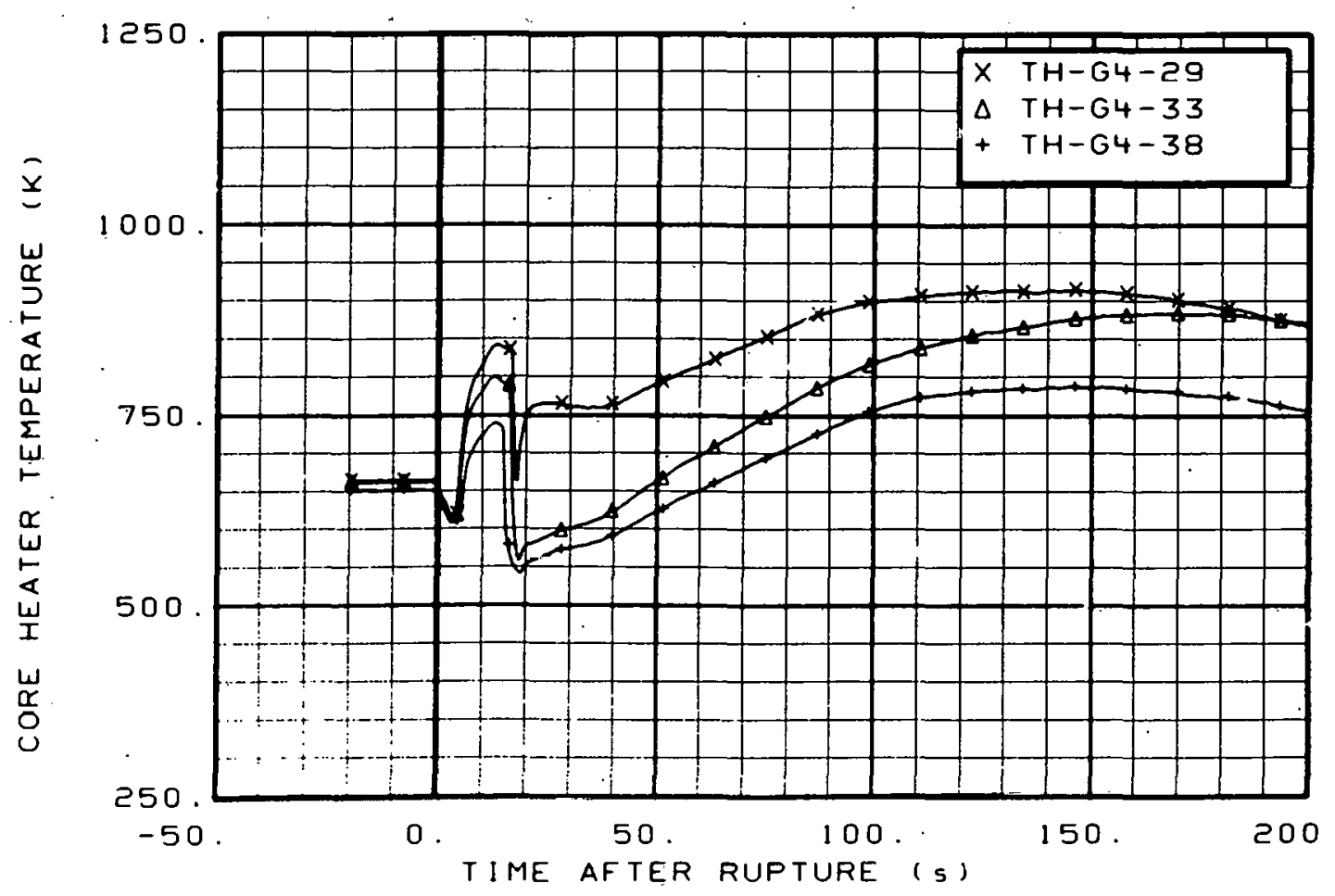

Fig. 123 Core heater temperature, Rod G-4 (TH-G4-29, TH-G4-33, and TH-G4-38), from -20 to $200 \mathrm{~s}$.

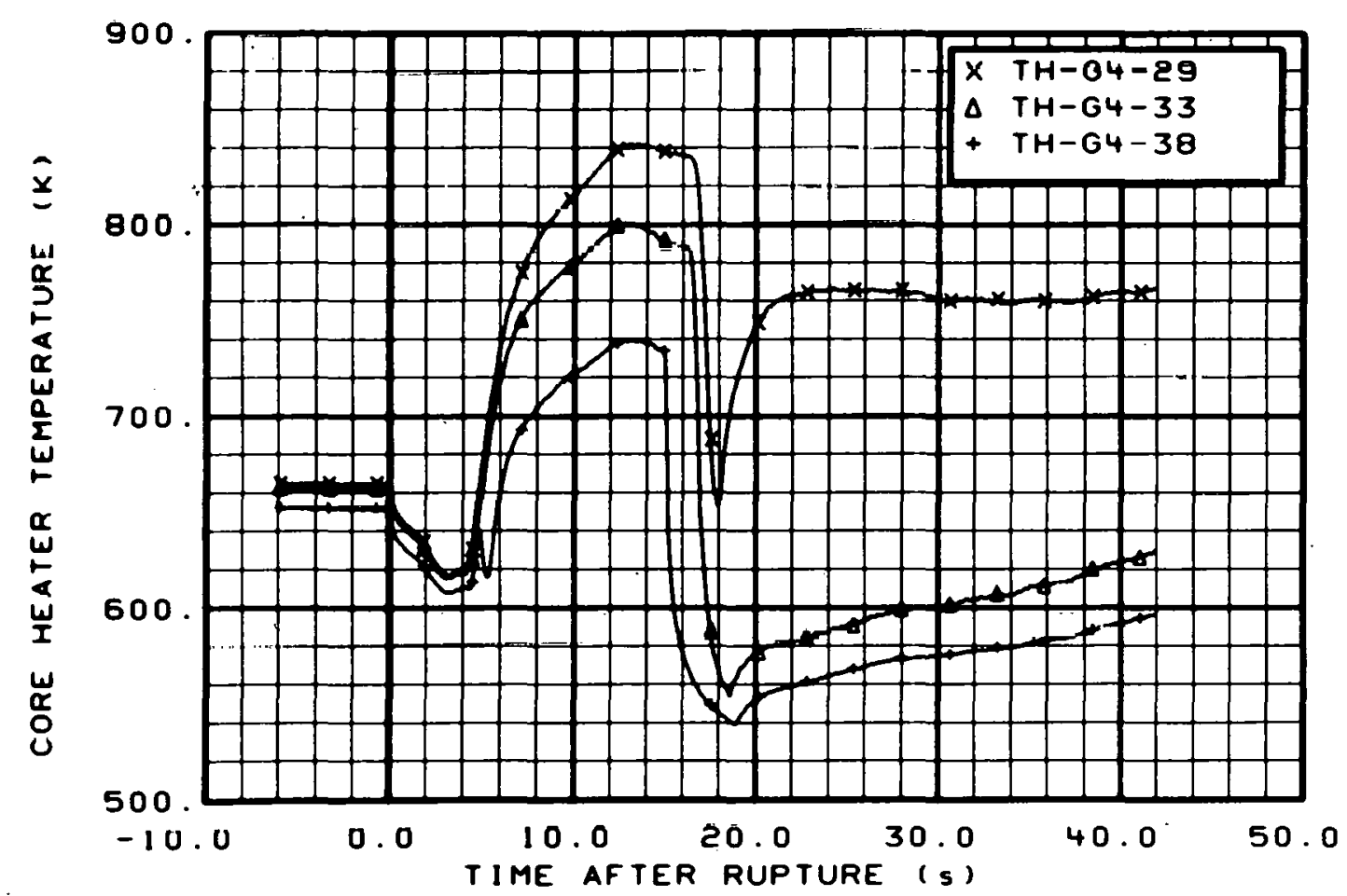

Fig. 124 Core heater temperature, Rod G-4 (TH-G4-29, TH-G4-33, and TH-G4-38), from -6 to $42 \mathrm{~s}$. 


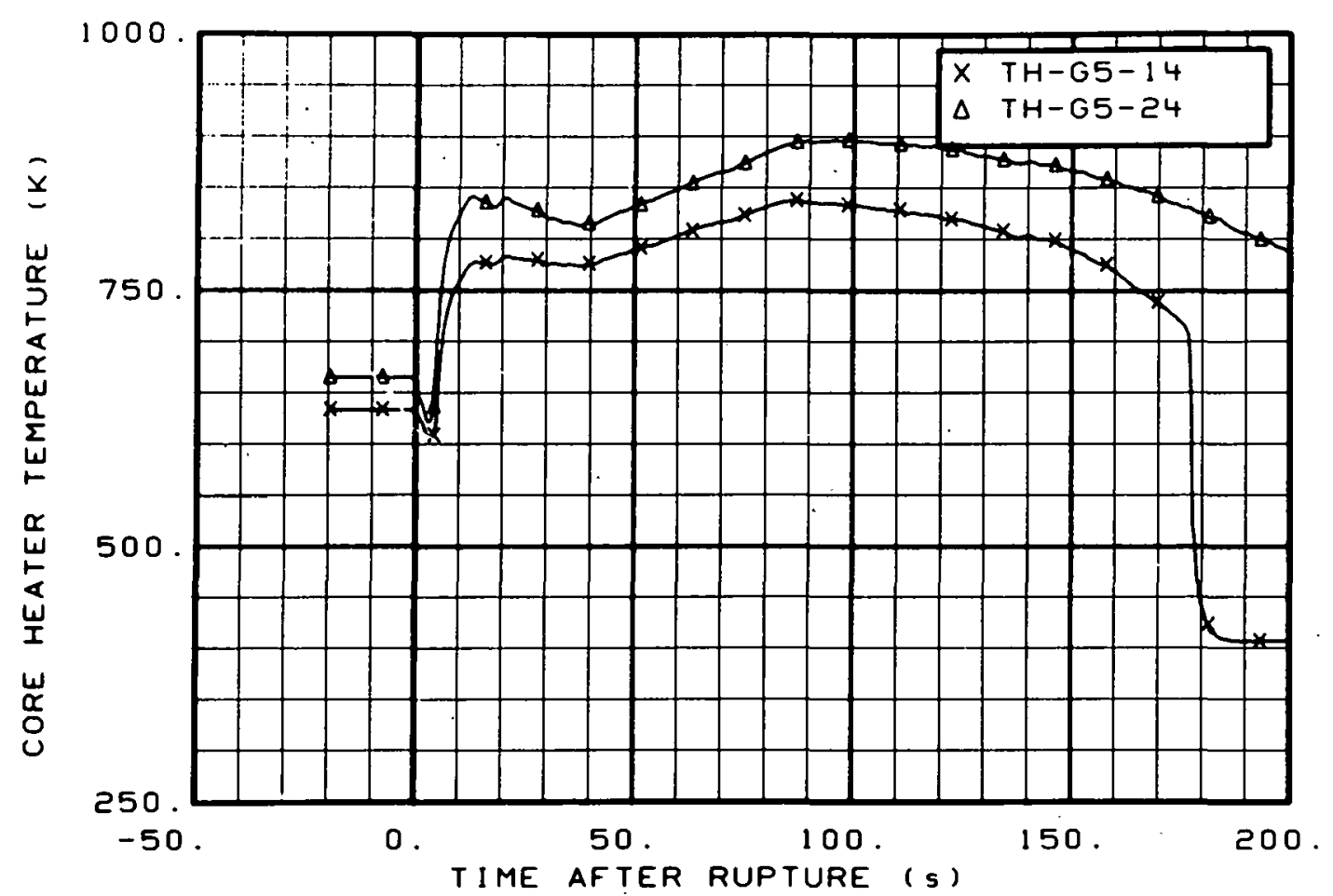

Fig. 125 Core heater temperature, Rod G-5 (TH-G5-14 and TH-G5-24), from -20 to $200 \mathrm{~s}$.

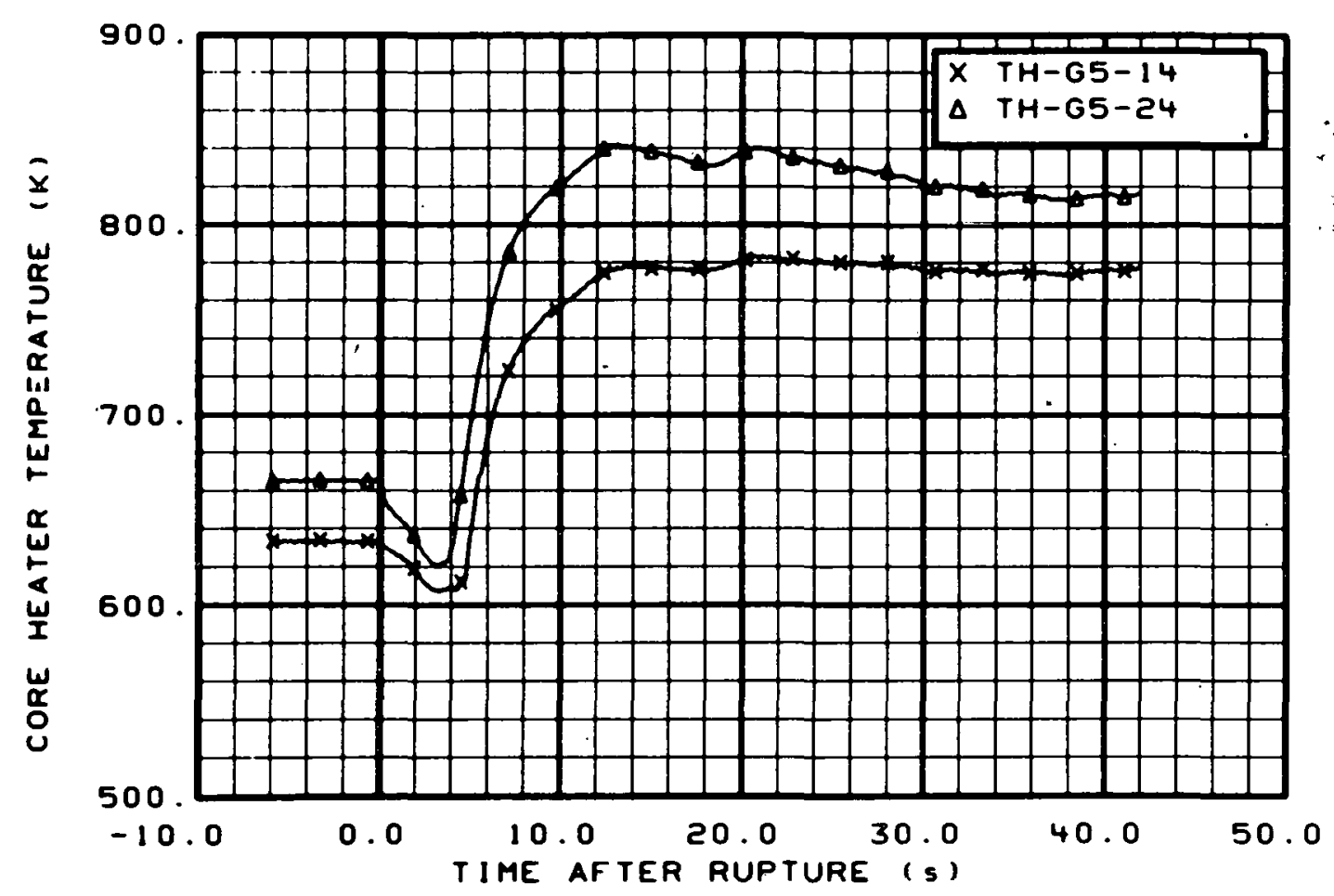

Fig. 126 Core heater temperature, Rod G-5 (TH-G5-14 and TH-G5-24), from -6 to $42 \mathrm{~s}$. 


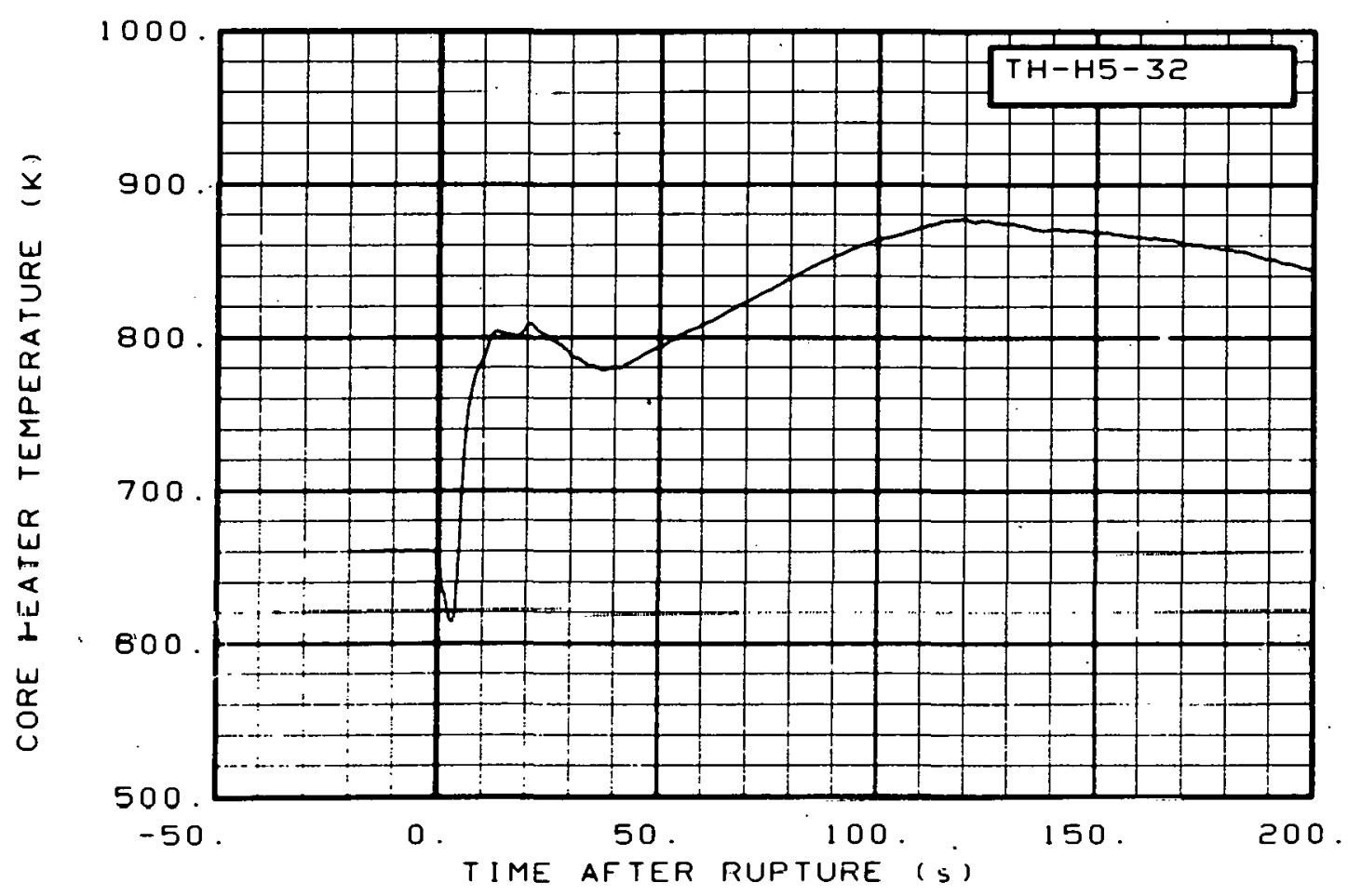

Fig. 127 Core heater temperature, Rod H-5 (TH-H5-32), from -20 to $200 \mathrm{~s}$.

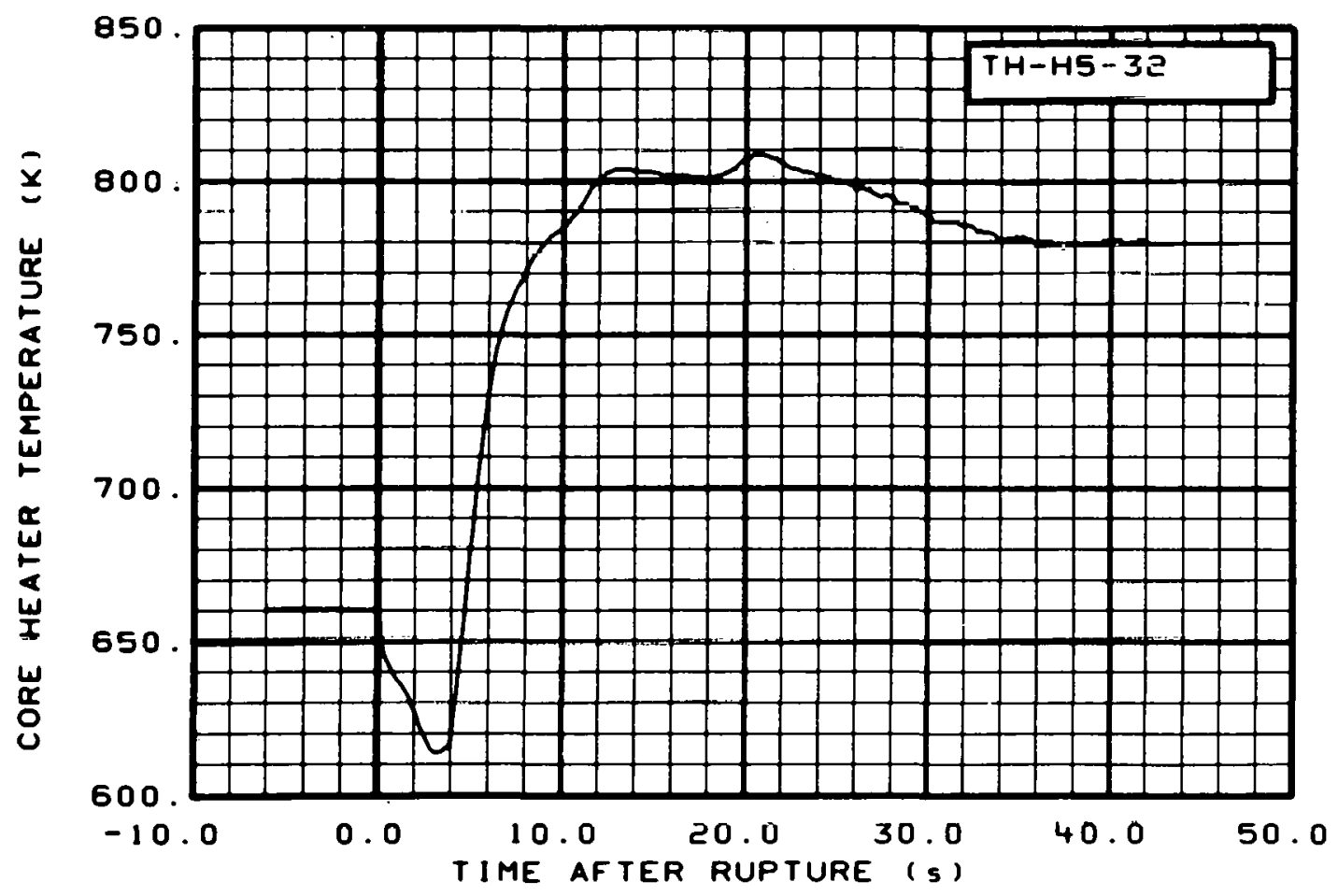

Fig. 128 Core heater temperature, Rod H-5 (TH-H5-32), from -6 to $42 \mathrm{~s}$. 


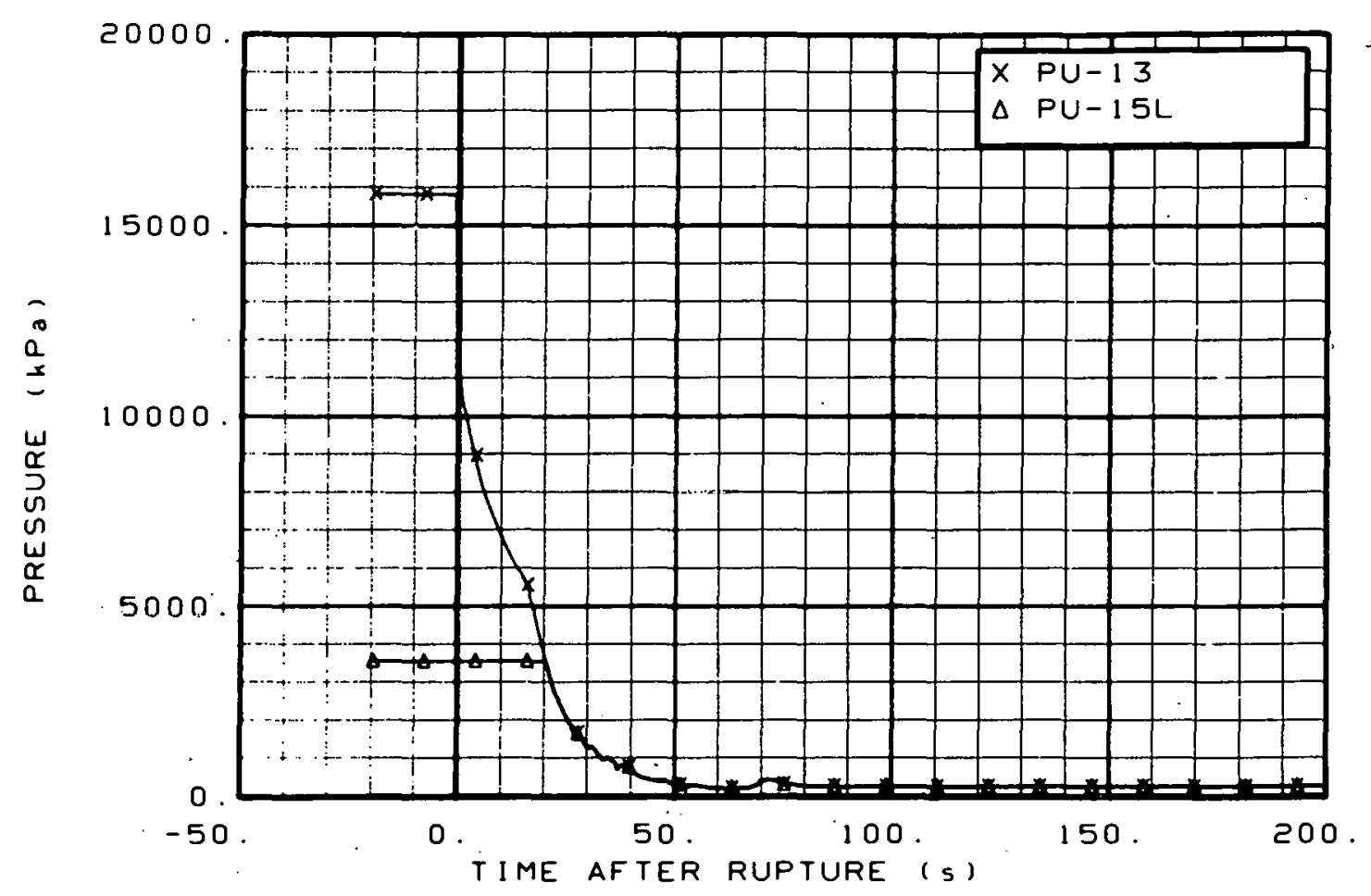

Fig. 129 Pressure in intact loop (PU-13 and PU-15L), from -20 to $200 \mathrm{~s}$.

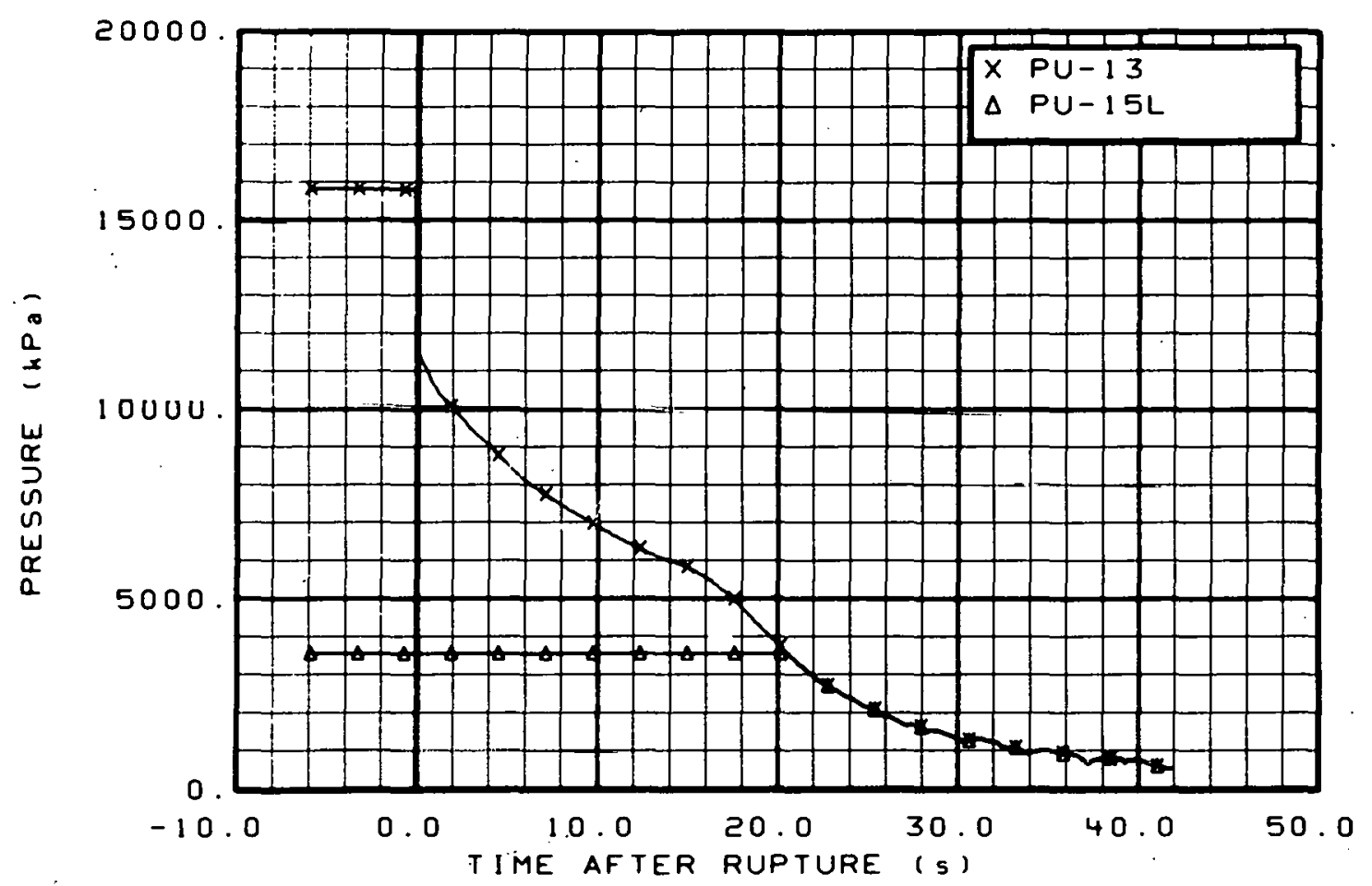

Fig. 130 Pressure in intact loop (PU-13 and PU-15L), from -6 to $42 \mathrm{~s}$. 


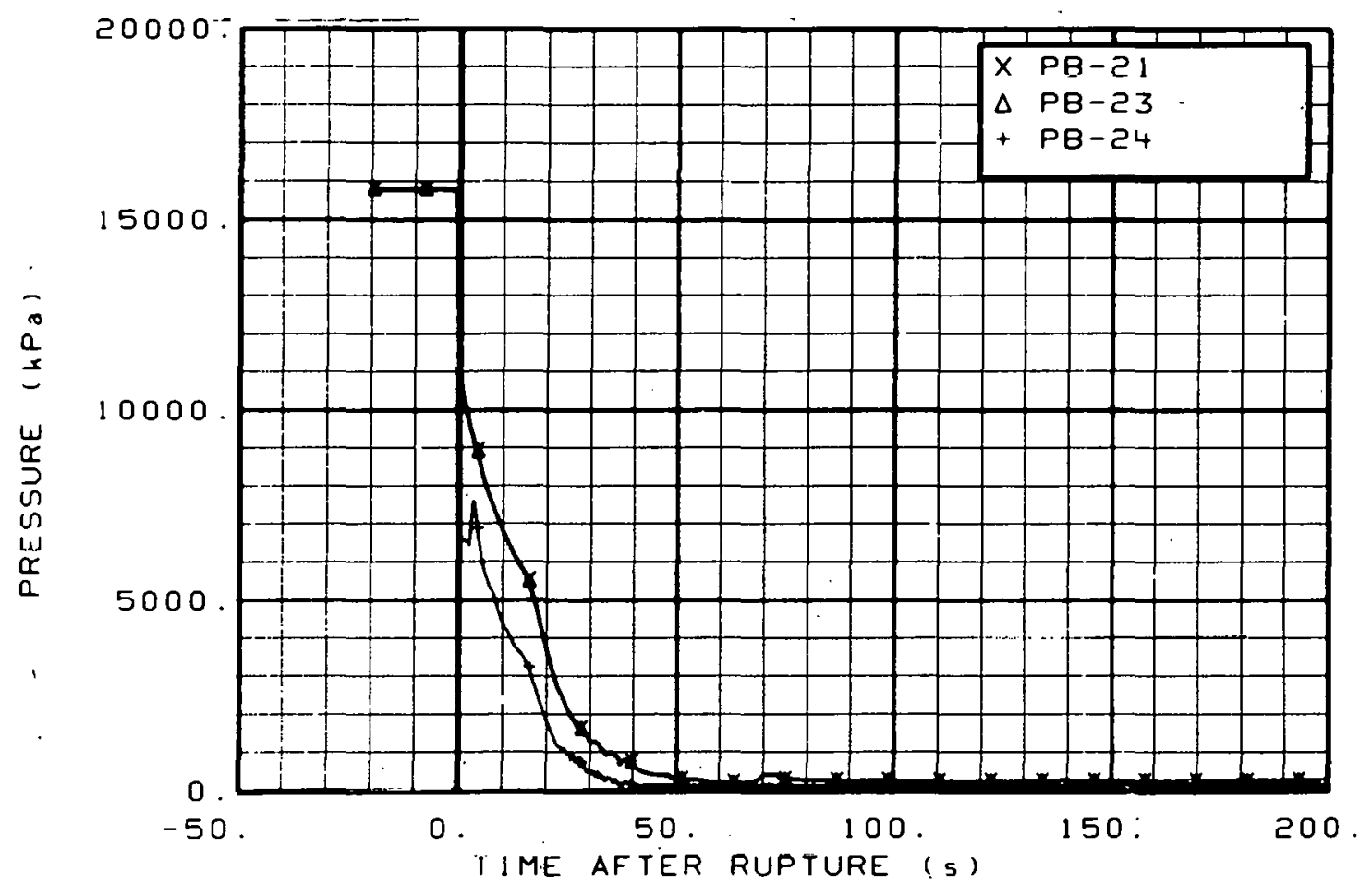

Fig. 131 Pressure in broken loop, vessel side (PB-21, PB-23, and PB-24), from -20 to $200 \mathrm{~s}$.

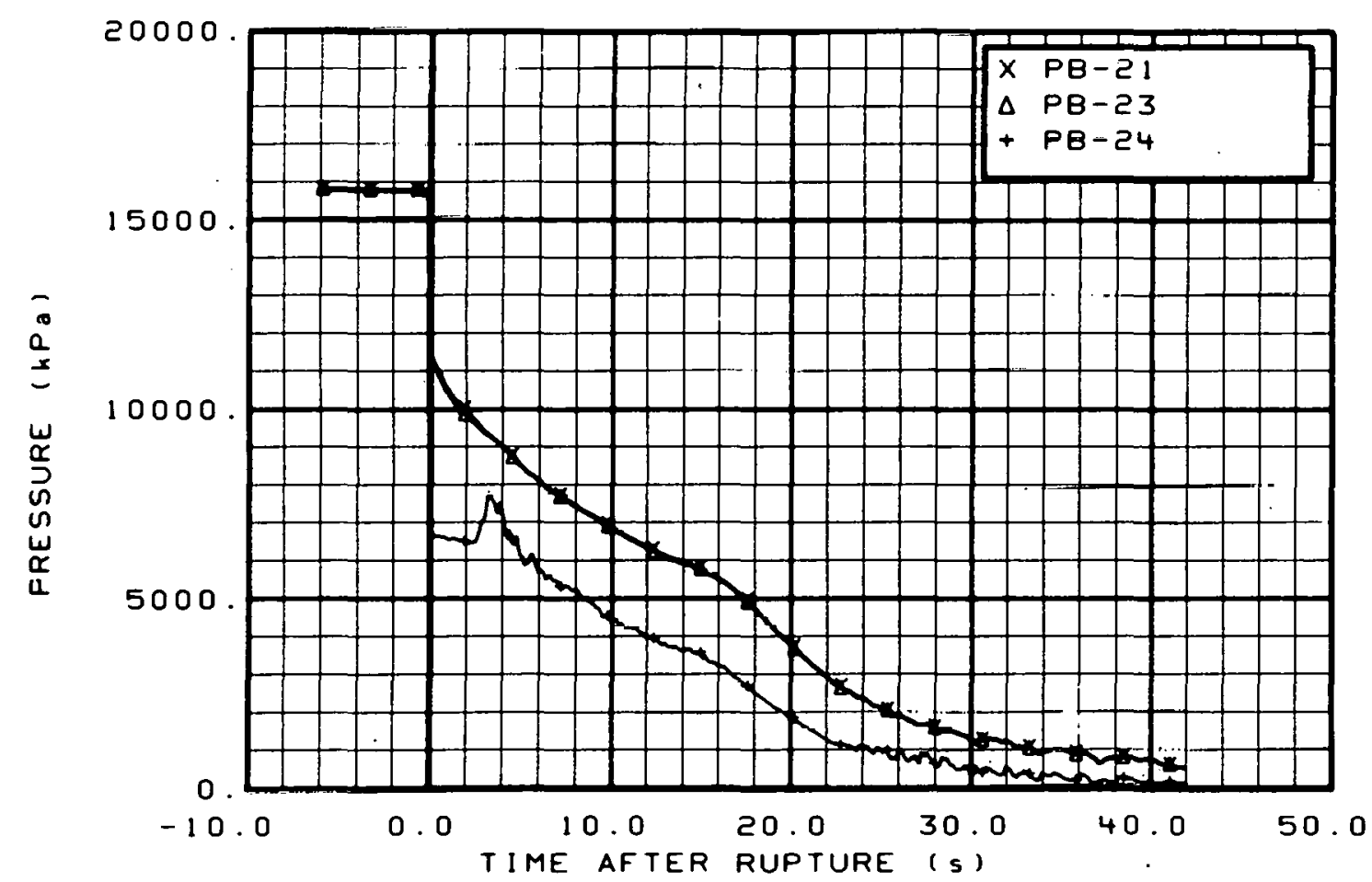

Fig. 132 Pressure in broken loop, vessel side (PB-21, PB-23, and PB-24), from -6 to $42 \mathrm{~s}$. 


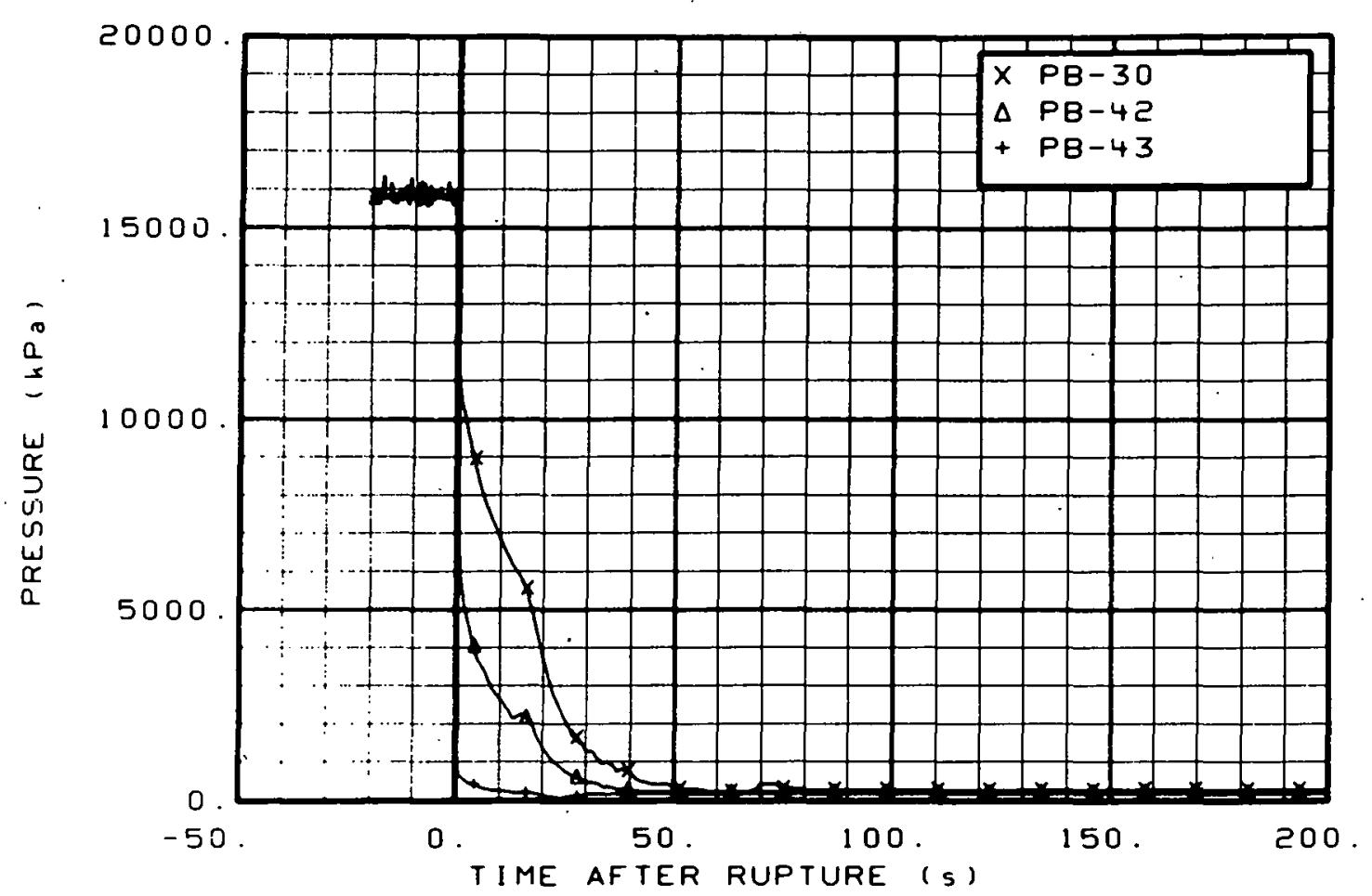

Fig. 133 Pressure in broken loop, pump side (PB-30, PB-42, and PB-43), from -20 to $200 \mathrm{~s}$.

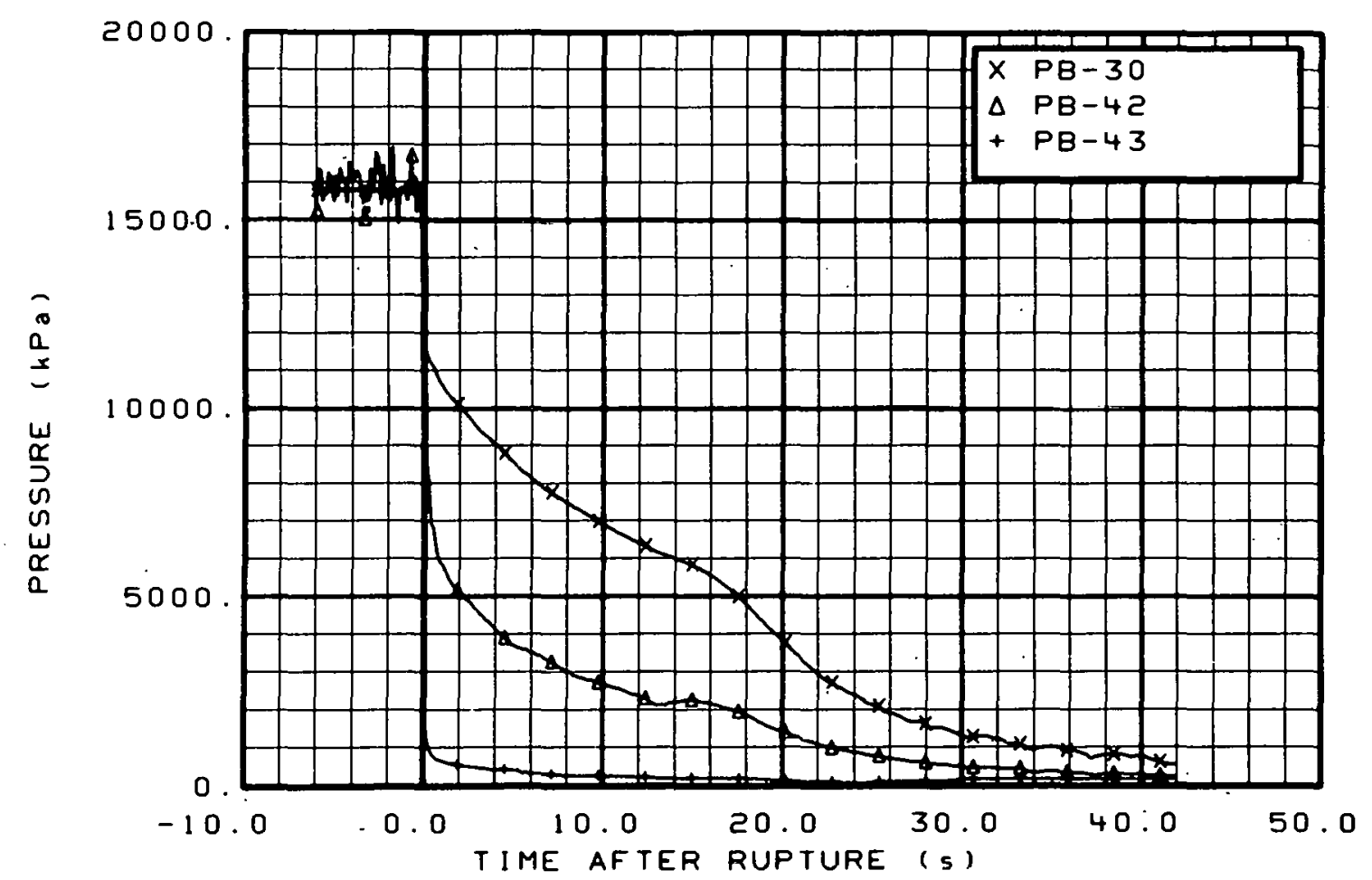

Fig. 134 Pressure in broken loop, pump side (PB-30, PB-42, and PB-43), from -6 to $42 \mathrm{~s}$. 


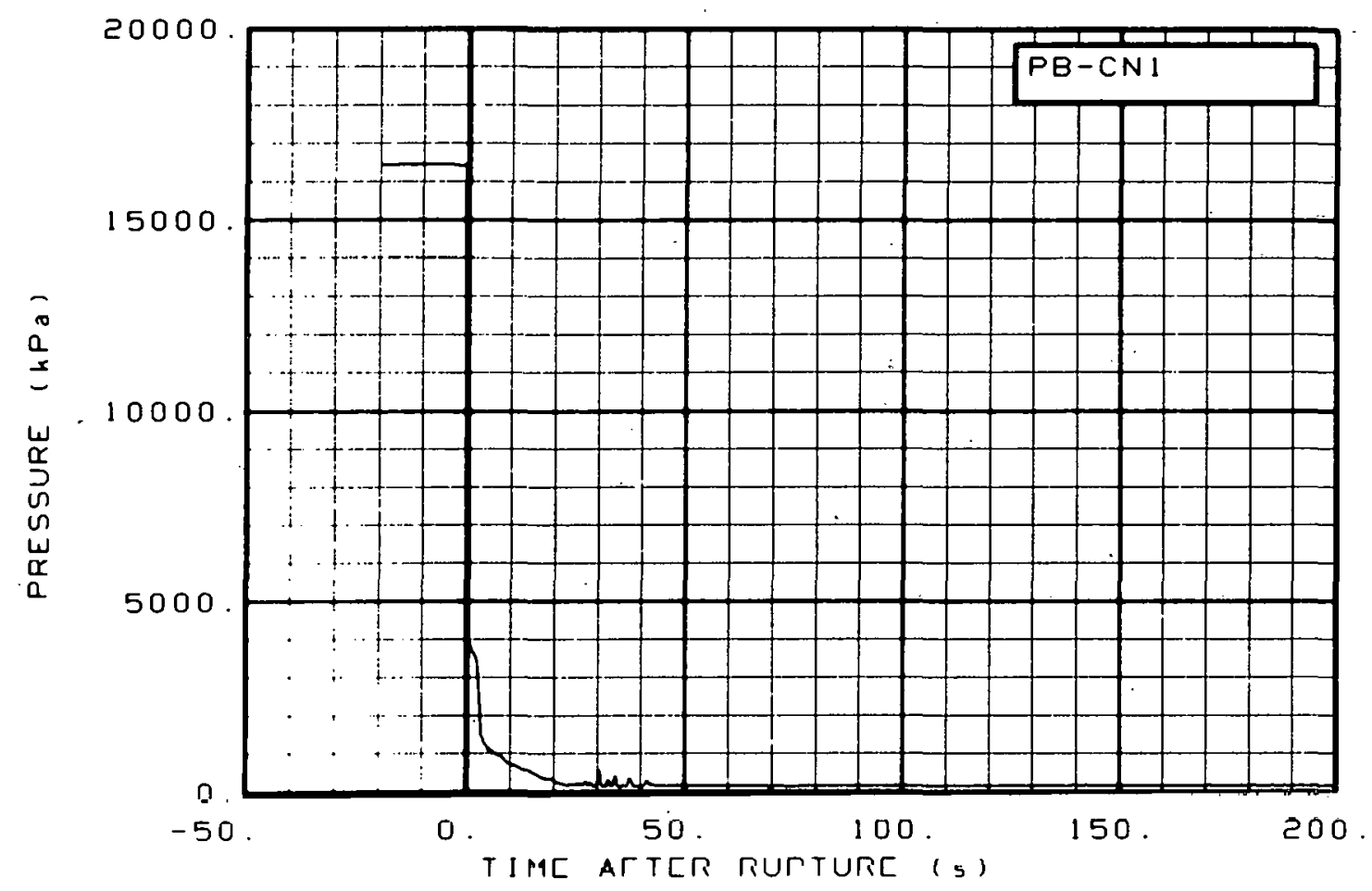

Fig. 135 Pressure in broken loop, vessel side ( $P B-C N 1$ ), from -20 to $200 \mathrm{~s}$.

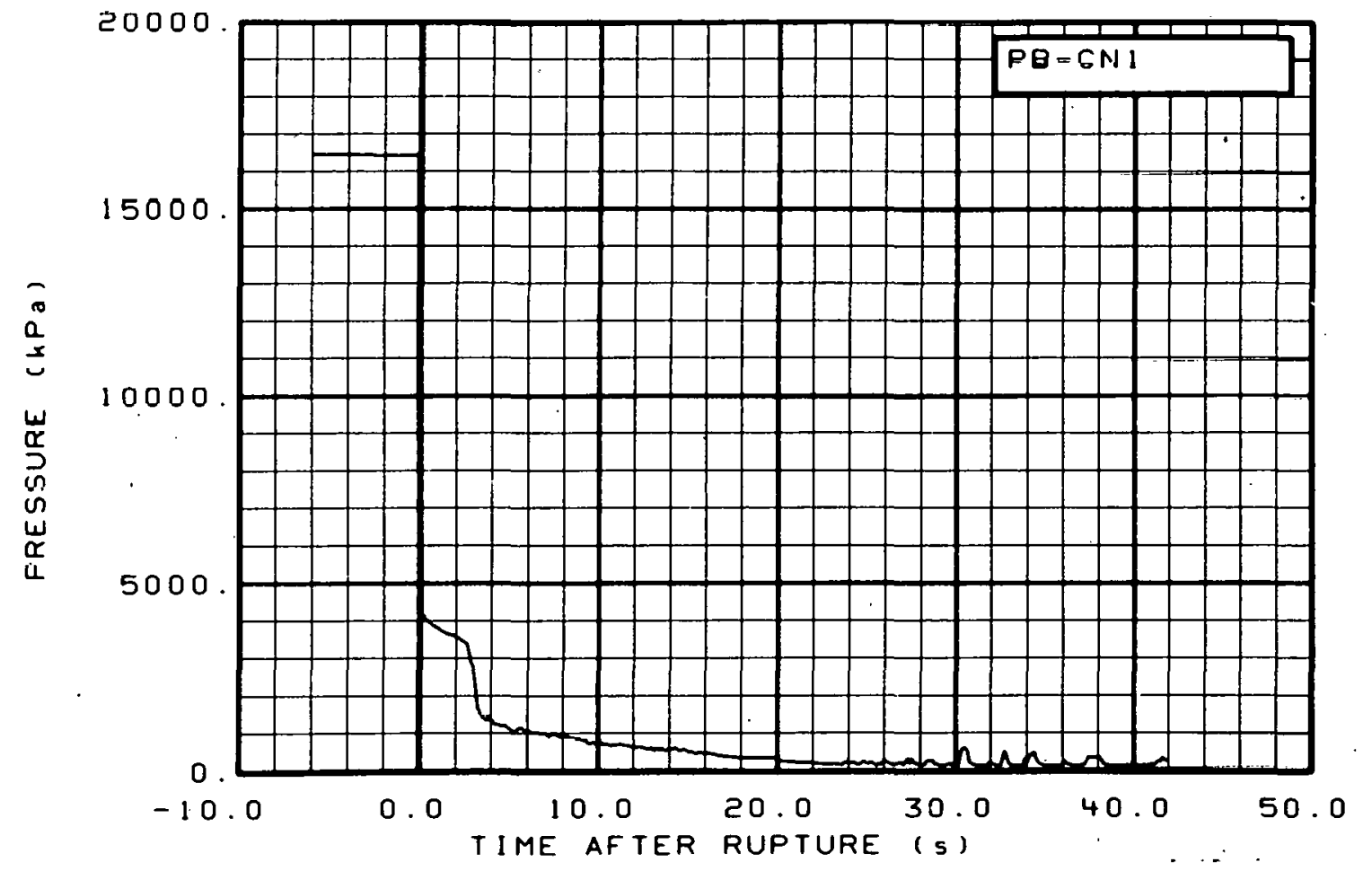

Fig. 136 Pressure in broken loop, vessel side (PB-CN1), from -6 to $42 \mathrm{~s}$. 


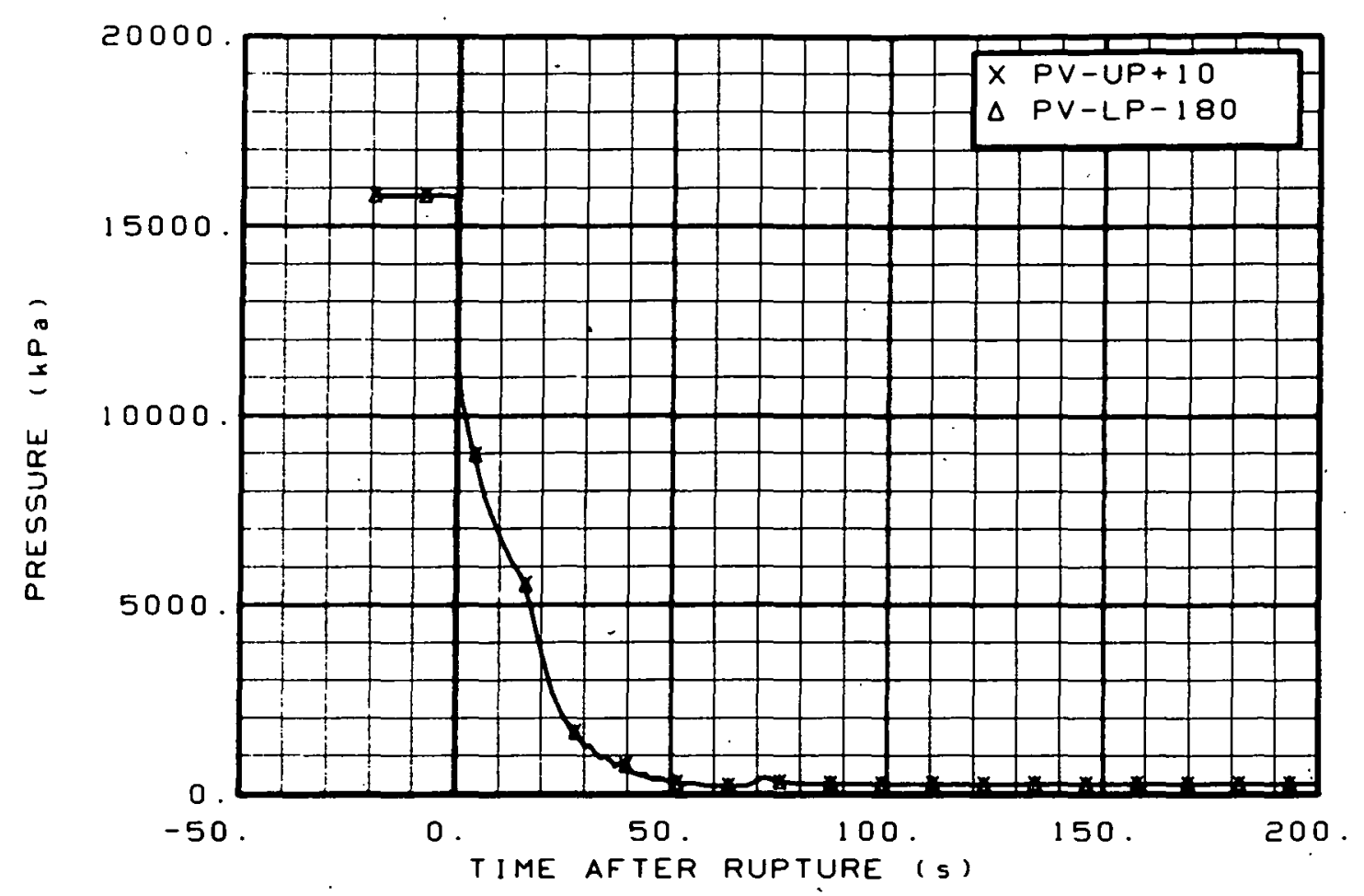

Fig. 137 Présure in vessel (PV-UP+10 and PV-LP-180), from -20 to $200 \mathrm{~s}$.

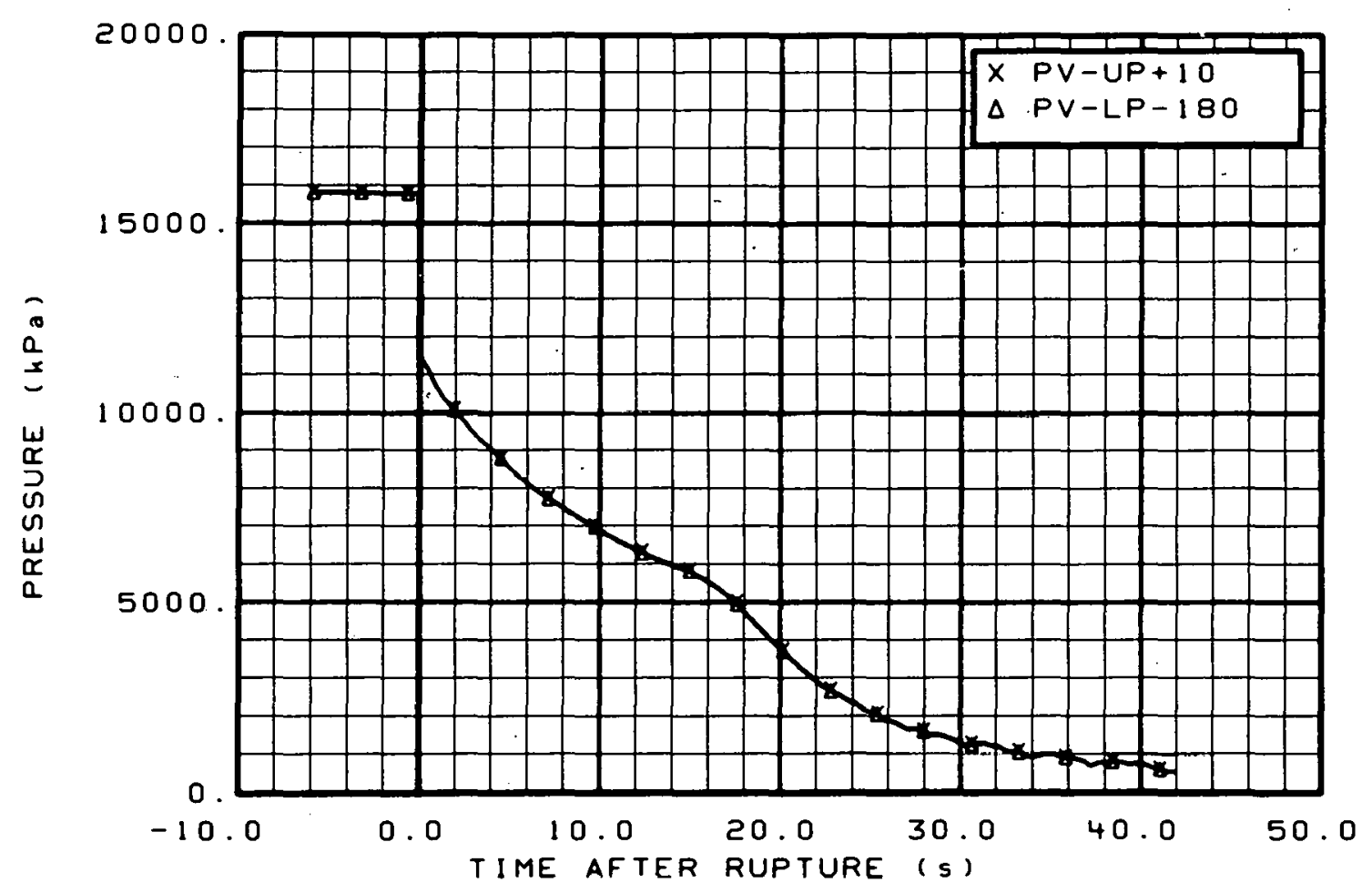

Fig. 138 Pressure in vessel (PV-UP+10 and PV-LP-180), from -6 to $42 \mathrm{~s}$. 


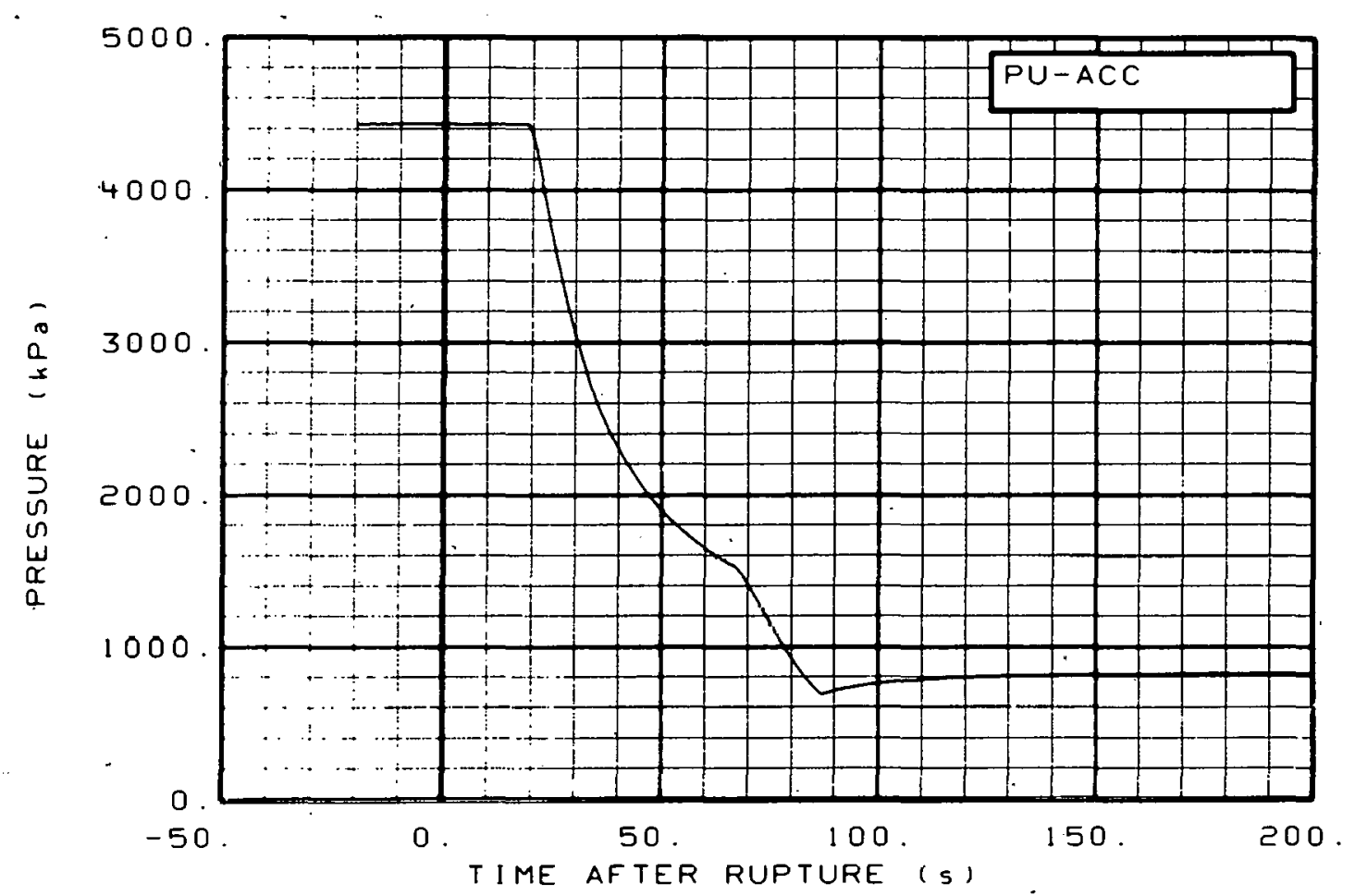

Fig. 139 Pressure in intact loop accumulator (PU-ACC), from -20 to $200 \mathrm{~s}$.

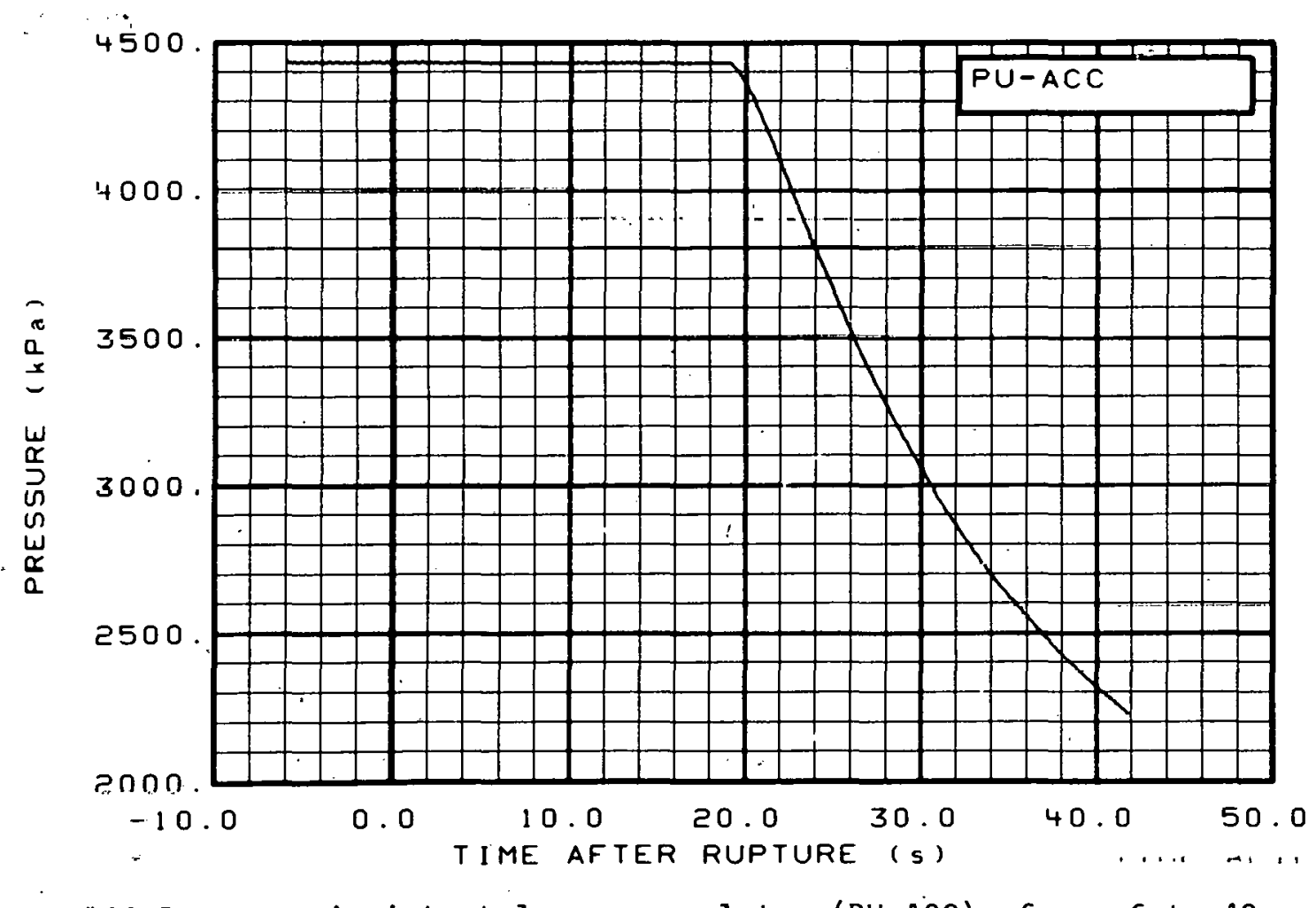

Fig. 140 Pressure in intact loop accumulator (PU-ACC), from -6 to $42 \mathrm{~s}$. 


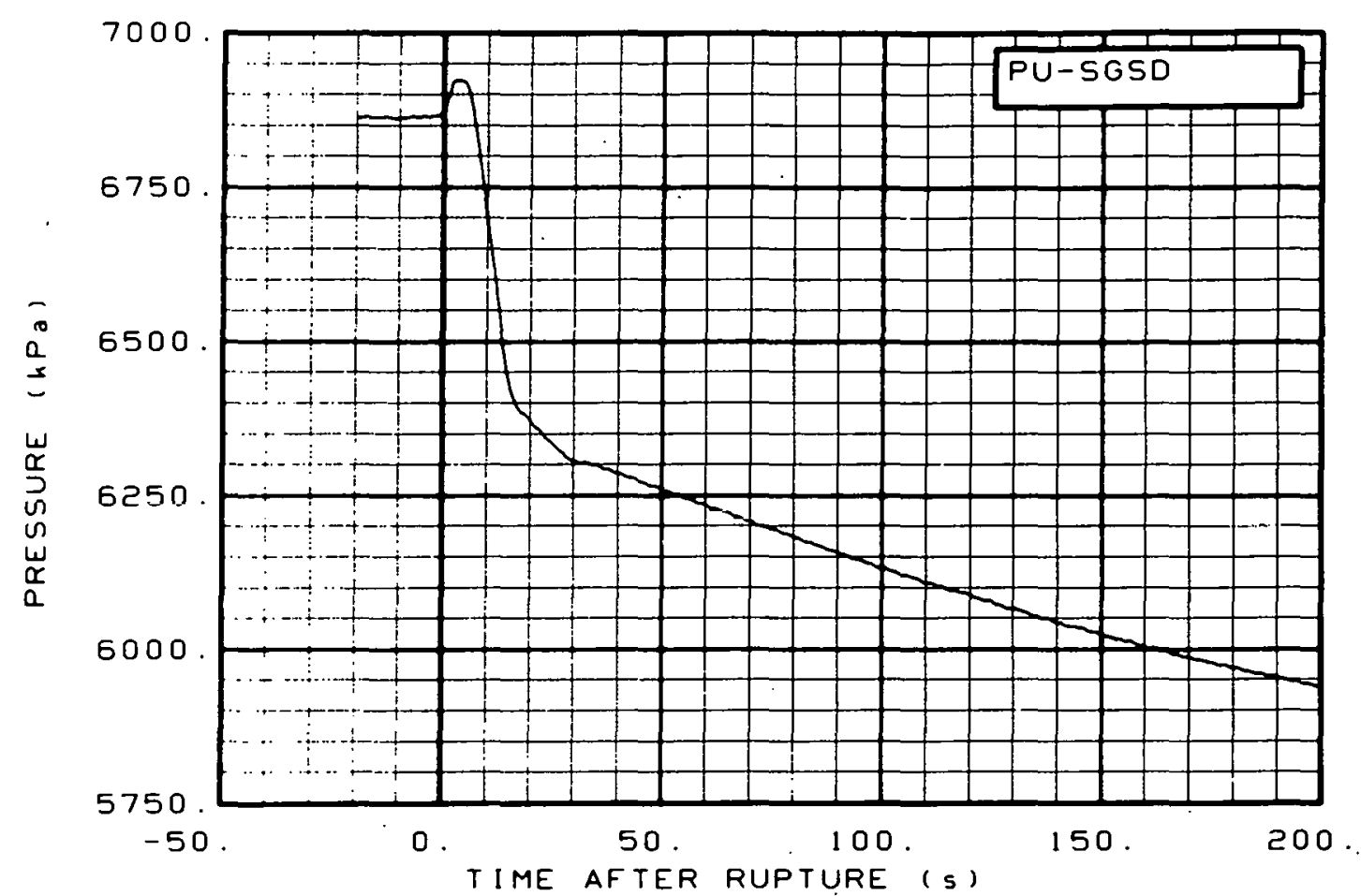

Fig. 141 Pressure in steam generator, secondary side (PU-SGSD), from -20 to $200 \mathrm{~s}$.

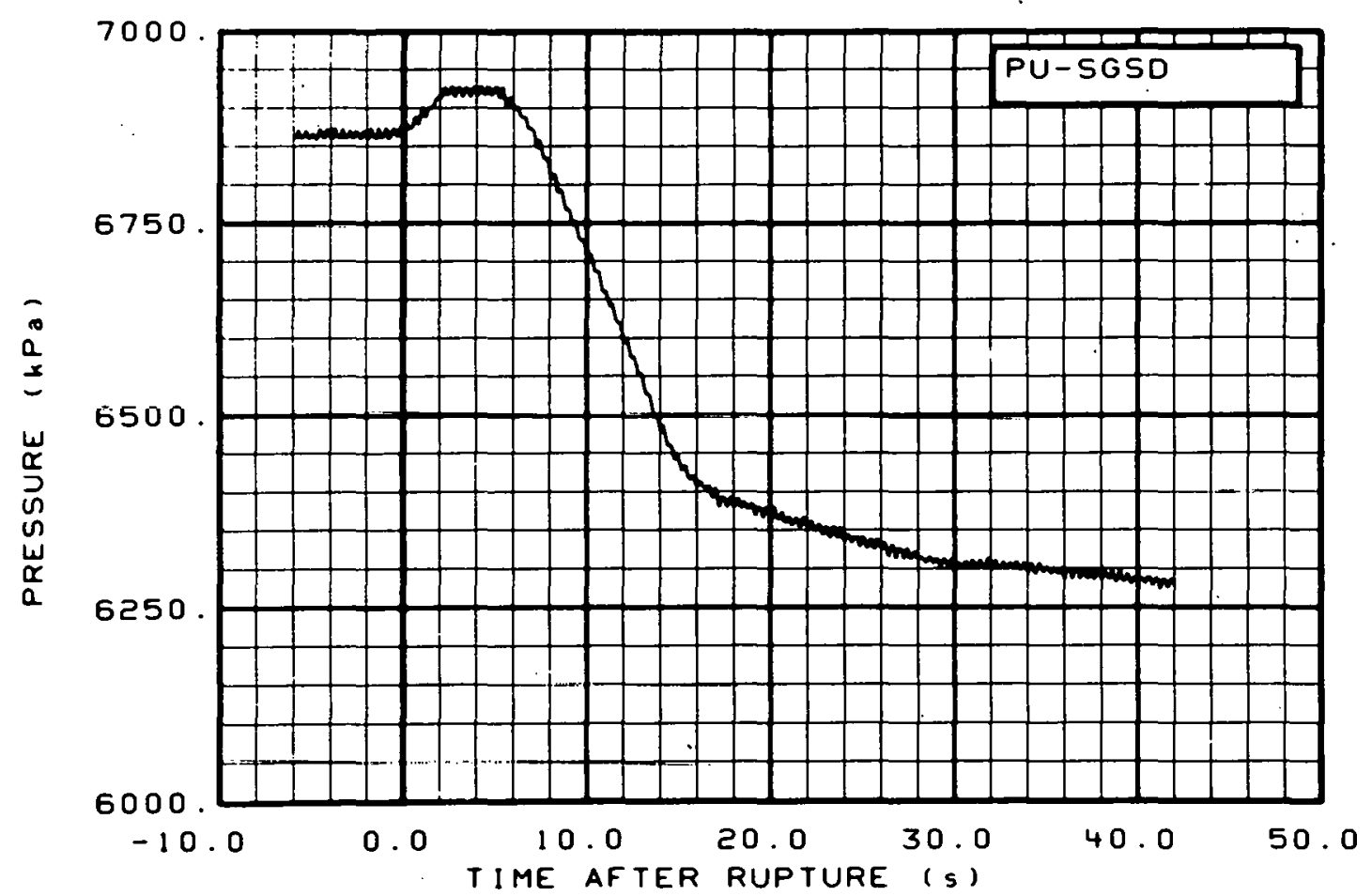

Fig. 142 Pressure in steam generator, secondary side (PU-SGSD), from -6 to $42 \mathrm{~s}$. 


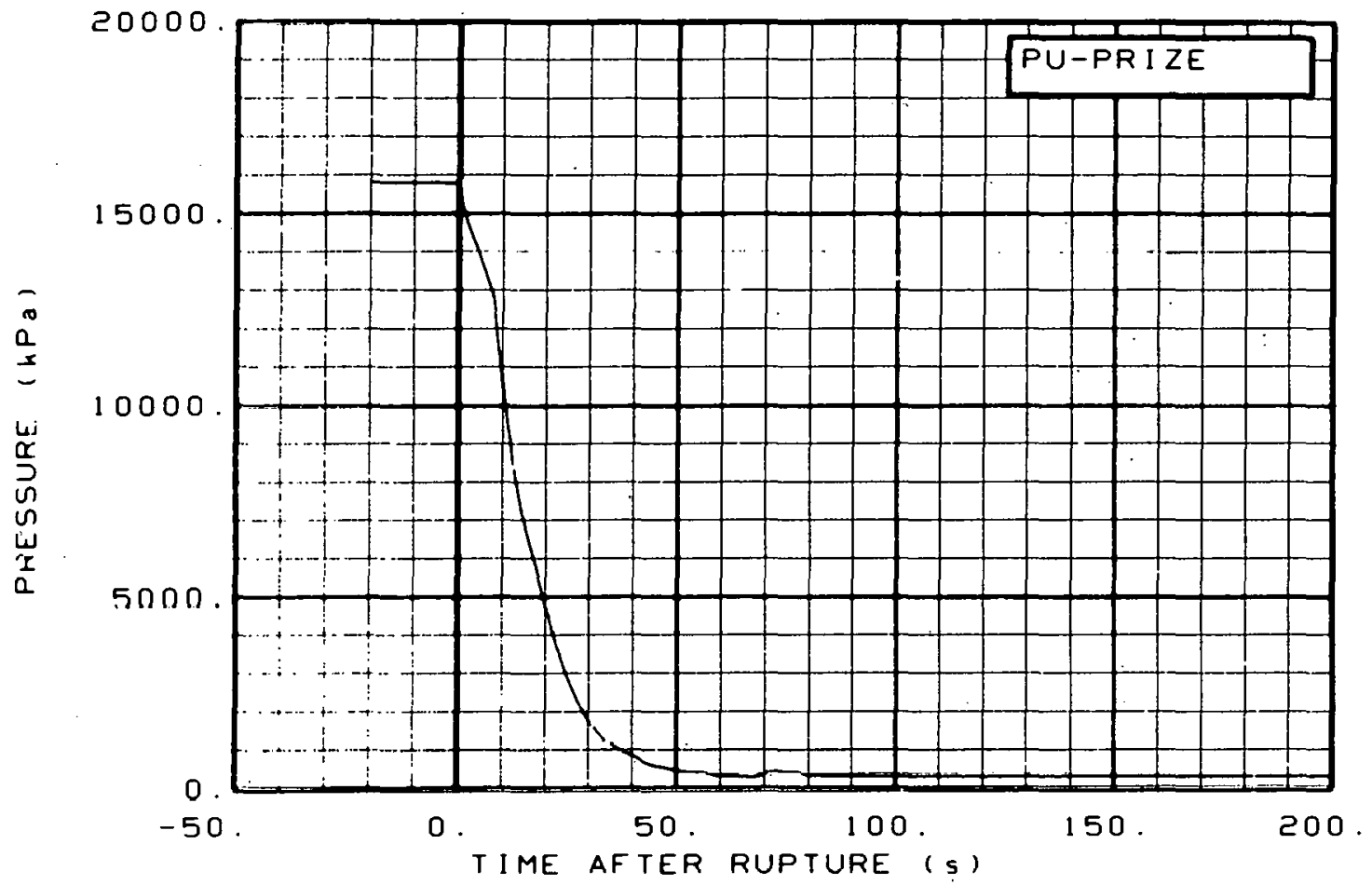

Fig. 143 Pressure in pressurizer.(PU-PRIZE), from -20 to $200 \mathrm{~s}$.

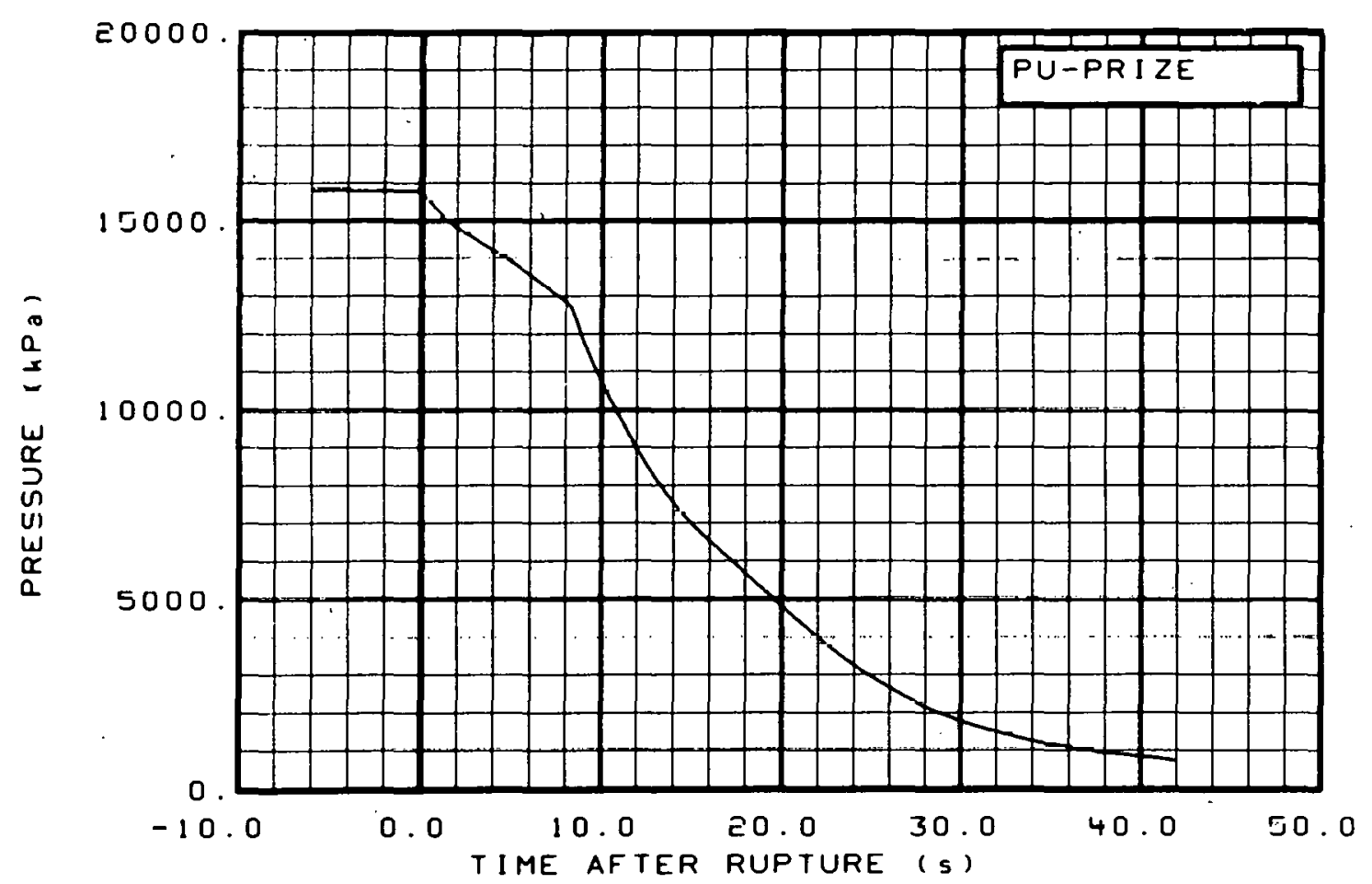

Fig. 144 Pressure in pressurizer (PU-PRIZE), from -6 to $42 \mathrm{~s}$. 


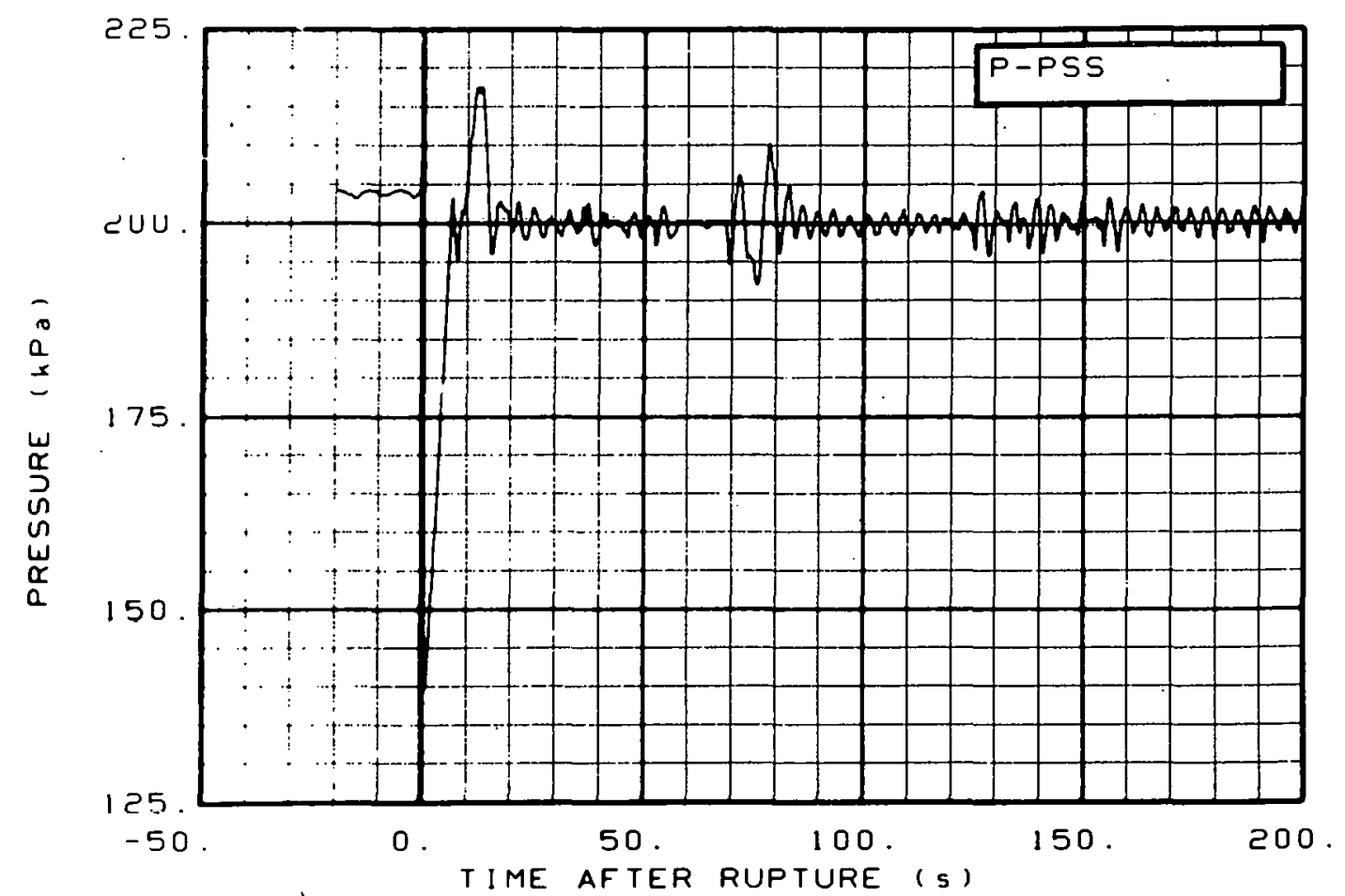

Fig. 145 Pressure in pressure suppression tank (P-PSS), from -20 to $200 \mathrm{~s}$.

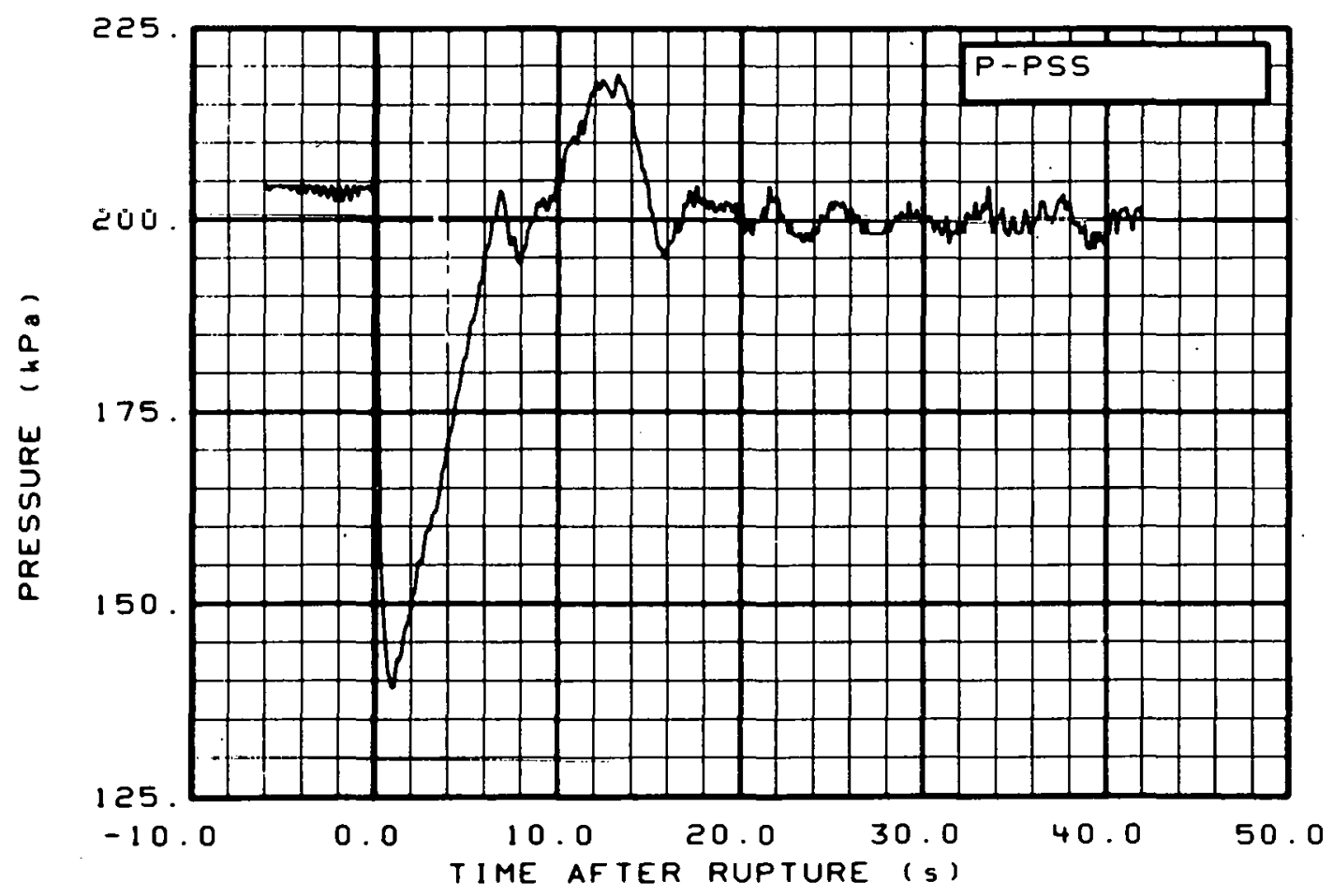

Fig. 146 Pressure in pressure suppression tank (P-PSS), from -6 to $42 \mathrm{~s}$. 


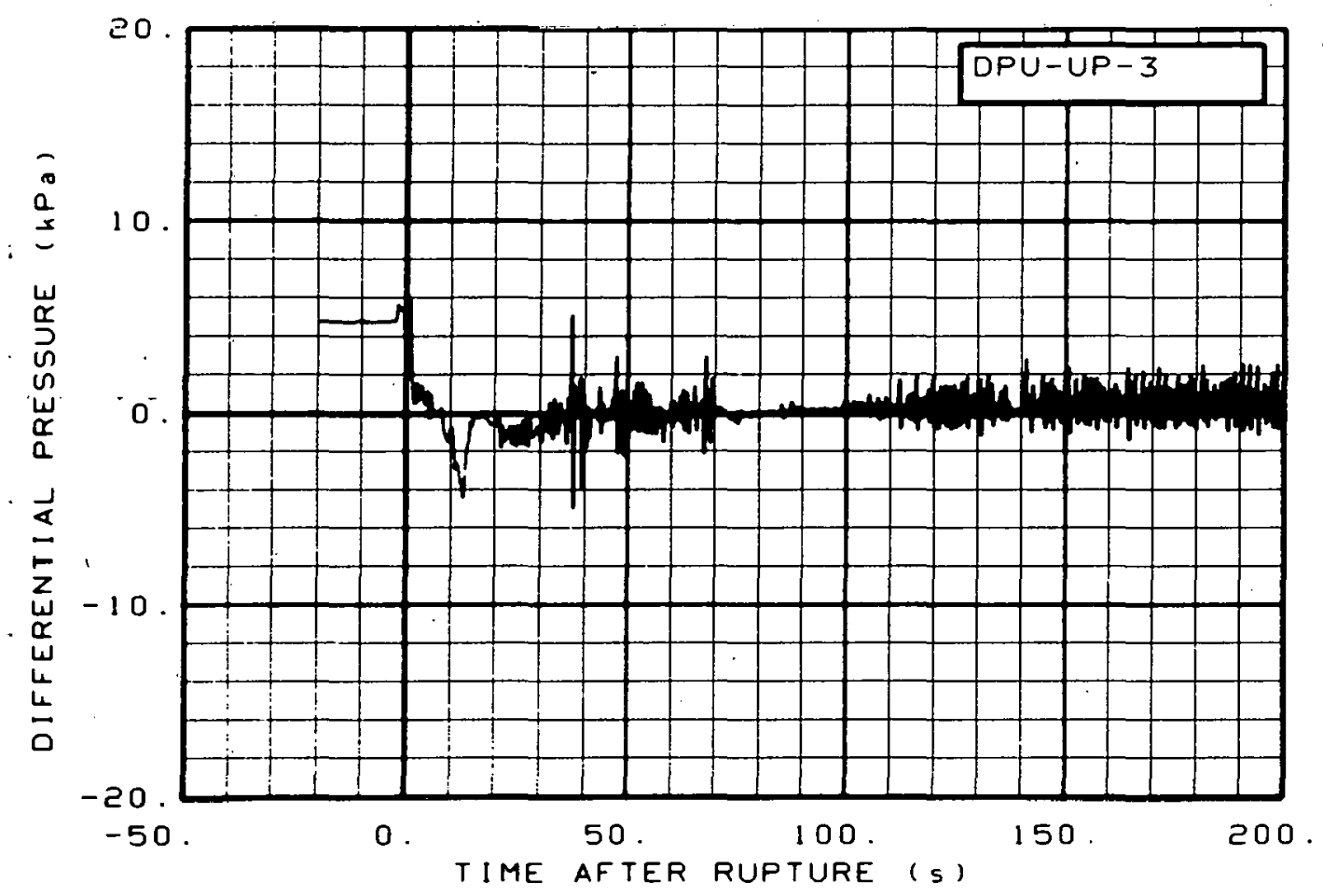

Fig. 147 Differential pressure in intact loop (DPU-UP-3), from -20 to $200 \mathrm{~s}$.

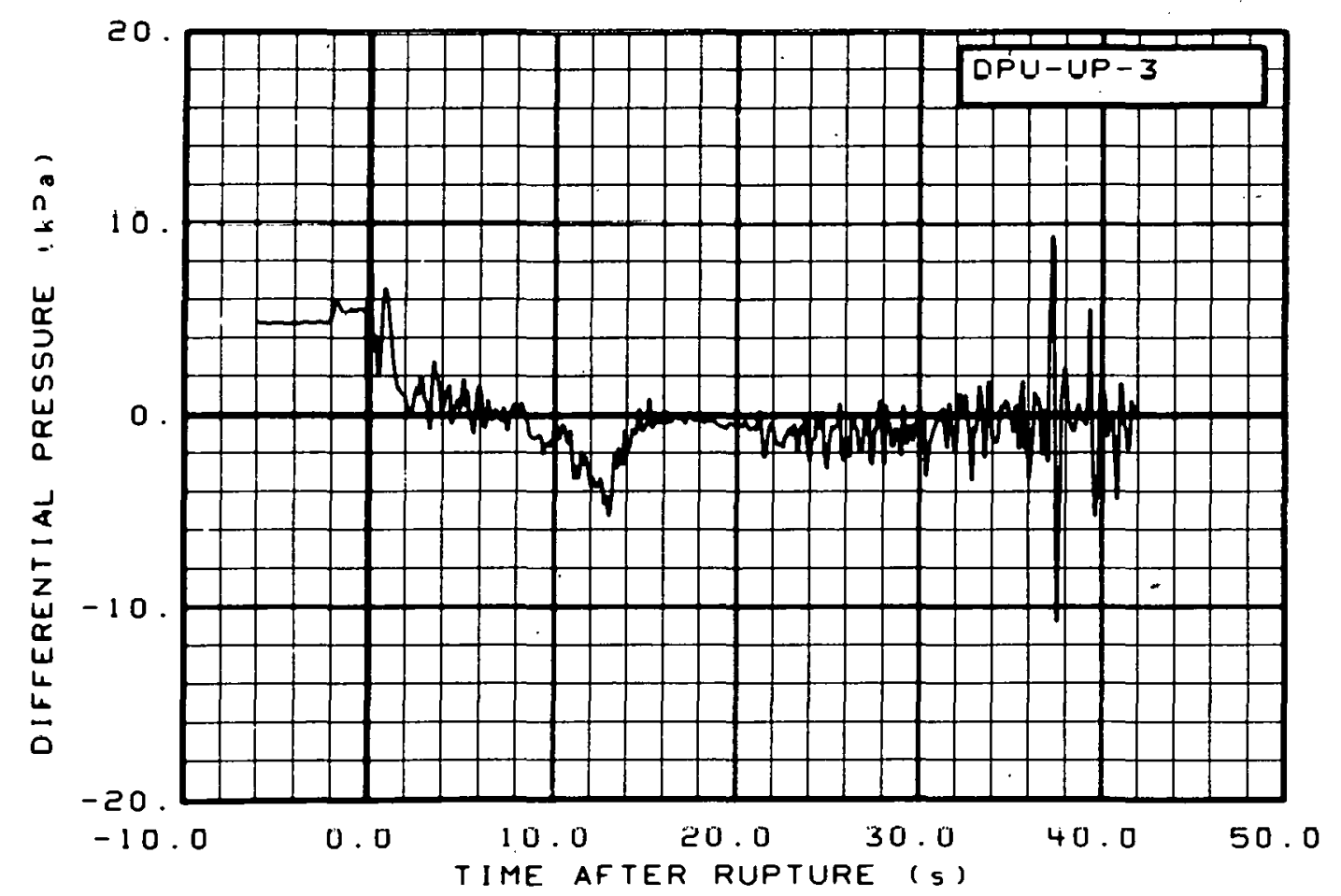

Fig:- 148 Differential pressure in intact loop (DPU-UP-3), from -6 to $42 \mathrm{~s}$. 


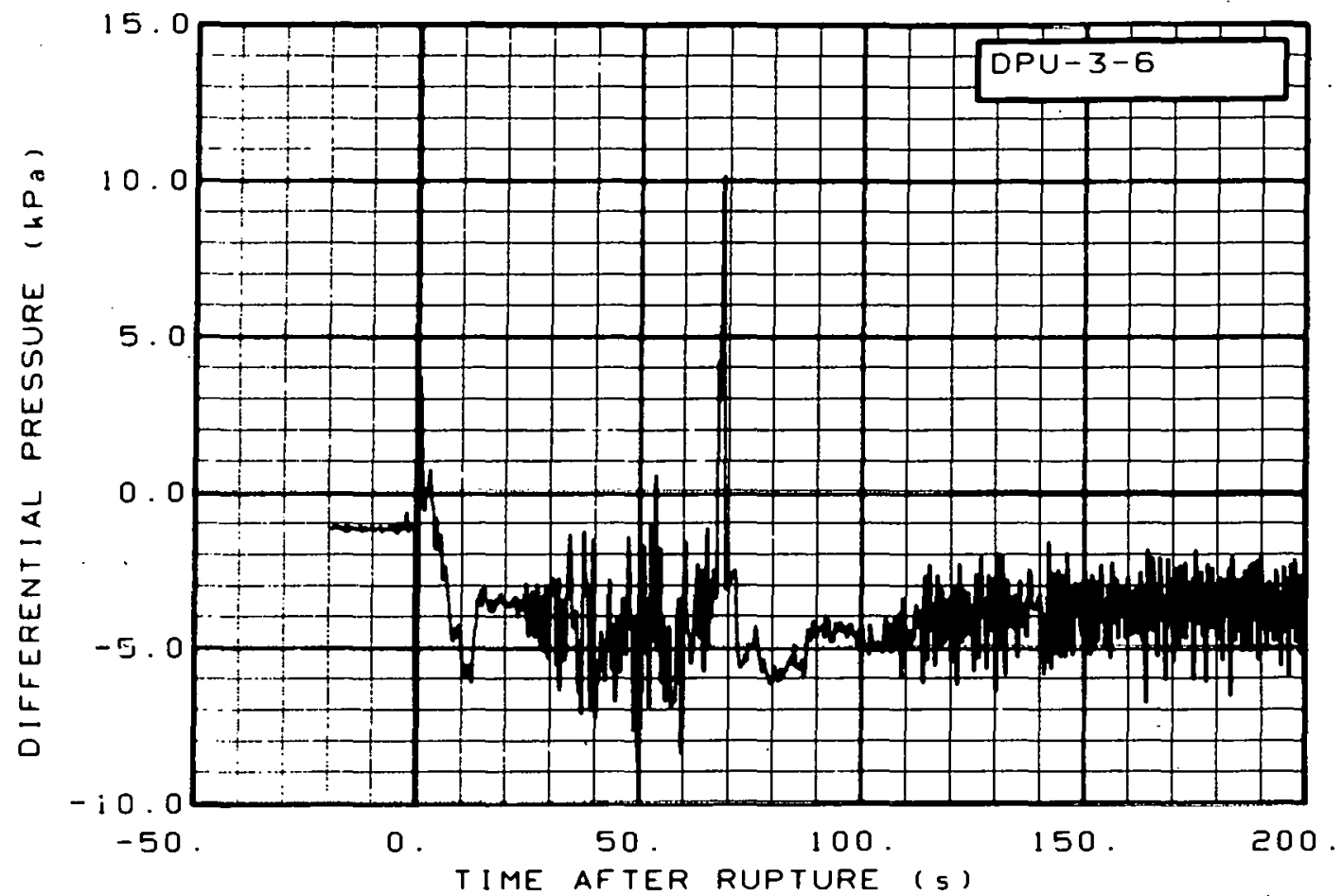

Fig. 149 Differential pressure in intact loop (DPU-3-6), from -20 to $200 \mathrm{~s}$.

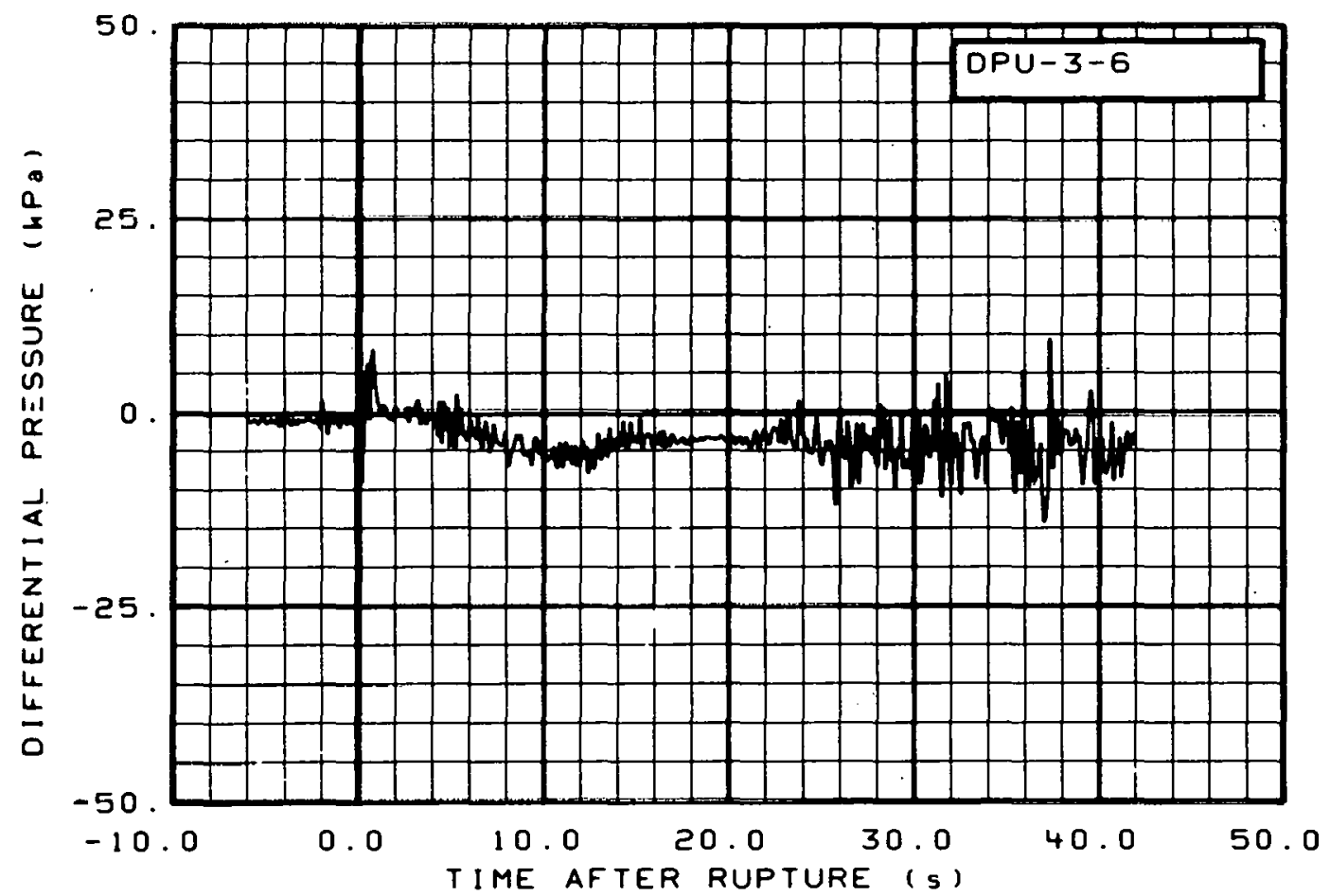

Fig. 150 Differential pressure in intact loop (DPU-3-6), from -6 to $42 \mathrm{~s}$. 


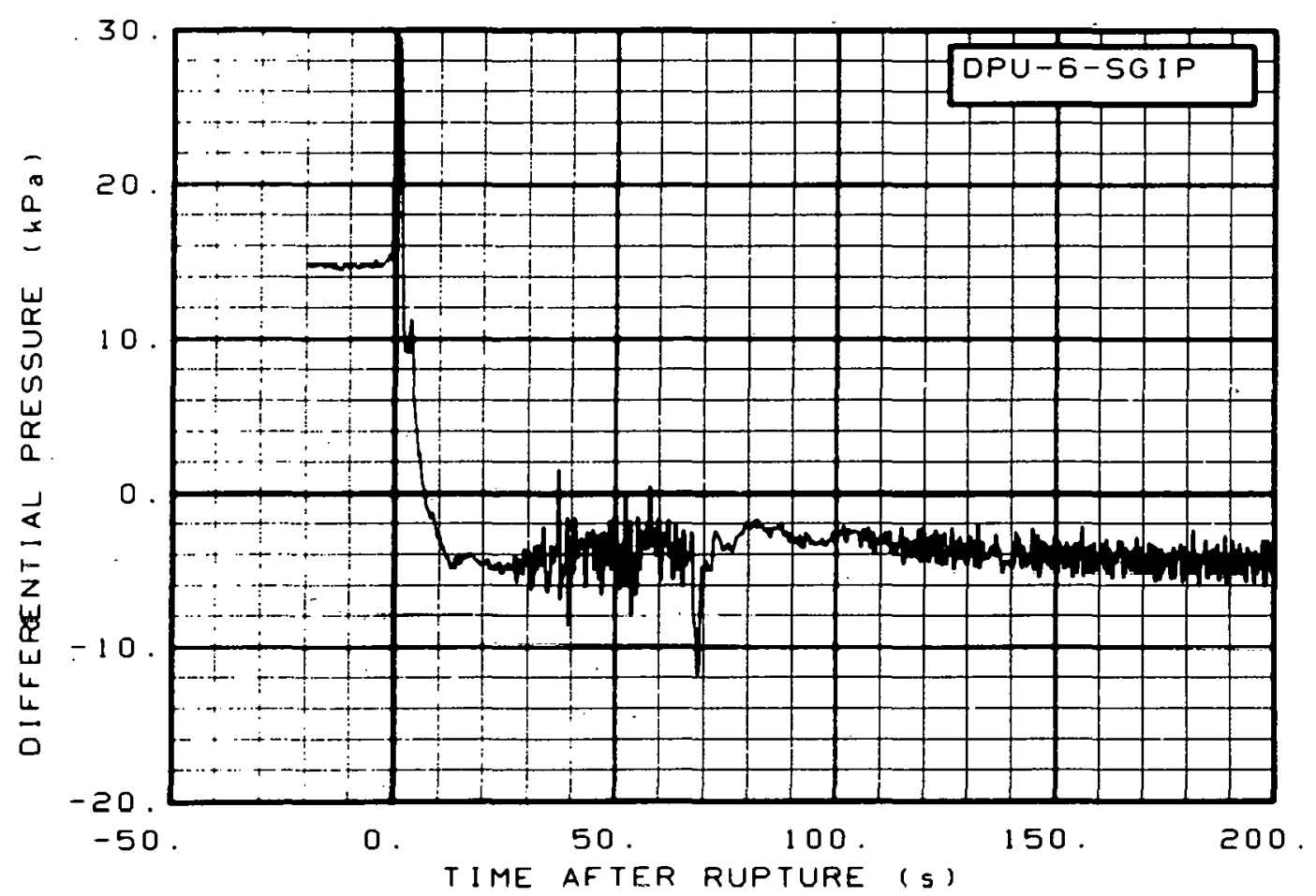

Fig. 151 Differential pressure in intact loop (DPU-6-SGIP), from -20 to $200 \mathrm{~s}$.

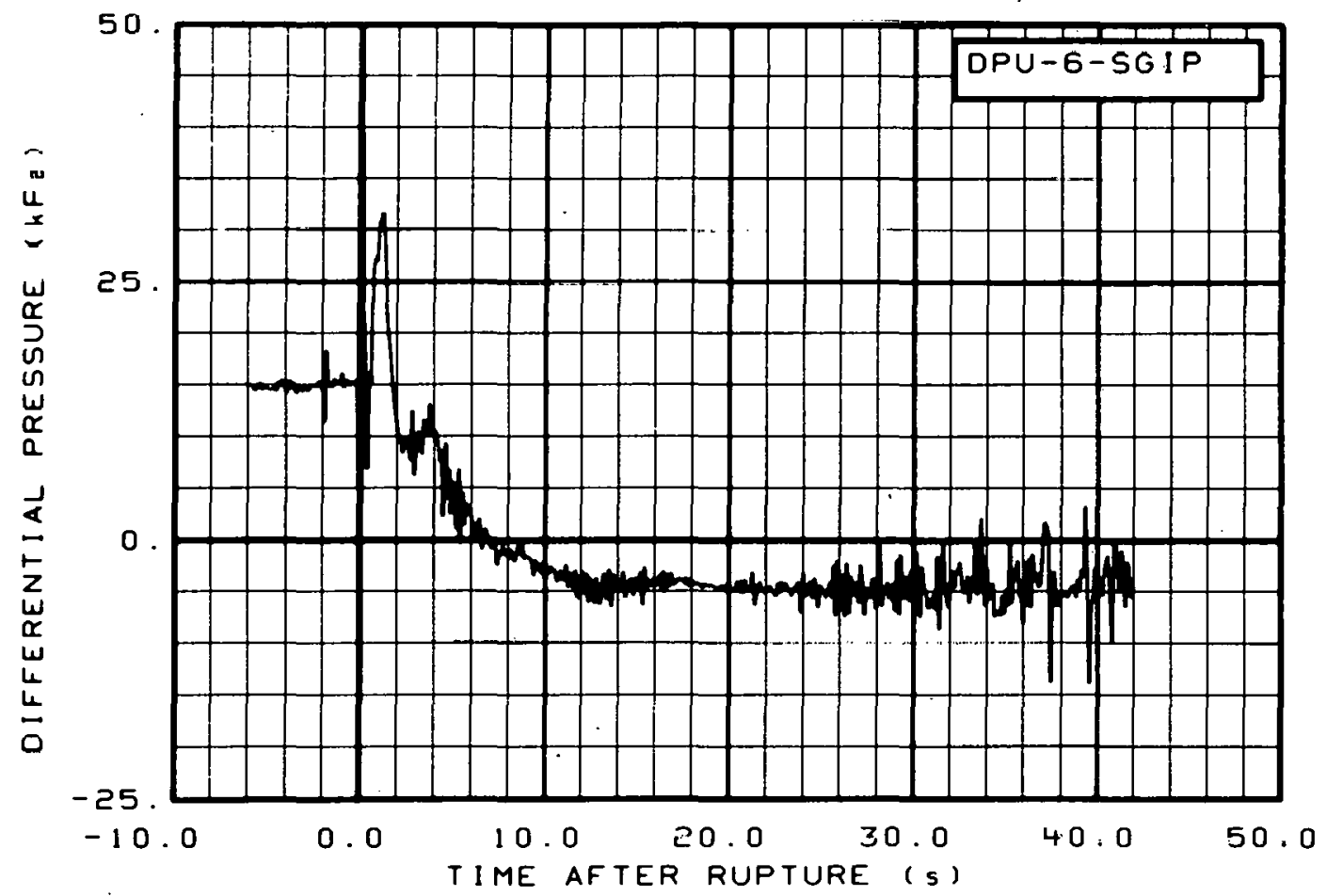

Fig. 152 Differential pressure in intact loop (DPU-6-SGIP), from -6 to $42 \mathrm{~s}$. 


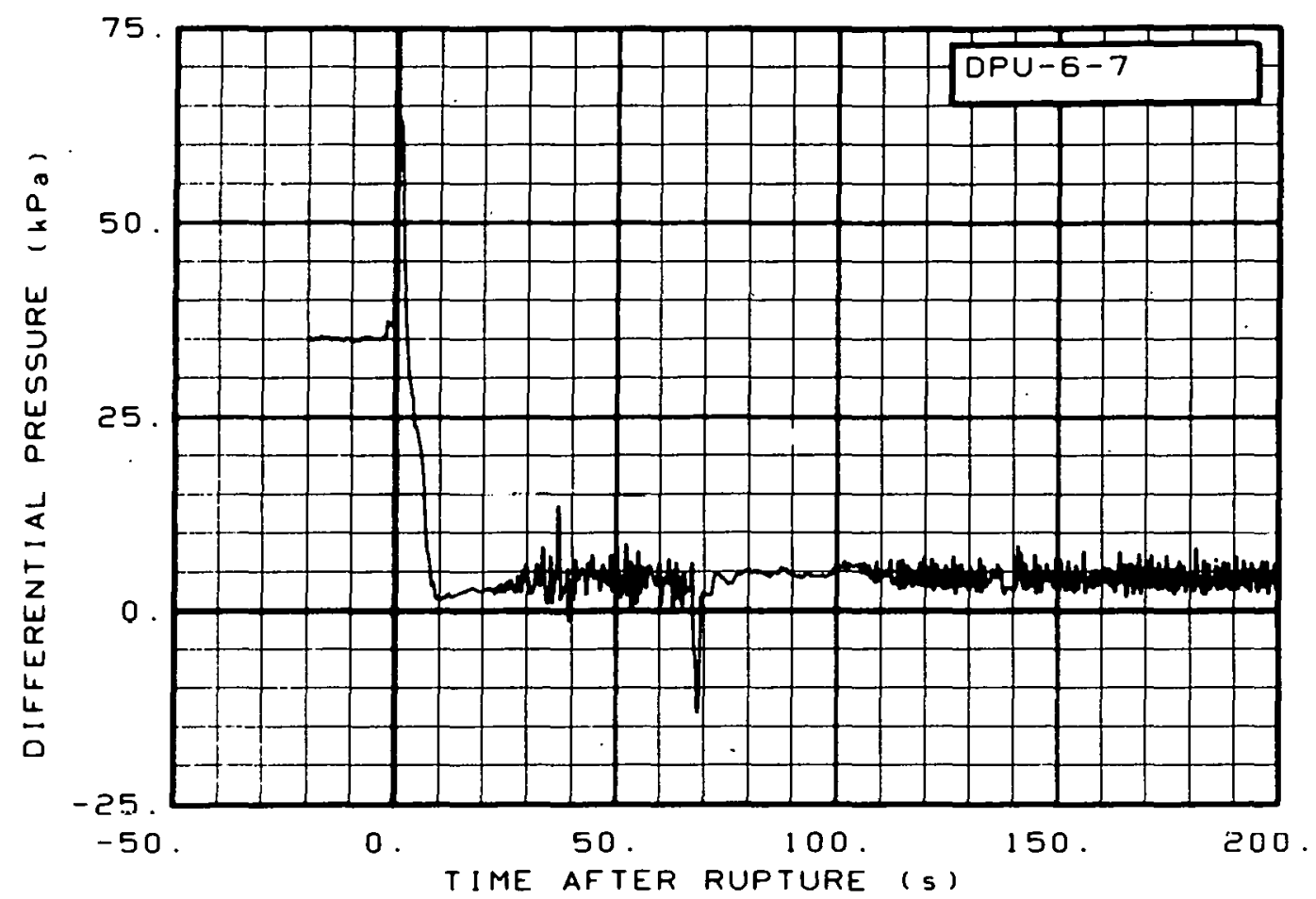

Fig. 153 Differential pressure in intact loop (DPU-6-7), from -20 to $200 \mathrm{~s}$.

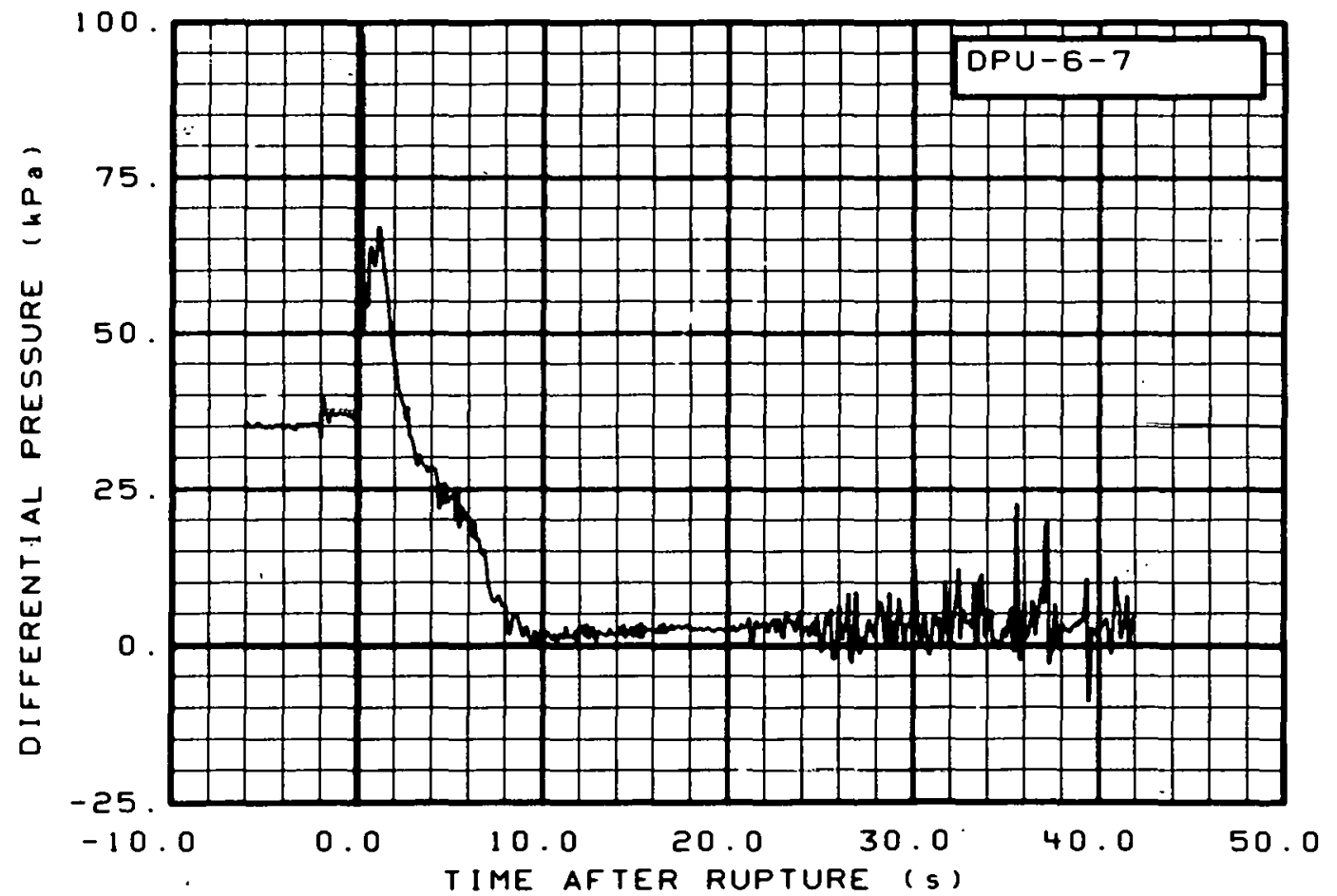

Fig. 154 Differential pressure in intact loop (DPU-6-7), from -6 to $42 \mathrm{~s}$. 


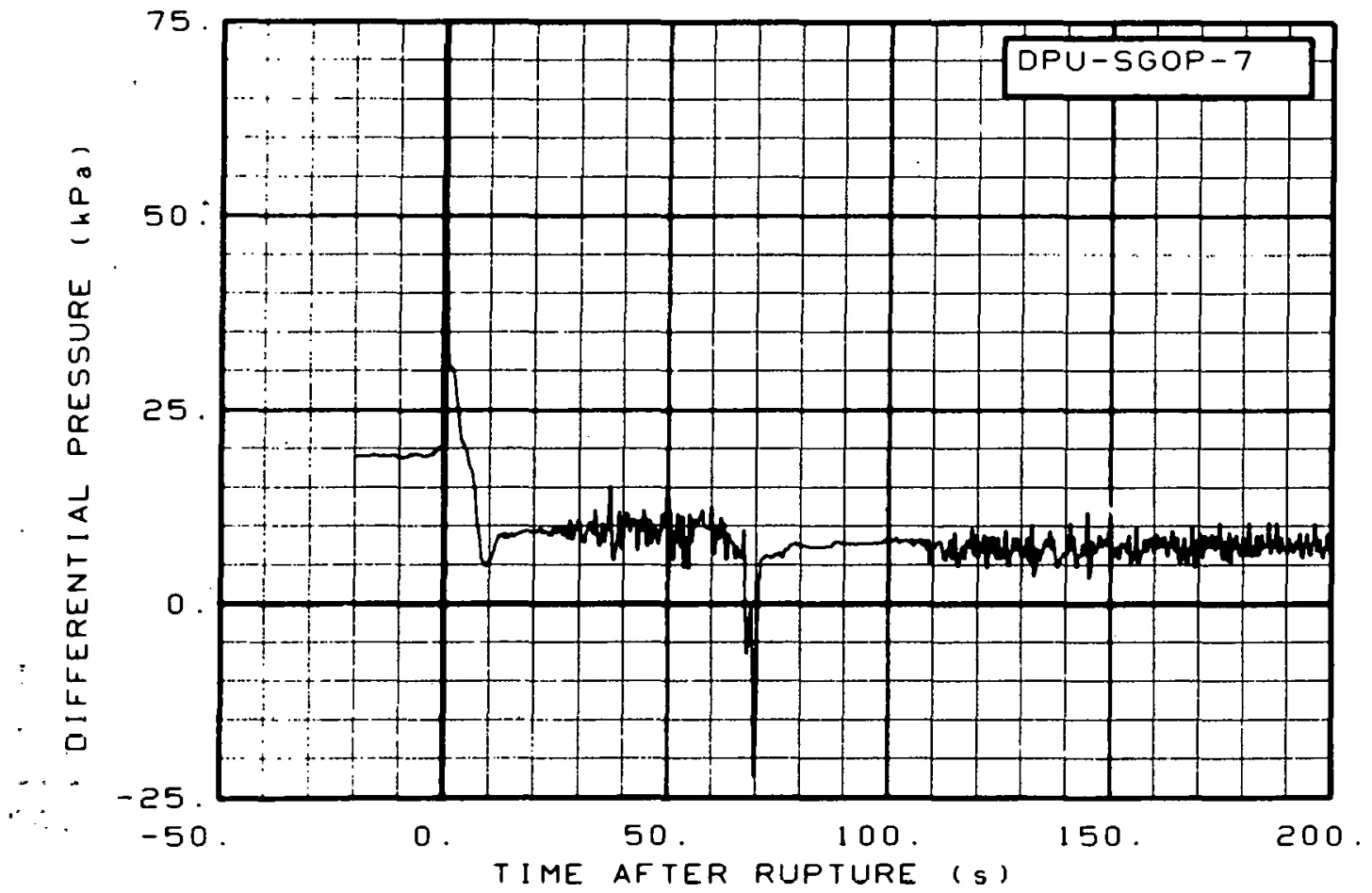

Fig. 155 Differential pressure in intact loop (DPU-SGOP-7), from -20 to $200 \mathrm{~s}$.

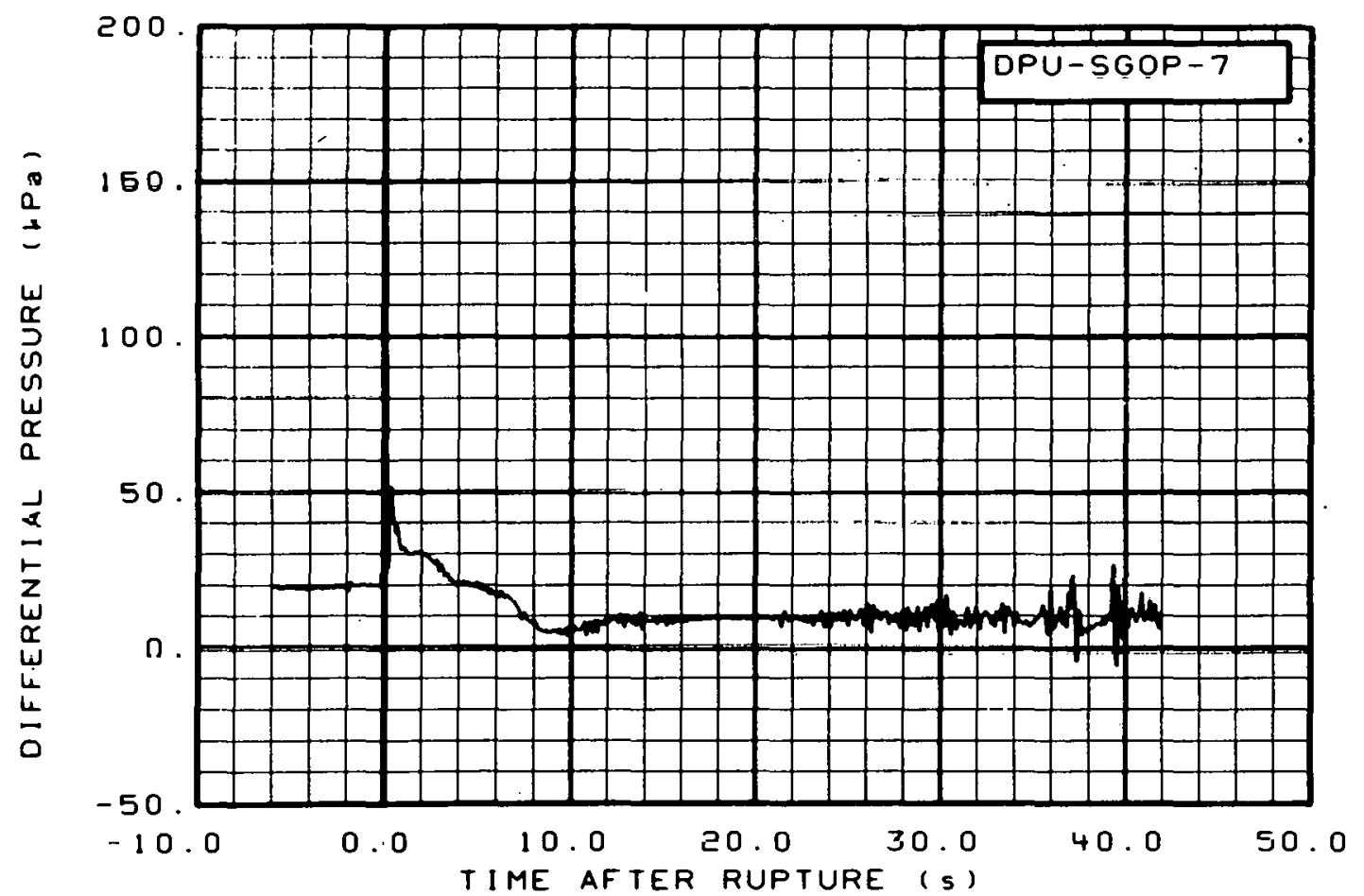

Fig. 156 Differential pressure in intact 10op (DPU-SGOP-7), from -6 to $42 \mathrm{~s}$. 


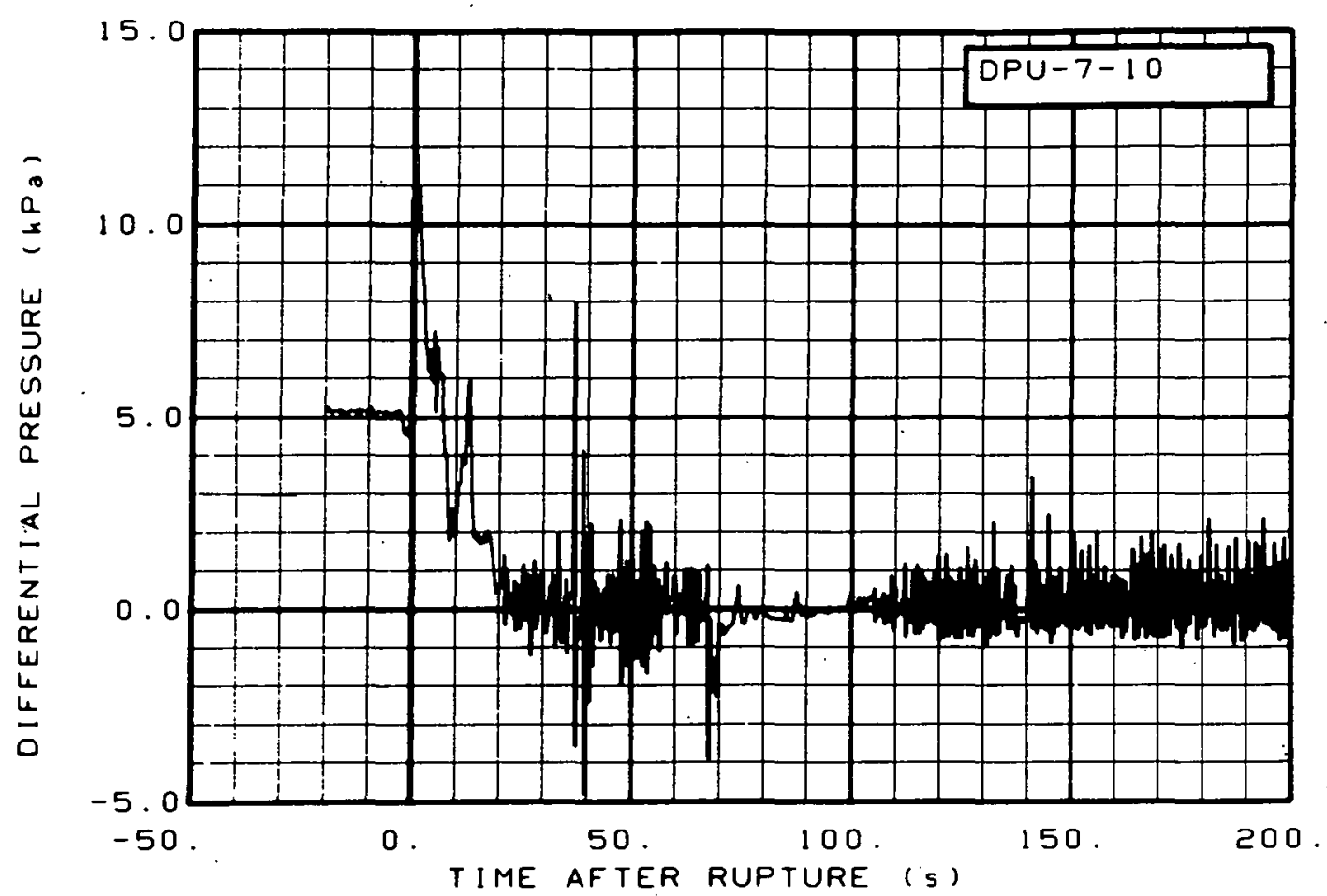

Fig. 157 Differential pressure in intact loop (DPU-7-10), from -20 . to $200 \mathrm{~s}$.

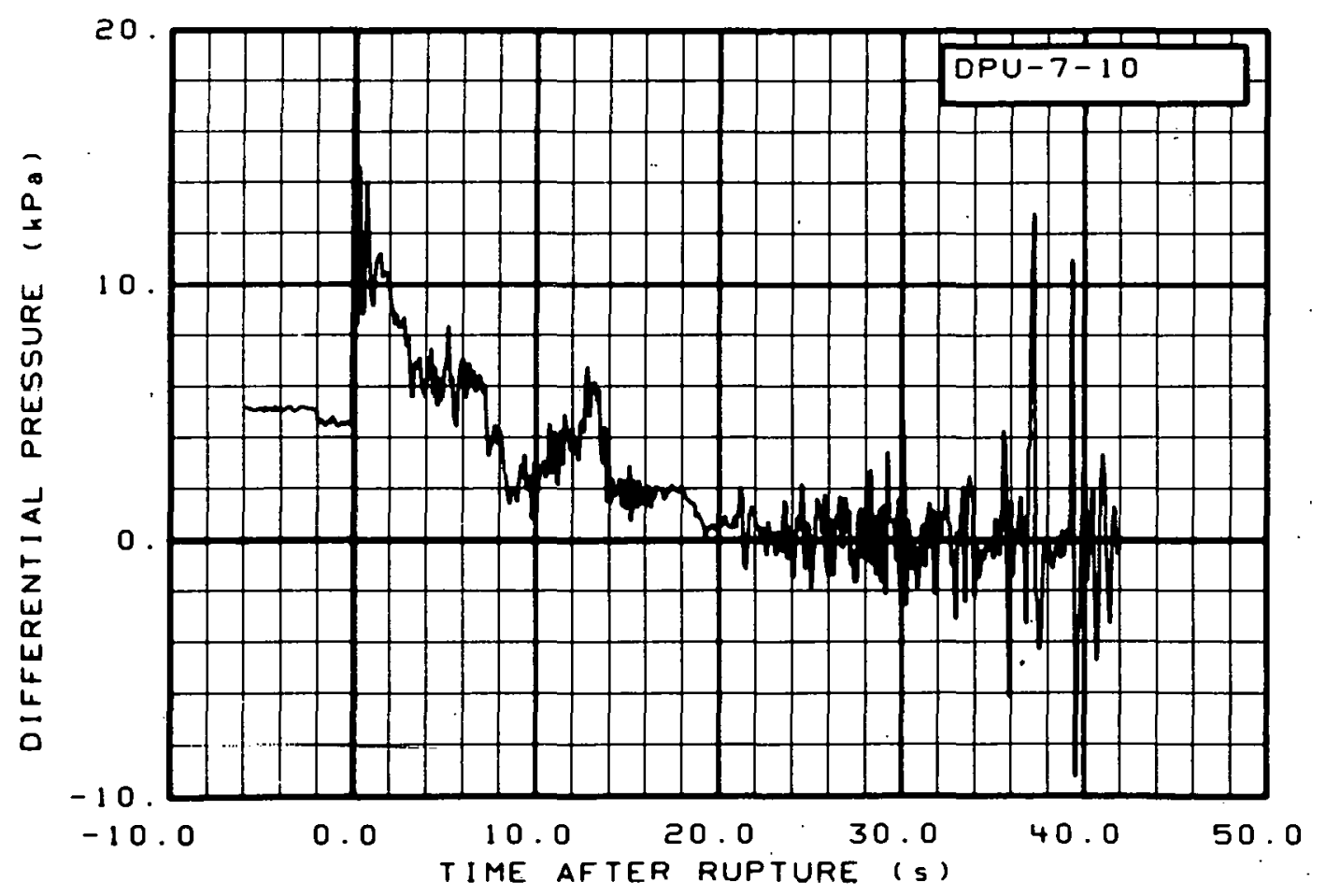

Fig. 158 Differential pressure in intact loop (DPU-7-10), from -6 to $42 \mathrm{~s}$. 


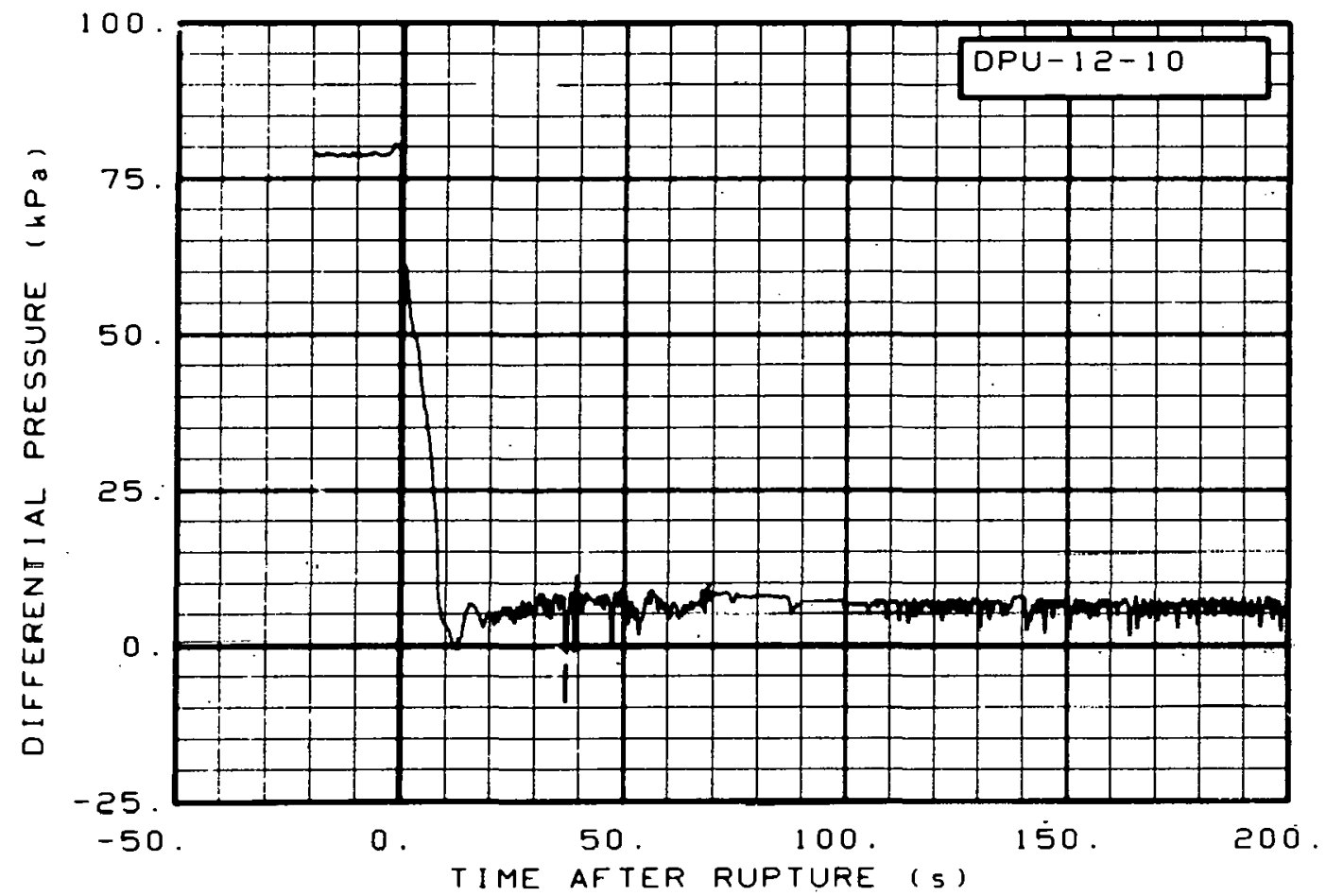

Fig. 159 Differential pressure in intact loop (DPU-12-10), from -20 to $200 \mathrm{~s}$.

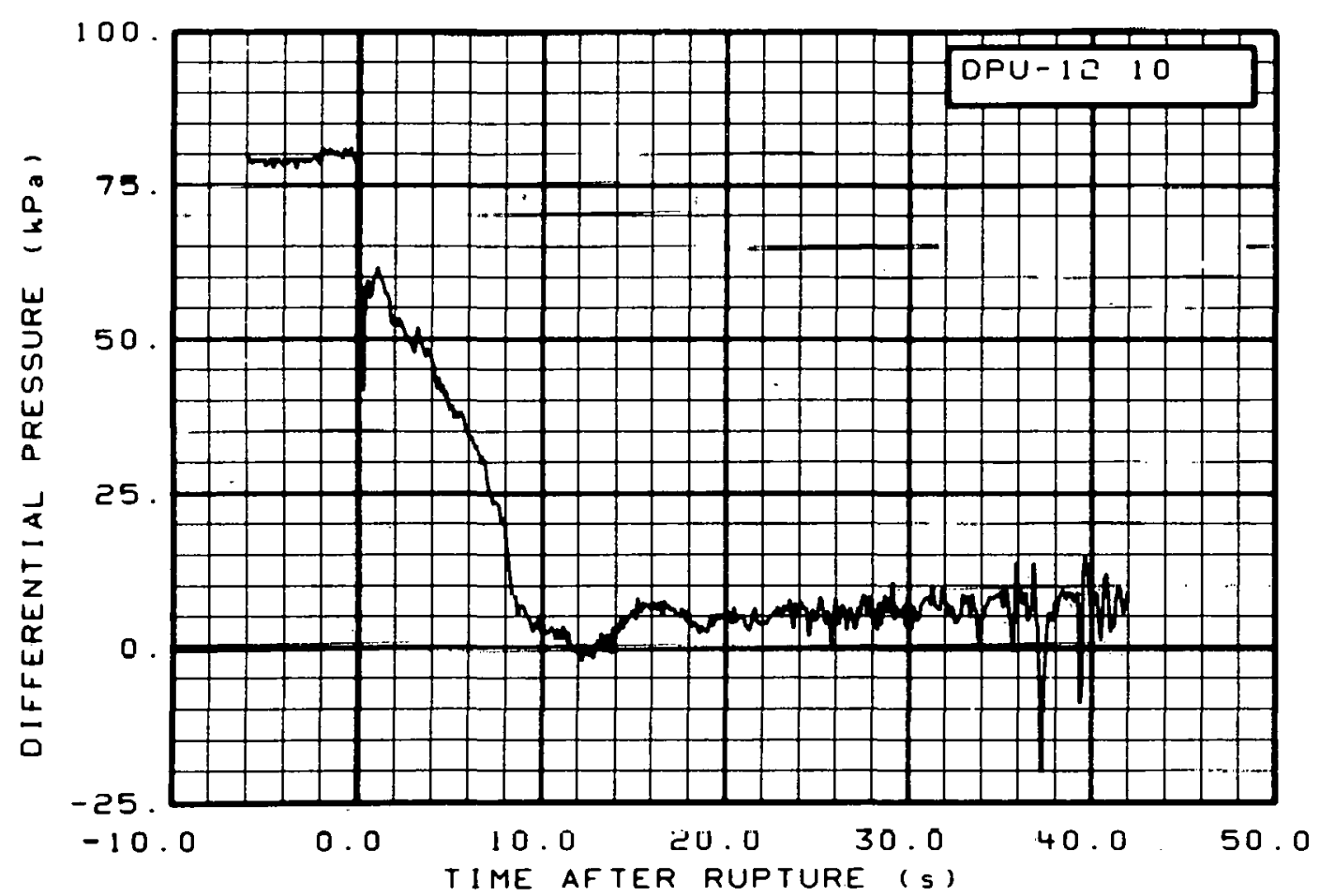

Fig. 160 Differential pressure in intact 10op. (DPU-12-10), from -6 to $42 \mathrm{~s}$. 


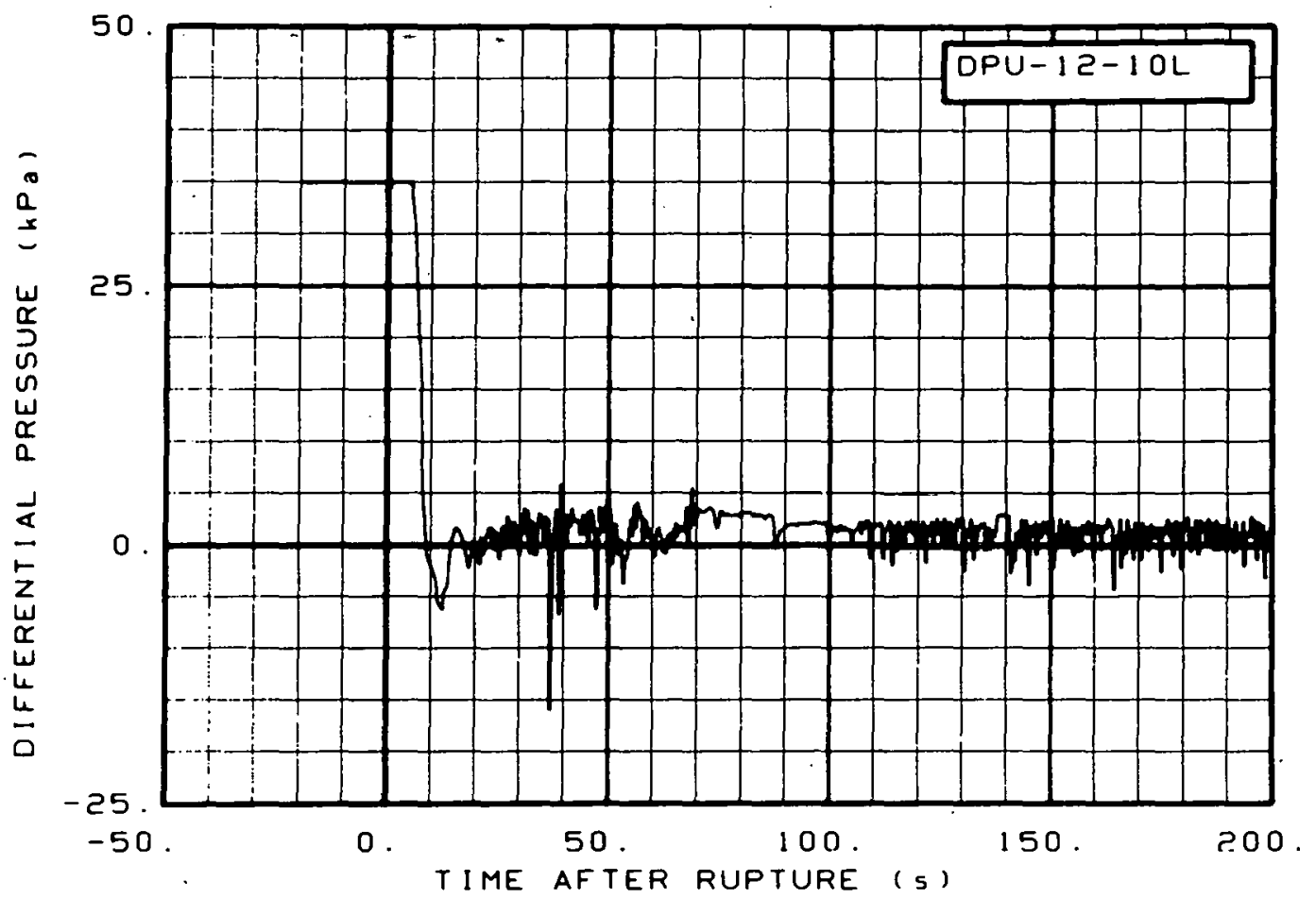

Fig. 161 Differential pressure in intact loop, low range (DPU-12-10L), from -20 to $200 \mathrm{~s}$.

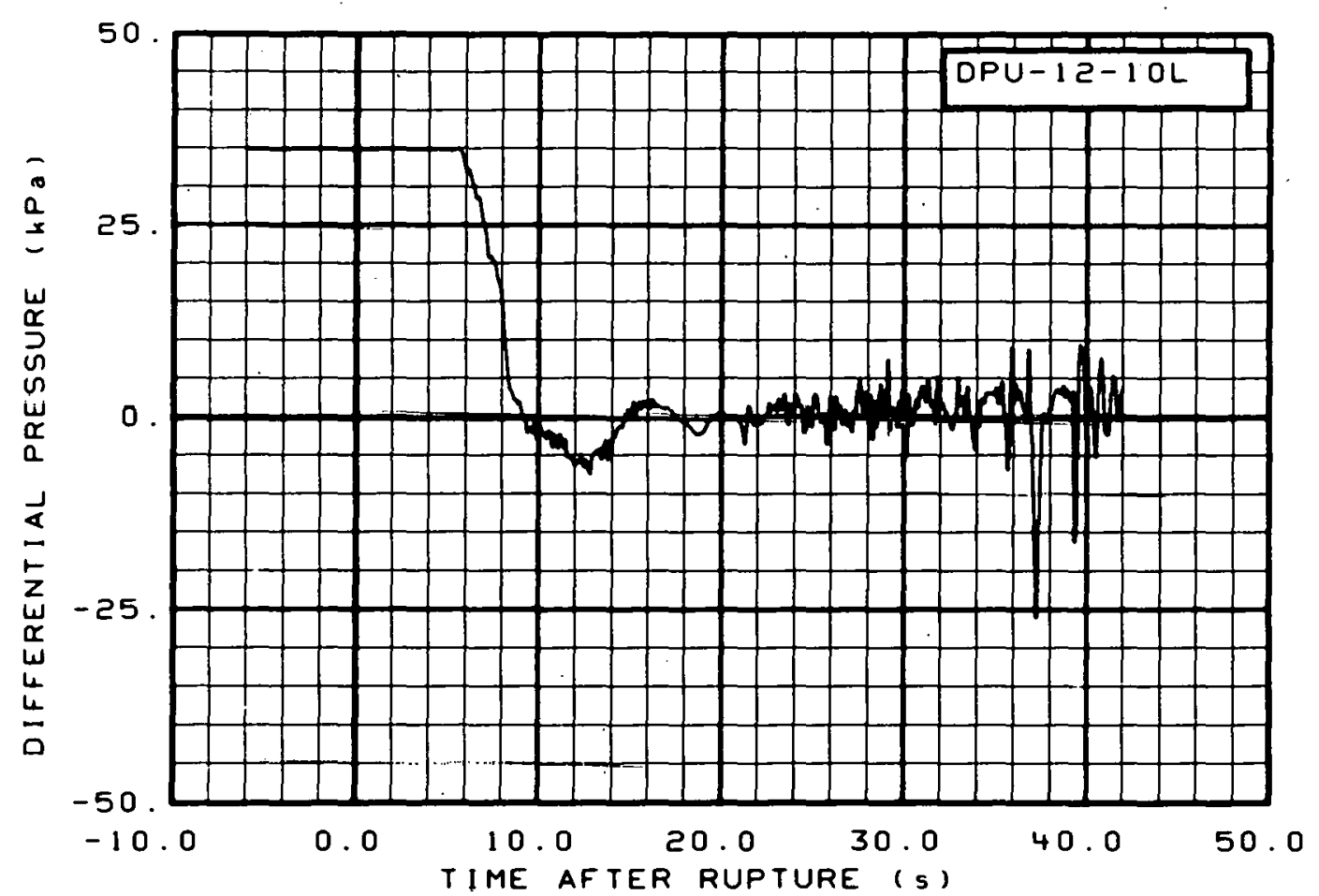

Fig. 162 Differential pressure in intact loop, low range (DPU-12-10L), from -6 to $42 \mathrm{~s}$. 


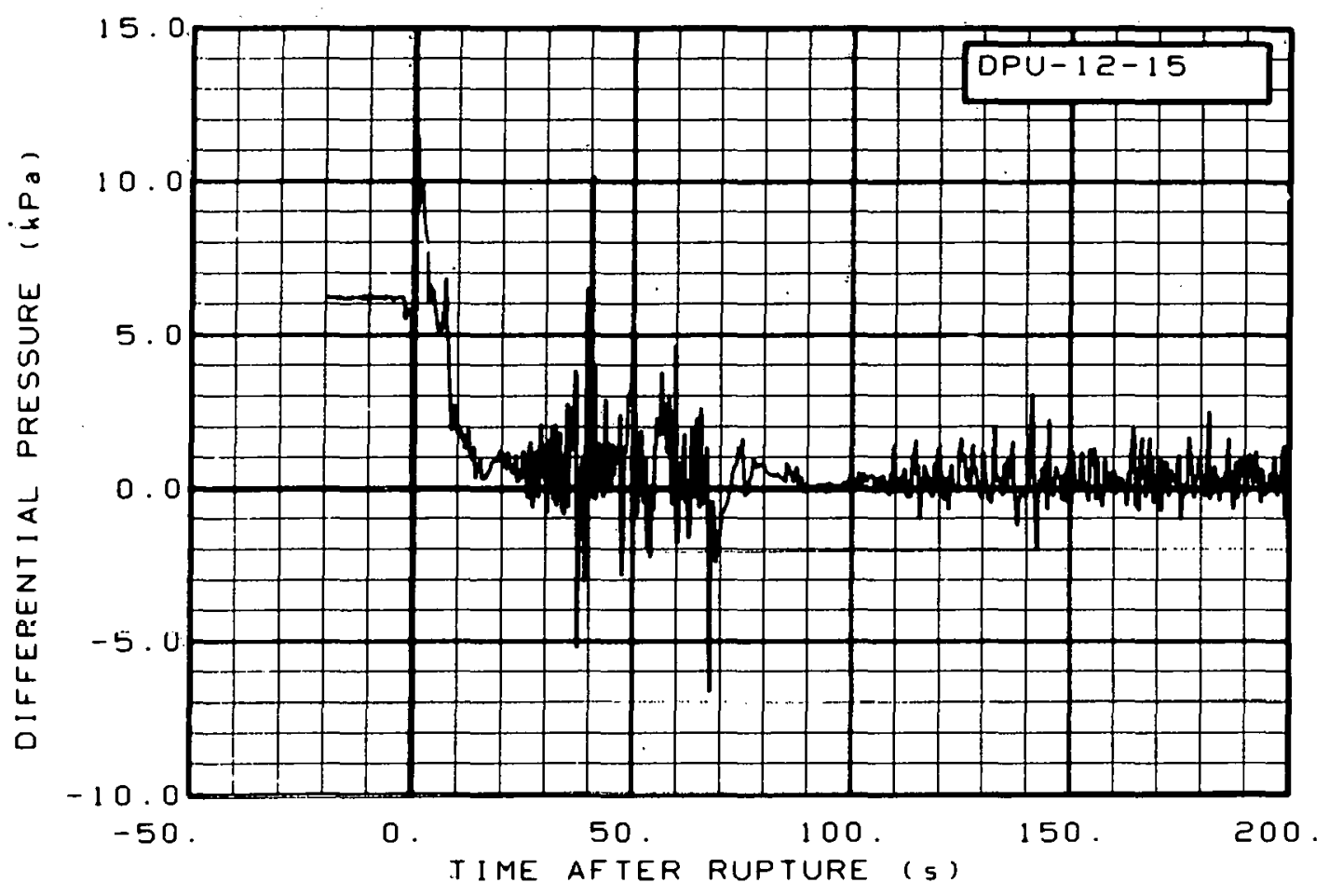

Fig. 163 Differential pressure in intact loop (DPU-12-15), from -20 to $200 \mathrm{~s}$.

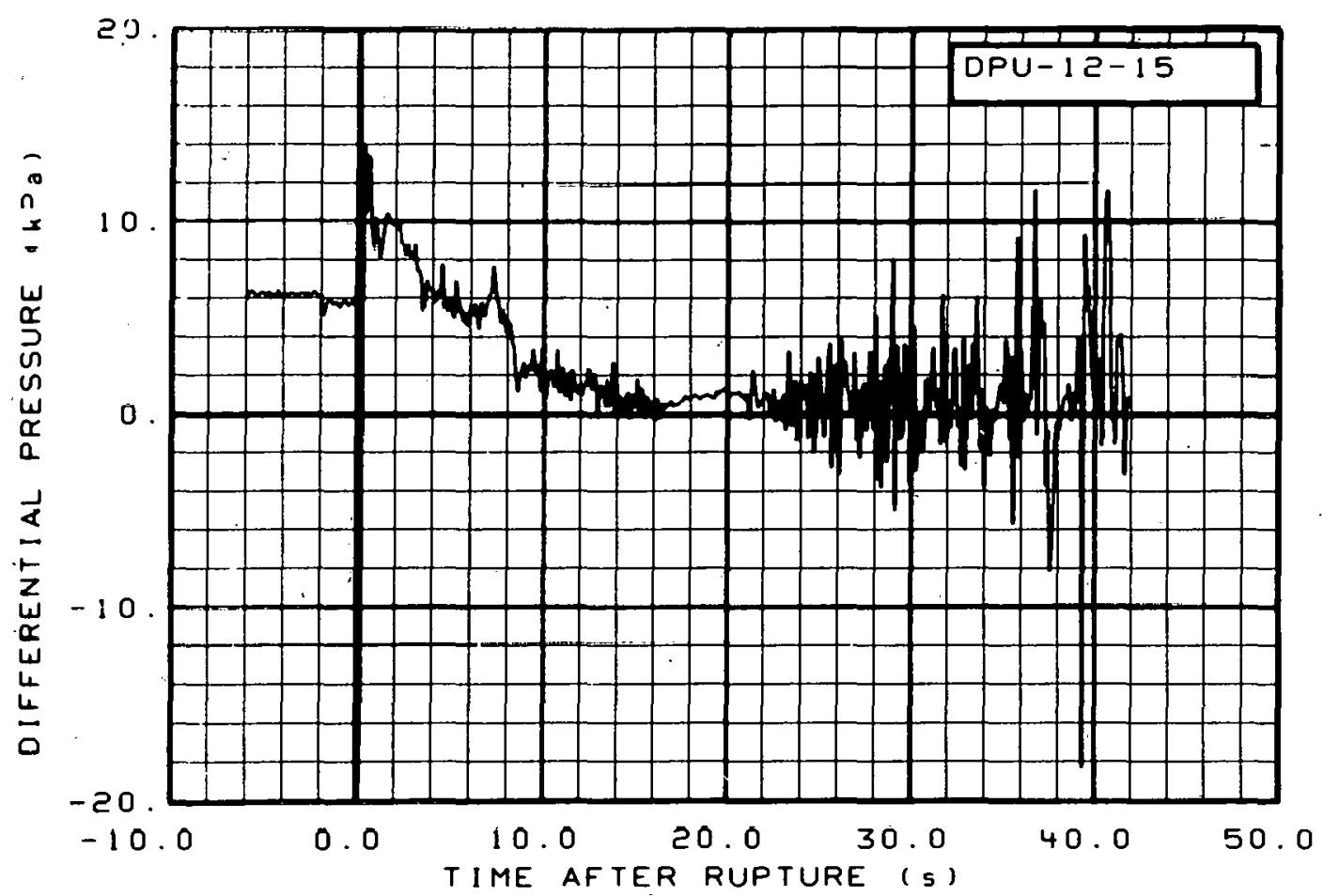

Fig. 164 Differential pressure in intact loop (DPU-12-15), from -6 to $42 \mathrm{~s}$. 


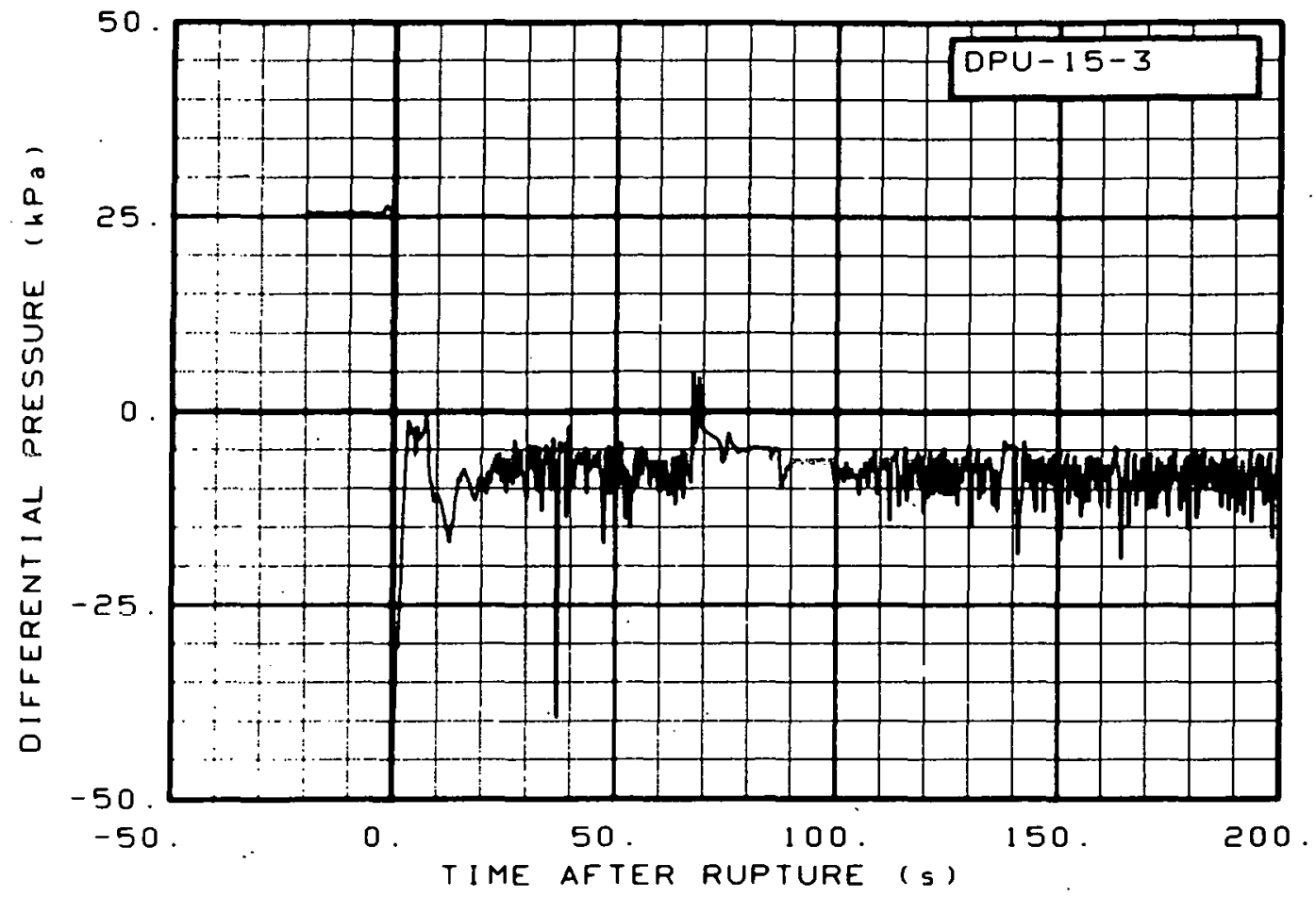

Fig. 165 Differential pressure in intact loop (DPU-15-3), from -20 , to $200 \mathrm{~s}$.

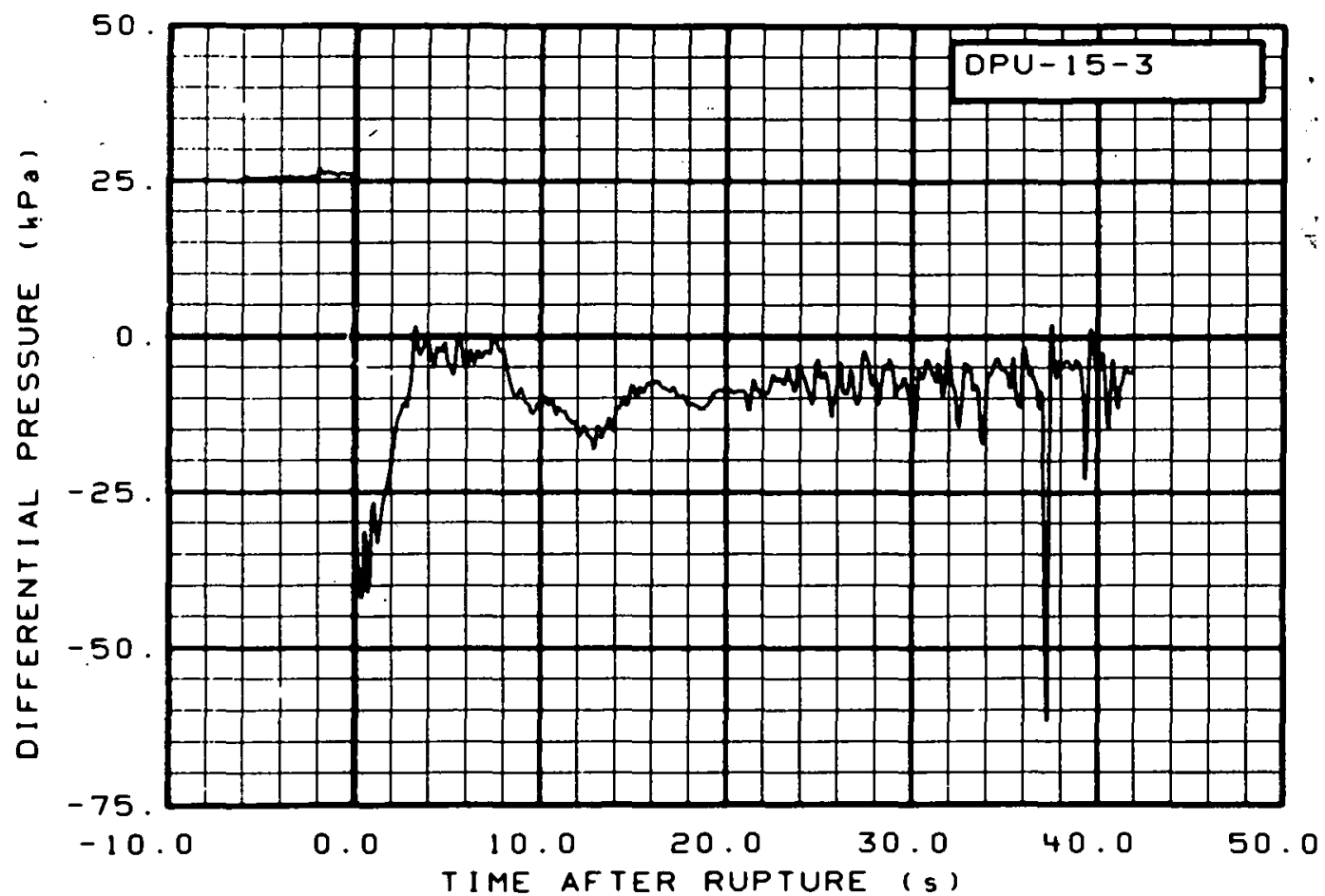

Fig. 166 Differential pressure in intact loop (DPU-15-3), from. -6 to $42 \mathrm{~s}$. 


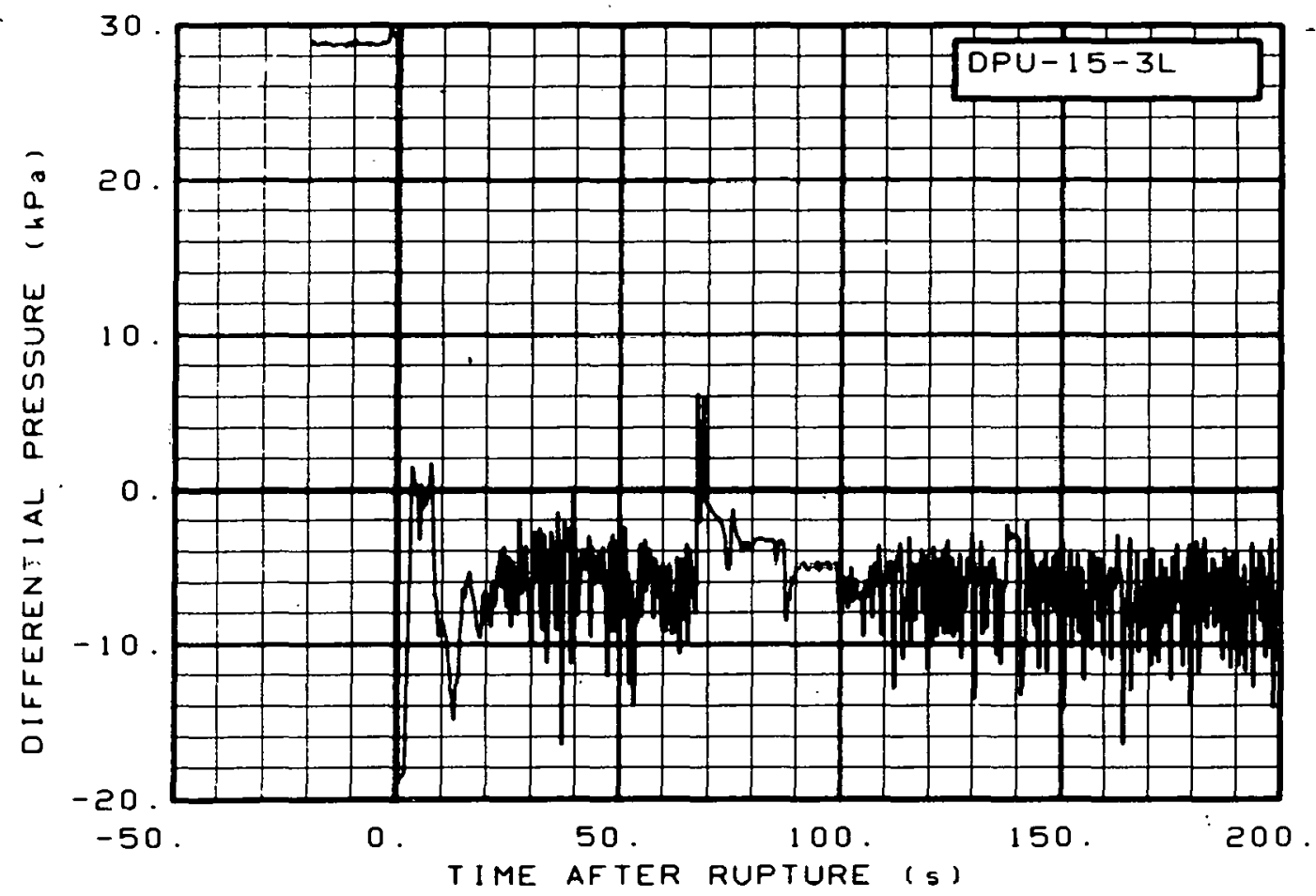

Fig. 167 Differential pressure in intact loop, low range (DPU-15-3L), from -20 to $200 \mathrm{~s}$.

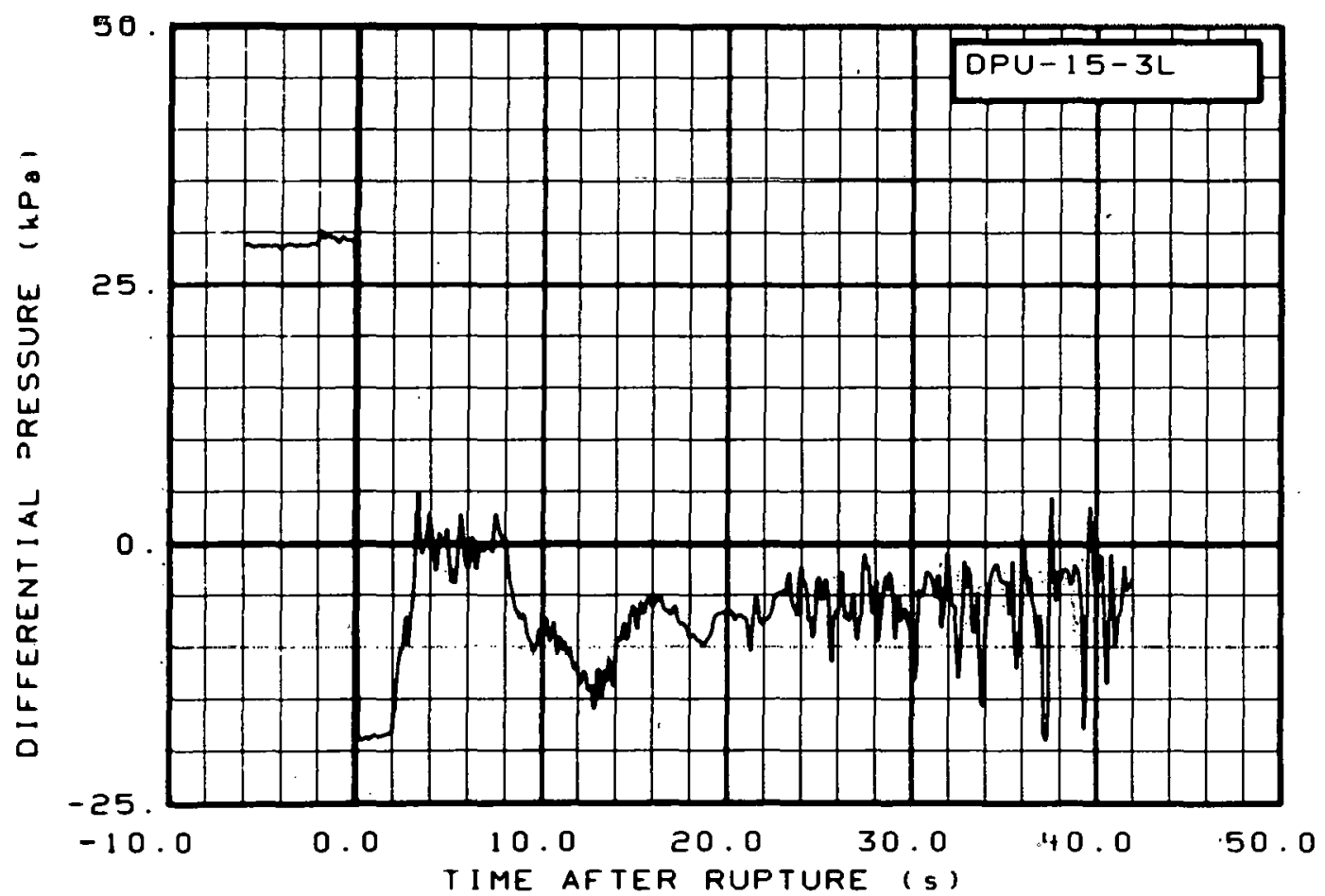

Fig. 168 Differential pressure in intact loop, low range (DPU-15-3L), from -6 to $42 \mathrm{~s}$. 


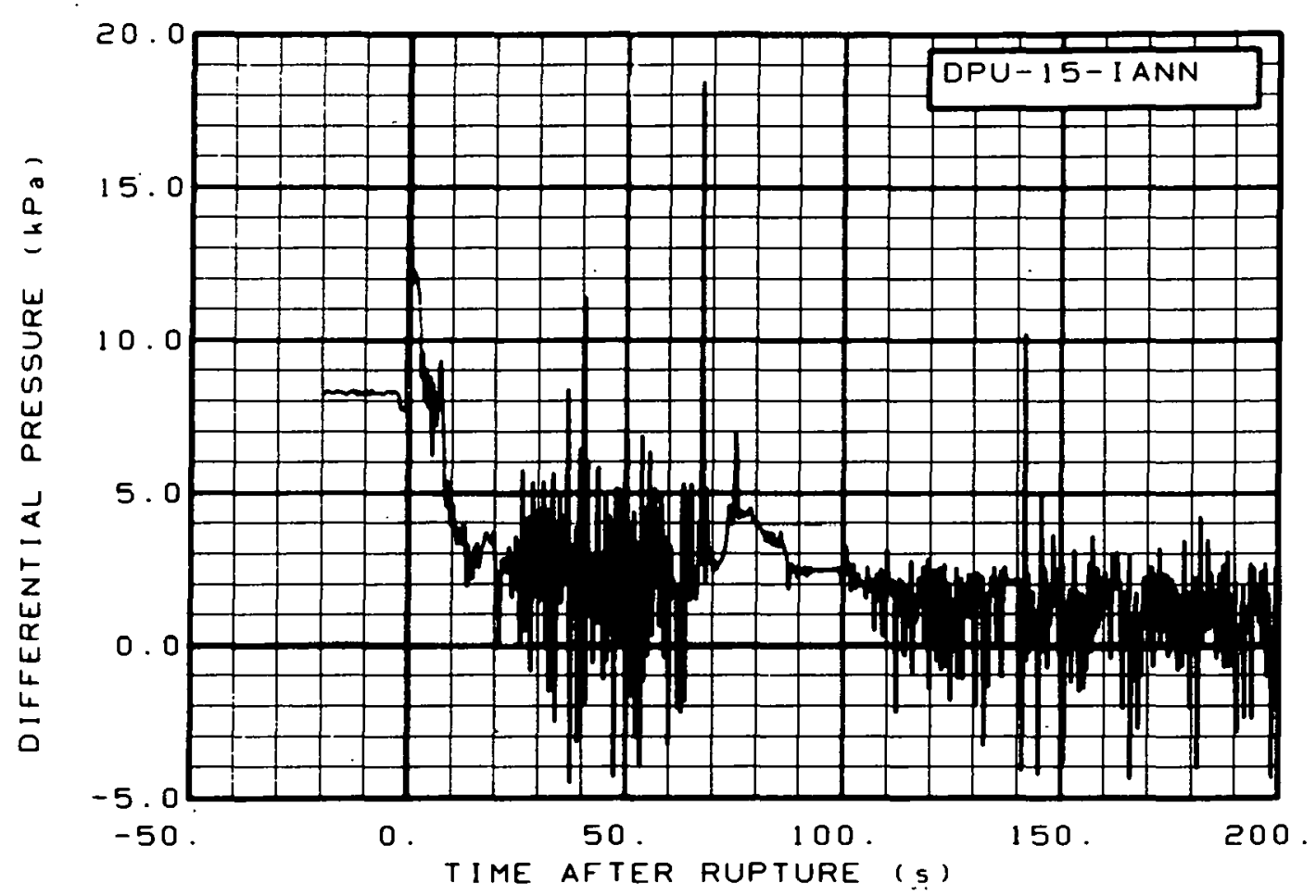

Fig. 169 Differential pressure in intact loop (DPU-15-IANN), from -20 to $200 \mathrm{~s}$.

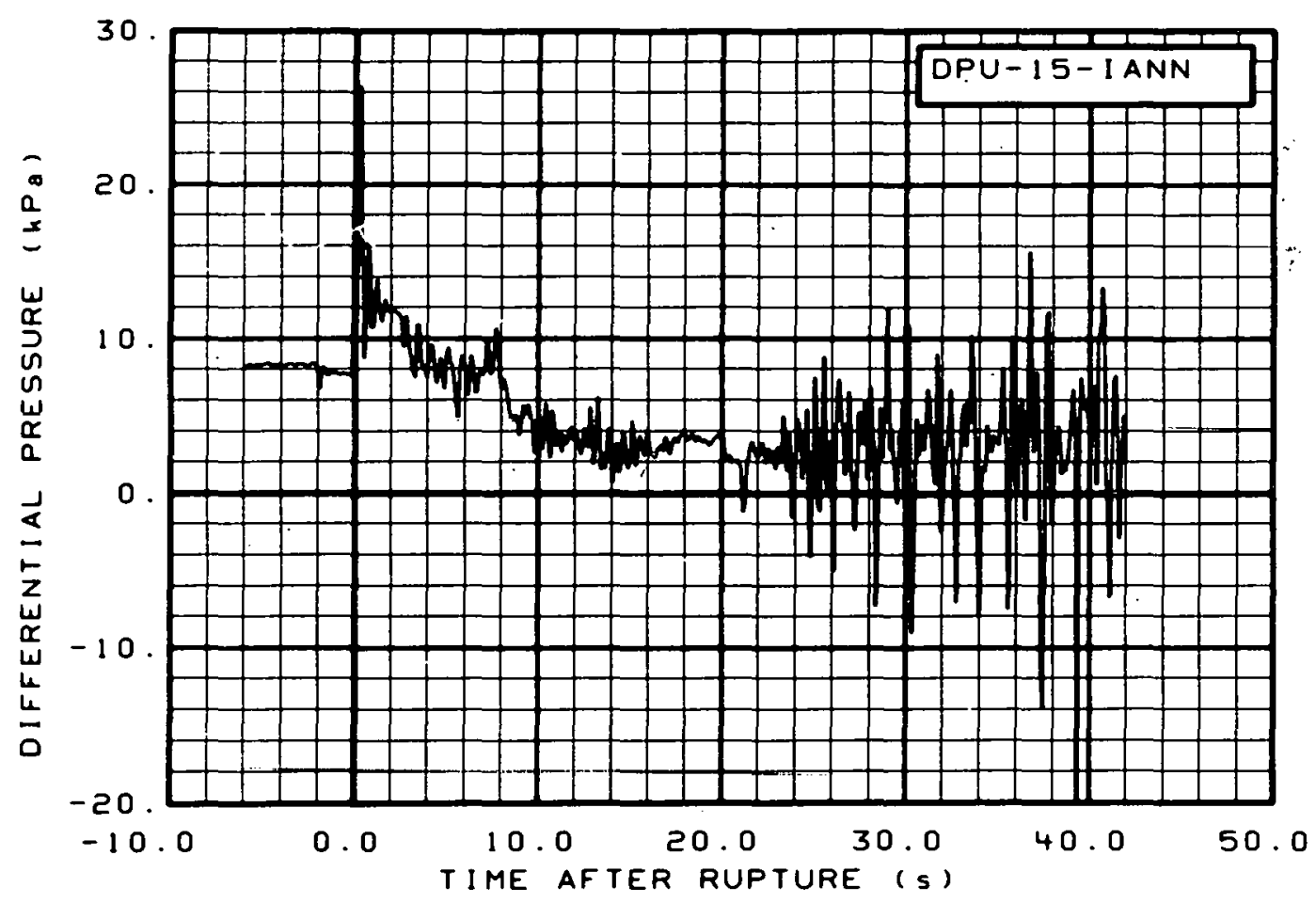

Fig. 170 Differential pressure in intact loop (DPU-15-IANN), from -6 to $42 \mathrm{~s}$. 


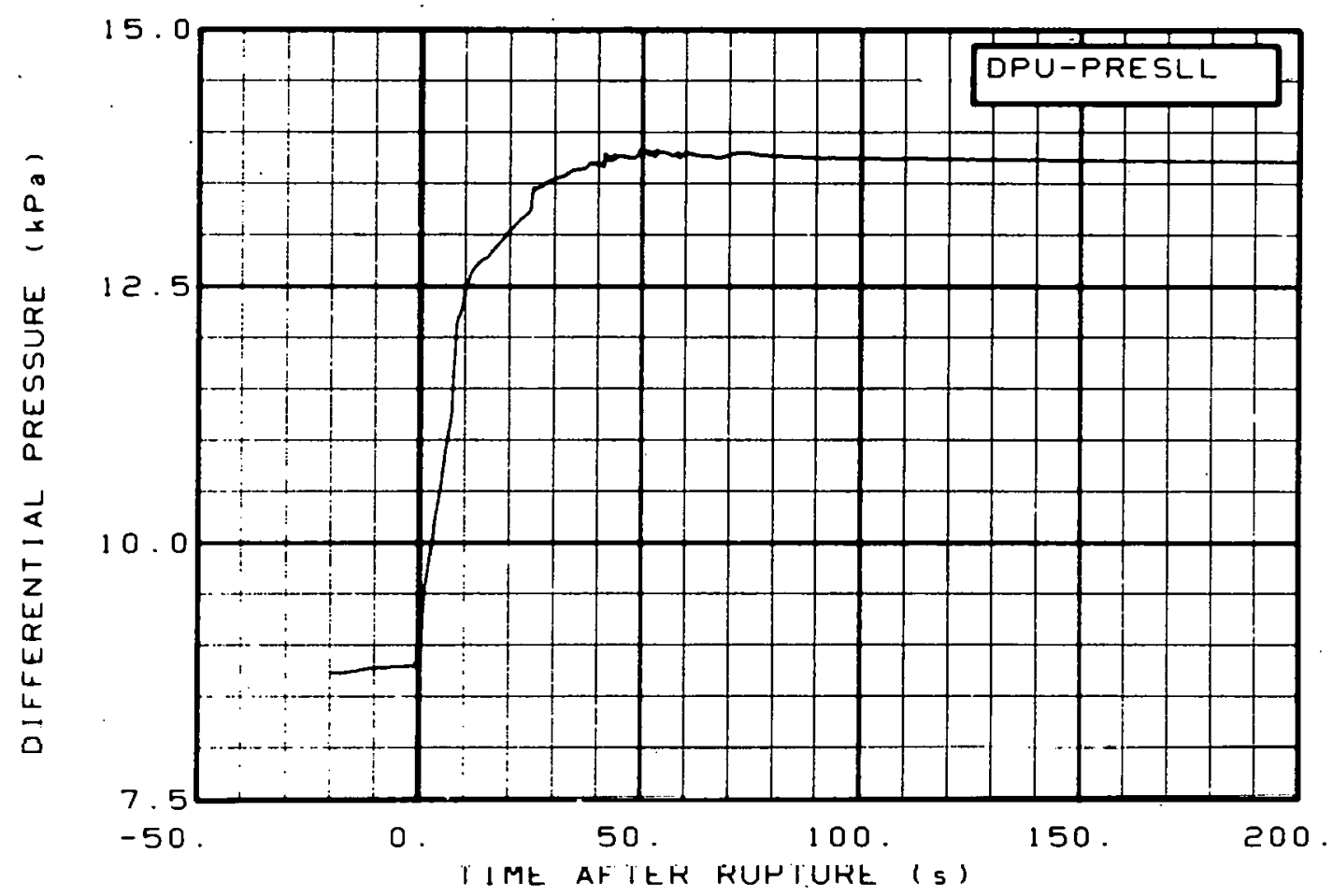

Fig. 171 Differential pressure in intact loop (DPU-PRESLL), from -20 to $200 \mathrm{~s}$.

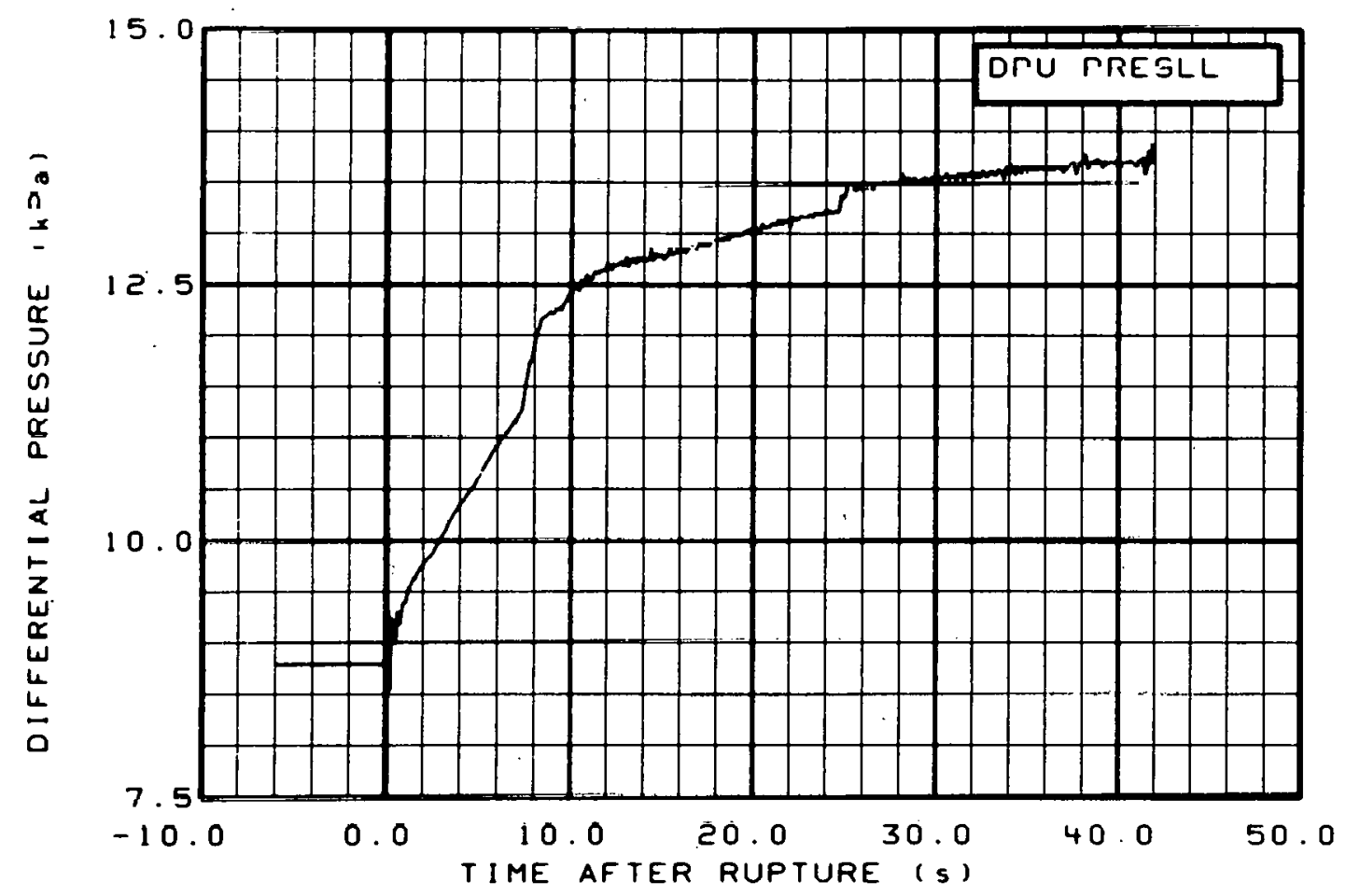

Fig. 172 Differential pressure in intact loop. (DPU-PRESLL), from -6 to $42 \mathrm{~s}$. 


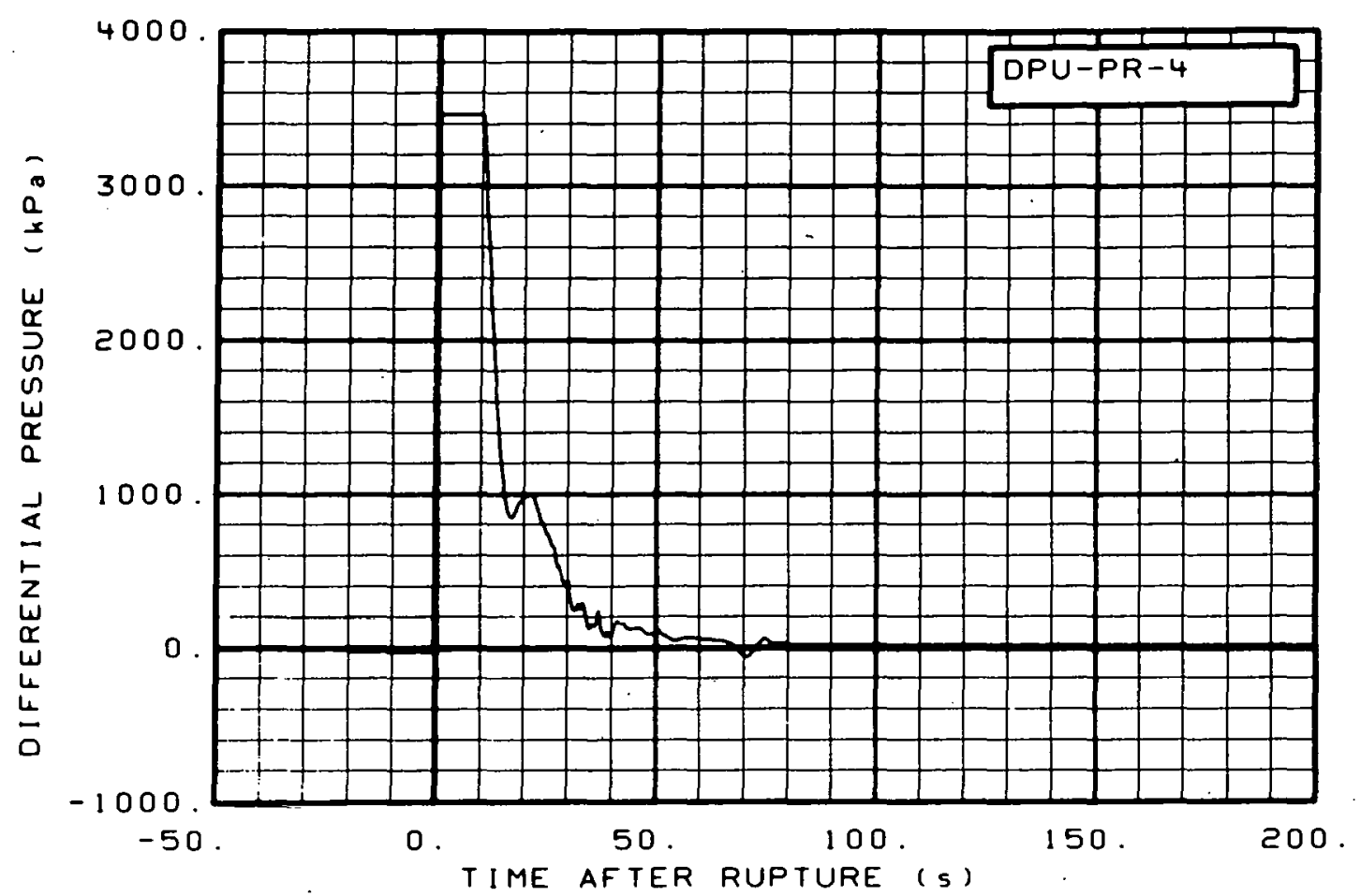

Fig. 173 Differential pressure in intact loop (DPU-PR-4), from -20 : to $200 \mathrm{~s}$.

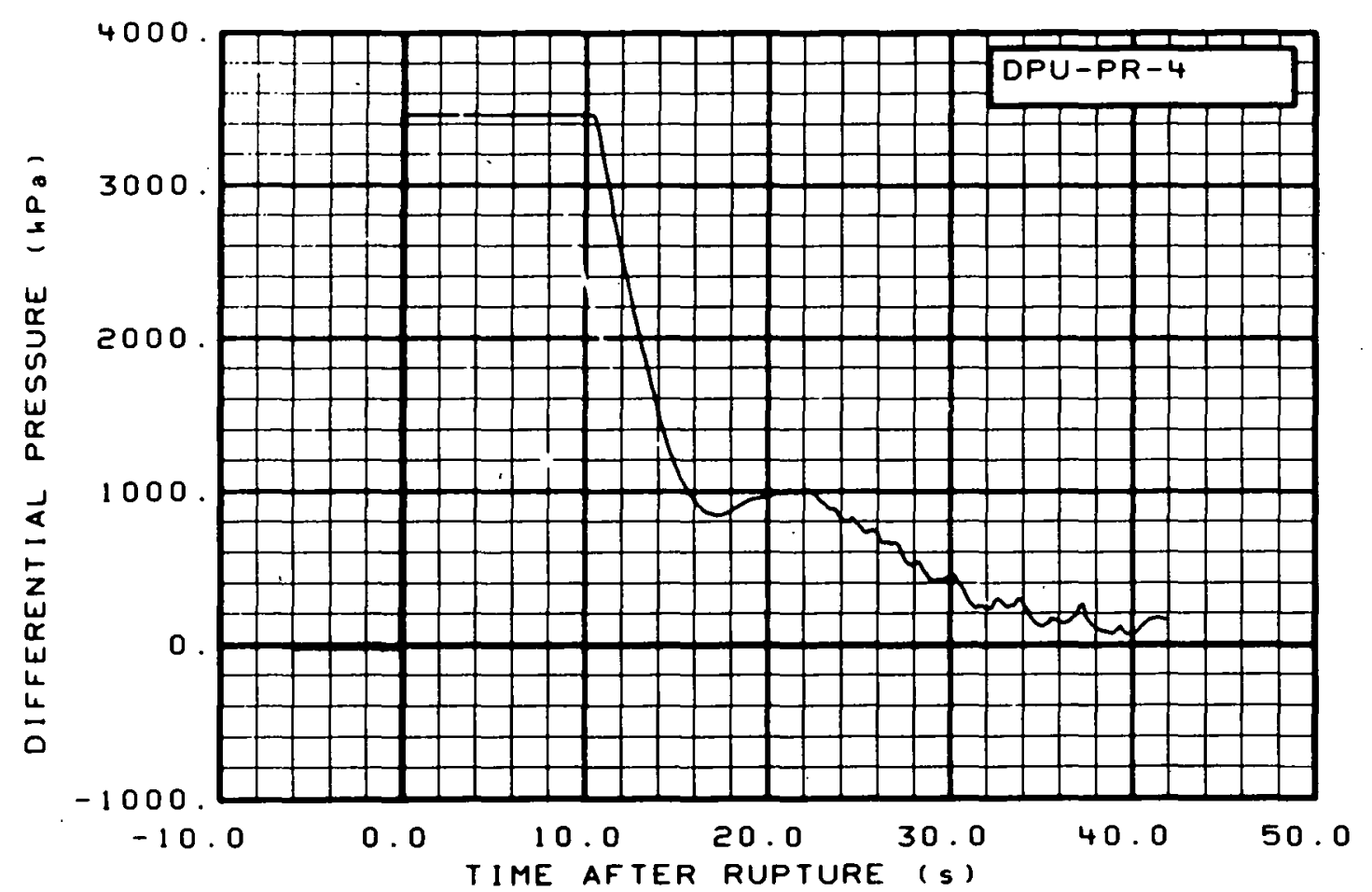

Fig. 174 Differential pressure in intact loop (DPU-PR-4), from -6 to $42 \mathrm{~s}$. 


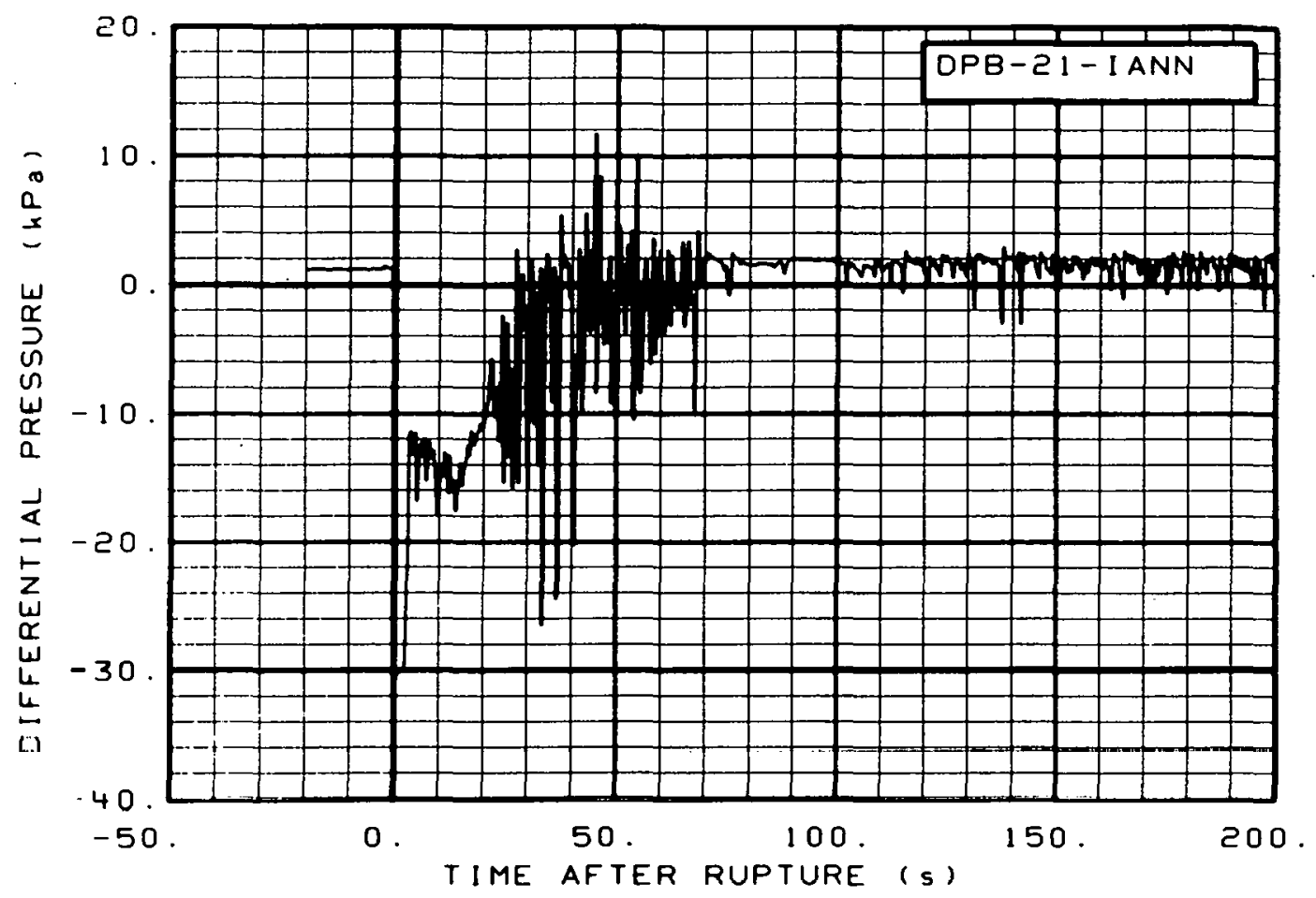

Fig. 175 Differential pressure in broken loop (DPB-21-IANN), from -20 to $200 \mathrm{~s}$.

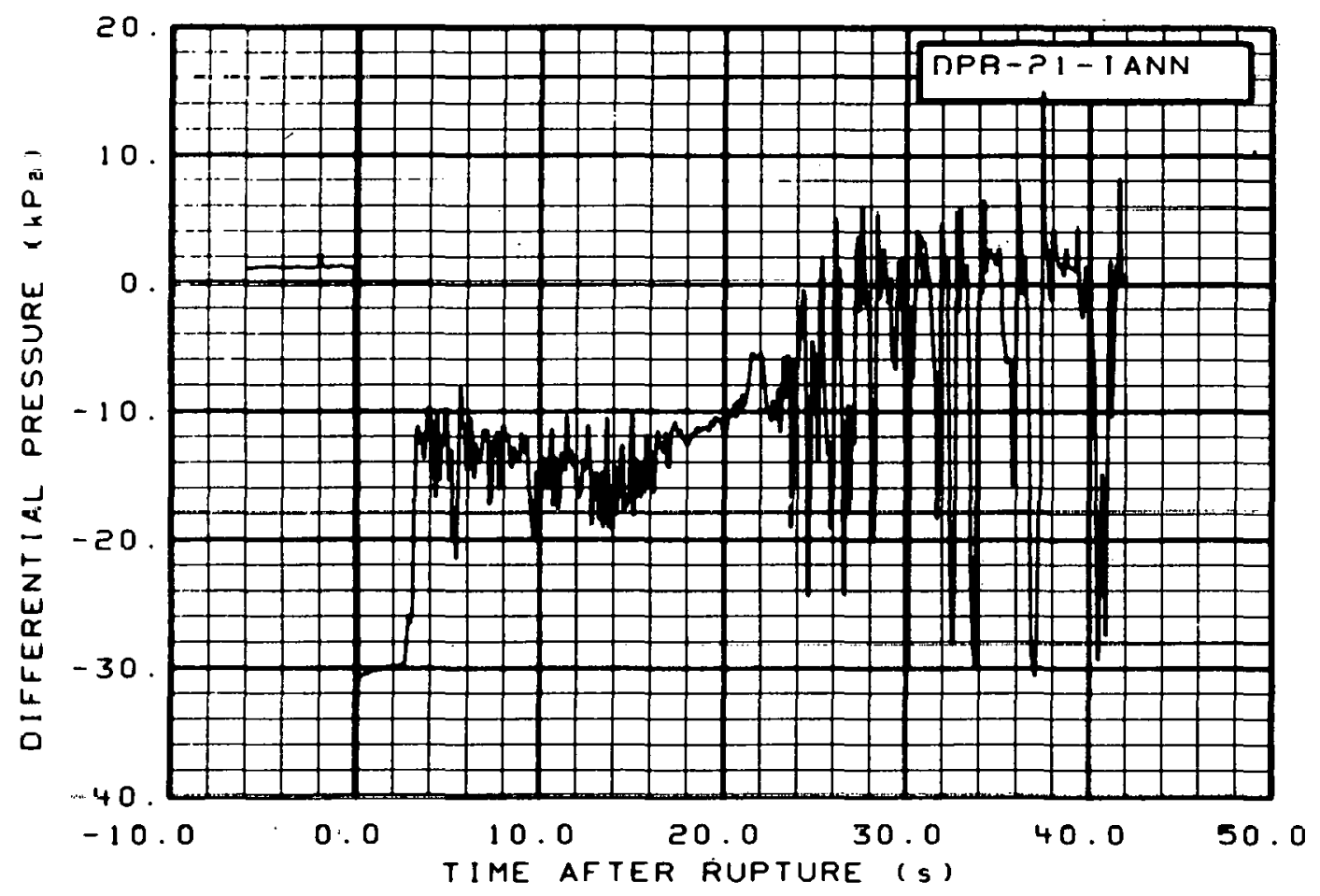

Fig. 176 Differential pressure in broken loop (DPB-21-IANN), from -6 to $42 \mathrm{~s}$. 


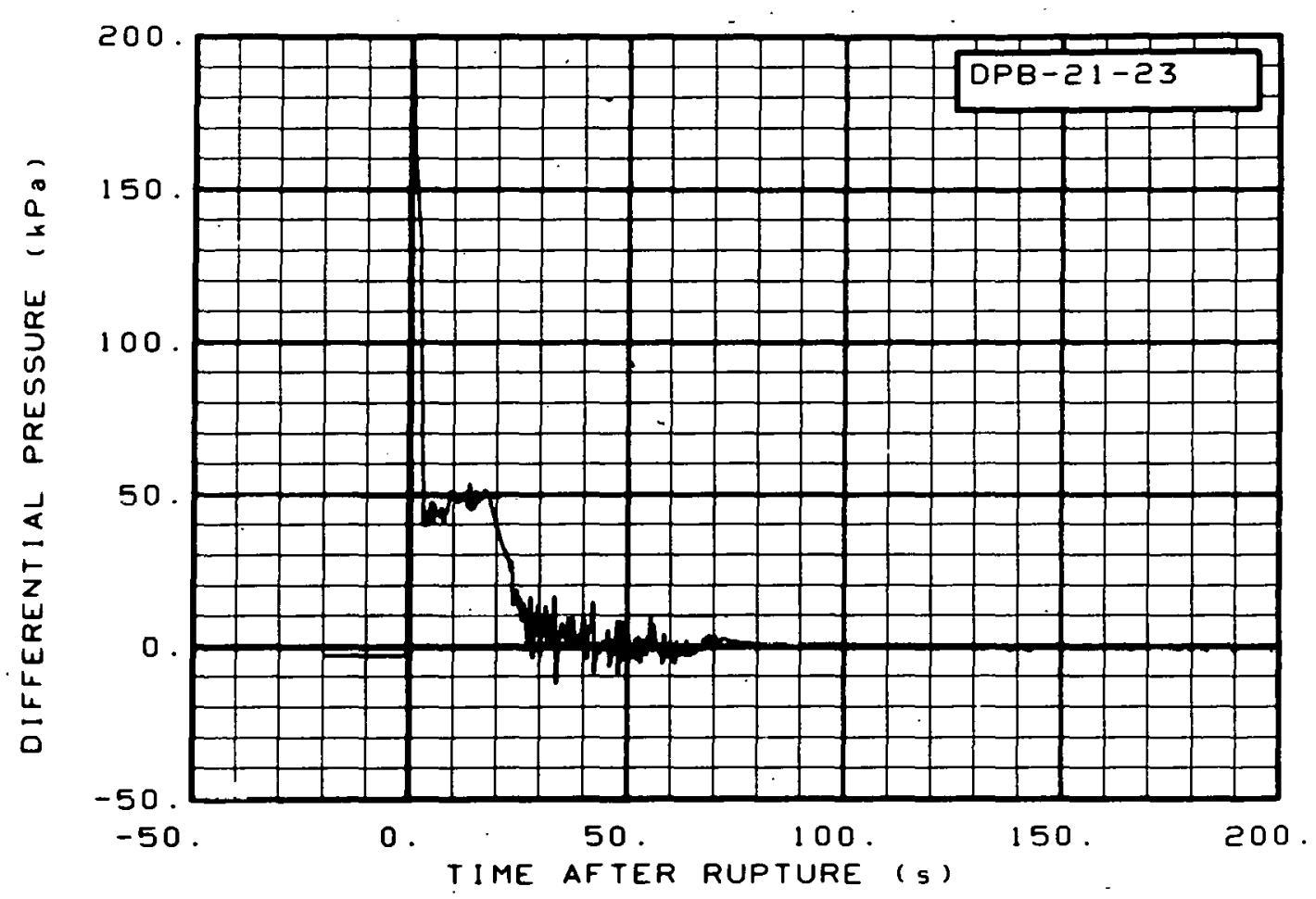

Fig. 177 Differential pressure in broken loop (DPB-21-23), from -20 to $200 \mathrm{~s}$.

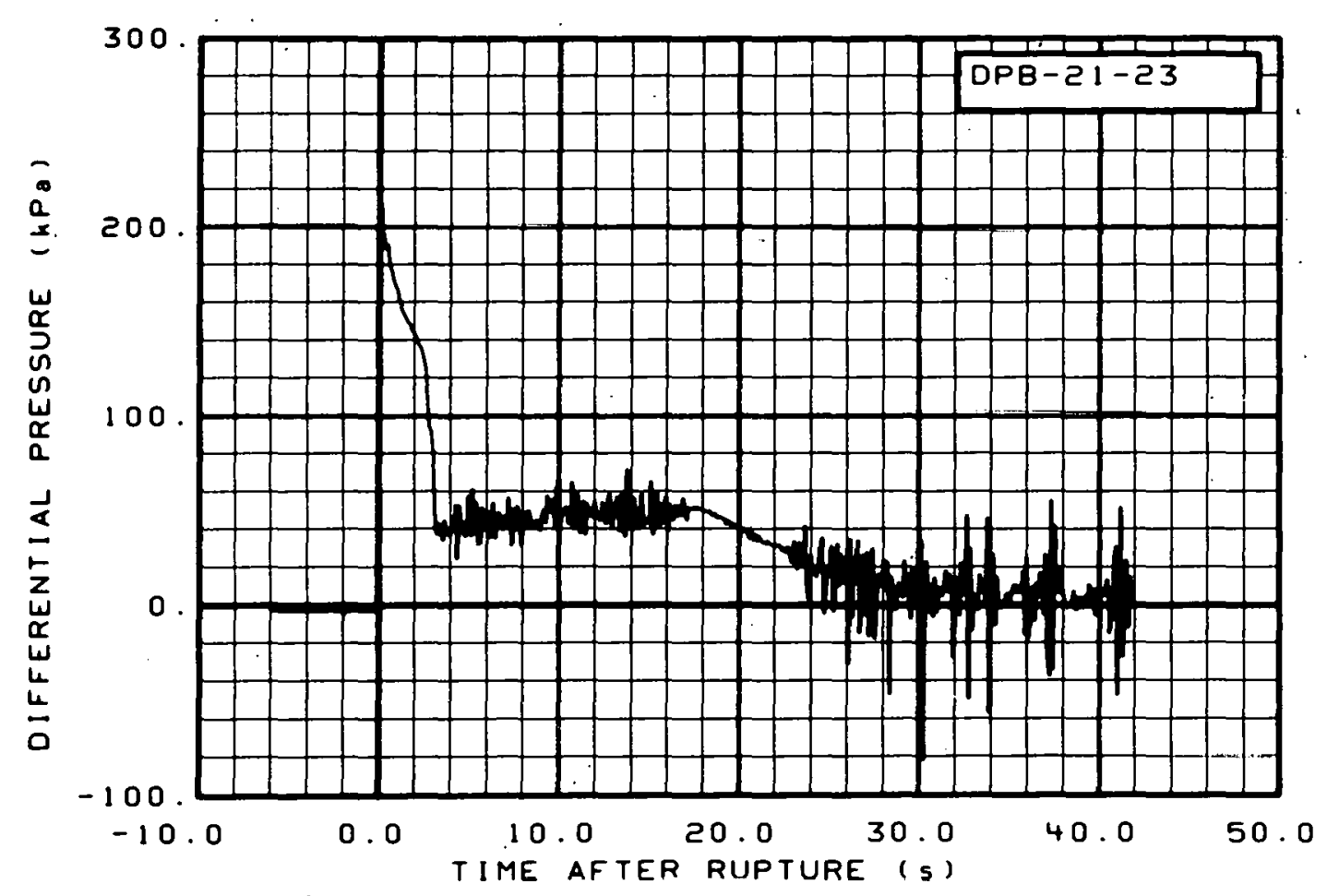

Fig. 178 Differential pressure in broken loop (DPB-21-23), from -6 to $42 \mathrm{~s}$. 


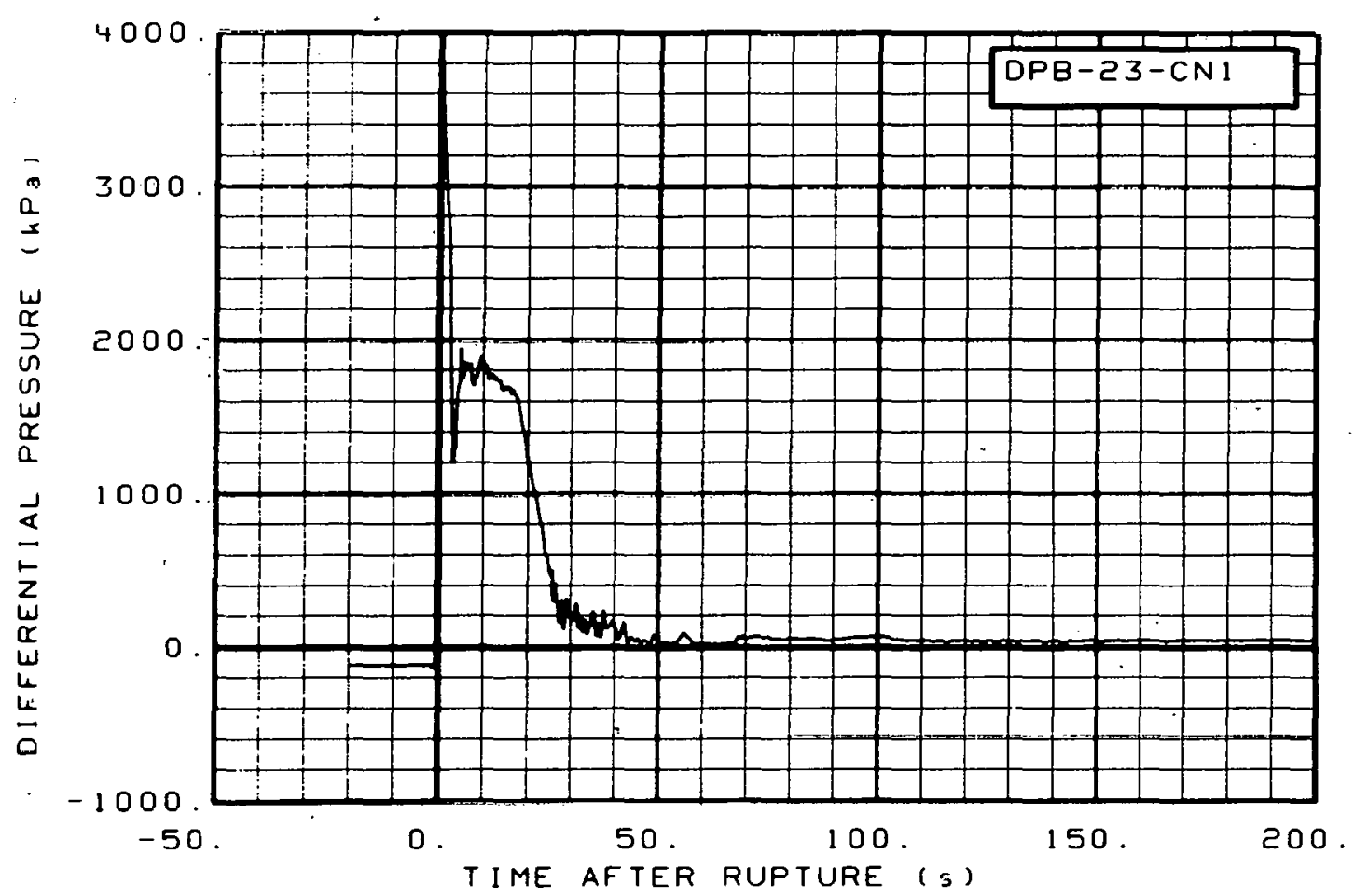

Fig. 17.9 Differential pressure in broken loop (DPB-23-CN1), from -20 to $200 \mathrm{~s}$.

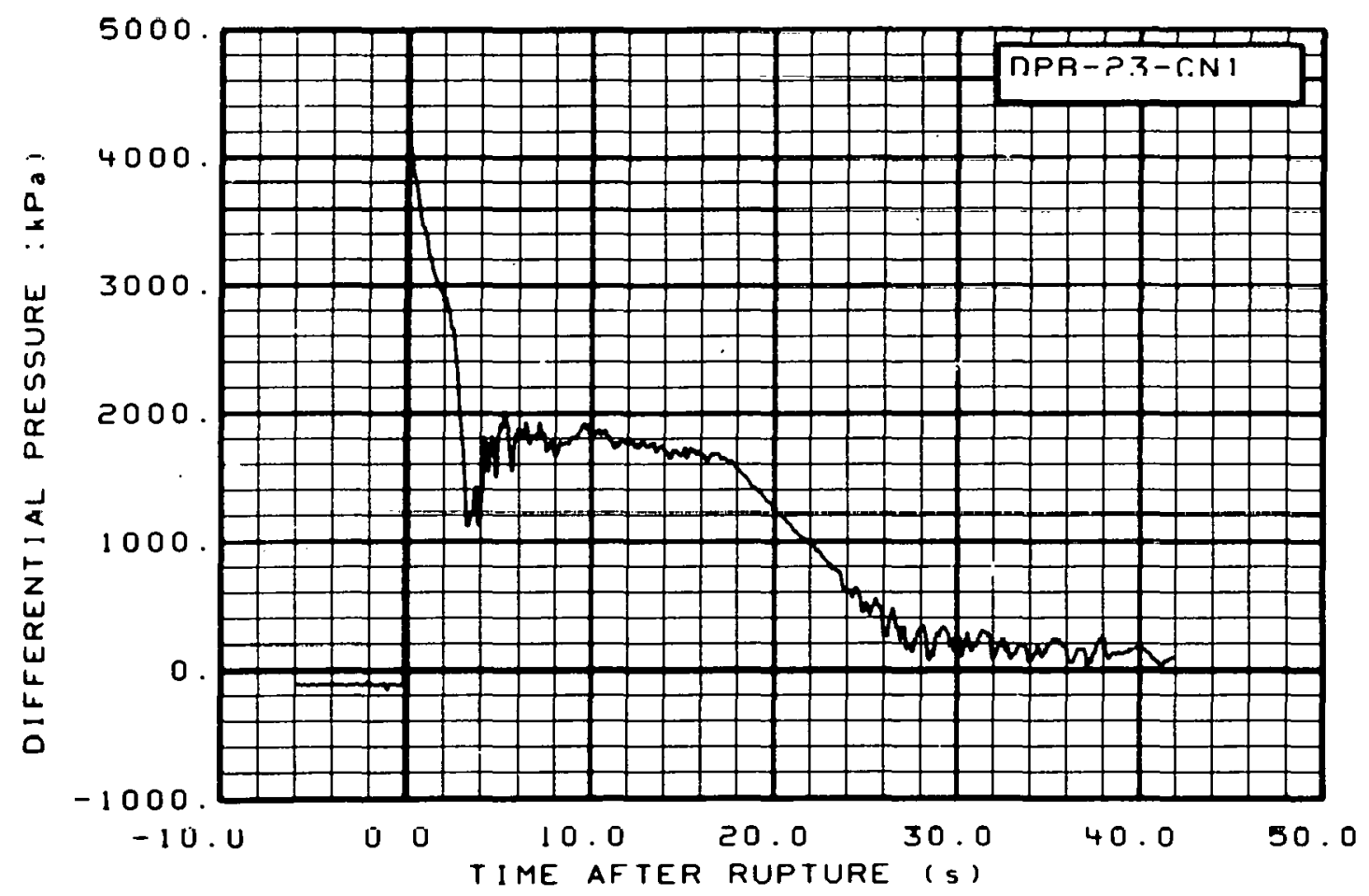

Fig. 180 Differential pressure in broken loop (DPB-23-CN1), from -6 to $42 \mathrm{~s}$. 


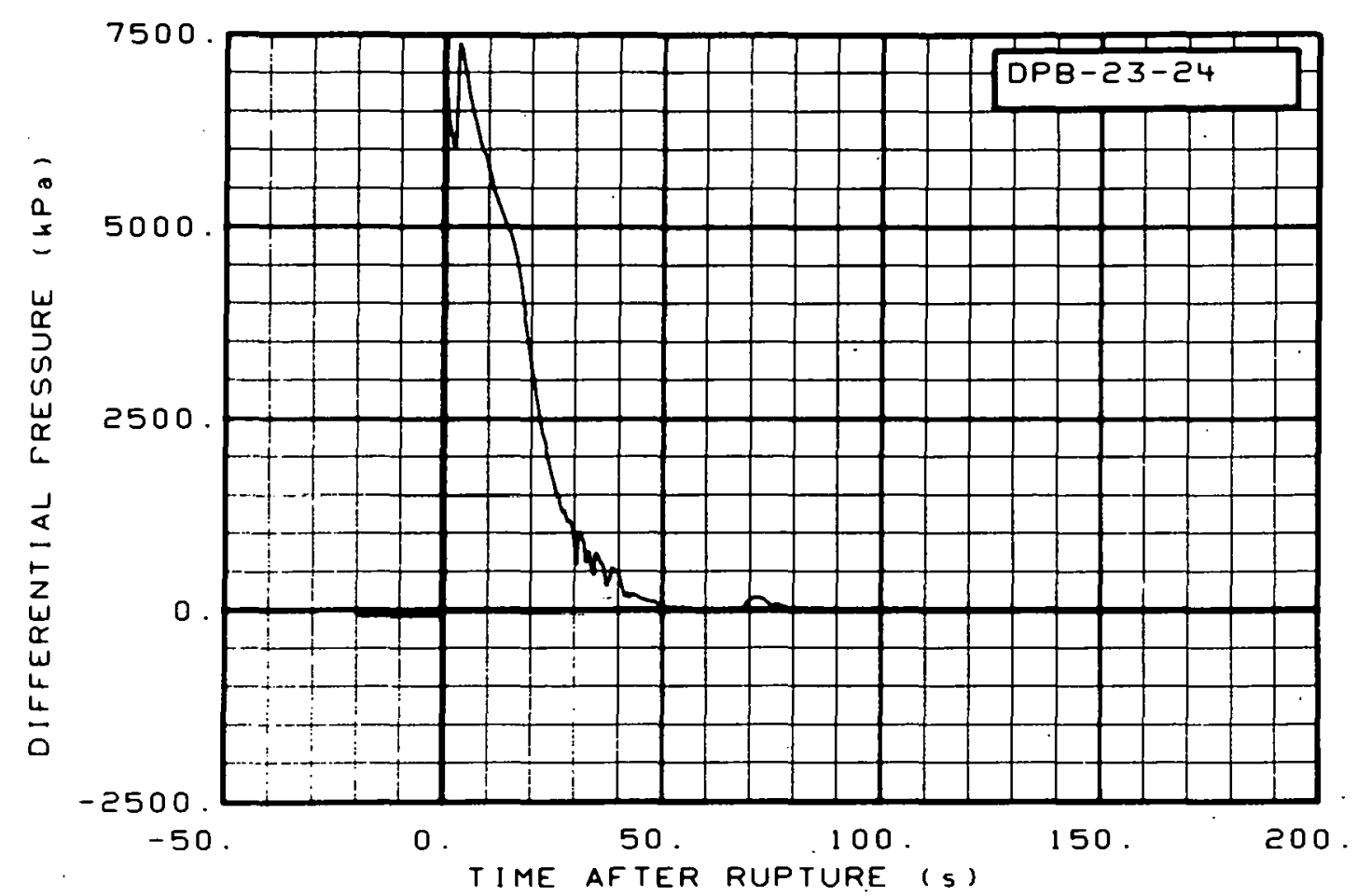

Fig. 181 Differential pressure in broken loop (DPB-23-24), from -20 to $200 \mathrm{~s}$.

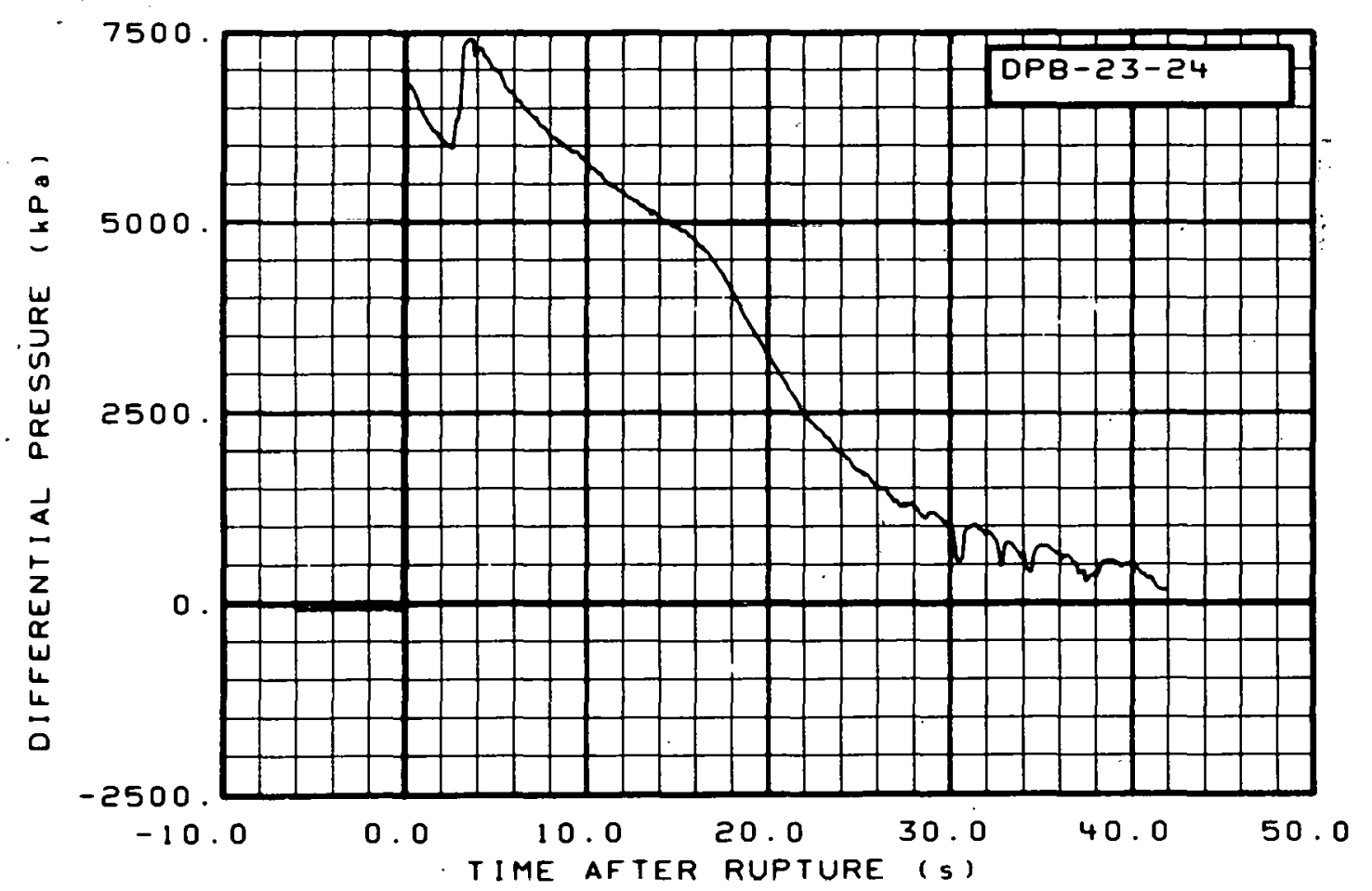

Fig. 182 Differential pressure in broken loop (DPB-23-24), from -6 t.o $42 \mathrm{~s}$. 


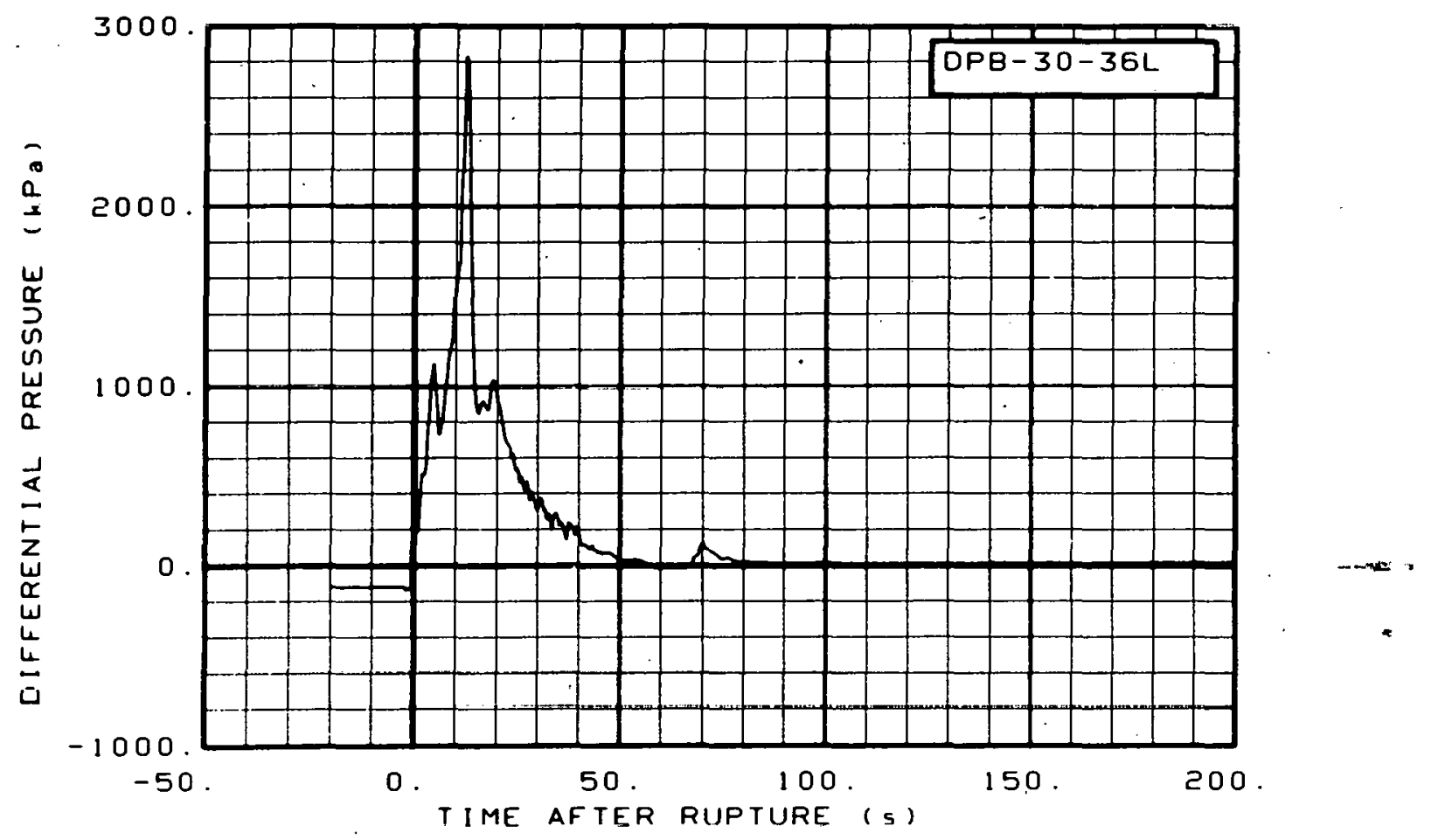

Fig. 183 Differential pressure in broken loop (DPB-30-36L), from -20 to $200 \mathrm{~s}$.

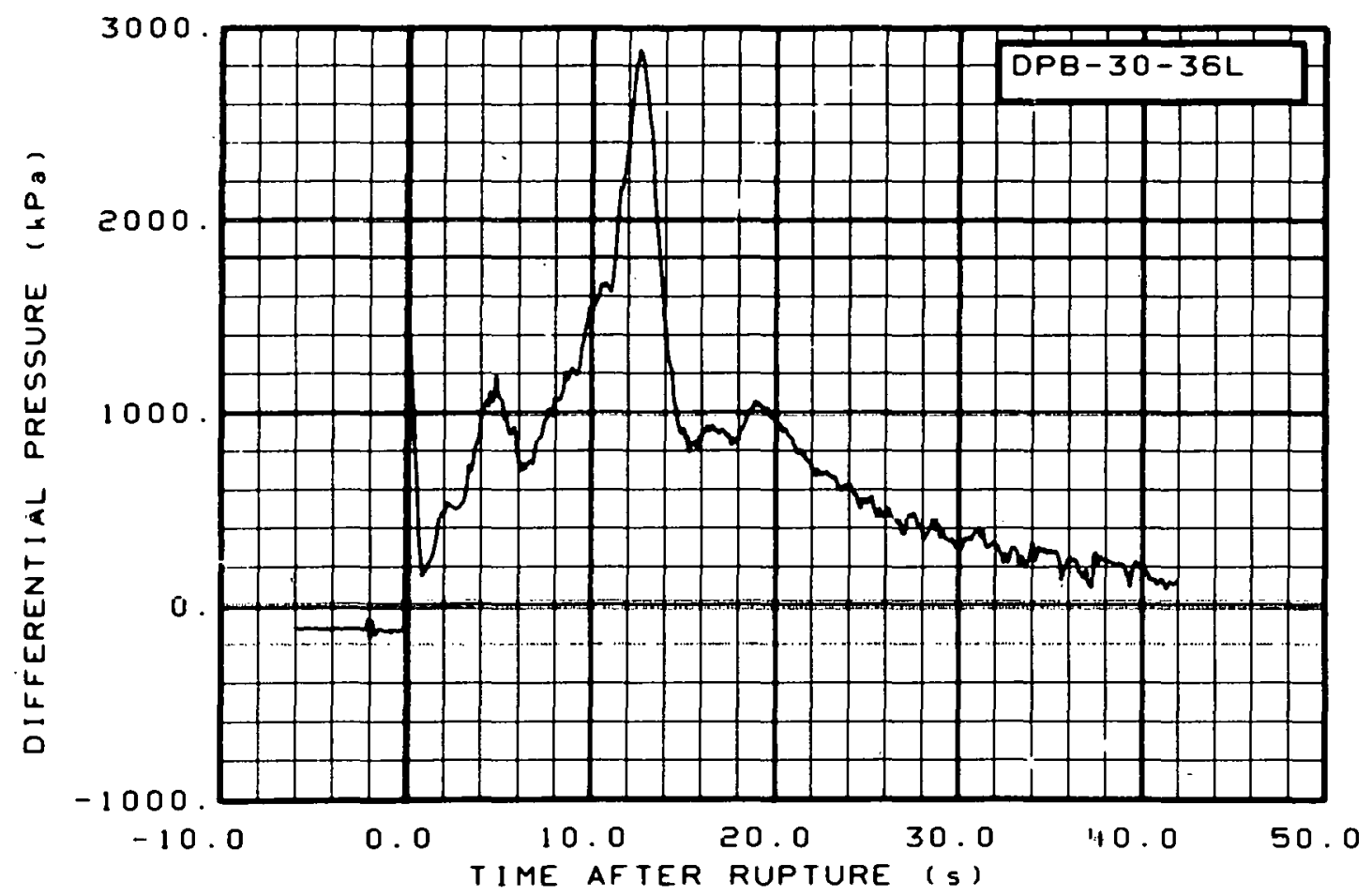

Fig. 184 Differential pressure in broken loop (DPB-30-36L), from -6 to $42 \mathrm{~s}$. 


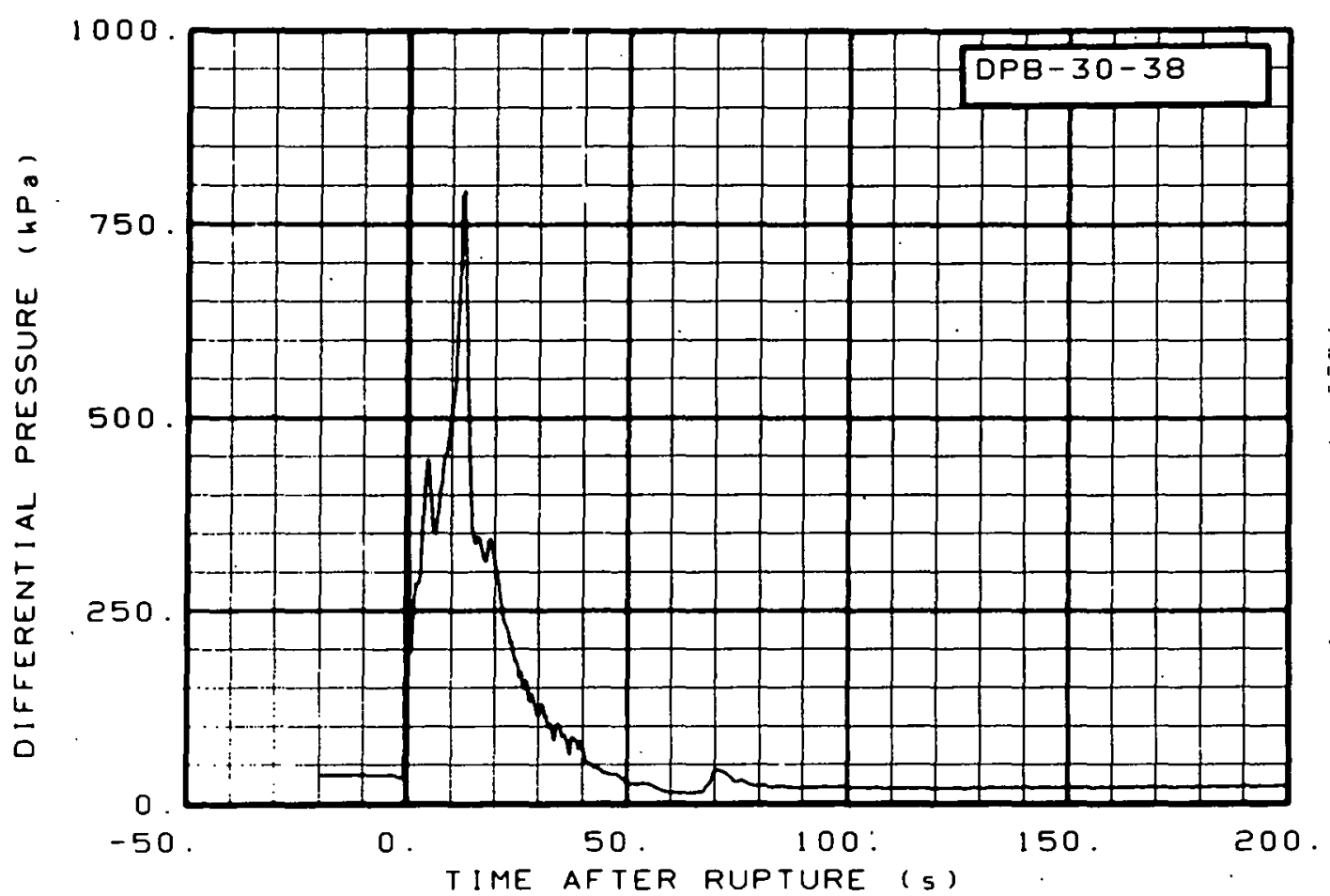

Fig. 185 Differential pressure in broken loop (DPB-30-38), from -20 to $200 \mathrm{~s}$.

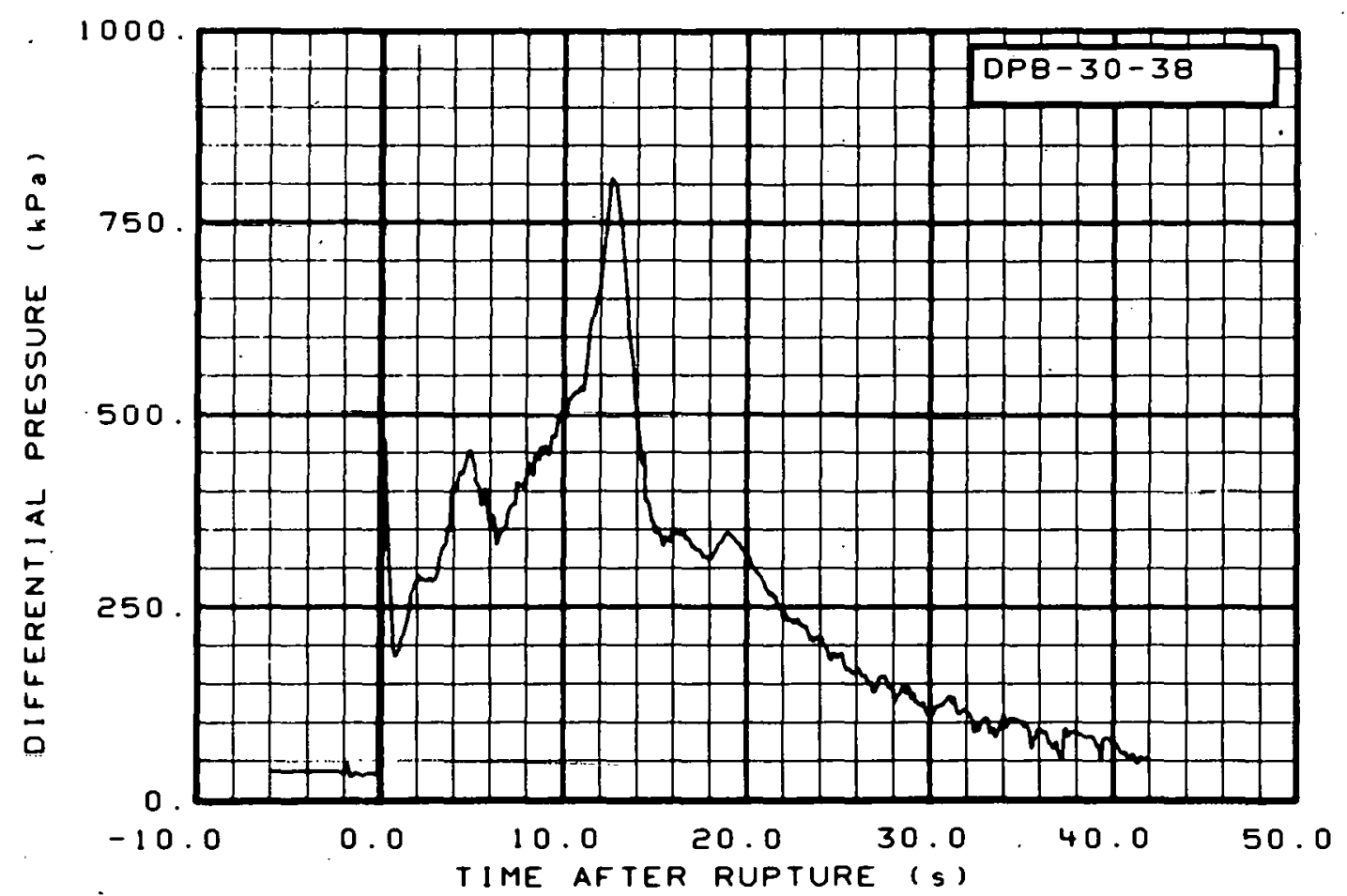

Fig. 186 Differential pressure in broken loop (DPB-30-38), from -6 to $42 \mathrm{~s}$. 


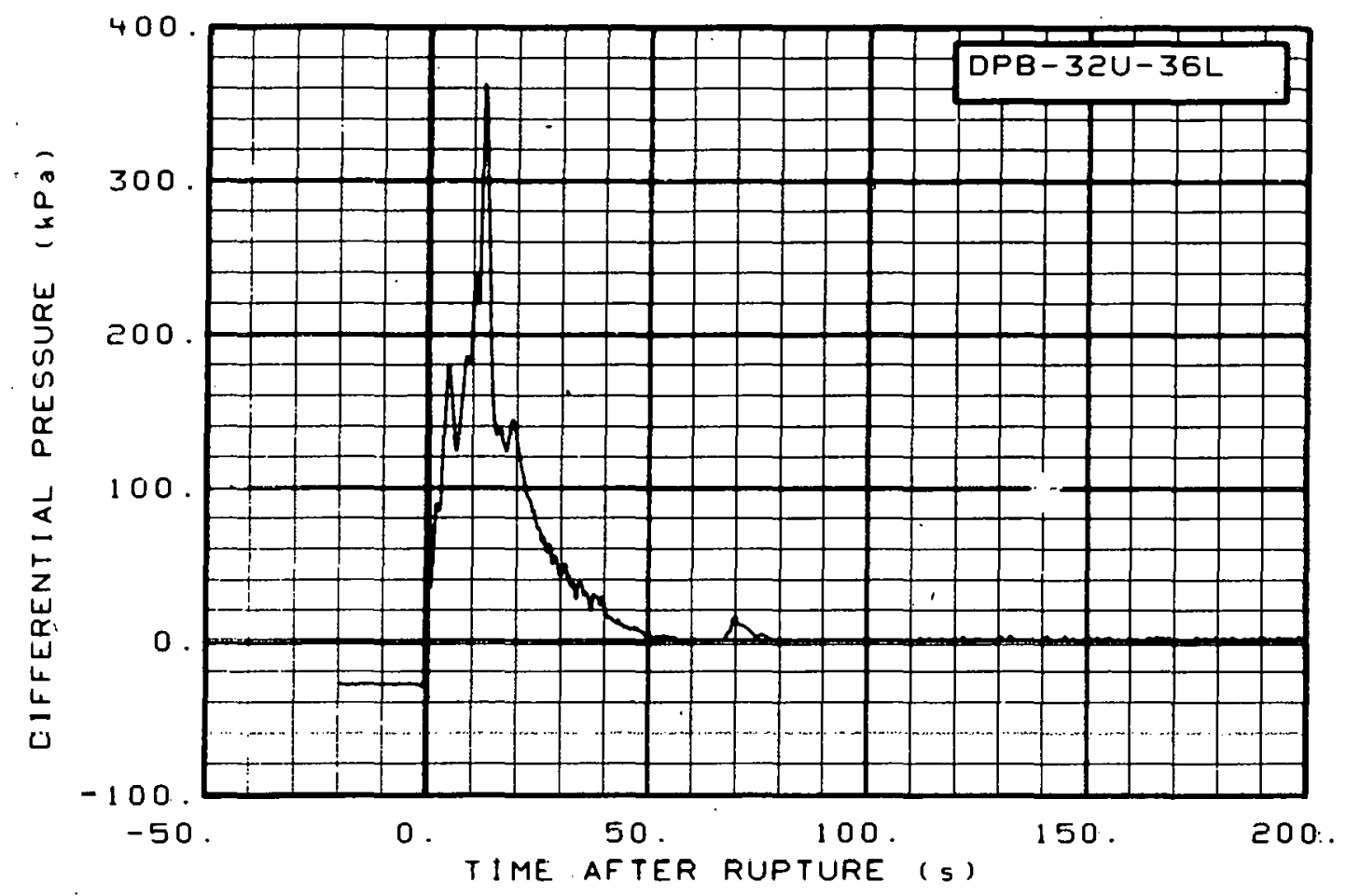

Fig. 187 Differential pressure in broken loop (DPB-32U-36L), from -20 to $200 \mathrm{~s}$.

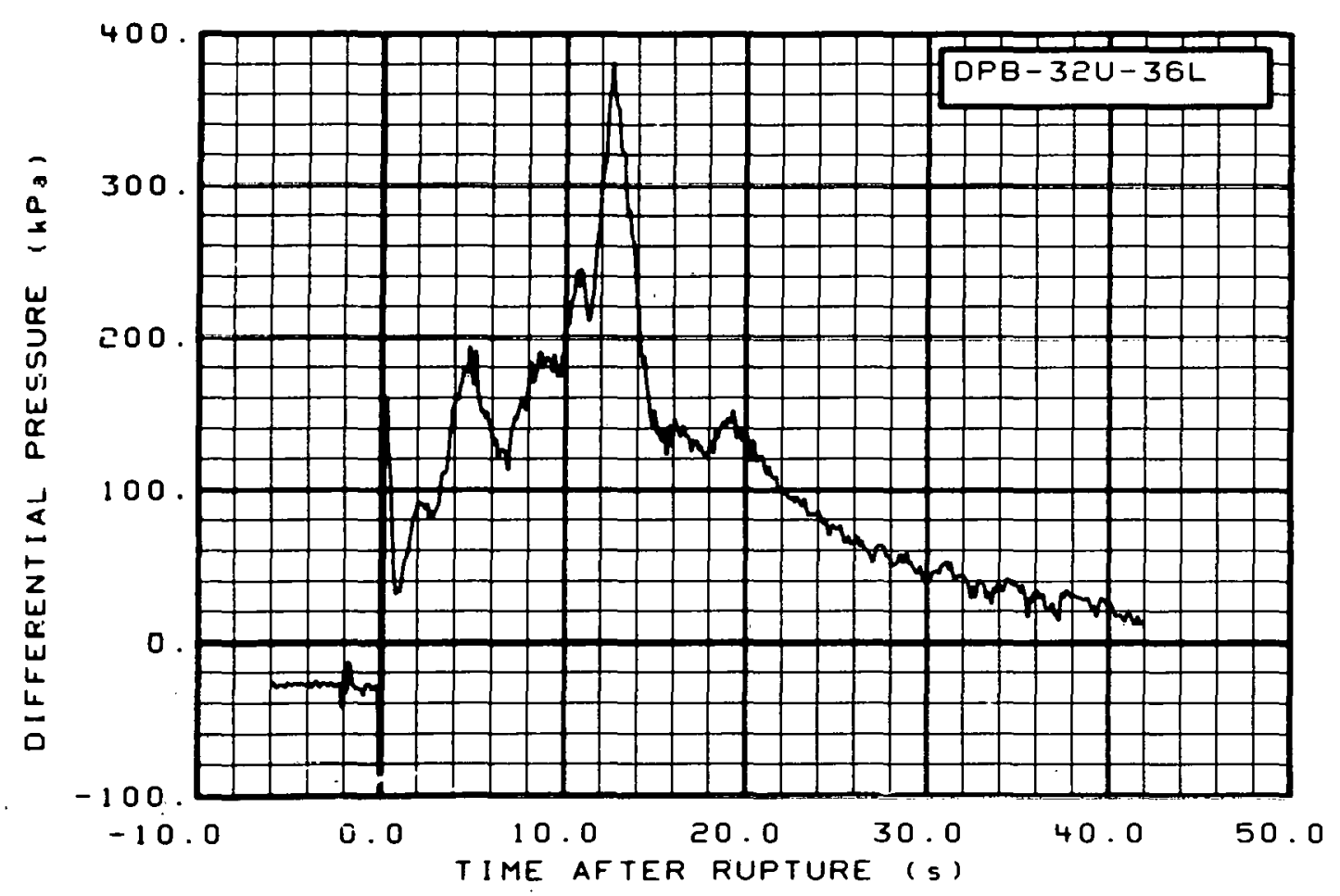

Fig. 188 Differential pressure in broken loop (DPB-32U-36L), from -6 to $42 \mathrm{~s}$. 


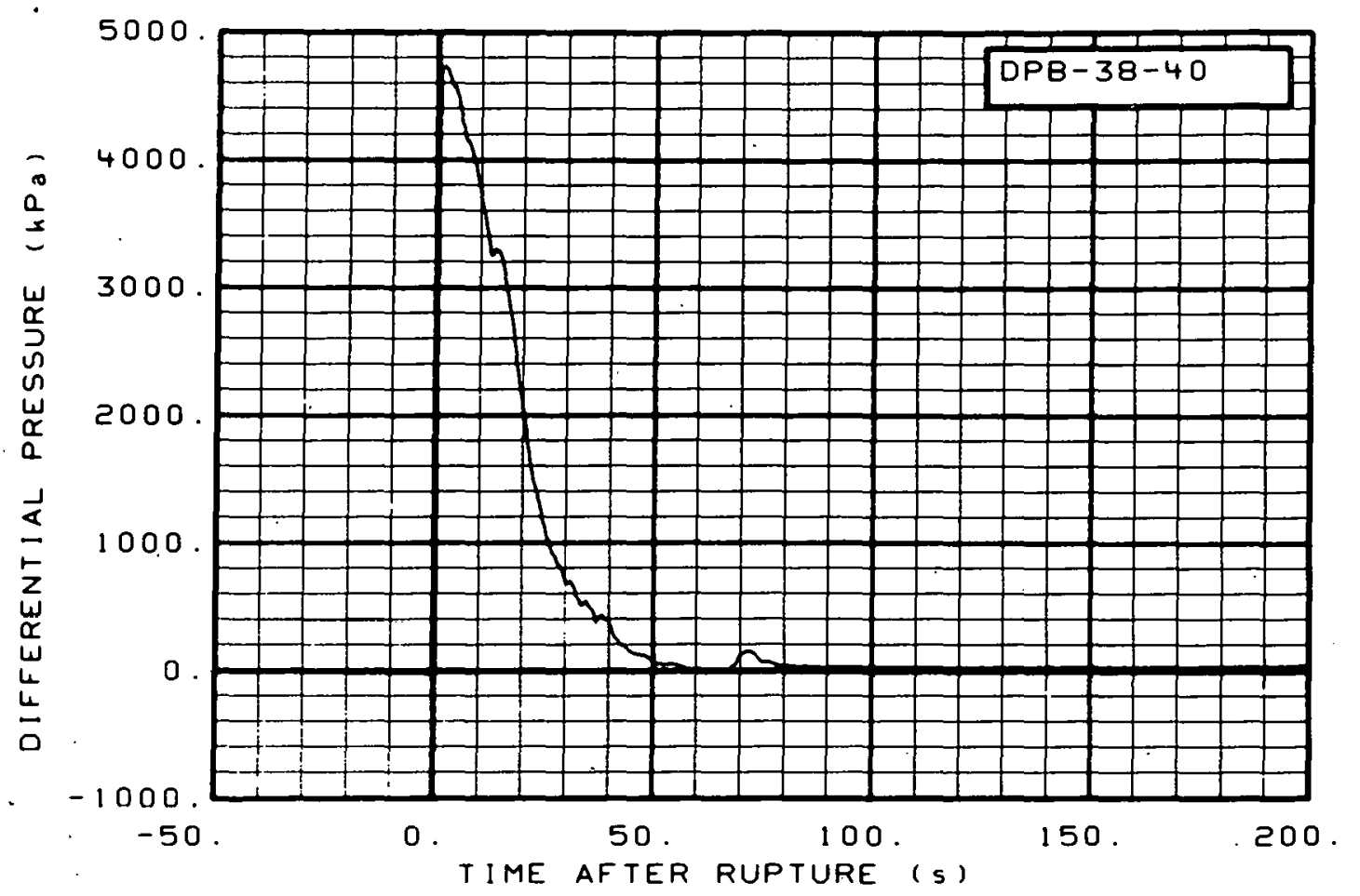

Fig. 189 Differential pressure in broken loop (DPB-38-40), from -20 to $200 \mathrm{~s}$.

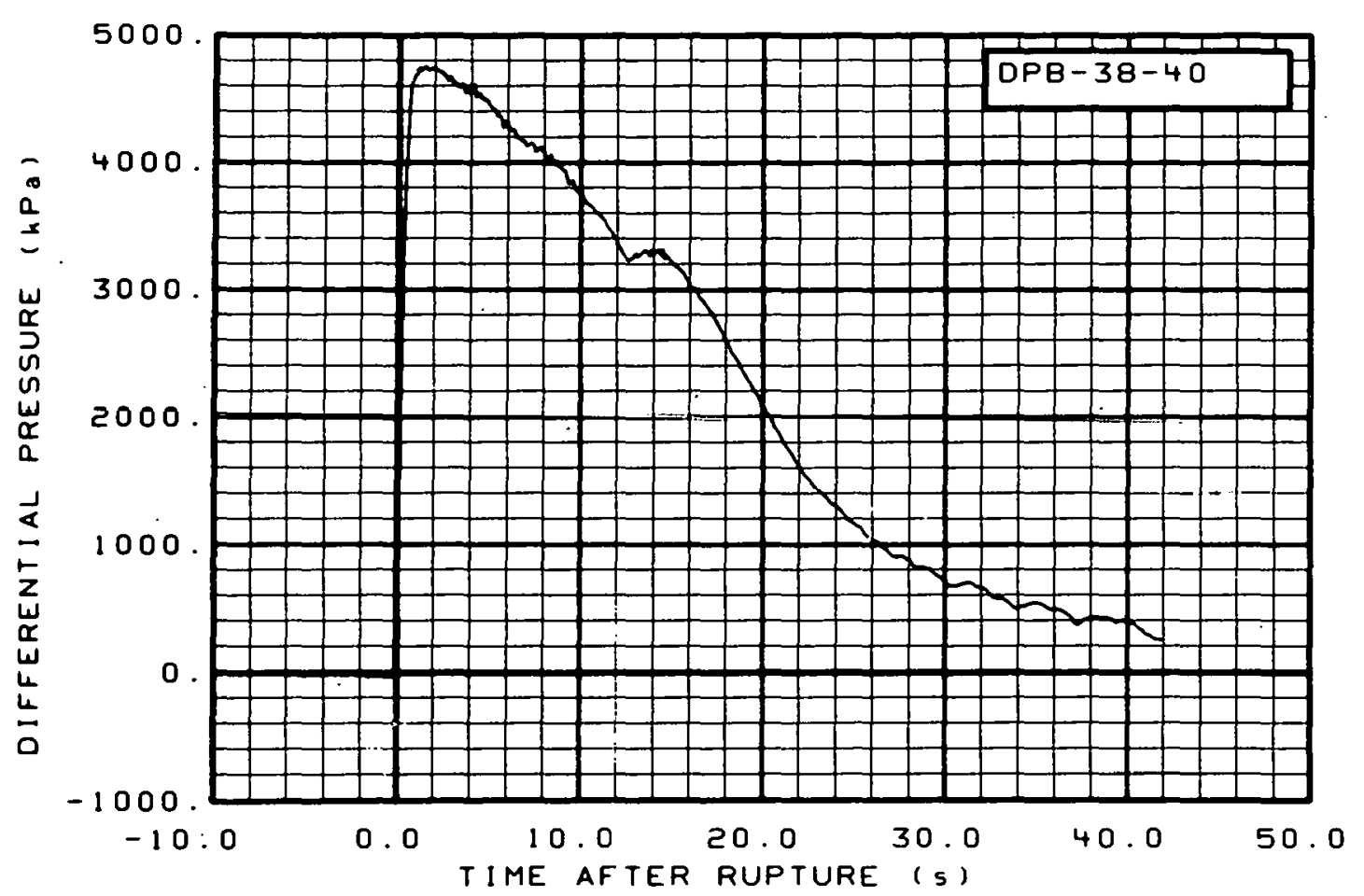

Fig. 190 Differential pressure in broken loop (DPB-38-40), from -6 to $42 \mathrm{~s}$. 


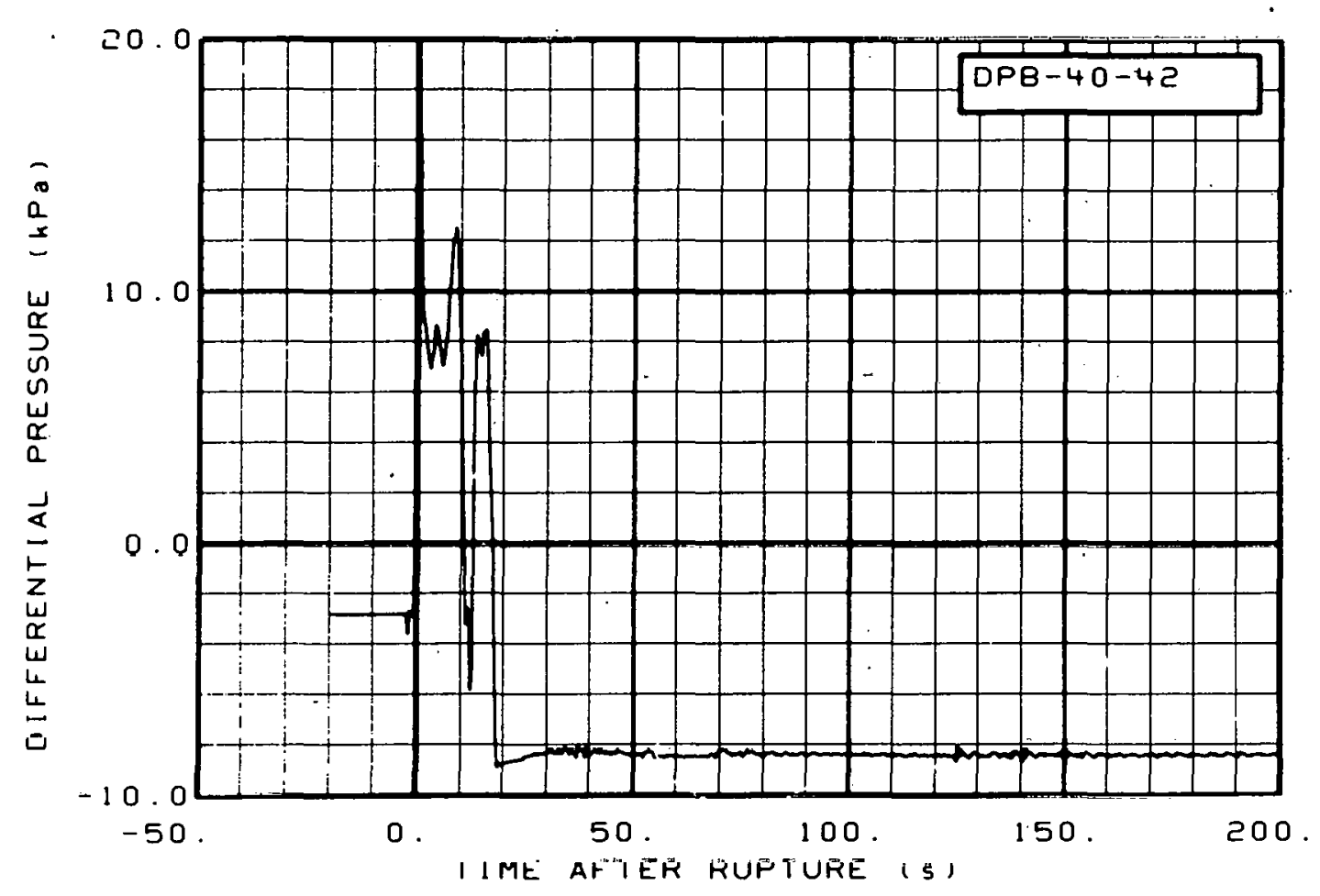

Fig. 191 Differential pressure in broken loop (DPB-40-42), from -20 to $200 \mathrm{~s}$.

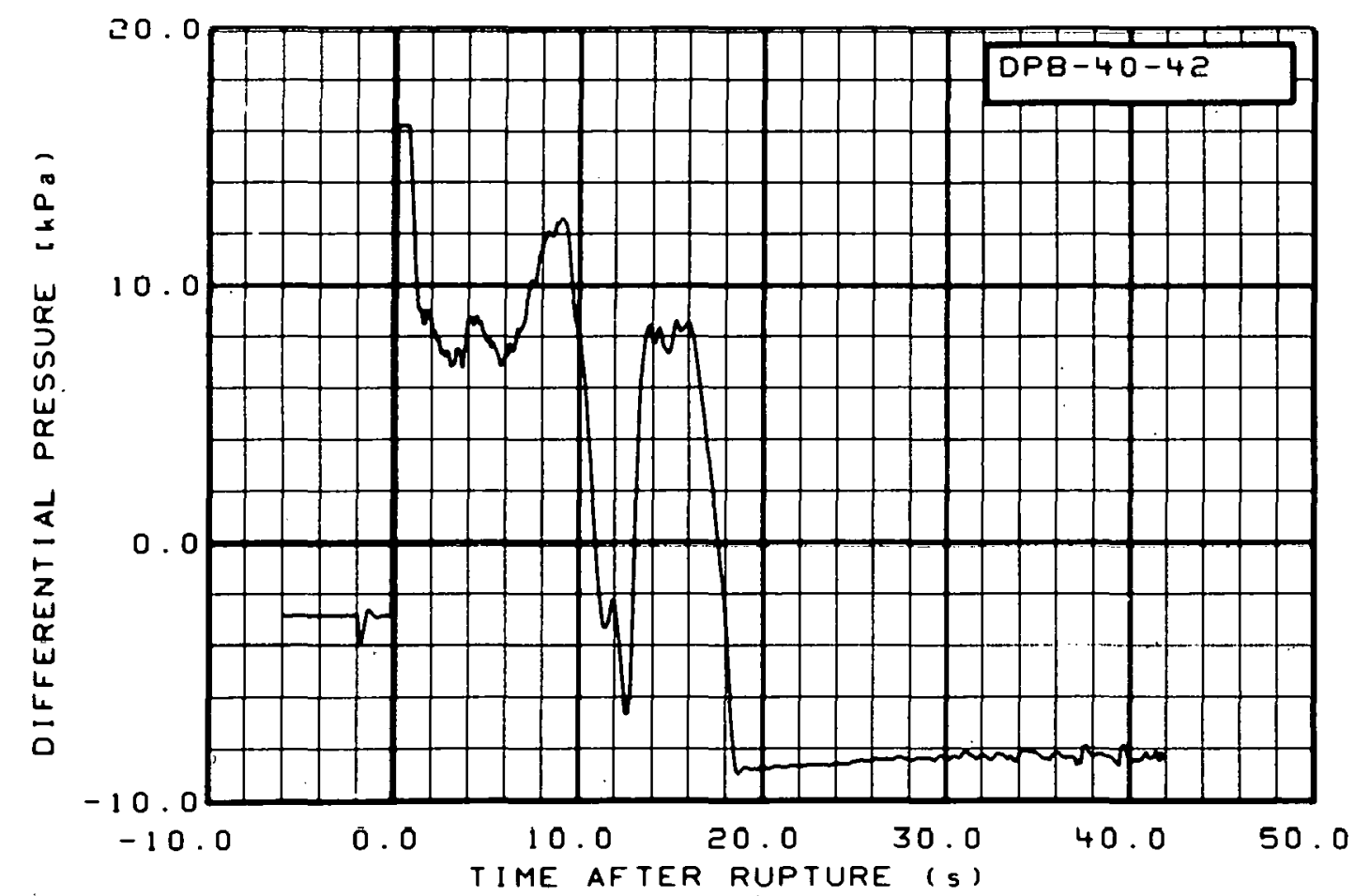

Fig. 192 Differential pressure in broken loop (DPB-40-42), from -6 to $42 \mathrm{~s}$. 


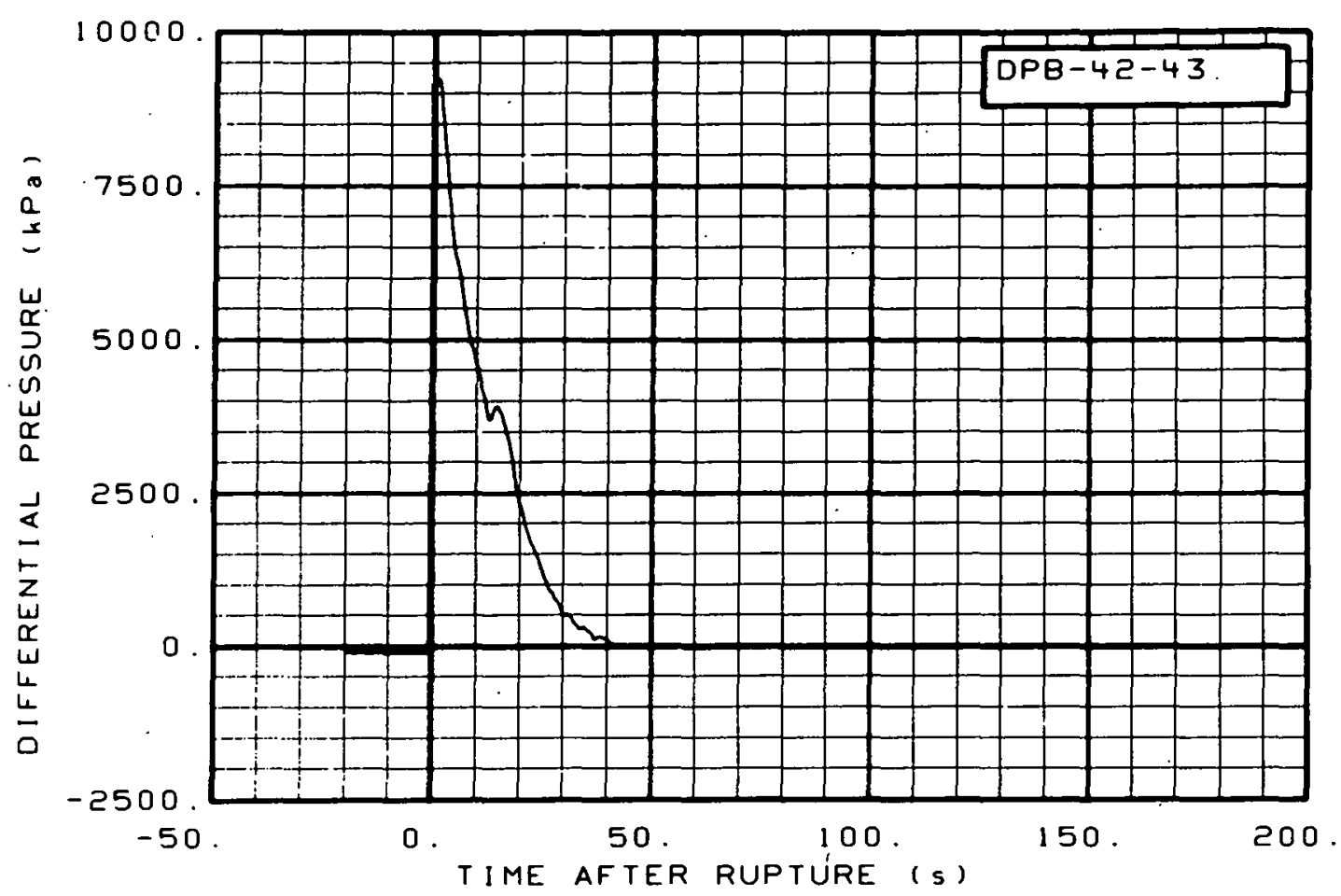

Fig. 193 Differential pressure in broken loop (DPB-42-43), from -20 to $200 \mathrm{~s}$.

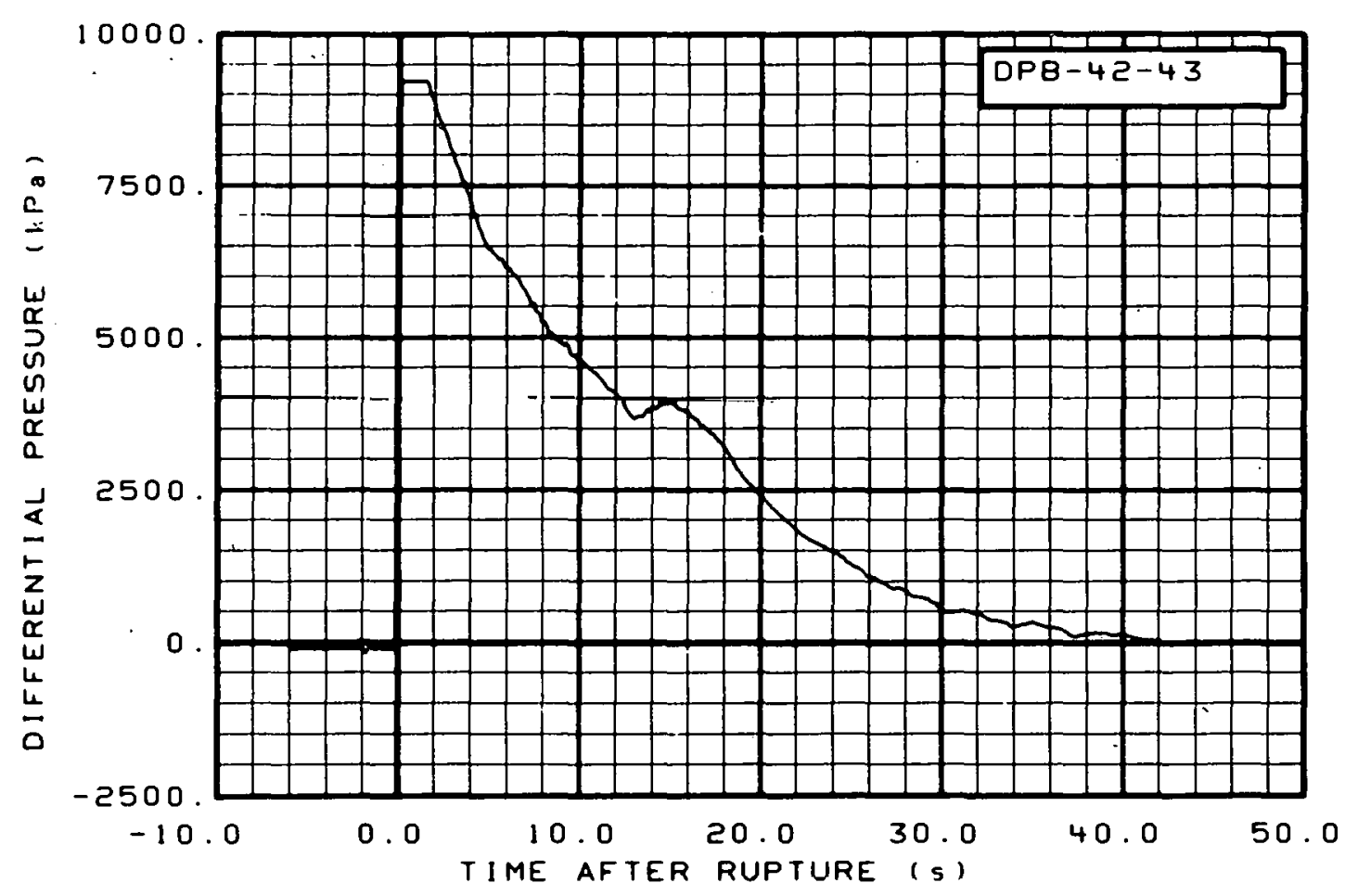

Fig. 194 Differential pressure in broken loop (DPB-42-43), from -6 to $42 \mathrm{~s}$. 


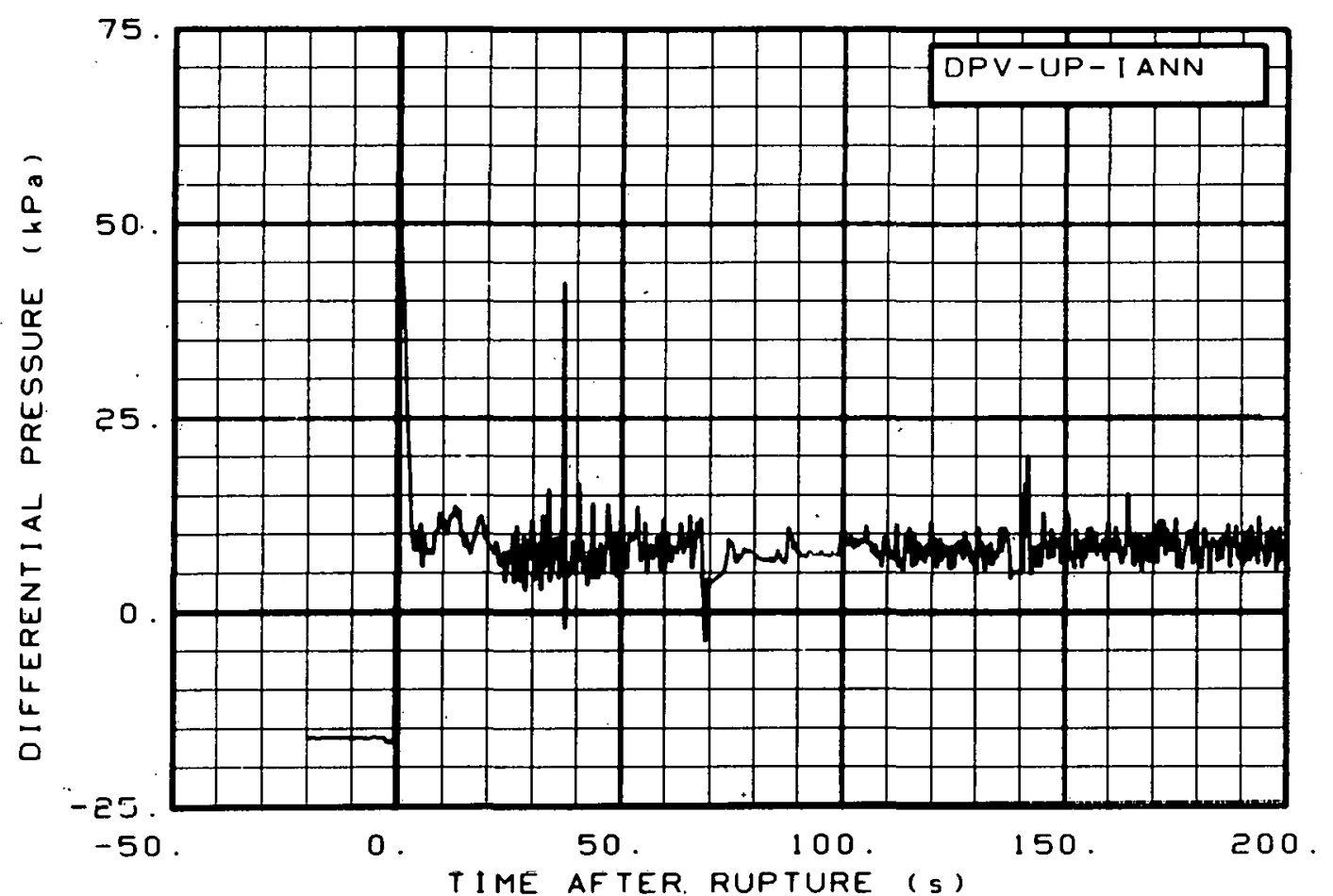

Fig. 195 Differential pressure in vessel (DPV-UP-IANN), from -20 to $200 \mathrm{~s}$.

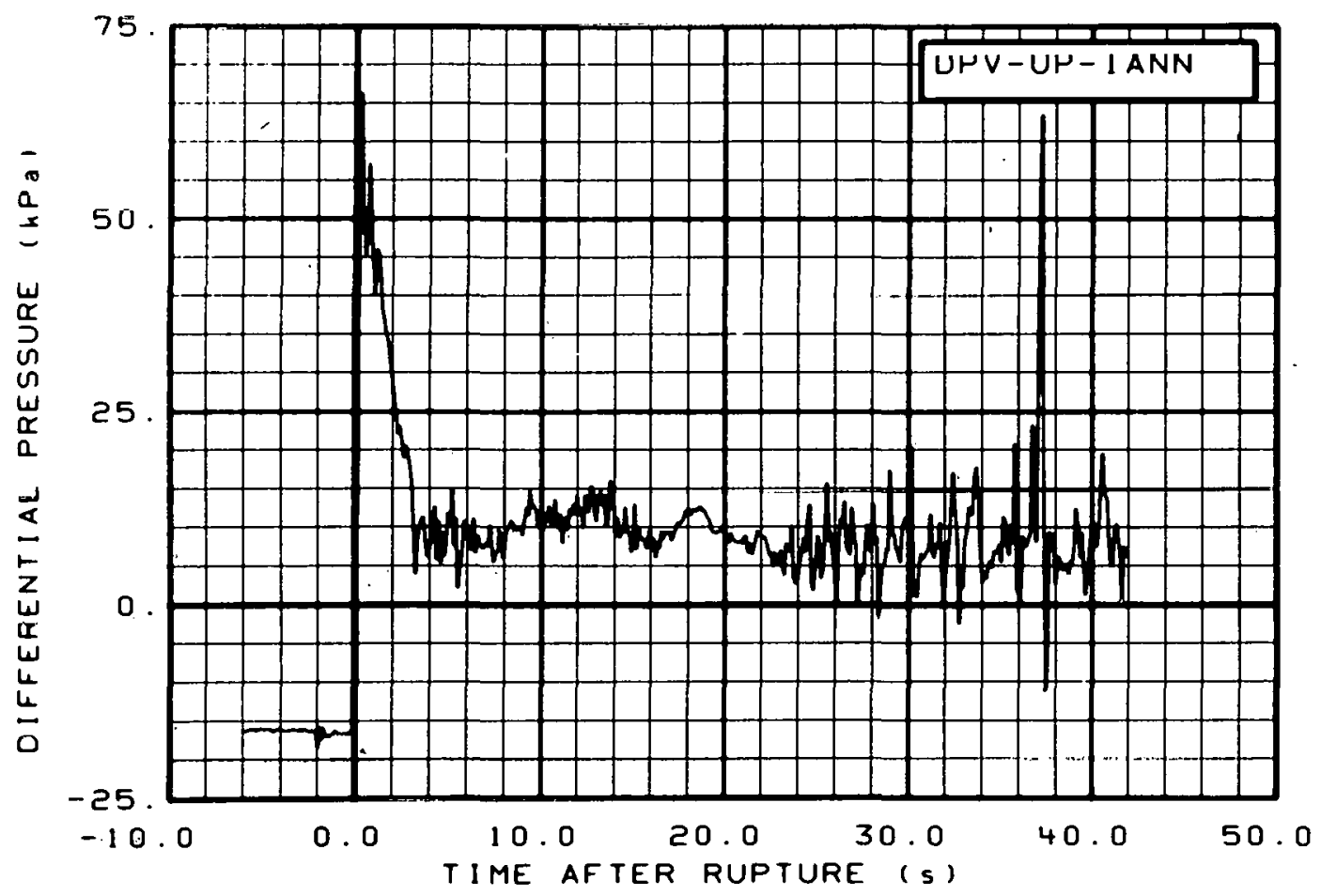

Fig. 196 Differential pressure in vessel (DPV-UP-IANN), from -6 to $42 \mathrm{~s}$. 


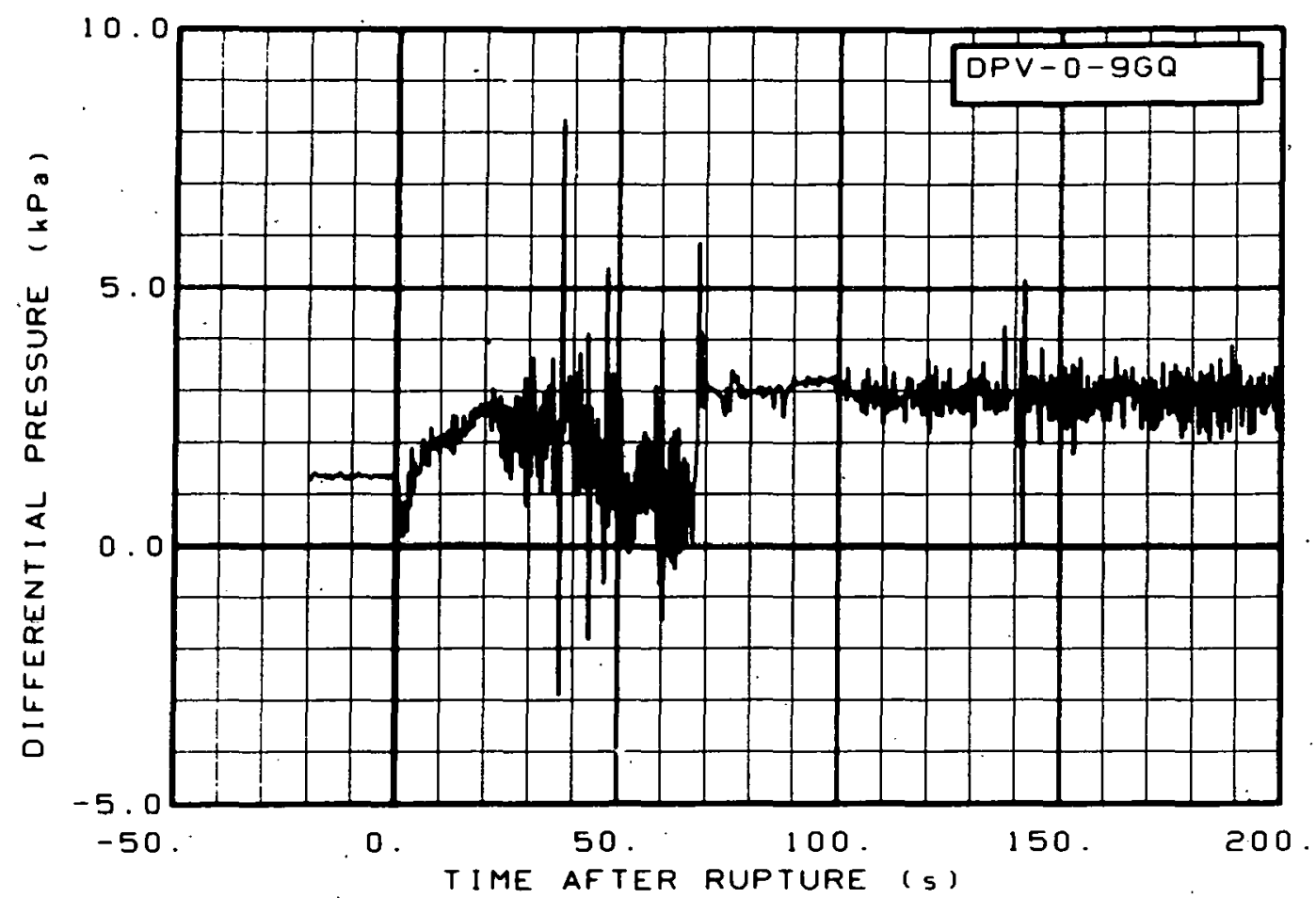

Fig. 197 Differential pressure in vessel (DPV-0-9GQ), from -20 to $200 \mathrm{~s}$.

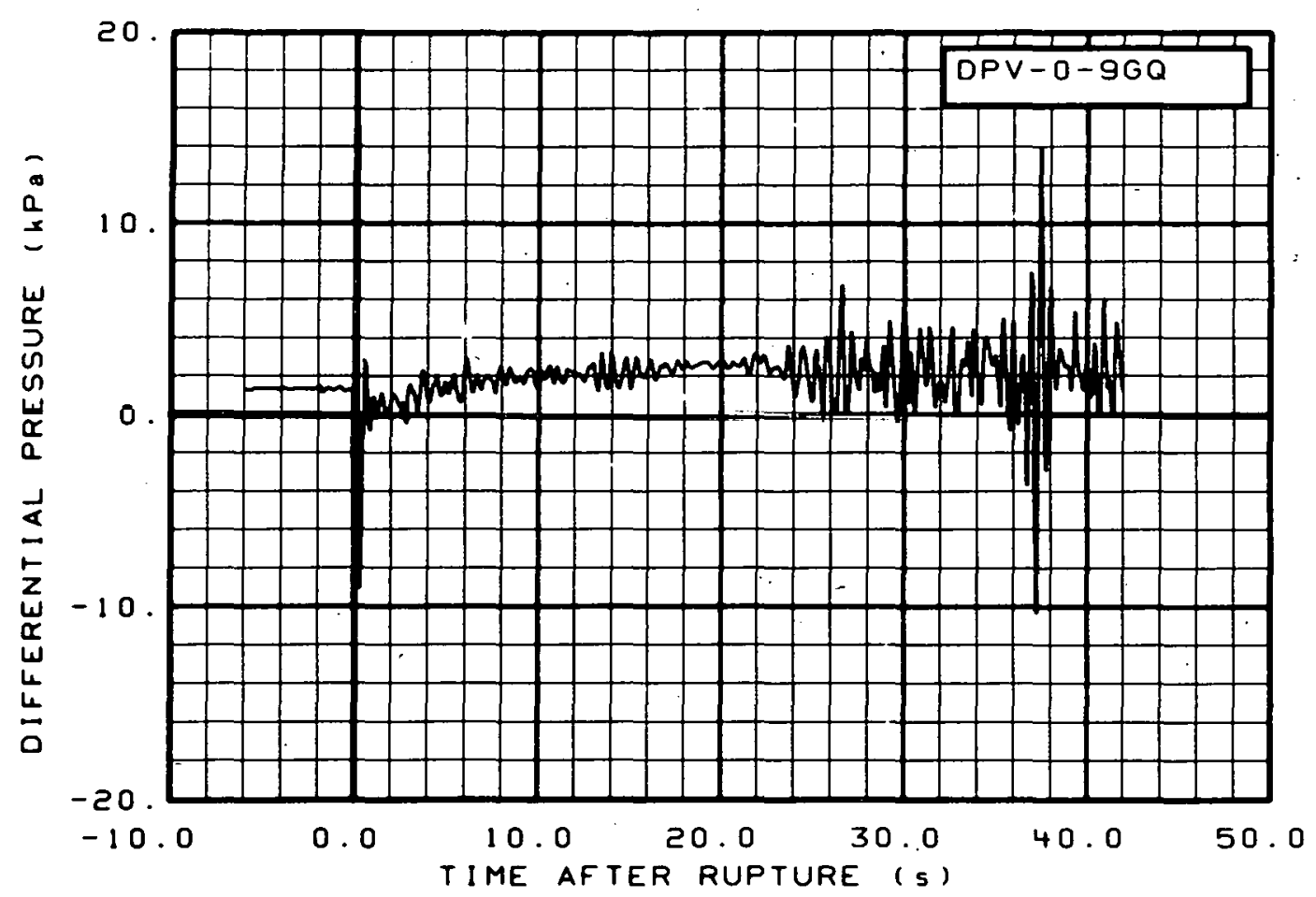

Fig. 198 Differential pressure in vessel (DPV-0-96Q), from -6 to $42 \mathrm{~s}$. 


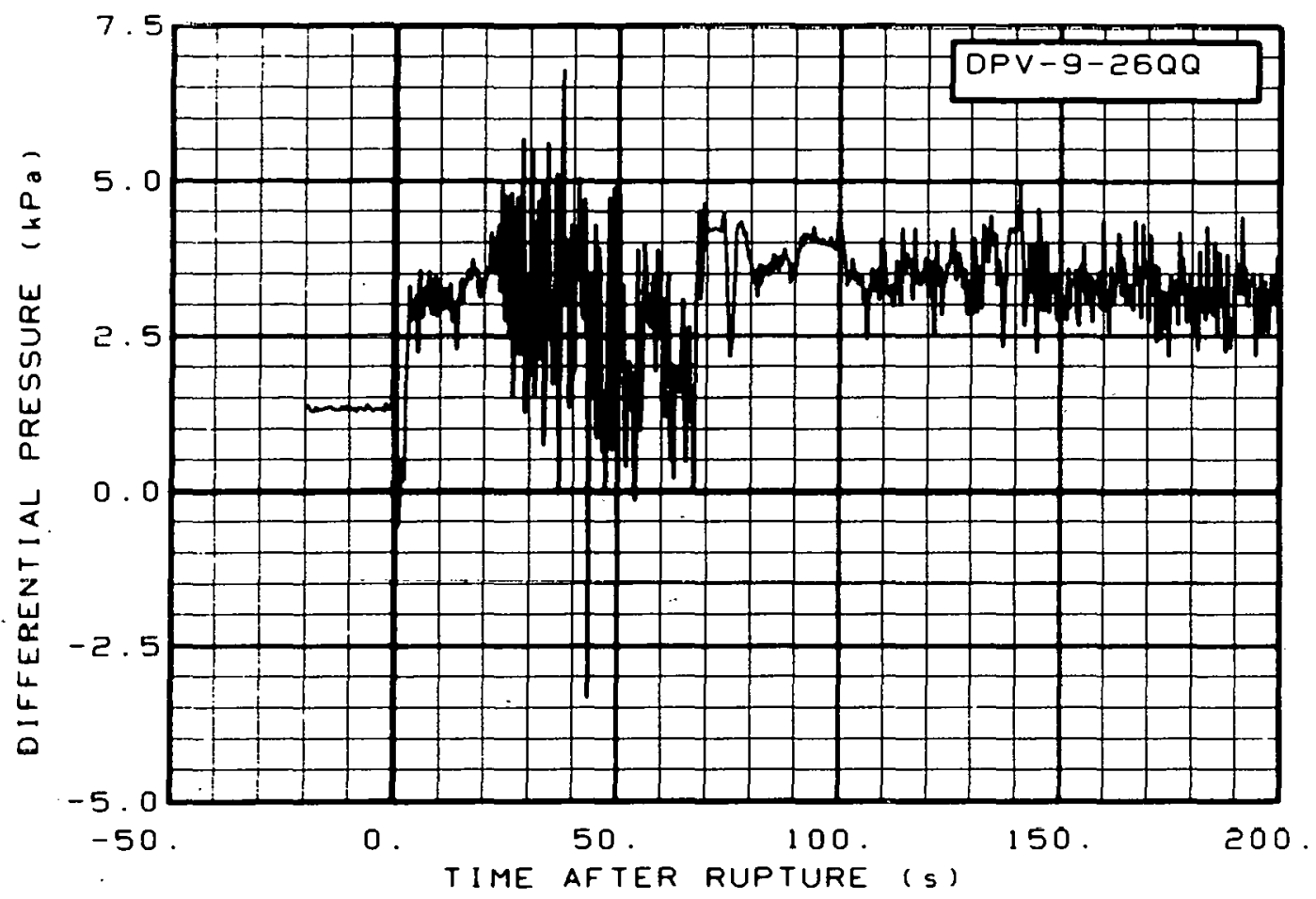

Fig. 199 Differential pressure in vessel (DPV-9-26QQ), from -20 to $200 \mathrm{~s}$.

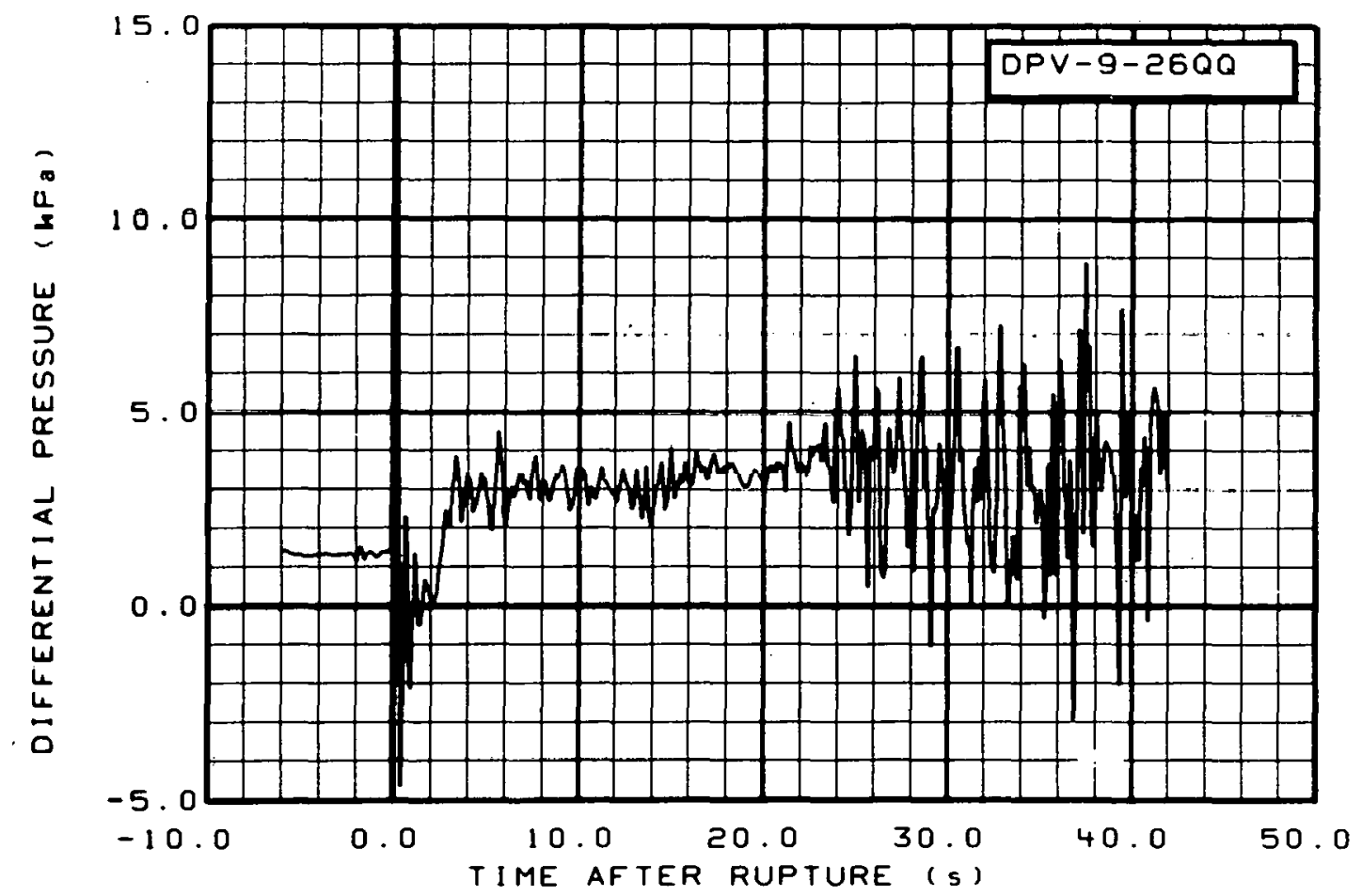

Fig. 200 Differential pressure in vessel (DPV-9-260Q), from -6 to $42 \mathrm{~s}$. 


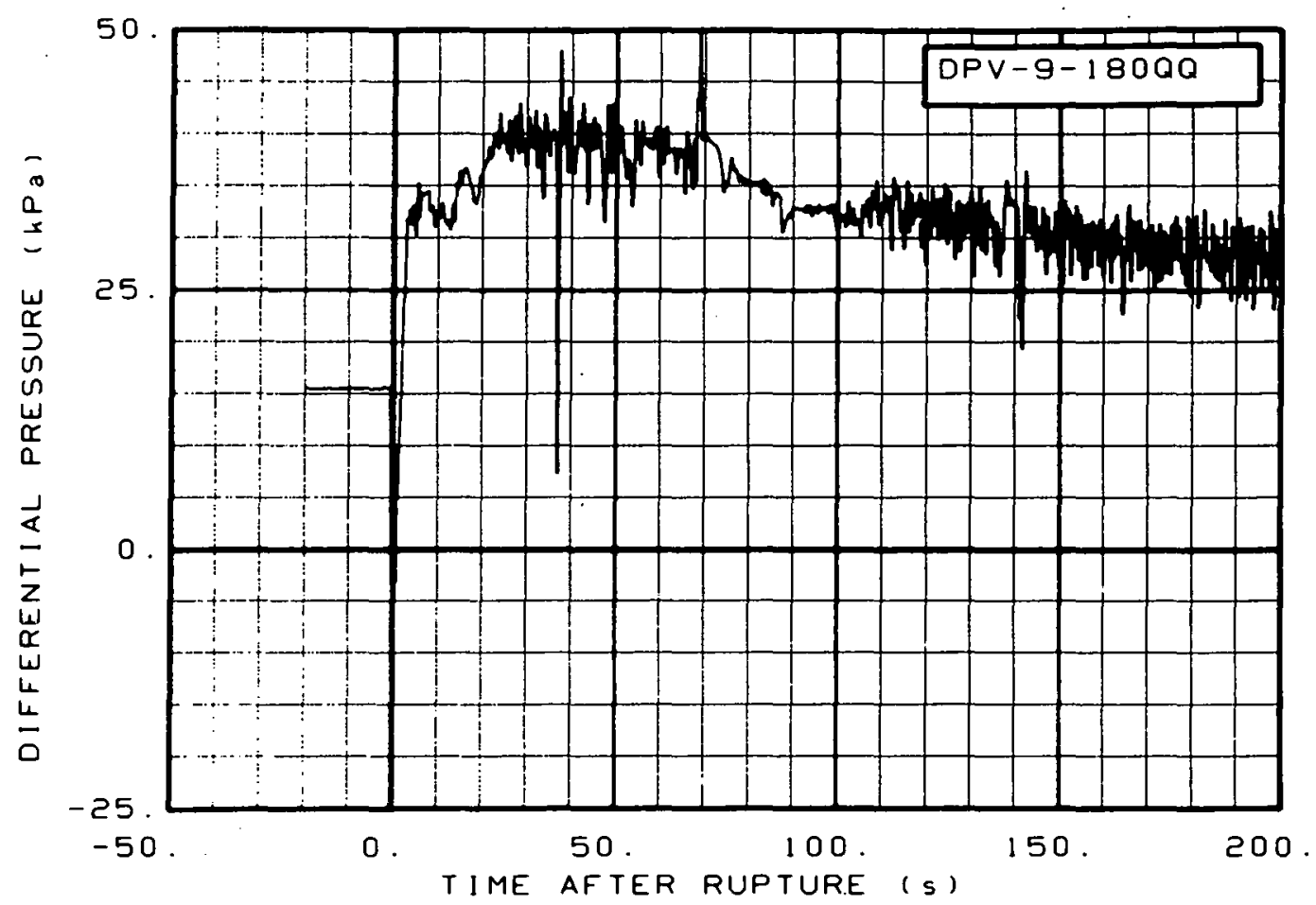

Fig. 201 Differential pressure in vessel (DPV-9-1800Q), from -20 to $200 \mathrm{~s}$.

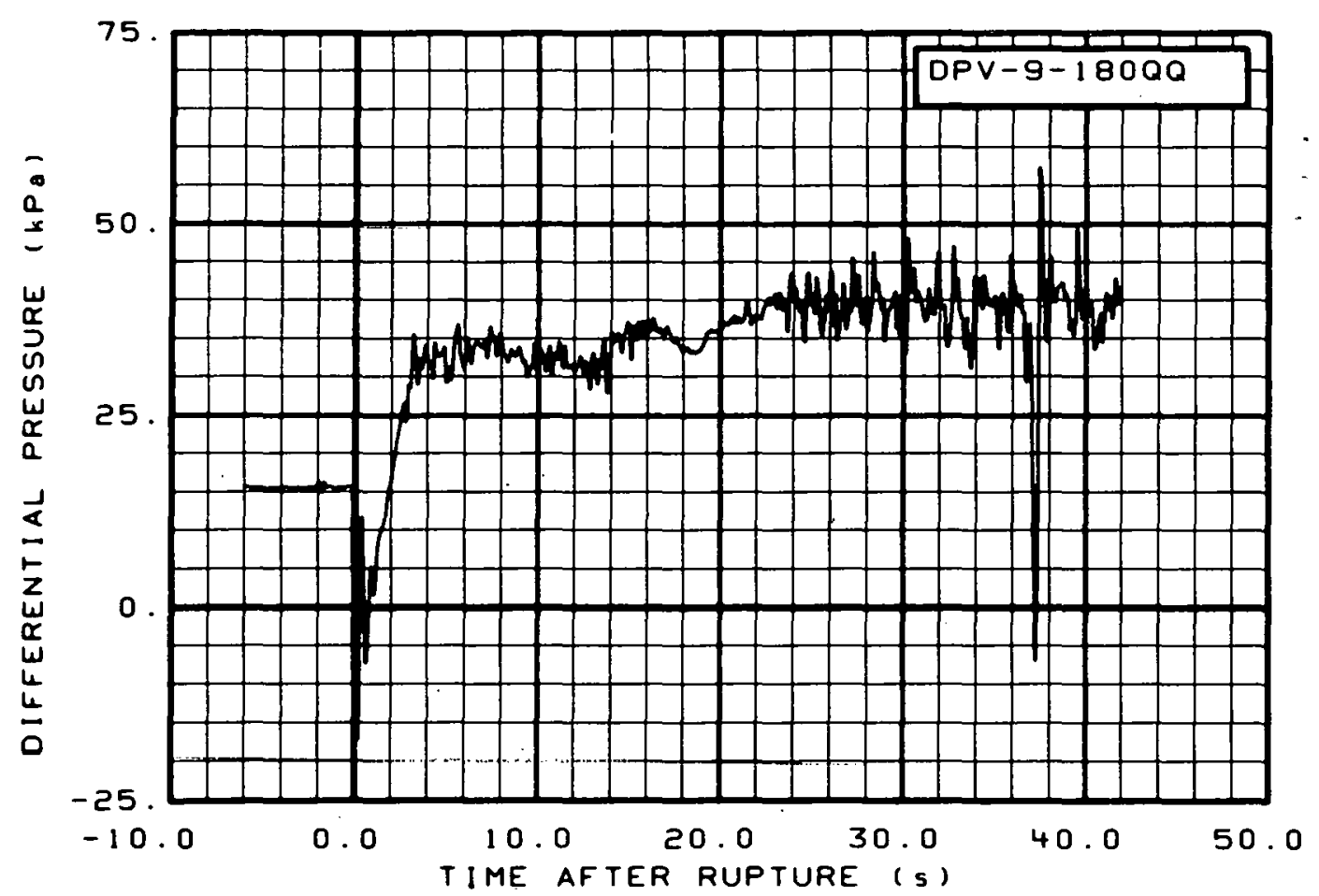

Fig. 202 Differential pressure in vessel (DPV-9-180QQ), from -6 to $42 \mathrm{~s}$. 


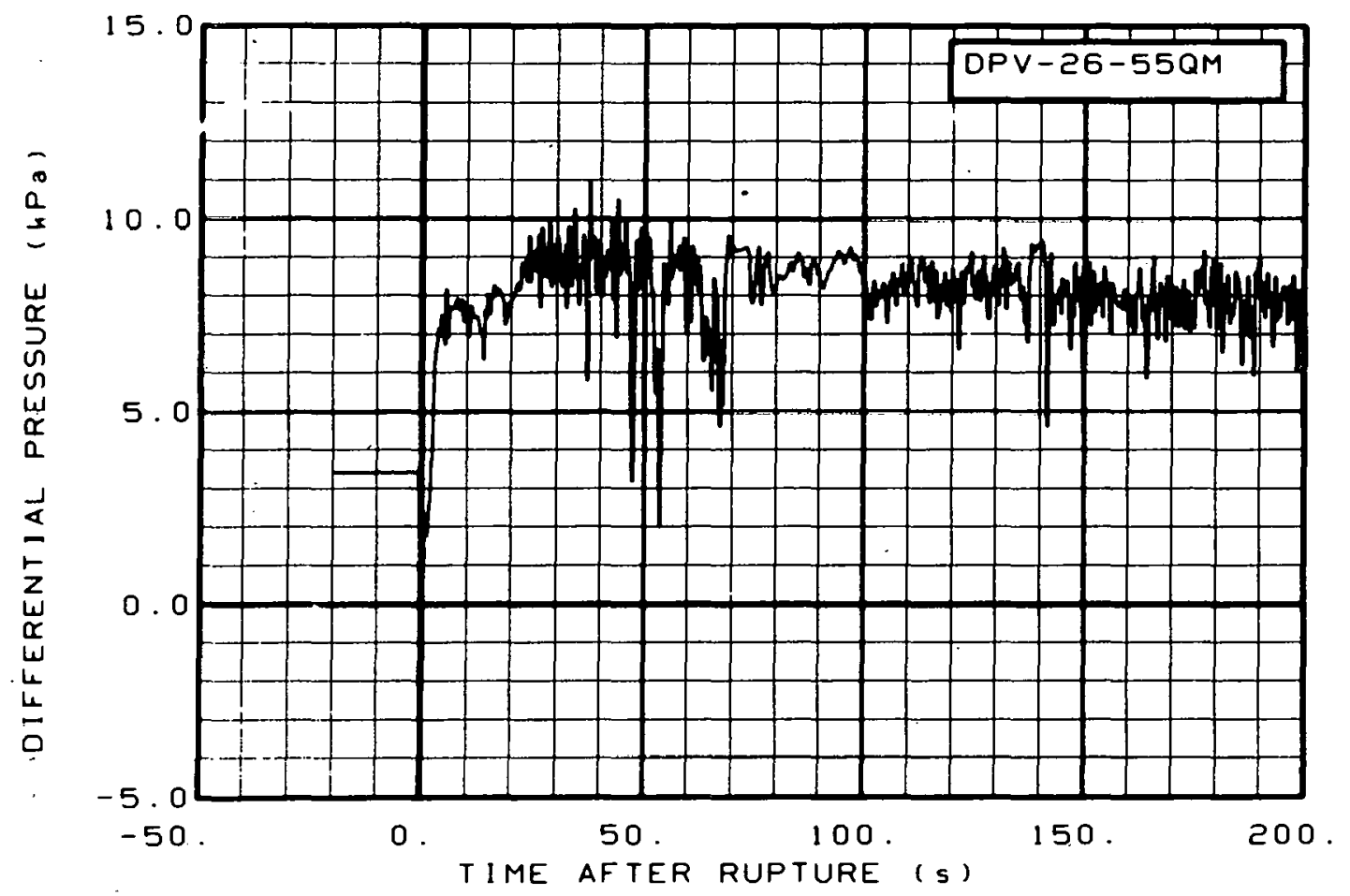

Fig. 203 Differential pressure in vessel (DPV-26-55QM), from -20 to $200 \mathrm{~s}$.

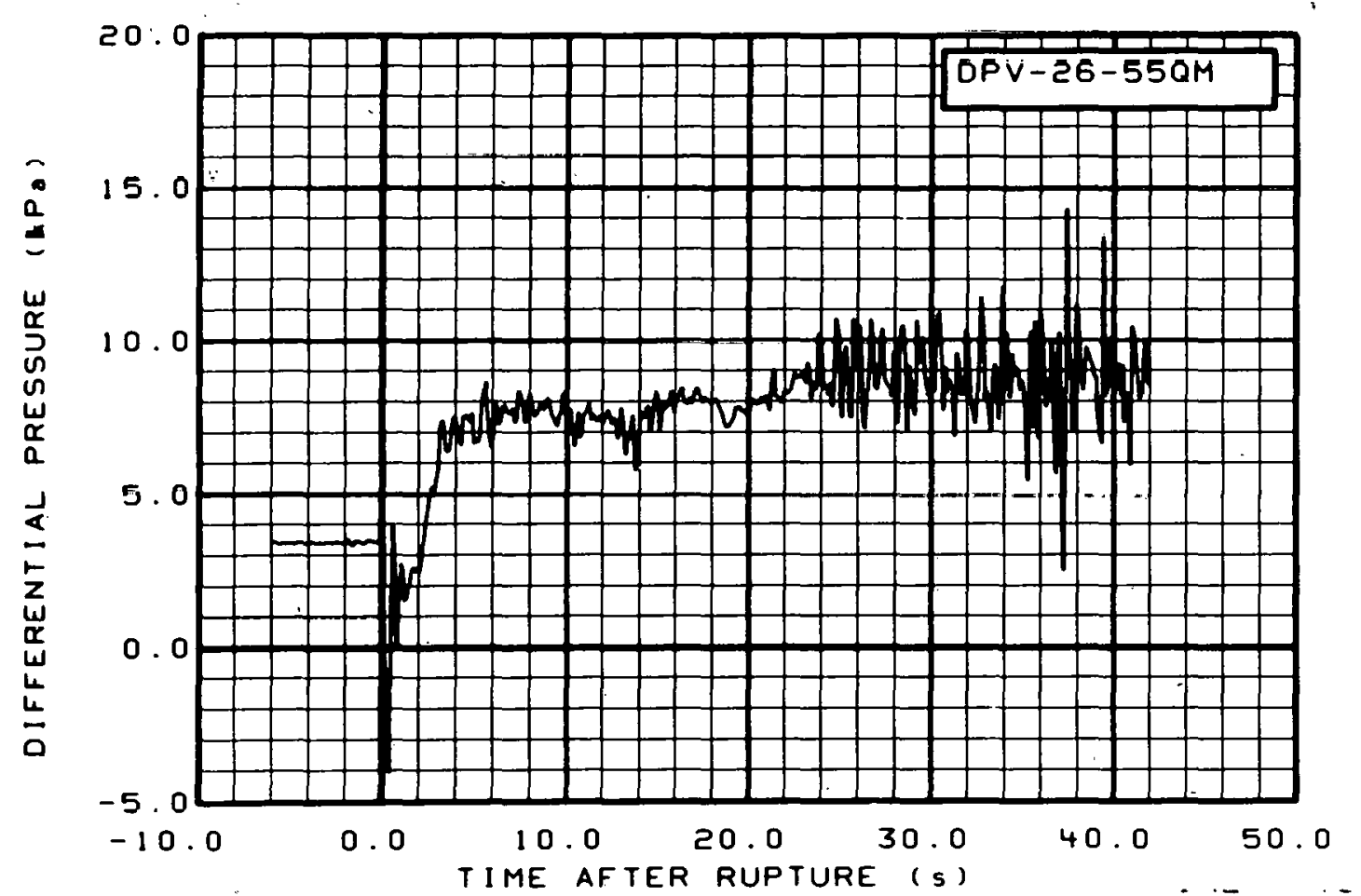

Fig. 204 Differential pressure in vessel (DPV-26-55QM), from -6 to $42 \mathrm{~s}$. 


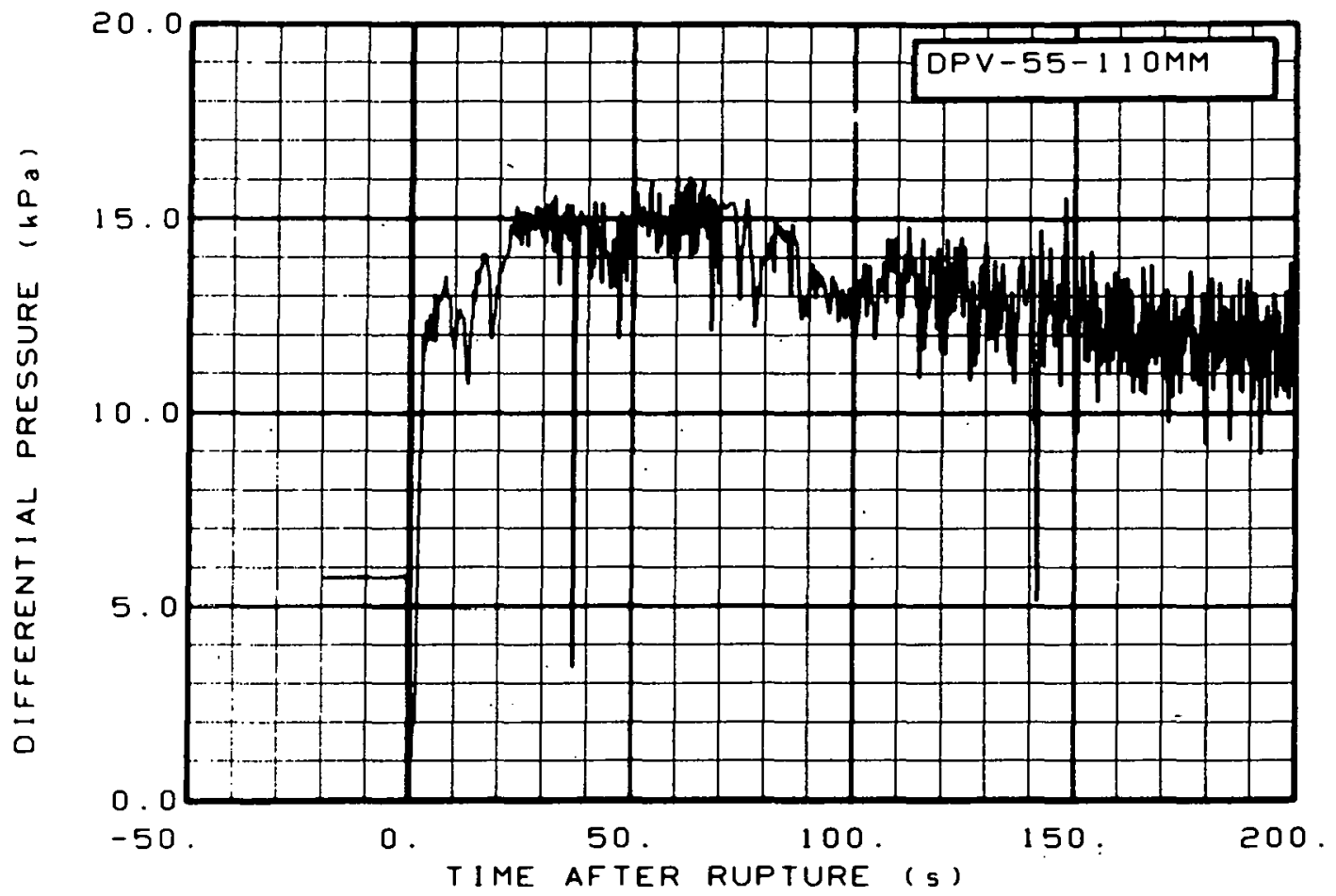

Fig. 205 Differential pressure in vessel (DPV-5.5-110MM), from -20 to $200 \mathrm{~s}$.

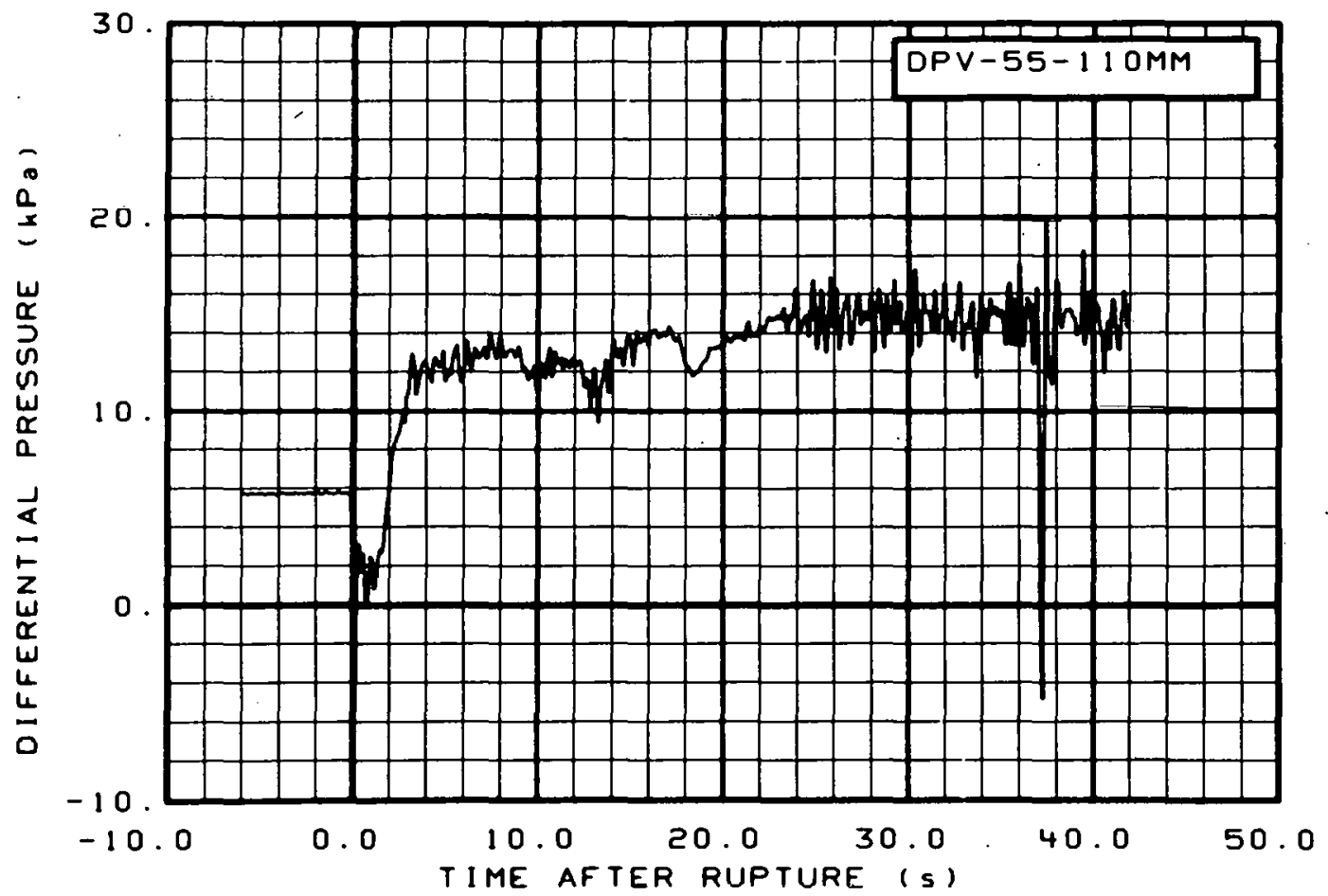

Fig. 206 Differential pressure in vessel (DPV-55-110MM), from -6 to $42 \mathrm{~s}$. 


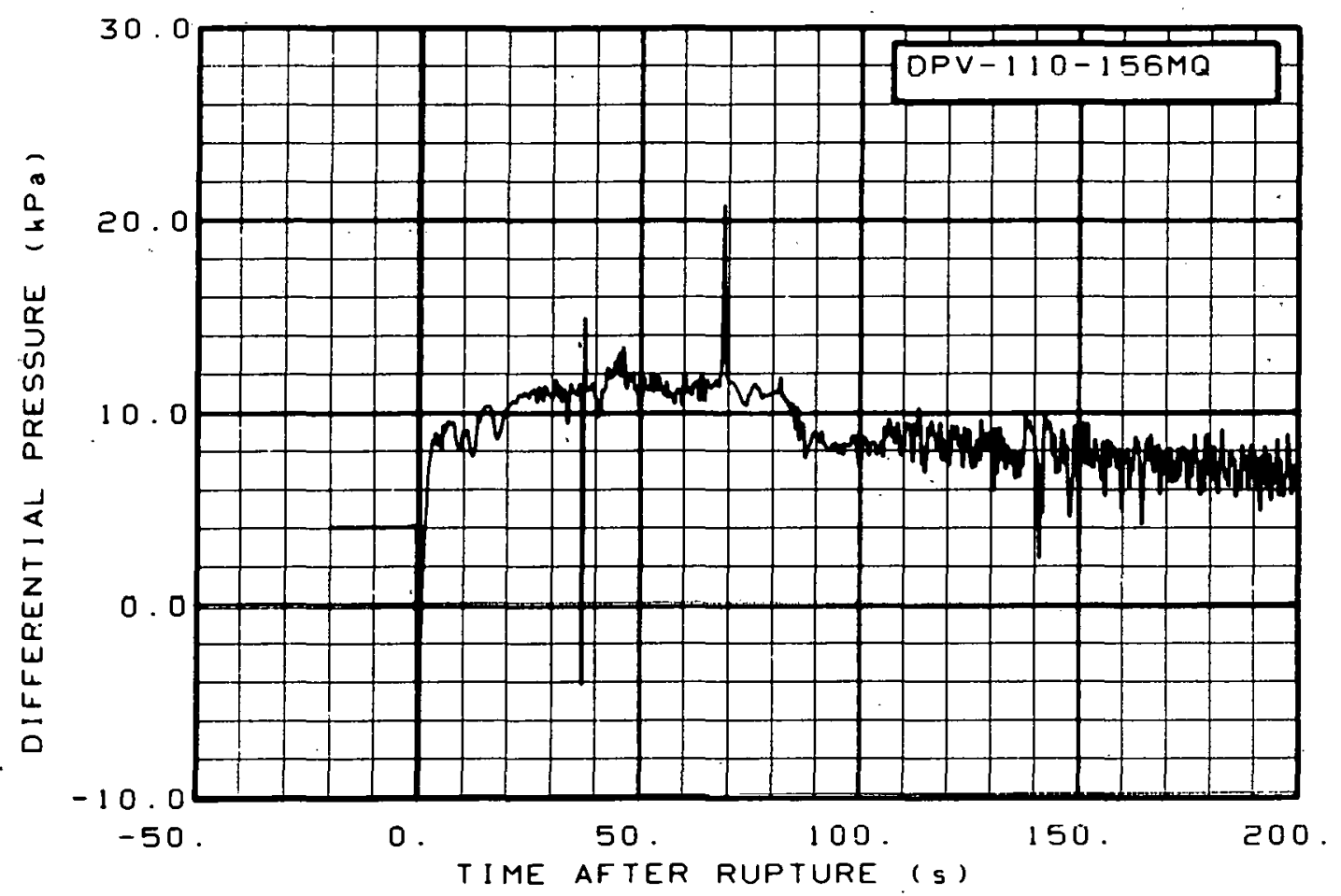

Fig. 207 Differential pressure in vessel (DPV-110-156MQ), from -20 to $200 \mathrm{~s}$.

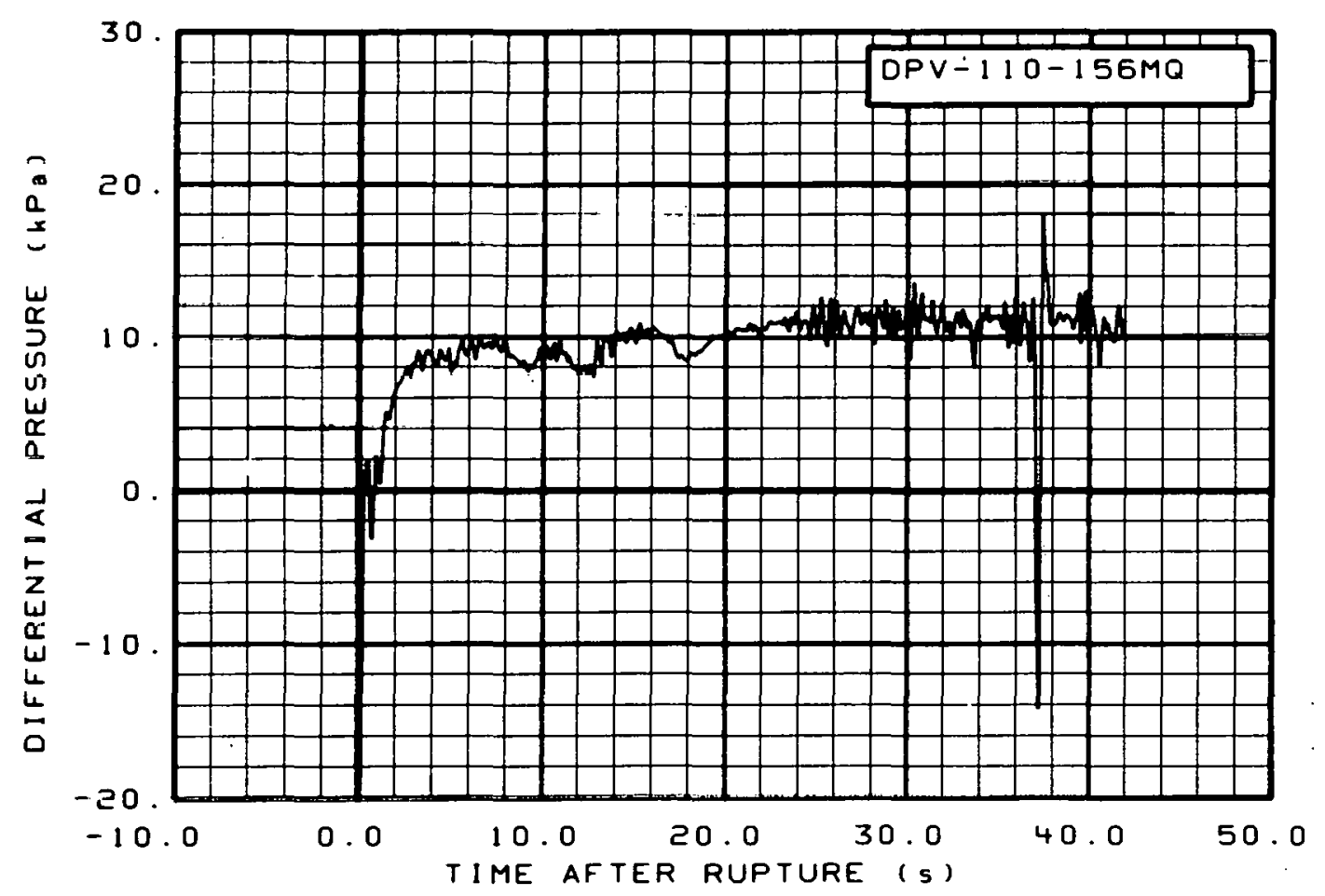

Fig. 208 Differential pressure in vessel (DPV-110-156MQ), from -6 to $42 \mathrm{~s}$. 


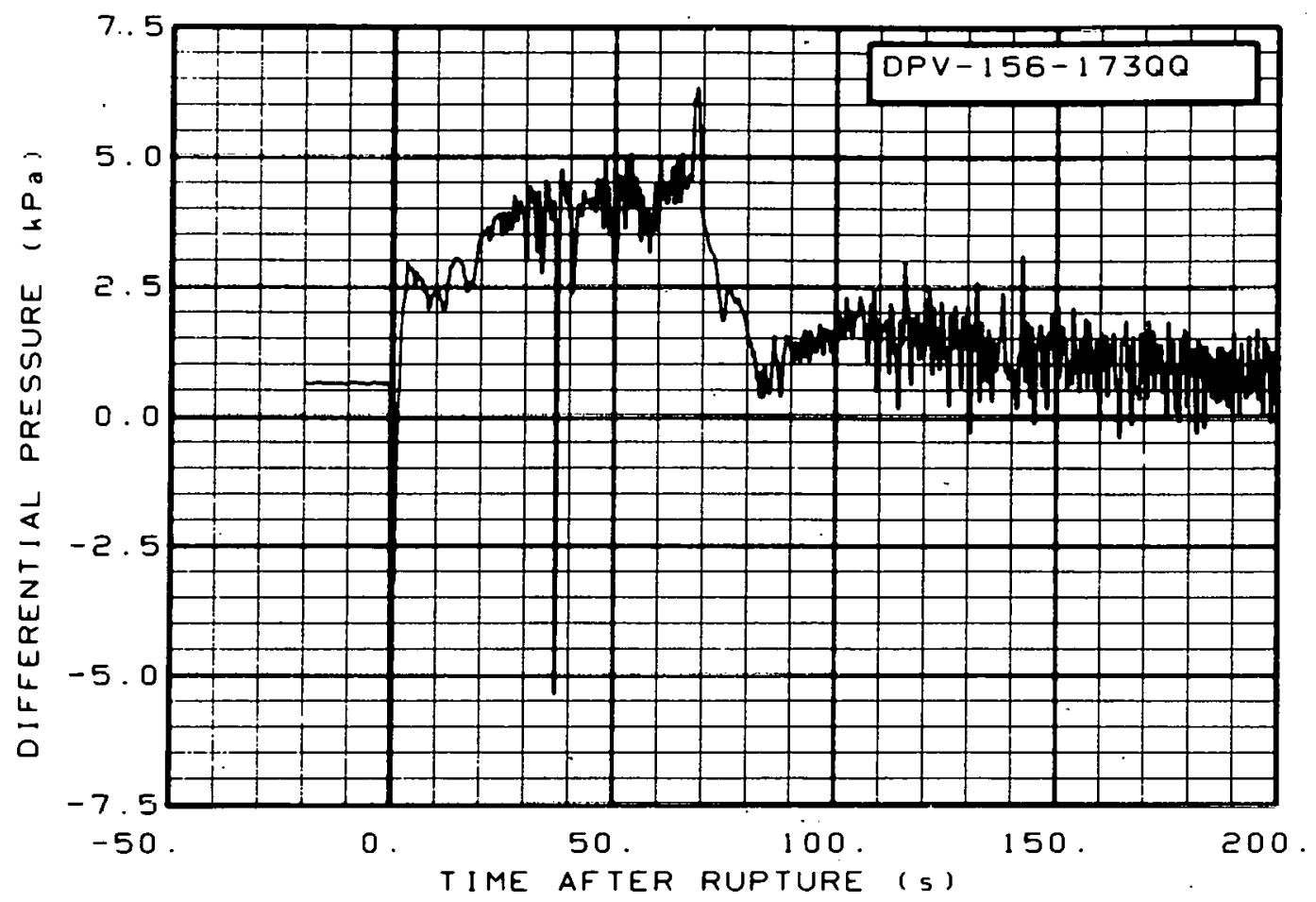

Fig. 209 Differential pressure in vessel (DPV-156-i730Q), from -20 to $200 \mathrm{~s}$.

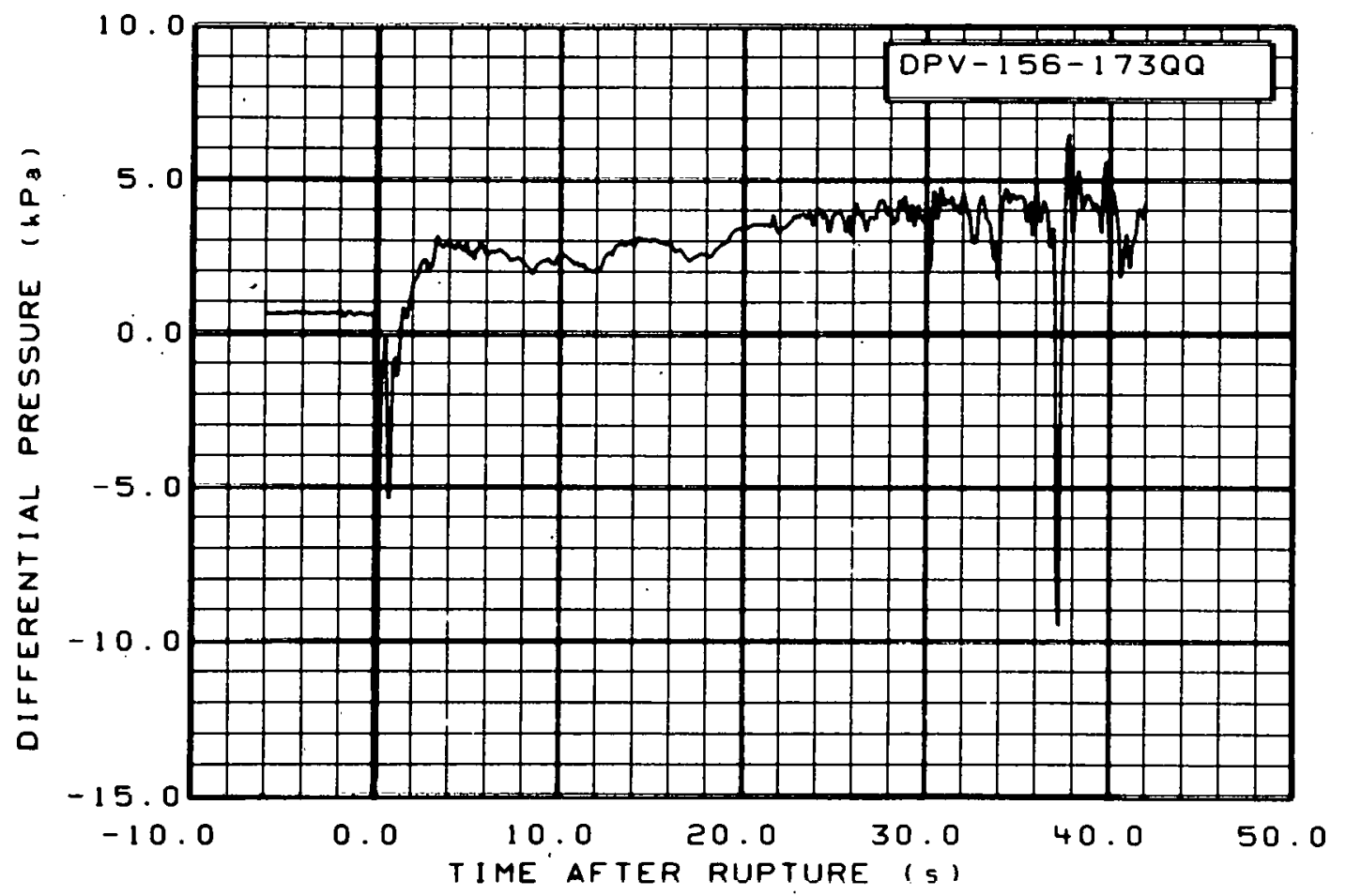

Fig. 210 Differential pressure in vessel (DPV-156-1730Q), from -6 to $42 \mathrm{~s}$. 


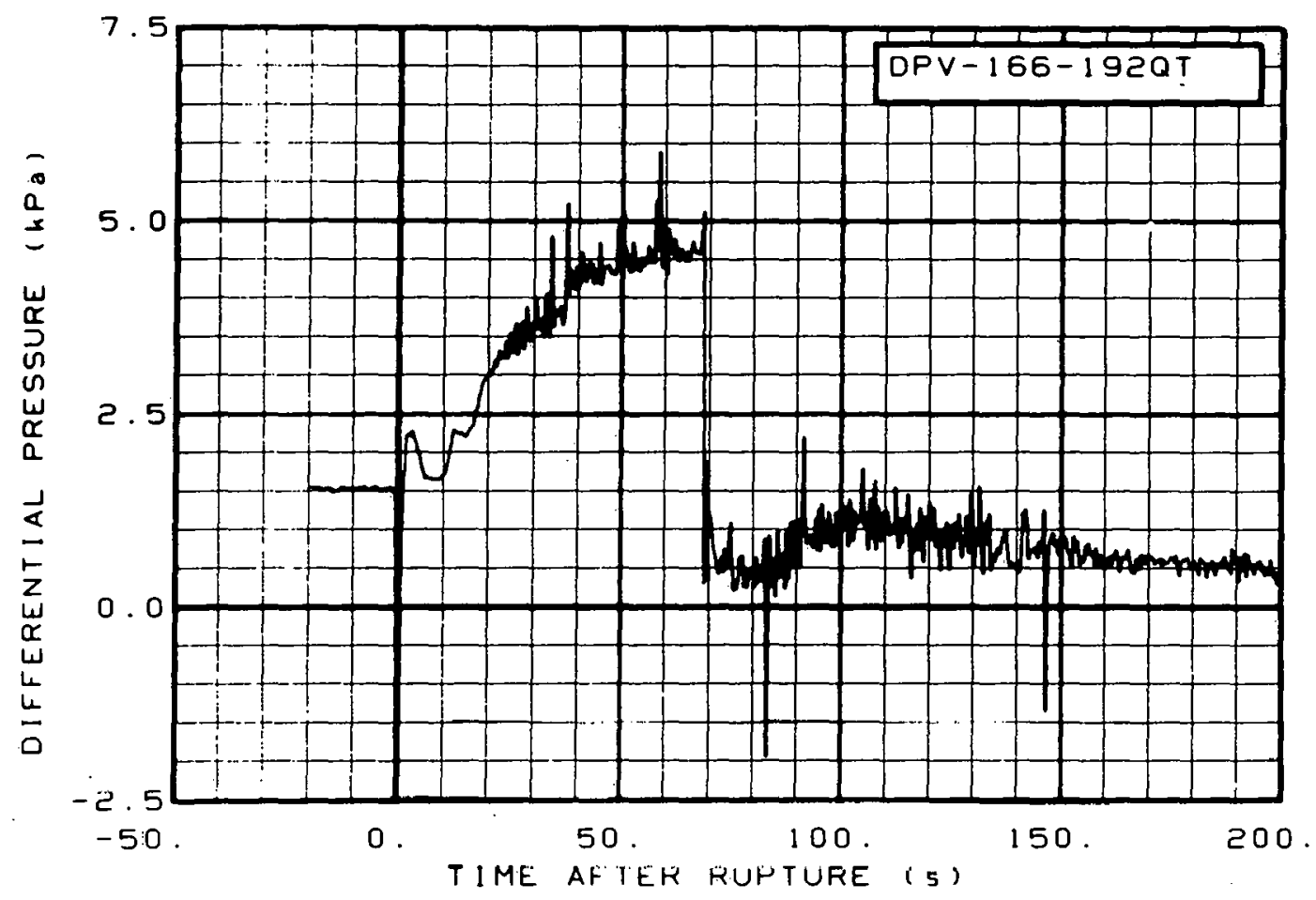

Fig. 211 Differential pressure in vessel (DPV-166-1920T), from -20 to $200 \mathrm{~s}$.

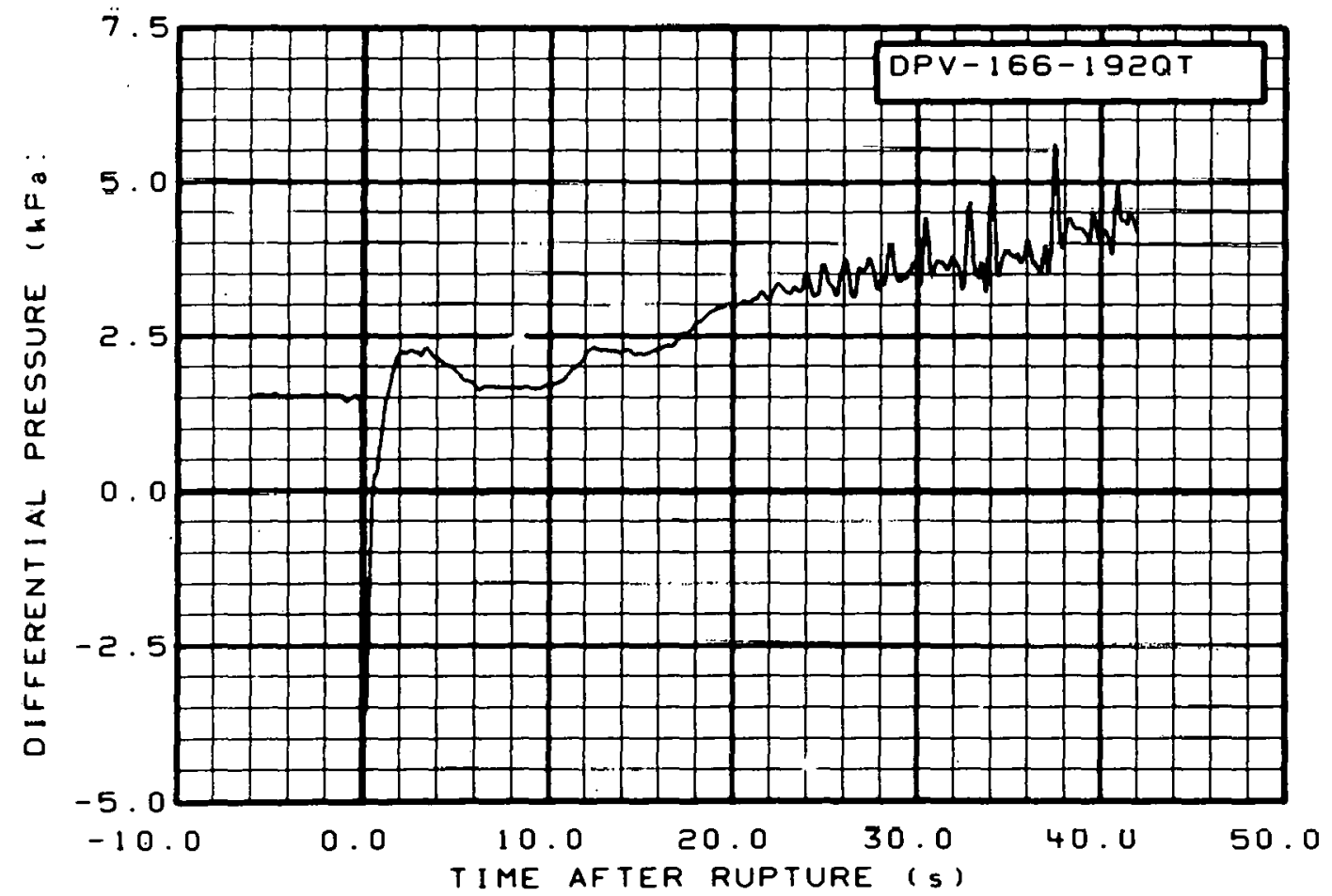

Fig. 212 Differential pressure in vessel (DPV-166-1920T), from -6 to $42 \mathrm{~s}$. 


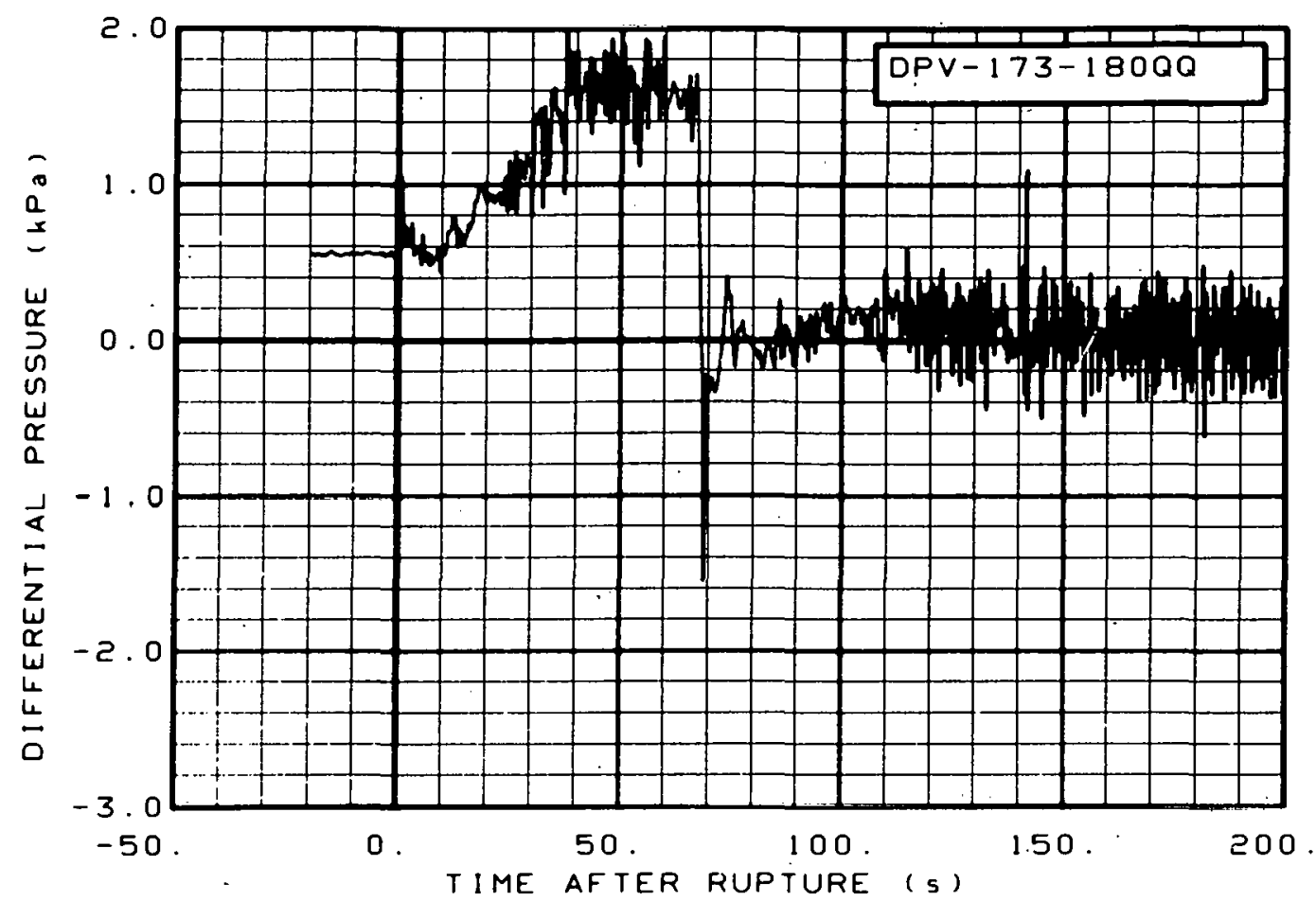

Fig. 213 Differential pressure in vessel (DPV-173-180QQ), from -20 to $200 \mathrm{~s}$.

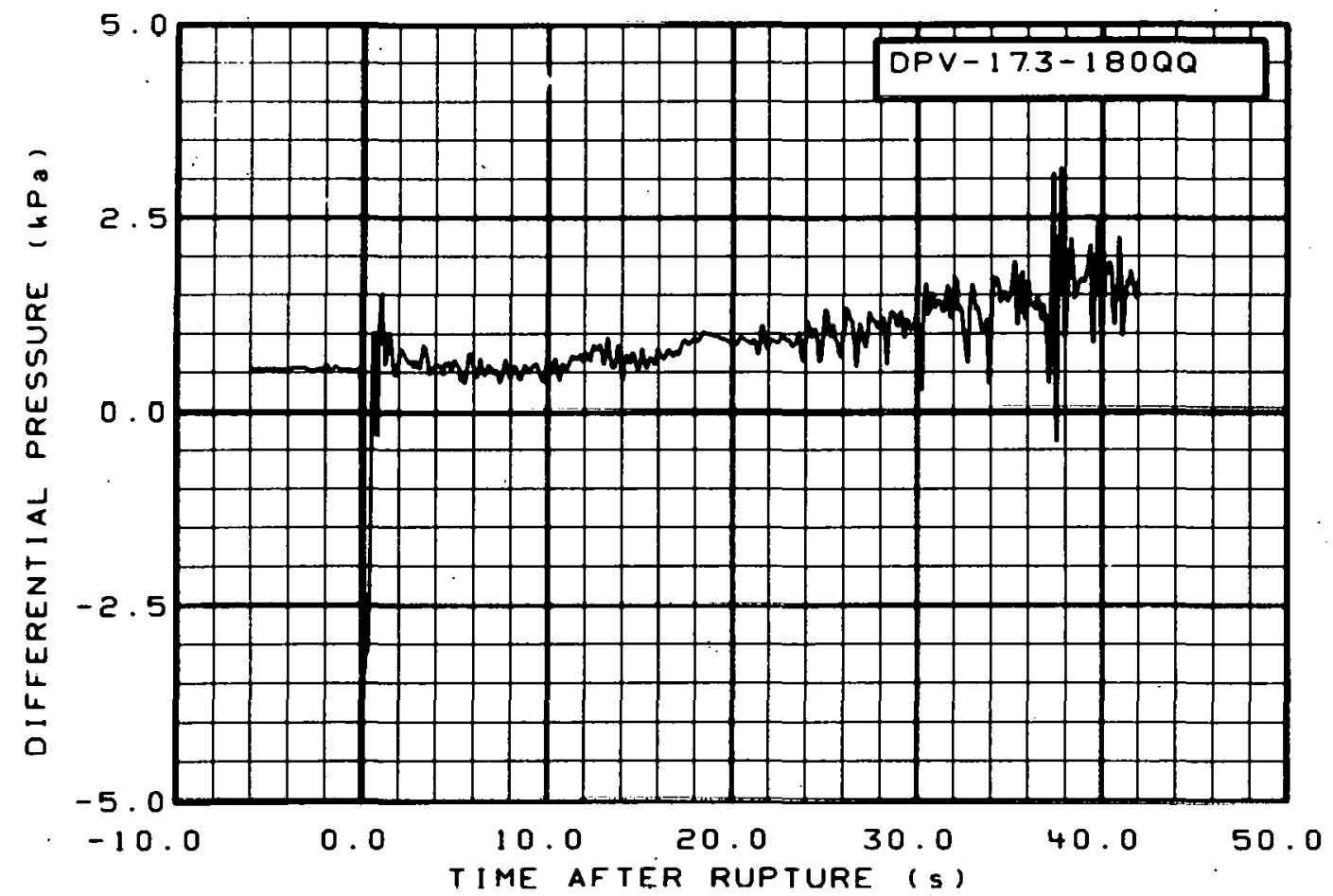

Fig. 214 Differential pressure in vessel (DPV-173-180QQ), from -6 to $42 \mathrm{~s}$. 


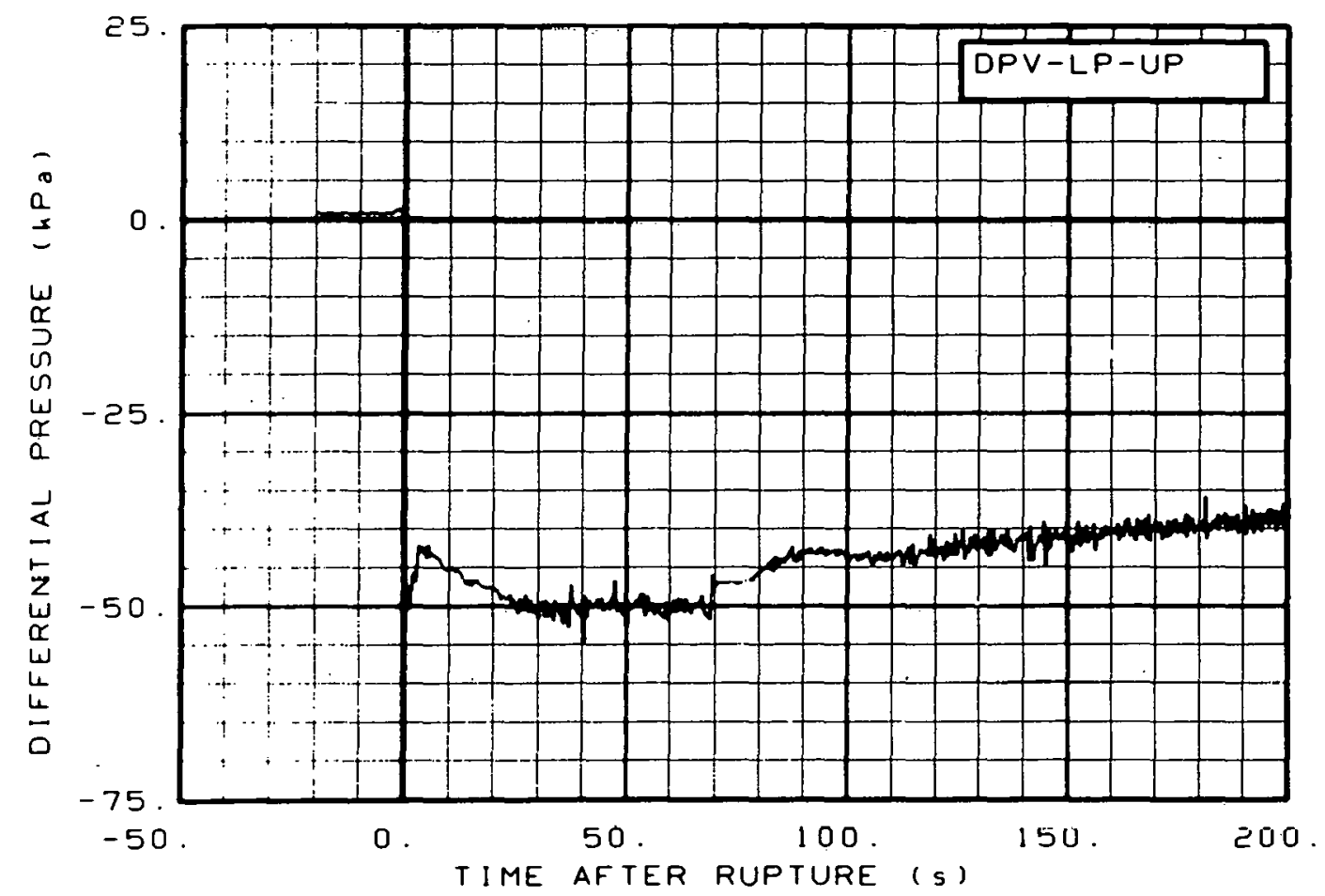

Fig. 215 Differential pressure in vessel (DPV-LP-UP), from -20 to $200 \mathrm{~s}$.

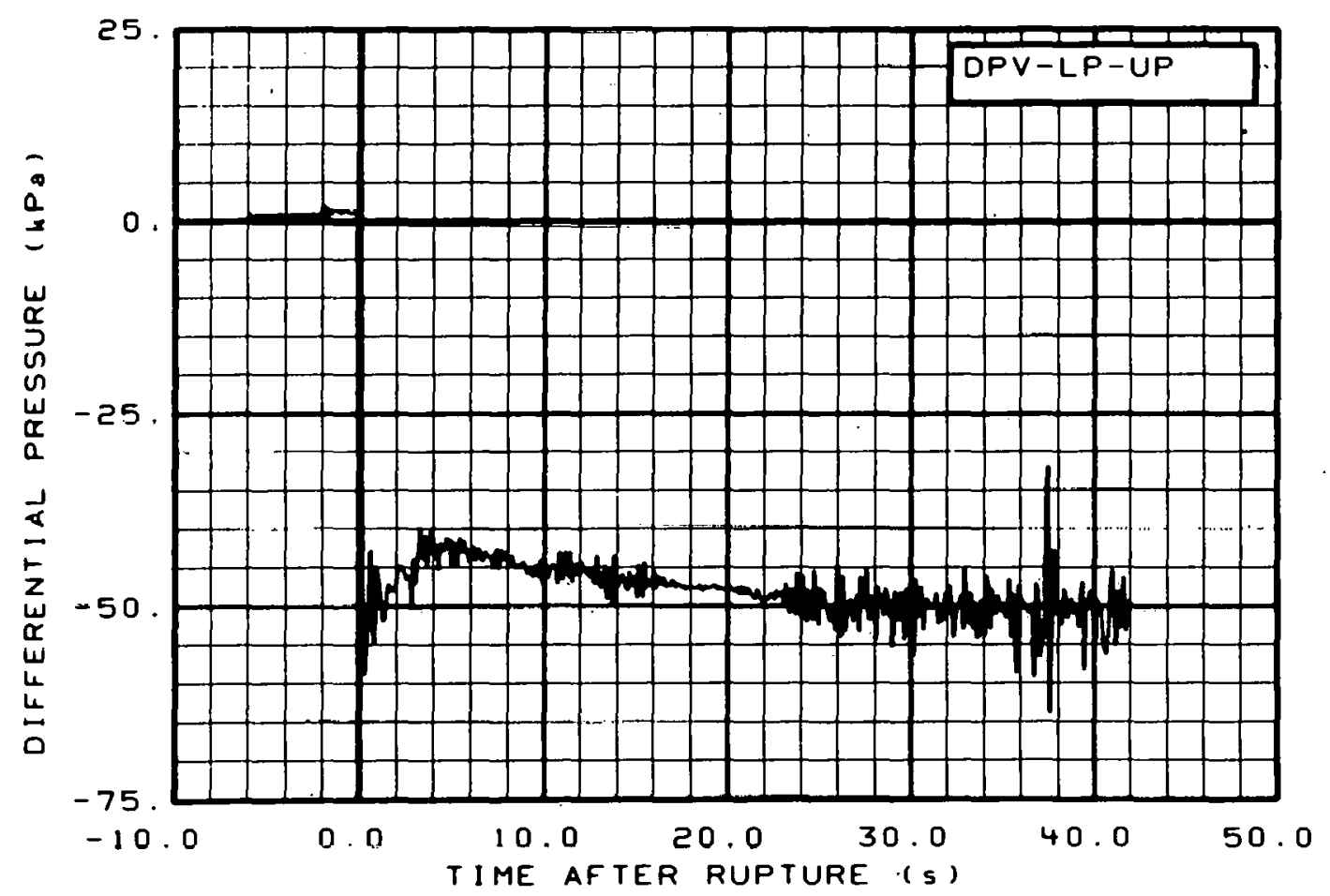

Fig. 216 Differential pressure in vessel (DPV-LP-UP), from -6 to $42 \mathrm{~s}$. 


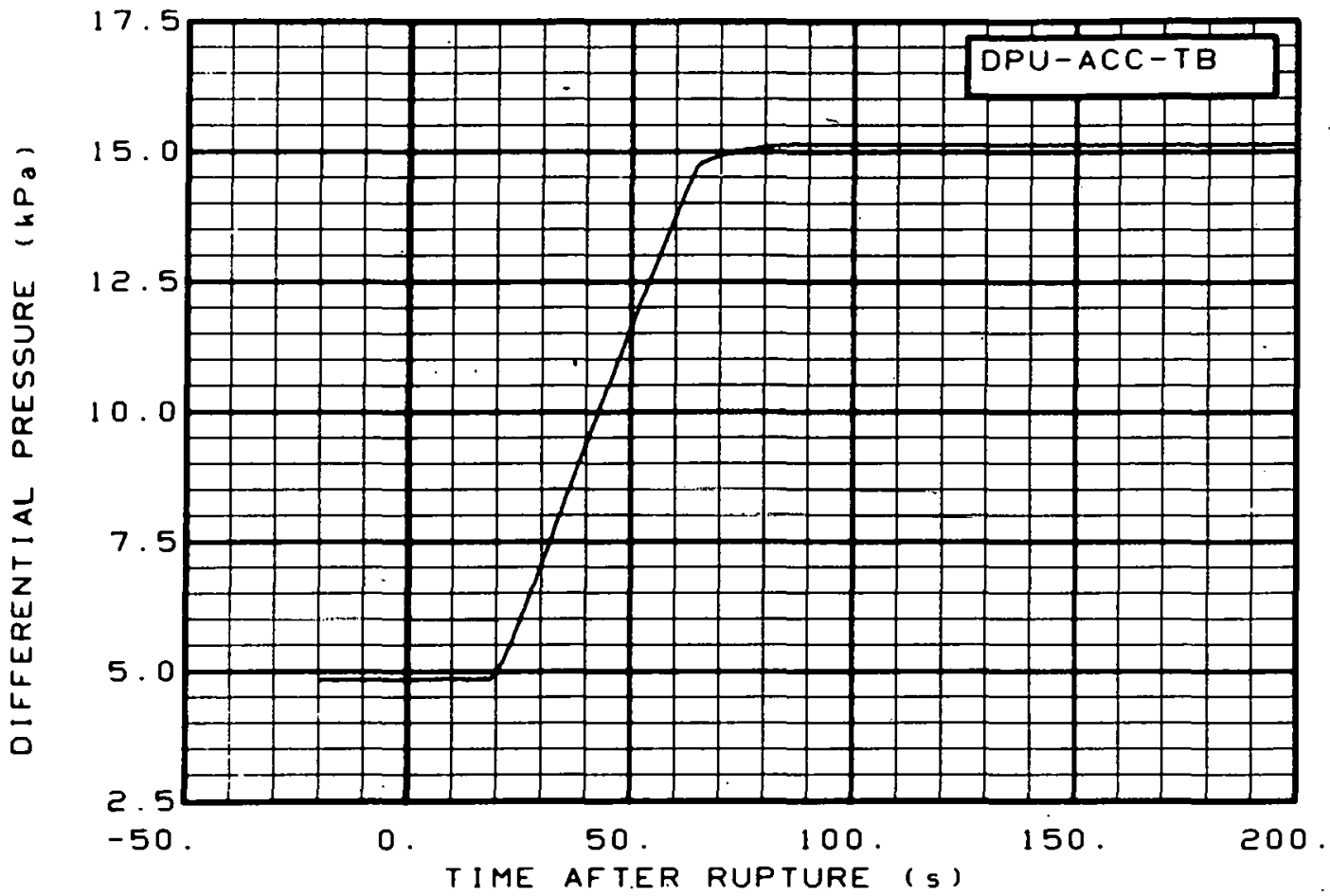

Fig. 217 Differential pressure in intact loop accumulator (DPU-ACC-TB), from -20 to $200 \mathrm{~s}$.

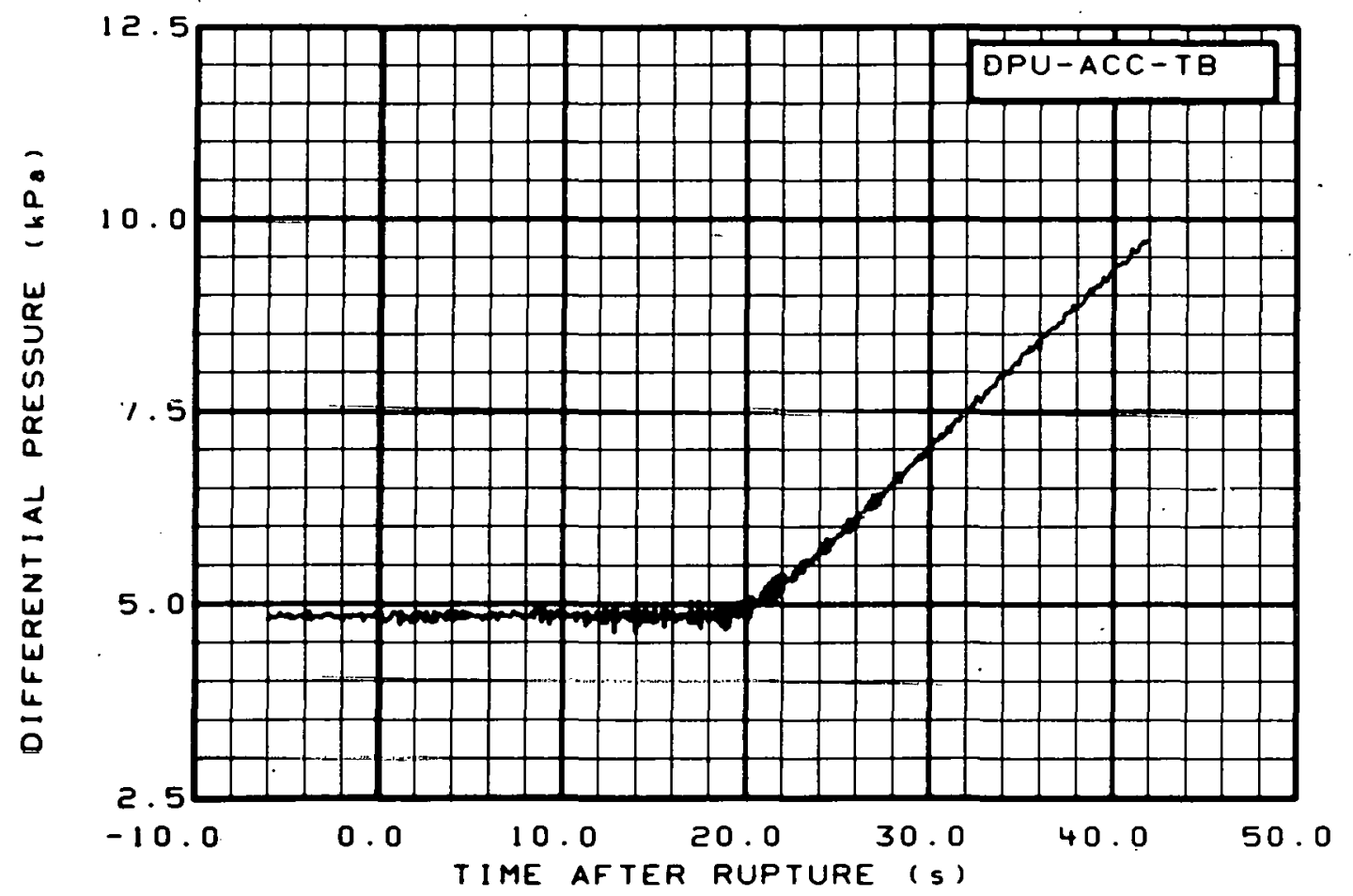

Fig. 218 Differential pressure in intact loop accumulator (DPU-ACC-TB), from -6 to $42 \mathrm{~s}$. 


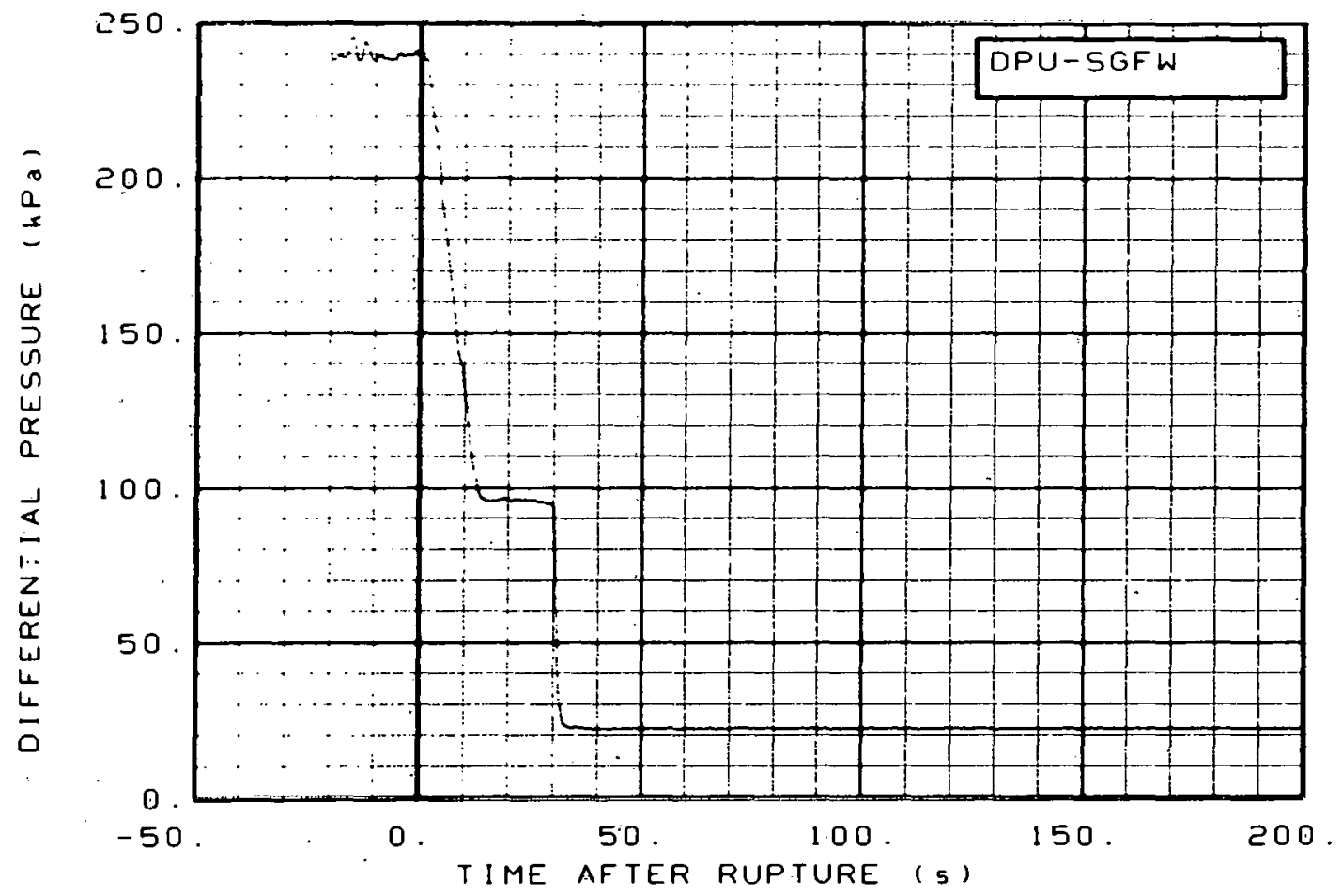

Fig. 219 Differential pressure across steam generator feedwater orifice (DPU-SGFW), from -20 to $200 \mathrm{~s}$.

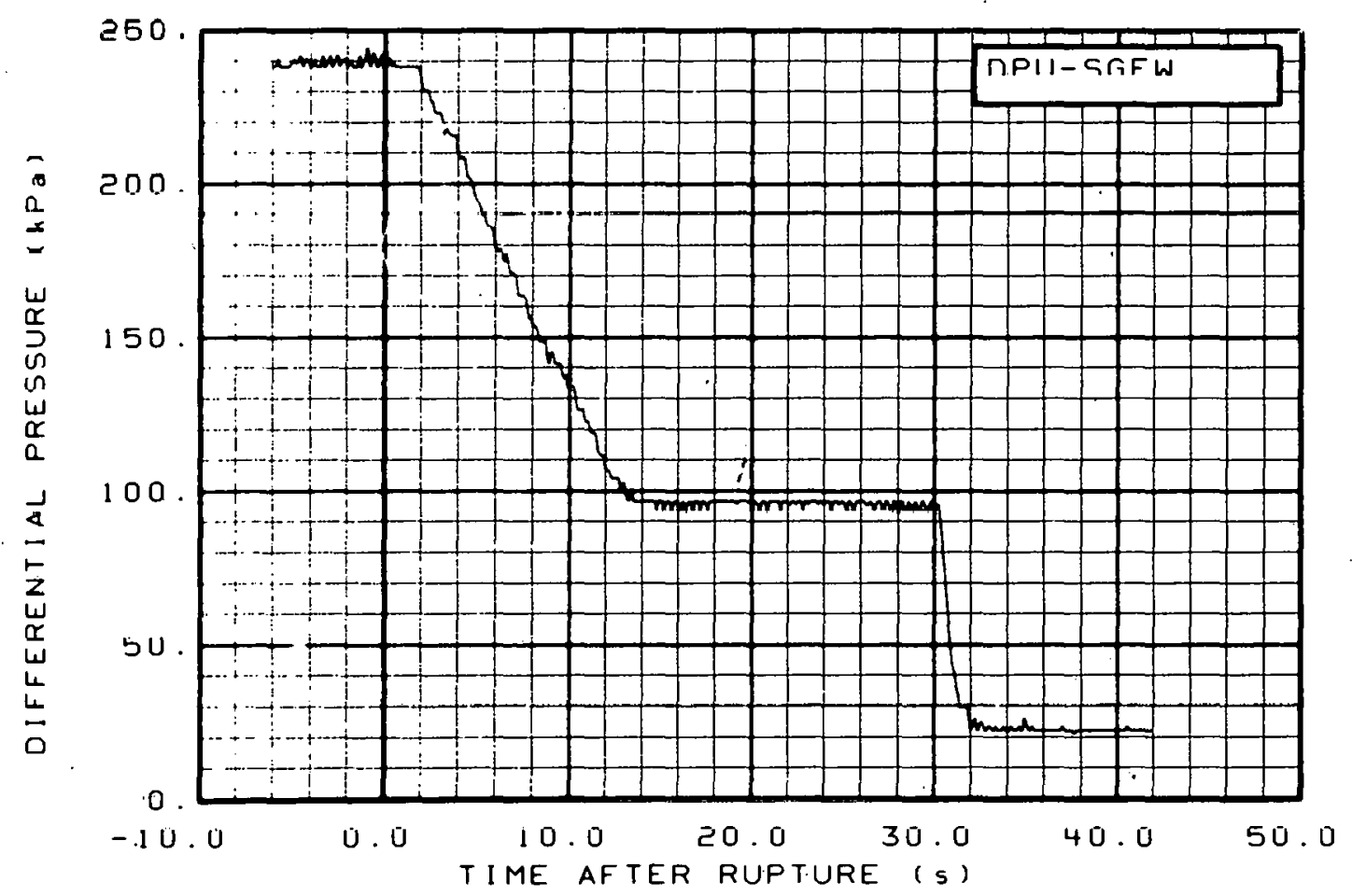

Fig. 220 Differential pressure across steam generator feedwater orifice (DPU-SGFW), from -6 to $42 \mathrm{~s}$. 


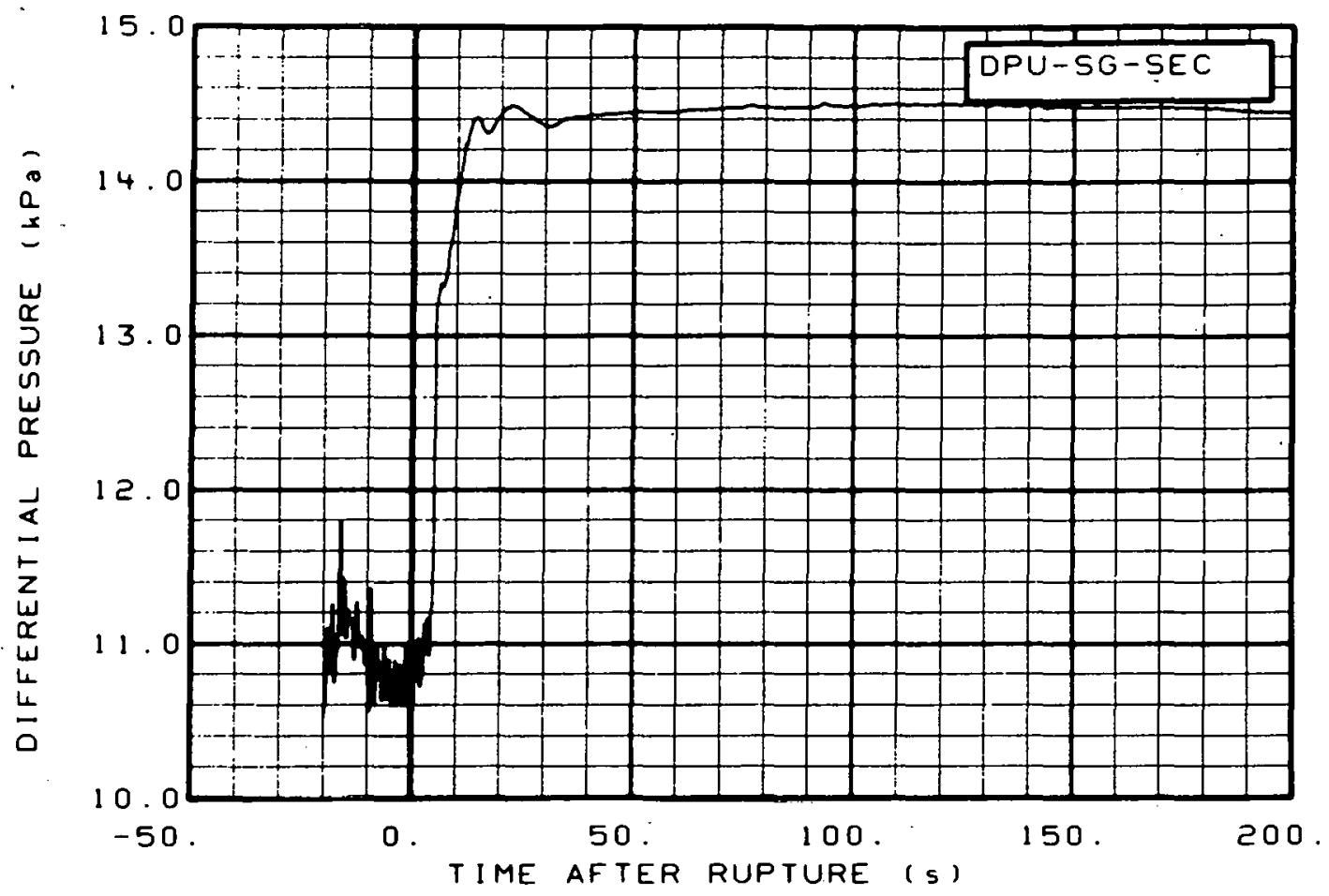

Fig. 221 Differential pressure in steam generator secondary (DPU-SG-SEC), from -20 to $200 \mathrm{~s}$.

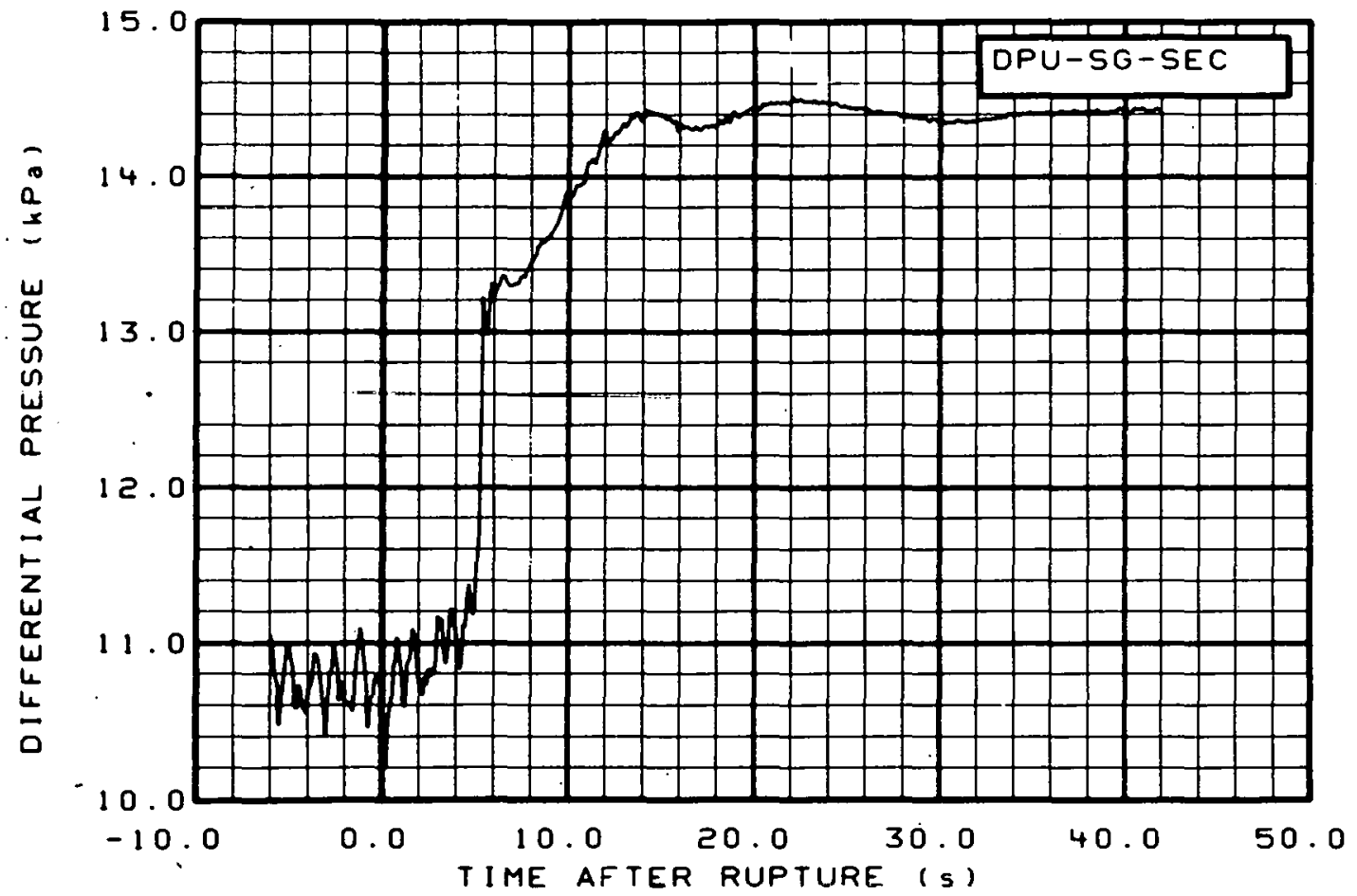

Fig. 222 Differential pressure in steam generator secondary (DPU-SG-SEC), from -6 to $42 \mathrm{~s}$. 


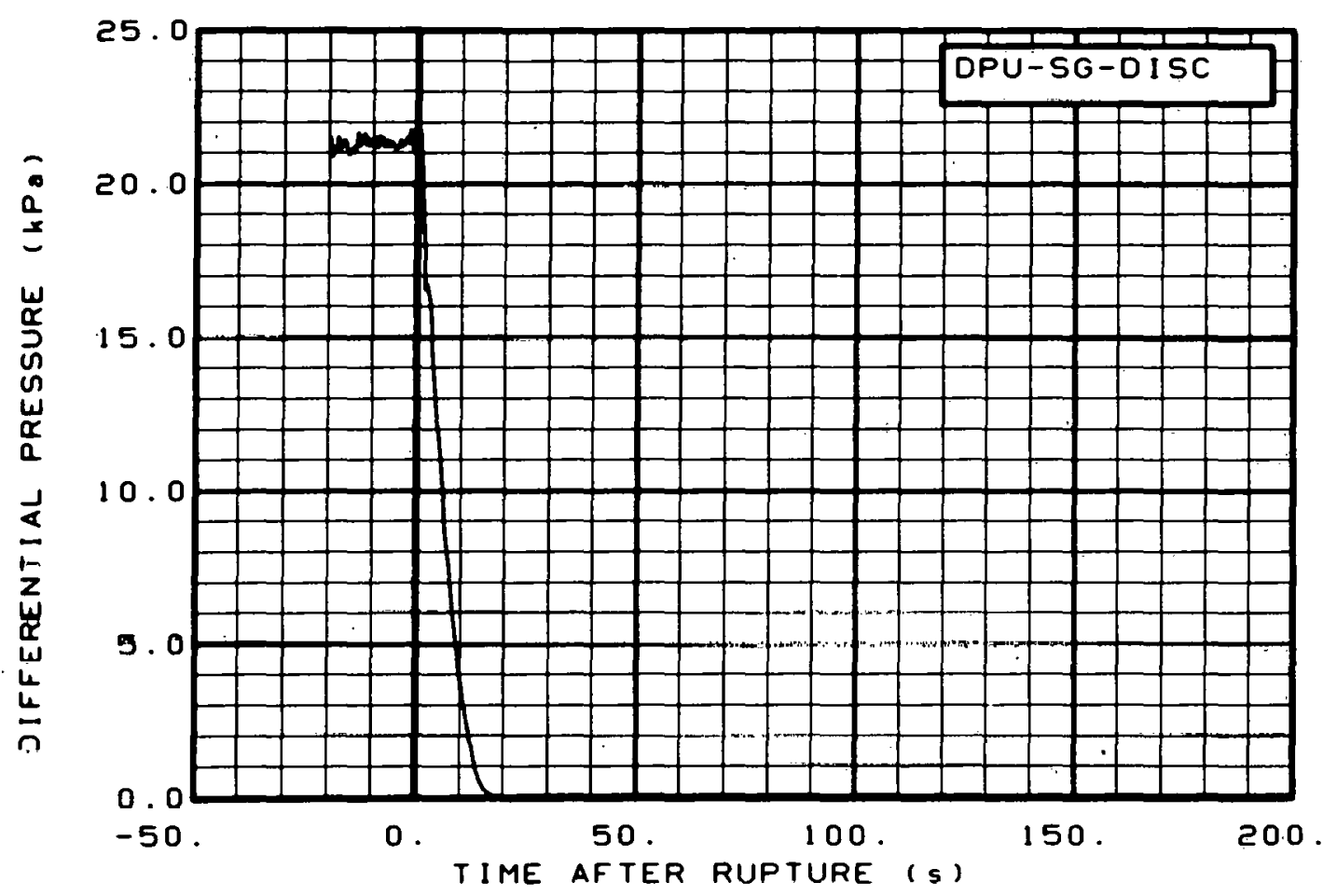

Fig. 223 Differential pressure across steam generator outlet orifice (DPU-SG-DISC), from -20 to $200 \mathrm{~s}$.

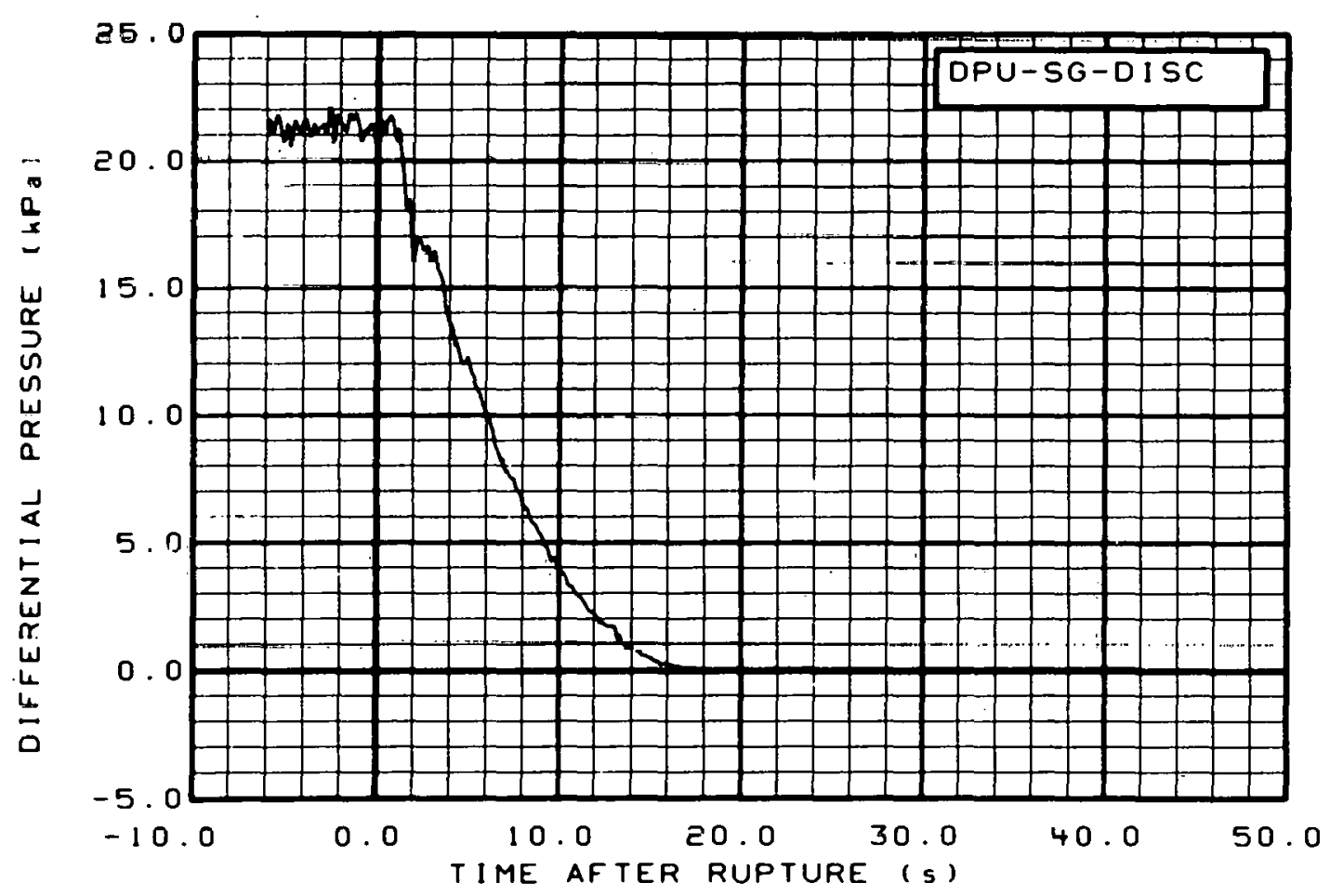

Fig. 224 Differential pressure across steam generator outlet orifice (DPU-SG-DISC), from -6 to $42 \mathrm{~s}$. 


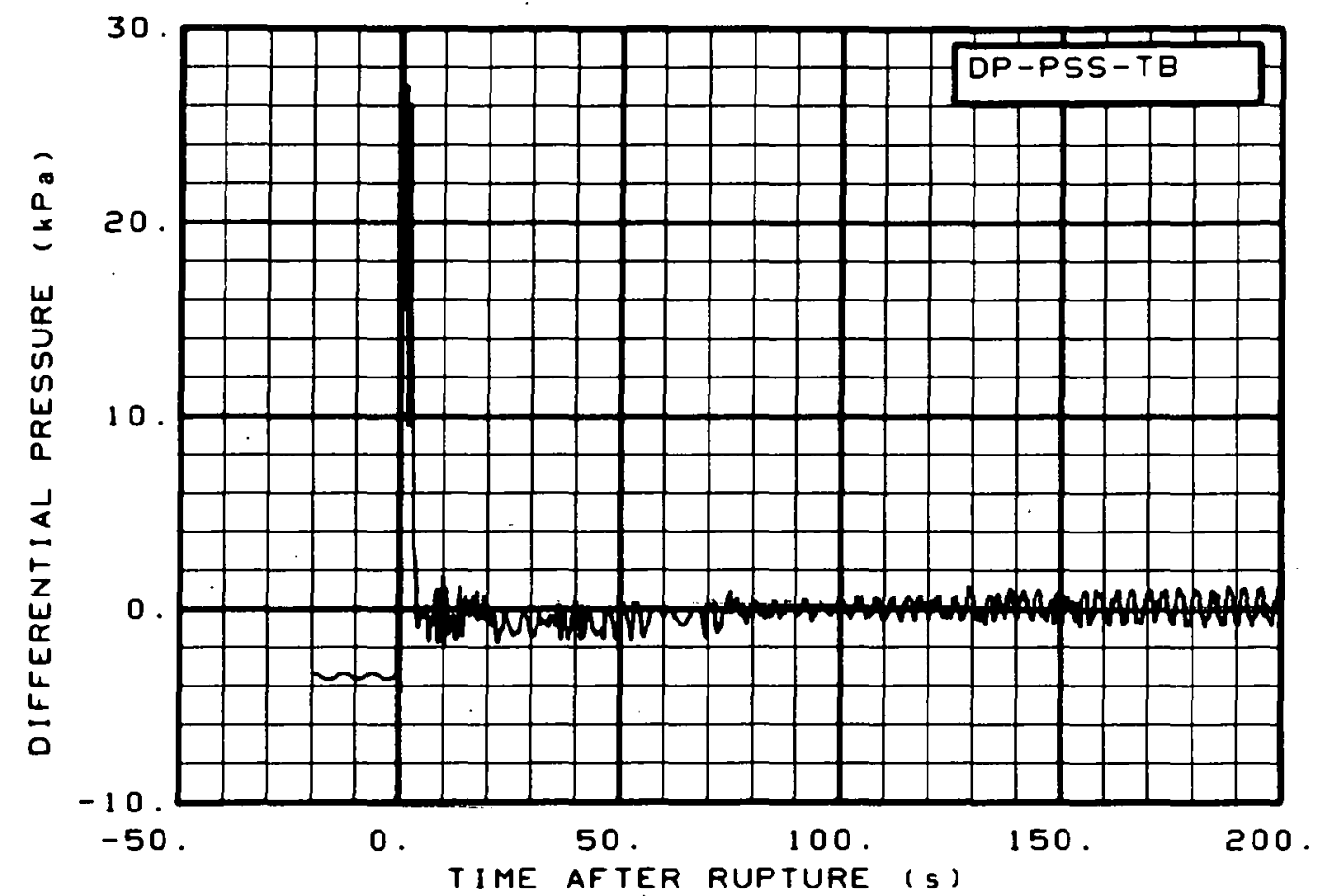

Fig. 225 Differential pressure in pressure suppression tank (DP-PSS-TB), from -20 to $200 \mathrm{~s}$.

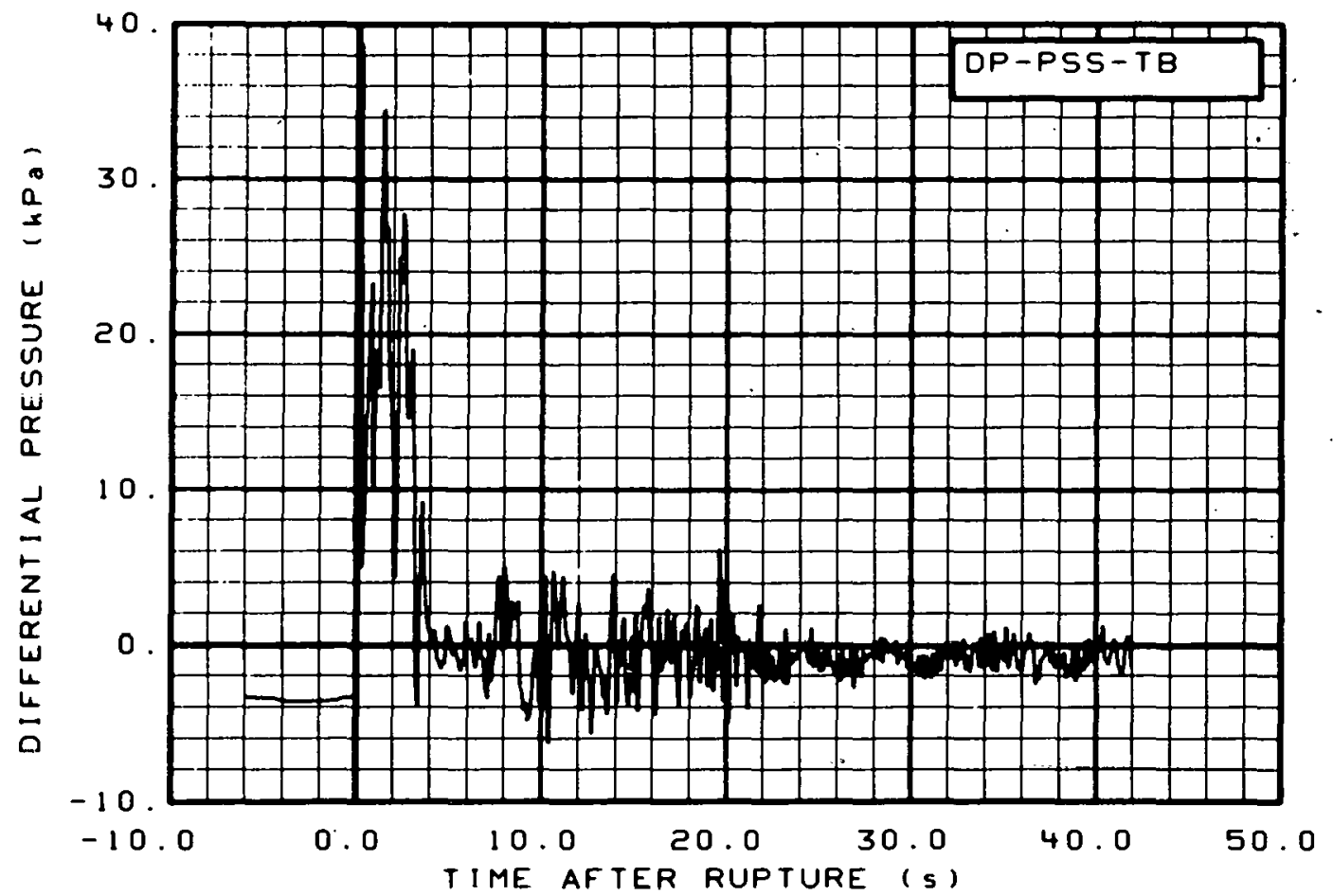

Fig. 226 Differential pressure in pressure suppression tank (DP-PSS-TB), from -6 to $42 \mathrm{~s}$. 


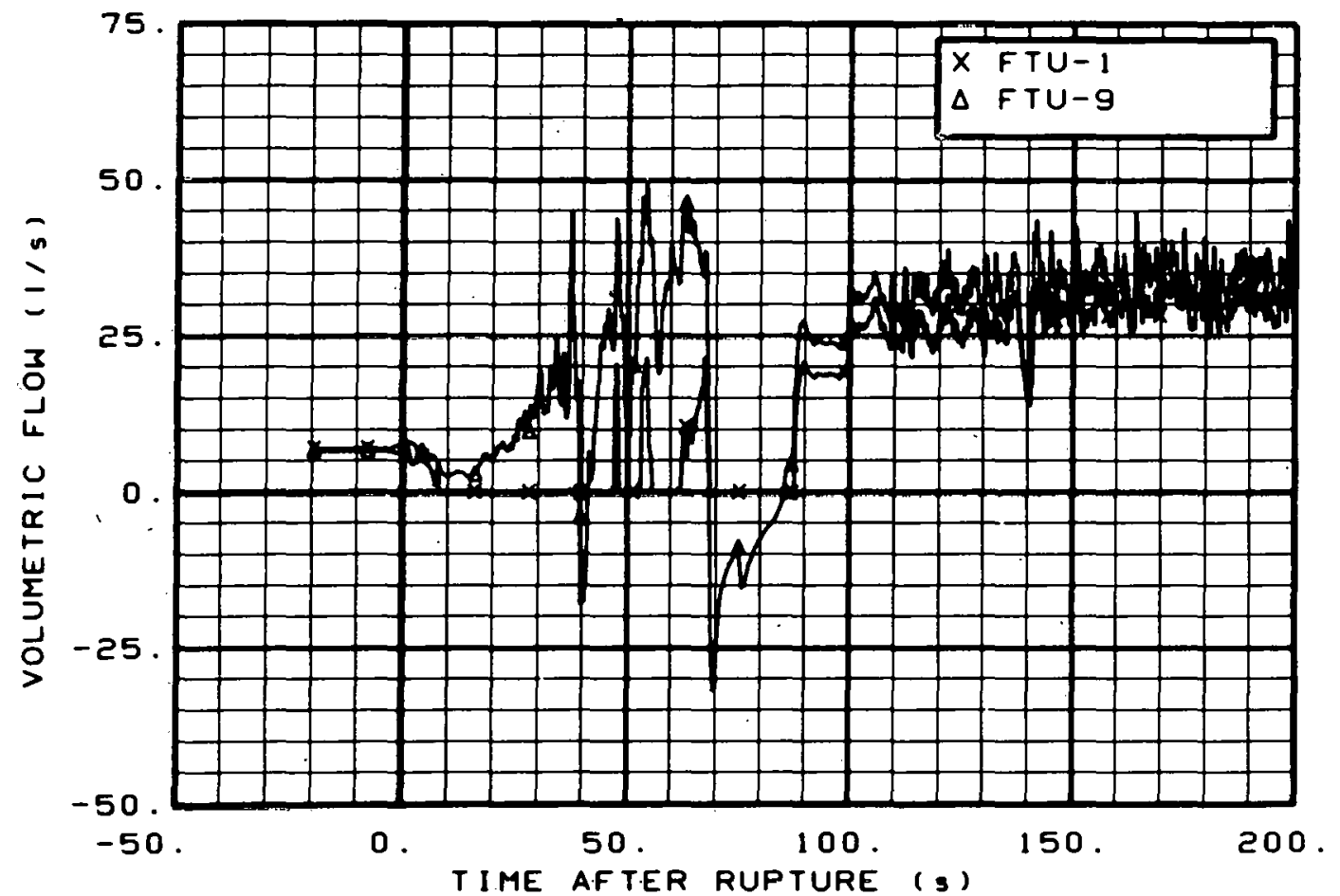

Fig. 227 Volumetric flow in intact loop (FTU-1 and FTU-9), from -20 to $200 \mathrm{~s}$.

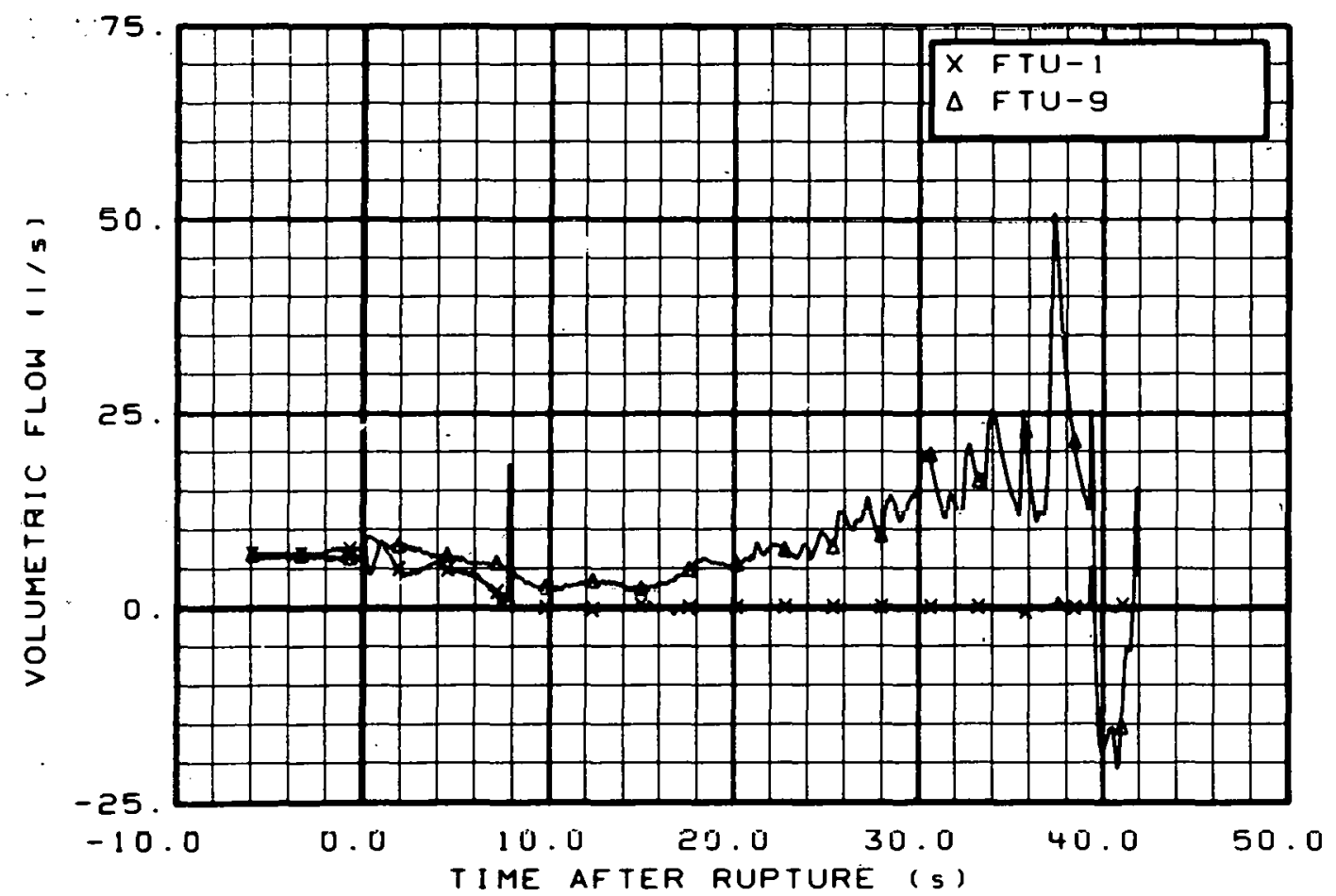

Fig. 228 Volumetric flow in intact loop (FTU-1 and FTU-9), from -6 to $42 \mathrm{~s}$. 


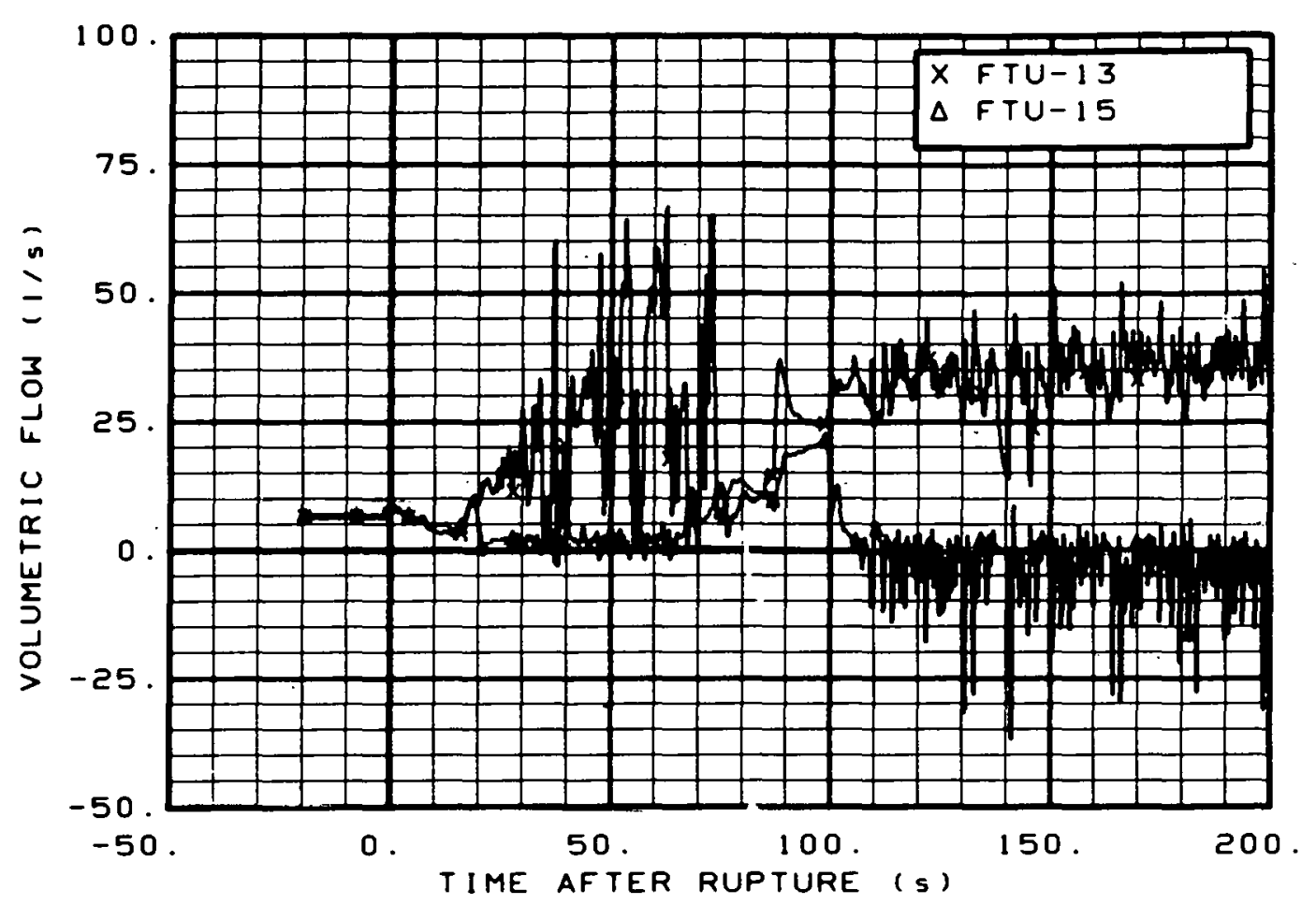

Fig. 229 Volumetric flow in intact loop (FTU-13 and FTU-15), from -20 to $200 \mathrm{~s}$.

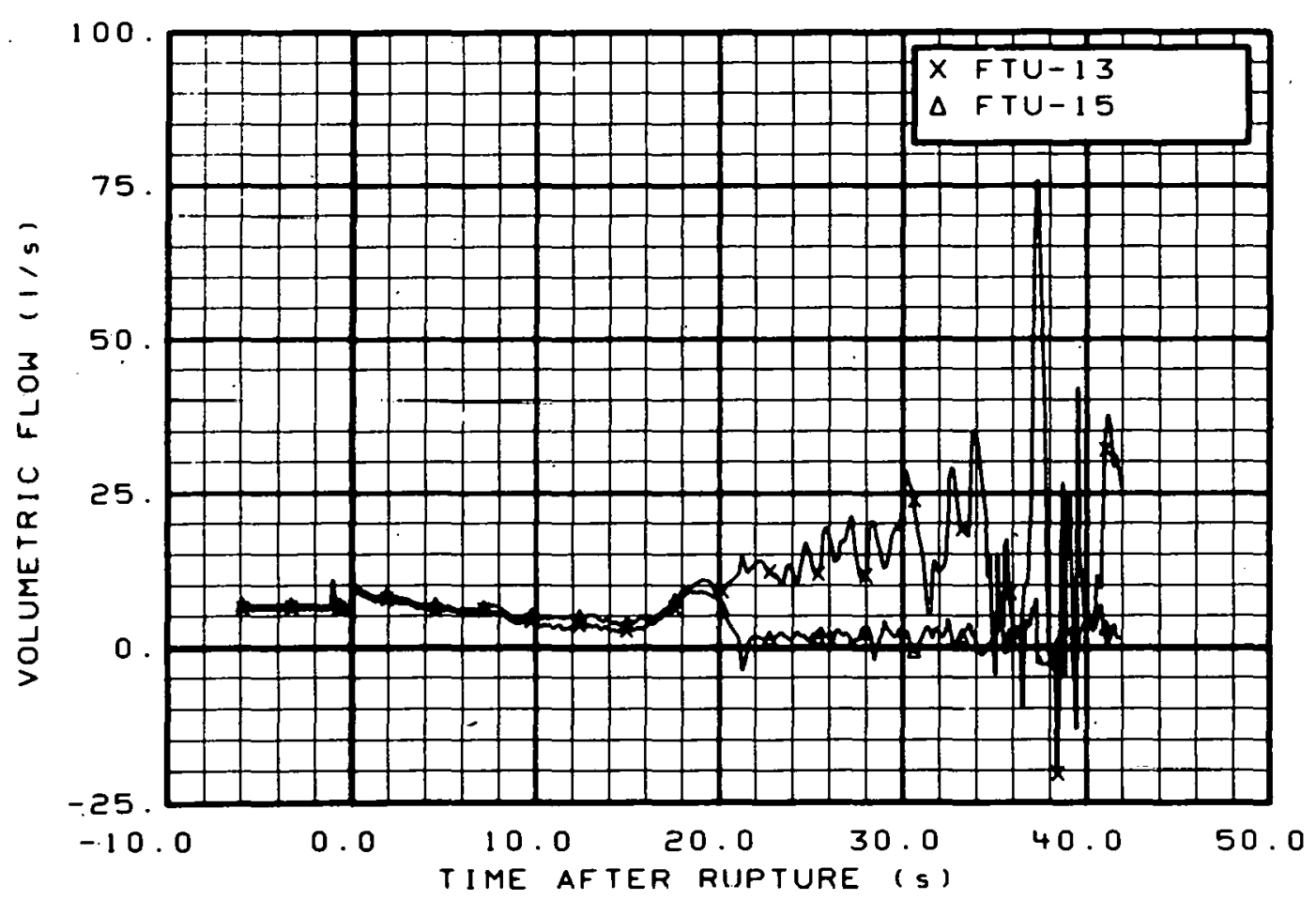

Fig. 230 Volumetric flow in intact loop (FTU-13 and FTU-15), from -6 to $42 \mathrm{~s}$. 


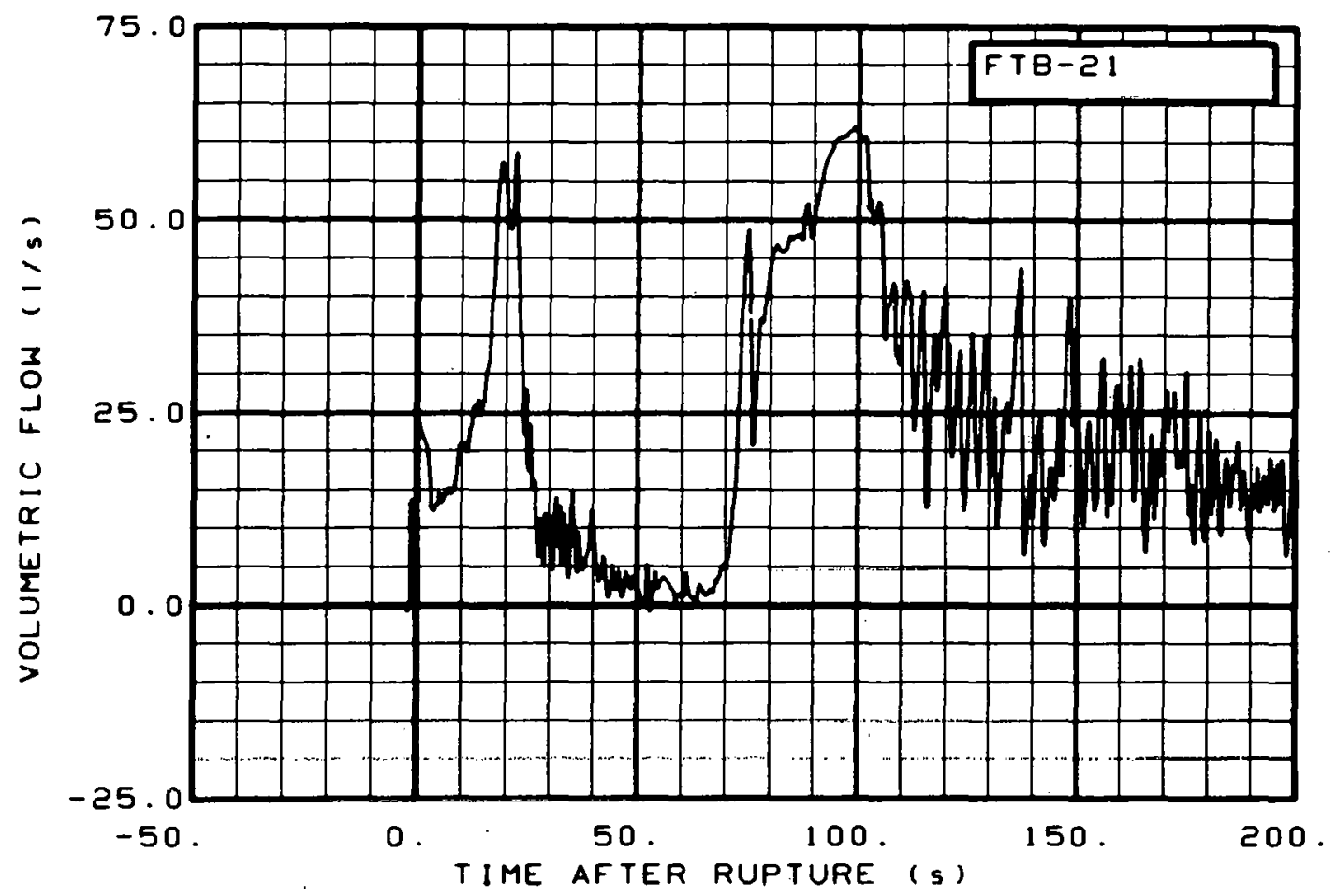

Fig. 231 Volumetric flow in broken loop (FTB-21), from -20 to $200 \mathrm{~s}$.

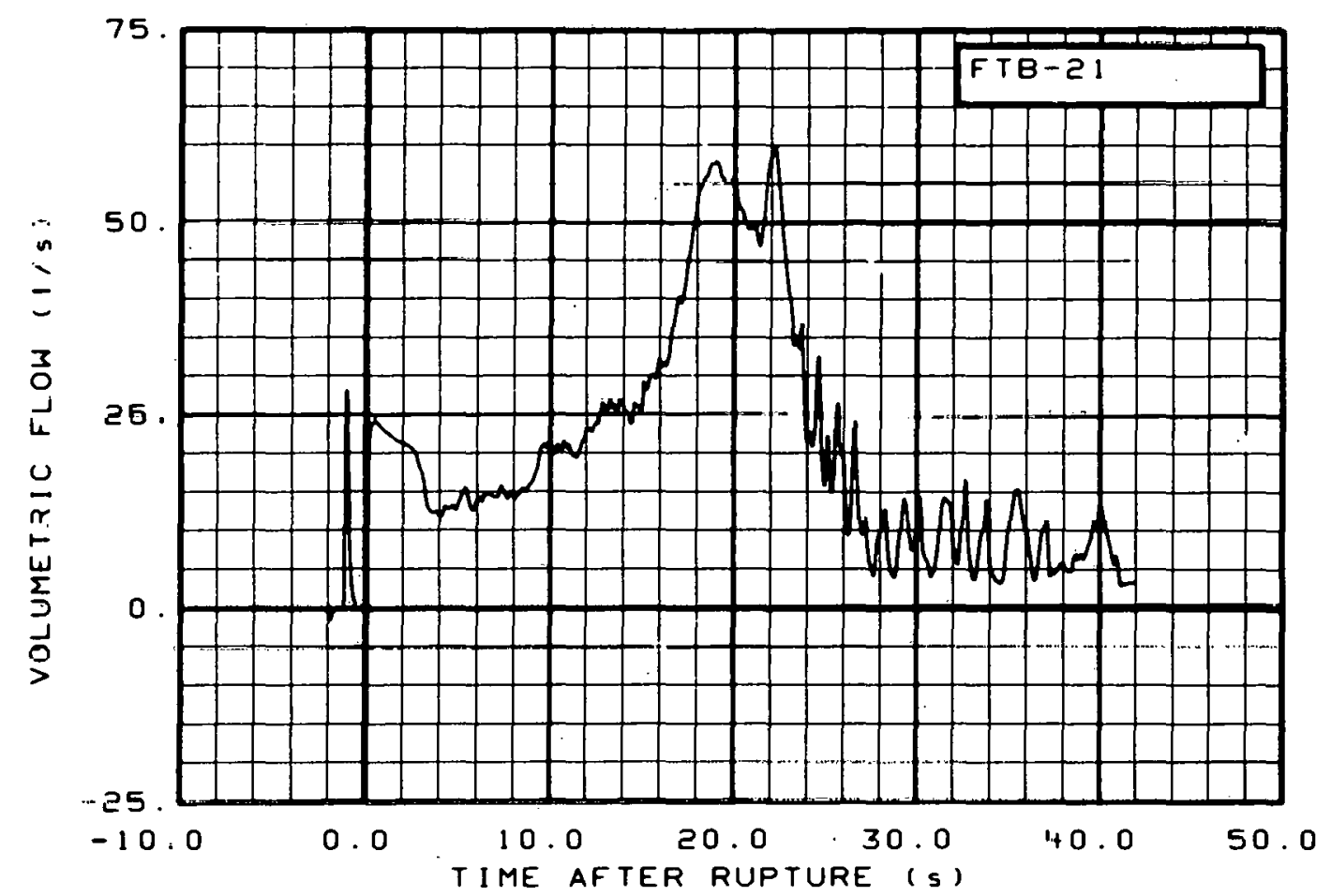

Fig. 232 Volumetric flow in broken loop (FTB-21), from -6 to $42 \mathrm{~s}$. 


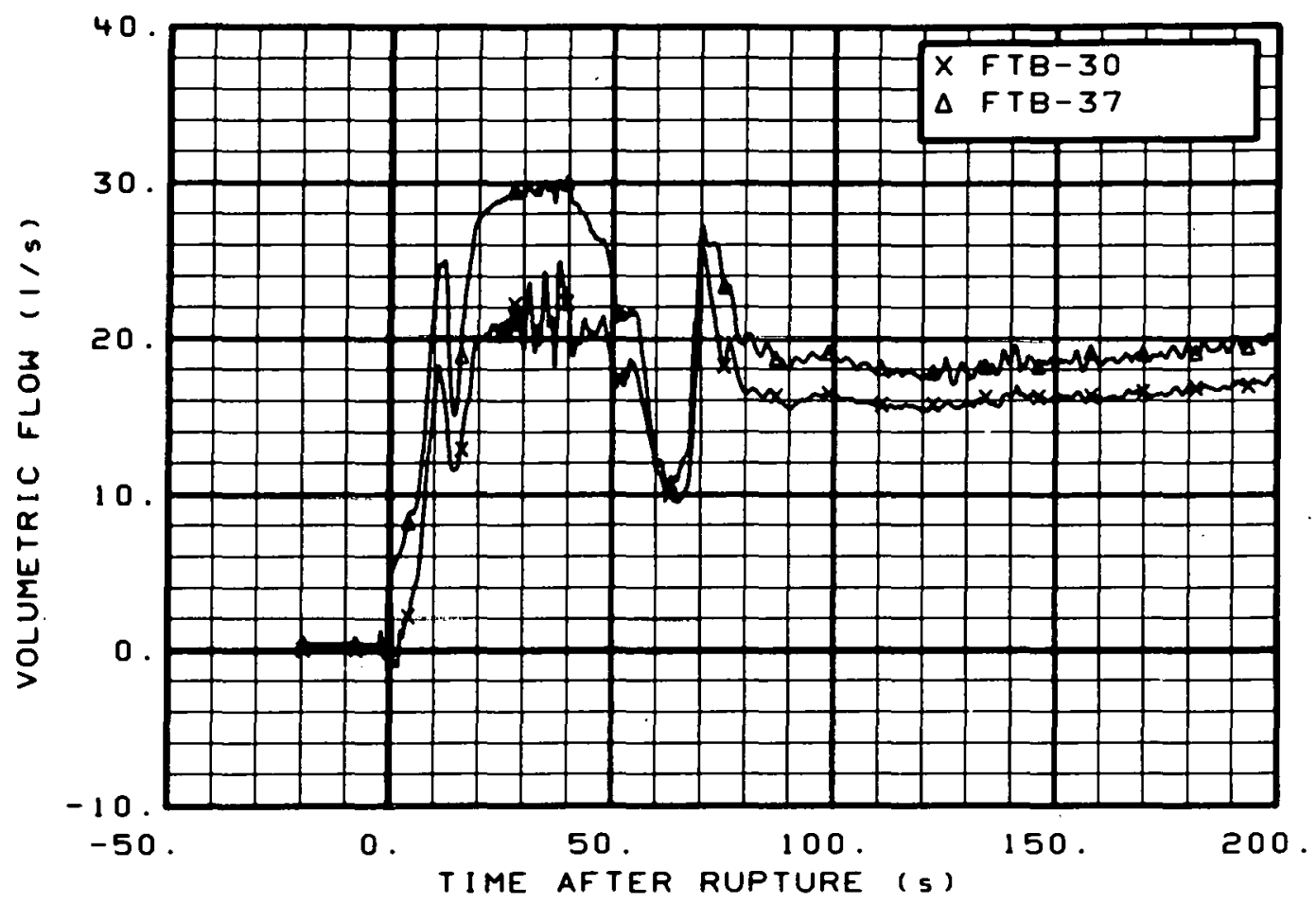

Fig. 233 Volumetric flow in broken loop (FTB-30 and FTB-37), from -20 to $200 \mathrm{~s}$.

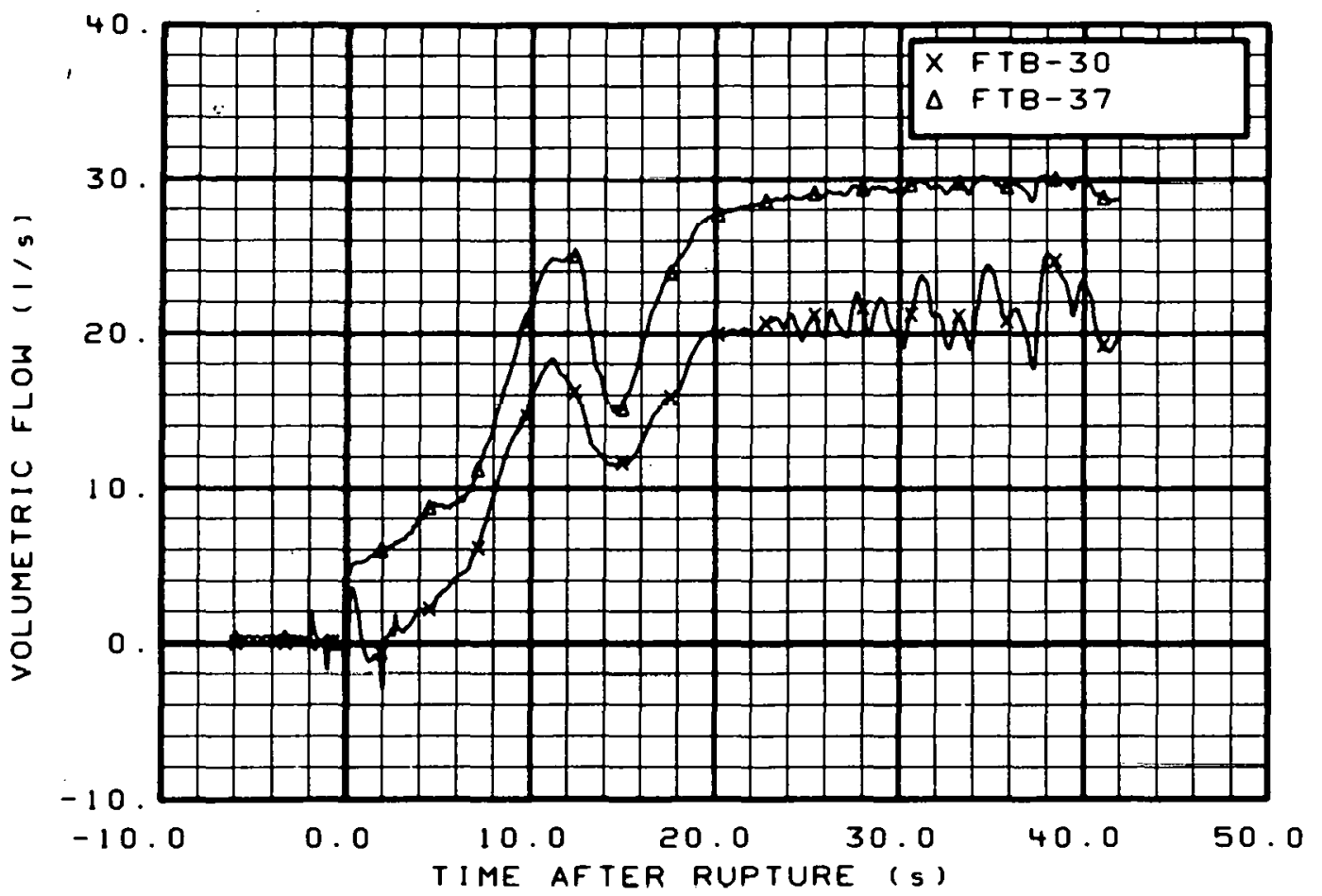

Fig. 234 Volumetric flow in broken loop (FTB-30 and FTB-37), from -6 to $42 \mathrm{~s}$. 


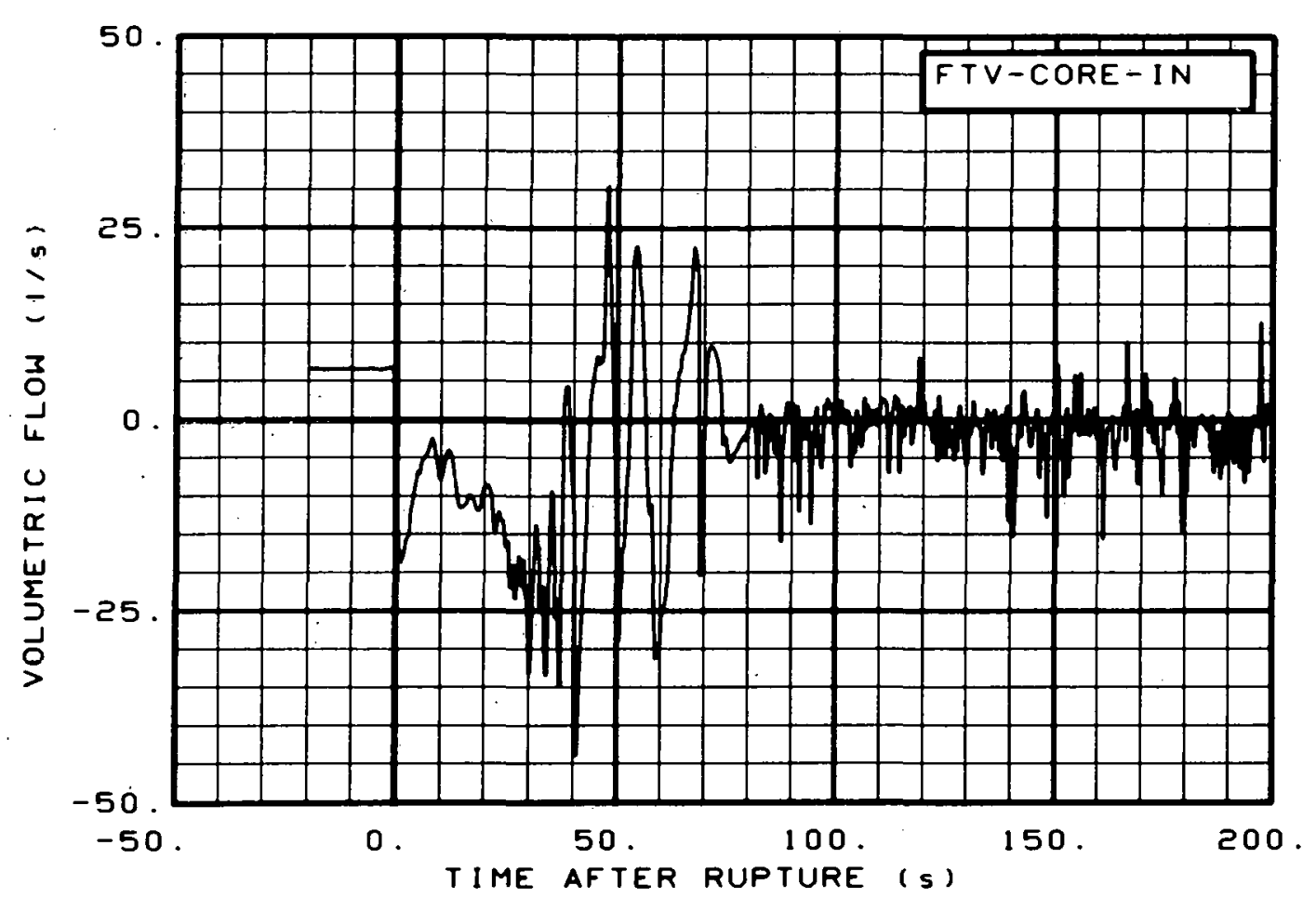

Fig. 235 Volumetric flow in core entrance (FTV-CORE-IN), from -20 to $200 \mathrm{~s}$.

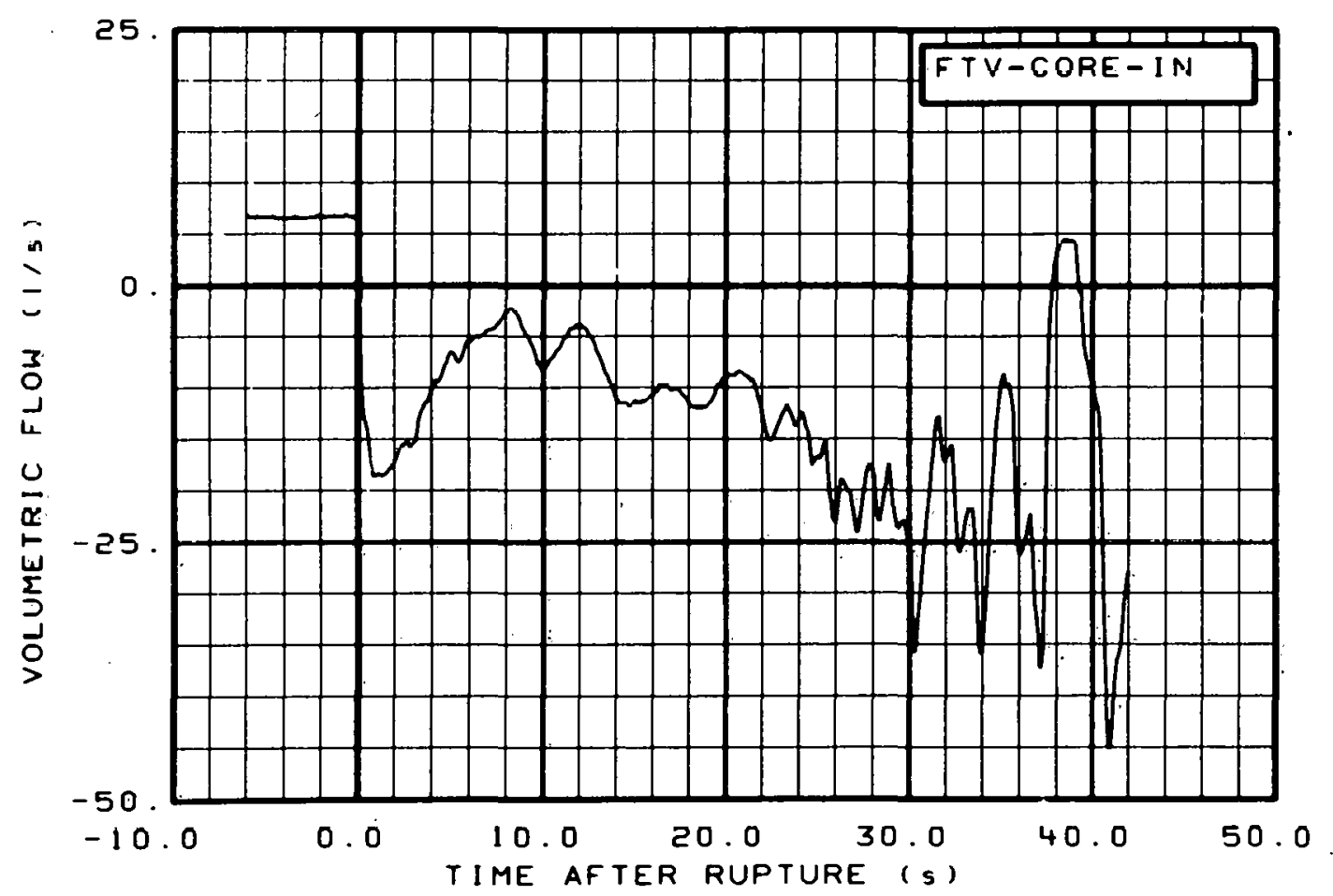

Fig. 236 Volumetric flow in core entrance (FTV-CORE-IN), from -6 to $42 \mathrm{~s}$. 


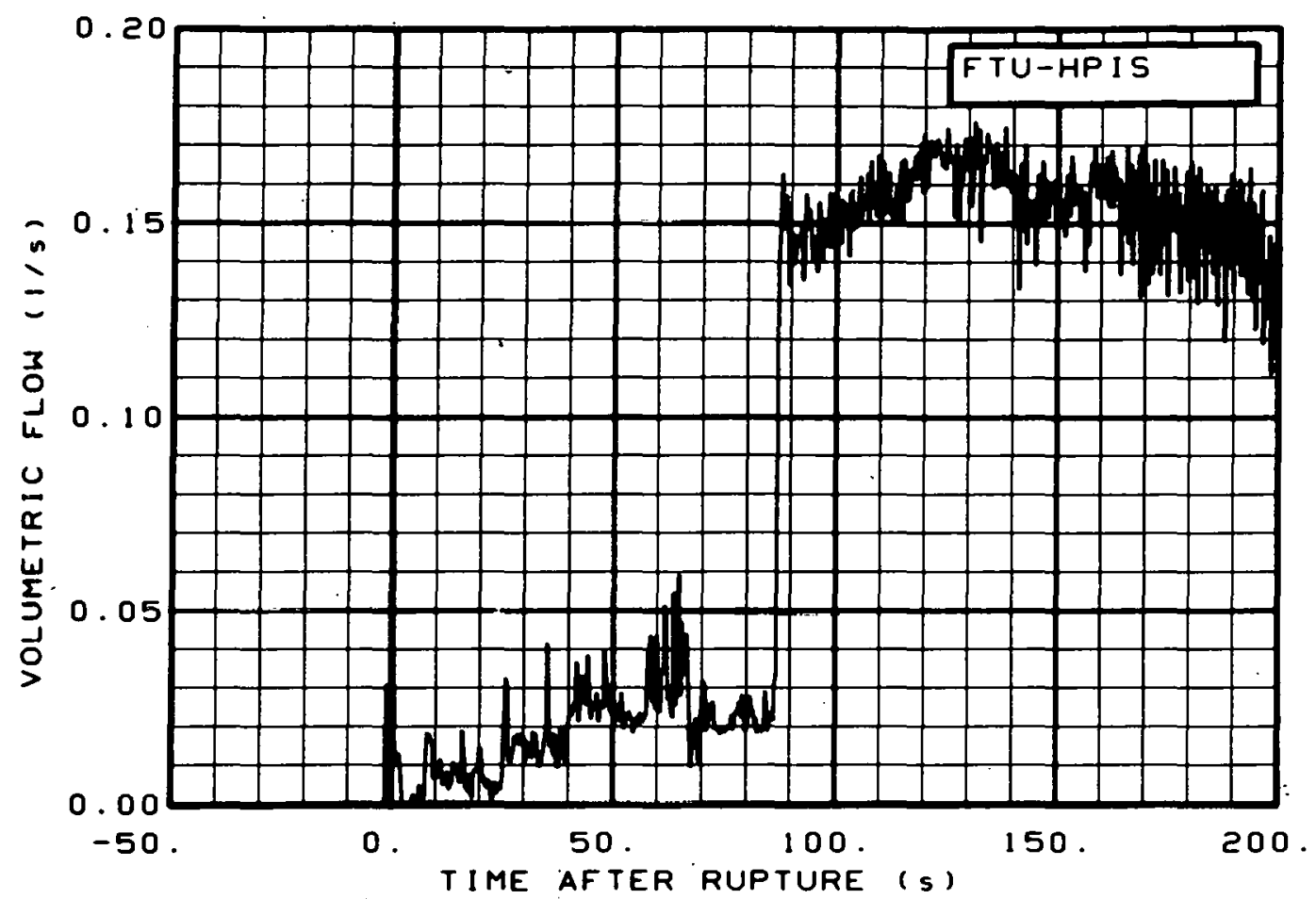

Fig. 237 Volumetric flow in intact loop high pressure injection line (FTU-HPIS), from -20 to $200 \mathrm{~s}$.

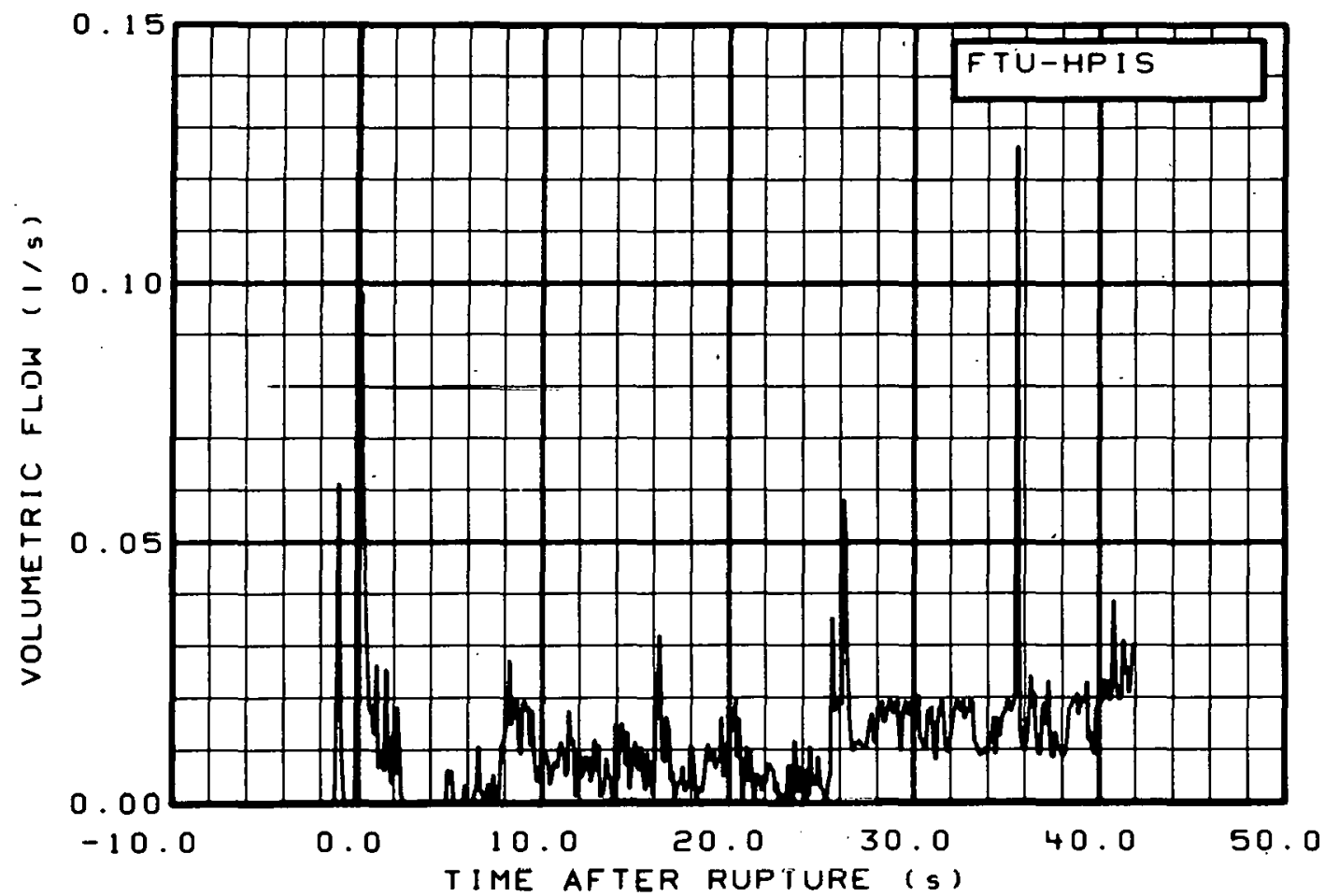

Fig. 238 Volumetric flow in intact loop high pressure injection line (FTU-HPIS), from -6 to $42 \mathrm{~s}$. 


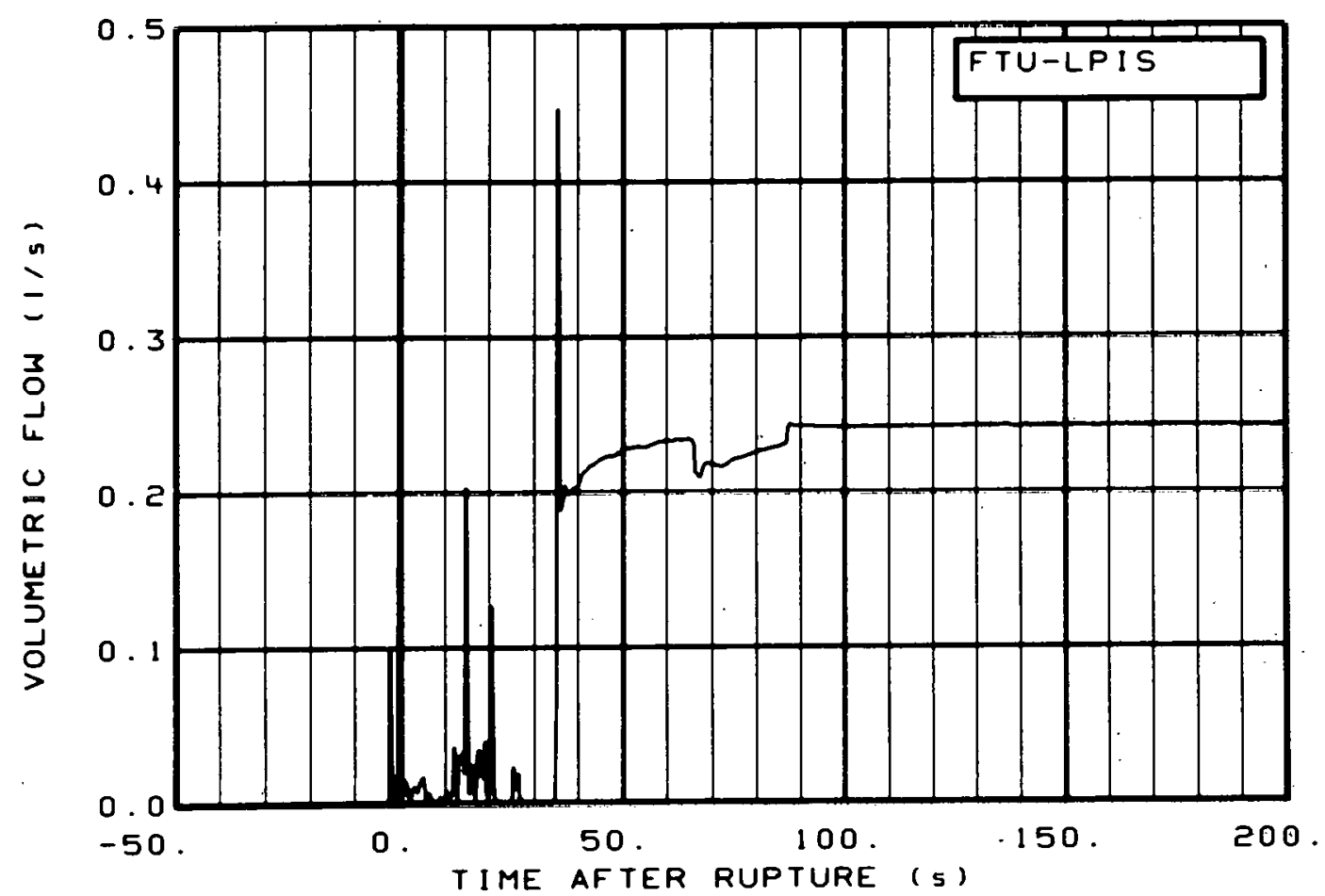

Fig. 239 Volumetric flow in intact loop low pressure injection line (FTU-LPIS), from -20 to $200 \mathrm{~s}$.

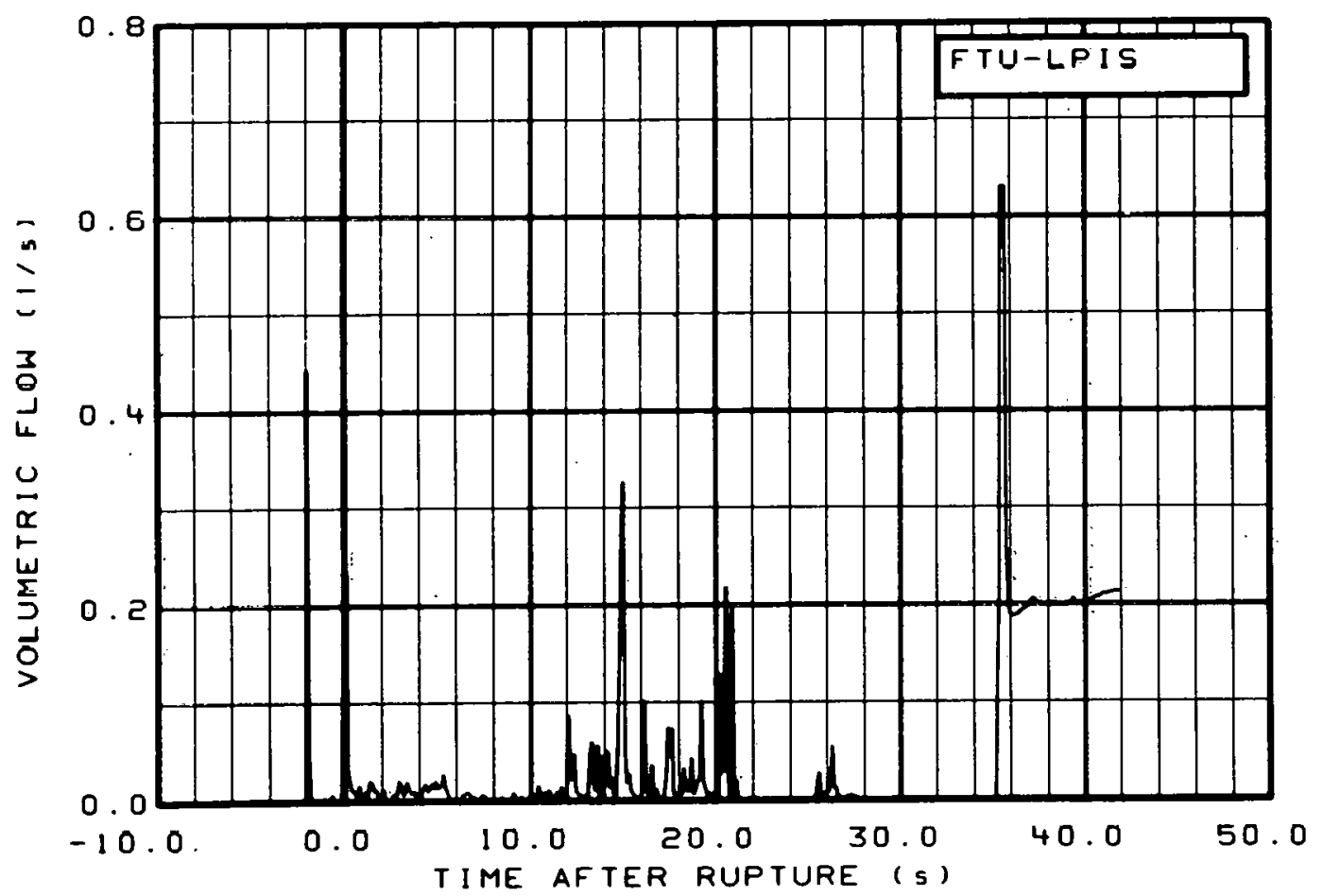

Fig. 240 Volumetric flow in intact loop low pressure injection line (FTU-LPIS), from -6 to $42 \mathrm{~s}$. 


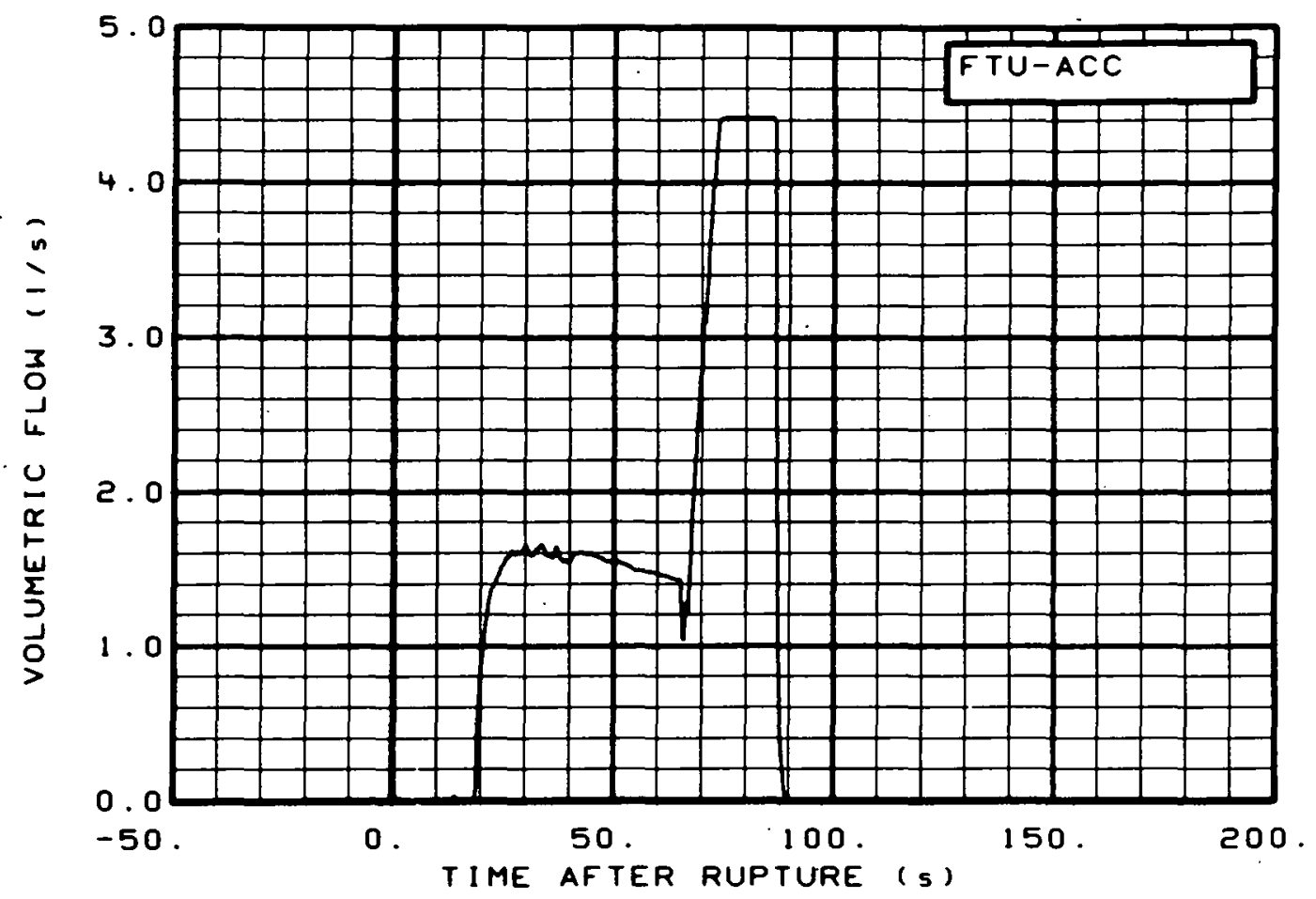

Fig. 241 Volumetric flow in intact loop accumulator discharge line (FTU-ACC), from -20 to $200 \mathrm{~s}$.

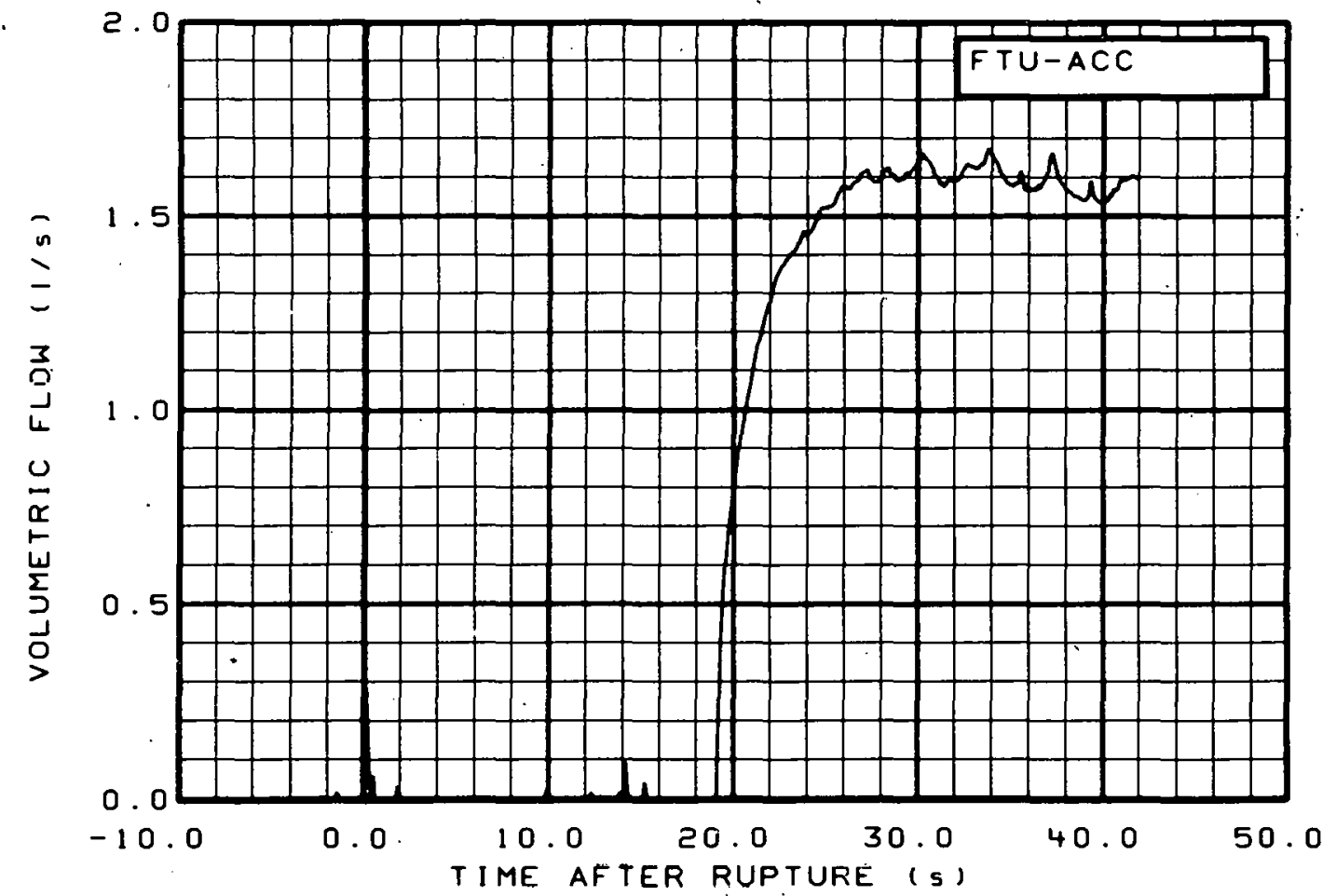

Fig. 242 Volumetric flow in intact loop acćumulator discharge line (FTU-ACC), from -6 to $42 \mathrm{~s}$. 


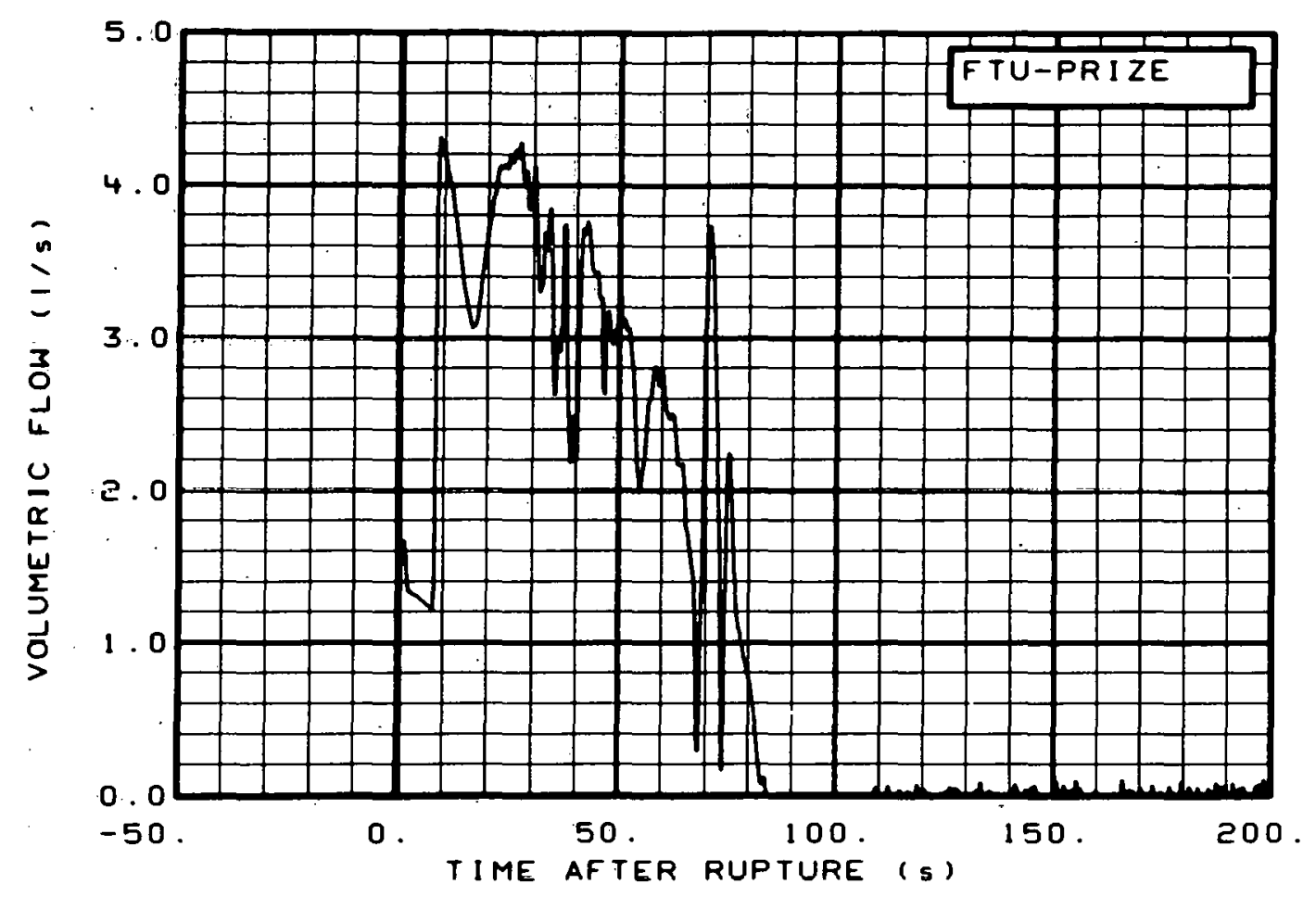

Fig. 243 Volumetric flow from pressurizer (FTU-PRIZE), from -20 to $200 \mathrm{~s}$.

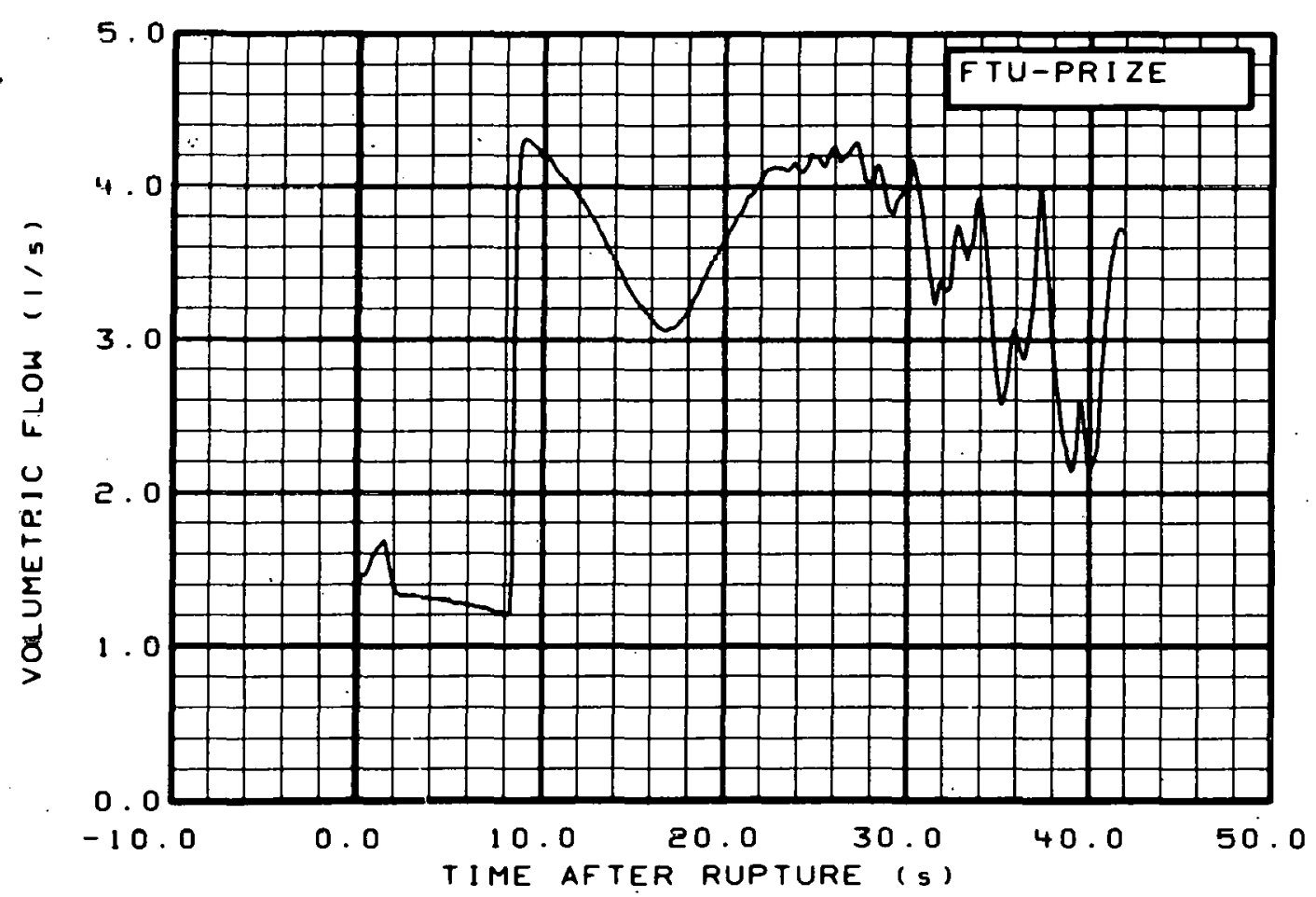

Fig. 244 Volumetric flow from pressurizer (FTU-PRIZE), from -6 to $42 \mathrm{~s}$. 


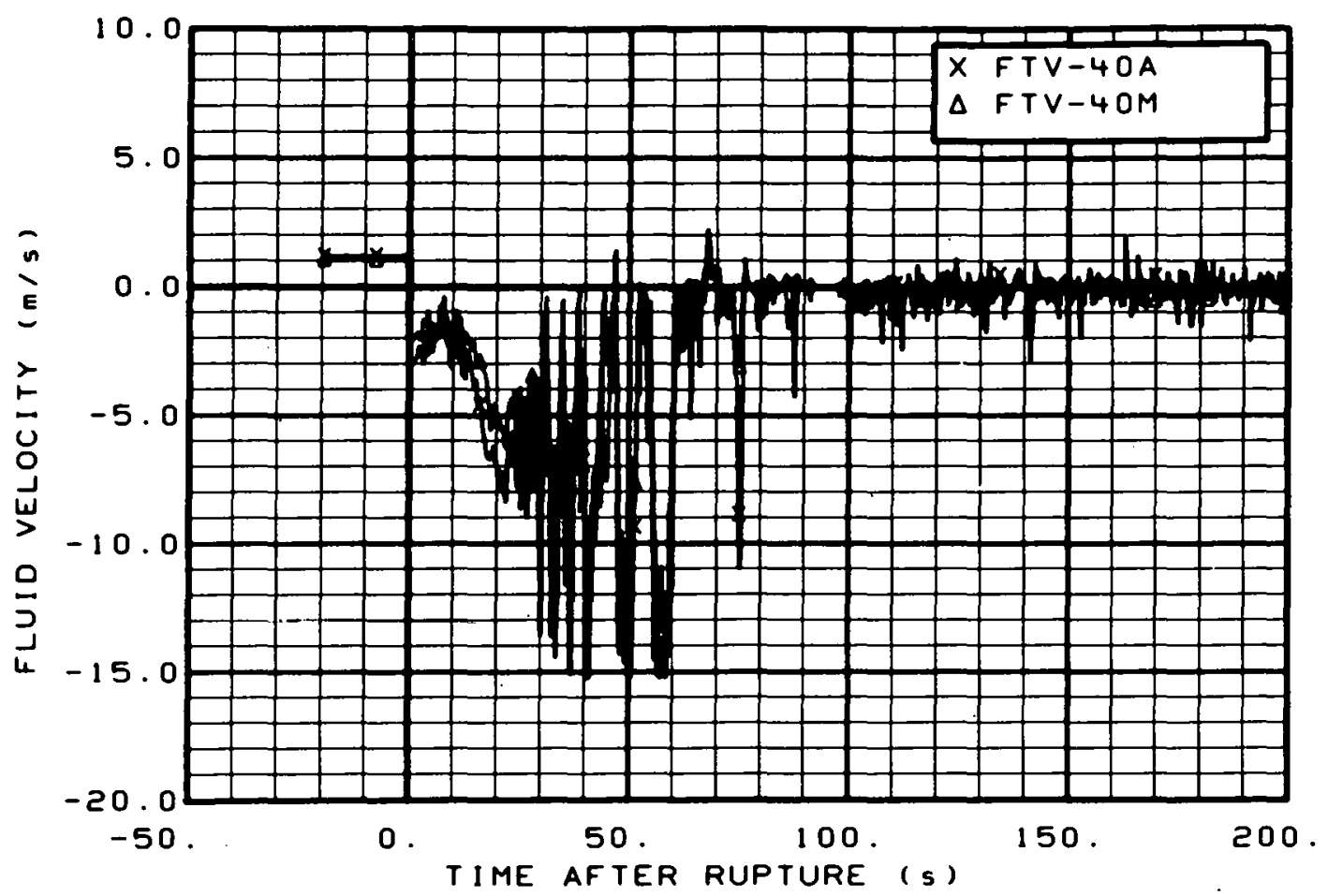

Fig. 245 Fluid velocity in vessel (FTV-40A and FTV-40M), from -20 to $200 \mathrm{~s}$.

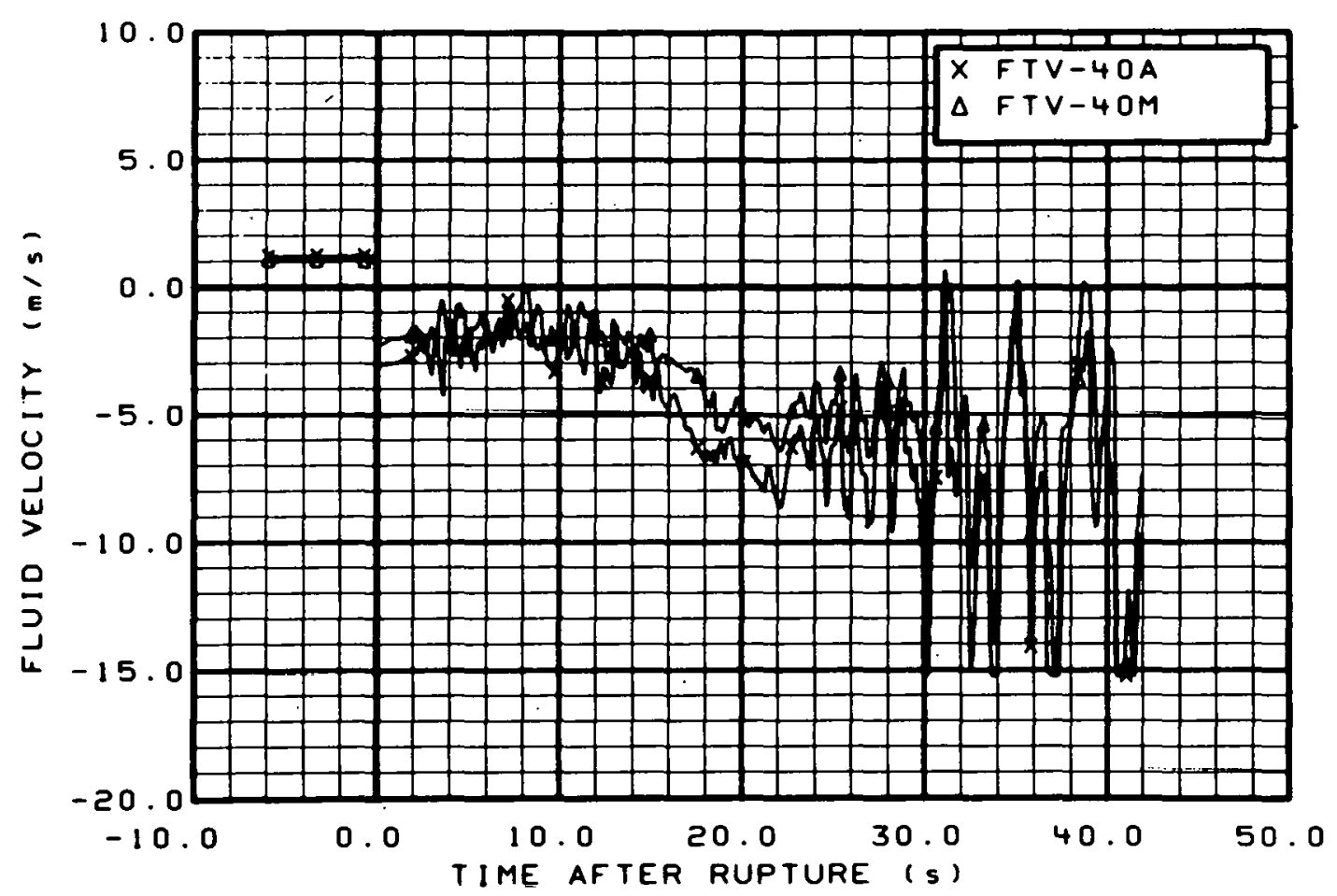

Fig. 246 Fluid velocity in vessel (FTV-40A and FTV-40M), from -6 to $42 \mathrm{~s}$. 


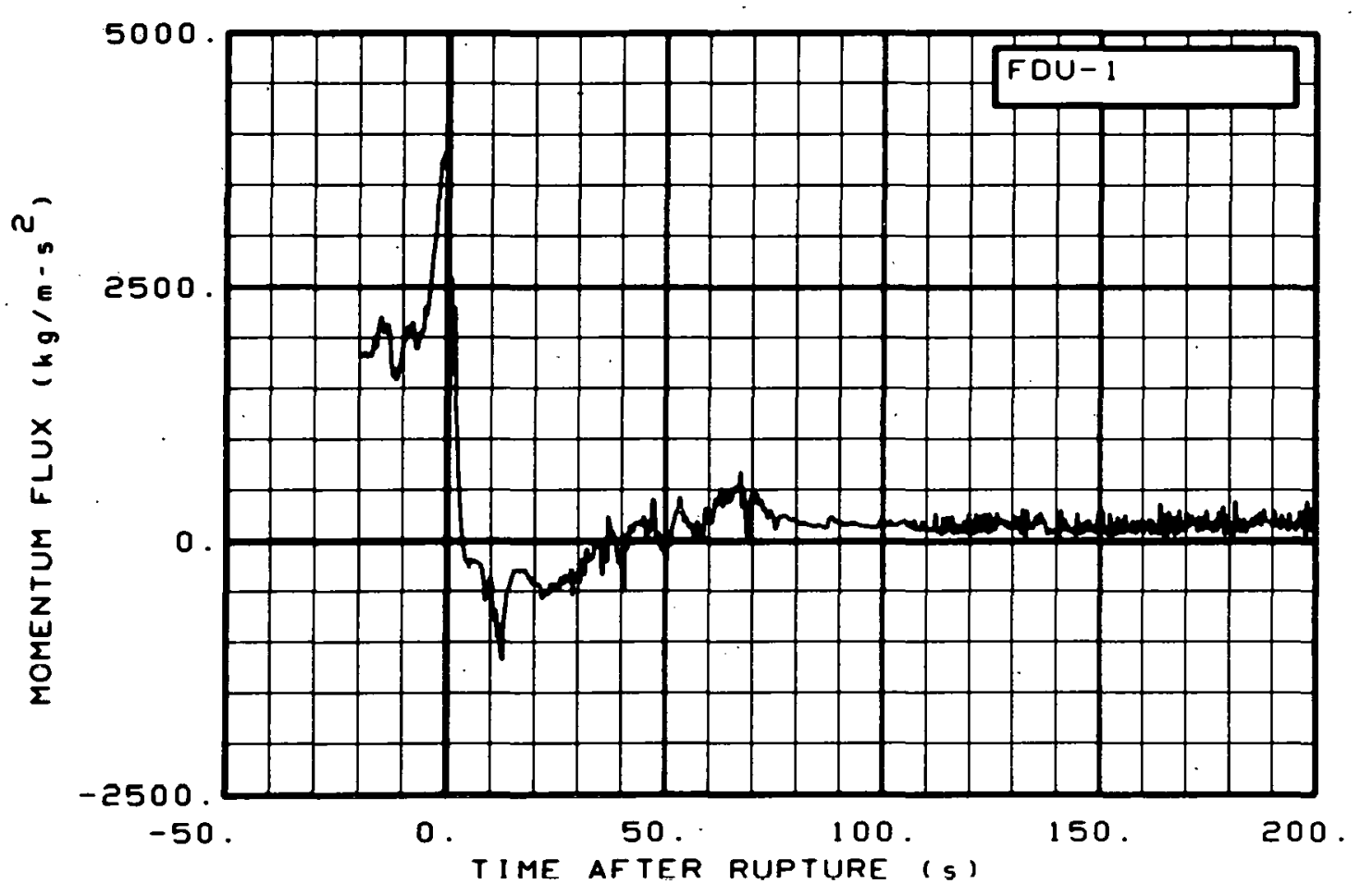

Fig. 247 Momentum flux in intact loop (FDU-1), from -20 to $200 \mathrm{~s}$.

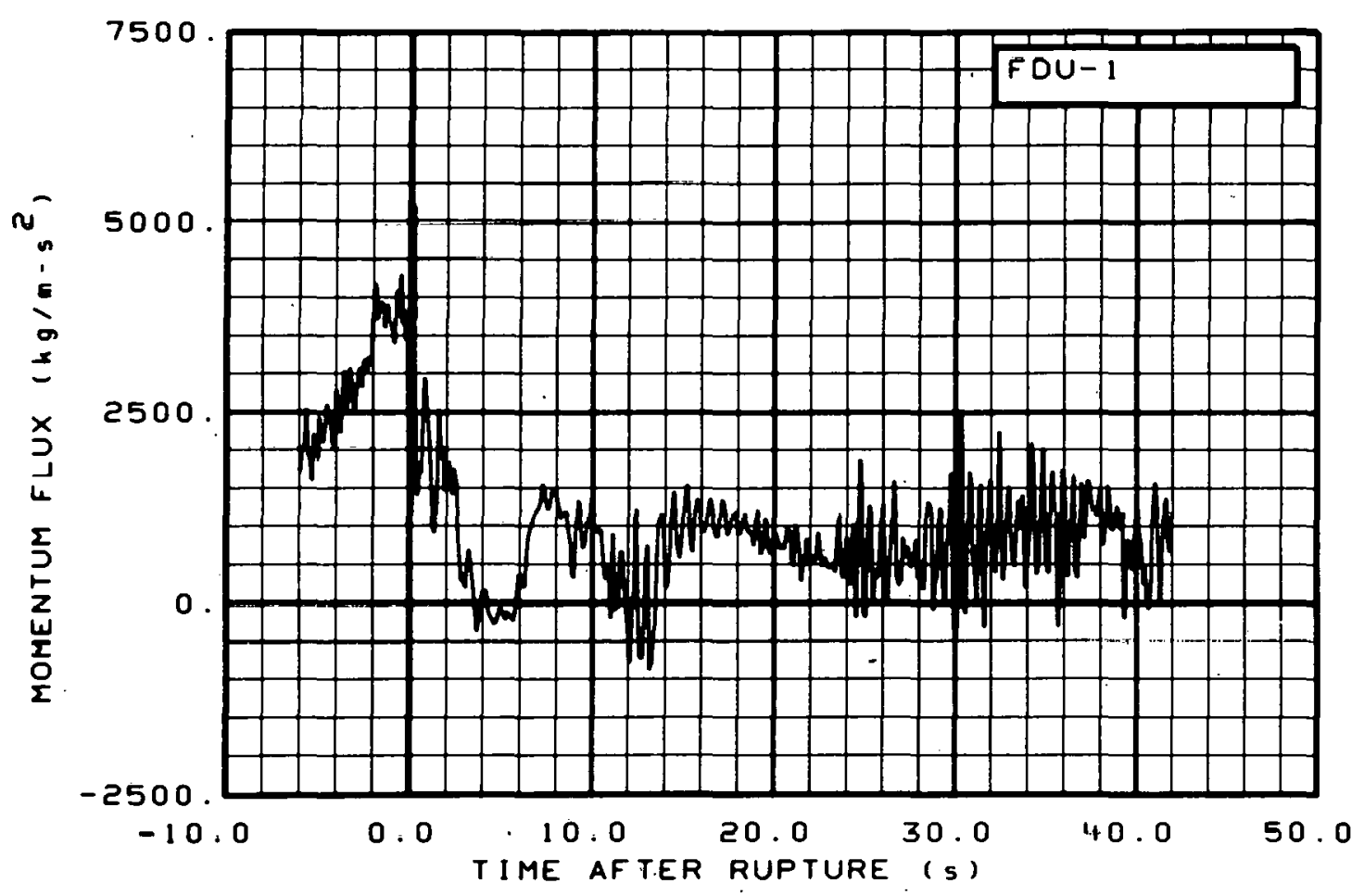

Fig. 248 Momentum flux in intact loop (FDU-1), from -6 to $42 \mathrm{~s}$. 


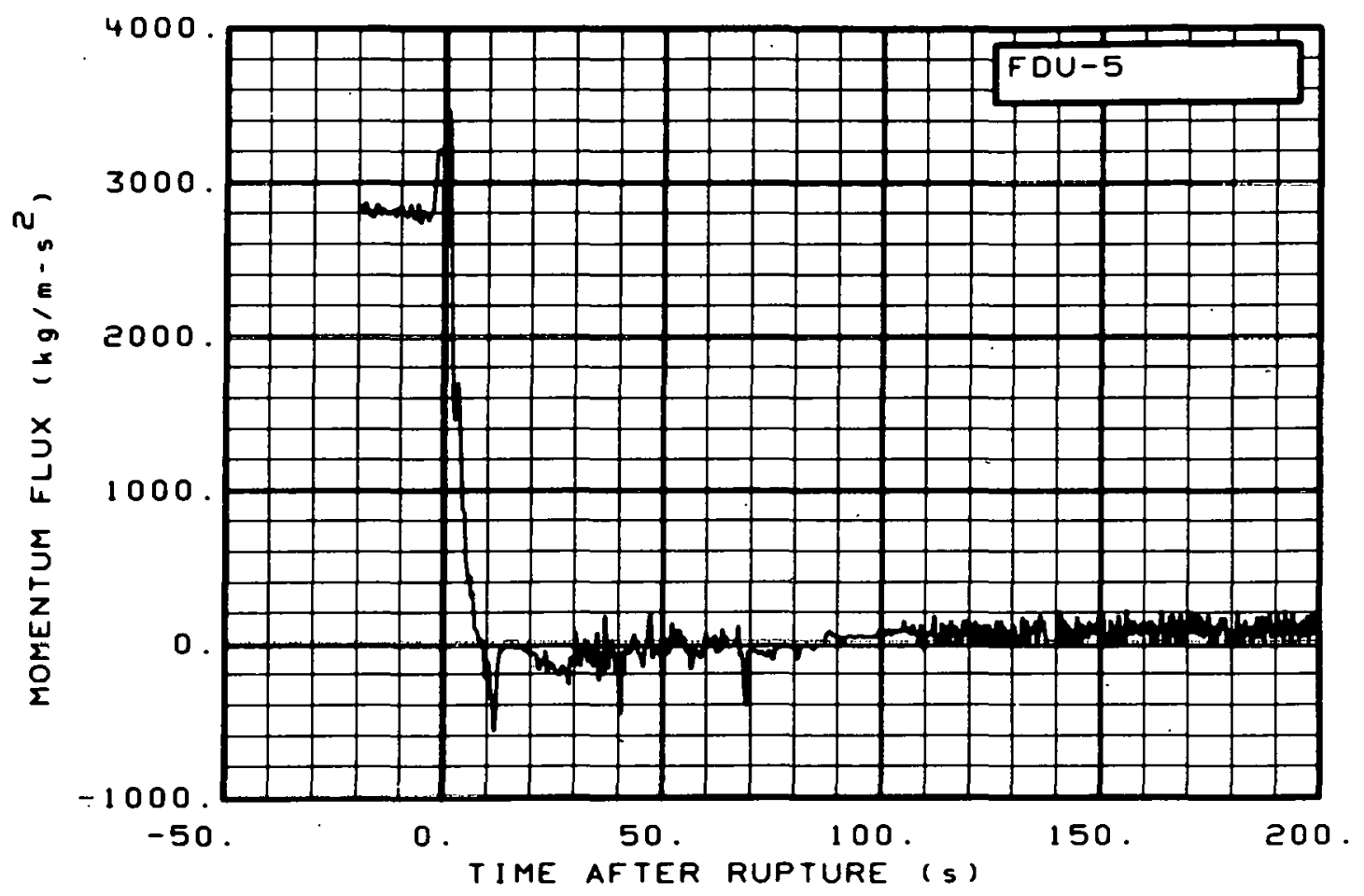

Fig. 249 Momentum flux in intact loop (FDU-5), from -20 to $200 \mathrm{~s}$.

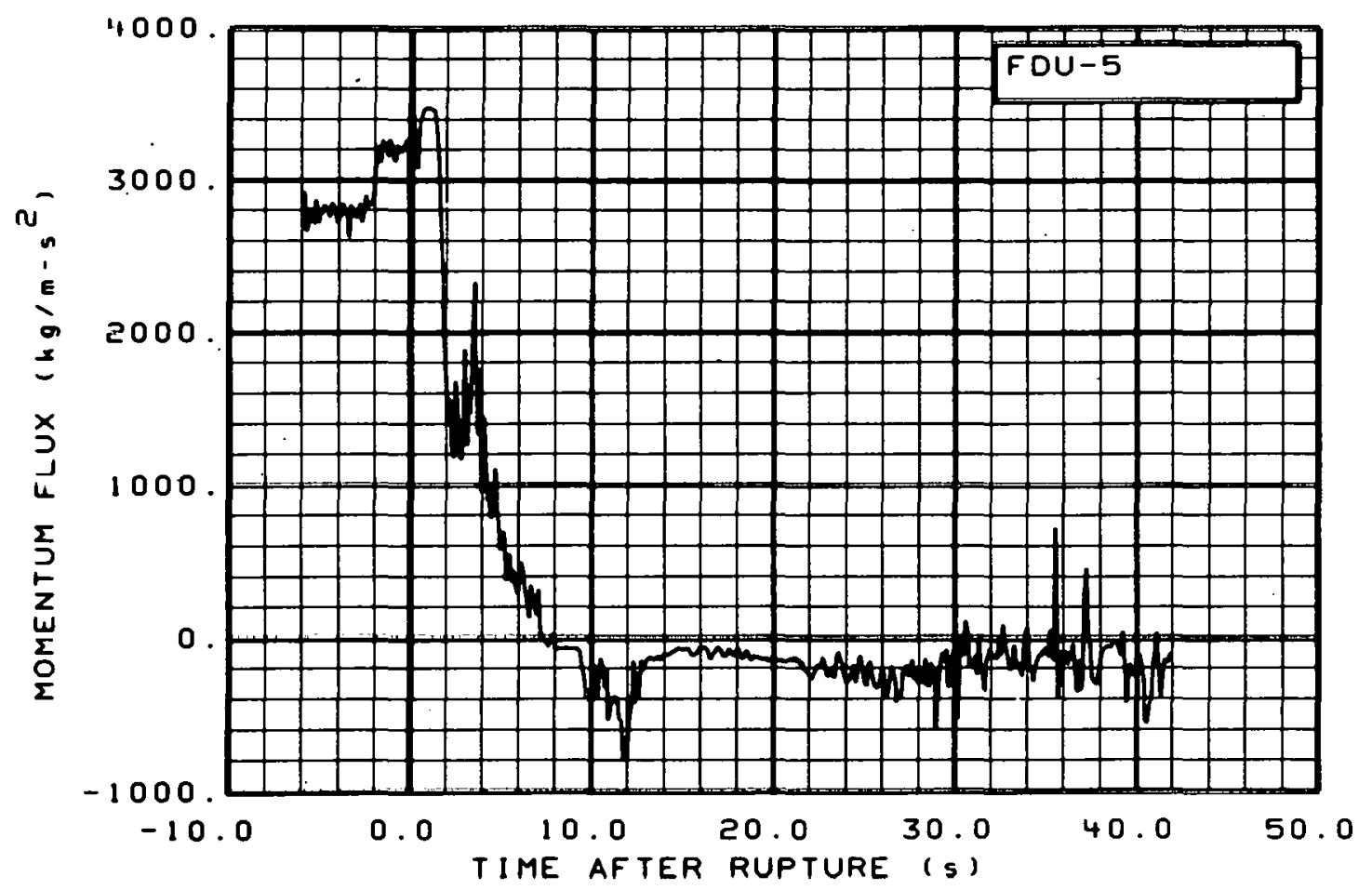

Fig. 250 Momentum flux in intact loop (FDU-5), from -6 to $42 \mathrm{~s}$. 


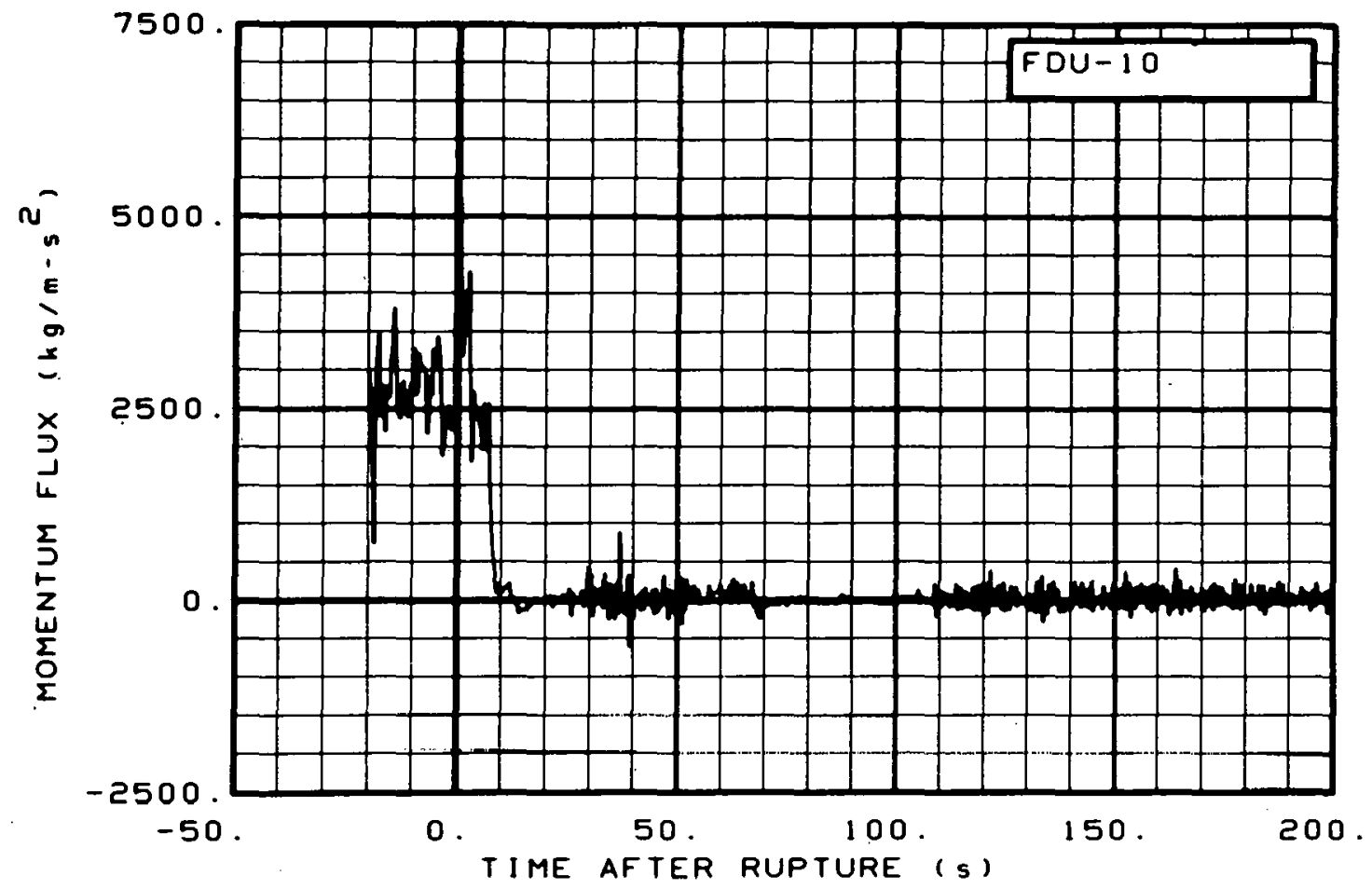

Fig. 251 Momentum flux in intact loop (FDU-10), from -20 to $200 \mathrm{~s}$.

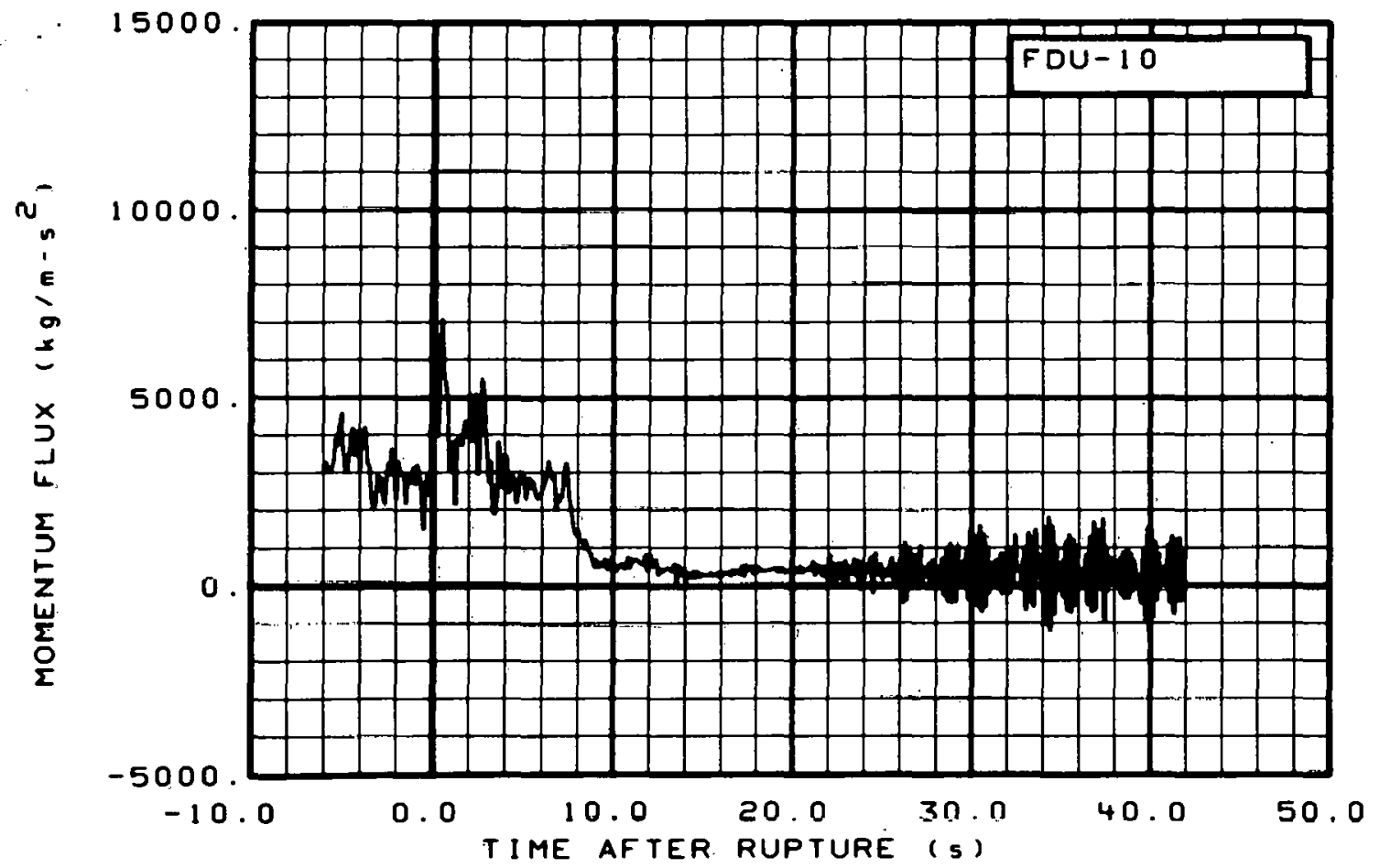

Fig. 252 Momentum flux in intact loop (FDU-10), from -6 to $42 \mathrm{~s}$. 


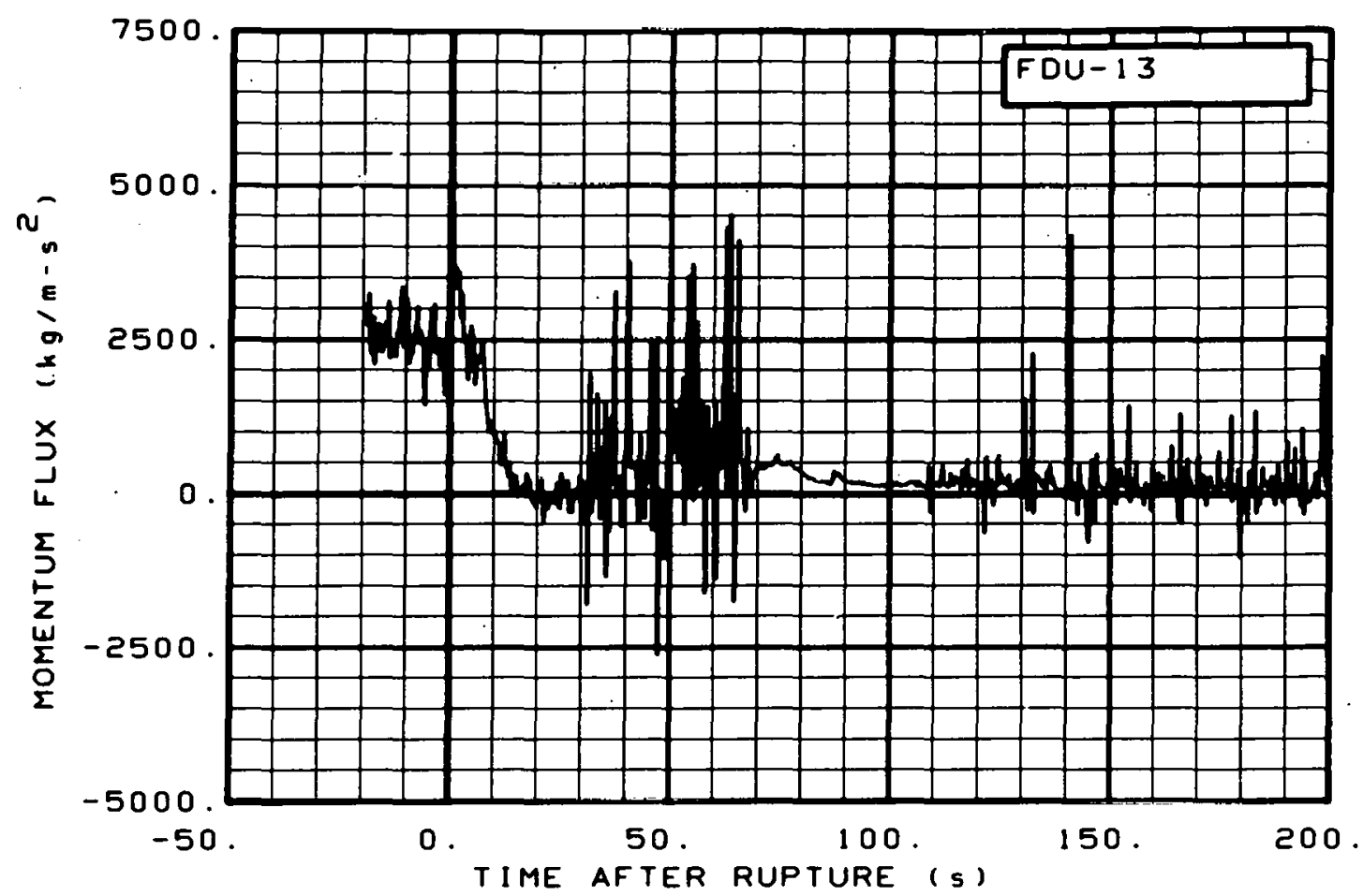

Fig. 253 Momentum flux in intact loop (FDU-13), from -20 to $200 \mathrm{~s}$.

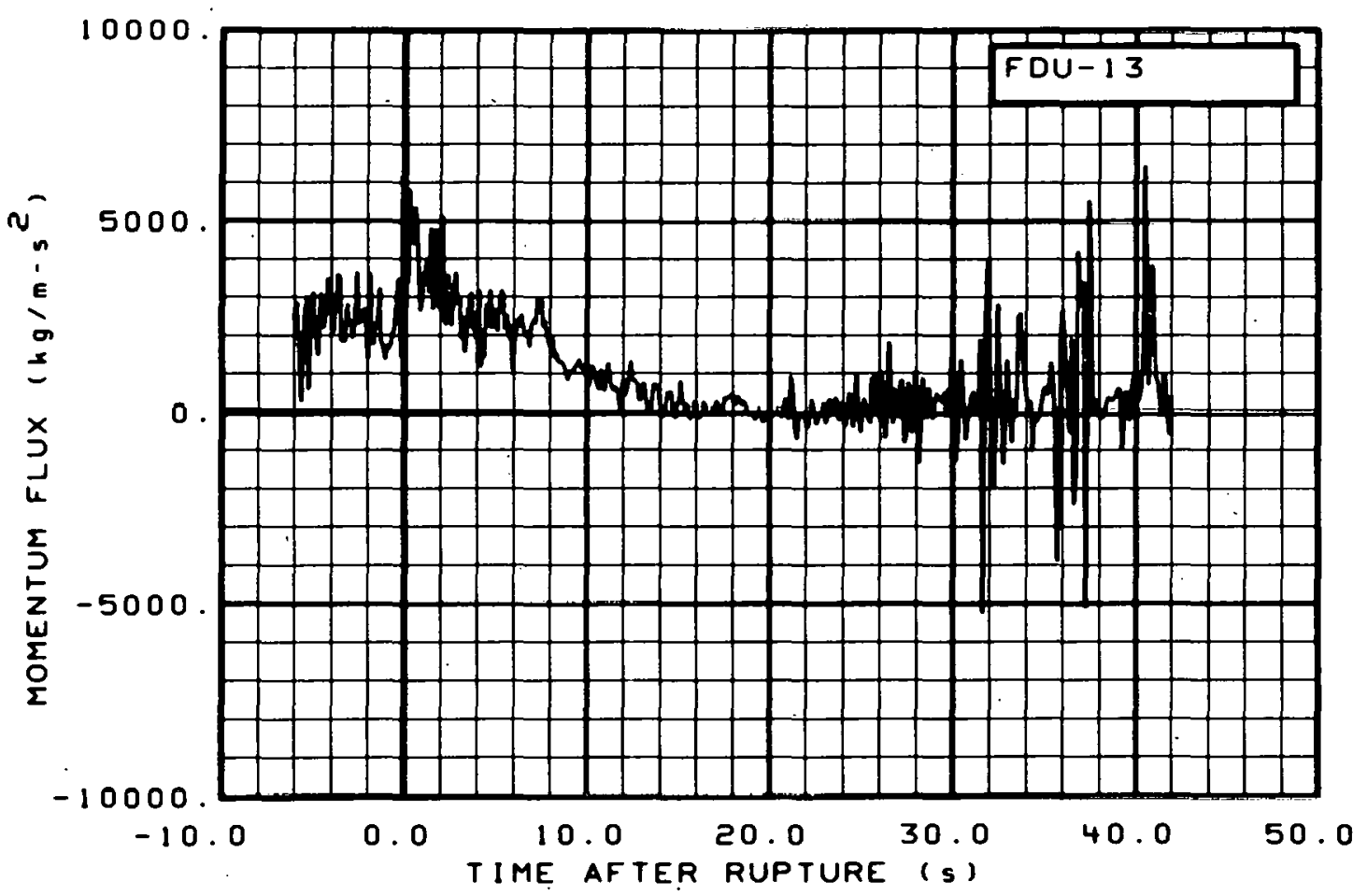

Fig. 254 Momentum flux in intact loop (FDU-13), from -6 to $42 \mathrm{~s}$. 


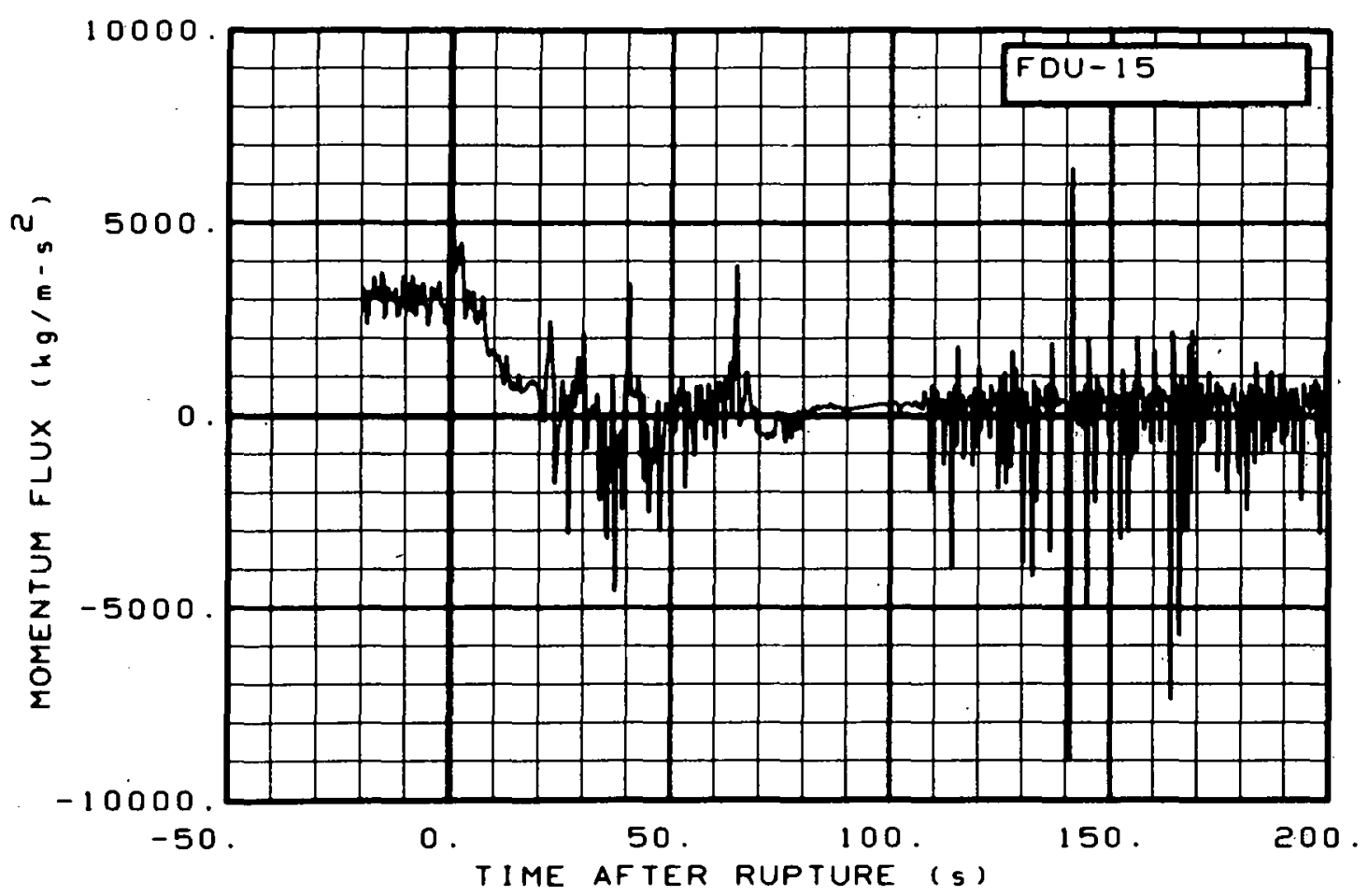

Fig. 255 Momentum flux in intact loop (FDU-15), from -20 to $200 \mathrm{~s}$.

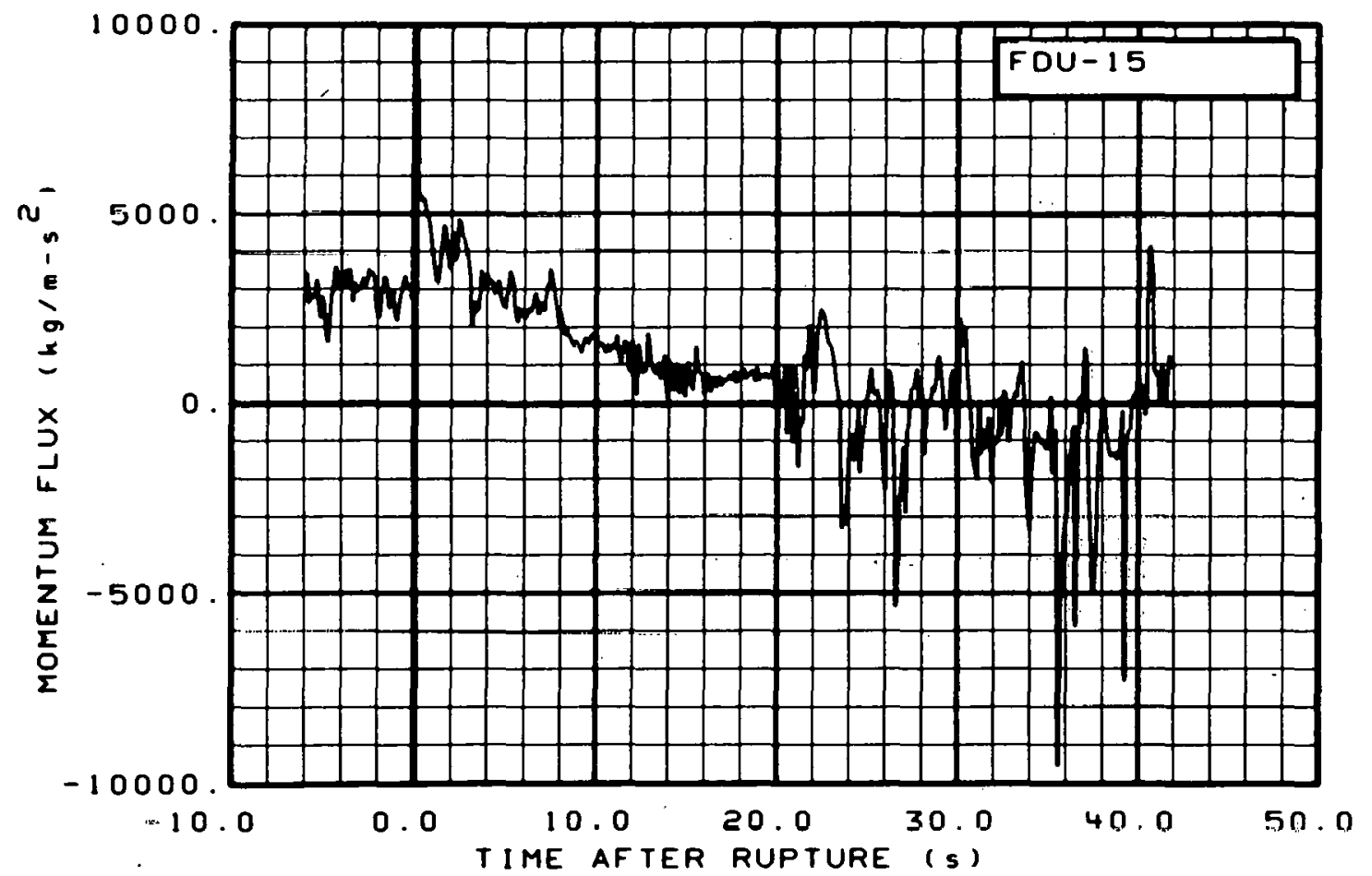

Fig. 256 Momentum flux in intact loop (FDU-15), from -6 to $42 \mathrm{~s}$. 


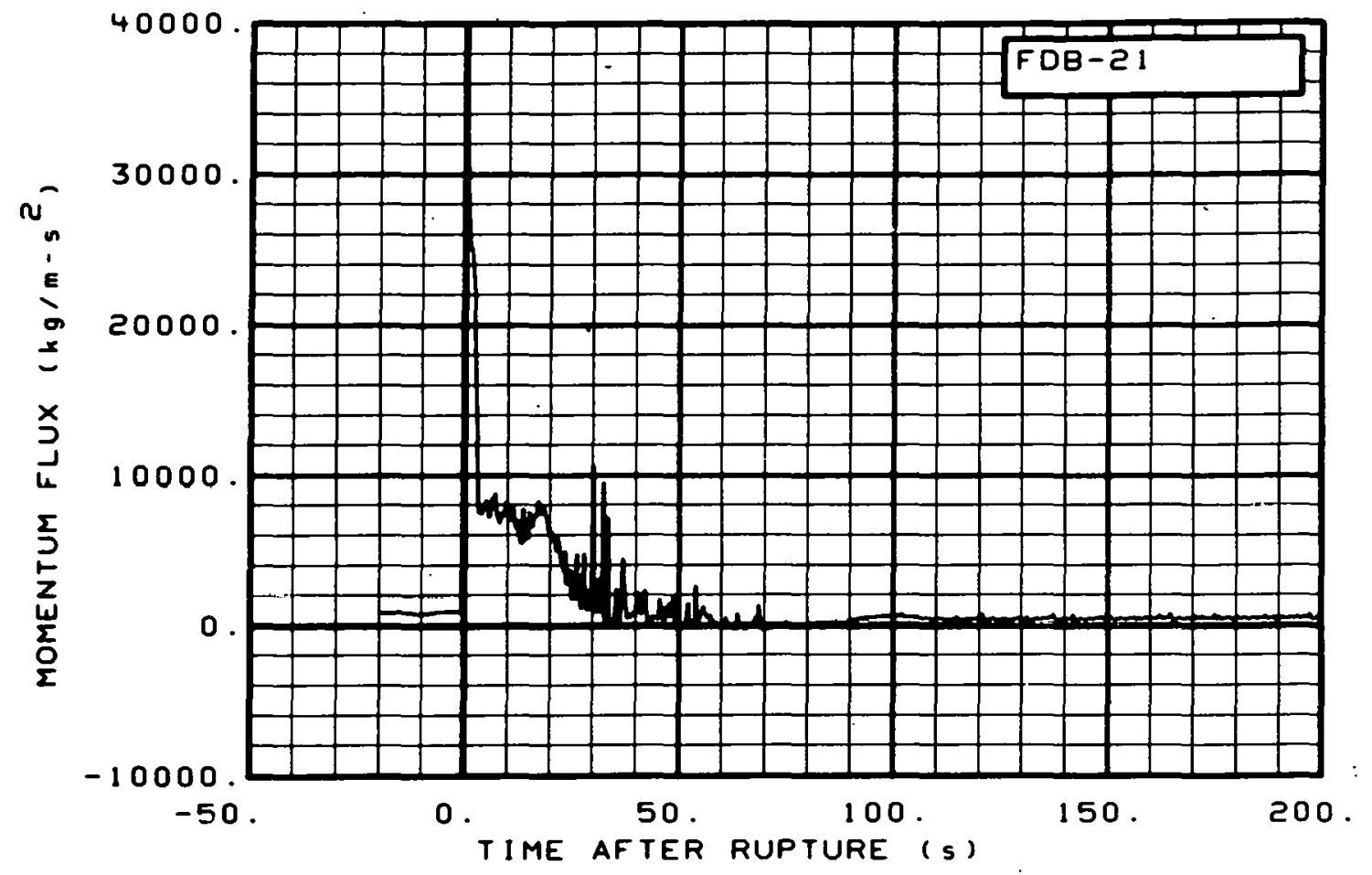

Fig. 257 Momentum flux in broken loop (FDB-21), from -20 to $200 \mathrm{~s}$.

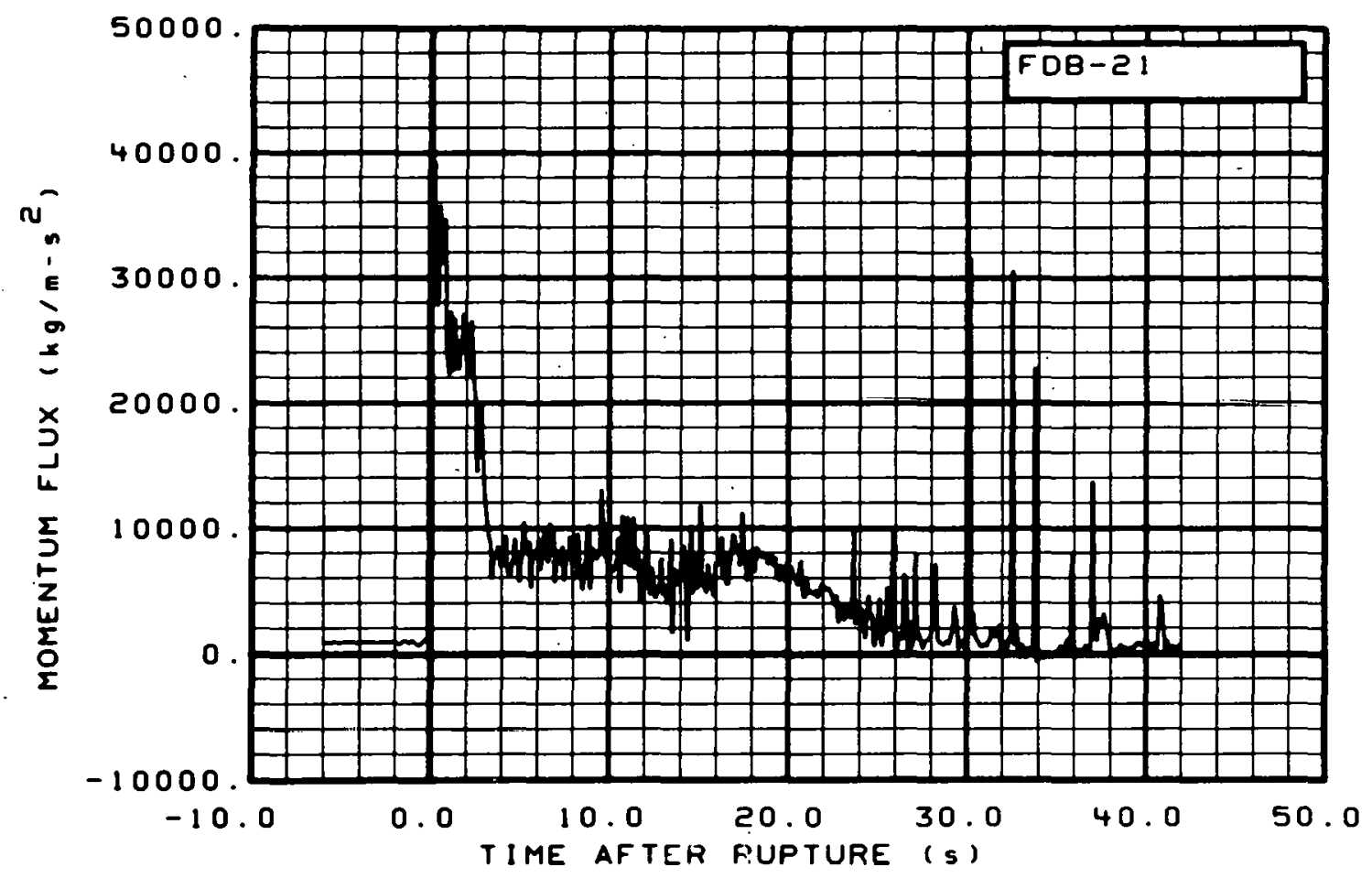

Fig. 258 Momentum flux in broken loop (FDB-21), from -6 to $42 \mathrm{~s}$. 


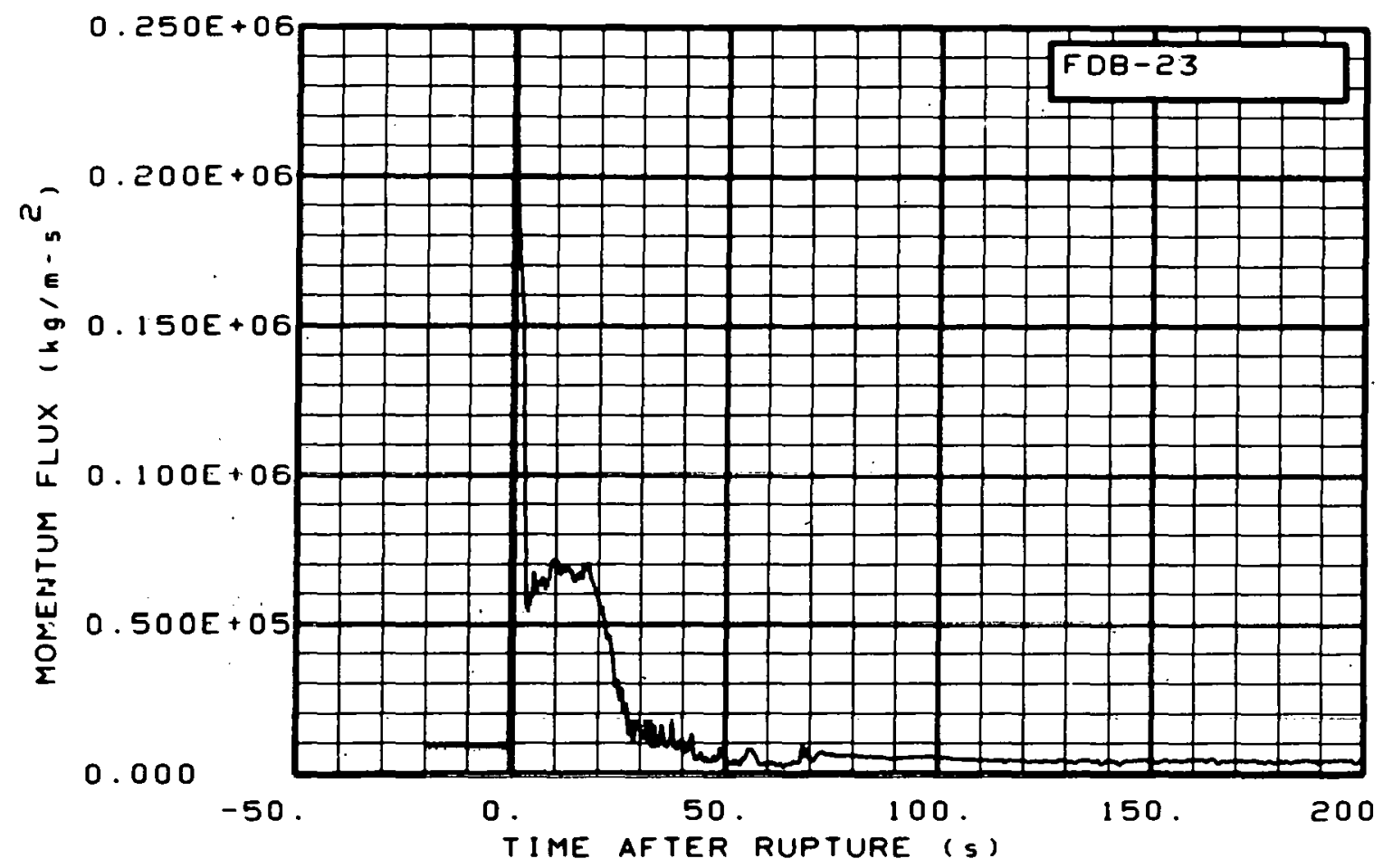

Fig. 259 Momentum flux in broken loop (FDB-23), from -20 to $200 \mathrm{~s}$.

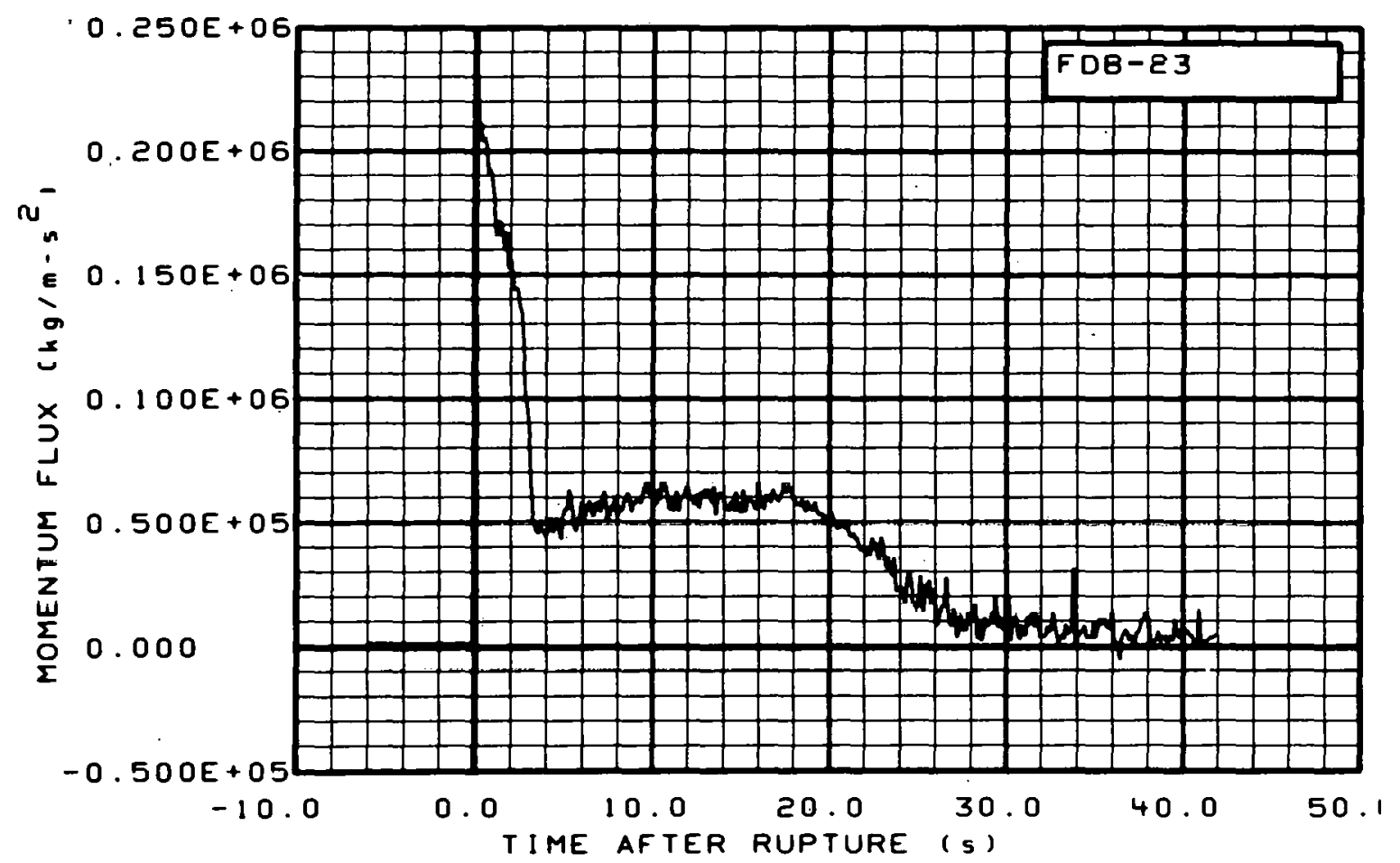

Fig. 260 Momentum flux in broken loop (FDB-23), from -6 to $42 \mathrm{~s}$. 


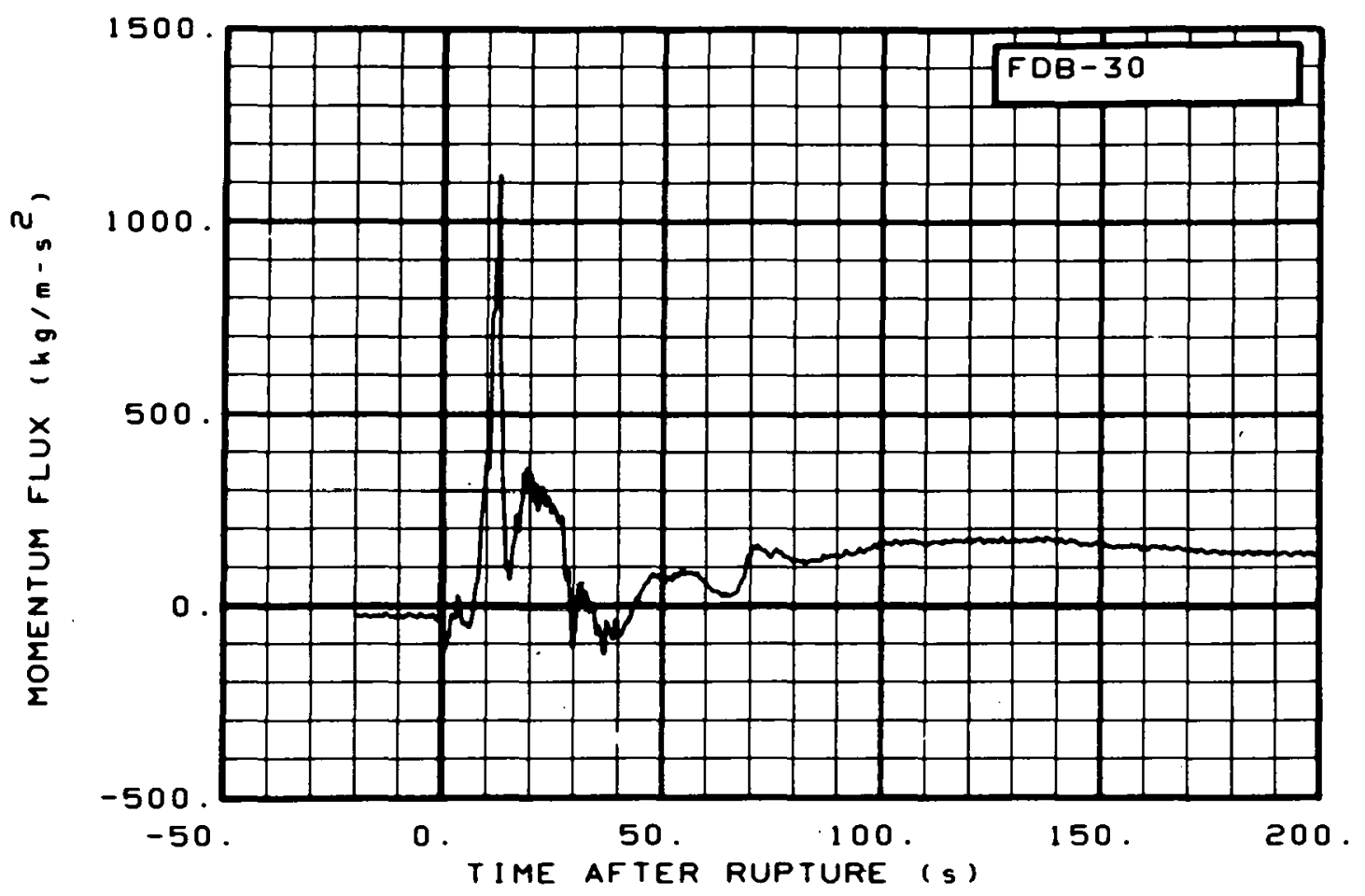

Fig. 261 Momentum flux in broken loop (FDB-30), from -20 to $200 \mathrm{~s}$.

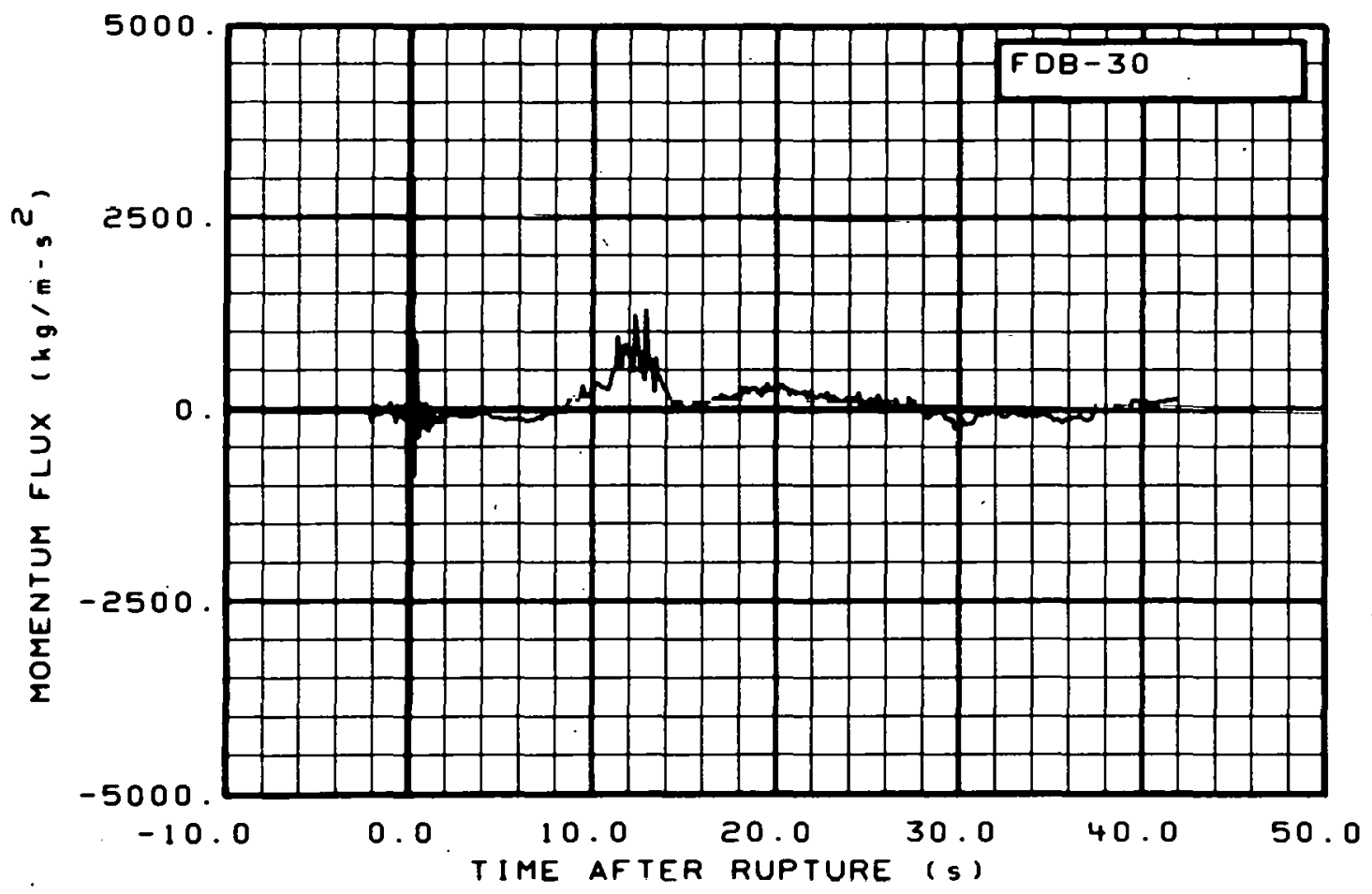

Fig. 262 Momentum flux in broken loop (FDB-30), from -6 to $42 \mathrm{~s}$. 


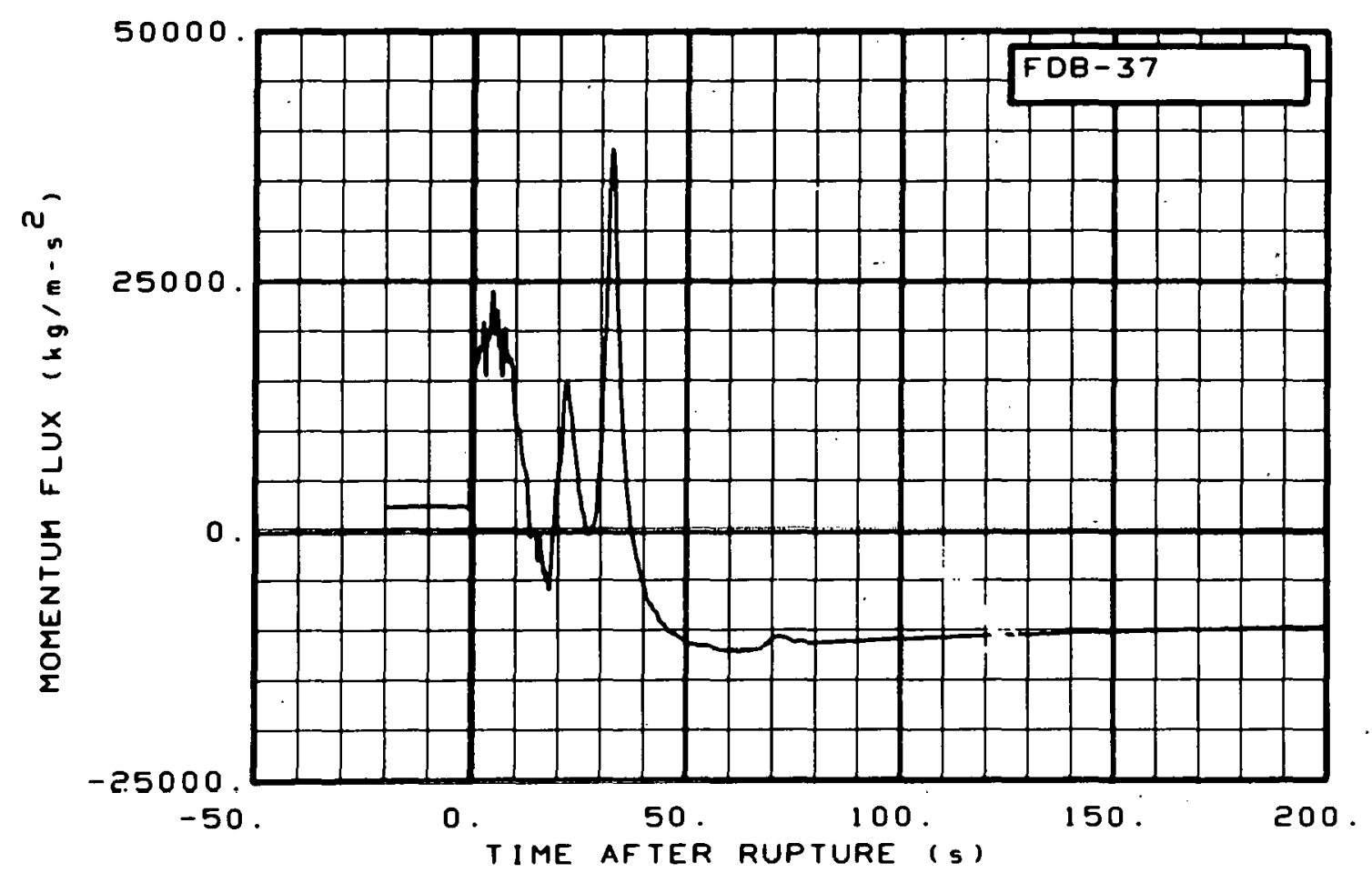

:Fig. 263 Momentum flux in broken loop (FDB-37), from -20 to $200 \mathrm{~s}$.

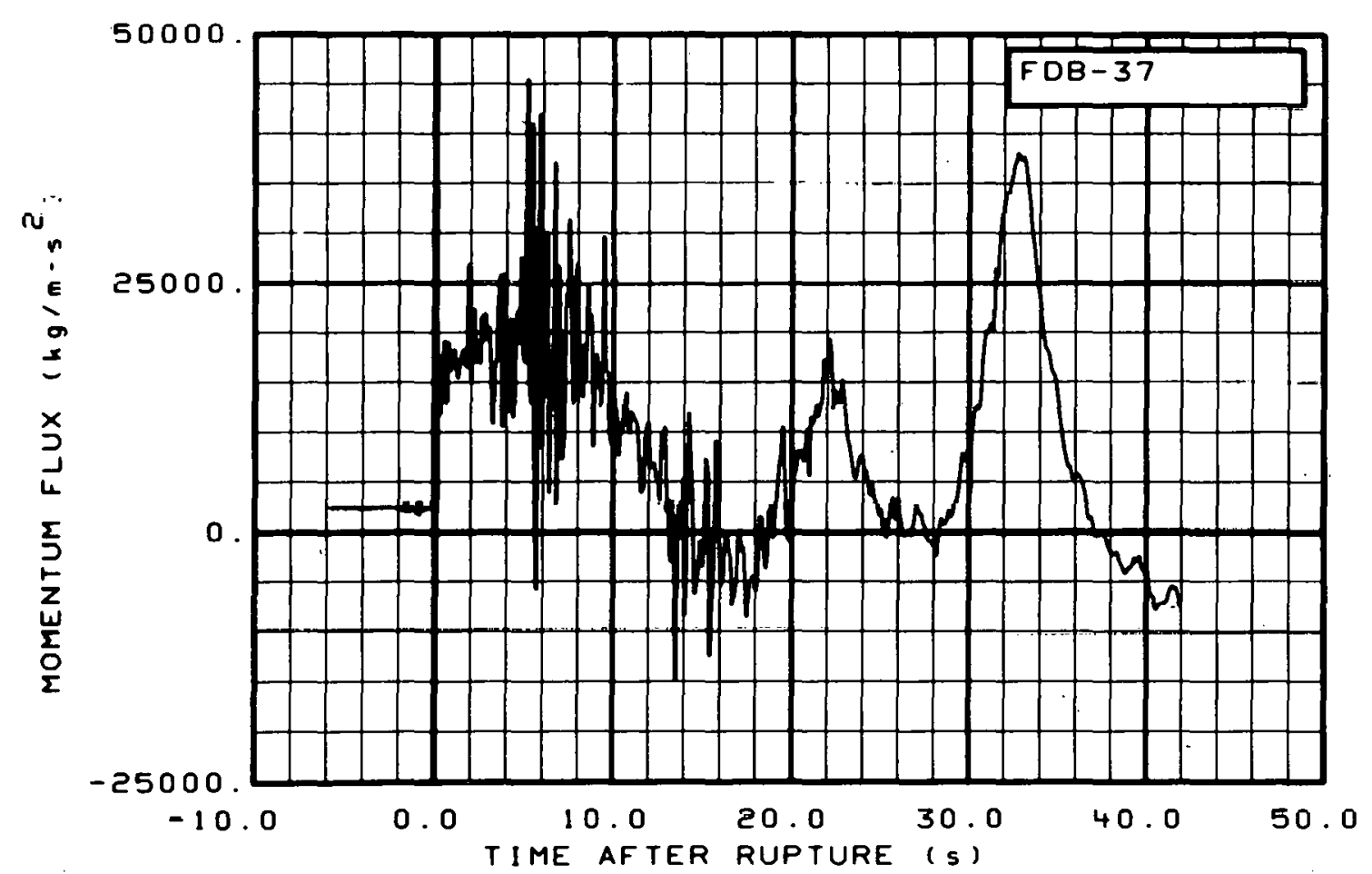

Fig. 264 Momentum flux in broken loop (FDB-37), from -6 to $42 \mathrm{~s}$. 


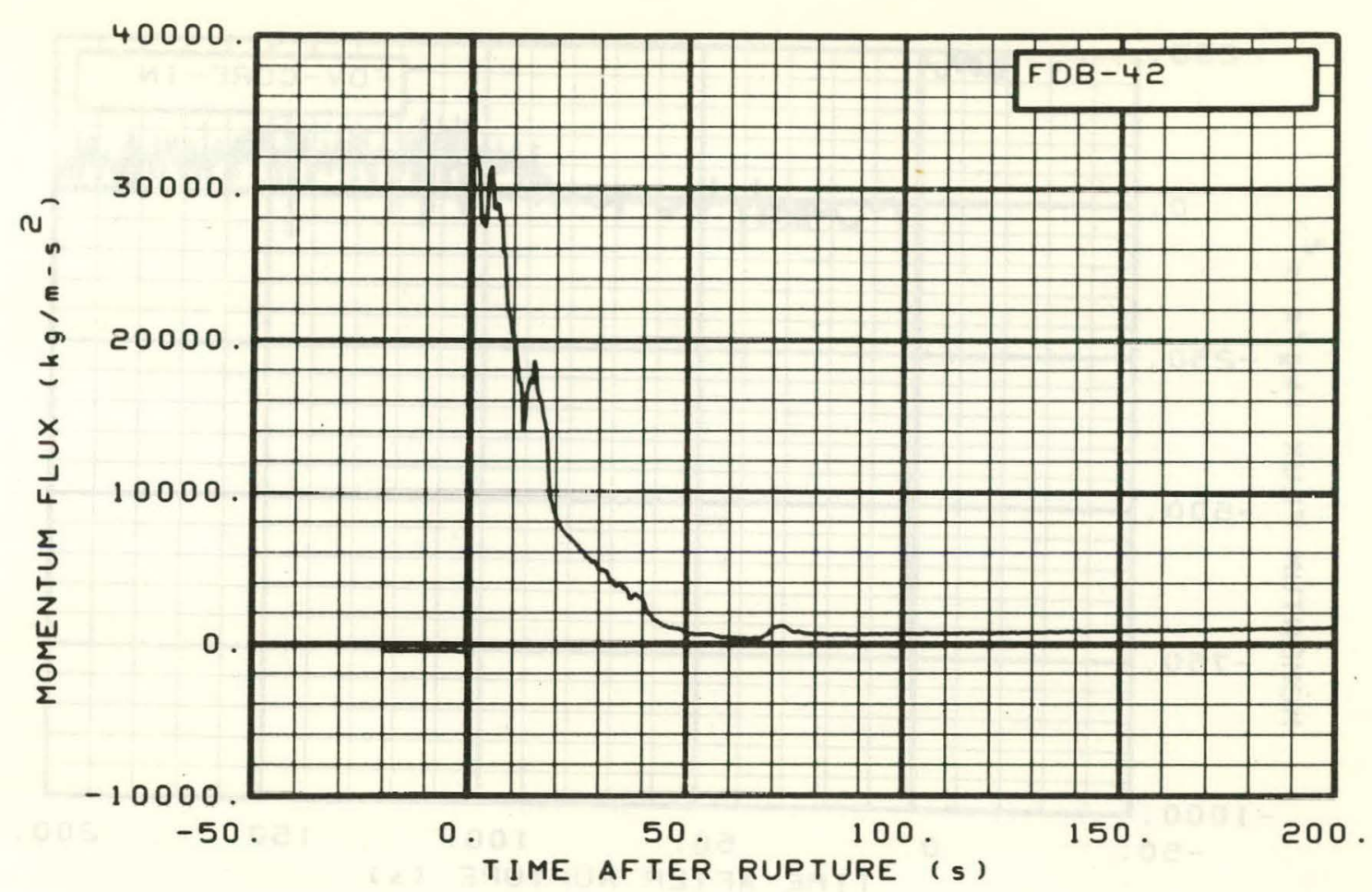

Fig. 265 Momentum flux in broken loop (FDB-42), from -20 to $200 \mathrm{~s}$.

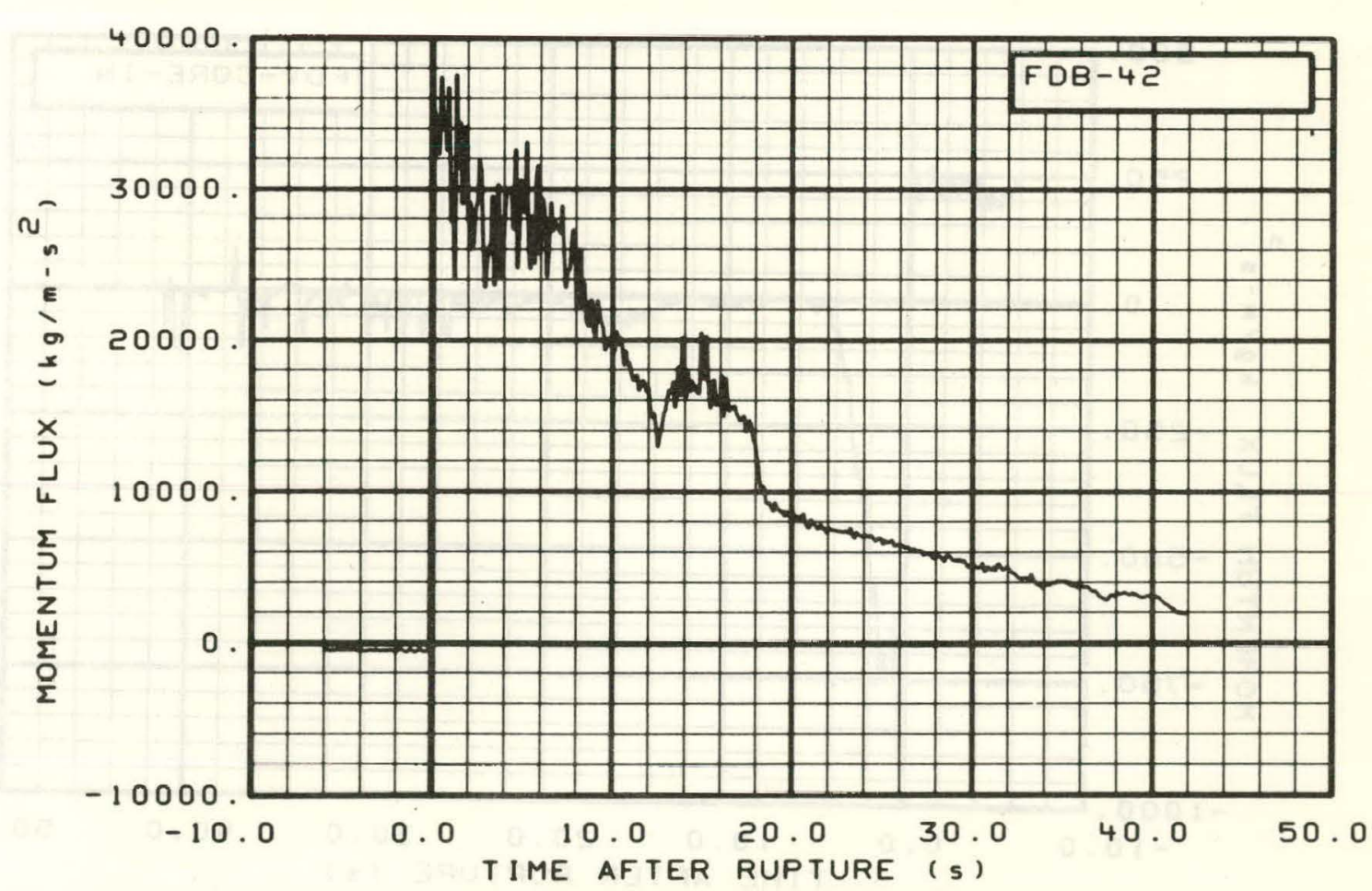

Fig. 266 Momentum flux in broken loop (FDB-42), from -6 to $42 \mathrm{~s}$. 


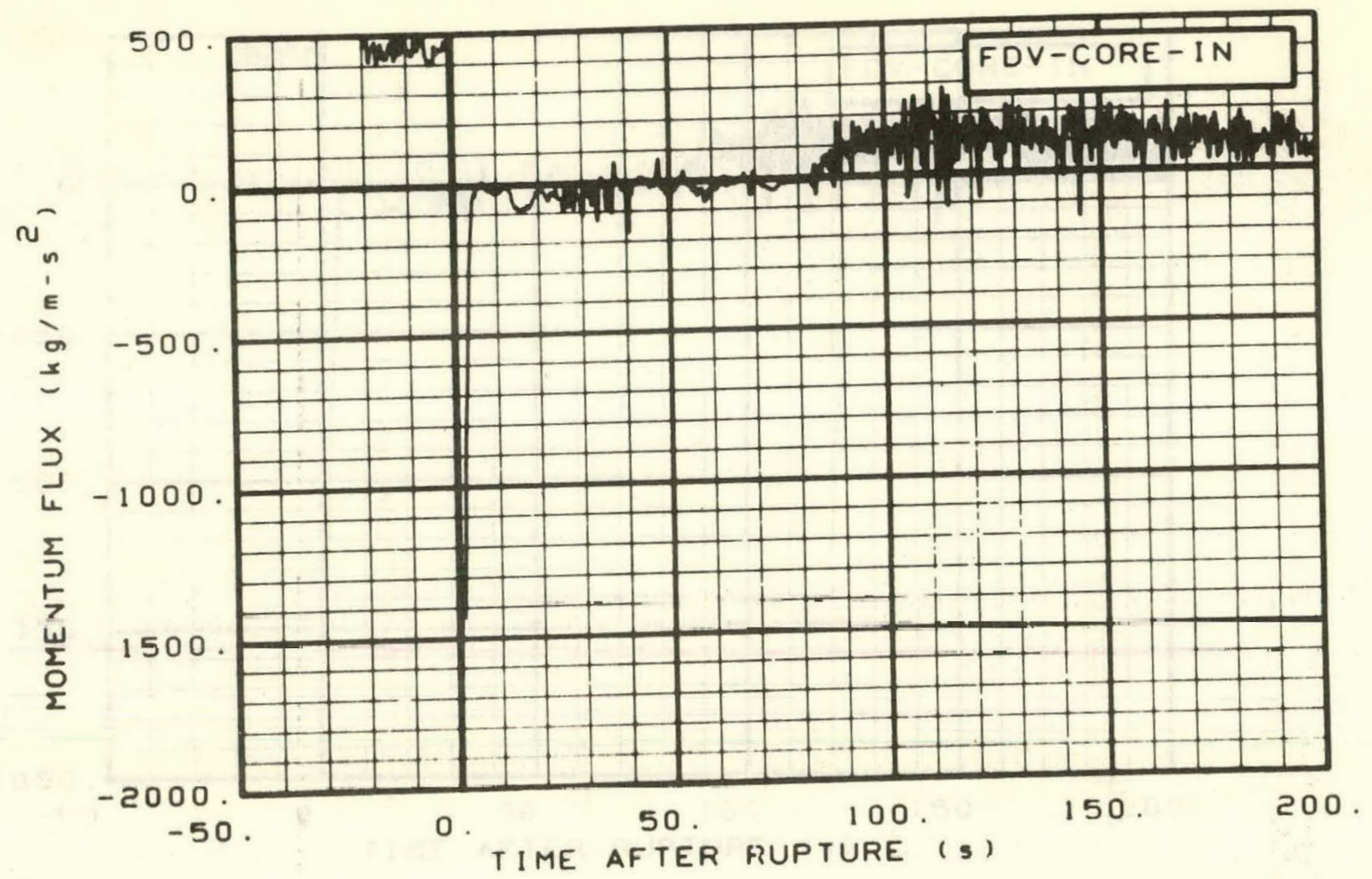

Fig. 267 Momentum flux in core entrance (FDV-CORE-IN), from -20 to $200 \mathrm{~s}$.

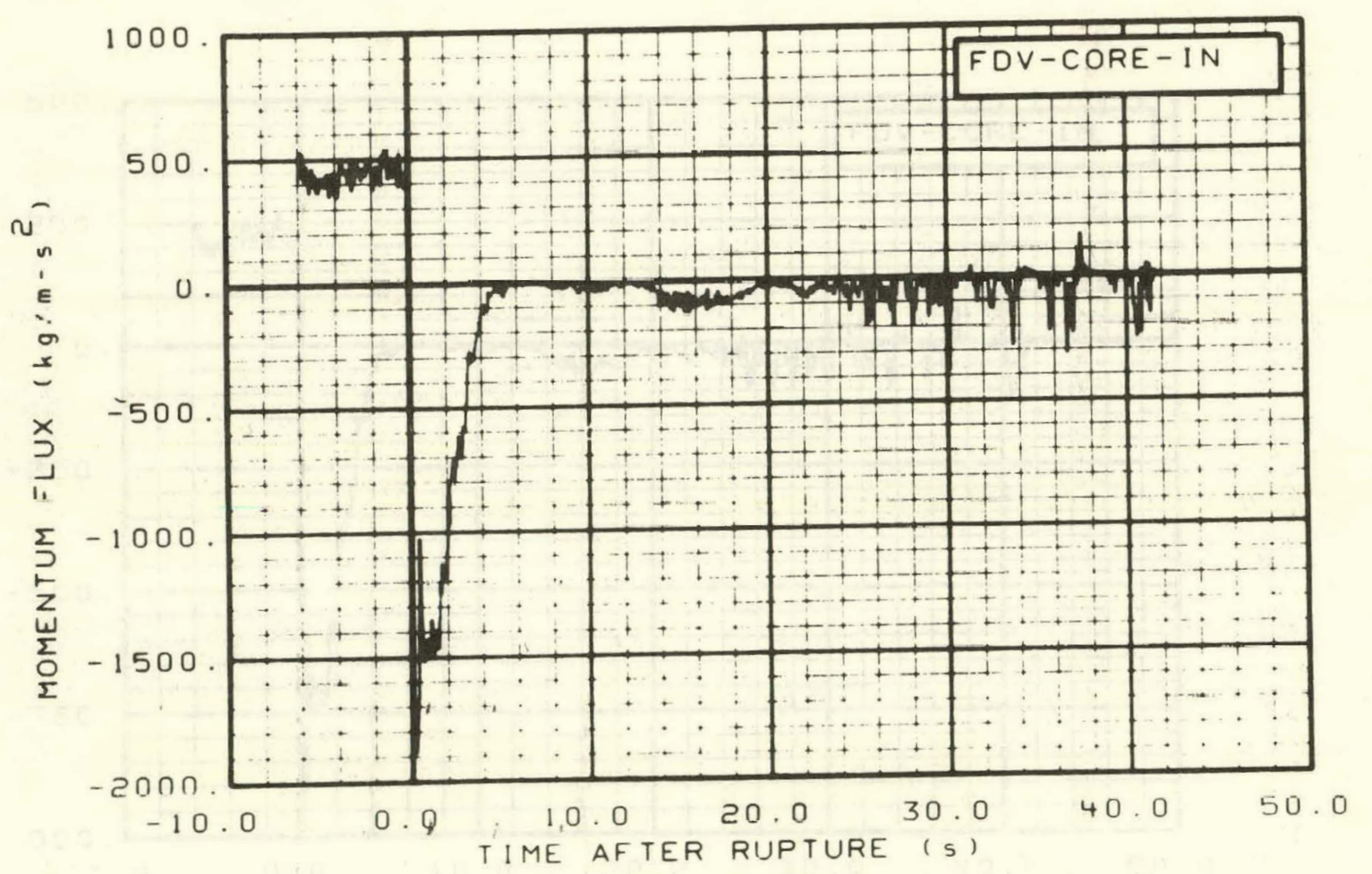

Fig. 268 Momentum flux in core entrance (FDV-CORE-IN), from -6 to $42 \mathrm{~s}$. 


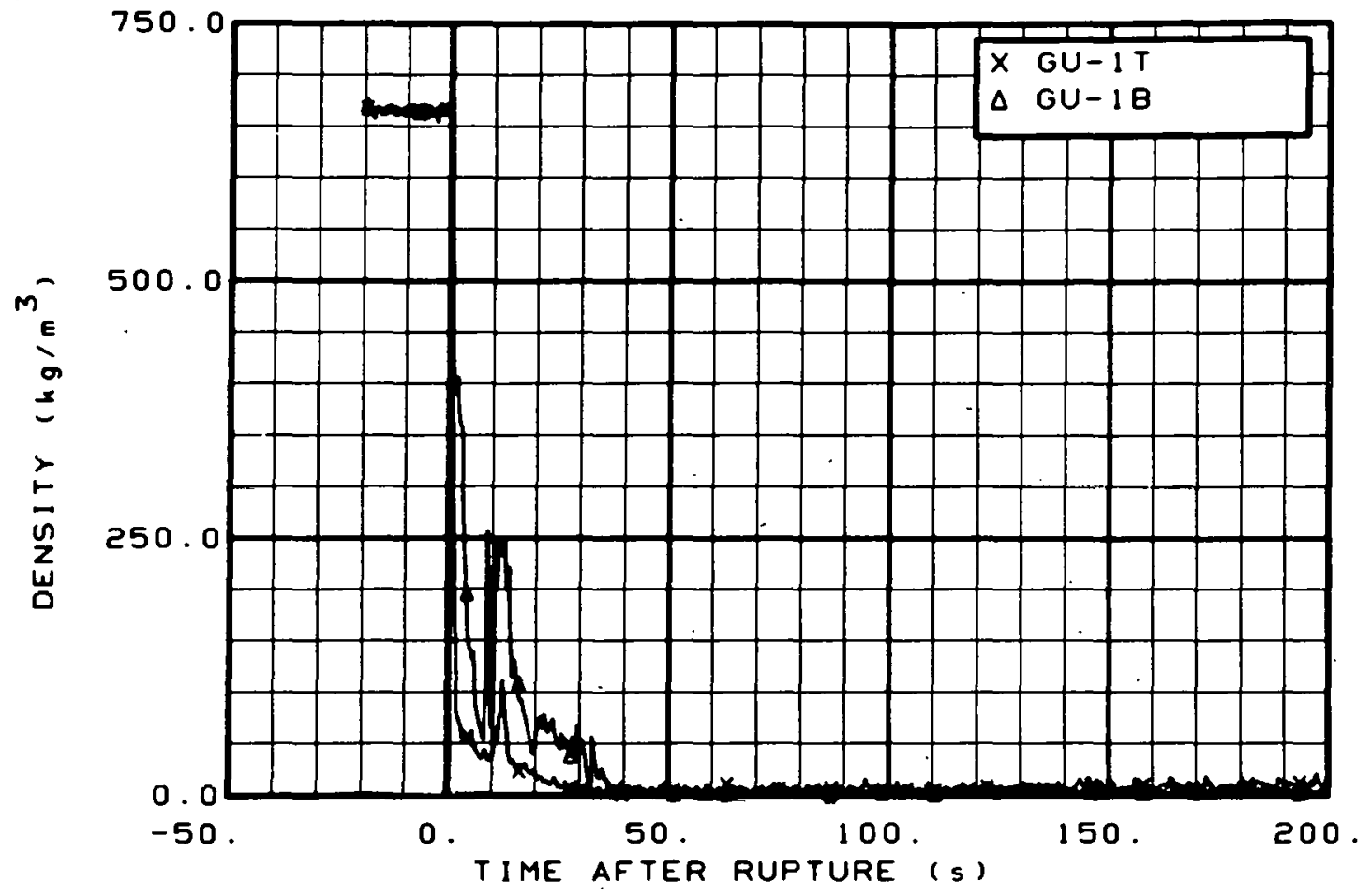

Fig. 269 Density in intact loop (GU-1T and GU-1B), from -20 to $200 \mathrm{~s}$.

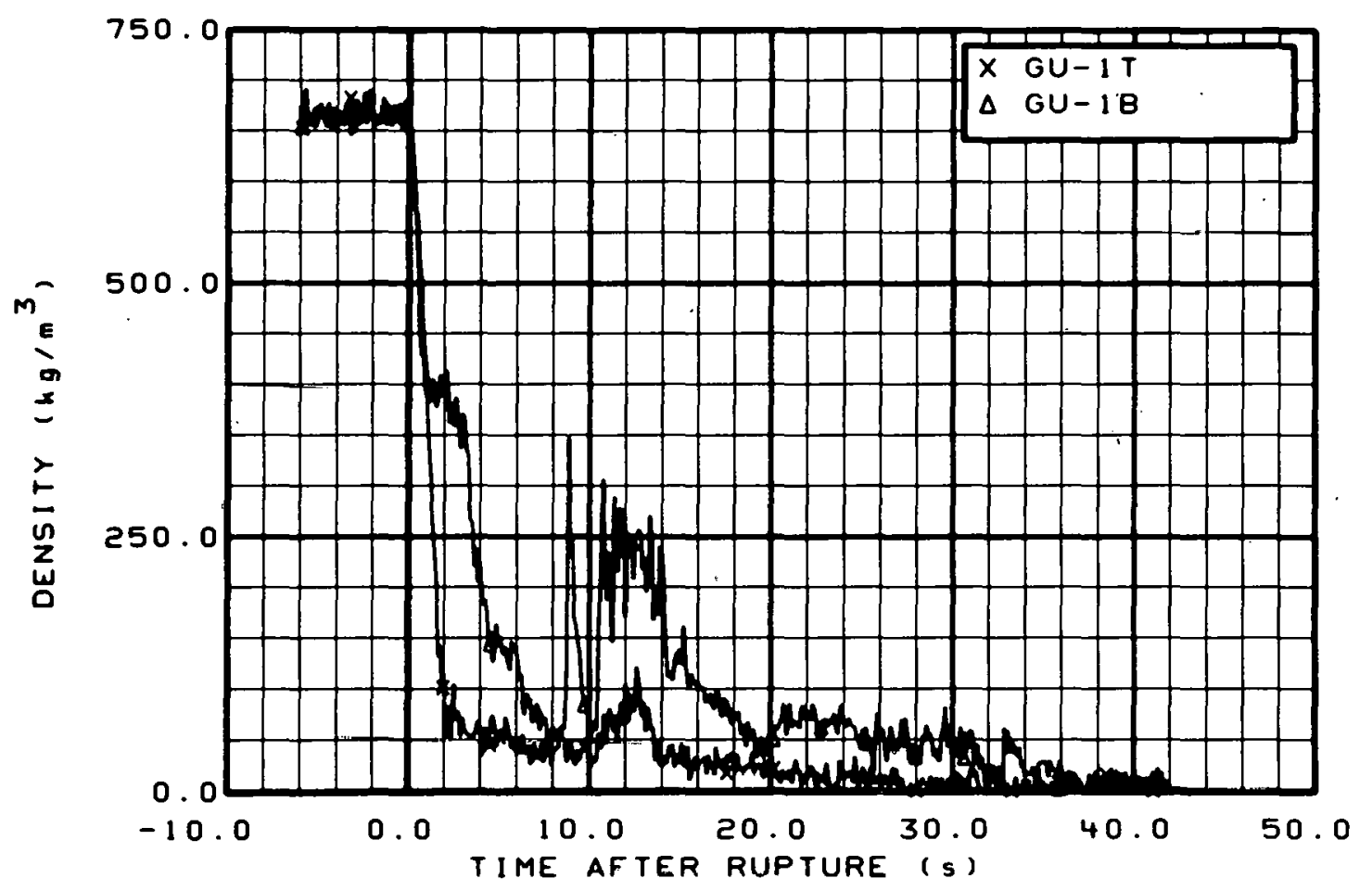

Fig. 270 Density in intact loop (GU-IT and GU-1B), from -6 to $42 \mathrm{~s}$. 


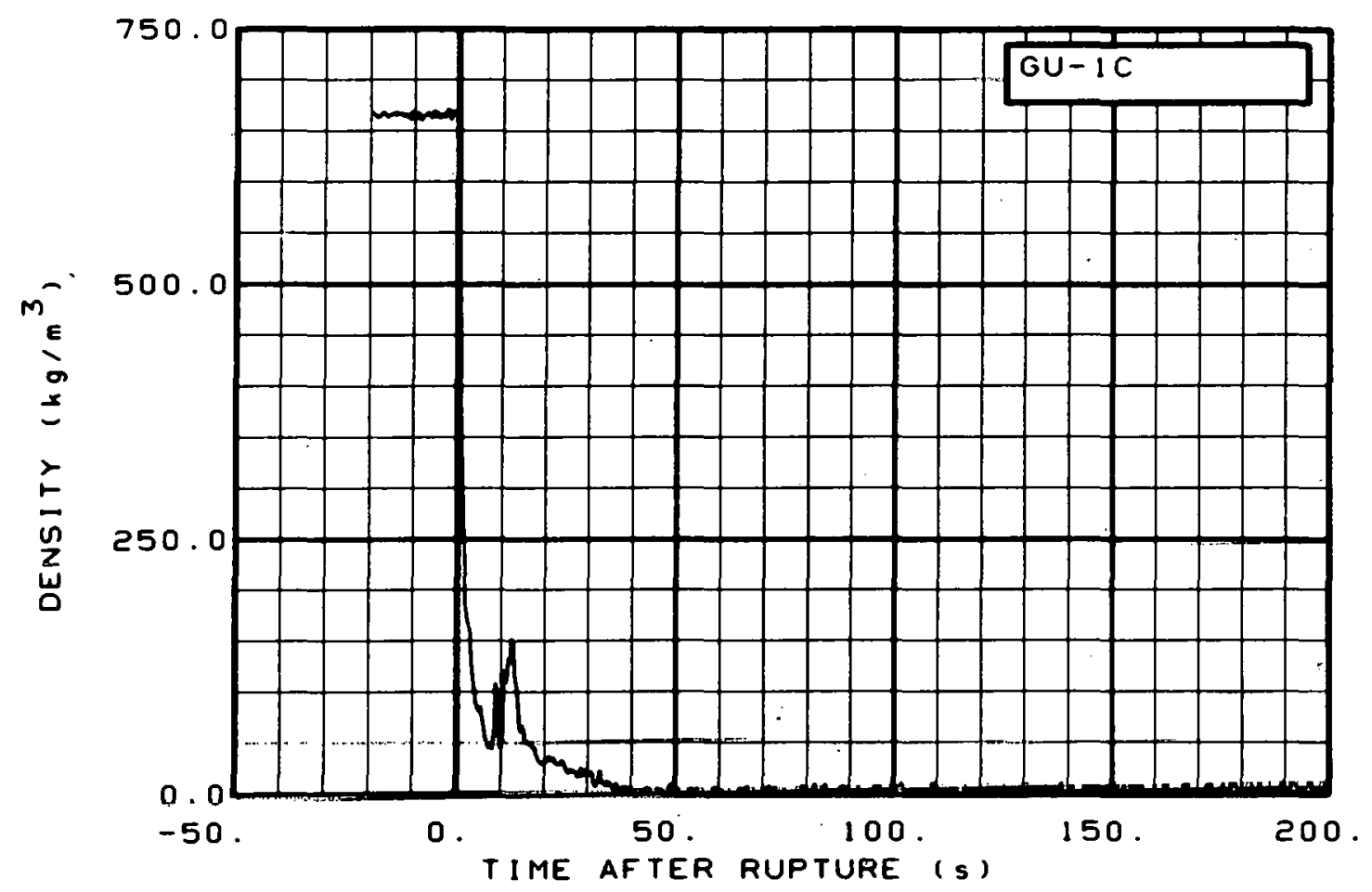

Fig. 271 Density in intact loop (GU-IC), from -20 to $200 \mathrm{~s}$.

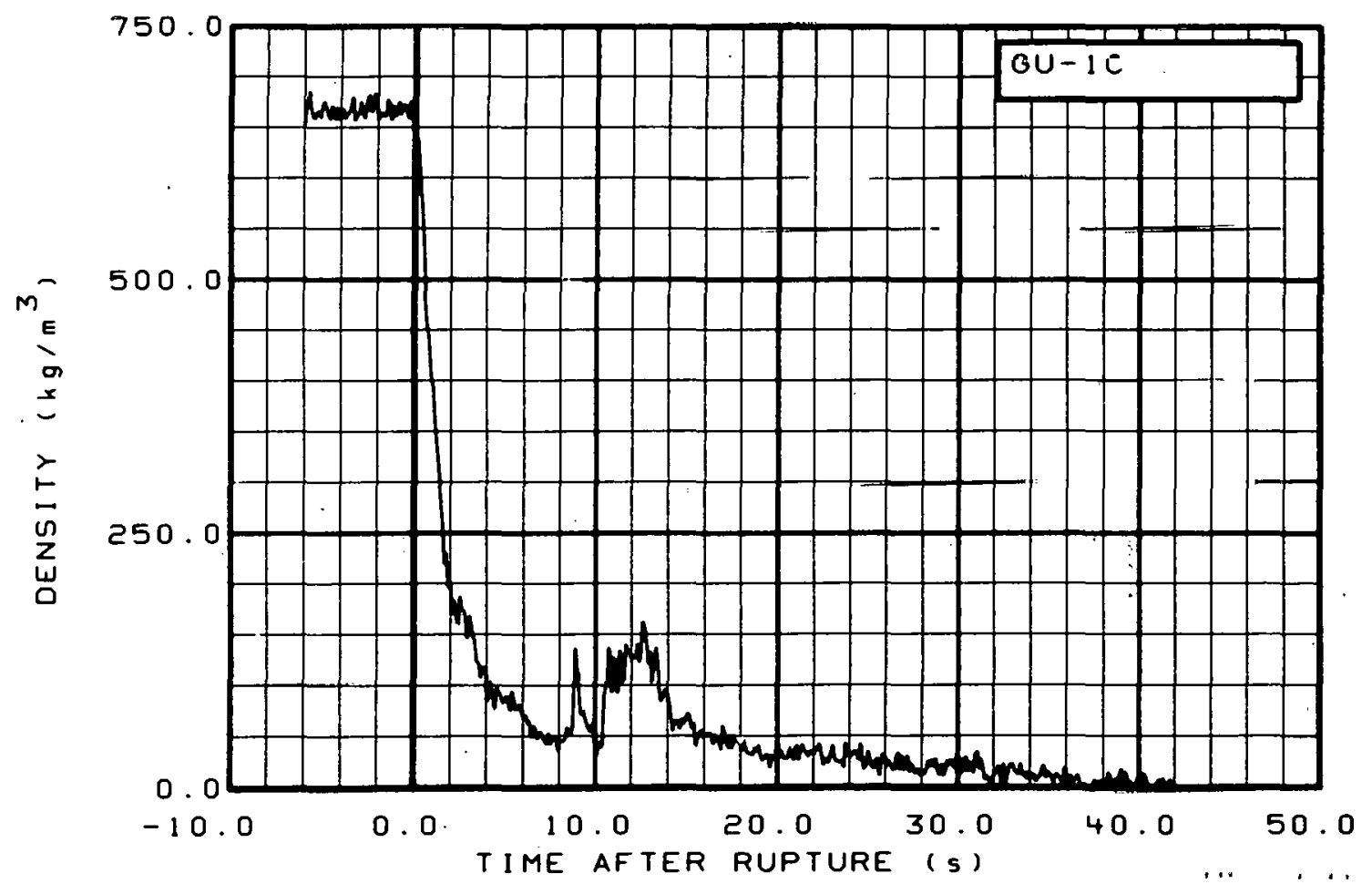

Fig. 272 Density in intact loop (GU-1C), from -6 to $42 \mathrm{~s}$. 


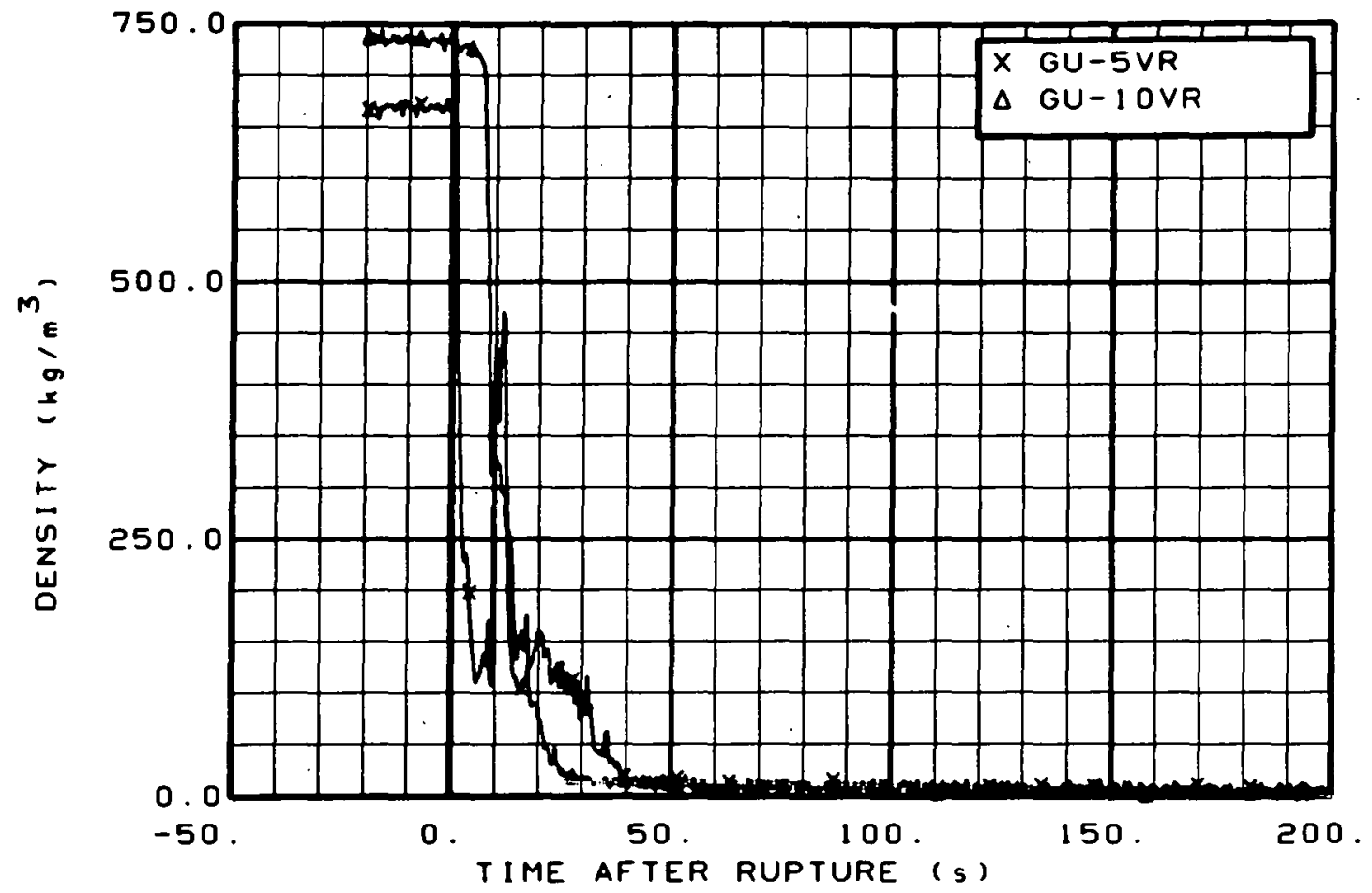

Fig. 273 Density in intact loop (GU-5VR and GU-10VR), from -20 to $200 \mathrm{~s}$.

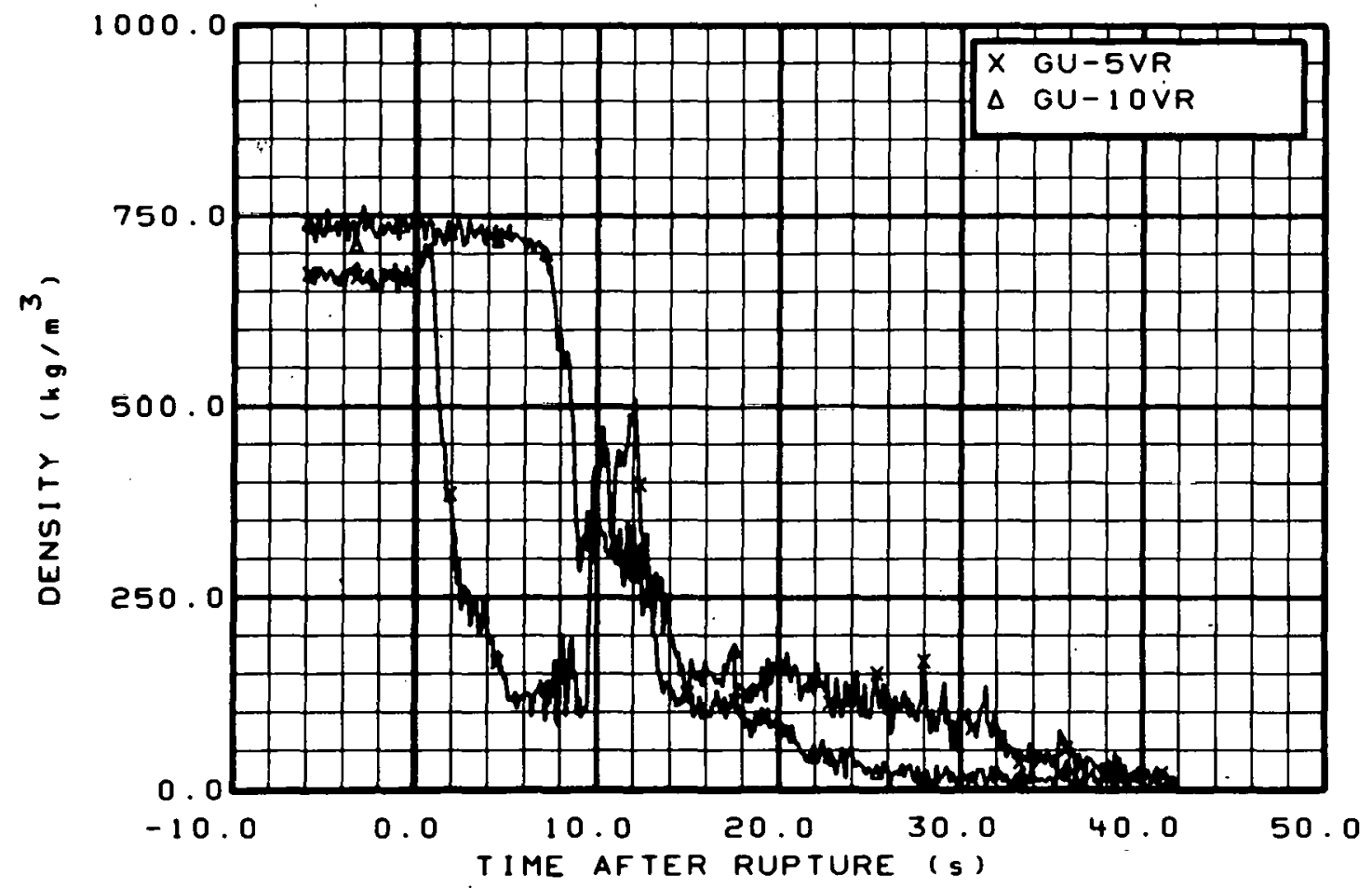

Fig. 274 Density in intact 100p (GU-5VR and GU-10VR), from -6 to $42 \mathrm{~s}$. 


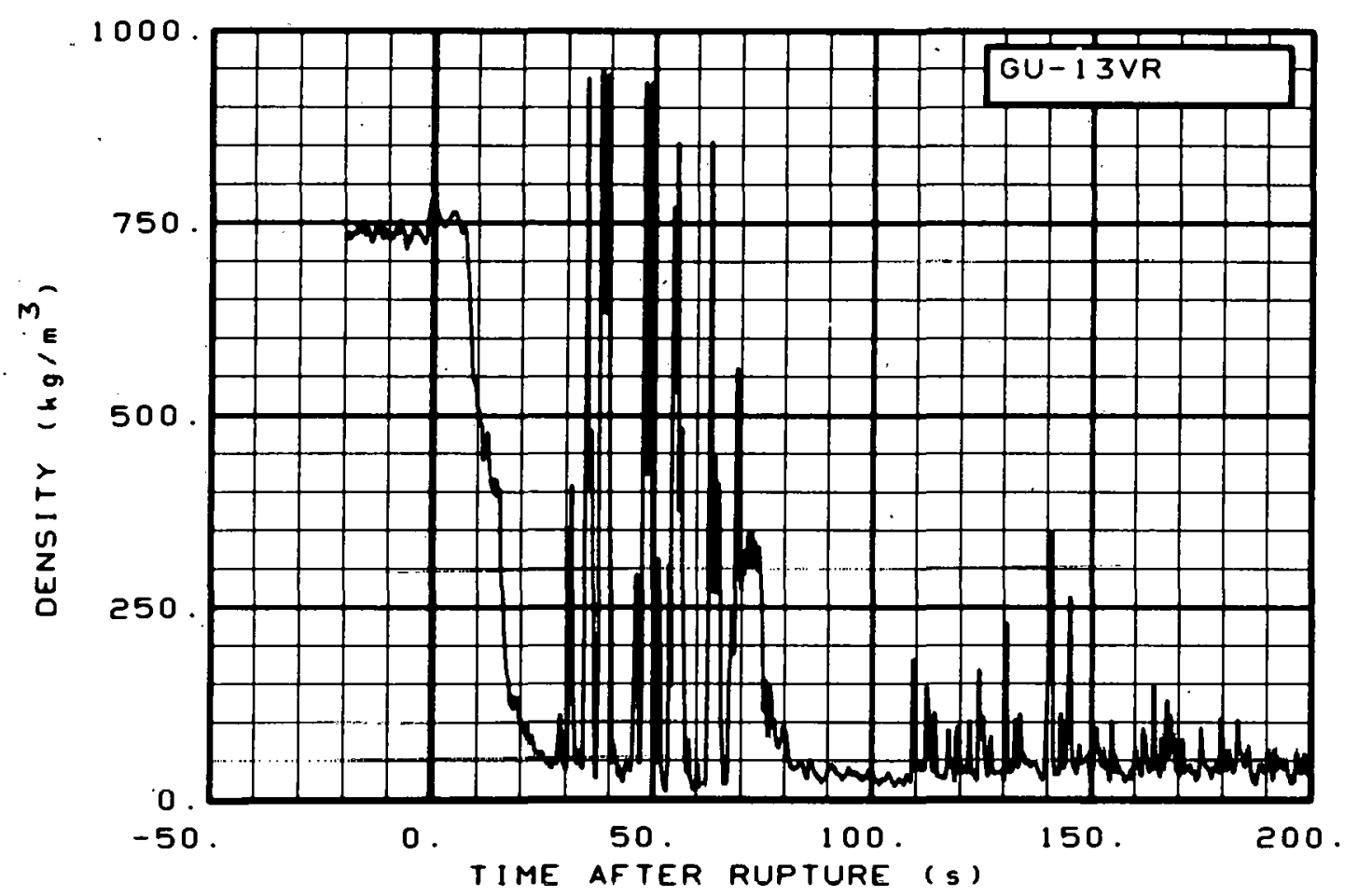

Fig. 275 Density in intact loop (GU-13VR), from -20 t.o 200 s.

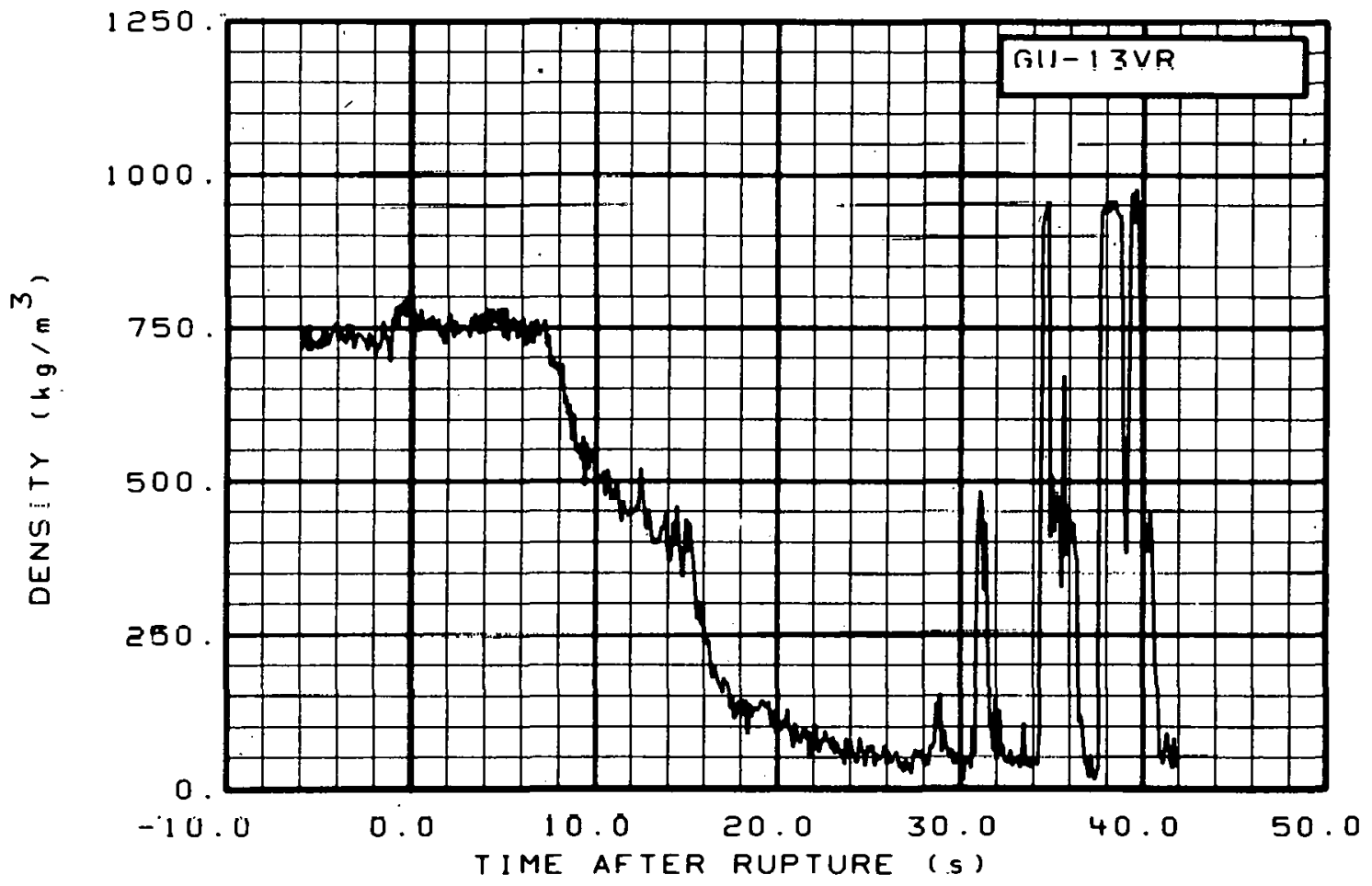

Fig. 276 Density in intact loop (GU-T3VR), from -6 to $42 \mathrm{~s}$. 


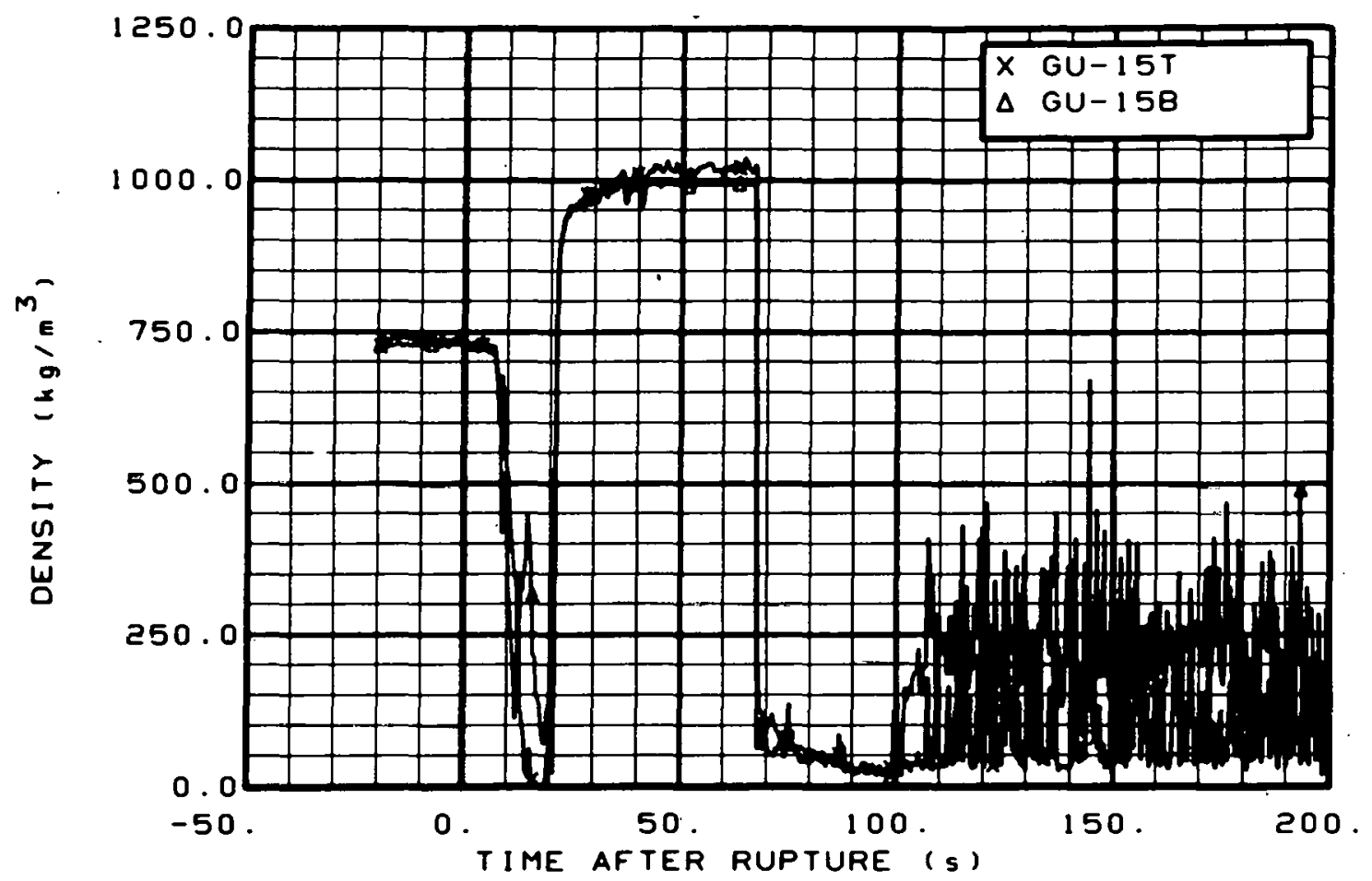

Fig. 277 Density in intact 10op (GU-15T and GU-15B), from -20 to $200 \mathrm{~s}$.

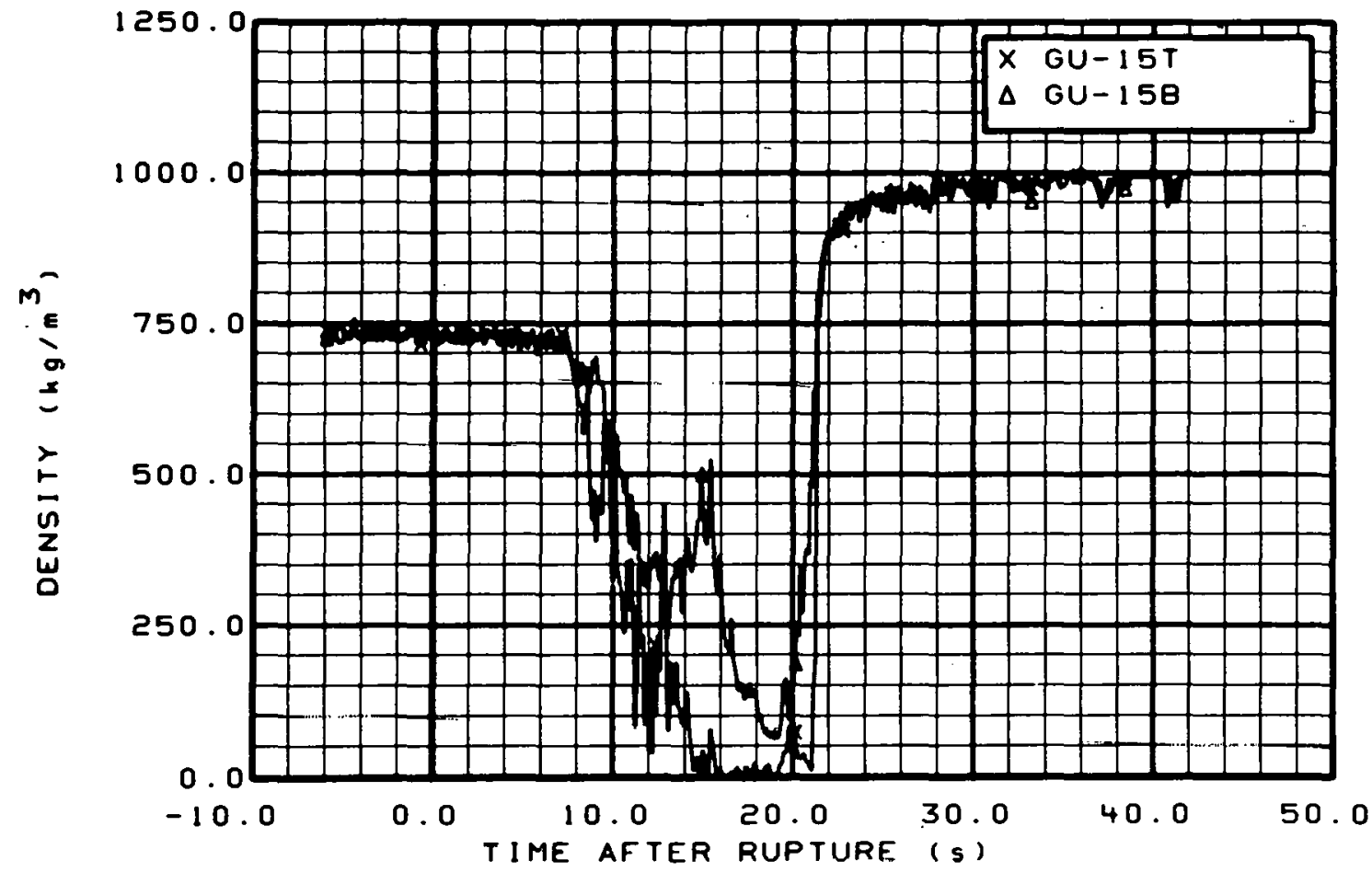

Fig. 278 Density in intact loop (GU-15T and GU-15B), from -6 to $42 \mathrm{~s}$. 


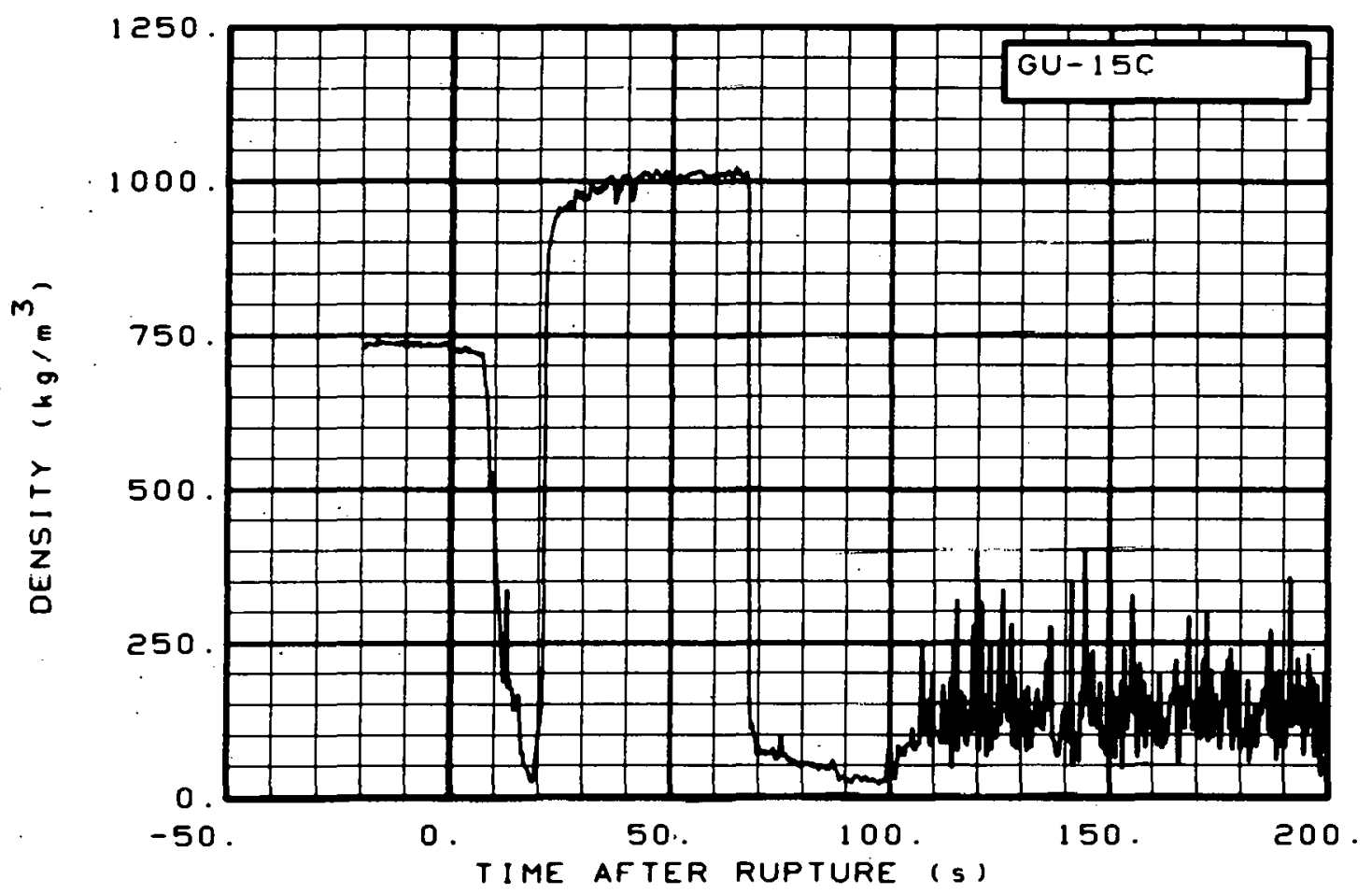

Fig. 279 Density in intact loop (GU-15C), from -20 to $200 \mathrm{~s}$.

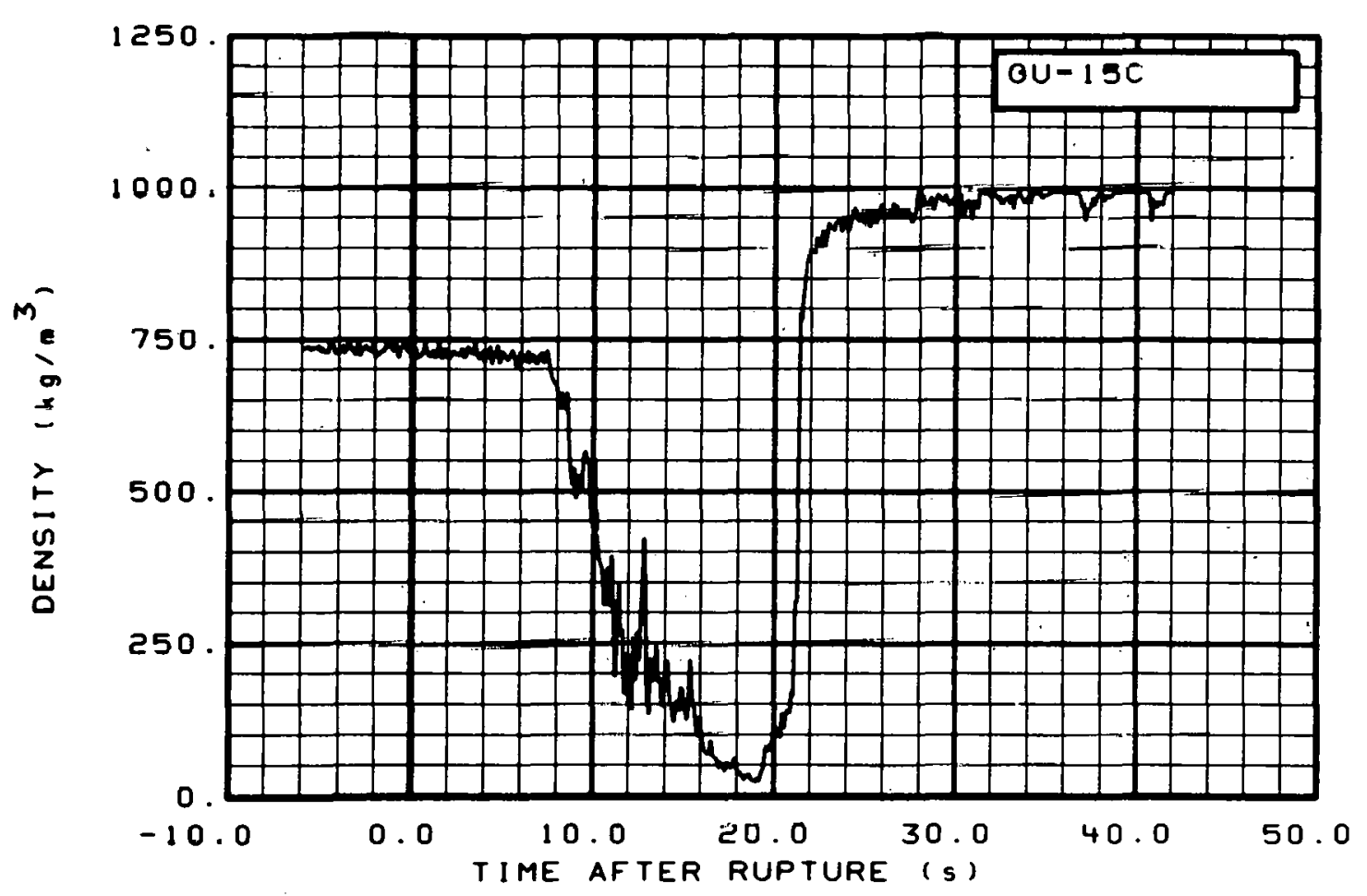

Fig. 280 Density in intact loop (GU-15C), from -6 to $42 \mathrm{~s}$. 


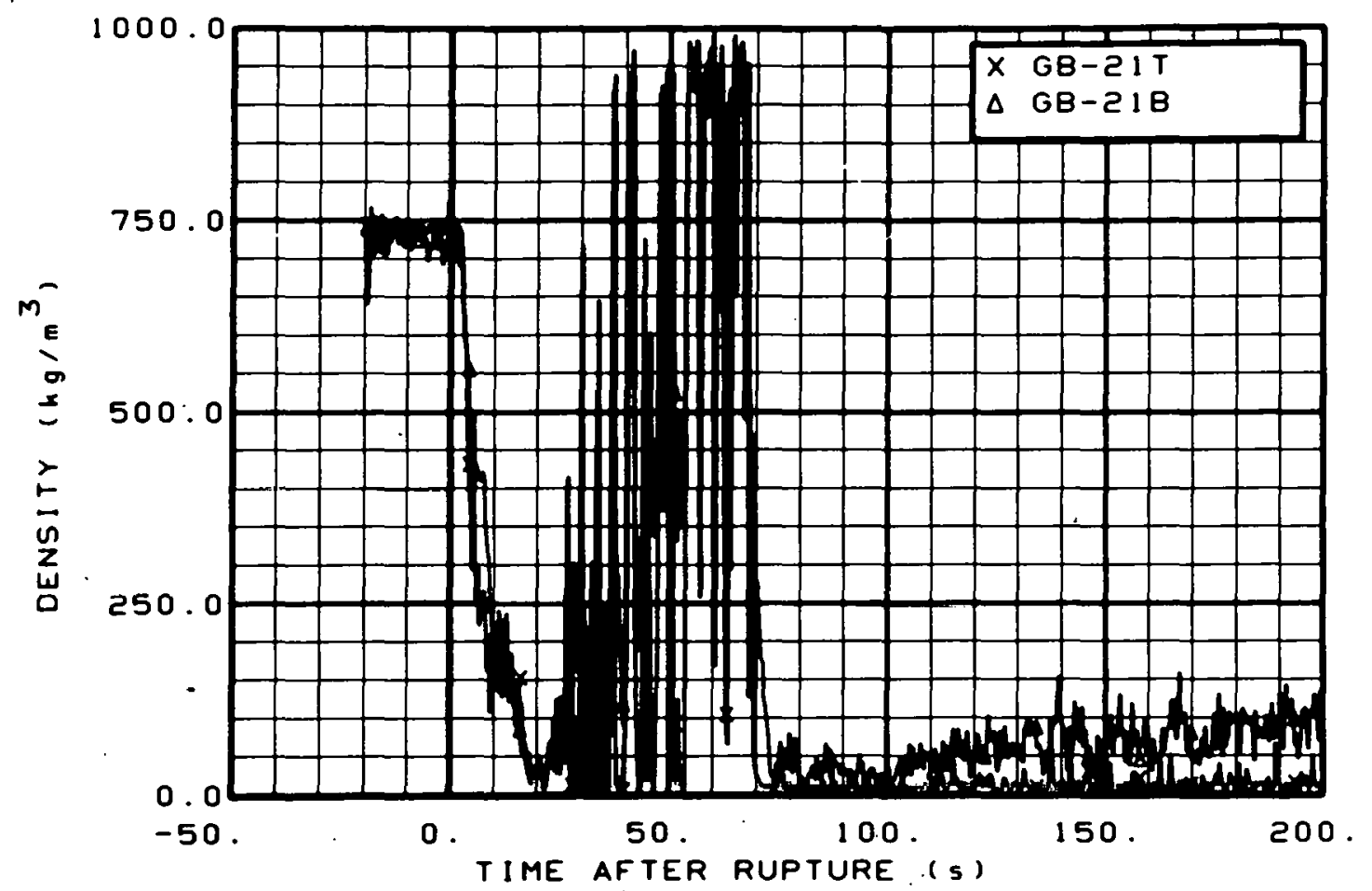

Fig. 281 Density in broken loop (GB-21T and GB-21B), from -20 to $200 \mathrm{~s}$.

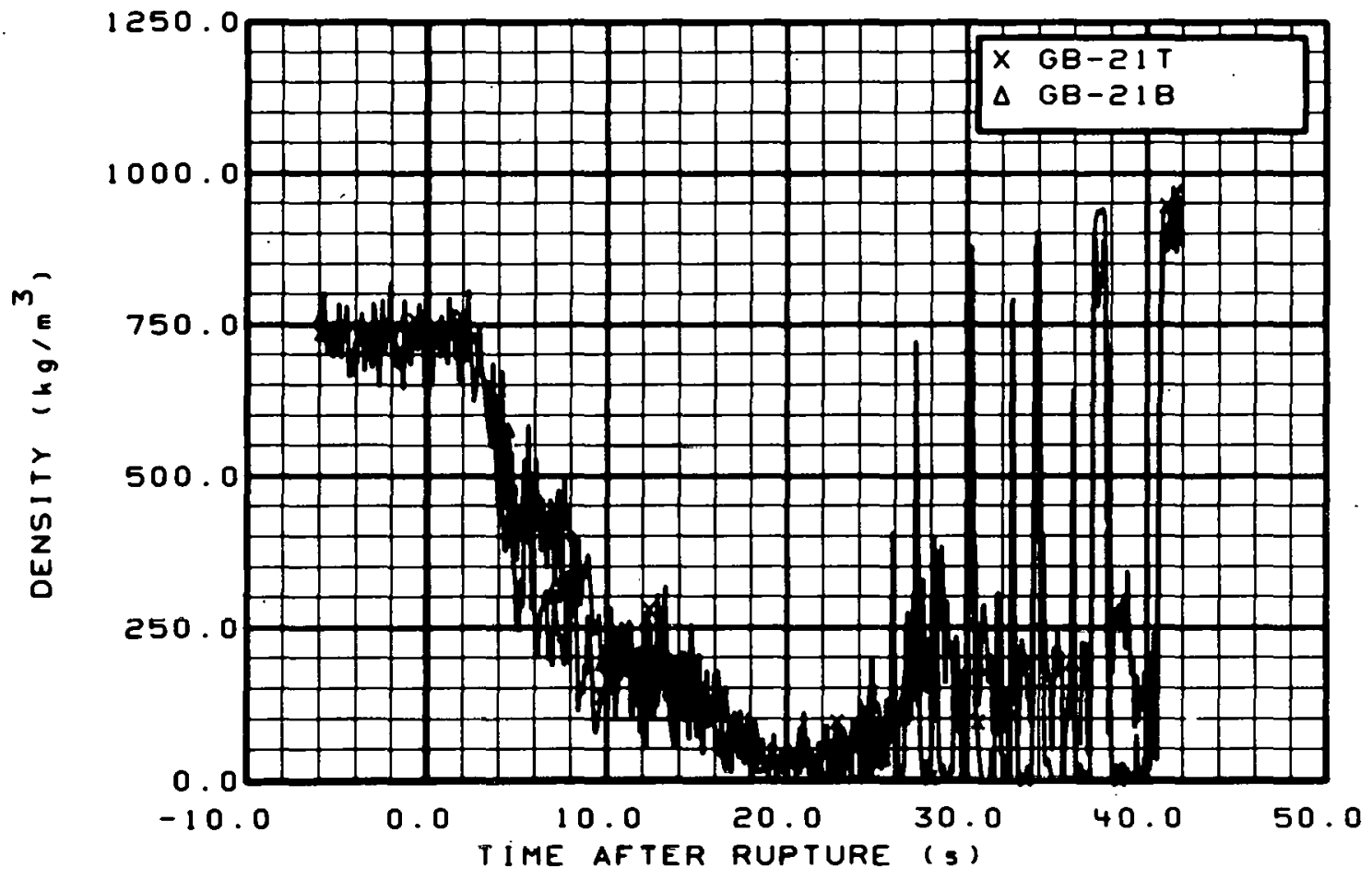

Fig. 282 Density in broken 1oop. (GB-21T and GB-21B), from -6 to $42 \mathrm{~s}$. 


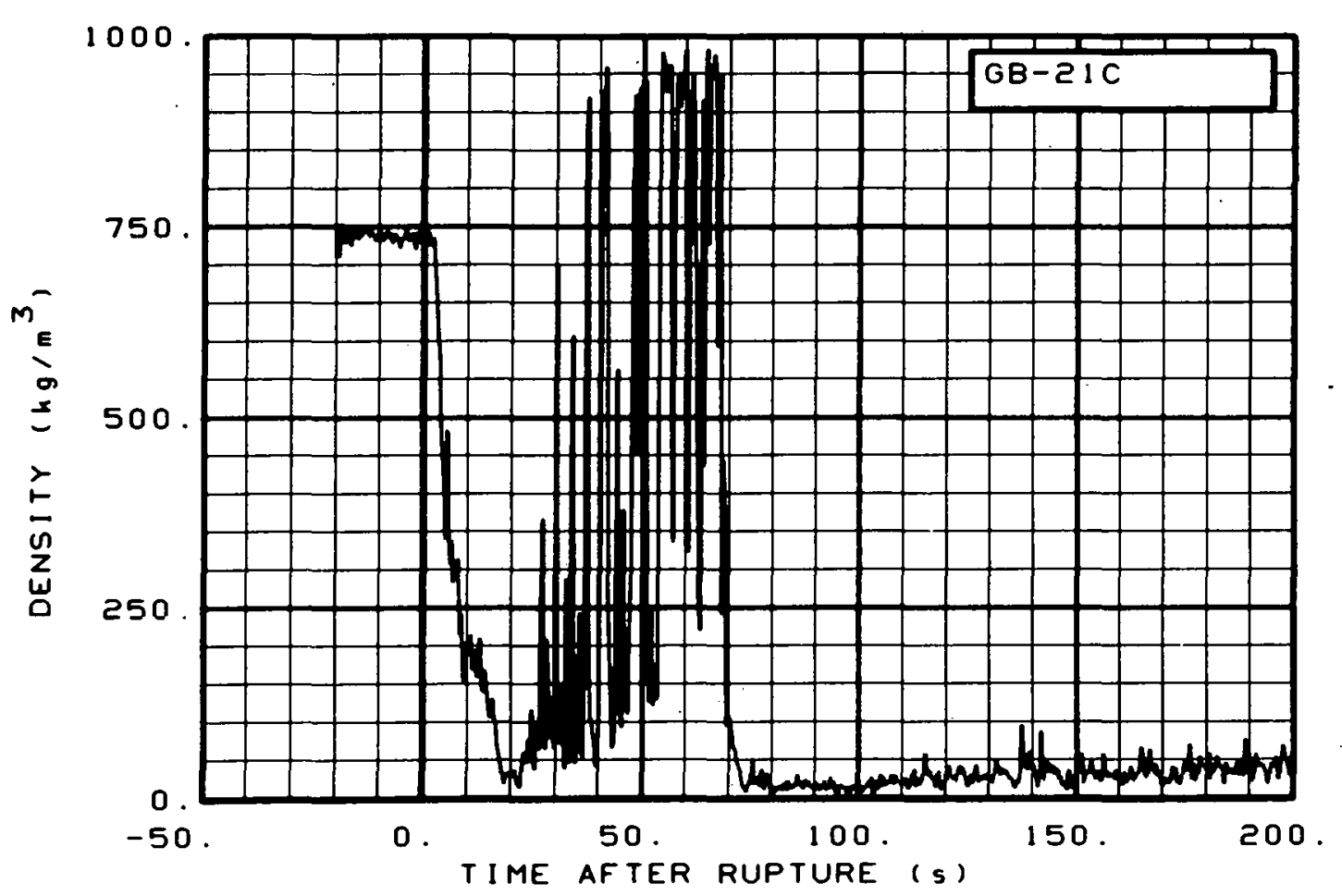

Fig. 283 Density in broken loop (GB-2TC), from -20 to $200 \mathrm{~s}$.

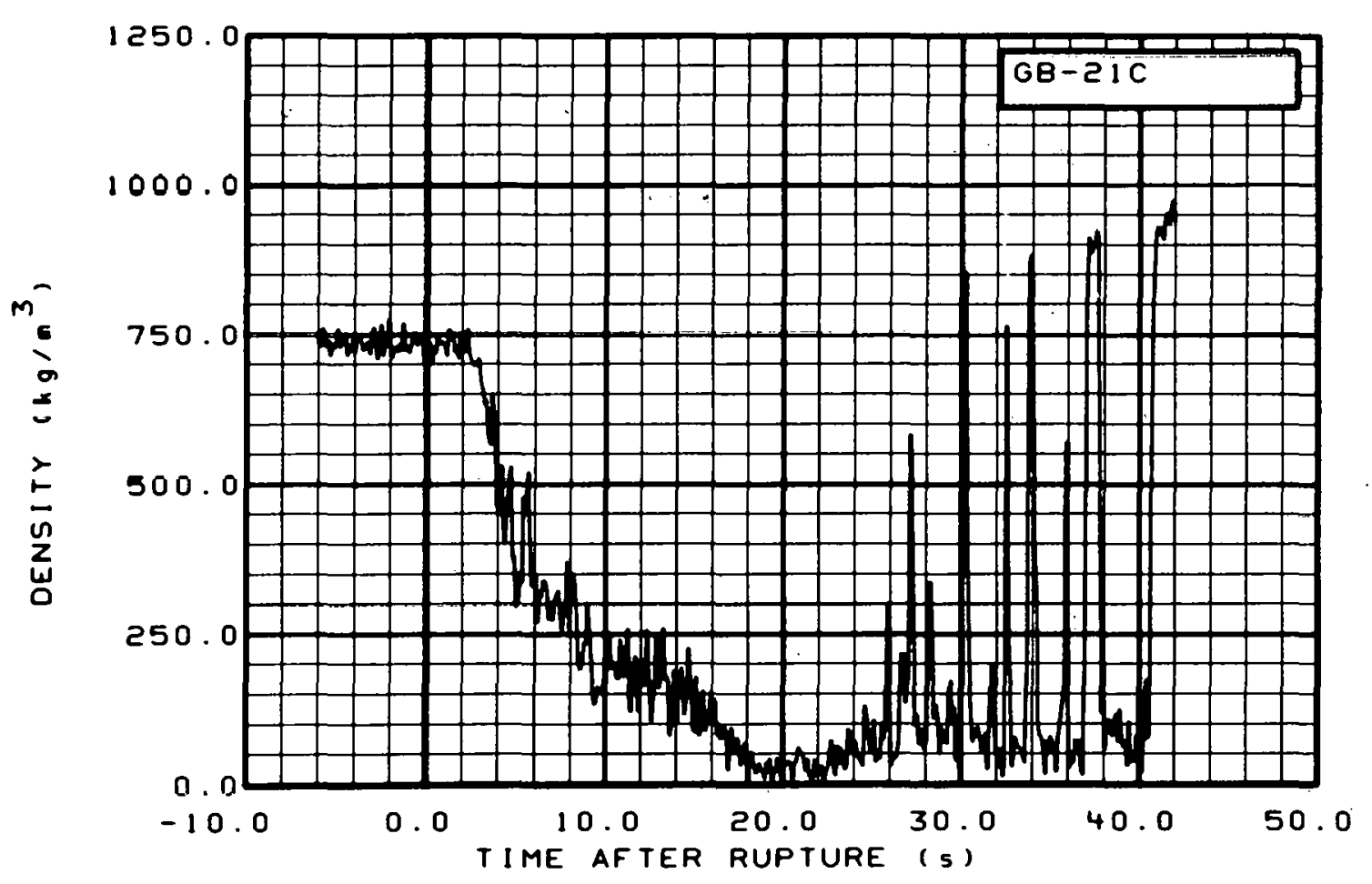

Fig. 284 Density in broken loop (GB-21C), from -6 to $42 \mathrm{~s}$. 


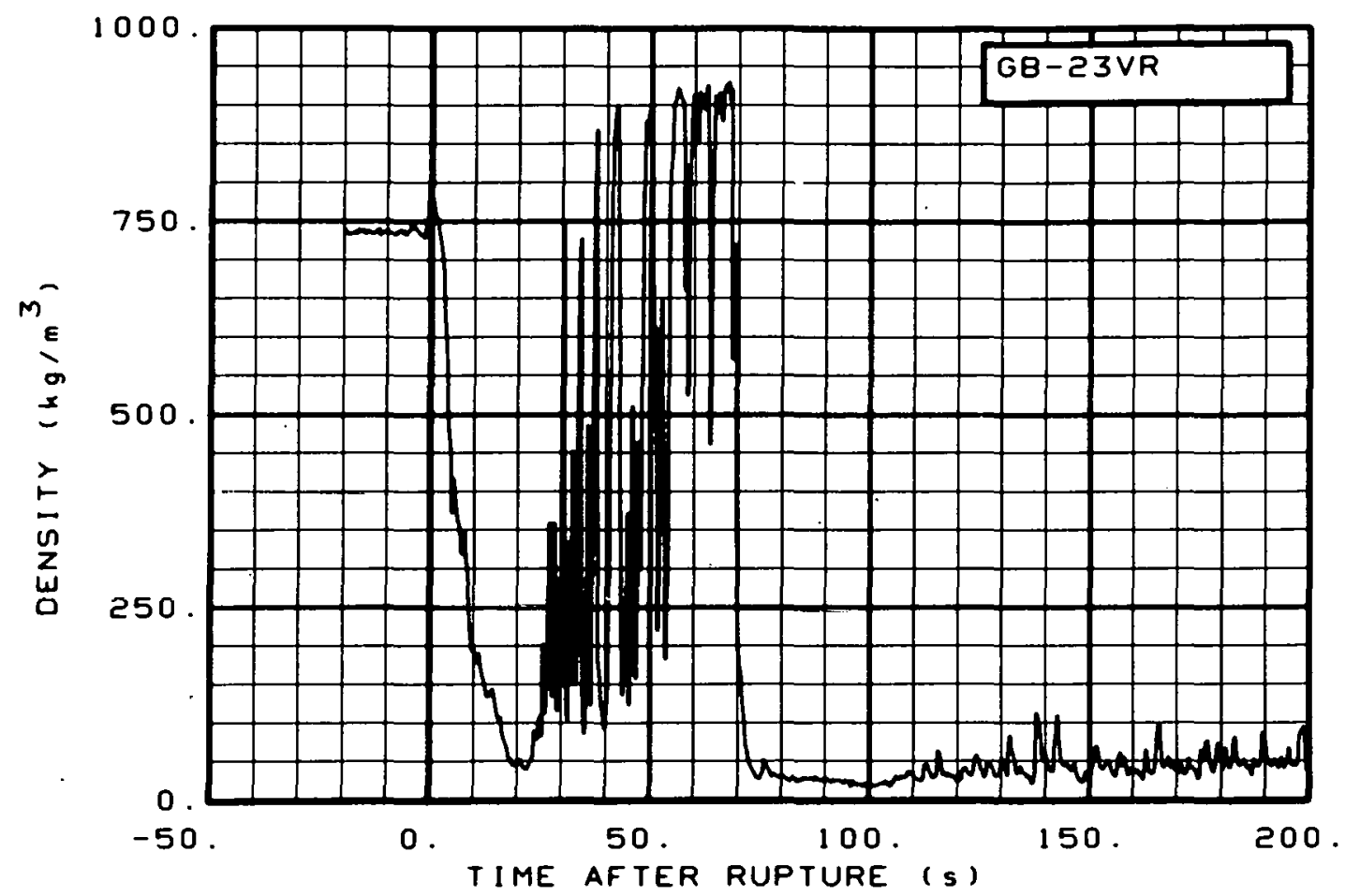

Fig. 285 Density in broken loop (GB-23VR), from -20 to $200 \mathrm{~s}$.

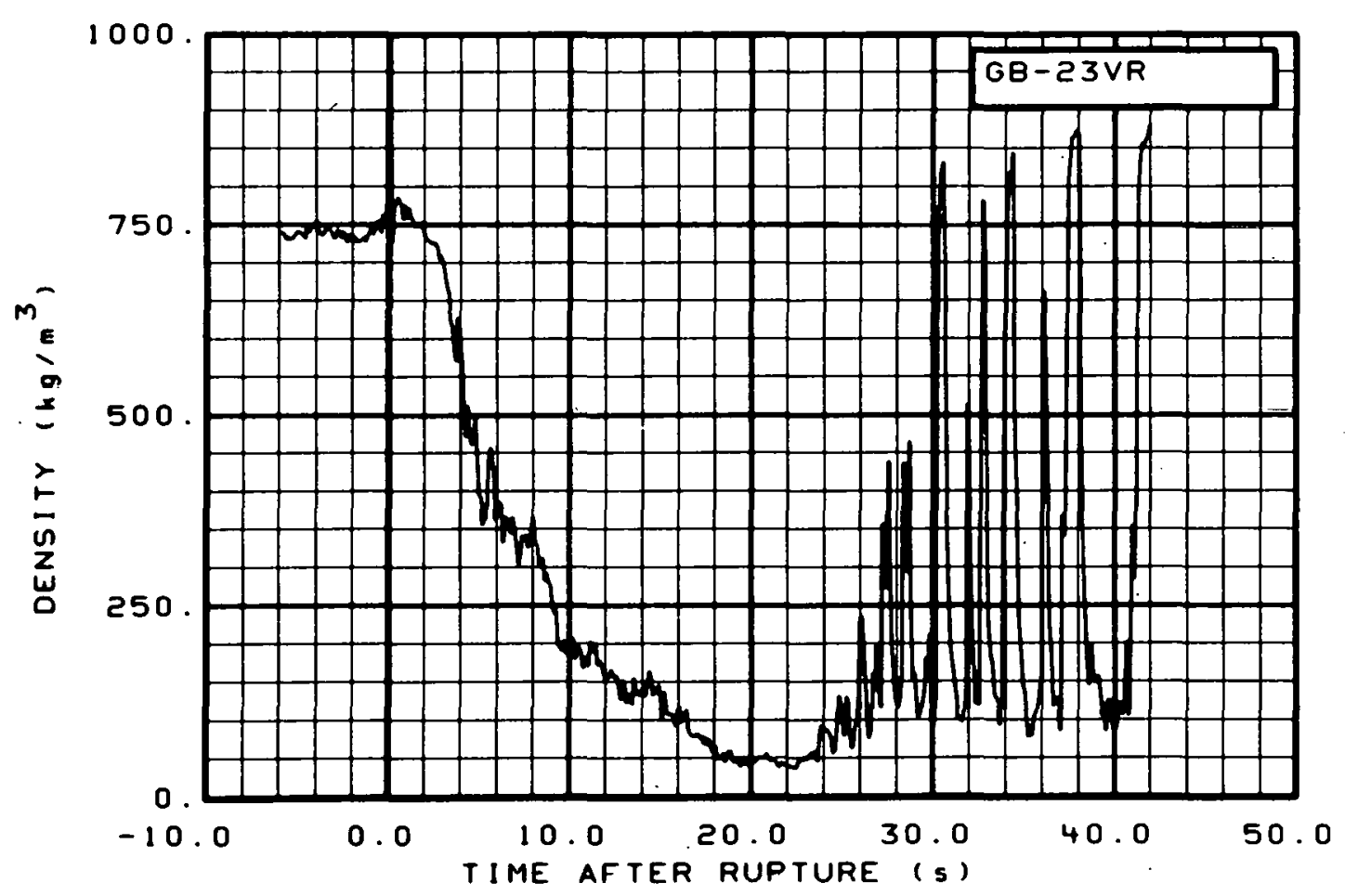

Fig. 286 Density in broken loop (GB-23VR), from -6 to $42 \mathrm{~s}$. 


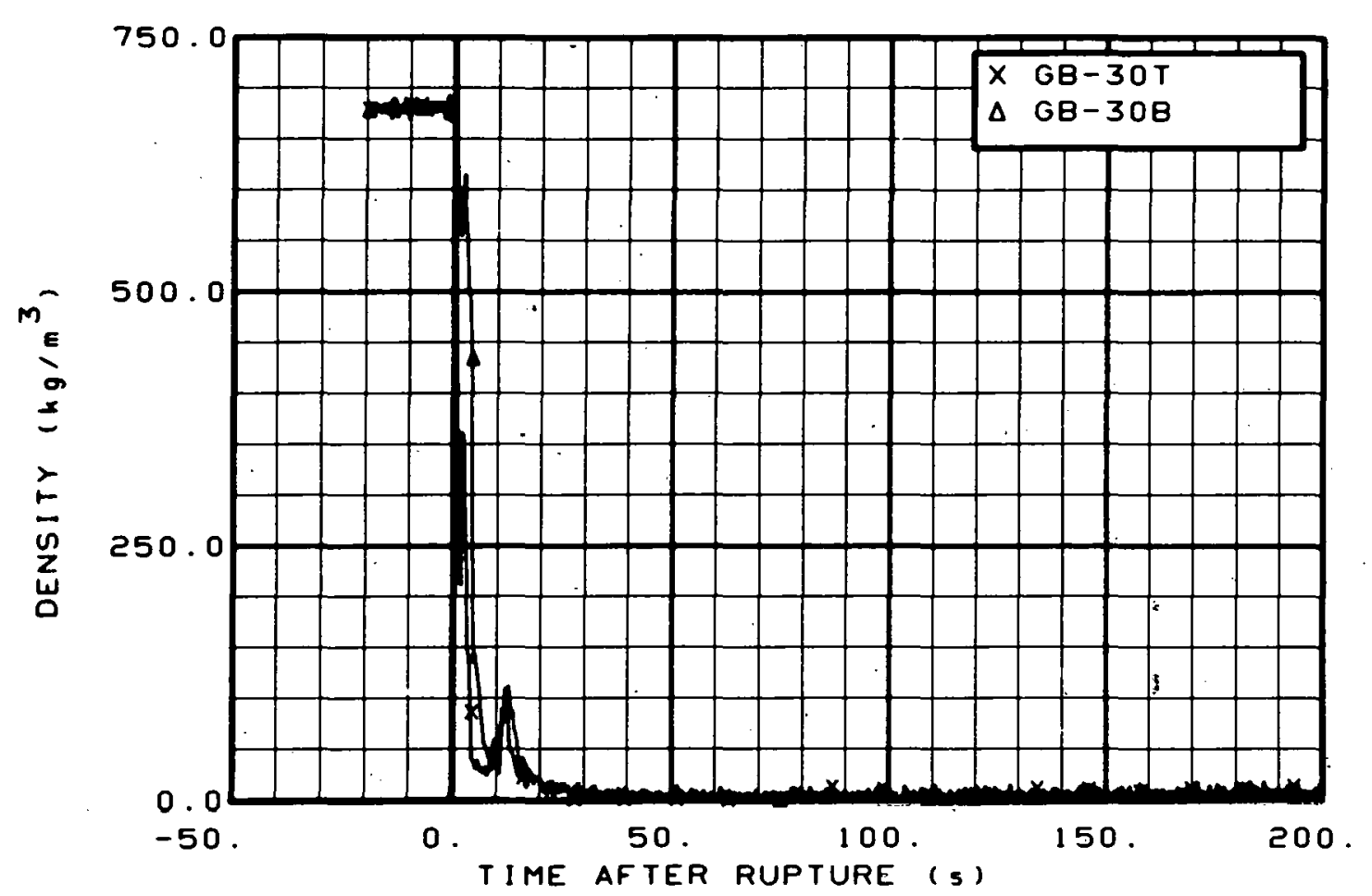

Fig. 287 Density in broken Toop (GB-30T and GB-30B), from -20 to $200 \mathrm{~s}$.

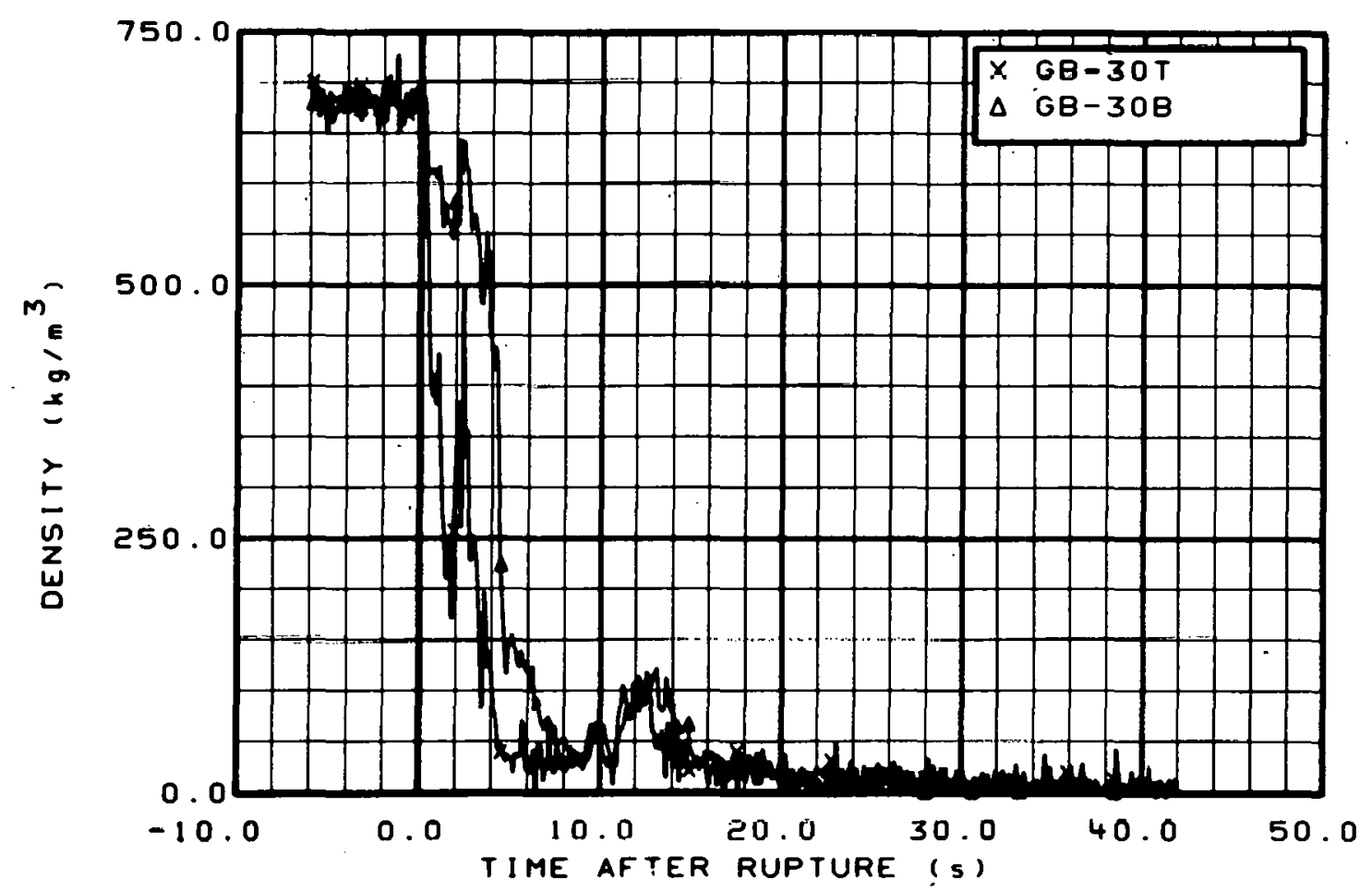

Fig. 288 Density in broken loop (GB-30T and GB-30B), from -6 to $42 \mathrm{~s}$. 


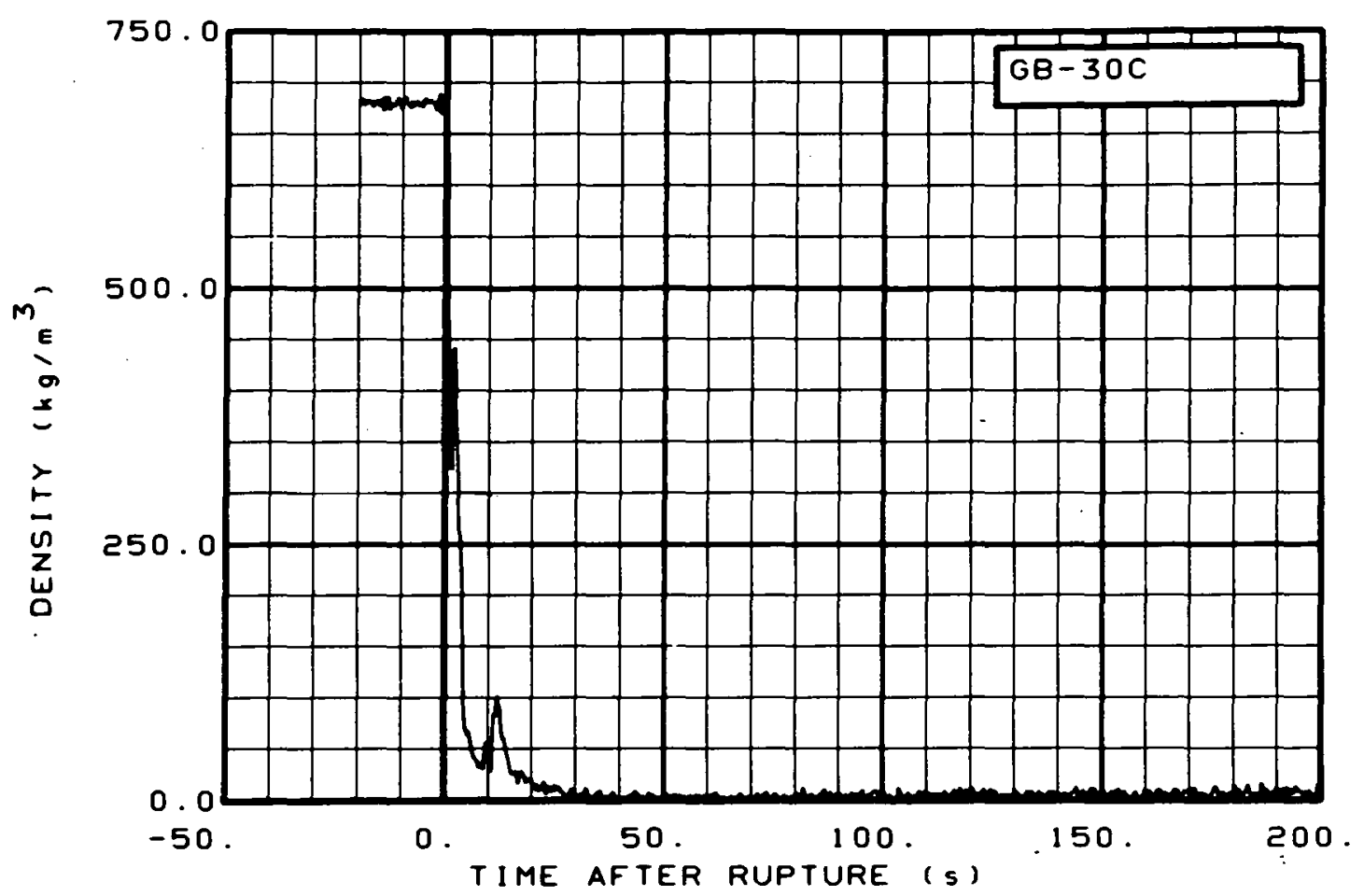

Fig. 289 Density in broken loop (GB-30C), from -20 to $200 \mathrm{~s}$.

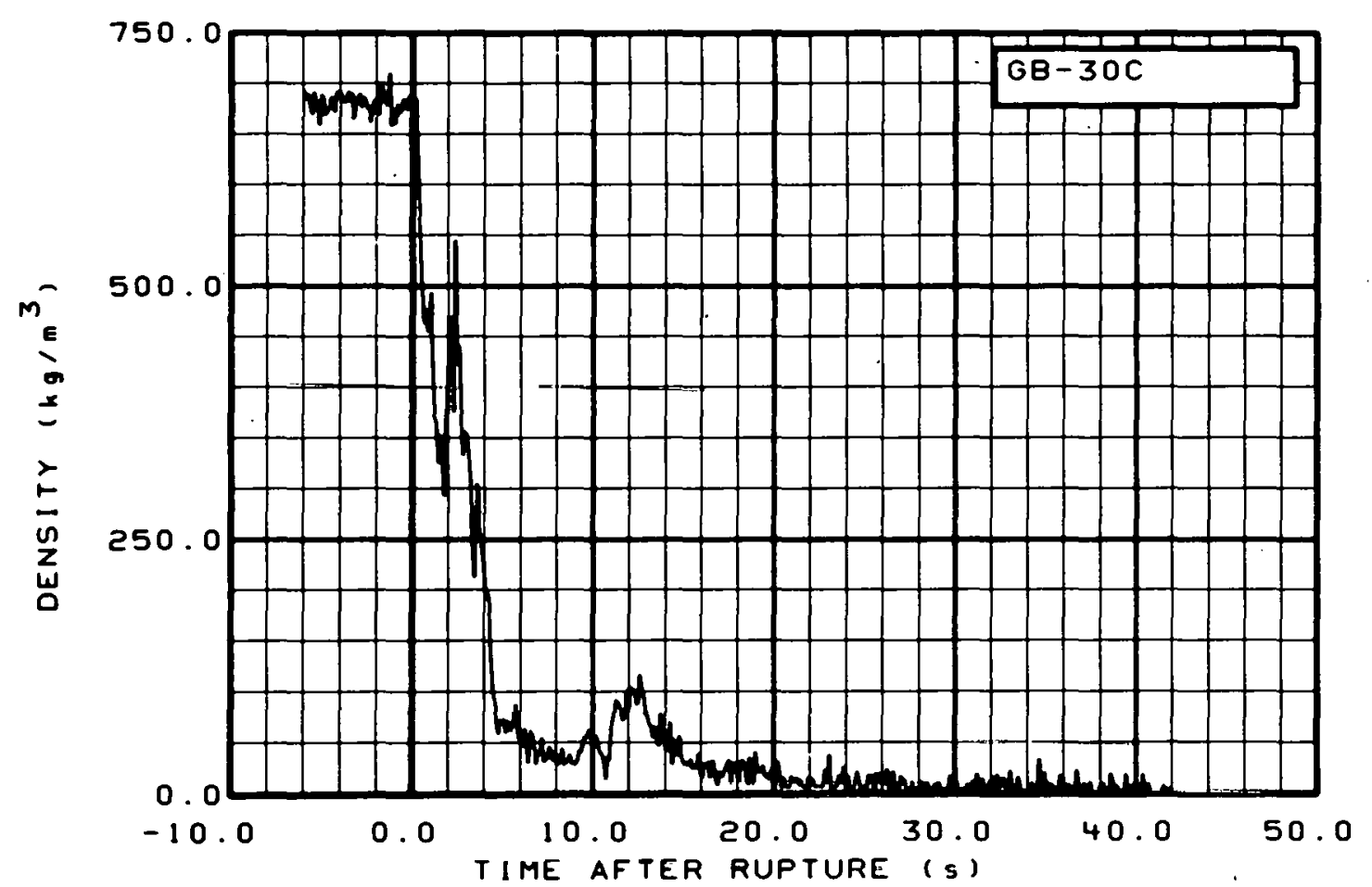

Fig. 290 Density in broken loop (GB-30C), from -6 to $42 \mathrm{~s}$. 


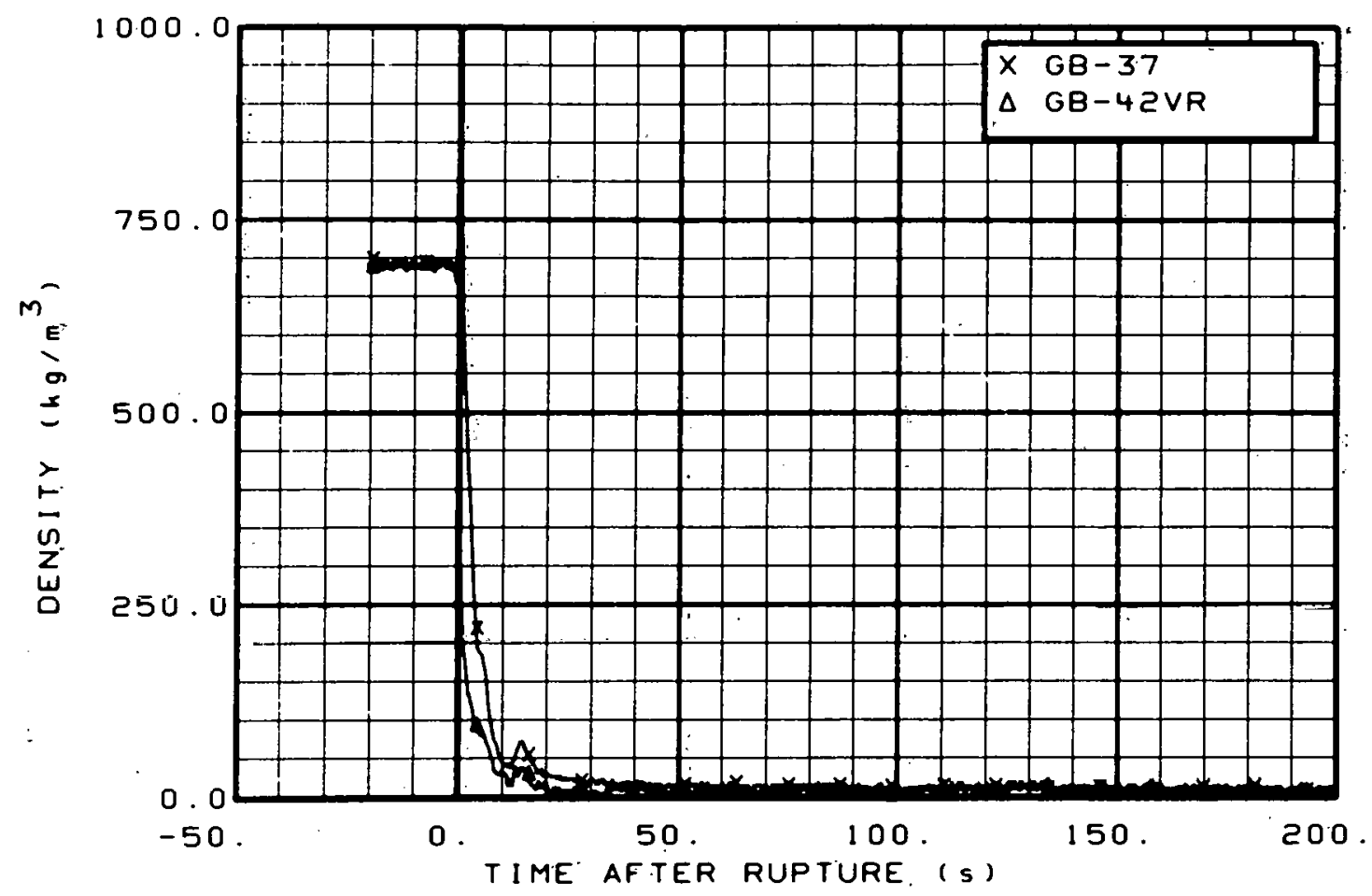

Fig. 291 Density in broken loop (GB-37 and GB-42VR), from -20 to $200 \mathrm{~s}$.

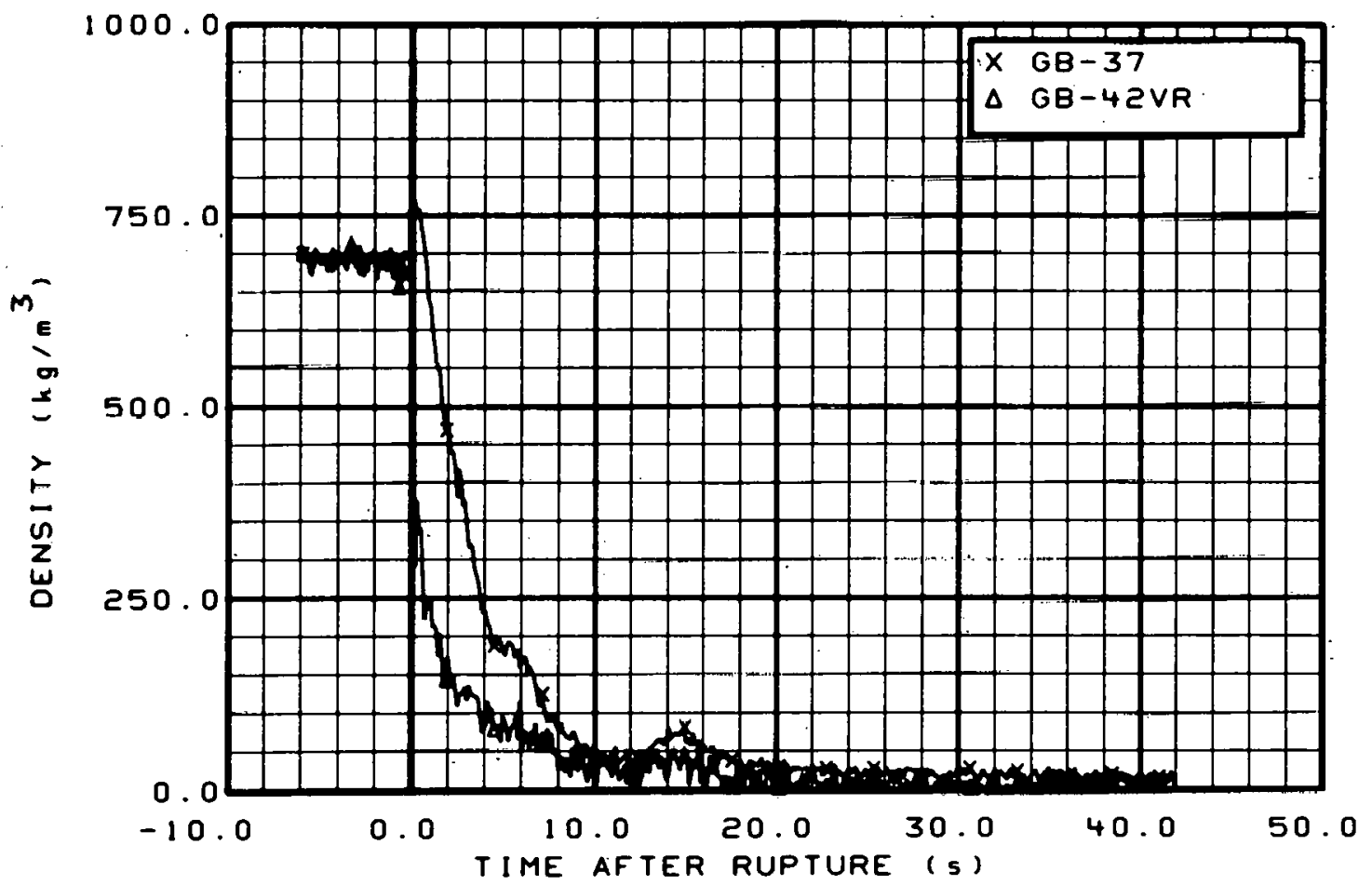

Fig. 292 Density in broken loop (GB-37 and GB-42VR.), from -6 to $42 \mathrm{~s}$. 


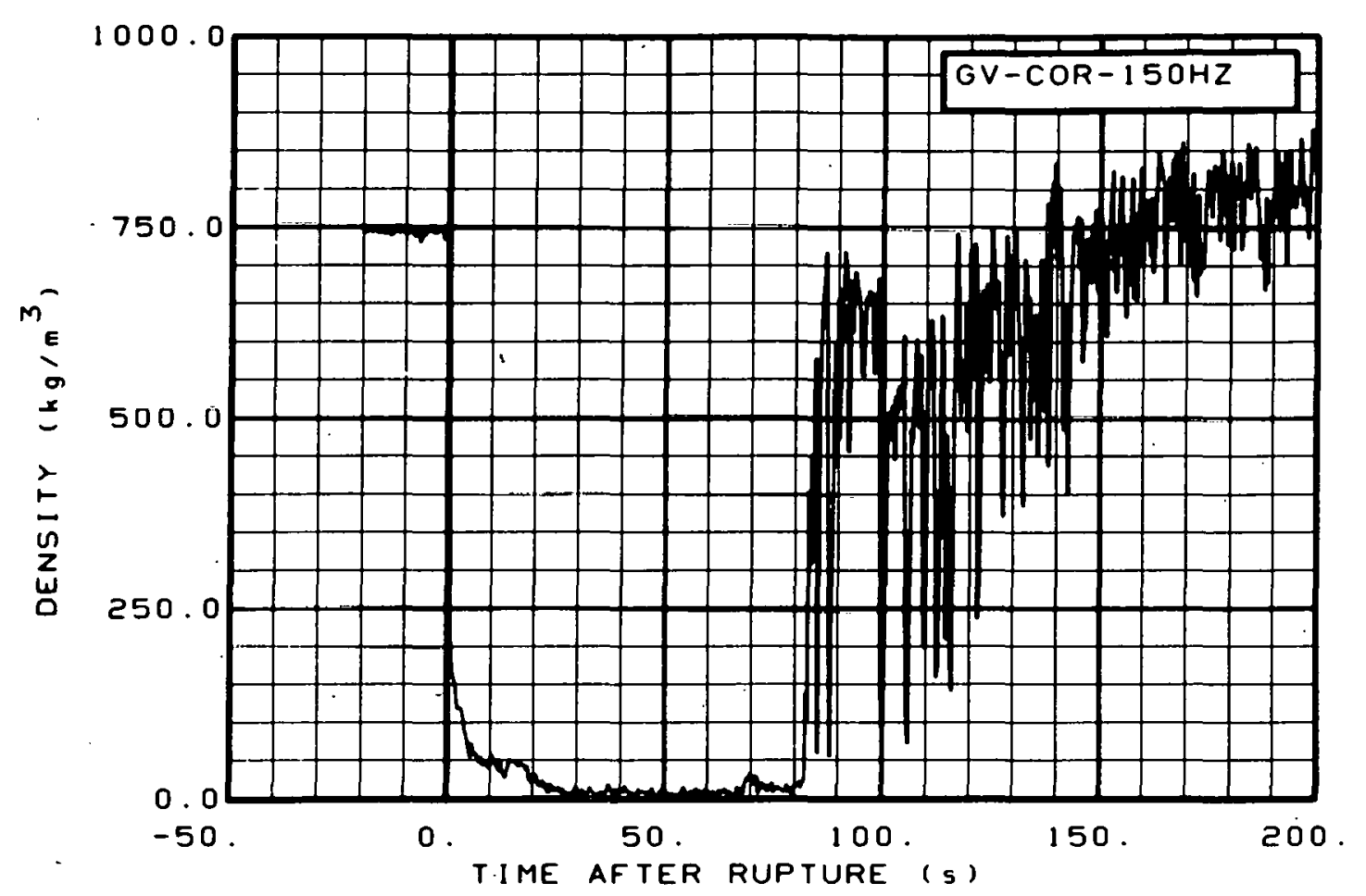

Fig. 293 Density in vessel (GV-COR-150HZ), from -20 to $200 \mathrm{~s}$.

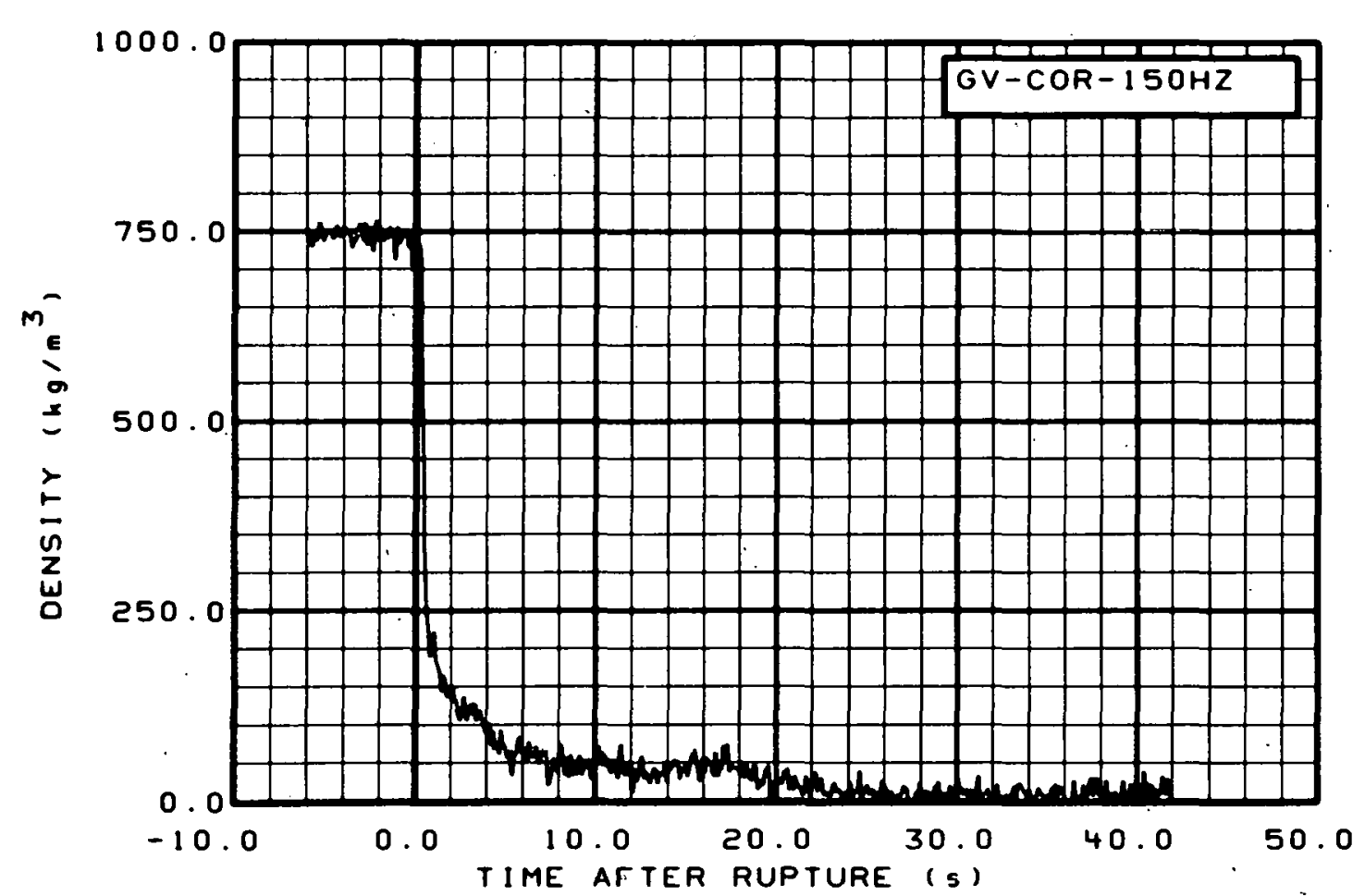

Fig. 294 Density in vesse1 (GV-COR-150HZ), from -6 to $42 \mathrm{~s}$. 


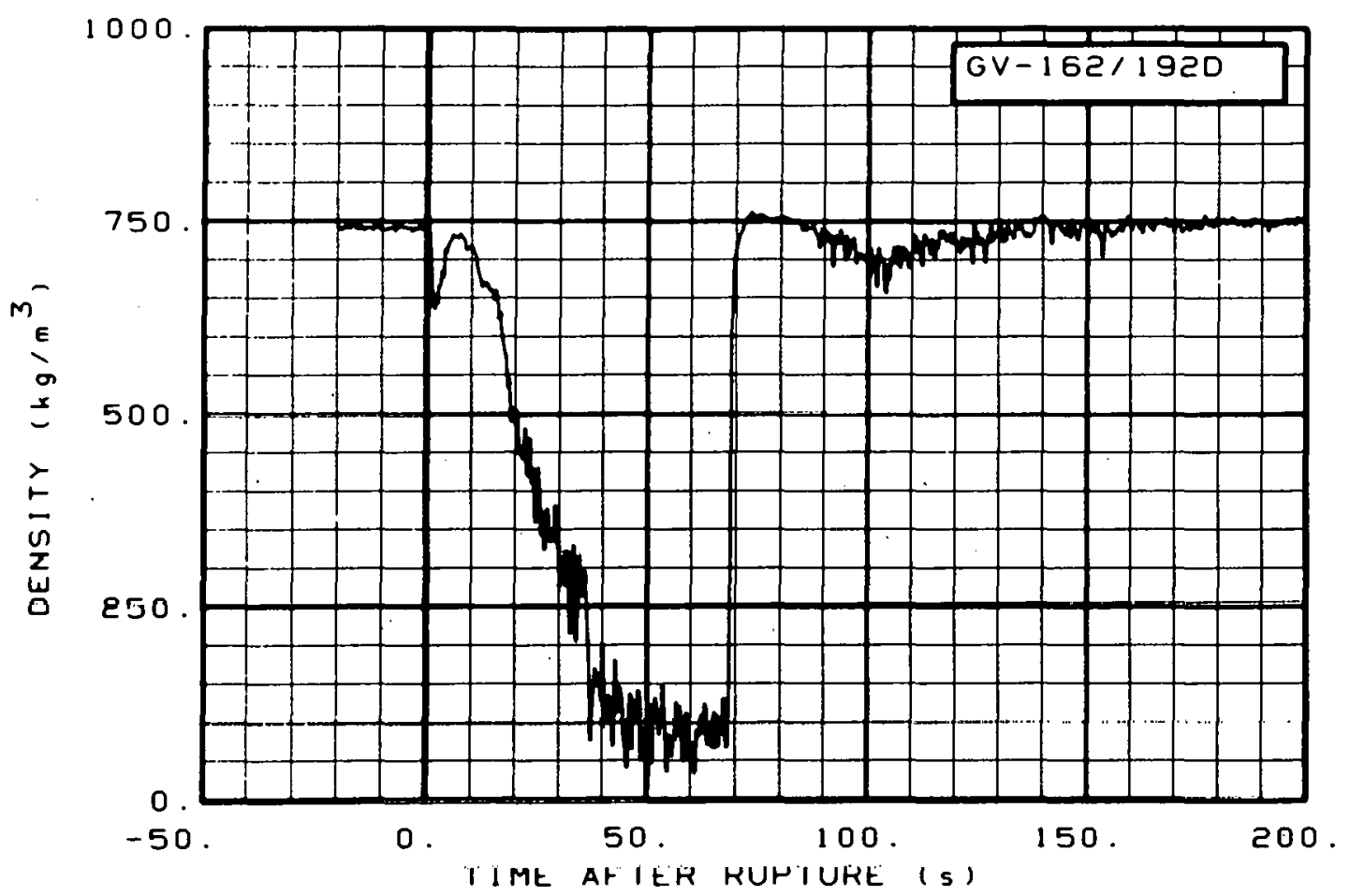

Fig. 295 Density in vessel (GV-162/192D), from -20 to $200 \mathrm{~s}$.

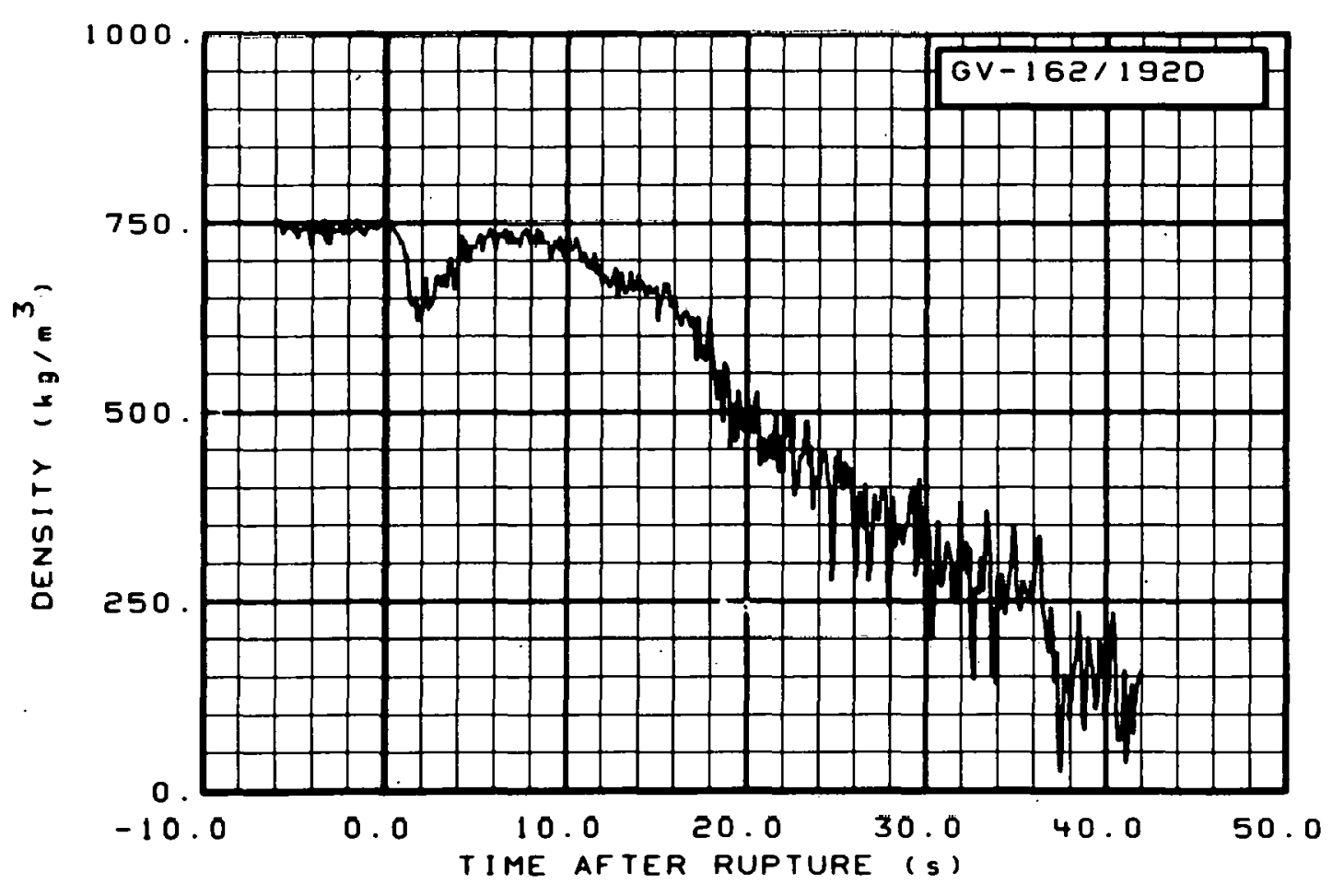

Fig. 296 Density in vessel (GV-162/192D), from -6 to $42 \mathrm{~s}$. 


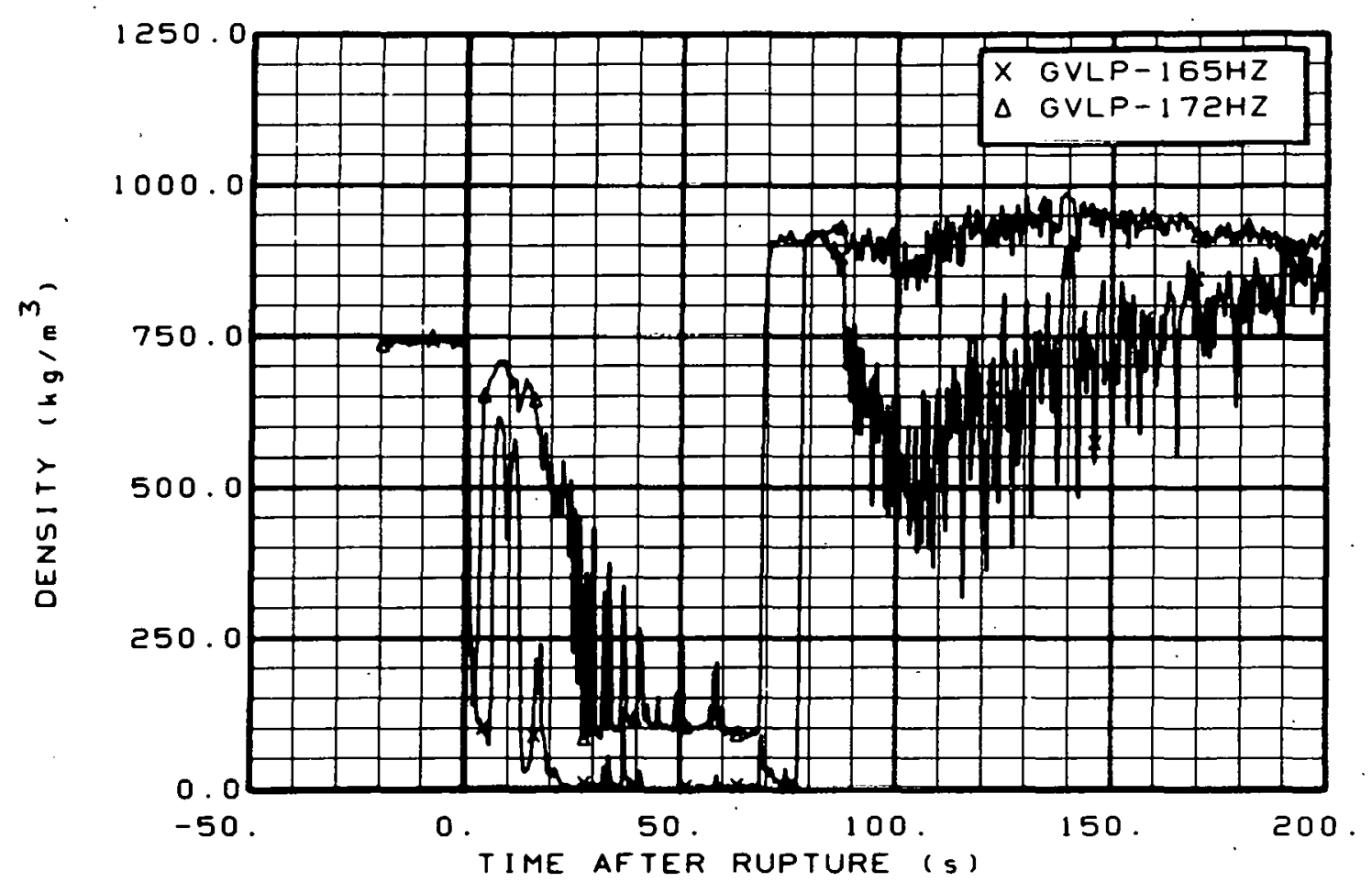

Fig. 297 Density in vessel (GVLP-165HZ and GVLP-172HZ), from -20 to $200 \mathrm{~s}$.

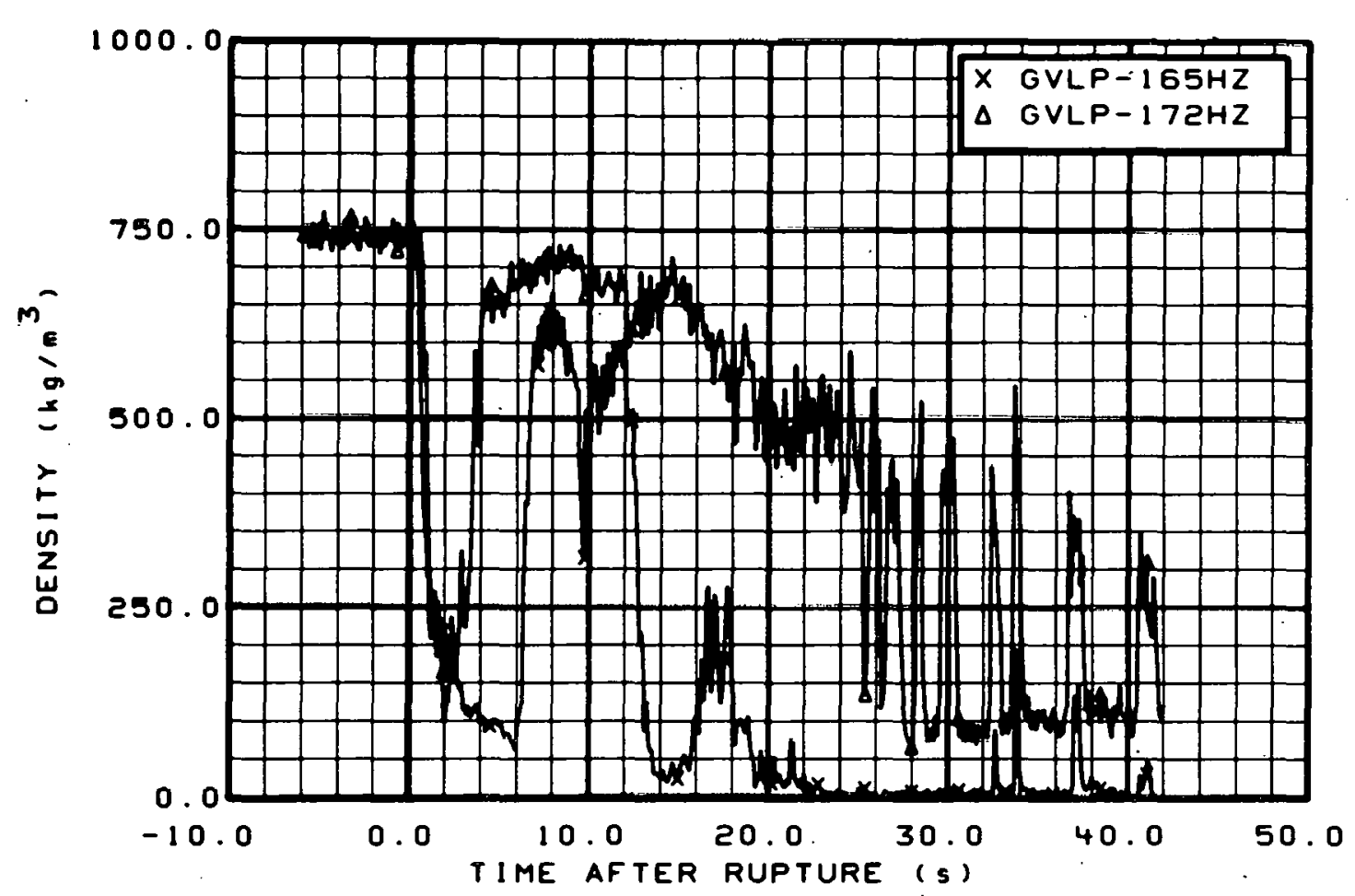

Fig. 298 Density in vessel (GVLP-165HZ and GVLP-172HZ), from -6 to $42 \mathrm{~s}$. 


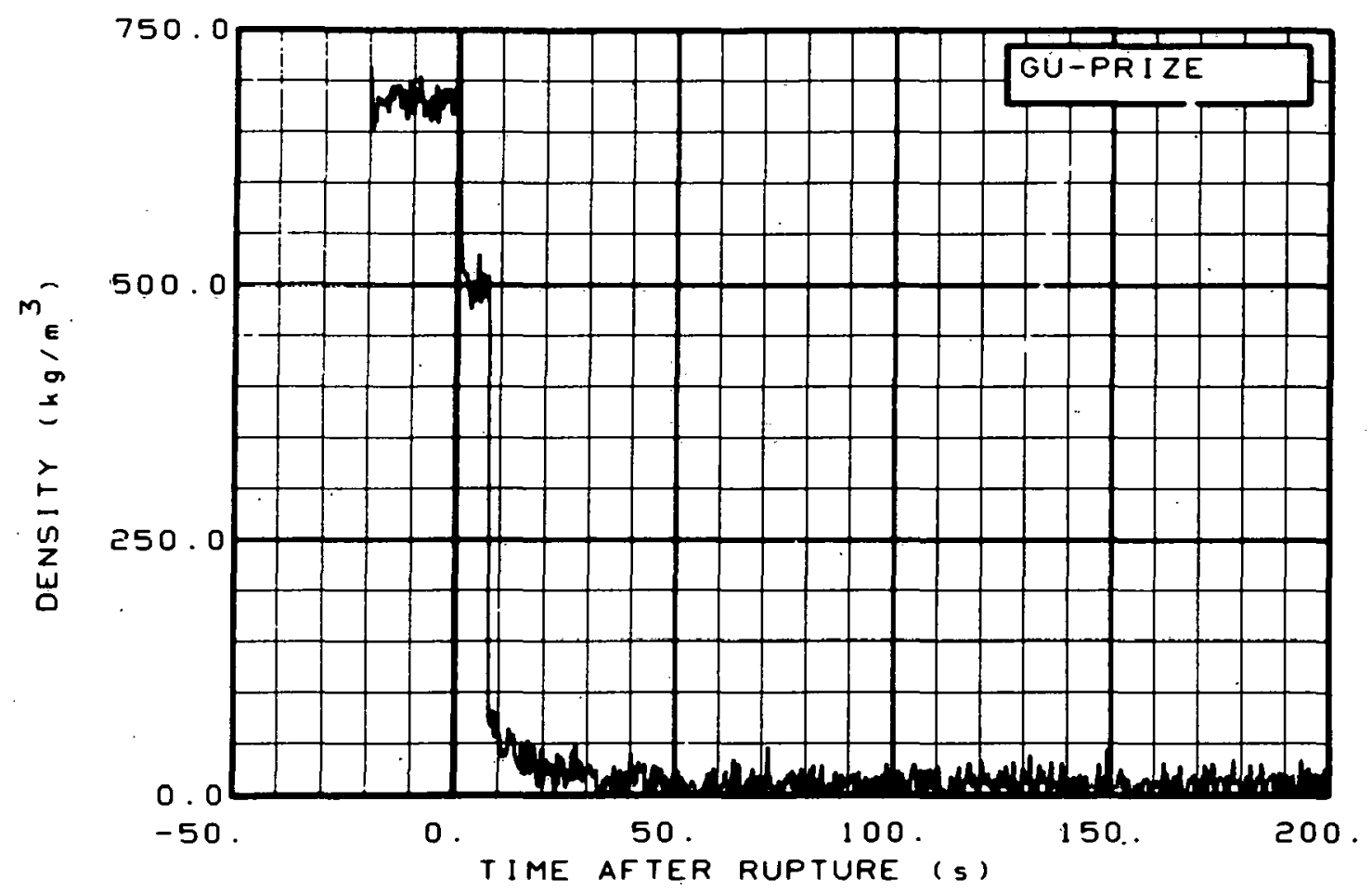

Fig. 299 Density in pressurizer (GU-PRIZE), from -20 to $200 \mathrm{~s}$.

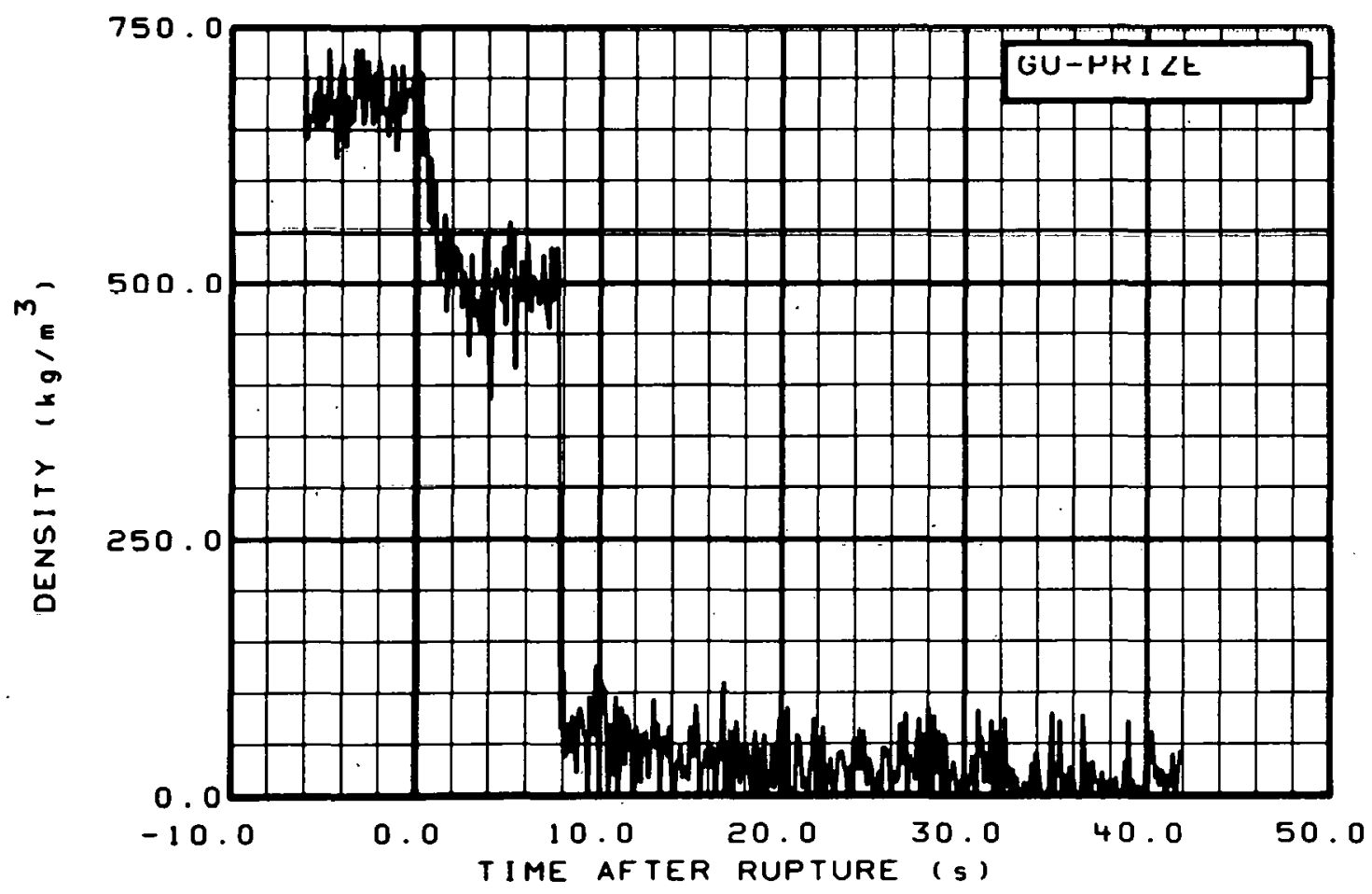

Fig. 300 Density in pressurizer (GU-PRIZE), from -6 to $42 \mathrm{~s}$. 


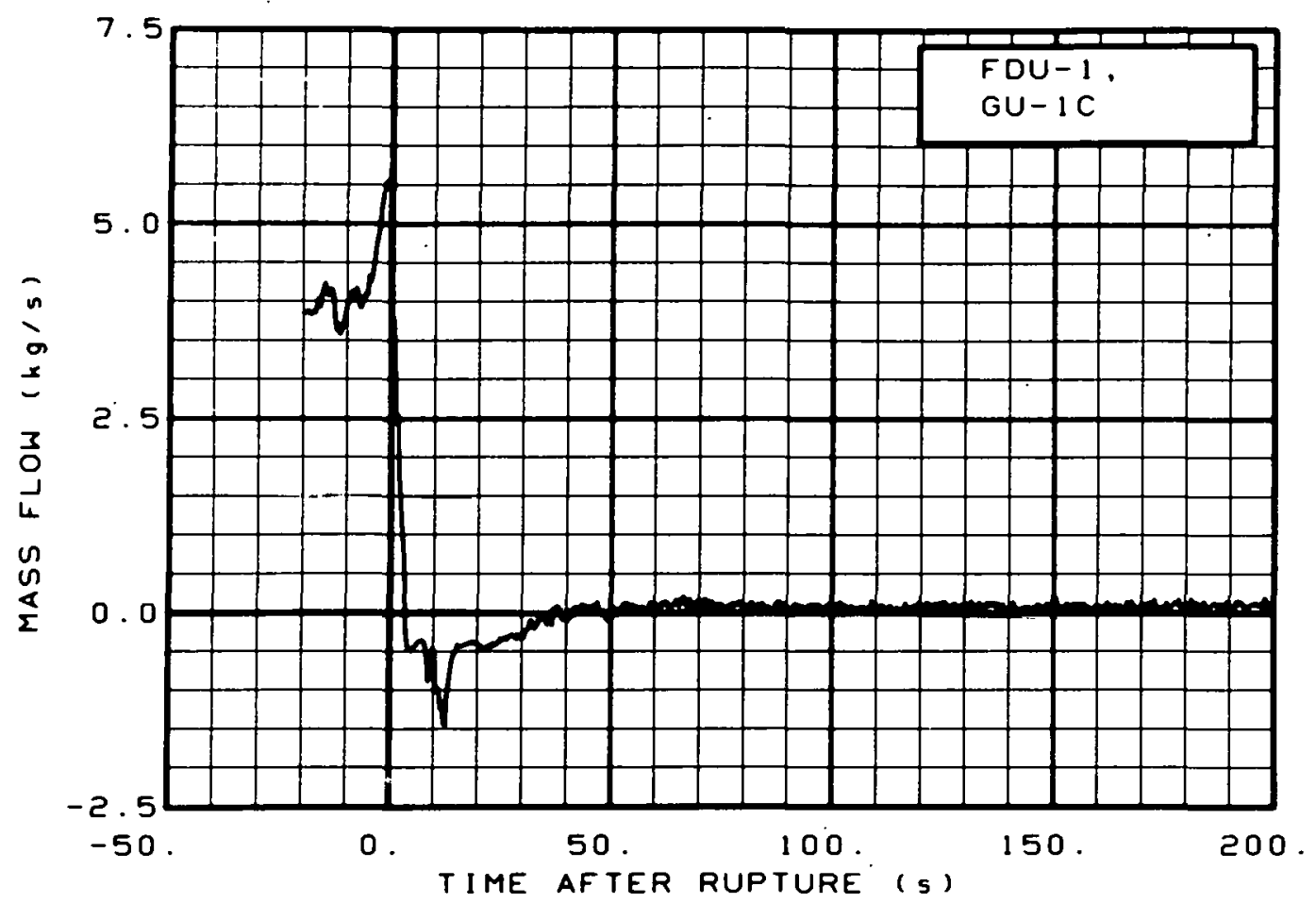

Fig. 301 Mass flow in intact loop (FDU-1, GU-1C), from -20 to $200 \mathrm{~s}$.

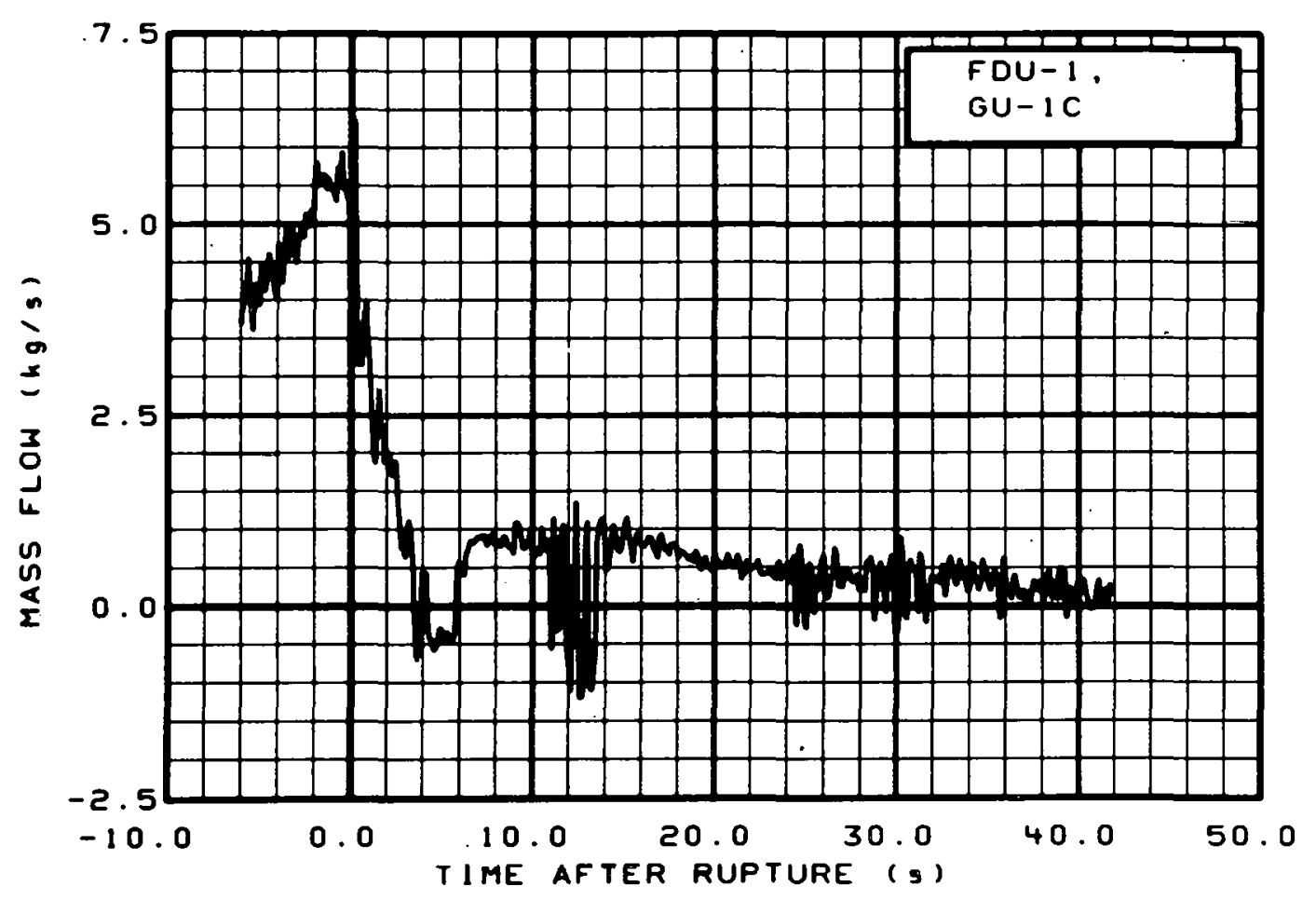

Fig. 302 Mass flow in intact loop (FDU-1, GU-1C), from -6 to $42 \mathrm{~s}$. 


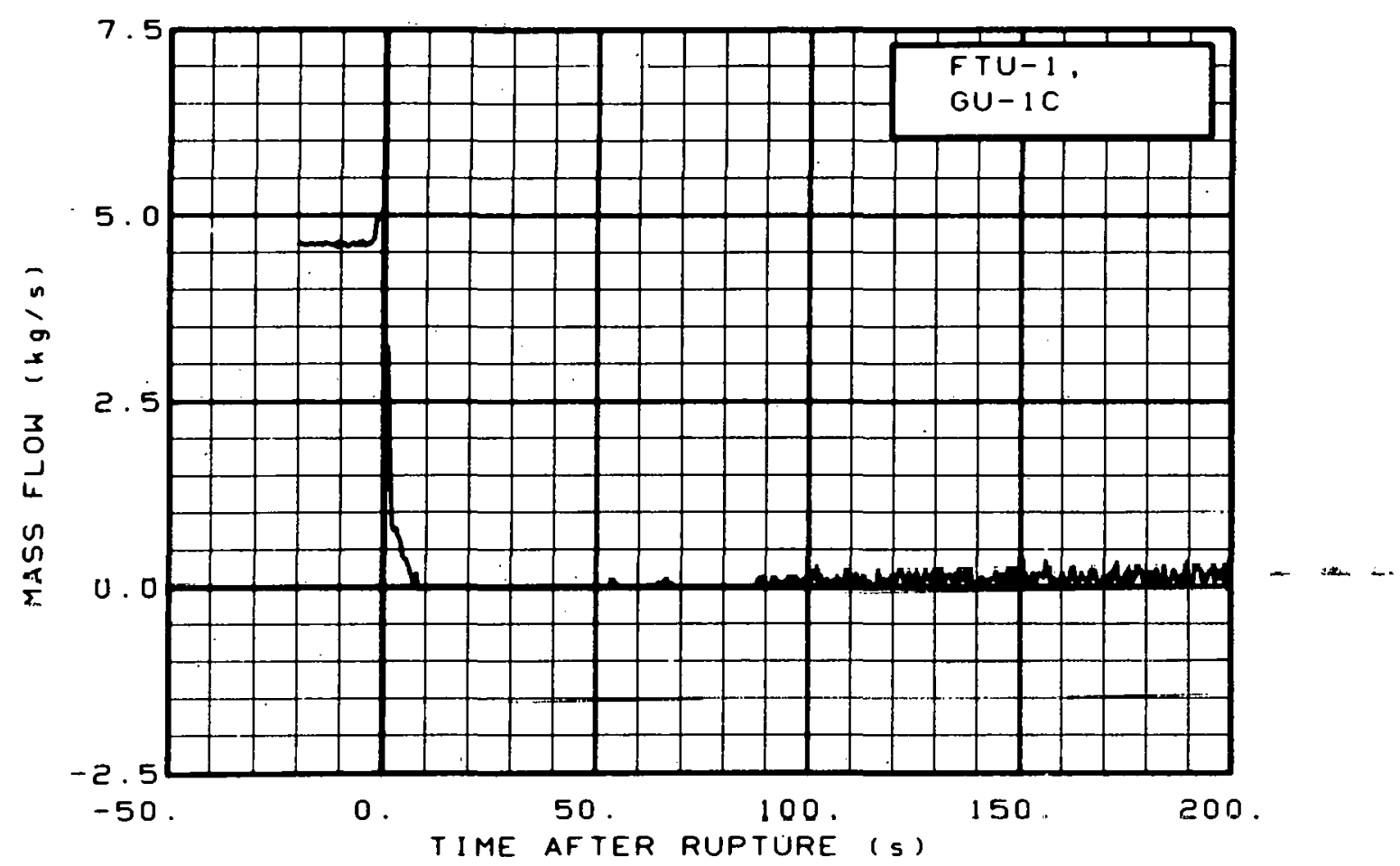

Fig. 303 Mass flow in intact loop (FTU-1, GU-1C), from -20 to $200 \mathrm{~s}$.

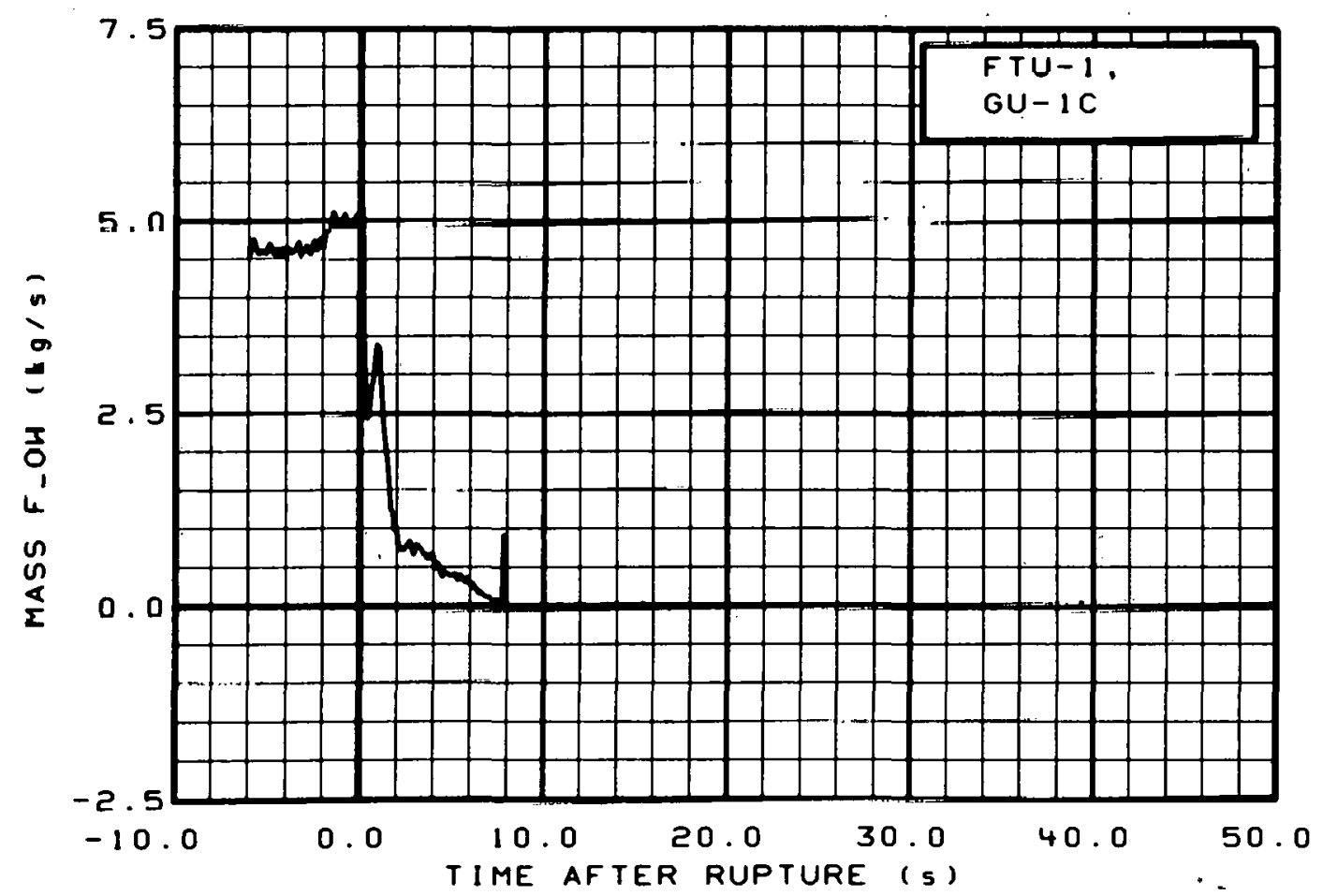

Fig. 304 Mass flow in intact loop (FTU-1, GU-1C), from -6 to $42 \mathrm{~s}$. 


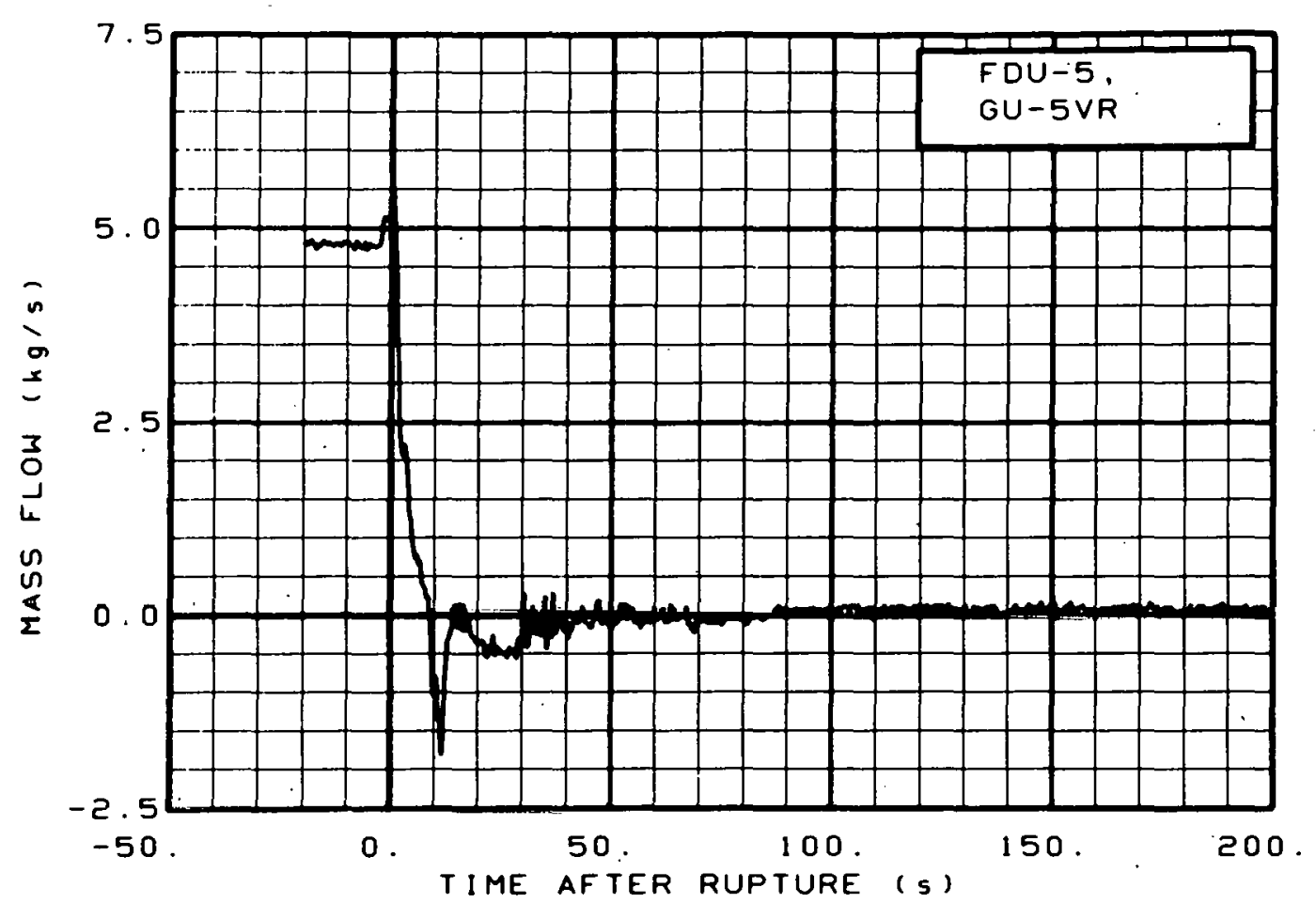

Fig. 305 Mass flow in intact loop (FDU-5, GU-5VR), from -20 to $200 \mathrm{~s}$.

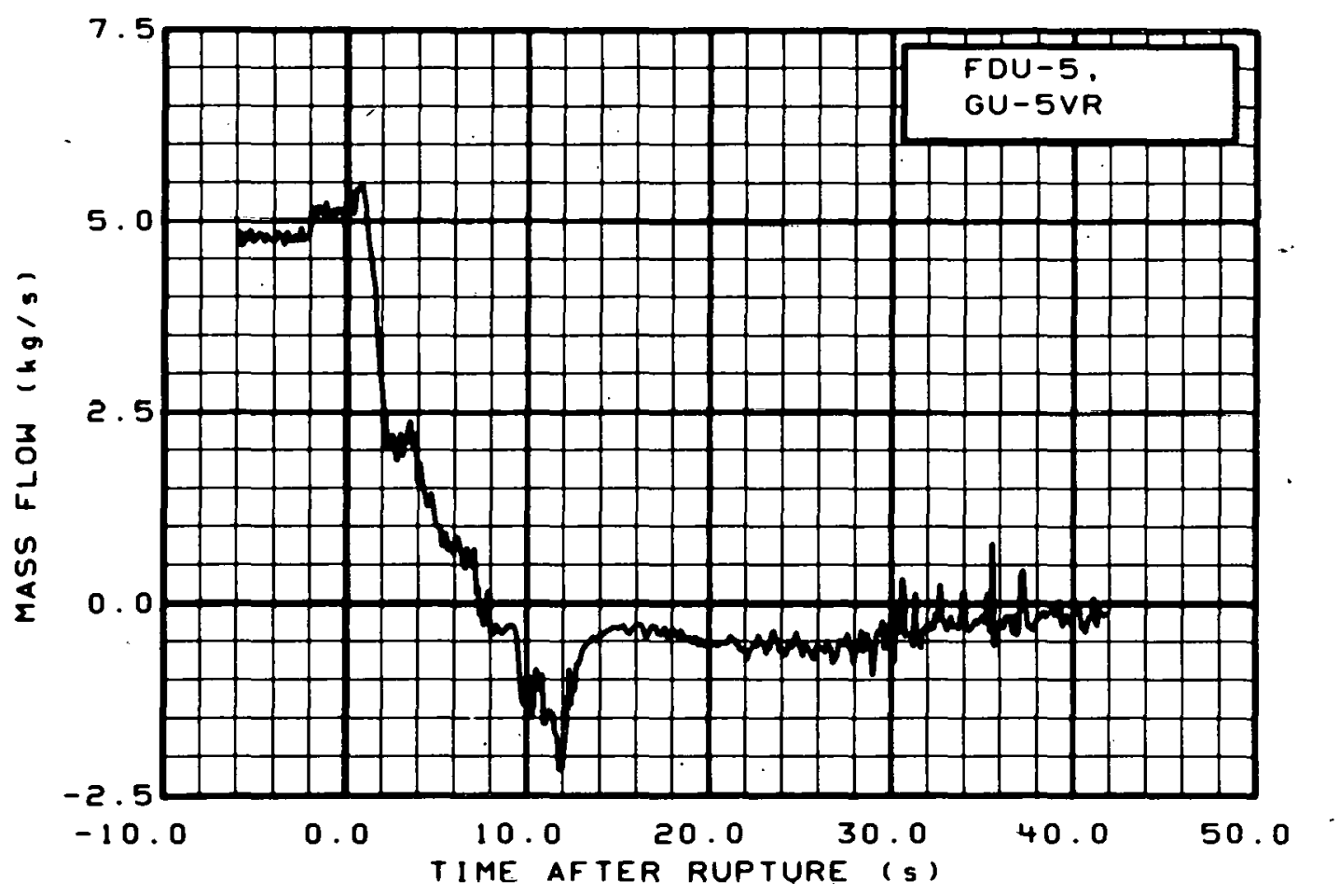

Fig. 306 Mass flow in intact loop (FDU-5, GU-5VR), from -6 to $42 . \mathrm{s}$. 


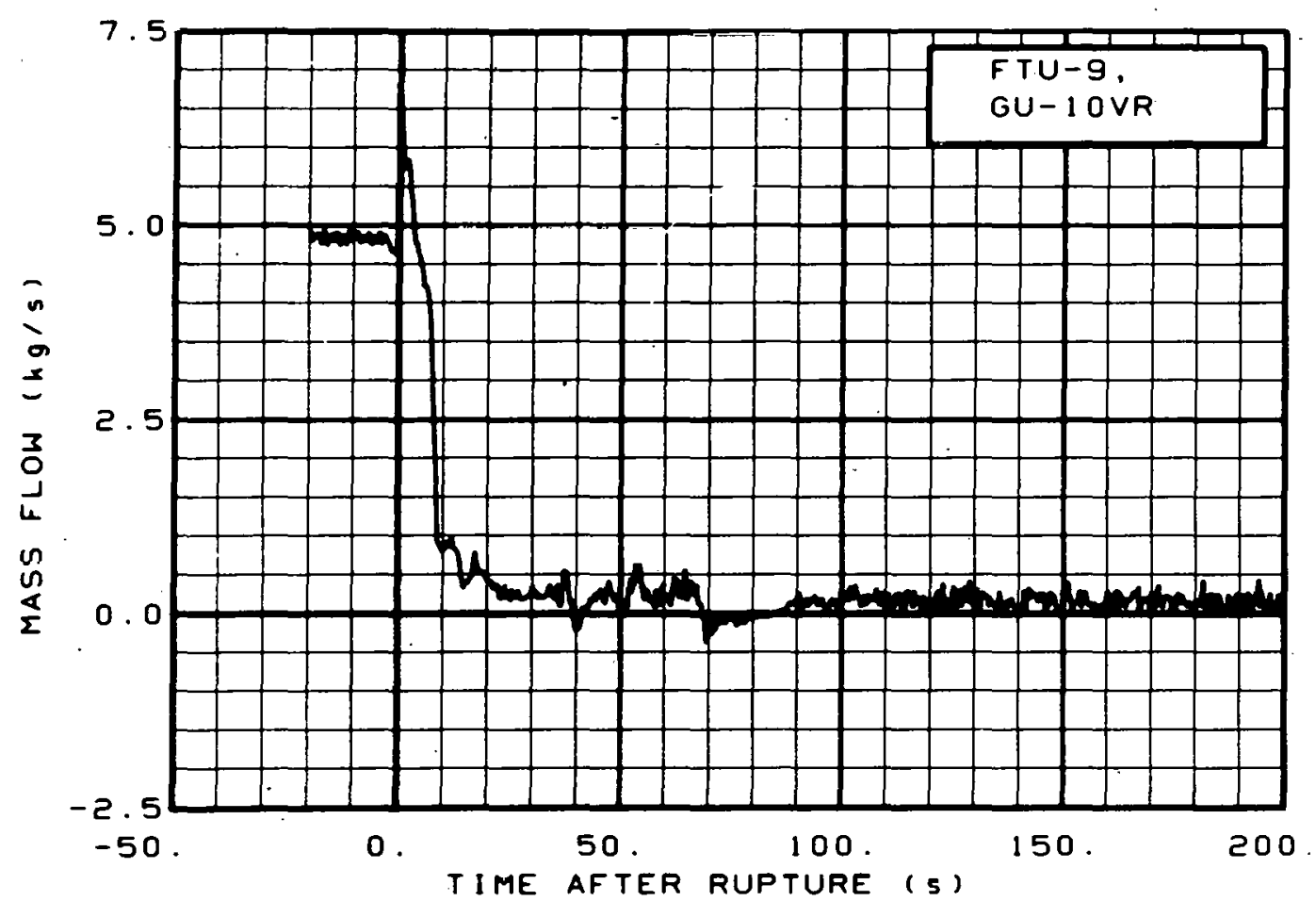

Fig. 307 Mass flow in intact loop (FTU-9, GU-10VR), from -20 to $200 \mathrm{~s}$.

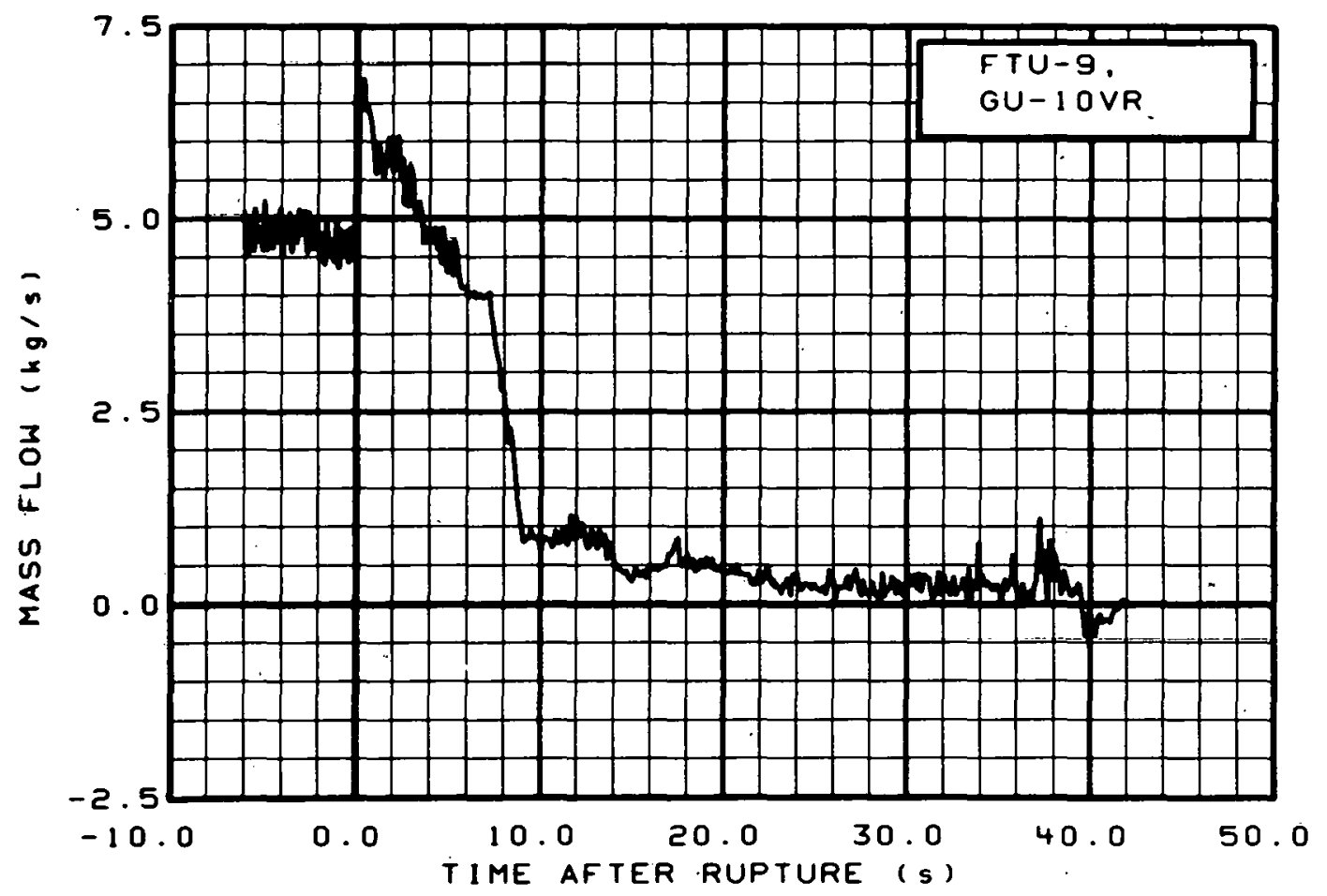

Fig. 308 Mass flow in intact loop (FTU-9, GU-10VR), from -6 to $42 \mathrm{~s}$. 


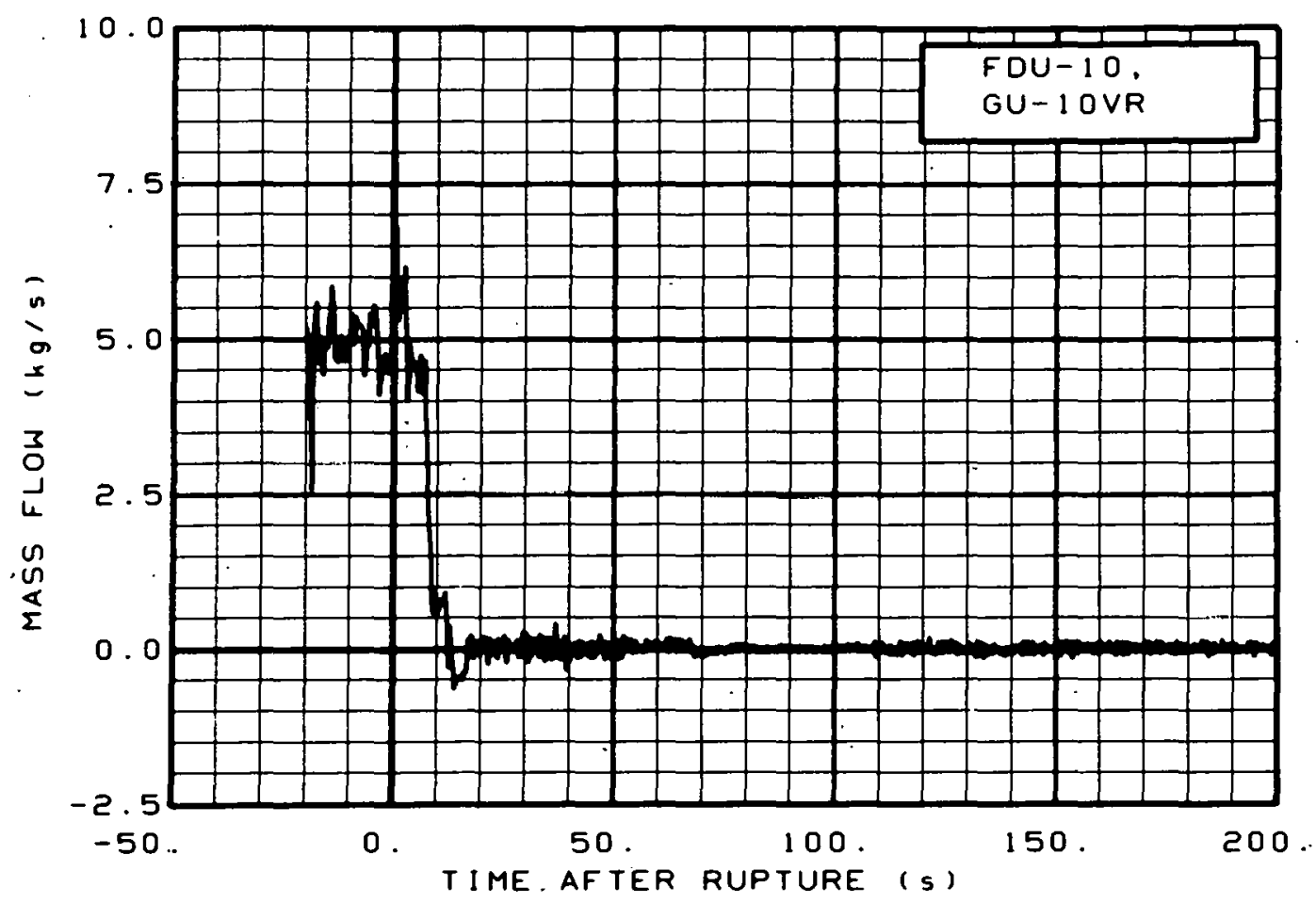

Fig. 309 Mass flow in intact loop (FDU-10, GU-10VR), from -20 to $200 \mathrm{~s}$.

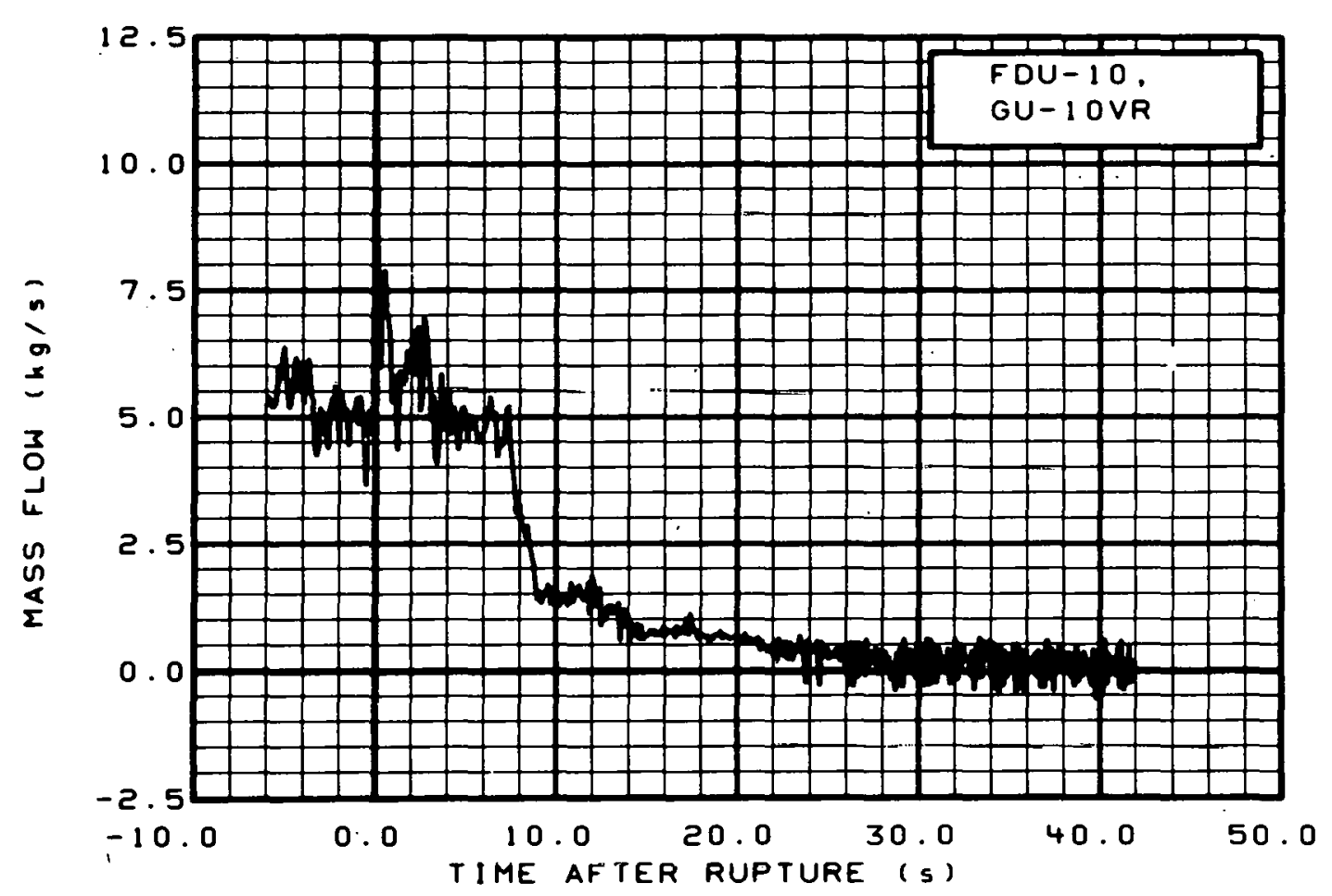

Fig. 310 Mass flow in intact loop (FDU-10, GU-10VR), from -6 to $42 \mathrm{~s}$. 


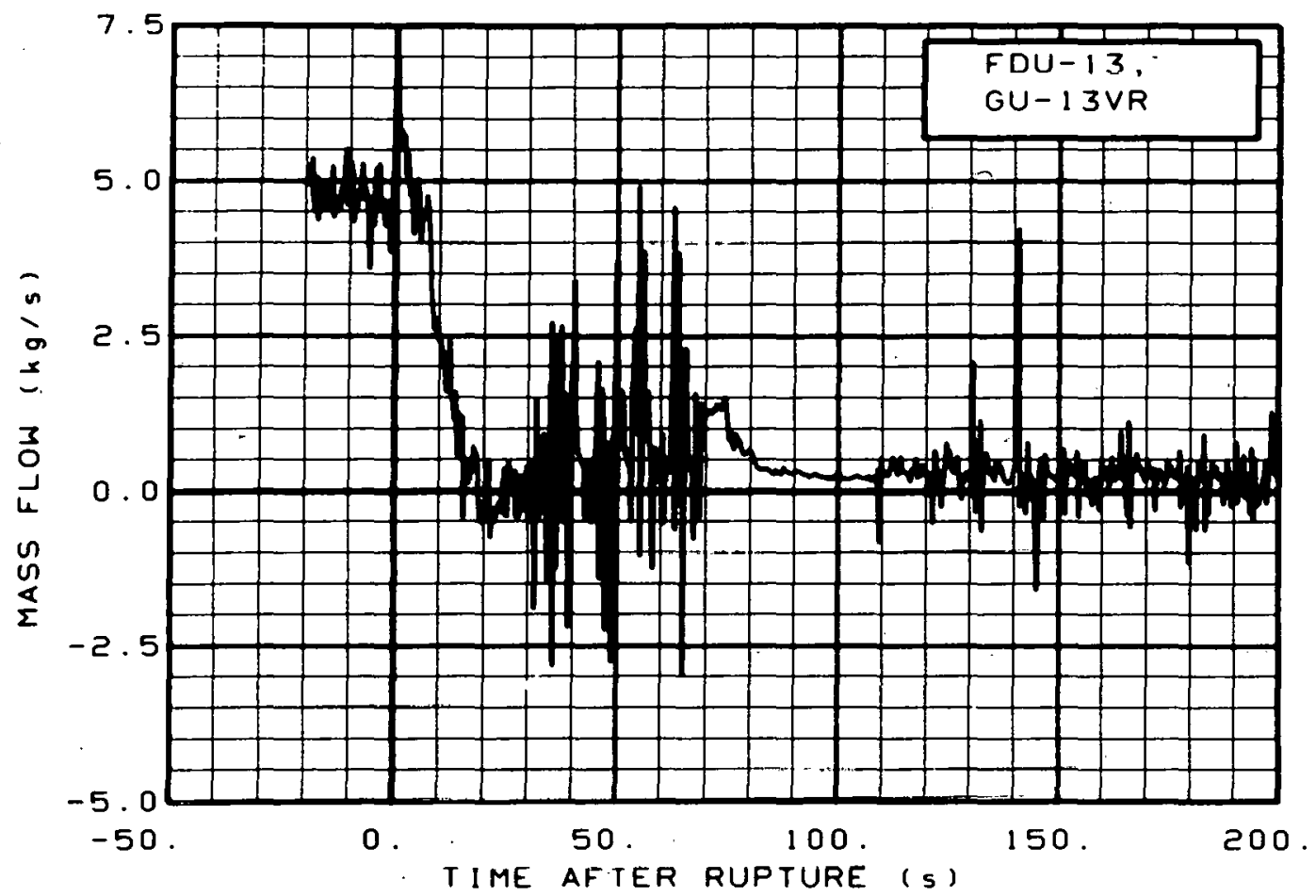

Fig. 311 Mass flow in intact loop (FDU-13, GU-13VR), from -20 to $200 \mathrm{~s}$.

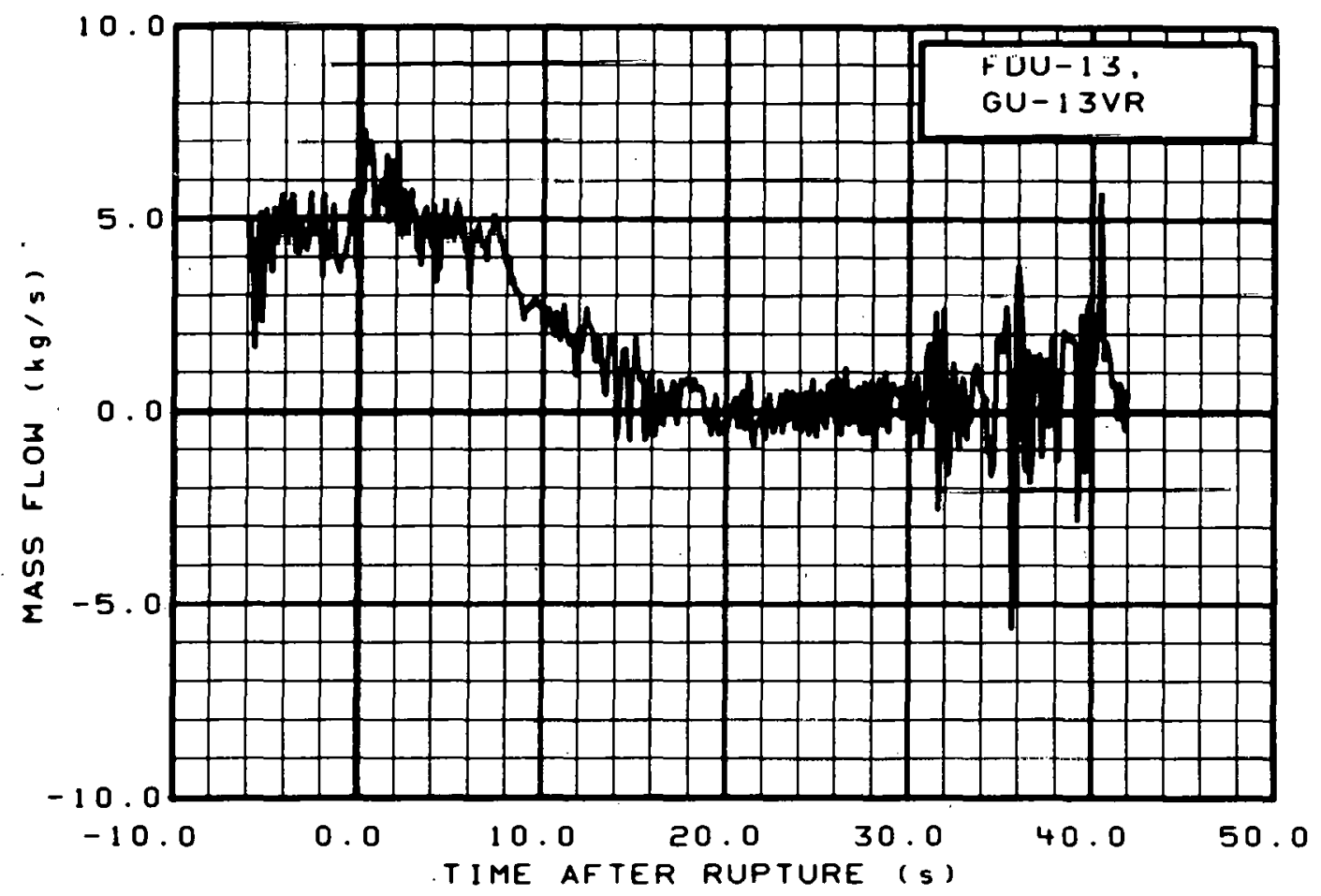

Fig. 312 Mass flow in intact loop (FDU-13, GU-13VR), from -6 to $42 \mathrm{~s}$. 


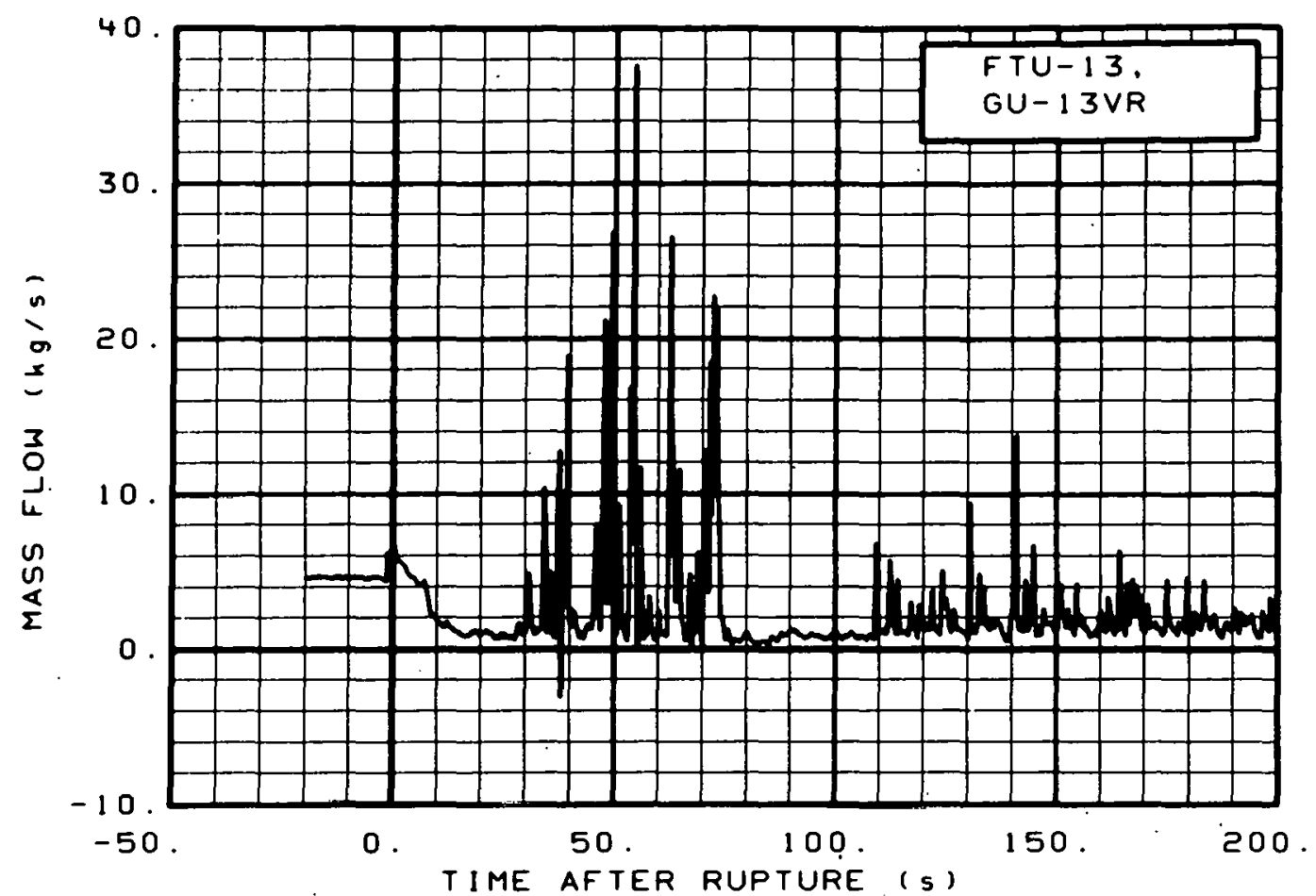

Fig. 313 Mass flow in intact loop (FTU-13, GU-13VR), from -20 to $200 \mathrm{~s}$.

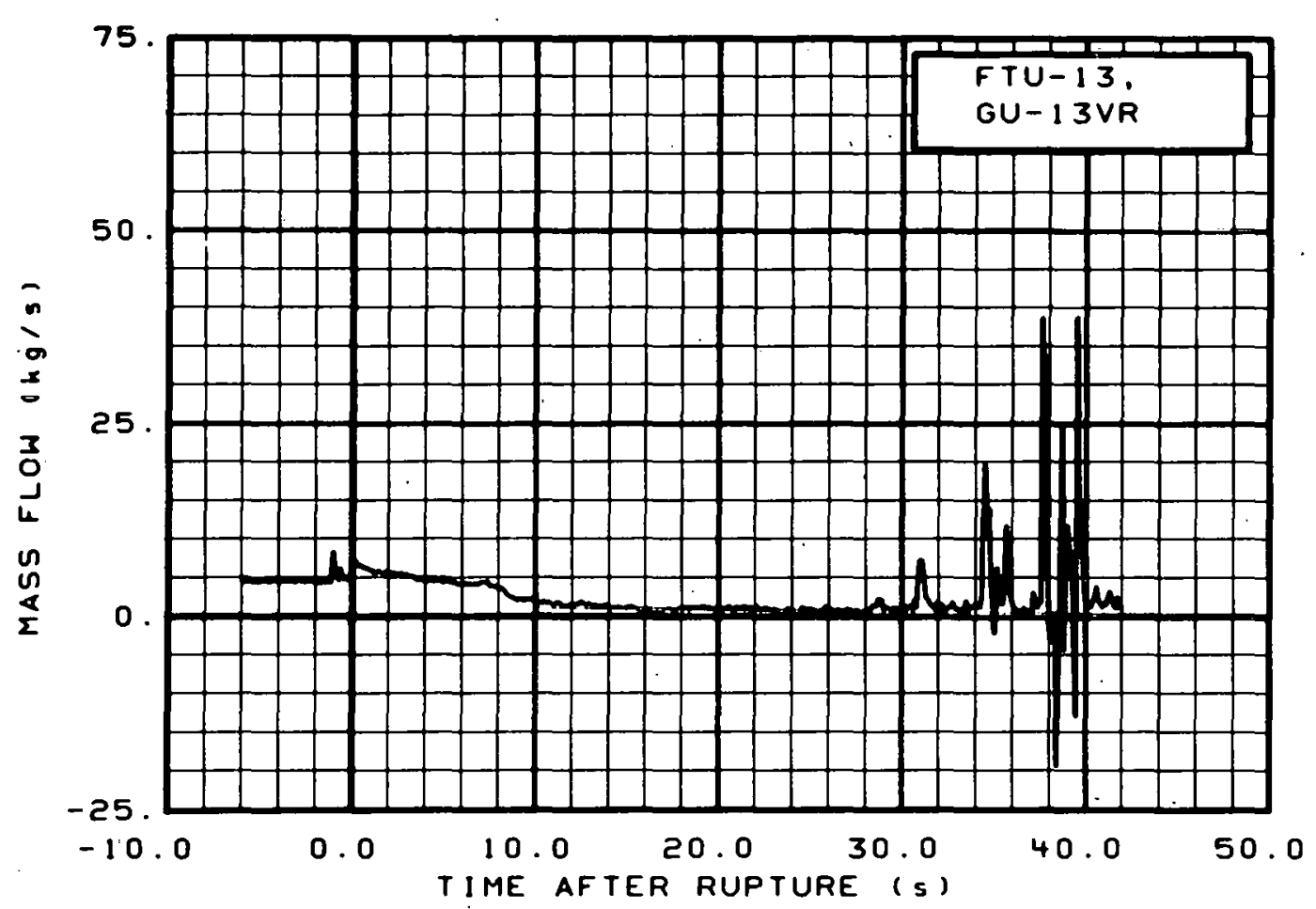

Fig. 314 Mass flow in intact loop (FTU-13, GU-13VR), from -6 to $42 \mathrm{~s}$. 


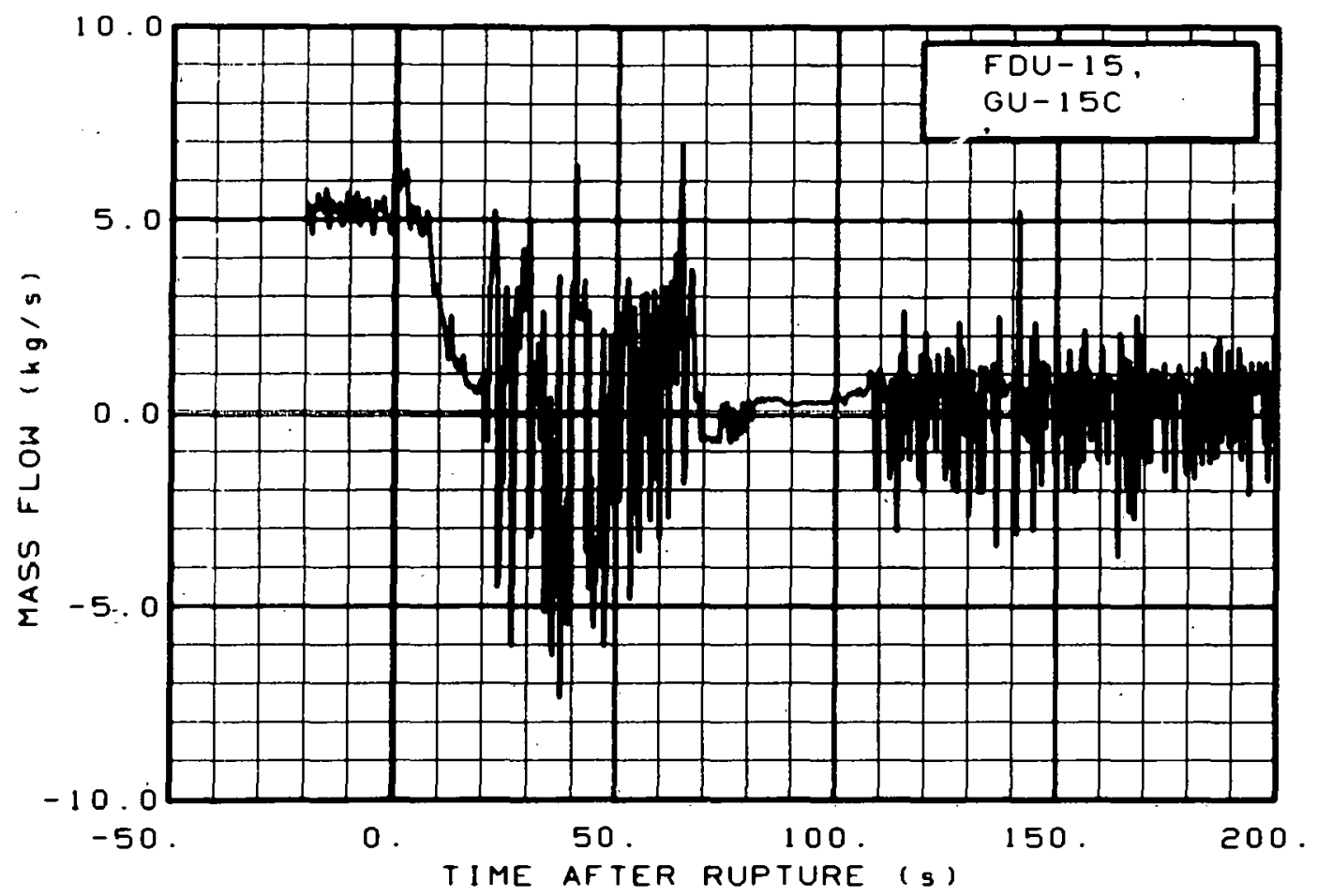

Fig. 315 Mass flow in intact loop (FDU-15, GU-15C), from -20 to $200 \mathrm{~s}$.

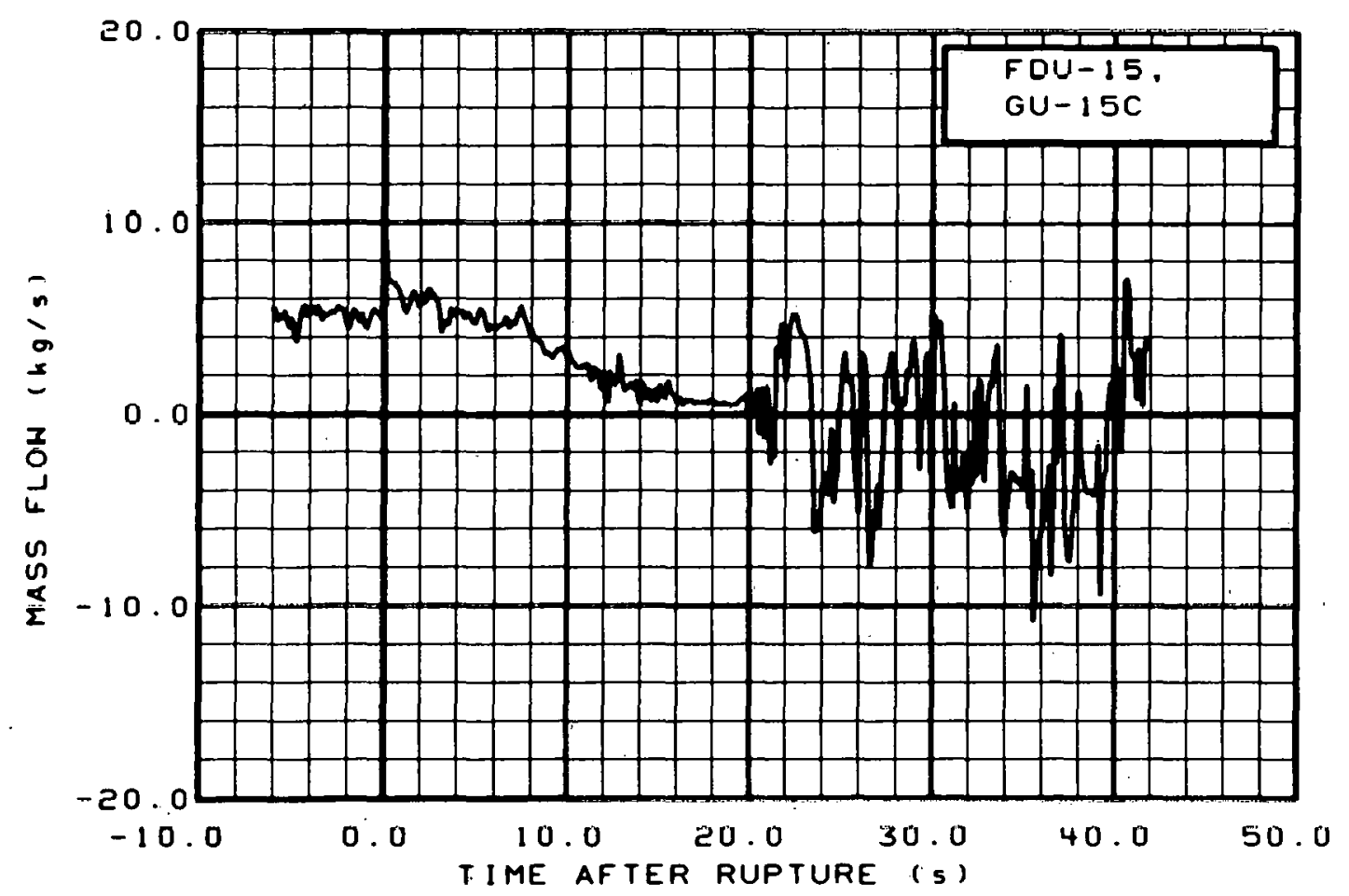

Fig. 316 Mass flow in intact loop (FDU-15, GU-15C), from -6 to $42 \mathrm{~s}$. 


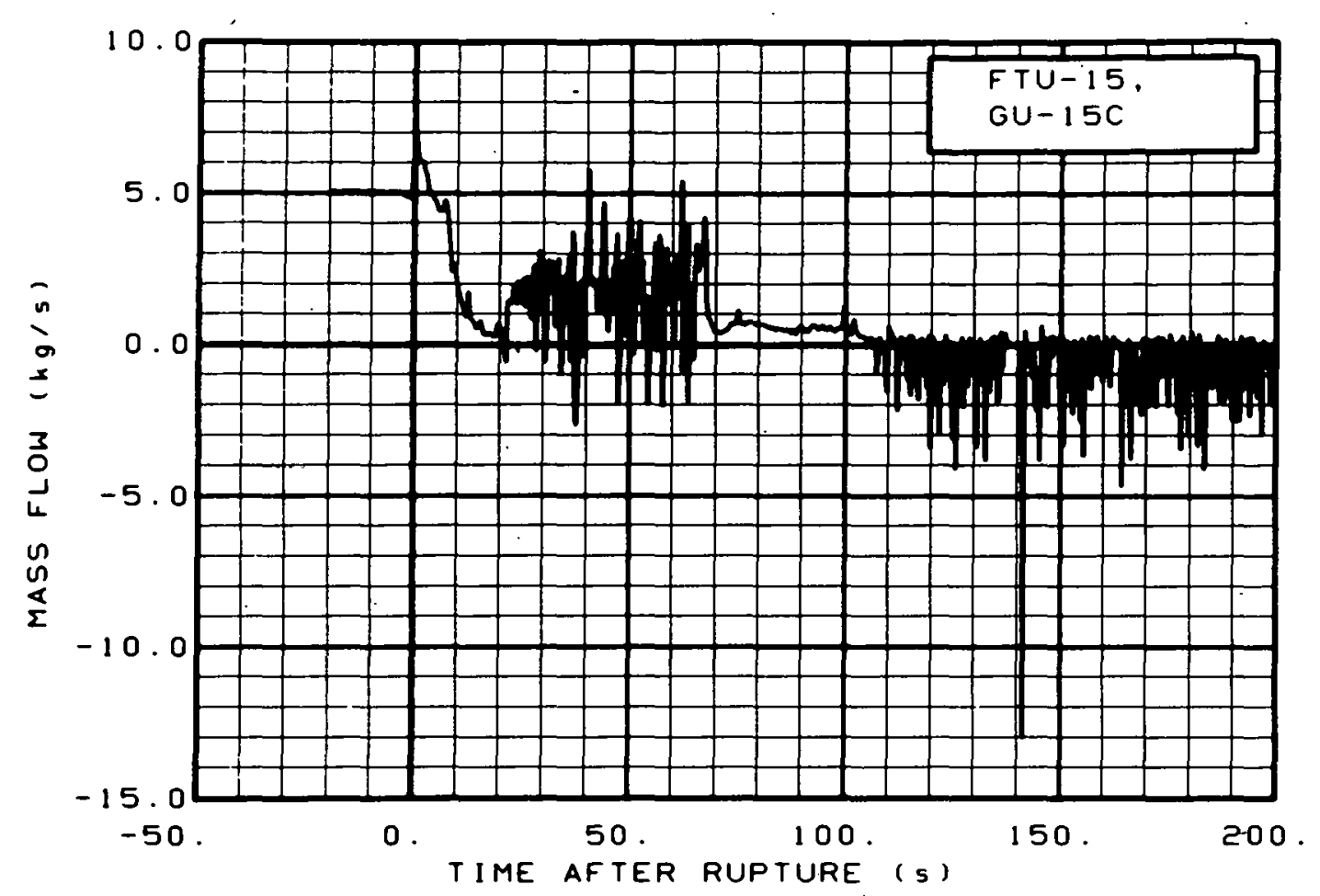

Fig. 317 Mass flow in intact loop (FTU-15, GU-15C), from -20 to $200 \mathrm{~s}$.

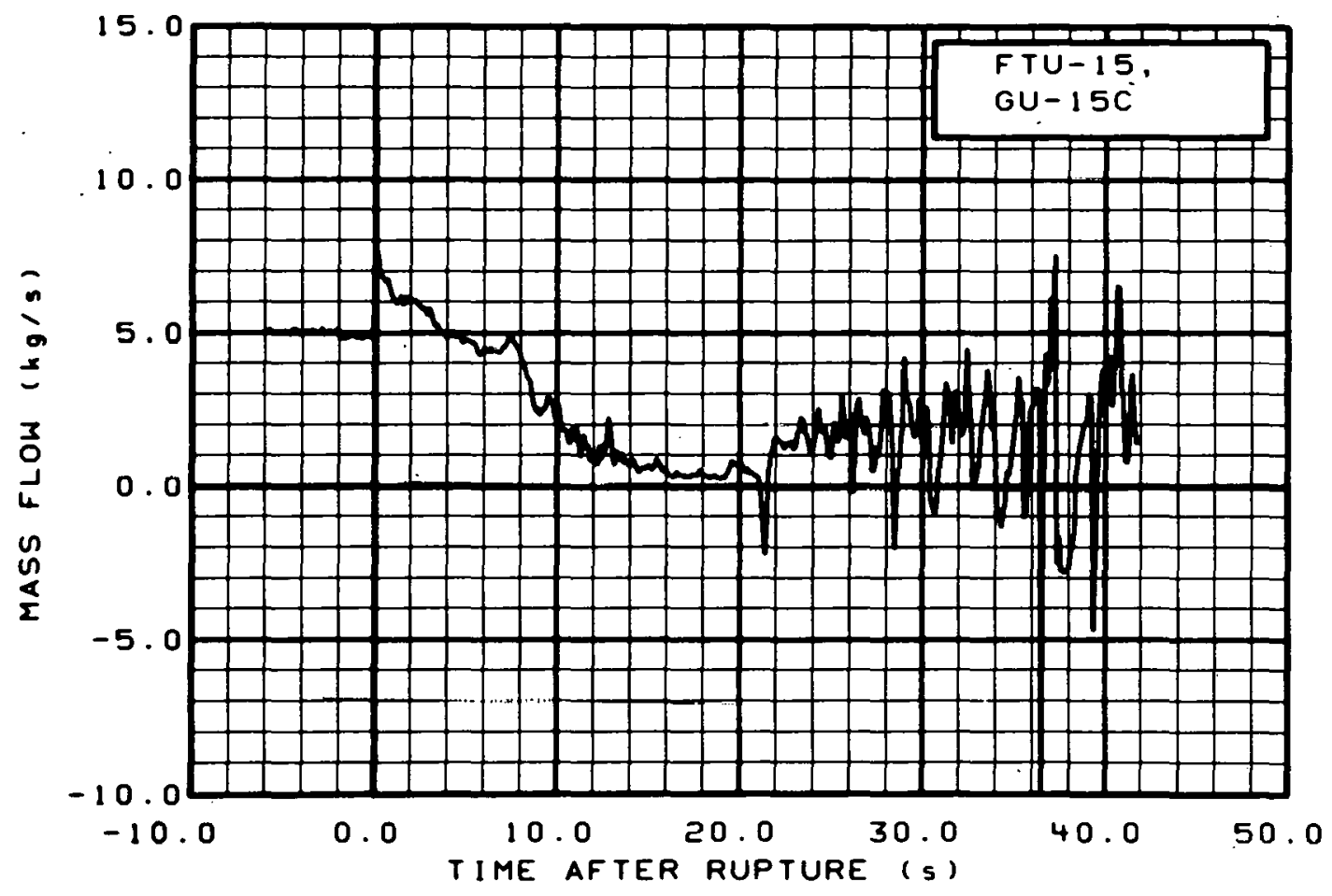

Fig. 318 Mass flow in intact loop (FTU-15, GU-15C), from -6 to $42 \mathrm{~s}$. 


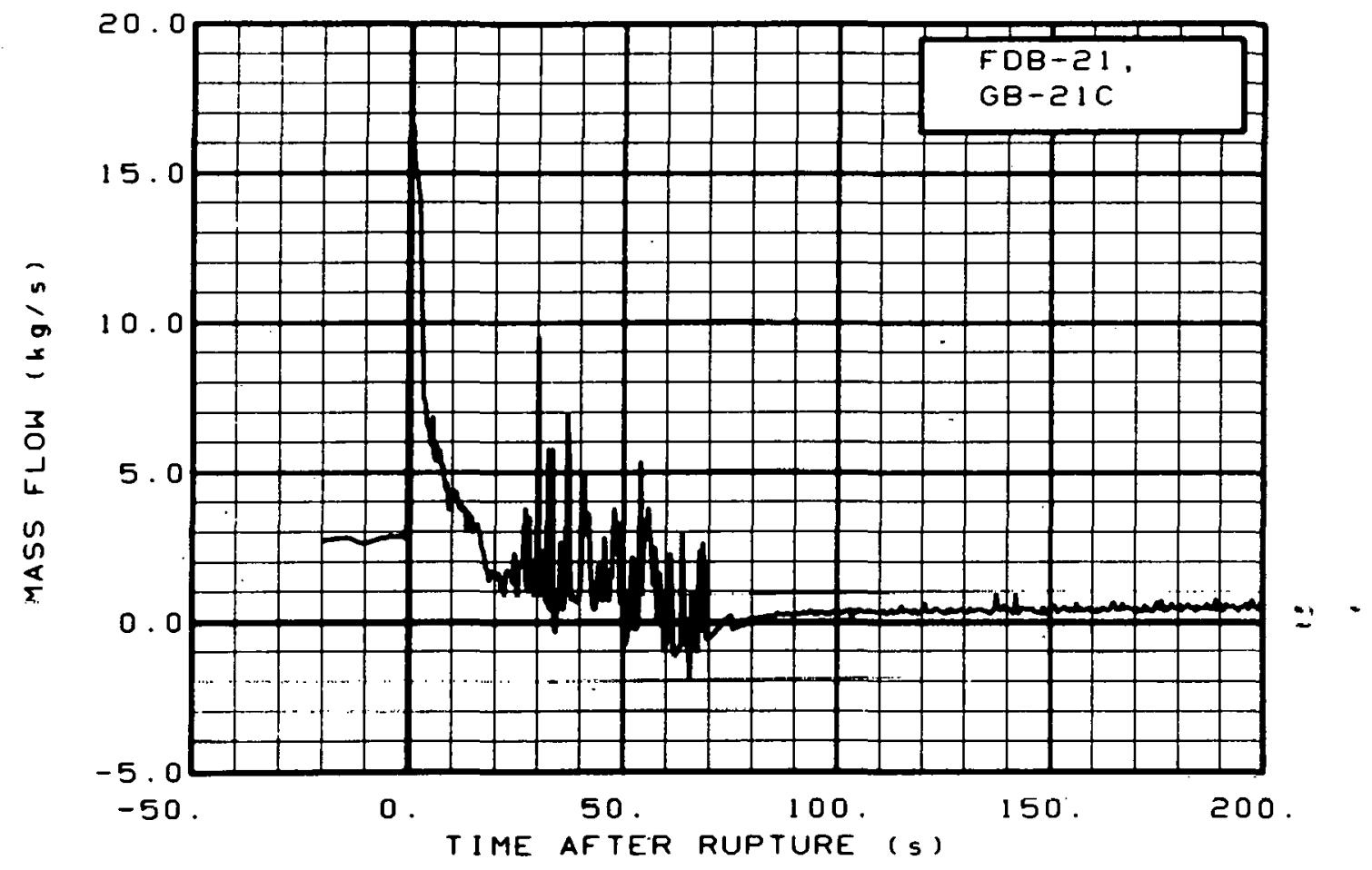

Fig. 319 Mass flow in intact loop (FDB-21, GB-21C), from -20 to $200 \mathrm{~s}$.

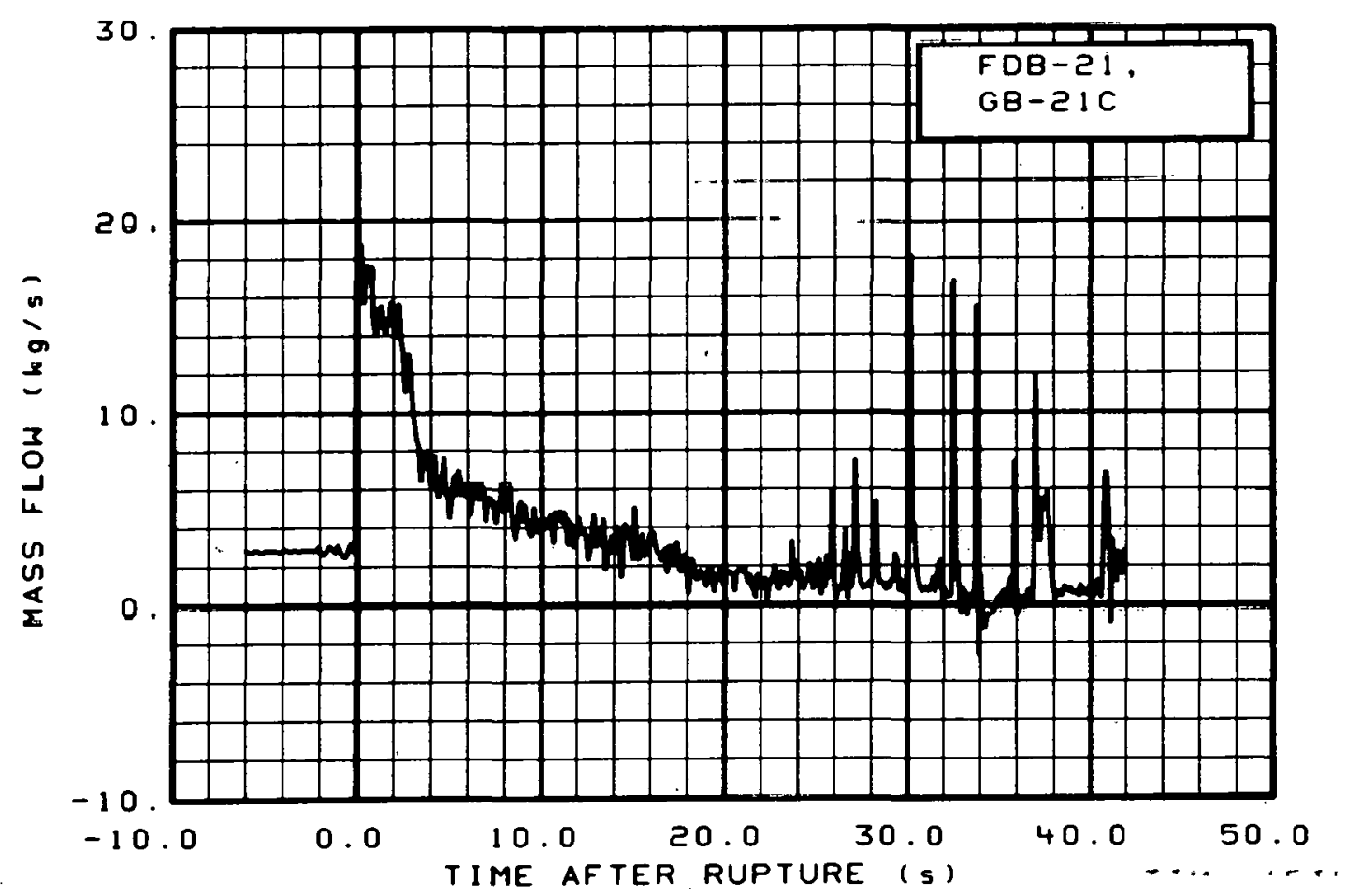

Fig. 320 Mass flow in intact loop (FDB-21, GB-21C), from -6 to $42 \mathrm{~s}$. 


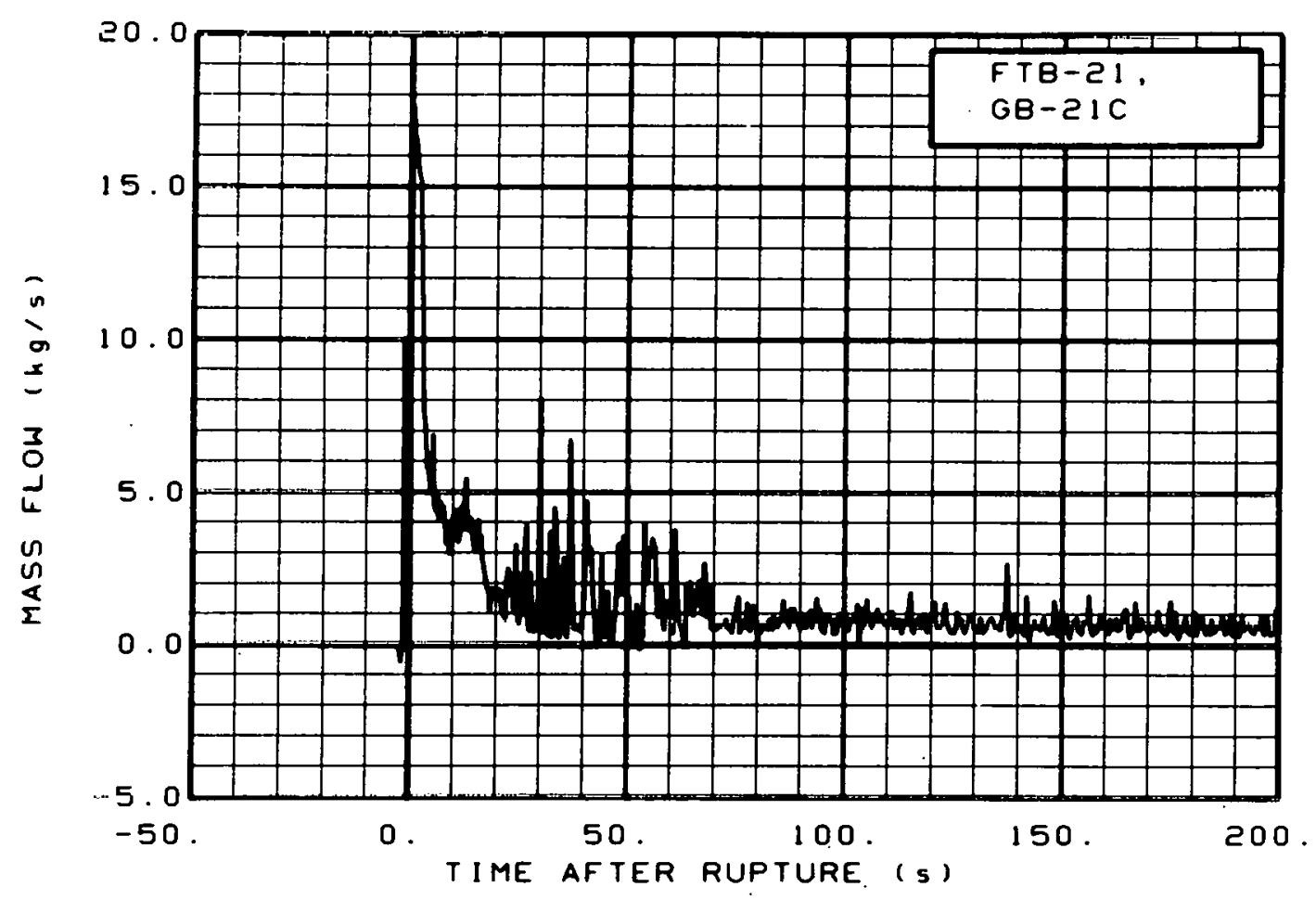

Fig. 327 Mass flow in broken loop (FTB-21, GB-21C), from -20 to $200 \mathrm{~s}$.

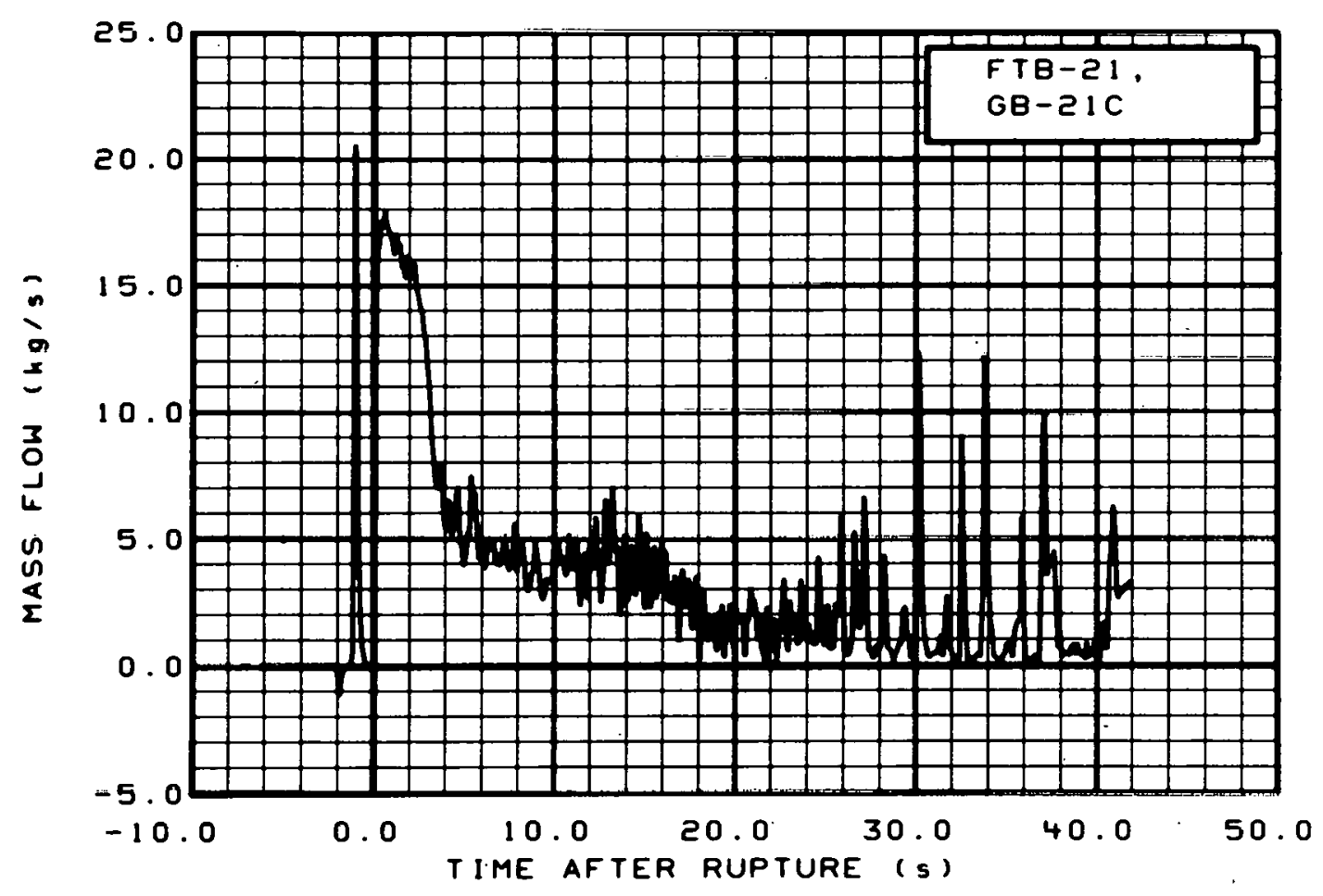

Fig. 322 Mass flow in broken loop (FTB-21, GB-21C), from -6 to $42 \mathrm{~s}$. 


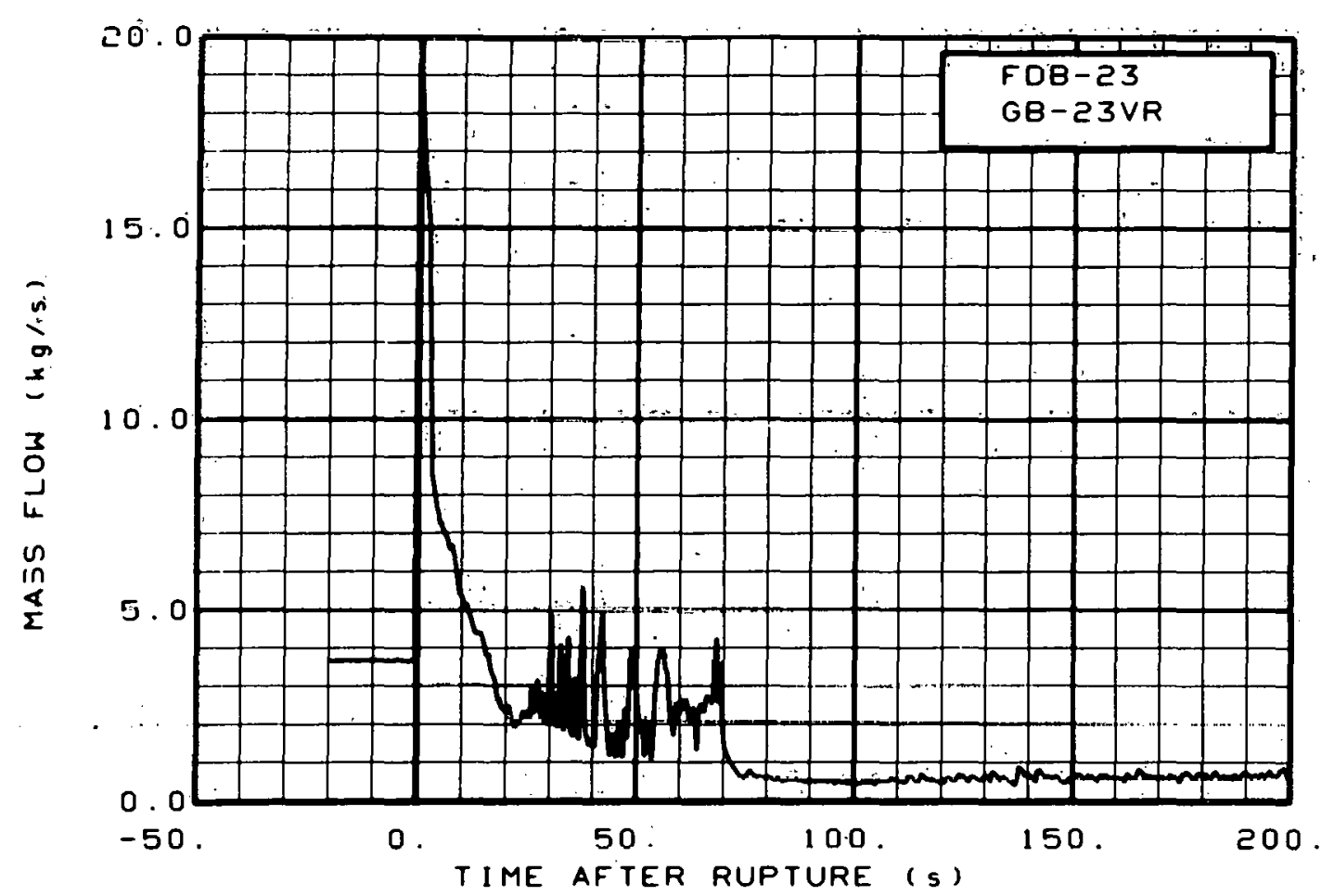

Fig. 323 Mass flow in broken loop (FDB-23, GB-23VR), from -20 to $200 \mathrm{~s}$.

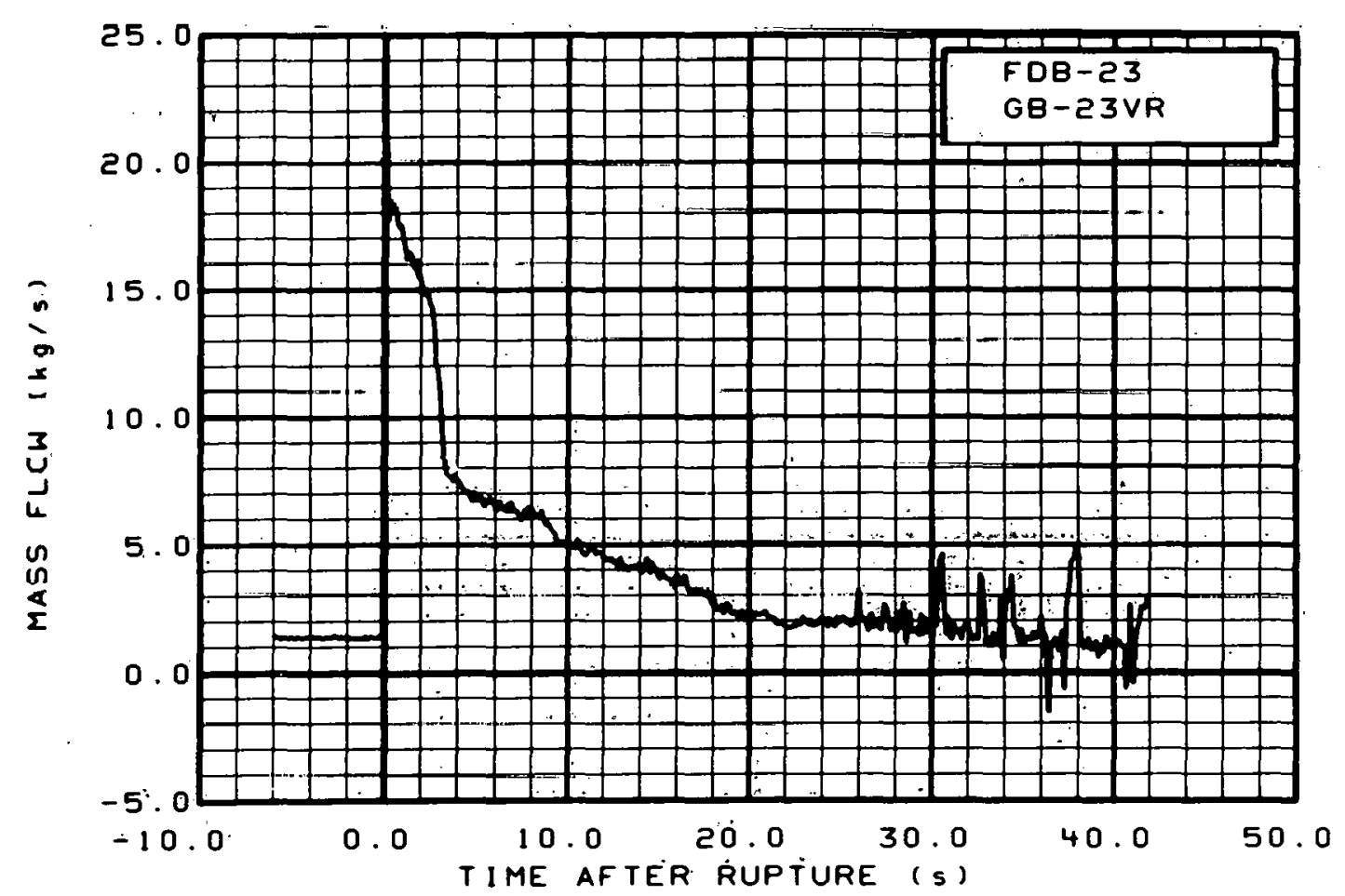

Fig. 324 Mass flow in broken loop (FDB-23, GB-23VR), from -6 to $42 \mathrm{~s}$. 


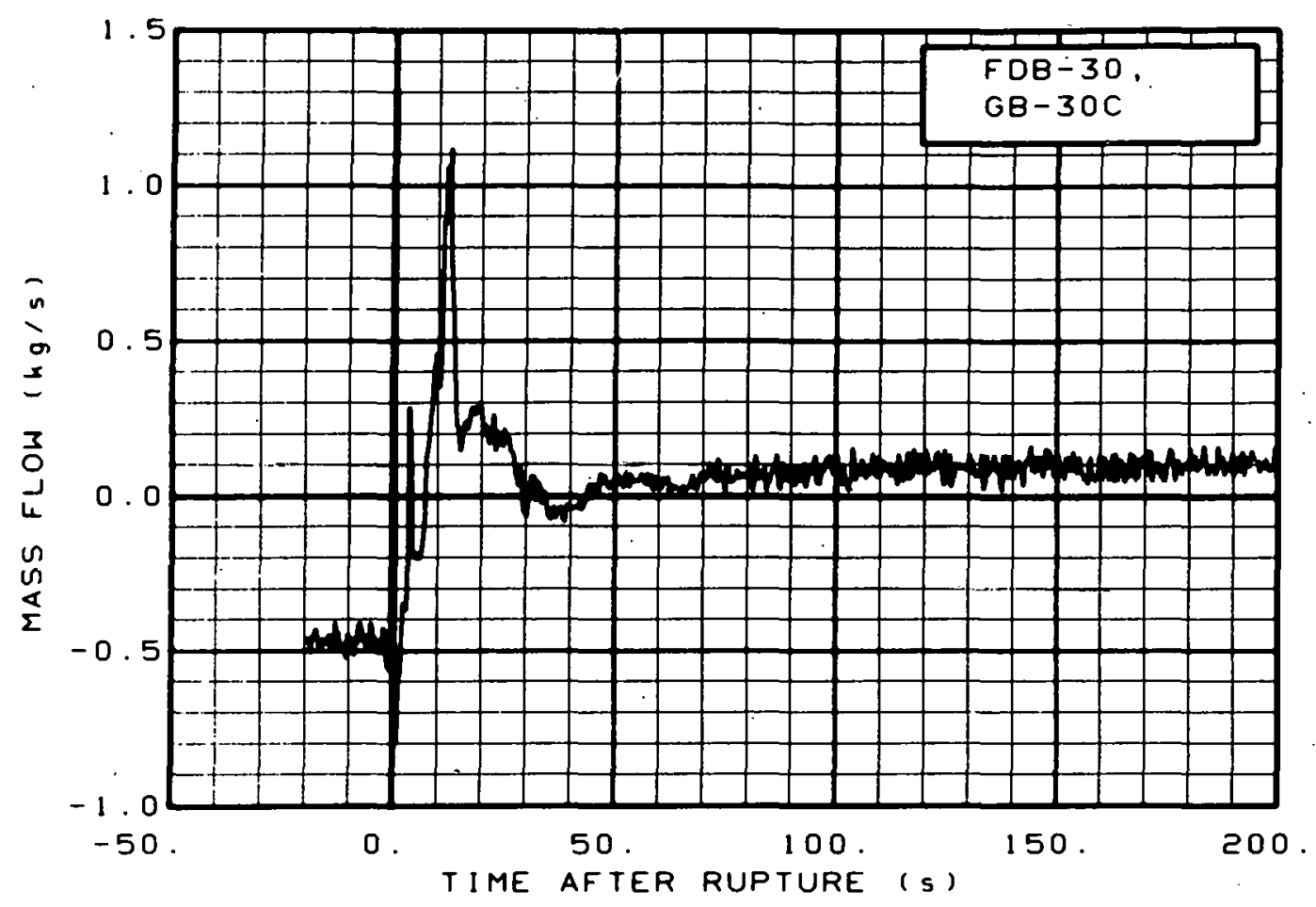

Fig. 325 Mass flow in broken loop (FDB-30, GB-30C), from -20 to $200 \mathrm{~s}$.

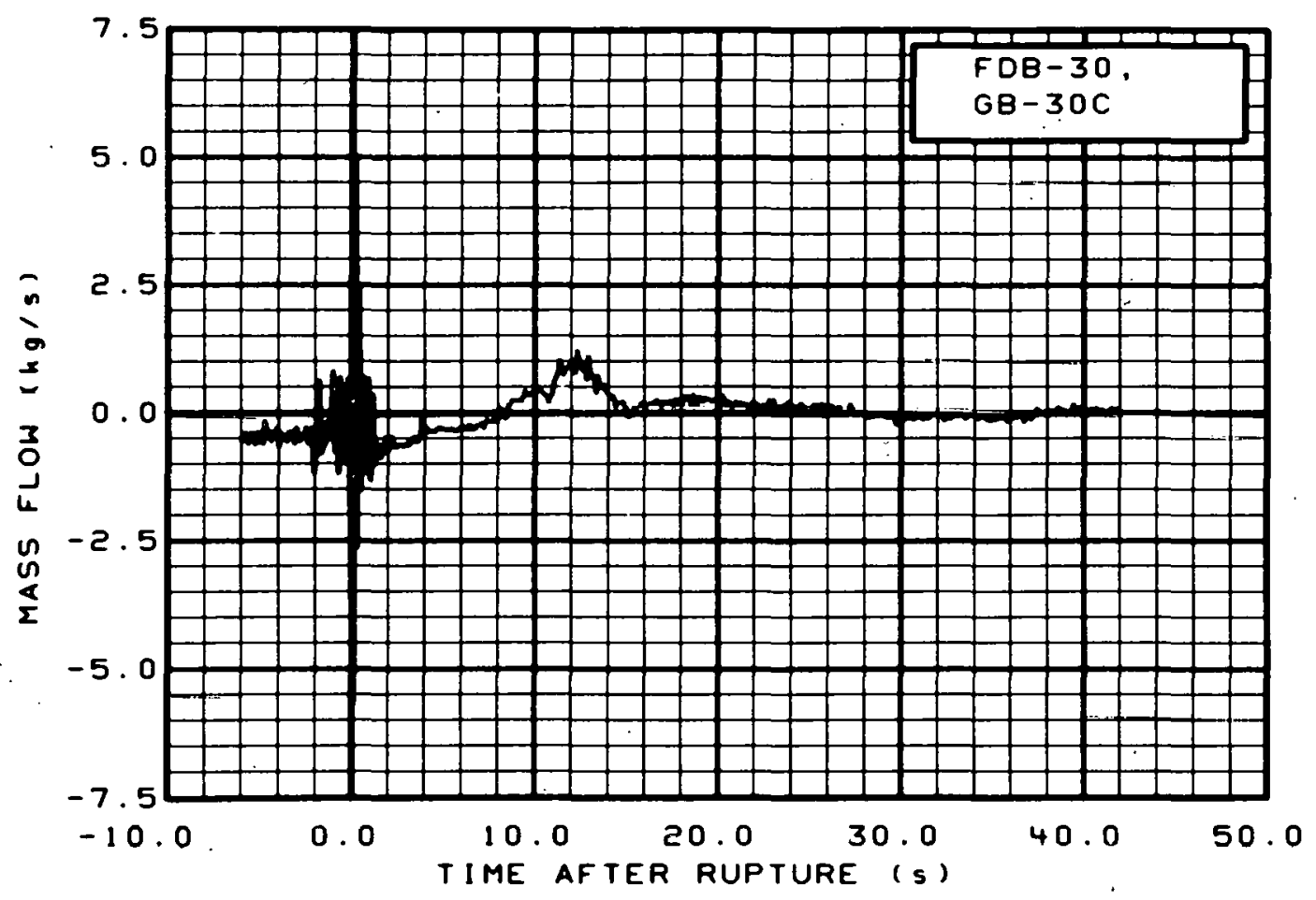

Fig. 326 Mass flow in broken loop (FDB-30, GB-30C), from -6 to $42 \mathrm{~s}$. 


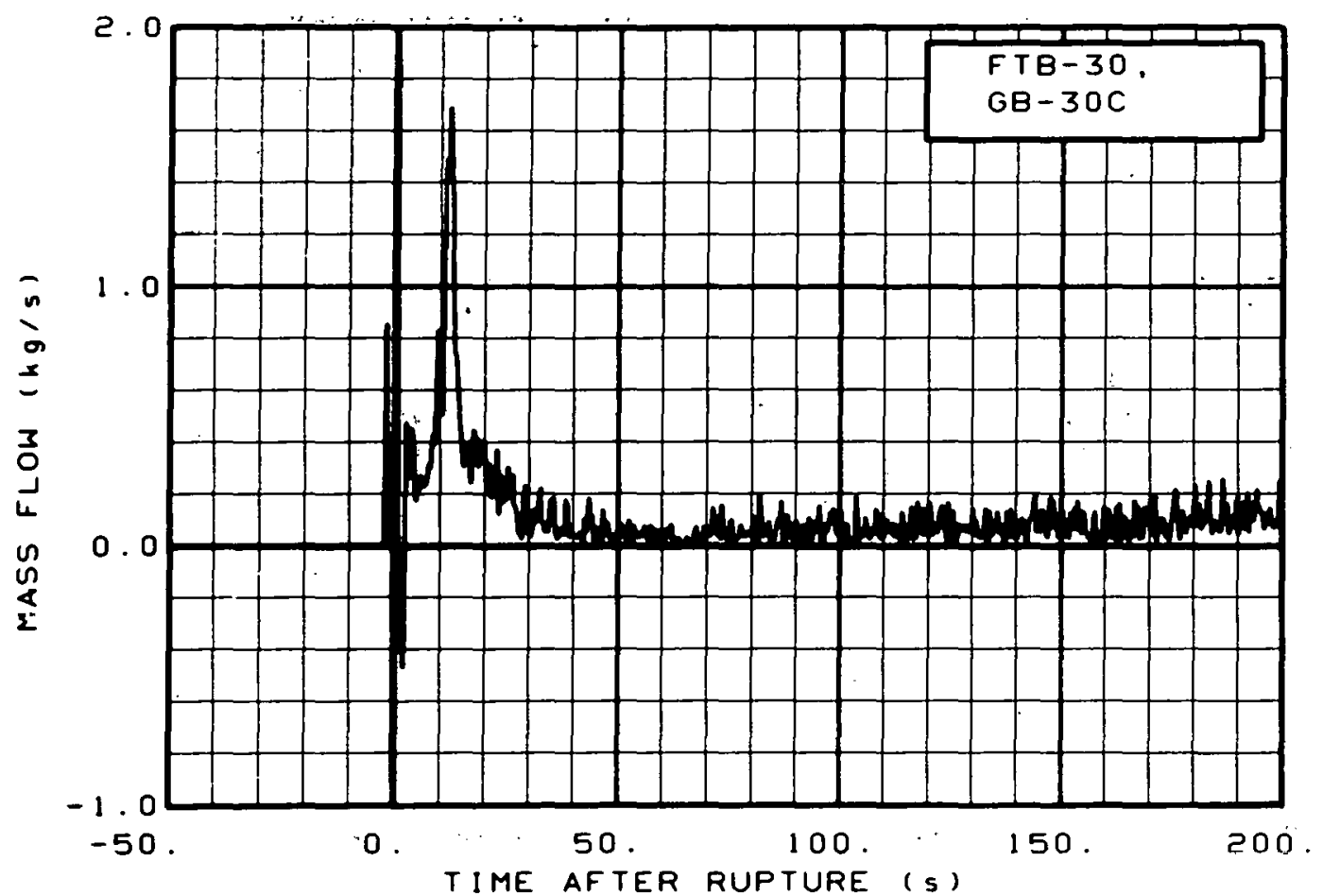

Fig. 327 Mass flow in broken loop (FTB-30, GB-30C), from -20 to $200 \mathrm{~s}$.

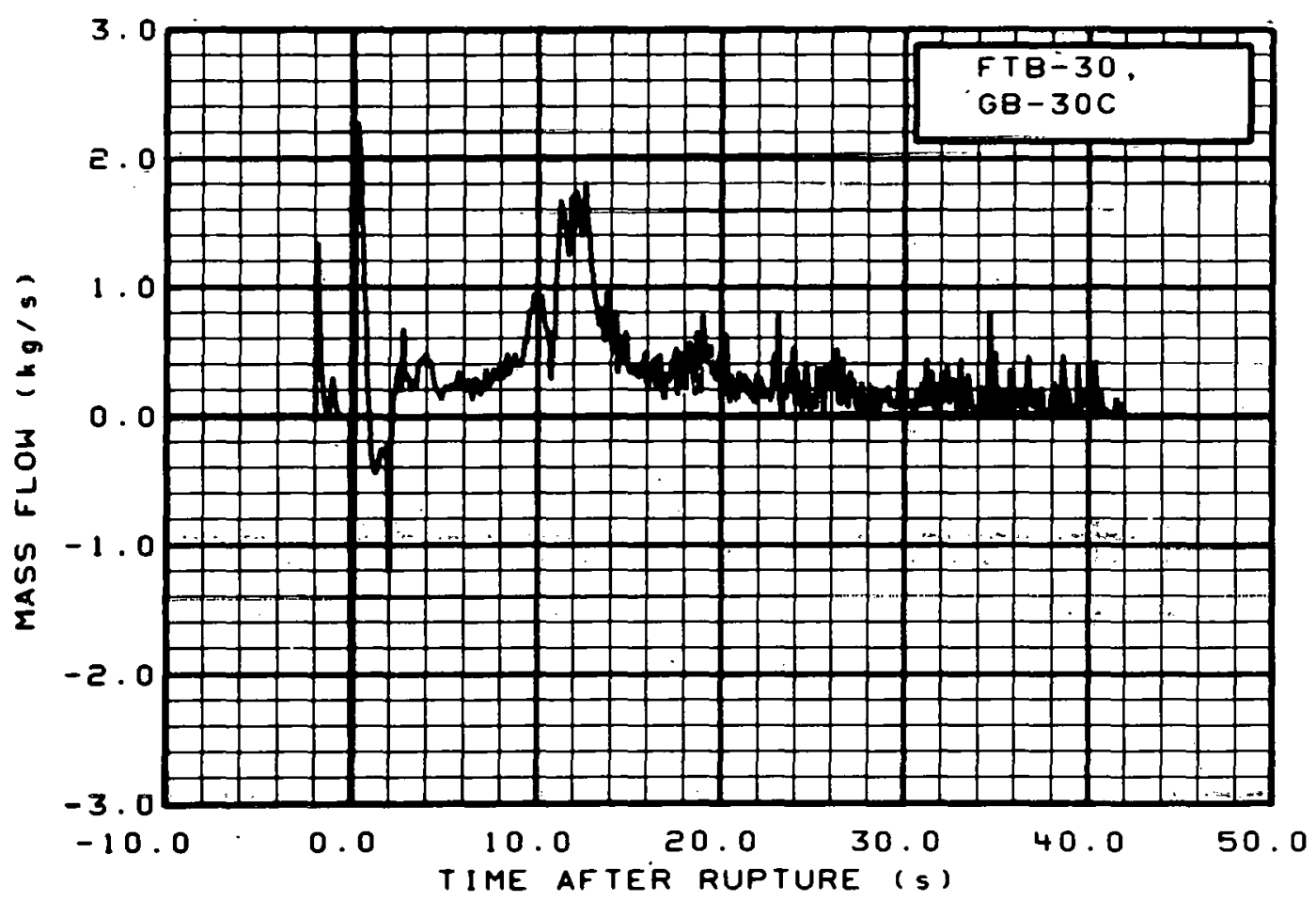

Fig. 328 Mass flow in broken loop (FTB-30, GB-30C), from -6 to $42 \mathrm{~s}$. 


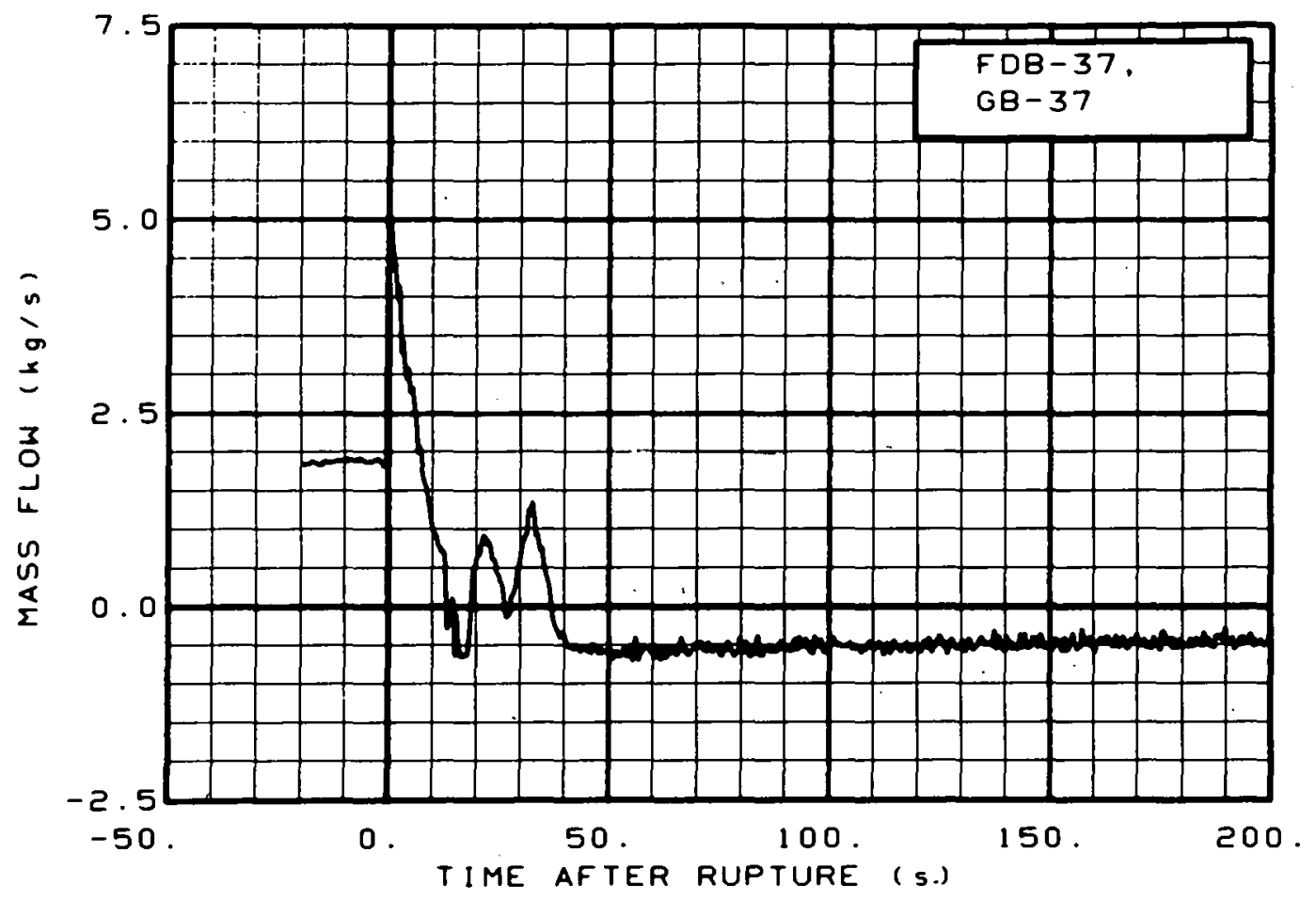

Fig. 329 Mass flow in broken loop (FDB-37, GB-37), from -20 to $200 \mathrm{~s}$.

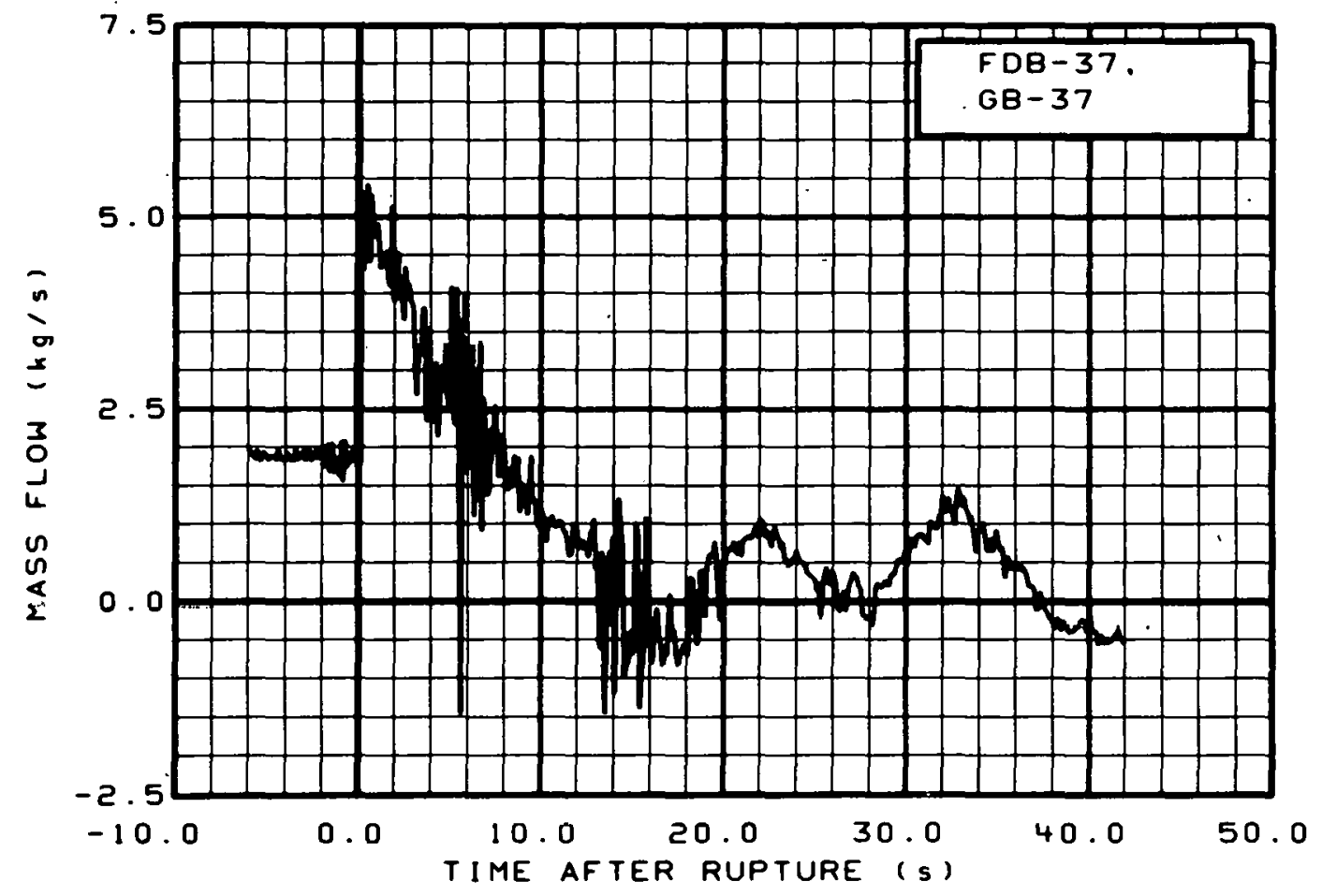

Fig. 330 Mass flow in broken loop (FDB-37, GB-37), from -6 to $42 \mathrm{~s}$. 


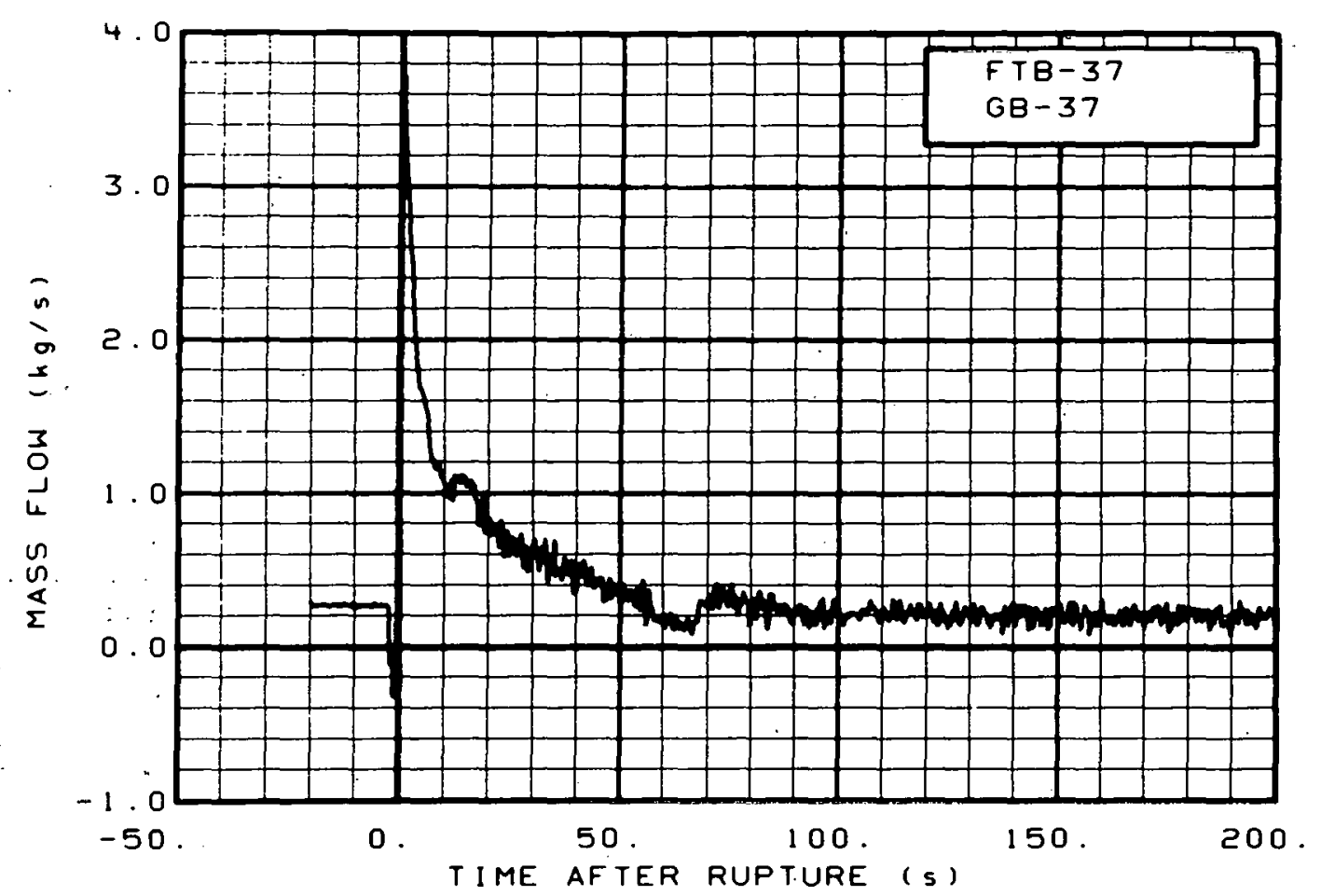

Fig. 331 Mass flow in broken loop (FTB-37, GB-37), from -20 to $200 \mathrm{~s}$.

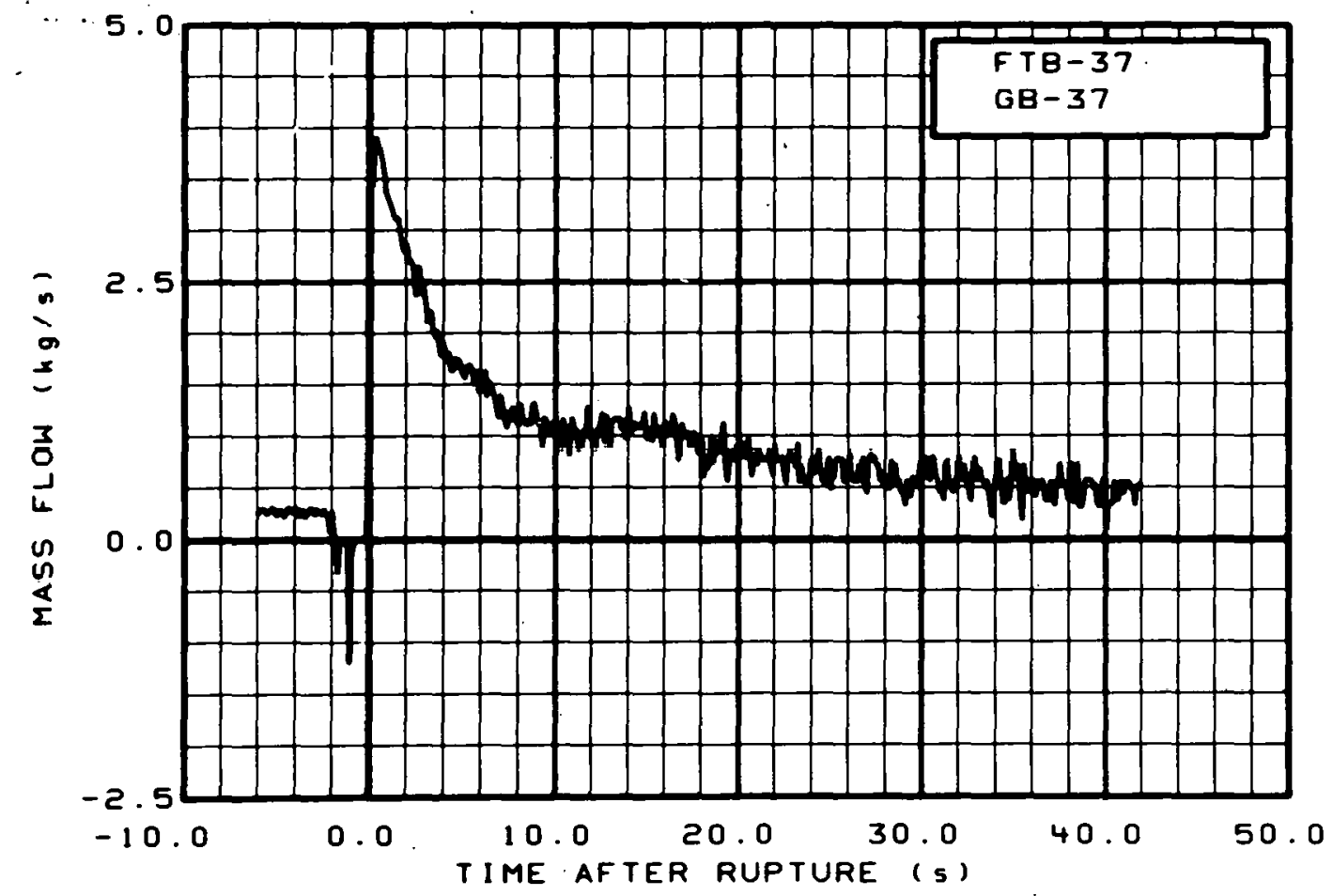

Fig. 332 Mass flow in broken loop (FTB-37, GB-37), from -6 to $42 \mathrm{~s}$. 


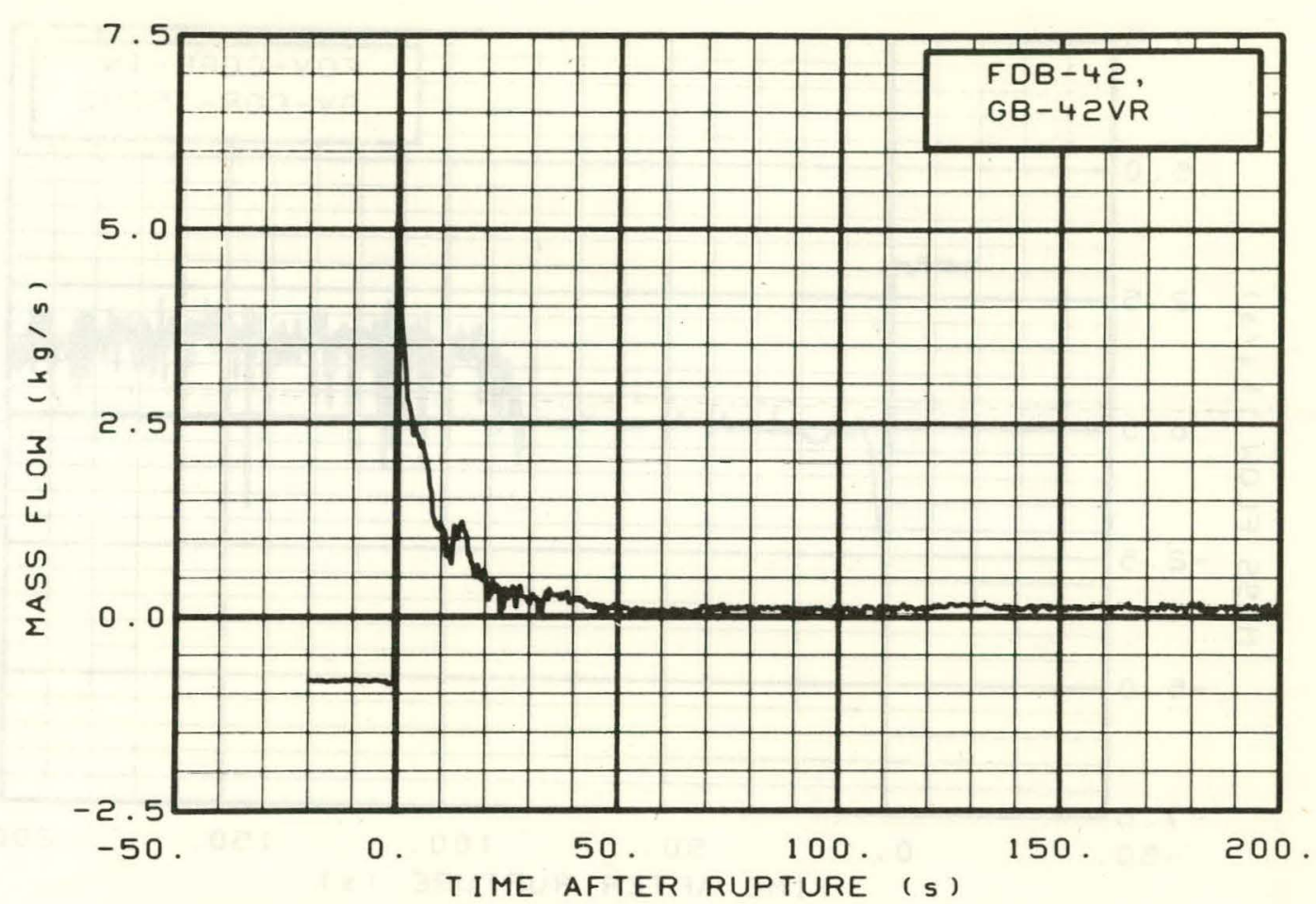

Fig. 333 Mass flow in broken loop (FDB-42, GB-42VR), from -20 to $200 \mathrm{~s}$.

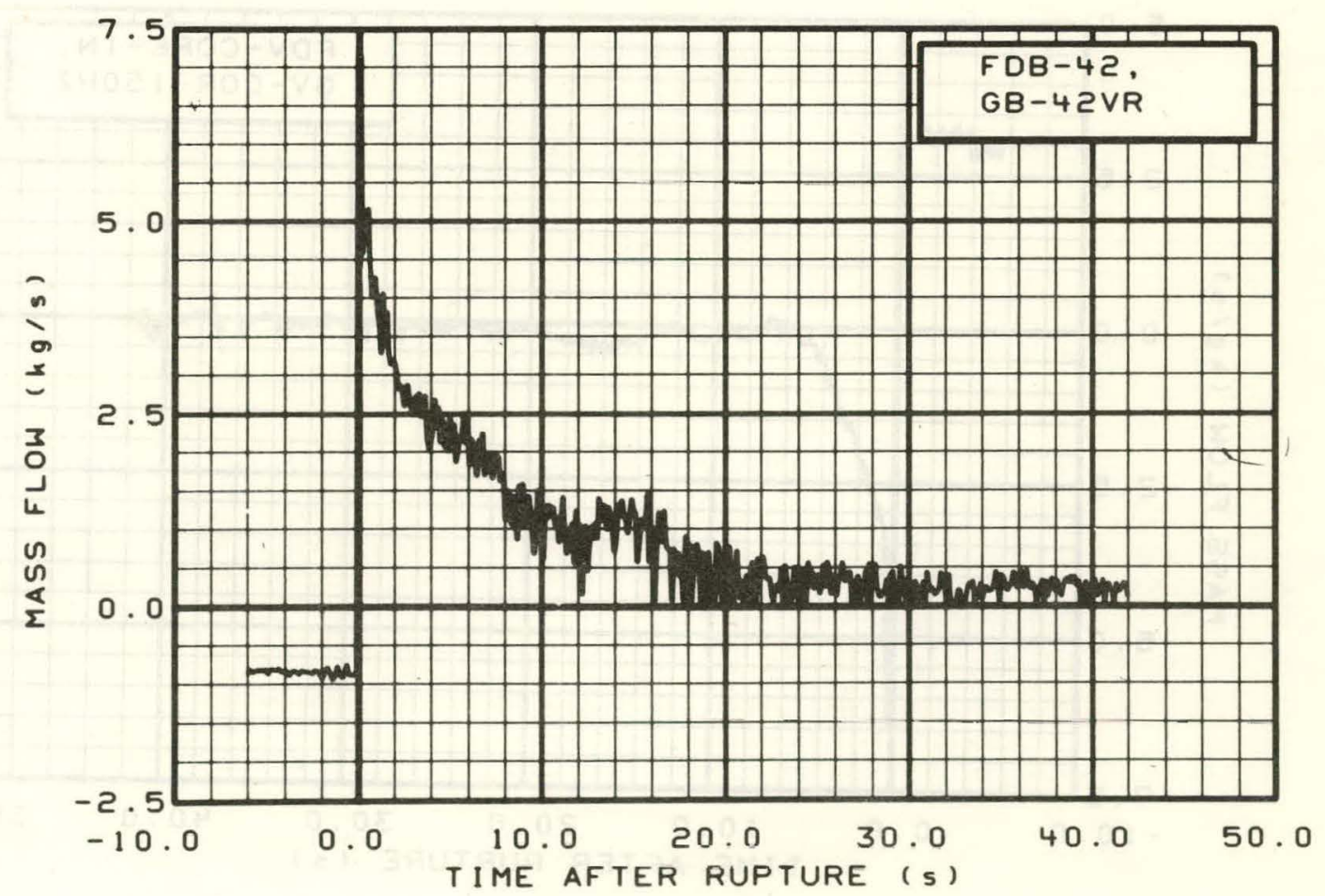

Fig. 334 Mass flow in broken loop (FDB-42, GB-42VR), from -6 to $42 \mathrm{~s}$. 


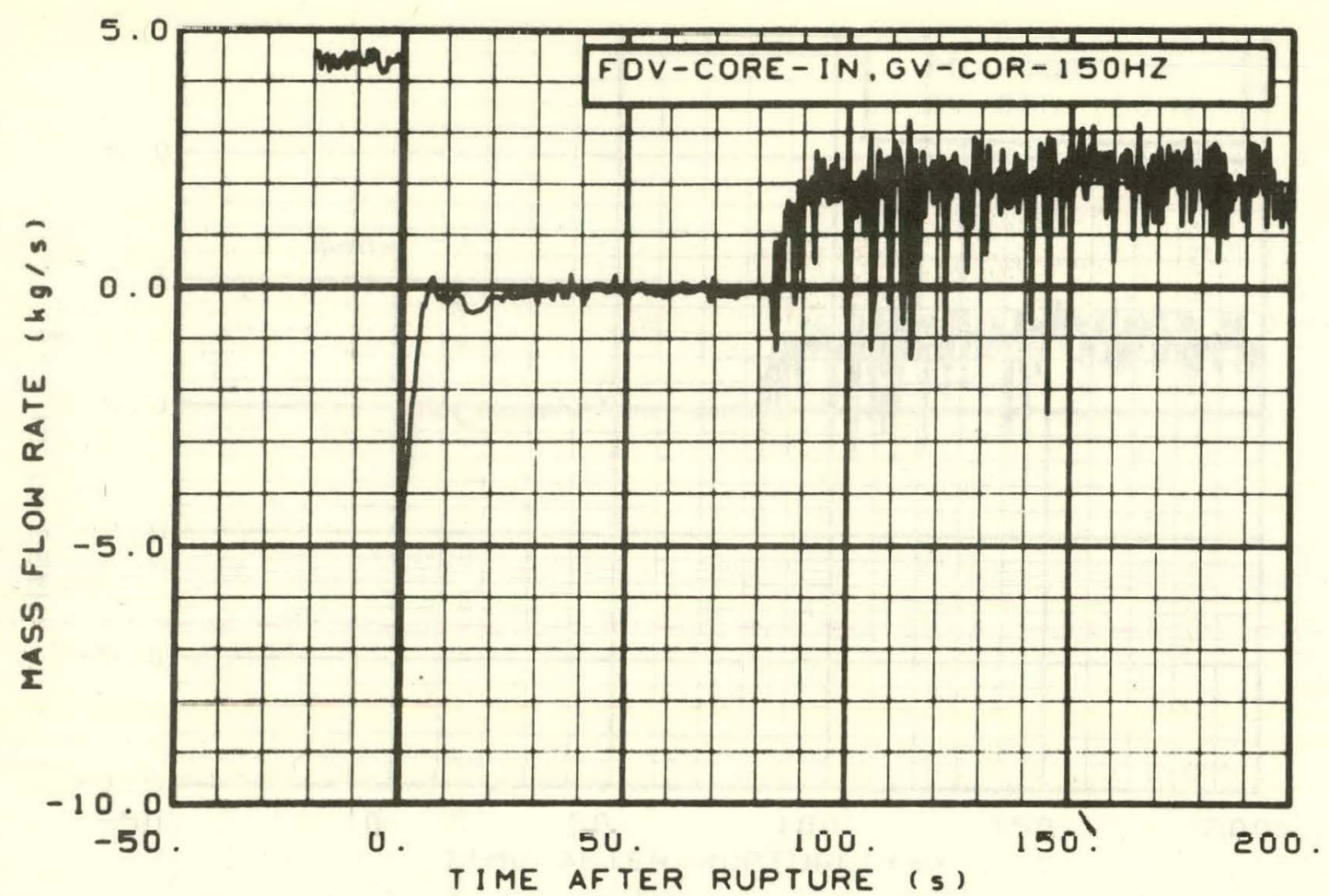

Fig. 335 Mass flow in vessel (FDV-CORE-IN, GV-COR-150HZ), from -20 to $200 \mathrm{~s}$.

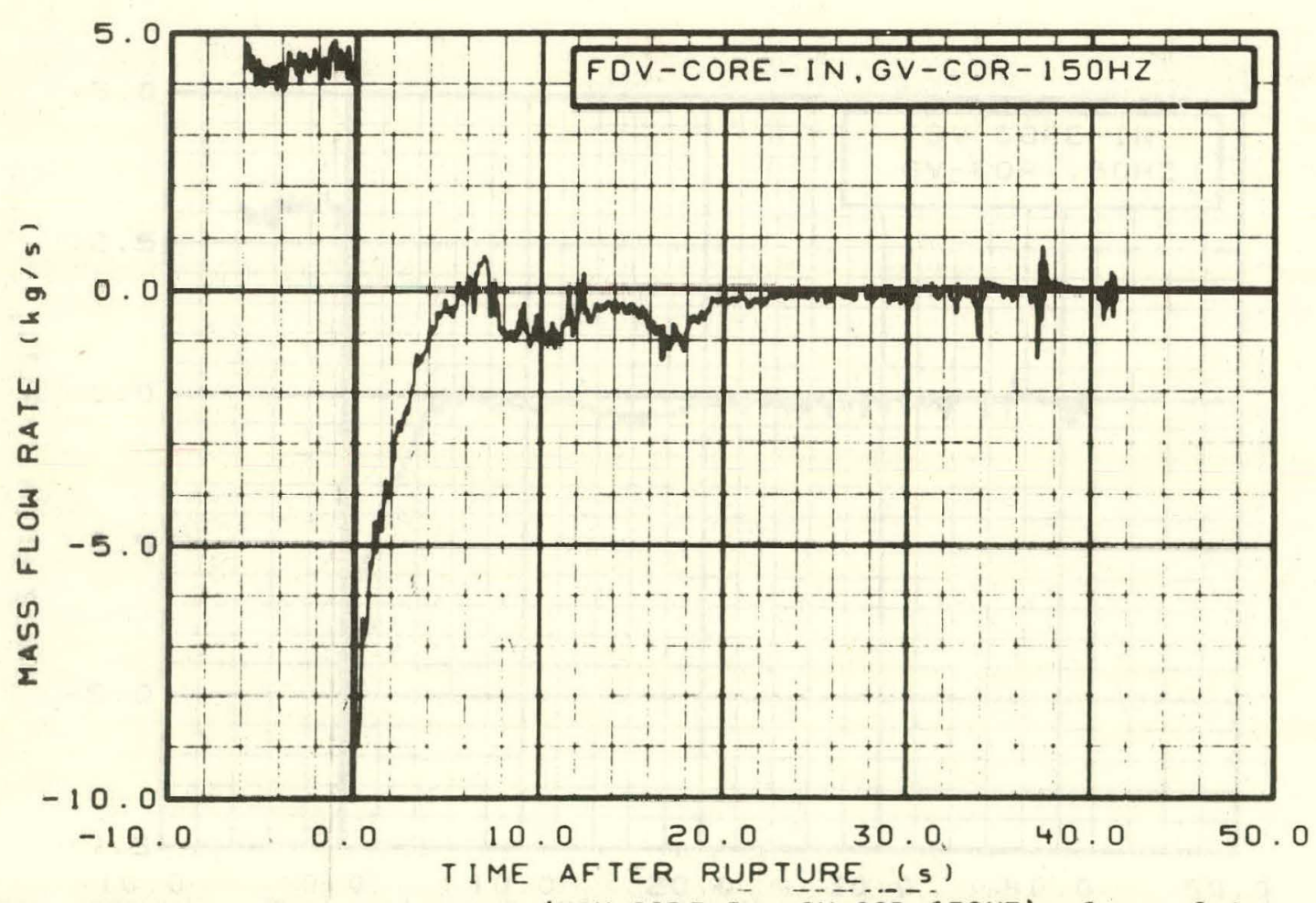

Fig. 302 Mass flow in vessel (FDV-CORE-IN, GV-COR-150HZ), from -6 to $42 \mathrm{~s}$. 


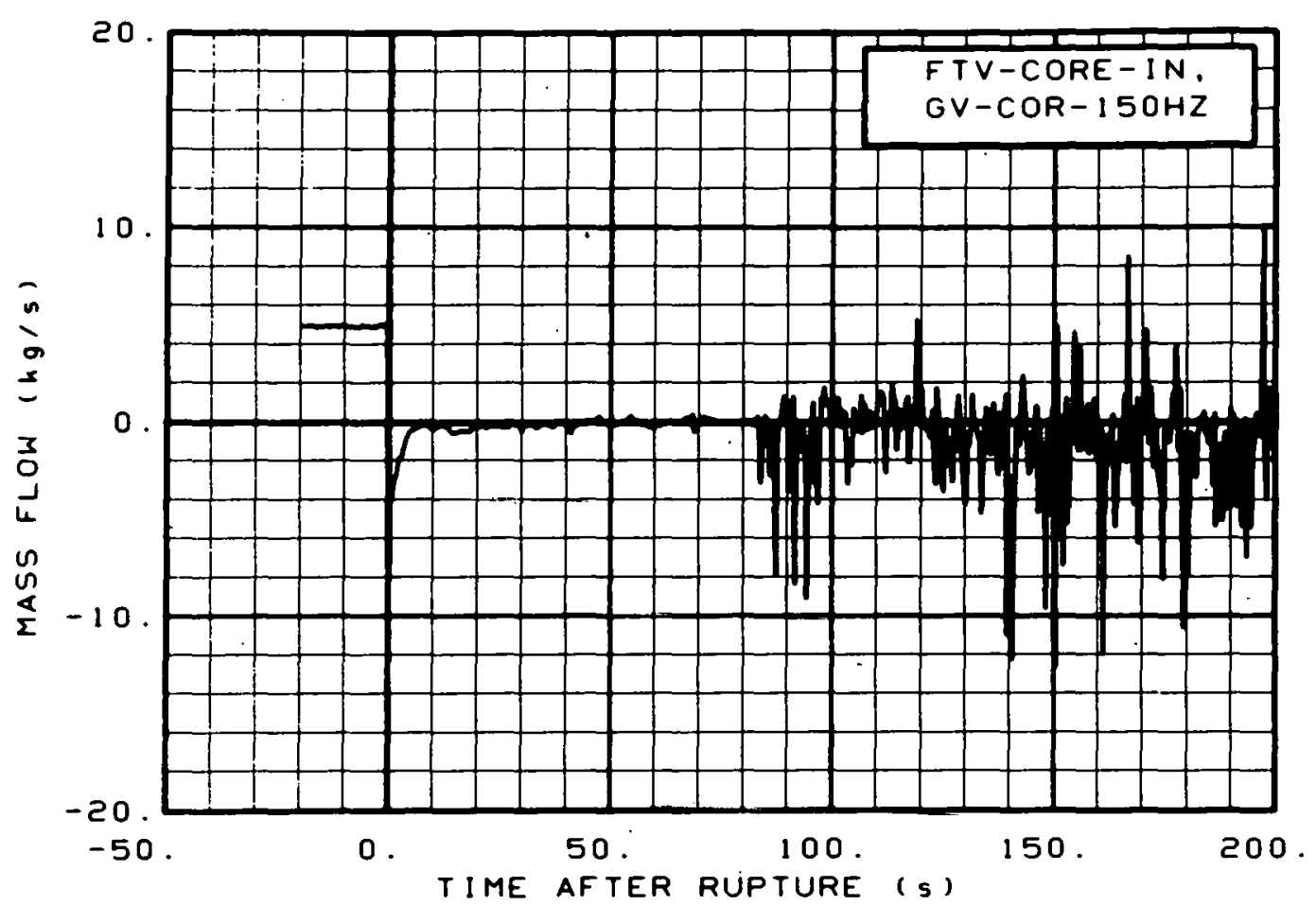

Fig. 337 Mass flow in vessel (FTV-CORE-IN, GV-COR-150HZ), from -20 to $200 \mathrm{~s}$.

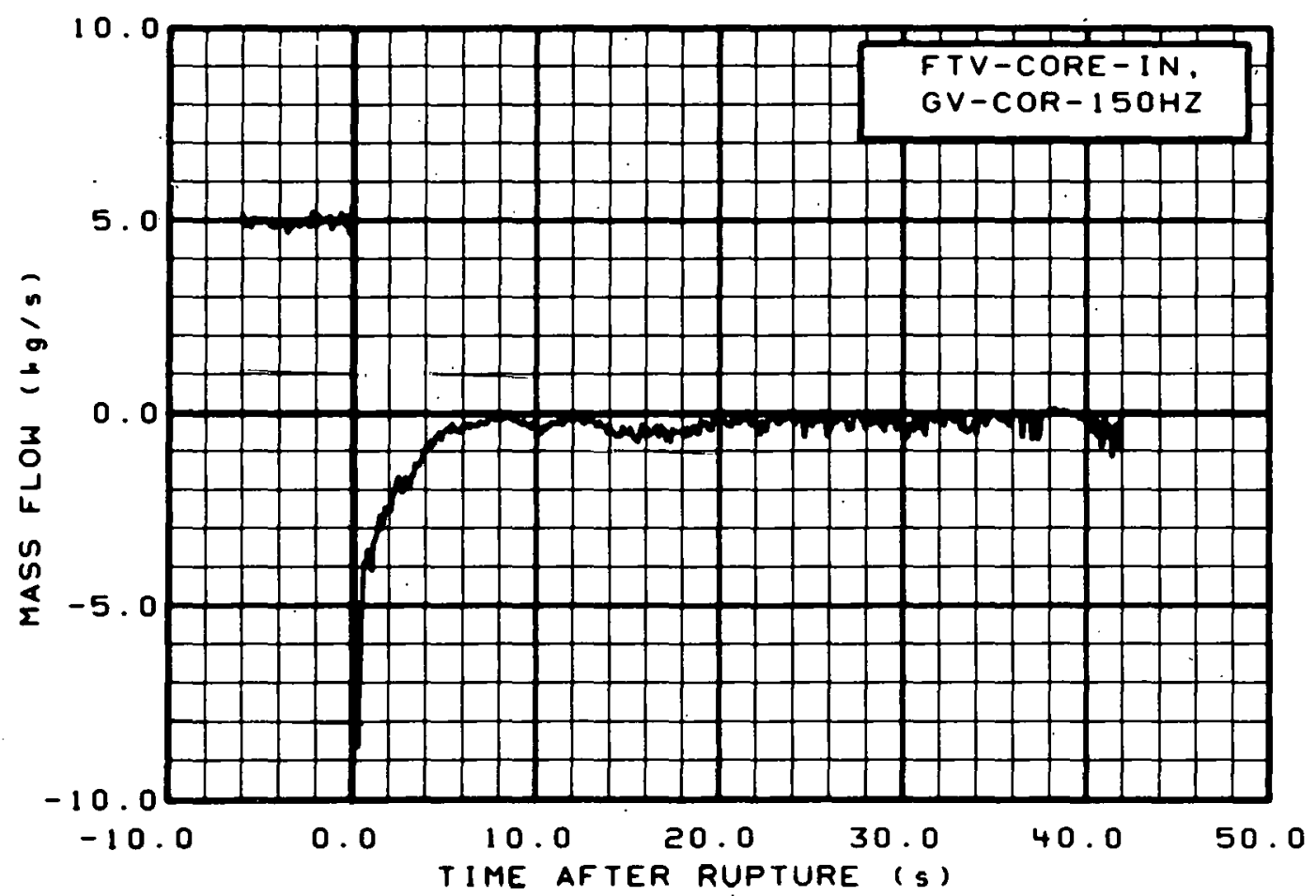

Fig. 338 Mass flow in vessel (FTV-CORE-IN, GV-COR-150HZ), from -6 to $42 \mathrm{~s}$. 


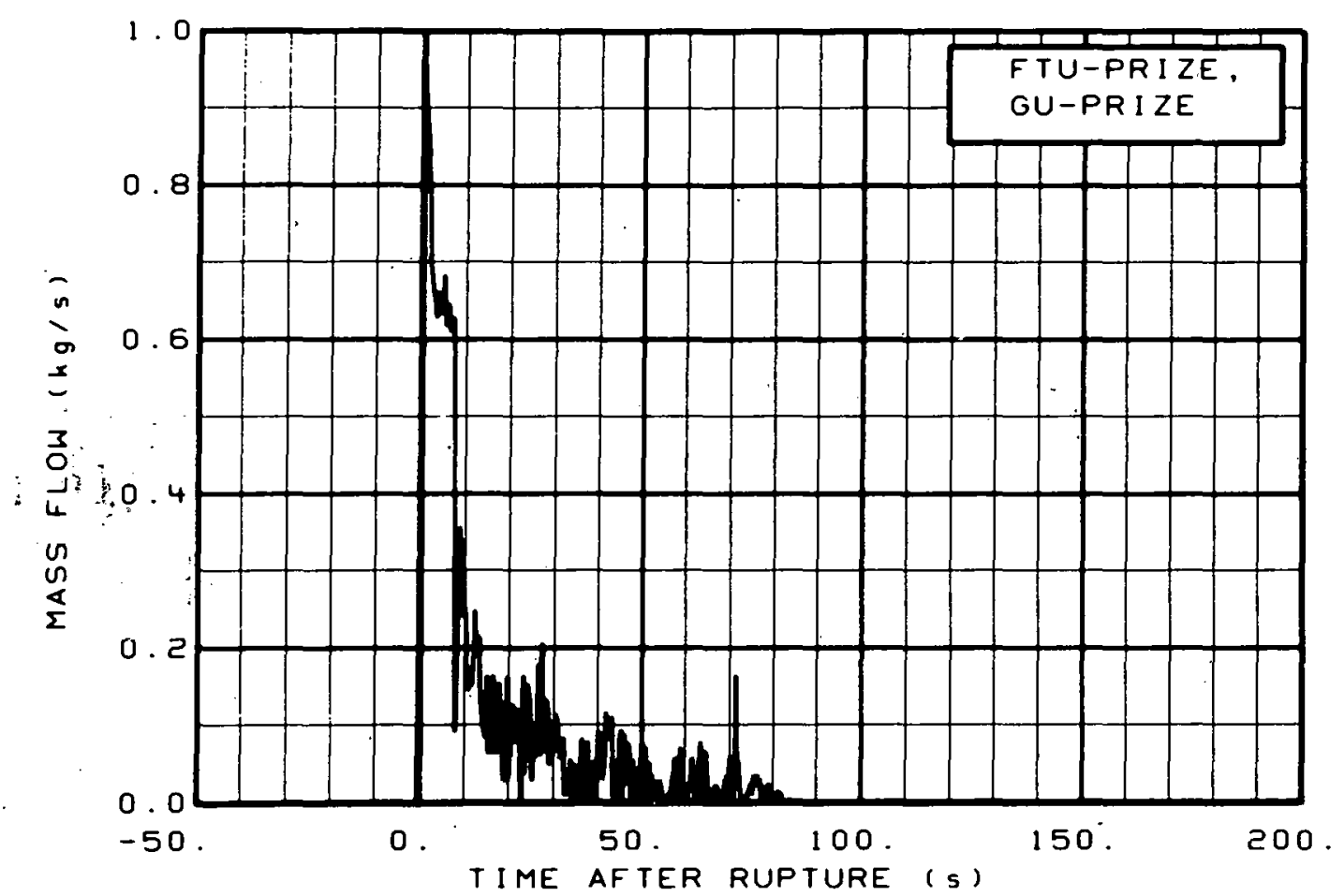

Fig. 339 Mass flow in pressurizer (FTU-PRIZE, GU-PRIZE), from -20 to $200 \mathrm{~s}$.

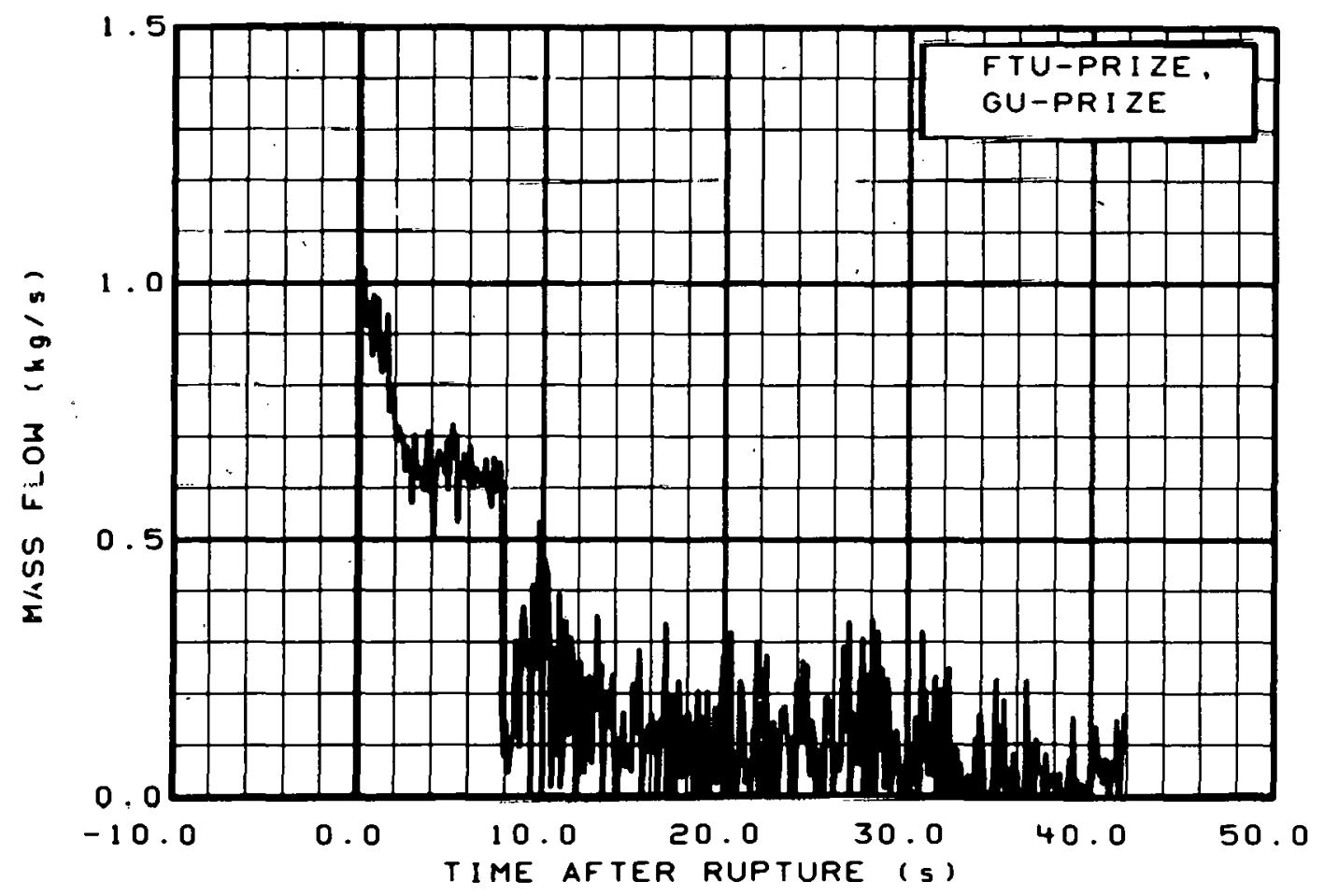

Fig. 340 Mass flow in pressurizer (FTU-PRIZE, GU-PRIZE), from -6 to $42 \mathrm{~s}$. 


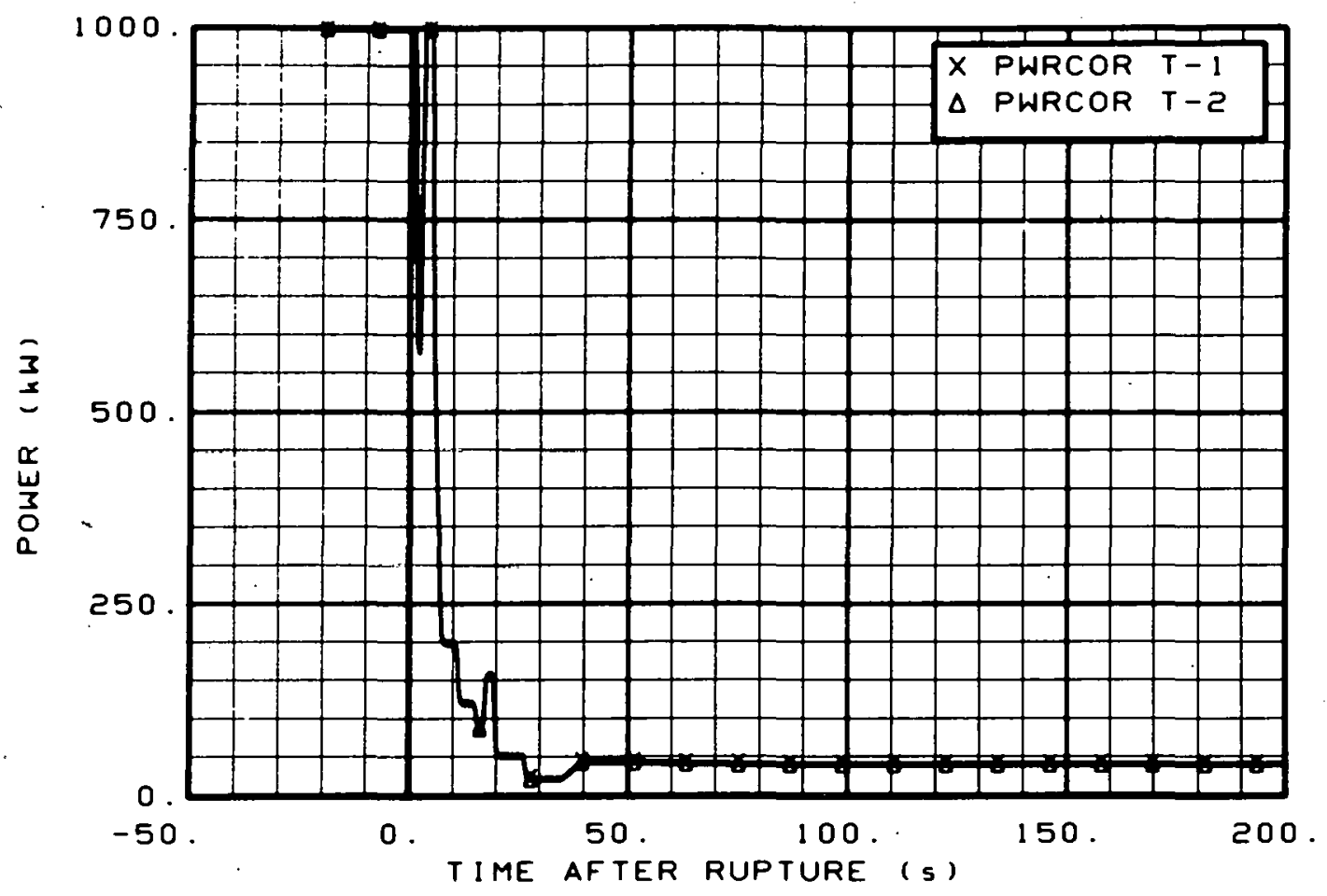

Fig. 341 Core heater rod total power (PWRCOR T-1 and PWRCOR T-2), from -20 to $200 \mathrm{~s}$.

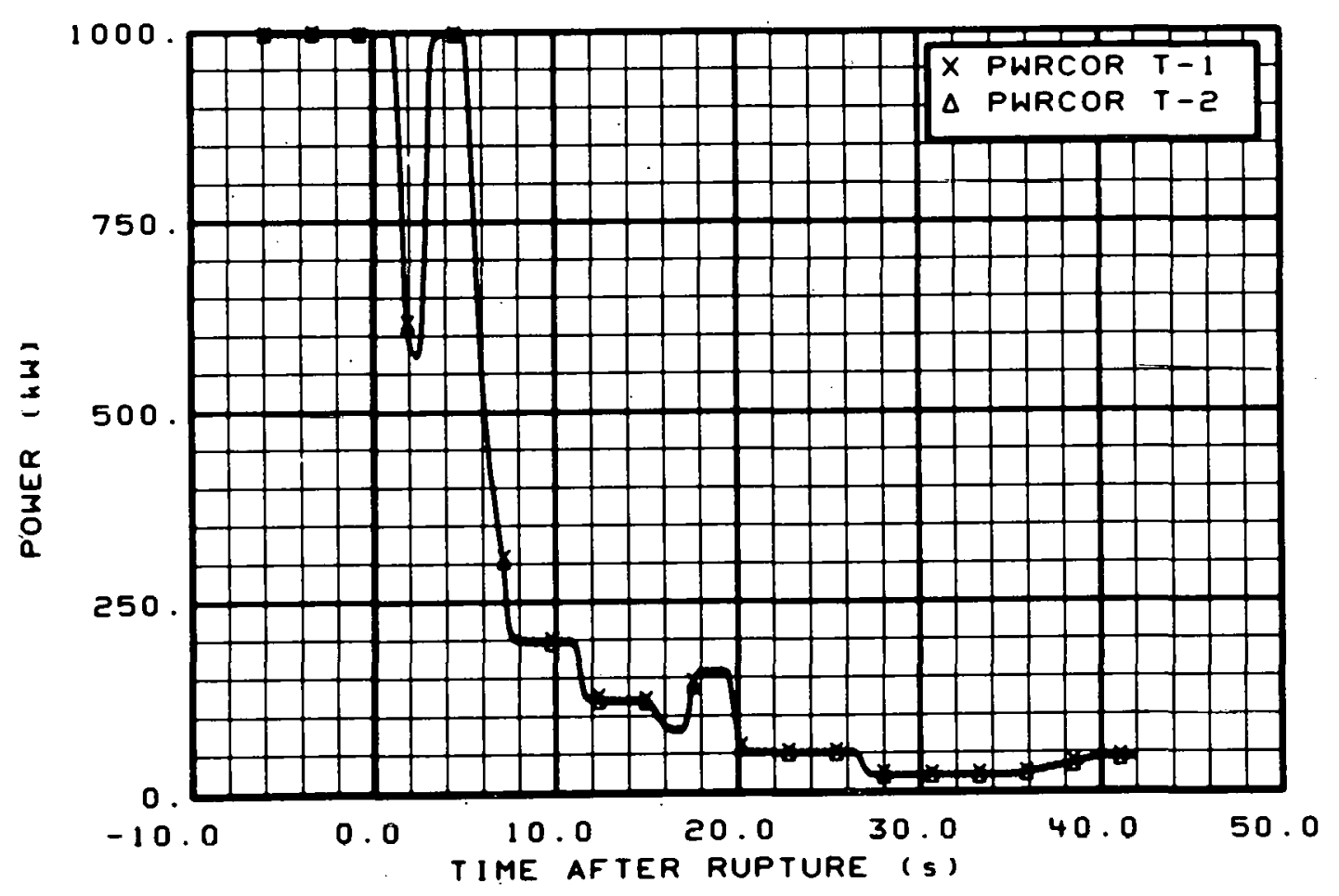

Fig. 342 Core heater rod total power (PWRCOR T-1 and PWRCOR T-2), from -6 to $42 \mathrm{~s}$. 


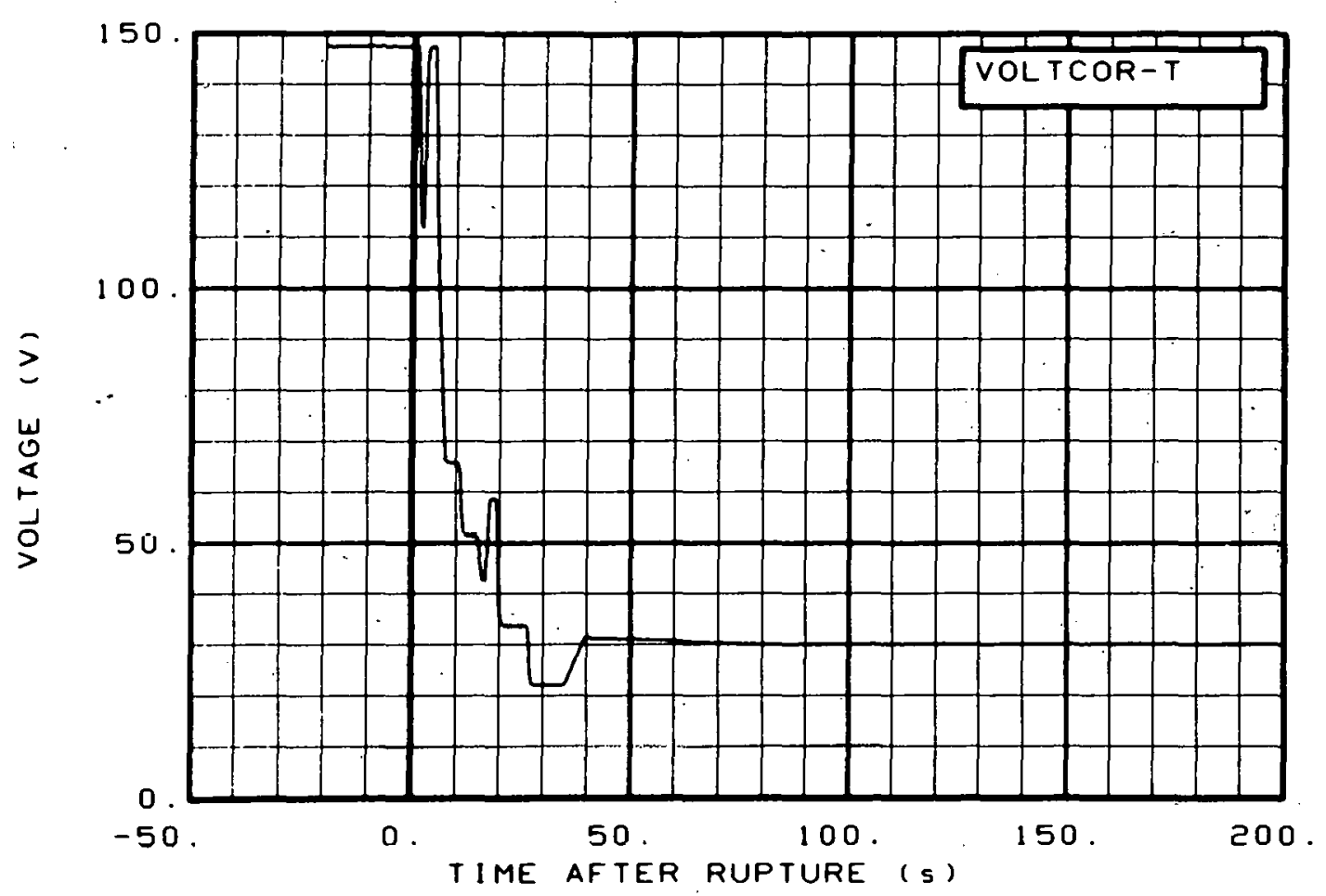

Fig. 343 Core heater voltage (VOLTCOR-T), from -20 to $200 \mathrm{~s}$.

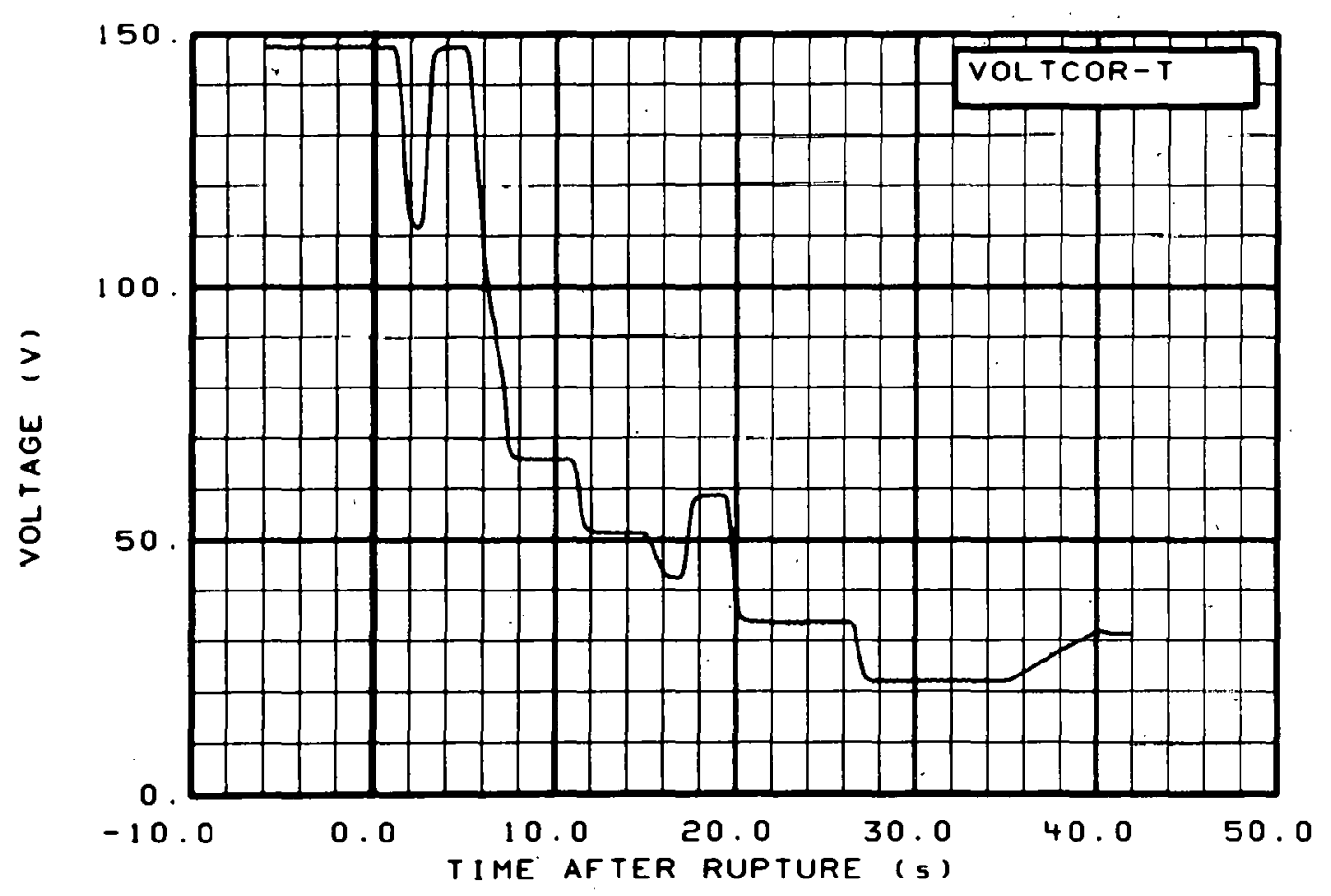

Fig. 344 Core heater voltage (VOLTCOR-T), from -6 to $42 \mathrm{~s}$. 


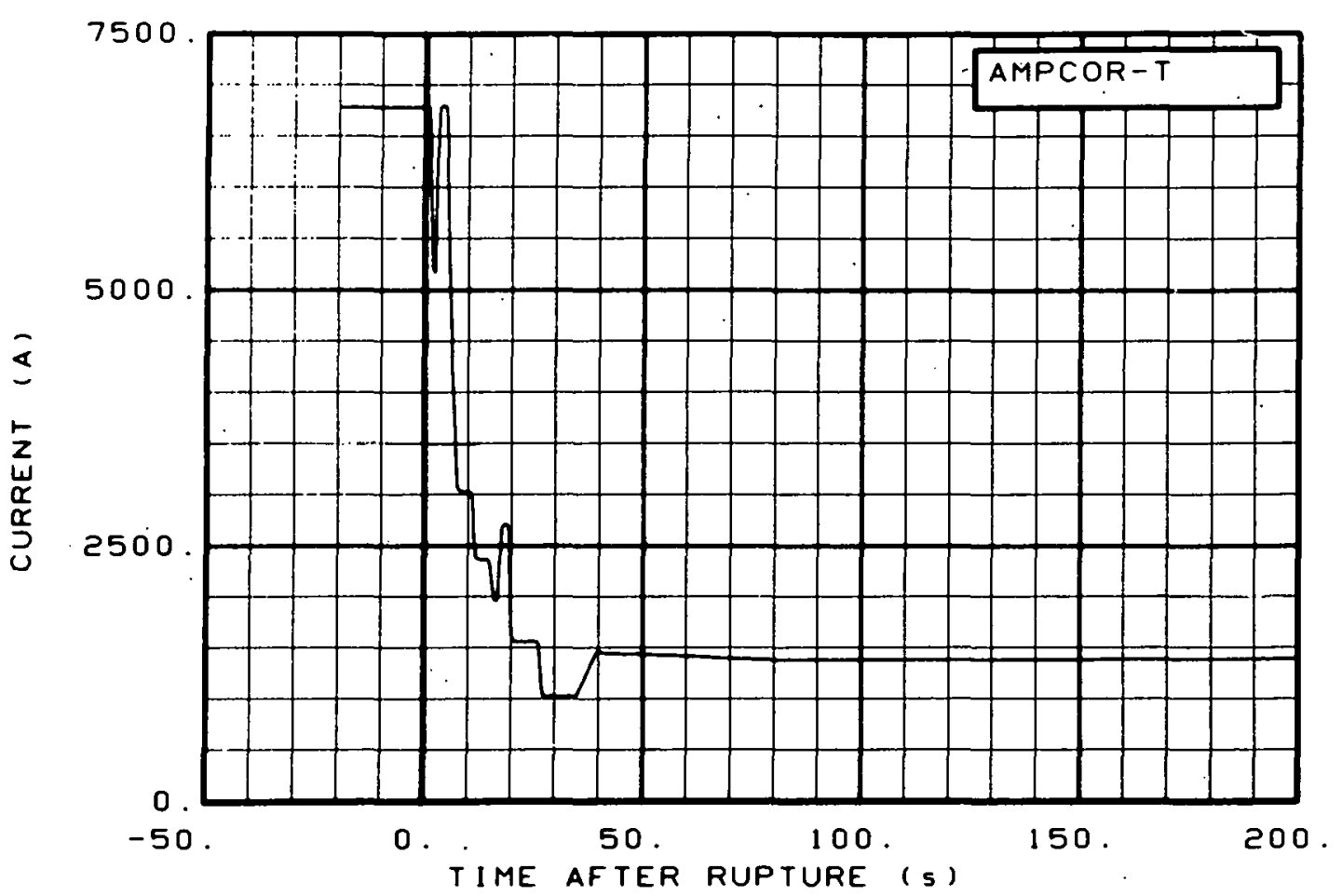

Fig. 345 Core heater total current (AMPCOR-T), from -20 to $200 \mathrm{~s}$.

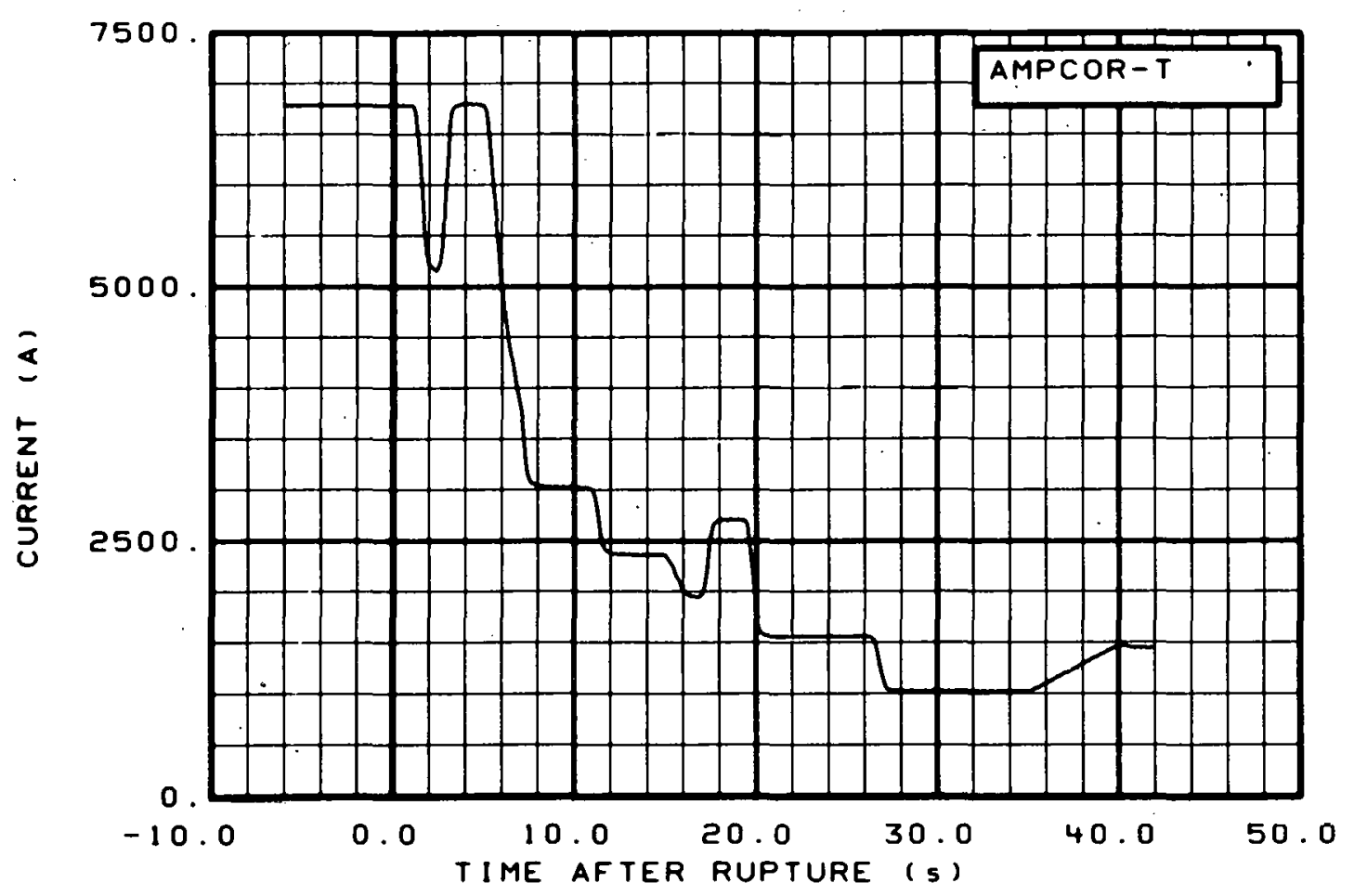

Fig. 346 Core heater total current (AMPCOR-T), from -6 to $42 \mathrm{~s}$. 


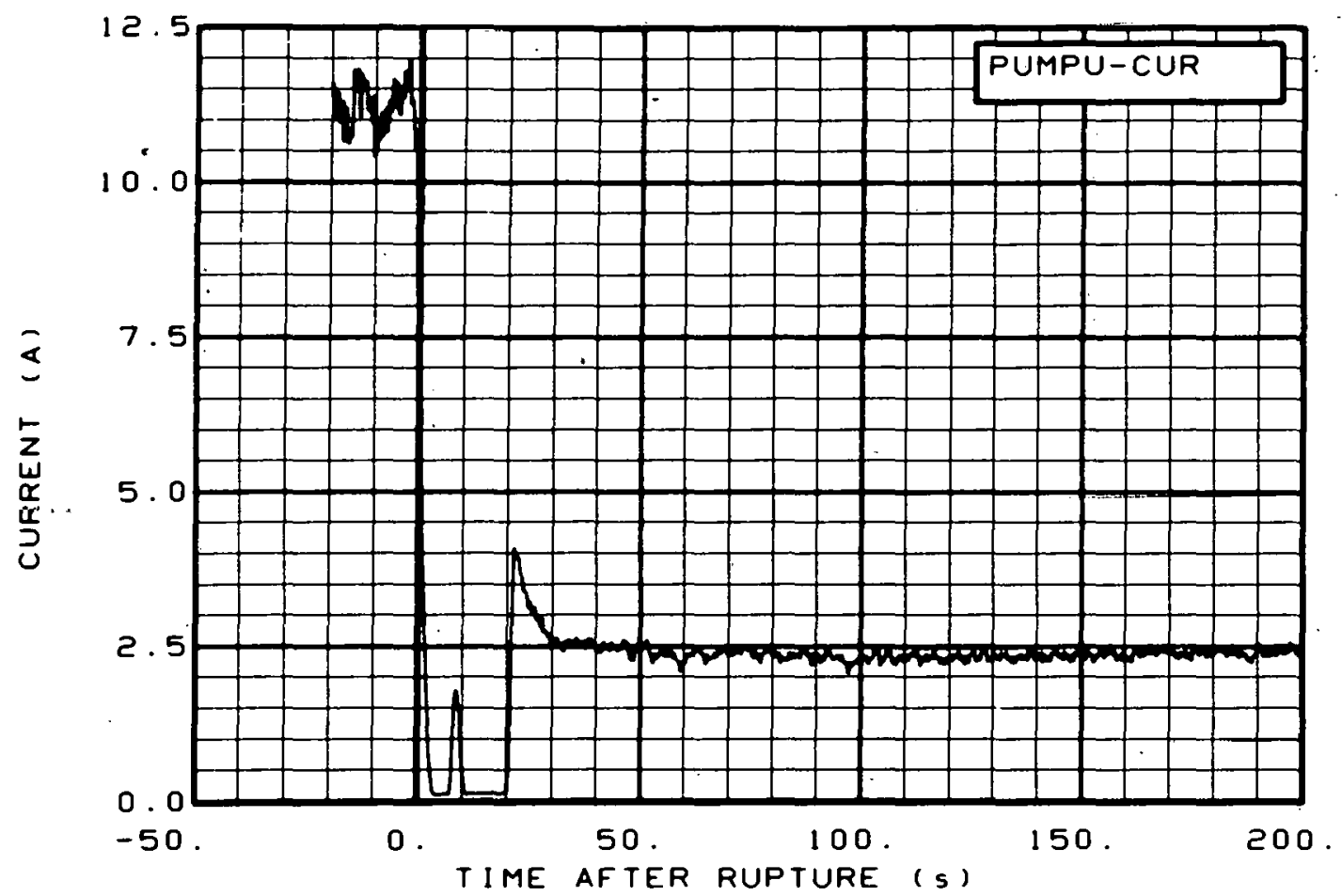

Fig. 347 Primary pump current (PUMPU-CUR), from -20 to $200 \mathrm{~s}$.

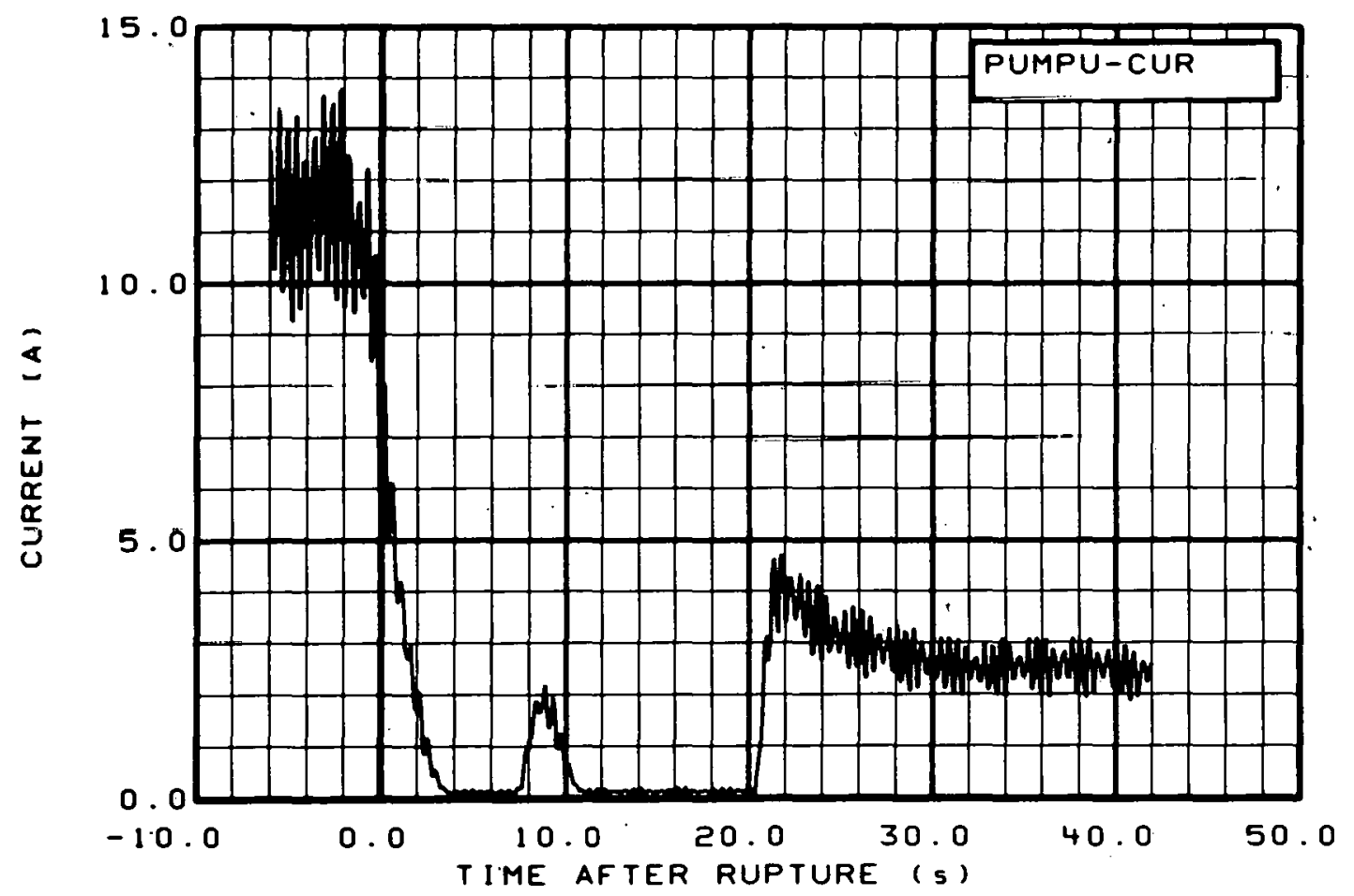

Fig. 348 Primary pump current (PUMPU-CUR), from -6 to $42 \mathrm{~s}$. 


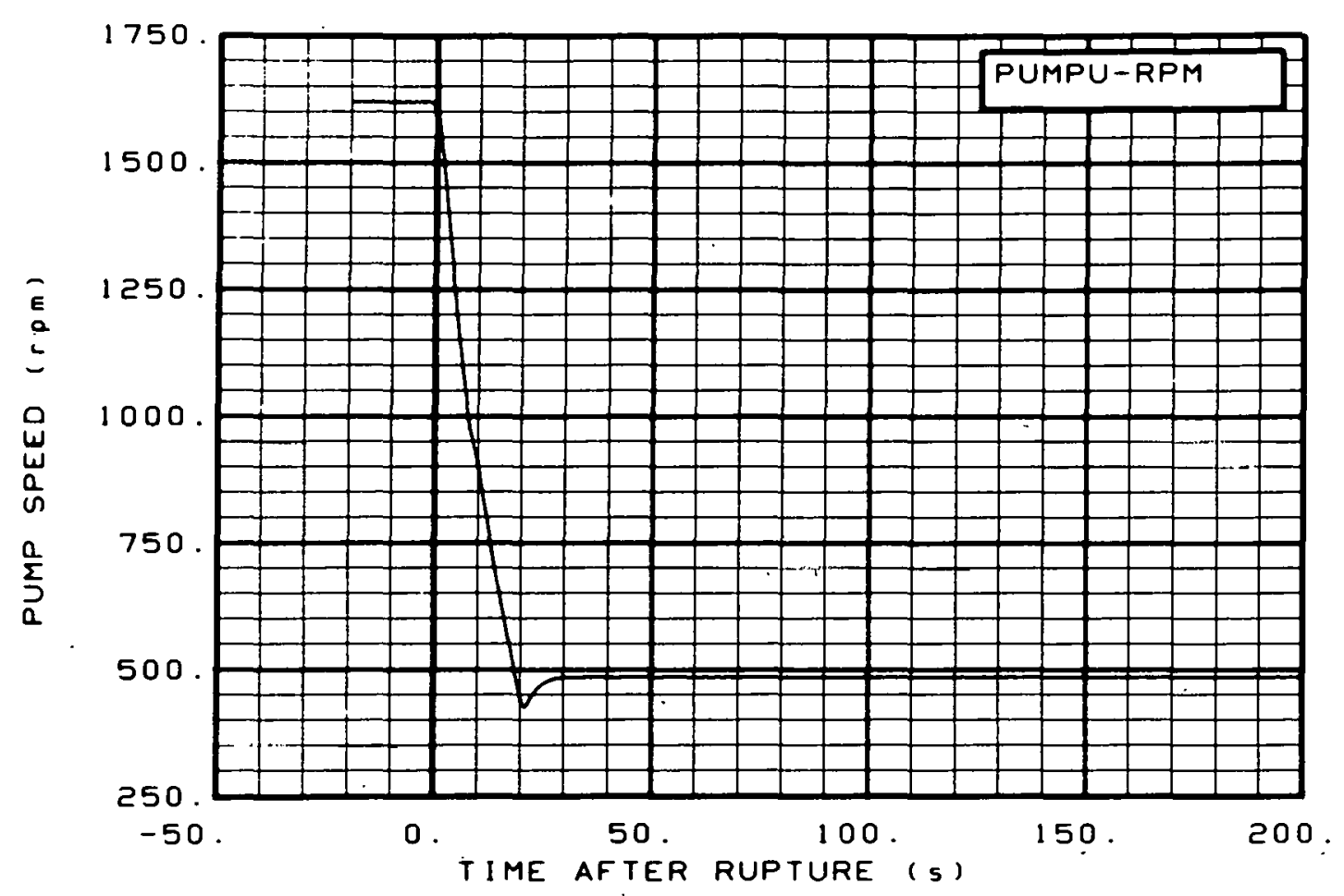

Fig. 349 Primary pump speed (PUMPU-RPM), from -20 to $200 \mathrm{~s}$.

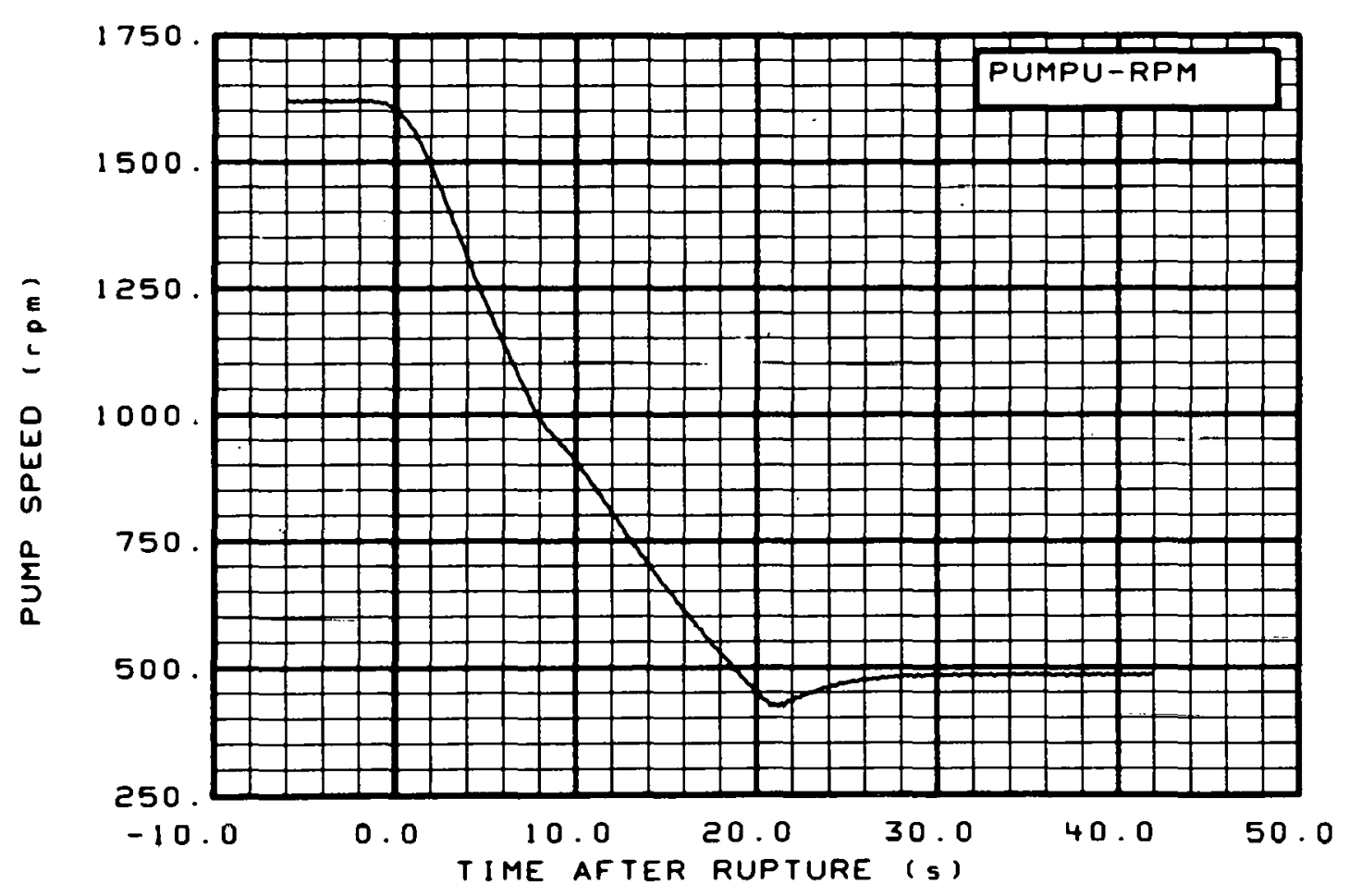

Fig. 350 Primary pump speed (PUMPU-RPM), from -6 to $42 \mathrm{~s}$. 


\section{REFERENCES}

1. E. M. Feldman and D: J. Olson, Semiscale Mod-1 Program and System Description for the Blowdown Heat Transfer Tests (Test Series 2), ANCR-1230 (August 1975).

2. V. Esparza and K. E. Sackett, Experiment Data Report for Semiscale Mod-1 Test S-06-5 (LOFT Counterpart Test) TREE-NUREG-1 125 (June 1977.):

3. "Acceptance Criteria for Emergency Core Cooling System for Light-Water-Cooled Nuclear Power Plants," 10 CFR-50. Federal Register, 39, 3 (Tanuary 4, 1974). 
APPENDIX A

POSTTEST ADJUSTMENTS TO DATA FROM SEMISCALE MOD-1 TEST S-06-6 
THIS PAGE

WAS INTENTIONALLY

LEFT BLANK 


\section{APPENDIX A}

\section{POSTTEST ADJUSTMENTS TO DATA FROM SEMISCALE MOD-1 TEST S-06-6}

Many of the transducers used in the Semiscale Mod-1 system exhibit significant sensitivity to one or more spurious inputs. Strain gage bridge circuits used in pressure transducers, differential pressure transducers, and drag discs are sensitive to changes in ambient temperature. Differential pressure cells are also sensitive to changes in system pressure. Photomultiplier tubes used as gamma ray detectors in the density transducers are sensitive to temperature changes, as well as to random variations in the locations of the radiation sources. Core power measurements depend on a calibrated resistor, whose resistance changes in value as a function of time and power level as it heats up.

Although the errors introduced into the data by spurious secondary inputs generally do not exceed the specified error ranges of the transducers, significant improvement in measurement accuracy can be achieved if the secondary sensitivity can be identified and removed. In the case of the drag discs, corrections are absolutely necessary because the signal due to temperature fluctuations can exceed that due to flow by several hundred percent. Since the exact values of the spurious inputs to which different transducers might be sensitive cannot often by easily predicted and are sometimes inconvenient to measure, secondary effects have been accounted for by correcting the data after the test rather than by using elaborate real time programs in the data acquisition system computer. The methods and results of the posttest data correction analysis for Test S-06-6 are presented in the following paragraphs and tables.

\section{PRESSURE MEASUREMENTS}

Corrections to pressure transducer measurements in the main system loop are based on data taken from the standard reference (Heise) gauge at Spool 4, taken $15 \mathrm{~s}$ before initiation of blowdown and at $300 \mathrm{~s}$ after initiation of blowdown. The pressure readings are adjusted to account for pressure :variations around the main loop, using the readings of nearby differential pressure cells. A linear correction is then applied to the pressure data to match the data to the calculated reference data at the two specified time points.

Correction of the steam generator secondary pressure (PU-SGSD) measurement is done in the same manner as for the main loop pressures using Heise gauges installed expressly for this purpose.

Pressure measurement corrections are performed using the data acquisition system (DAS) computer using the following equation:

$$
F^{\prime}(t)-C_{0}+C_{1}[F(t)]
$$


where

$$
\begin{aligned}
F^{\prime}(t) & =\text { corrected data } \\
F(t) & =\text { raw data } \\
C_{0} & =\text { offset } \\
C_{1} & =\text { scaling factor. }
\end{aligned}
$$

The values of the offset and scaling factor are given in Table A-I.

\section{TABLE A-I}

CONSTANTS FOR PRESSURE MEASUREMENT

CORRECTIONS (TESTT S-06-6)

\begin{tabular}{cccc}
$\begin{array}{c}\text { Detector } \\
\text { Identification }\end{array}$ & $C_{0}$ & $C_{1}$ & $\cdots$ \\
\hline PU-SGSD & -12.9 & 1.0294 & \\
PB-CN1 & -27.5 & 1.0155 \\
PB-42 & 2.0 & 1.0146 \\
PB-24 & -42.7 & 1.0133 \\
PV-LP-180 & 16.6 & 0.9907 \\
\hline
\end{tabular}

\section{DIFFERENTIAL PRESSURE MEASUREMENTS}

Pressure sensitivity in the differential pressure cells in the main system loop is determined from the pretest system pressure check. Digital data are recorded for all measurements at ambient temperature, with no system flow, at pressures of ambient, 1380 , $3450,6900,10350,13800$, and $15500 \mathrm{kPa}$. The output of differential pressure cells is plotted against system pressure, with the resulting plots used to describe the pressure response of the transducers.

The response of the differential pressure cells due to ambient temperature is determined from a digital data scan taken at $533 \mathrm{~K}$ and $12150 \mathrm{kPa}$ with no system flow. The measured transducer outputs are corrected for pressure and compared with the values calculated due :only to the density difference between the water inside the loop $(533 \mathrm{~K})$ and outside the loop in the sense lines ( 300 to $311 \mathrm{~K}$ ). 
The difference between the measured pressure corrected value and the calculated value is the thermal drift. After the data scan at $533 \mathrm{~K}$ is made, no more opportunities exist to obtain data with the pump stopped and the system full of liquid; therefore, for lack of later data, the thermal drift calculated from the $533 \mathrm{~K}$ data is assumed to be constant throughout the test.

For some differential pressure measurements, the data scan at $533 \mathrm{~K}$ cannot be used as a reference for thermal drift, so other references are used. For these detectors, and those having nonlinear pressure sensitivities, the corrections are performed according to the following equations:

$F^{\prime}(t)=K F(t)+c_{1}$ for $t<t_{1}$ or when no $t_{i}$ are listed for time points $t$, where $t_{1} \leqslant t \leqslant t_{n}$

$$
F^{\prime}(t)=K \cdot F(t)+c_{i}+\frac{t-t_{i}}{t_{i+1}-t_{i}}\left(c_{i+1}-c_{i}\right) \text { for } t_{i} \leq t \leq t_{i+1} \text { and, }
$$

where $i$ takes on values 1 and $n-1$

$$
F^{\prime}(t)=K F(t)+C_{n} \text { for } t>t_{n}
$$

where

$$
\begin{array}{ll}
\mathbf{t} & =\text { time } \\
\mathrm{F}^{\prime}(\mathrm{t}) & =\text { corrected data } \\
\mathrm{F}(\mathrm{t}) & =\text { raw data } \\
\mathrm{K} & =\text { scaling factor } \\
\mathrm{C}_{1} \text { and } \mathrm{t}_{\mathrm{i}} & =\text { corrections and time points. }
\end{array}
$$

The values of the constants are given in Table A-II. 


\begin{tabular}{|c|c|c|c|c|c|c|c|}
\hline $\begin{array}{l}\text { Detector } \\
\text { Identification }\end{array}$ & $\underline{K}$ & $\mathrm{C}_{1}$ & $t_{1}$ & $\mathrm{C}_{2}$ & $t_{2}$ & $\mathrm{C}_{3}$ & $t_{3}$ \\
\hline DPU-ACC-TB & 1 & -1.41 & 0 & & & & \\
\hline DPV-0-9G0 & 1 & 0.287 & 0 & 0.528 & 0.01 & 0.942 & 35.0 \\
\hline DPU-3-6 & 1 & -0.389 & 0 & -0.748 & 0.01 & -.7 .437 & 35.0 \\
\hline DPU-6-7 & 1 & 0.784 & .0 & 0.163 & 0.01 & -0.870 & 35.0 \\
\hline DPU-UP-3 & 1 & -1.999 & 0 & & 0.01 & & 35.0 \\
\hline DPU-PRSELL & 1 & 0.137 & 0 & $\therefore$ & 0.01 & 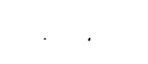 & 35.0 \\
\hline DPU-12-10 & 1 & -3.34 & 0 & -0.998 & $0: 01$ & 3.69 & 35.0 \\
\hline$D P V-26-550 M$ & 1 & 0.234 & 0 & 1.29 & 0.01 & 1.74 & 35.0 \\
\hline DPV-LP-UP & 1 & -0.496 & 0 & -1.116 & 0.01 & -2.35 & 35.0 \\
\hline
\end{tabular}

\section{MOMENTUM FLUX MEASUREMENT}

The temperature sensitivity of drag discs is determined from pretest warmup data taken at 366 and $533 \mathrm{~K}$ with no system flow. The temperature and pressure sensitivity is removed before the data are converted to momentum flux.. The temperature of each transducer is taken from the signal of a nearby fluid or metal temperature thermocnuple. Slight corrections for errors in setting the transducer output to zero at ambient conditions are also made at this time. Corrections are made using the following equation:

$$
F^{\prime}(t)-F(t)+C_{0}-T_{i} T(t)-P_{j} \dot{P}(t)
$$

where

$$
\begin{aligned}
& F^{\prime}(t)=\text { corrected data } \\
& F(t)=\text { raw data } \\
& T_{i}=\text { temperature sensitivity }
\end{aligned}
$$




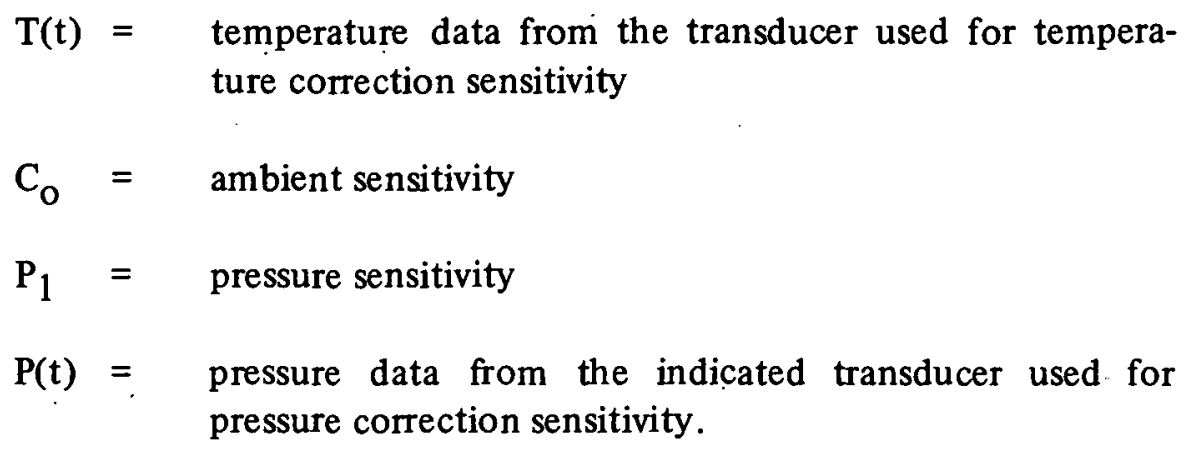

Values of the constants are given in Table A-III. 


\section{TABLE A-III}

CONSTANTS FOR MOMENTUM FLUX -

MEASUREMENT CORRECTIONS (TEST S-06-6)

\begin{tabular}{|c|c|c|c|c|c|c|}
\hline \multicolumn{2}{|c|}{$\begin{array}{l}\text { Detector } \\
\text { Identification }\end{array}$} & $\mathrm{C}_{0}$ & $T_{i}$ & $T(t)^{[a]}$ & $P_{1}$ & $P(t)^{[c]}$ \\
\hline \multicolumn{2}{|c|}{ FDU- 5} & 0 & -0.000414 & RBU -2 & $0.000 \quad 001.72$ & $P V-U P+10$ \\
\hline \multicolumn{2}{|c|}{ FDV-CORE-IN } & 0 & -0.000190 & TFV-LP-22 & & \\
\hline \multicolumn{2}{|c|}{ FDU- 10} & 0 & 0.000383 & TFU- 10 & 0.00000674 & PU-PRIZE \\
\hline \multicolumn{2}{|c|}{ FDU- 13} & 0 & 0.001564 & RBII-14A & & \\
\hline \multicolumn{2}{|c|}{ FDB $-30^{[b]}$} & 0 & -0.001336 & TFB-30 & $0.000 \quad 00106$ & $P B-30$ \\
\hline \multicolumn{2}{|c|}{ FDB-21 } & 0 & -0.001521 & TFB-20 & $-0.000004 \quad 15$ & $\mathrm{~PB}-21$ \\
\hline \multicolumn{2}{|c|}{ FDB-23 } & 0 & 0.001112 & TFB-23 & -0.000003 .38 & $P B-23$ \\
\hline \multicolumn{2}{|c|}{$F D D-42$} & 0 & -0.001339 & TFB̈- $4 \bar{C}$ & & \\
\hline \multicolumn{2}{|c|}{ FDB $-37^{[b]}$} & 0 & 0.0006858 & TFB-37. & & \\
\hline \multicolumn{2}{|c|}{ FDU- 1} & 0.30 & -0.0000360 & RBU-2 & -0.00000210 & $P V-U P+10$ \\
\hline \multicolumn{2}{|c|}{ FDU- 15} & $0^{\prime}$ & -0.0024120 & RBU- $74 A$ & -0.00000283 & PU-13 \\
\hline \multicolumn{7}{|c|}{$\begin{array}{l}\text { La] } T(t) \text { is the temperature data used for temperature sensitivity cor- } \\
\text { rection. The symbols listed identify the thermocouples from which }\end{array}$} \\
\hline \multicolumn{7}{|c|}{$\begin{array}{l}\text { [b] Temperature sensitivity corrections were applied as usual; however, } \\
\text { because FDB- } 30 \text { and FDB- } 37 \text { are mounted horizontally, during blow- } \\
\text { down they were partially filled with subcooled water which affected } \\
\text { the temperature sensitivity. Therefore, the leliperdice senstriv- } \\
\text { ity correction is more uncertain than that applied to other temp- } \\
\text { erature sensitivity corrections. }\end{array}$} \\
\hline$[c]$ & $\begin{array}{l}P(t) \text { is } t \\
\text { pressure }\end{array}$ & 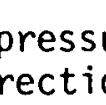 & $\begin{array}{l}\text { data from } \\
\text { sensitivity }\end{array}$ & e in & transducer & ed for \\
\hline
\end{tabular}




\section{DENSITY MEASUREMENTS}

Density calculations are based on the voltage output of the photomultiplier tubes in the gamma-attentuation densitometer assemblies. The equation used for converting voltage to density is as follows:

$$
\rho=(1 / C) \ln \{D /[A F(t)+B]\}
$$

where
$\rho=$ the density in $\mathrm{kg} / \mathrm{m}^{3}$
C $=$ a constant based on the length of the gamma beam path
$\mathrm{D}=\mathrm{a}$ theoretical voltage for zero attenuation inside the vessel
A $=$ an amplification factor
$\mathrm{B}=\mathrm{a}$ biasing factor
$F(t)=$ the transducer voltage output.

Constants $\mathbf{A}$ and $\mathbf{B}$ are adjusted to match the final data to density values calculated from measured pressure and temperature values at the preblowdown and postdrain conditions, effectively giving the data an in-place calibration. The values of the constants for various transducers are given in Table A-IV.

The density measurements GVLP-172HZ, GV-COR-150HZ, and GV-162/192D which precalculate the logarithm function, and hence have a simpler conversion formula:

$$
\begin{array}{ll}
\text { GVLP-172HZ } & \rho^{\prime}=-40.39 \mathrm{~F}(\mathrm{t})-2338.6 \\
\text { GV-COR-150HZ } & \rho=-58.07 \mathrm{~F}(\mathrm{t})-2787.2 \\
\text { GV-162/192D } & \rho=
\end{array}
$$

where $F(t)$ is the transducer voltage output.

Some: density measurements are obtained using a two-beam gamma densitometer which operates on the same basic principle of gamma attentuation as does the single-beam gamma densitometer. Each beam originates from the same gamma source and is allowed to pass through separate portions of the piping cross-sectional flow area to obtain an average density measurement in that particular region. The geometrical relationship of the gamma beam path through the piping and geometrically related variables used for processing of data from a two-beam gamma densitometer are shown in Figure A-1. 
TABLE A-IV.

CONSTANTS FOR DENSITY MEASUREMENT

CONVERSIONS TO ENGINEERING UNITS (TEST S-06-6)

\begin{tabular}{|c|c|c|c|c|c|}
\hline & ID & A & B & $C$ & D. \\
\hline & GU-5VR & $1.16 !$ & -0.687 & 0.0006 & 5.48 \\
\hline & GU-10VR & 1.099 & -0.452 & 0.000 .6 & 6.89 \\
\hline & GU-13VR & 1.686 & -2.137 & 0.0006 & 3.43 \\
\hline & $G B-42 V R$ & 1.018 & +0.147. & 0.0004 & 8.25 \\
\hline & $6 i b-37$ & 2.057 & -4.310 & 0.0006 & 4.41 \\
\hline & GB-23VR & 1.133 & $-0.6 n 4$ & 0.0006 & 7.00 \\
\hline & GVLP-165HZ & 1.043 & -0.206 & 0.0006 & 6.84 \\
\hline & GU-PRIZE & 1.118 & -0.098 & 0.0006 & 1.195 \\
\hline & GB-21B & .1 .092 & -0.469 & 0.0005 & 8.27 \\
\hline & $G B-21 T$ & .1 .093 & -0.367 & 0.0004 & 6.92 \\
\hline$\because$ & $G R-3 \cap B$ & 1.053 & -0.154 & 0.0005 & 8.24 \\
\hline & $\mathrm{GB}-3 \cap \mathrm{T}$ & 1,200 & -0.999 & 0.0004 & 6.48 \\
\hline & $G U-7 B$ & 1.036 & & 0.0005 & 8.49 \\
\hline & GU-1T & 1.047 & -0.061 & 0.0004 & 7.19 \\
\hline & fill-15B & 1.028 & +0.043 & 0.0005 & 8.88 \\
\hline & GU-15T & 1.121 & -0.631 & 0.0004 & 7.87 \\
\hline
\end{tabular}

T'he averagc :dchsity measured by each individunl gnmma beam is obtained using the same equation as is used for the single-beam gamma densitometers. Values for the constants for the single-beam density measurements obtained with the two-beam gamma densitometers are presented in Table A-IV along with the constants for single-beam gamma densitometcrs.

In the Semiscale Mod-1 system, two-beam gamma densitometers provide added information. which allows the calculation of a better average density than that obtained from a single beam. A mathematical model is used for processing the two-beam data to 


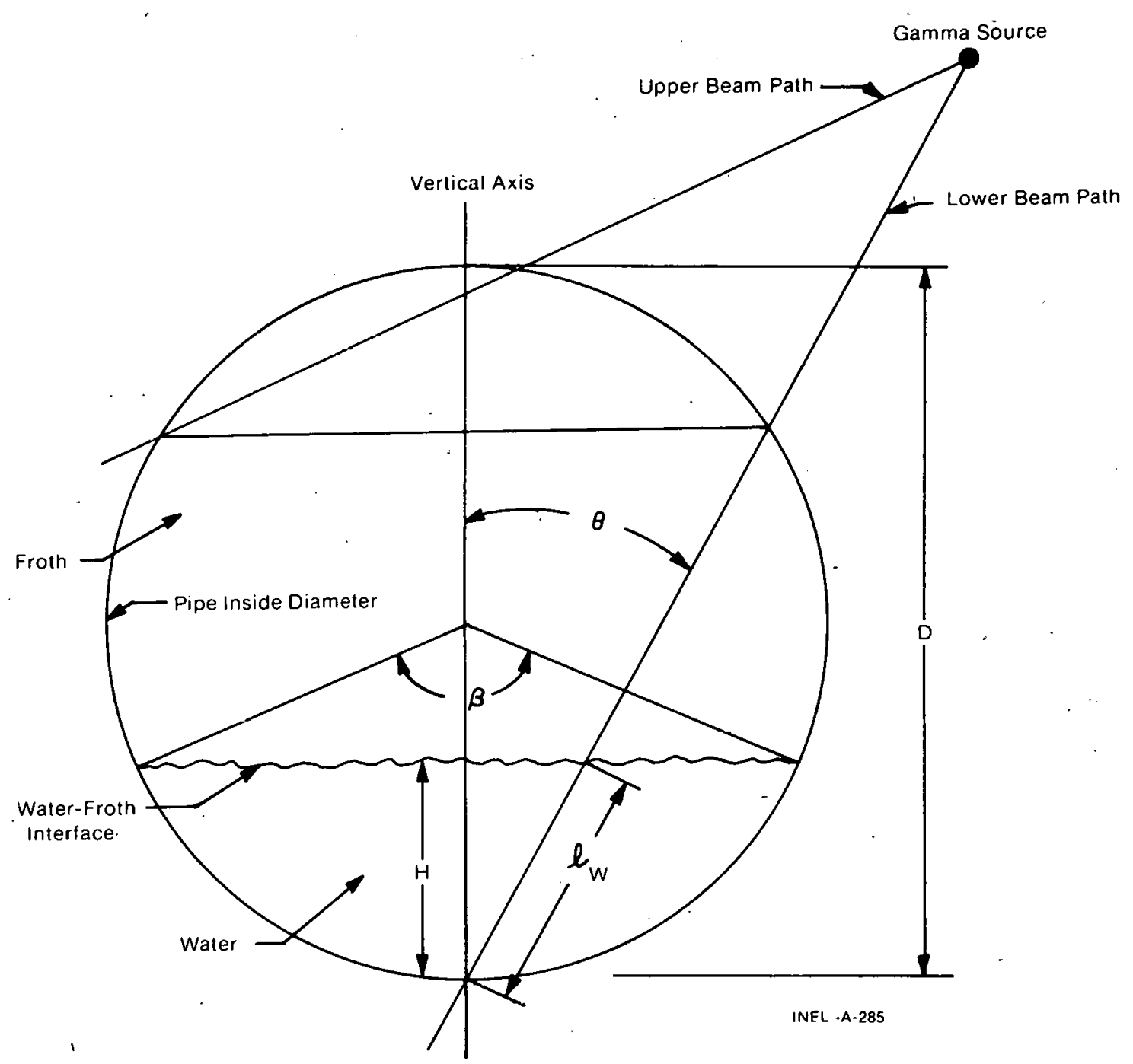

Fig. A-1 Geometry used for processing of density data obtained from two-beam gamma densitometers.

obtain the improved average density information. The processing method used is based on a froth-water model coupled with information from the two individual gamma beams and related beam path and piping cross-sectional geometry. The resulting information is recorded and reported under the density measurement identification ending with a " $\mathrm{C}$ ", for example, GB-21C.

The use of the froth-water model for obtaining average density from a two-beam gamma densitometer is based on observations indicating that flow regimes in the Semiscale Mod-1 system can be modeled by a layer of water on the bottom of the pipe with a degree of froth on the surface. For homogeneous flow conditions such as all froth or all liquid the model remains valid. At any point in time slug flow is also modeled. The froth-water model does not model annular or inverted annular flows very well. However, these flows are not 
expected to exist for significant portions of a Semiscale Mod-1 system blowdown in horizontal piping. Density gradients from the top to the bottom of the pipe may exist showing no distinct location change from water to froth. This flow is neither totally homogeneous nor stratified, but the froth-water model does provide an adcquate approximation of the average density characteristic of this flow pattern.

The average density obtained by using the gamma beam geometry shown in Figure A-1 and by applying the froth-water model is given by:

$$
\bar{\rho}=\alpha_{f} \rho_{1} \div\left(1-\alpha_{f}\right) \rho_{w} \mathrm{~kg} / \mathrm{m}^{3}
$$

where

$$
\begin{aligned}
& \bar{\rho}=\text { average cross-sectional density } \\
& \rho_{1}=\begin{array}{l}
\text { average denstty meäasured by the upper gamma beam } \\
\text { (measures the froth density) }
\end{array} \\
& \rho_{\mathrm{w}}=\text { density of liquid water (at local system conditions) } \\
& \alpha_{\mathrm{f}}=1 \div(1 / 2 \pi)(\sin \beta-\beta)=\text { froth fraction. }
\end{aligned}
$$

The angle which $\beta$ represents is shown in Figure A-1. Values for $\beta$ are obtained as follows:

$$
\beta=2 \cos ^{-1}(1-2 h)
$$

where

$$
h=\frac{H}{D}=\cos ^{2} \dot{\theta}\left(\frac{\rho_{2}-\rho_{1}}{\rho_{w}-\rho_{1}}\right)
$$

where

$$
\begin{aligned}
& \mathrm{H}=\ell_{\mathrm{w}} \cos \theta\left(\ell_{\mathrm{w}} \text { and } 0 \text { are defined in Figure } \mathrm{A}-1\right) \\
& \mathrm{D}=\text { piping inside diameter } \\
& \rho_{2}=\text { the average density measured by the lower gnmma beam. }
\end{aligned}
$$

Average density is not calculated using the two-beam froth-water model when the angle $\theta$ is not favorable due to system hardware restrictions in positioning the source. The froth-water model requires separate density sampling in both the upper and-lower portions of the spiping cross section. 
APPENDIX B

SELECTED DATA WITH ESTIMATED TOTAL ERROR BANDS FROM SEMISCALE MOD-1 TEST S-06-6 
THIS PAGE WAS INTENTIONALLY LEFT BLANK 


\section{APPENDIX B. \\ SELECTED DATA WITH ESTIMATED TOTAL ERROR BANDS FROM SEMISCALE MOD-1 TEST S-06-6}

Analysis has been performed on selected data from Test S-06-6 to provide a guide to the uncertainty associated with data measurements in the Semiscale Mod-1 system. The end result of the analysis is presented as error bands about the measured data which represent a 95\% confidence level.

The error bands are obtained by combining uncertainties obtained from analysis of the data itself (random error) and engineering analysis of the measurement system (engineering error). The procedure by which error bands were established for the data presented in this appendix is described in the following paragraphs.

The data trace under analysis was empirically fitted with a linear difference equation, which was subject to a white noise input at each sampling time point. The objective of the empirical fitting procedure was to characterize the white noise, which was taken to represent the random error. The procedures for fitting the difference equation are discussed in depth in Reference B-1. A data trace was often segmented and different equations were fitted to each segment with statistical correlations between successive observations accounted for by the fitting procedure. The white noise input was assumed to arise from a normally distributed population. The standard deviation of the white noise, as found during the fitting procedures, was taken as an estimate of the random error standard deviation and is shown in Table B-I.

Other errors in the data exist because of such factors as variability in installation procedures and techniques, calibration errors, variability in materials, and temperature and pressure sensitivities. These errors and the procedures for estimating them are discussed in Reference B-2. They are referred to as engineering errors and the estimates are largely subjective. Because of the continuing effort to improve the accuracy of the medsured data, such as through the use of better transducers, better signal conditioning and processing equipment, and better calibration and installation techniques, the engineering errors for data from most of the transducer systems have changed from those published in Reference B- 2 . Table B-II provides a summary of engineering error values obtained from current analysis techniques as applied to the data presented herein. 
TABLE B-I

RANDIM ERROR VARIANCE TEST (S-06-6)

\begin{tabular}{|c|c|c|c|c|}
\hline Measurement & $\begin{array}{c}\text { Random Error } \\
\text { Variance } \\
\sigma_{F}\end{array}$ & $\begin{array}{l}\text { Period of } \\
\text { Application } \\
\text { (s) } \\
\end{array}$ & Figure & Comments \\
\hline TFB-23 & $\begin{array}{l}2.085 \\
9.375 \\
0.858\end{array}$ & $\begin{aligned} 0 & \text { to } 29 \\
29 & \text { to } 91 \\
91 & \text { to } 200\end{aligned}$ & B-1 & $\begin{array}{l}\text { The error bands should be smaller than } \\
\text { what is represented from } 88 \text { to } 91 \mathrm{~s}[\mathrm{c}]\end{array}$ \\
\hline TFV-ANN-35A & $\begin{array}{l}2.614 \\
7.908 \\
0.470\end{array}$ & $\begin{array}{l}0 \cdot \text { to } 25 \\
25 \text { to } 80 \\
80 \text { to } 200\end{array}$ & B-2 & \\
\hline TFV-LP- 15 & $\begin{array}{l}3.766 \\
0.311\end{array}$ & $\begin{array}{c}0 \text { to } 72 \\
72 \text { to } 200\end{array}$ & $B-3$ & \\
\hline TFG-6DE-67 & $\begin{array}{r}1.42 \varepsilon \\
5.754 \\
38.779 \\
13.195\end{array}$ & $\begin{array}{r}0 \text { to } 34 \\
34 \text { to } 87 \\
87 \text { to } 159 \\
159 \text { to } 200\end{array}$ & B-4 & . \\
\hline TFU-SG4 & $\begin{array}{l}0.062 \\
0.028\end{array}$ & $\begin{array}{rll}0 & \text { to } & 36 \\
36 & \text { to } & 200\end{array}$ & B-5 & \\
\hline TFU-PRIZE & $\begin{array}{l}3.947 \\
1.478 \\
0.099\end{array}$ & $\begin{array}{l}0 \text { to } 30 \\
30 \text { to } 106 \\
106 \text { to } 200\end{array}$ & $B-6$ & . \\
\hline TMU- $15 T 16$ & 0.322 & 0 to 200 & $B-7$ & \\
\hline TMV-CI-35A & $\begin{array}{l}0.596 \\
2.535 \\
0.473 \\
0.094\end{array}$ & $\begin{aligned} & 0 \text { to } 49 \\
& 49 \text { to } 80 \\
& 80 \text { to } 102 \\
& 102 \text { to } 200\end{aligned}$ & B-8 & $\therefore$ \\
\hline
\end{tabular}


TABLE B-I (continued)

\begin{tabular}{|c|c|c|c|c|}
\hline Measurement & $\begin{array}{c}\text { Random Error } \\
\text { Varjance } \\
\sigma_{\mathrm{R}}\end{array}$ & $\begin{array}{l}\text { Period of } \\
\text { Application } \\
\text { (s) }\end{array}$ & Figure & Comments \\
\hline TH-E4-09. & $\begin{array}{r}2.466 \\
1.006 \\
27.420 \\
0.263\end{array}$ & $\begin{array}{r}0 \text { to } 24 \\
24 \text { to } 154 \\
154 \text { to } 164 \\
164 \text { to } 200\end{array}$ & $B-9$ & $\begin{array}{l}\text { The error bands should be smaller than } \\
\text { what is represented from } 161 \text { to } 164 \\
\text { [c] }\end{array}$ \\
\hline TH-E4-27 & $\begin{array}{l}4.649 \\
1.127\end{array}$ & $\begin{aligned} 0 & \text { to } 24 \\
24 & \text { to } 261\end{aligned}$ & B- 10 & \\
\hline TH-E4-55 & $\begin{array}{l}5.966 \\
0.544\end{array}$ & $\begin{aligned} 0 & \text { to } 22 \\
22 & \text { to } 200\end{aligned}$ & $B-11$ & . \\
\hline PU- 13 & $\begin{array}{l}3.910 \\
0.754\end{array}$ & $\begin{array}{cc}0 & \text { to } 77 \\
77 & \text { to } 200\end{array}$ & $B-12$ & \\
\hline PB-23 & $\begin{array}{l}4.031 \\
0.707\end{array}$ & $\begin{array}{c}0 \text { to } 77 \\
77 \text { to } 200\end{array}$ & B-13 & \\
\hline DPU-6-7 & $\begin{array}{l}0.237 \\
0.389 \\
0.060 \\
0.213\end{array}$ & $\begin{array}{r}0 \text { to } 27 \\
27 \text { to } 72 \\
72 \text { to } 106 \\
106 \text { to } 200\end{array}$ & $B-14$ & \\
\hline DPU-7-10 & $\begin{array}{l}0.121 \\
0.191 \\
0.023 \\
0.104\end{array}$ & $\begin{array}{r}0 \text { to } 31 \\
31 \text { to } 73 \\
73 \text { to } 105 \\
105 \text { to } 200\end{array}$ & $B-15$ & $\begin{array}{l}\text { The error bands should be smaller than } \\
\text { what is represented from } 0 \text { to } 73^{[a]} \\
\text { and from } 105 \text { to } 200 \mathrm{~s} \text { [a]. }\end{array}$ \\
\hline$D P U-12-10$ & $\begin{array}{l}0.426 \\
0.601 \\
0.125 \\
0.187\end{array}$ & $\begin{array}{r}0 \text { to } 39 \\
39 \text { to } 57 \\
57 \text { to } 140 \\
140 \text { to } 200\end{array}$ & $B-76$ & \\
\hline
\end{tabular}


TABLE B-I (continued)

\begin{tabular}{|c|c|c|c|c|}
\hline Measurement & $\begin{array}{c}\text { Random Error } \\
\text { Varjance } \\
\sigma_{\mathrm{R}} \\
\end{array}$ & $\begin{array}{l}\text { Period of } \\
\text { Application } \\
\text { (s) } \\
\end{array}$ & Figure & Comments \\
\hline DPU-12-15 & $\begin{array}{l}0.081 \\
0.270 \\
0.035 \\
0.119\end{array}$ & 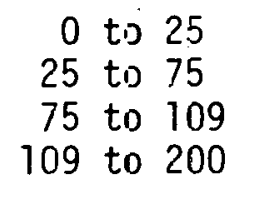 & B-17 & $\begin{array}{l}\text { The enror bands should be smaller than } \\
\text { what is represented from } 25 \text { to } 75^{[a]} \\
\text { and } 109 \text { to } 200^{[a]} \text {. }\end{array}$ \\
\hline DPV-LP-UP & $\begin{array}{l}0.159 \\
0.08 \dot{3} \\
0.173\end{array}$ & $\begin{array}{r}0.5 \text { to } 72 \\
72 \text { to } 118 \\
118 \text { to } 200\end{array}$ & $B-18$ & \\
\hline FTU $=1$ & $\begin{array}{r}8.093 \\
62.990 \\
0.765 \\
40.035\end{array}$ & $\begin{array}{l}0 \text { to } 47 \\
47 \text { to } 72 \\
72 \text { to } 87 \\
87 \text { to } 200\end{array}$ & $B-19$ & $\begin{array}{l}\text { The error bands should be smalier than } \\
\text { what is represented from } 47 \text { to } 72 \mathrm{~s} \\
\text { and } 8 \varepsilon \text { to } 100 \mathrm{~s}^{[\mathrm{b}]} \text {. }\end{array}$ \\
\hline FTU-15 & $\begin{array}{r}10.152 \\
24.184 \\
18.057 \\
104.723\end{array}$ & 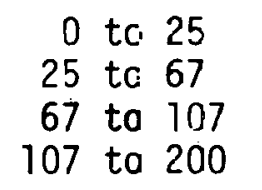 & $B-20$ & \\
\hline FTU-HPIS & $\begin{array}{l}0.102 \\
0.166\end{array}$ & $\begin{array}{c}0 \text { to } 87 \\
87 \text { to } 200\end{array}$ & $B-21$ & \\
\hline F̈TU-LPIS & $\begin{array}{l}0.752 \\
0.233 \\
0.006\end{array}$ & $\begin{aligned} & 0 \text { to } 39 \\
& 39 \text { to } 90 \\
& 90 \text { to } 200\end{aligned}$ & $B-22$ & \\
\hline FTU-ACC & $\begin{array}{l}0.082 \\
0.577 \\
\dot{3} .816 \\
0.023\end{array}$ & $\begin{array}{l}0.5 \text { to } 18 \\
18 \text { to } 65 \\
65 \text { to } 92 \\
92 \text { to } 200\end{array}$ & $B-23$ & $\begin{array}{l}\text { The error bands should be smaller than } \\
\text { what is represented from } 74 \text { to } 87 \mathrm{~s}^{[\mathrm{b}]} \\
\text { and from } 90 \text { to } 92 \mathrm{~s}[\mathrm{c}]\end{array}$ \\
\hline
\end{tabular}


TABLE B-I (continued)

\begin{tabular}{|c|c|c|c|c|}
\hline Measurement & $\begin{array}{c}\text { Random Error } \\
\text { Varjance } \\
\sigma_{\mathrm{R}} \\
\end{array}$ & $\begin{array}{c}\text { Period of } \\
\text { Application } \\
\text { (s) } \\
\end{array}$ & Figure & Comments \\
\hline FTV $-40 A$ & $\begin{array}{l}2.595 \\
8.889 \\
1.809\end{array}$ & $\begin{array}{c}0 \text { to } 29 \\
29 \text { to } 79 \\
79 \text { to } 200\end{array}$ & B-24 & \\
\hline FTV-40M & $\begin{array}{l}2.119 \\
8.081 \\
1.327\end{array}$ & $\begin{array}{c}0 \text { to } 29 \\
29 \text { to } 73 \\
73 \text { to } 200\end{array}$ & B-25 & \\
\hline GUI-1T & $\begin{array}{l}0.981 \\
0.230\end{array}$ & $\begin{array}{l}0 \text { to } 18 \\
18 \text { to } 200\end{array}$ & $B-26$ & $\begin{array}{l}\text { The error bands are smaller than what } \\
\text { is represented from } 0 \text { to } 17 \mathrm{~s} \text { [b]. }\end{array}$ \\
\hline GU- IB & $\begin{array}{l}3.080 \\
0.686 \\
0.135\end{array}$ & $\begin{array}{ll}0 & \text { to } 17 \\
17 & \text { to } 43 \\
43 & \text { to } 200\end{array}$ & B-27 & \\
\hline GU-1C & $\begin{array}{l}1.092 \\
0.193\end{array}$ & $\begin{array}{l}0 \text { to } 18 \\
18 \text { to } 200\end{array}$ & B-28 & $\begin{array}{l}\text { The error bands should be smaller than } \\
\text { what is represented from } 15 \text { to } 18 \mathrm{~s}[\mathrm{c}]\end{array}$ \\
\hline GU-10VR & $\begin{array}{l}1.554 \\
0.170\end{array}$ & $\begin{aligned} 0 & \text { to } 28 \\
28 & \text { to } 200\end{aligned}$ & $B-29$ & $\begin{array}{l}\text { The error bands should be smaller than } \\
\text { what is represented from } 0 \text { to } 28 \mathrm{~s} \text { [b]. }\end{array}$ \\
\hline GU-15T & $\begin{array}{l}5.571 \\
2.526 \\
0.488 \\
6.932\end{array}$ & $\begin{aligned} 0 & \text { to } 25 \\
25 & \text { to } 71 \\
71 & \text { to } 107 \\
107 & \text { to } 200\end{aligned}$ & $B-30$ & $\begin{array}{l}\text { The error bands should be smaller than } \\
\text { what is represented from } 0 \text { to } 67 \mathrm{~s} \text { [b]. }\end{array}$ \\
\hline GU-15B & $\begin{array}{l}2.716 \\
3.543 \\
1.401 \\
7.440\end{array}$ & $\begin{aligned} 0 & \text { to } 25 \\
25 & \text { to } 71 \\
71 & \text { to } 107 \\
107 & \text { to } 200\end{aligned}$ & B-31 & $\begin{array}{l}\text { The error bands should be smaller than } \\
\text { what is represented from } 0 \text { to } 67 \mathrm{~s} \text { [b]. }\end{array}$ \\
\hline
\end{tabular}


TABLE B-I (continued)

\begin{tabular}{|c|c|c|c|c|}
\hline Measurement & $\begin{array}{c}\text { Rèndom Error } \\
\text { Variance } \\
\sigma_{R}\end{array}$ & $\begin{array}{l}\text { Period of } \\
\text { Application } \\
\text { (s) } \\
\end{array}$ & Figure & Comments \\
\hline GU-15C & $\begin{array}{l}4.195 \\
2.749 \\
0.630 \\
6.344\end{array}$ & $\begin{aligned} 0 & \text { to } 25 \\
25 & \text { to } 71 \\
.71 & \text { to } 107 \\
107 & \text { to } 200\end{aligned}$ & B-32 & $\begin{array}{l}\text { The error sands stiould be smaller than } \\
\text { what is represented from } 0 \text { to } 67 \mathrm{~s}[\mathrm{~b}] \text {. }\end{array}$ \\
\hline GB-23VR & $\begin{array}{r}1.200 \\
-10.162 \\
0.223 \\
0.926\end{array}$ & $\begin{array}{r}0 \text { to } 25 \\
=5 \text { to } 76 \\
=6 \text { to } 115 \\
115 \text { to } 200\end{array}$ & $B-33$ & $\begin{array}{l}\text { The error bands should be smaller than } \\
\text { what is represented from } 73 \text { to } 76 \mathrm{~s} \text { [c] }\end{array}$ \\
\hline GV-COR-15OHZ & $\begin{array}{l}0.445 \\
8.169 \\
2.906\end{array}$ & $\begin{aligned} 0 & \text { to } \\
32 & \text { to } 146 \\
176 & \text { to } 200\end{aligned}$ & B-34 & \\
\hline GVLP- $165 \mathrm{HZ}$ & $\begin{array}{l}3.549 \\
0.996 \\
5.719 \\
2.352\end{array}$ & $\begin{aligned} 0 & \text { to } 21 \\
21 & \text { to } 77 \\
77 & \text { to } 183 \\
184 & \text { to } 200\end{aligned}$ & $\mathrm{~B}-35$ & $\begin{array}{l}\text { The error bands should be smaller than } \\
\text { what is represented from } 78 \text { to } 88 \mathrm{~s}^{[\mathrm{b}]}\end{array}$ \\
\hline $\begin{array}{c}\text { GV̈LP- } 172 \mathrm{HZ} \\
.\end{array}$ & $\begin{array}{l}3.241 \\
5.779 \\
3.152 \\
1.088\end{array}$ & $\begin{array}{r}0 \text { to } 24 \\
24 \text { to } 44 \\
44 \text { to } 73 \\
73 \text { to } 200\end{array}$ & $B-36$ & $\begin{array}{l}\text { The error bands should be smaller than } \\
\text { what is represented from } 70 \text { to } 85 \mathrm{~s} \text { [b] }\end{array}$ \\
\hline FDU- 1, GU- IC & $\begin{array}{l}0.364 \\
0.098\end{array}$ & $\begin{aligned} 0 & \text { to } 25 \\
25 & \text { to } 200\end{aligned}$ & B- 37 & \\
\hline FTU-1, GU-1C & $\begin{array}{l}0.198 \\
0.195\end{array}$ & $\begin{array}{r}0 \text { to } 101 \\
101 \text { to } 200\end{array}$ & $B-38$ & \\
\hline
\end{tabular}


TABLE B-I (continued)

\begin{tabular}{|c|c|c|c|c|}
\hline Measurement & $\begin{array}{c}\text { Random Error } \\
\text { Varjance } \\
\sigma_{\mathrm{R}}\end{array}$ & $\begin{array}{l}\text { Period of } \\
\text { Application } \\
\text { (s) } \\
\end{array}$ & Figure & Comments \\
\hline $\begin{array}{l}\text { FDU-5, } \\
\text { GU-5VR }\end{array}$ & $\begin{array}{l}0.640 \\
0.284 \\
0.064 \\
0.077\end{array}$ & $\begin{array}{l}0 \text { to } 18 \\
18 \text { to } 71 \\
71 \text { to } 109 \\
109 \text { to } 200\end{array}$ & $B-39$ & \\
\hline $\begin{array}{l}\text { FTU-13, } \\
\text { GU-13VR }\end{array}$ & $\begin{array}{l}1.011 \\
2.967 \\
0.175 \\
1.105\end{array}$ & 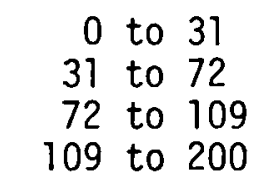 & $B-40$ & \\
\hline $\begin{array}{l}\text { FTU- 15, } \\
\text { GU- } 15 \mathrm{C}\end{array}$ & $\begin{array}{l}0.560 \\
3.314 \\
0.276 \\
3.128\end{array}$ & 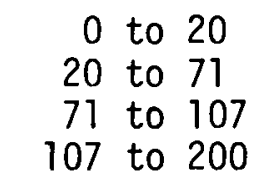 & B-41 & $\begin{array}{l}\text { The error bands should be smaller than } \\
\text { what is represented from } 20 \text { to } 27 \mathrm{~s} \text { [b] } \\
\text { and from } 68 \text { to } 71 \mathrm{~s}[\mathrm{c}] \text {. }\end{array}$ \\
\hline $\begin{array}{l}\text { FDB-21 } \\
\text { GB-21C }\end{array}$ & $\begin{array}{l}1.129 \\
3.445 \\
0.251\end{array}$ & $\begin{aligned} 0 & \text { to } 24 \\
24 & \text { to } 72 \\
72 & \text { to } 200\end{aligned}$ & B- 42 & . \\
\hline $\begin{array}{r}F T B-21, \\
\text { GB-2 iC }\end{array}$ & $\begin{array}{l}1.918 \\
2.713 \\
0.609\end{array}$ & $\begin{aligned} 0 & \text { to } 24 \\
24 & \text { to } 72 \\
72 & \text { to } 200\end{aligned}$ & $B-43$ & $\begin{array}{l}\text { The error bands should be smaller than } \\
\text { what is represented from } 0 \text { to } 79 \mathrm{~s}^{[\mathrm{a}]} \text {. }\end{array}$ \\
\hline $\begin{array}{l}\text { FTV-CORE-IN, } \\
\text { GV-COR- } 150 \mathrm{HZ}\end{array}$ & $\begin{array}{l}0.563 \\
3.751 \\
7.635\end{array}$ & $\begin{array}{r}0 \text { to } 82 \\
82 \text { to } 139 \\
139 \text { to } 200\end{array}$ & B-44 & $\begin{array}{l}\text { The error bands should be smaller than } \\
\text { what is represented from } 82 \text { to } 200 \\
\text { [a]. }\end{array}$ \\
\hline
\end{tabular}


TABLE R-I (continued)

\begin{tabular}{|c|c|c|c|c|}
\hline Measurement & $\begin{array}{c}\text { Random Error } \\
\text { Varjance } \\
\sigma_{\mathrm{R}}\end{array}$ & $\begin{array}{c}\text { Period of } \\
\text { Application } \\
\text { (s) }\end{array}$ & Fiqure & Comments \\
\hline
\end{tabular}

[a] The variability in the data has two components. One is the ranidom error and the other is the systematic error. In this recion, the random component dominates the systematic component. The width of the error band is due primariy to the variance of the random underlying process. The large variability does not reflect the inability of the measuring instrument to accurately measure the process.

[b] The larger estimited error band occurs when there is a rapid transient change during which insufficient data are provide- to allow estimation of the error. Inclusion of large transients in the estimation increases the estimated error.

[c] Due to present software limitztions, error bards will appear larger than expected wherever segments with different $s^{*} z e$ error banc's are nierged tocether. 


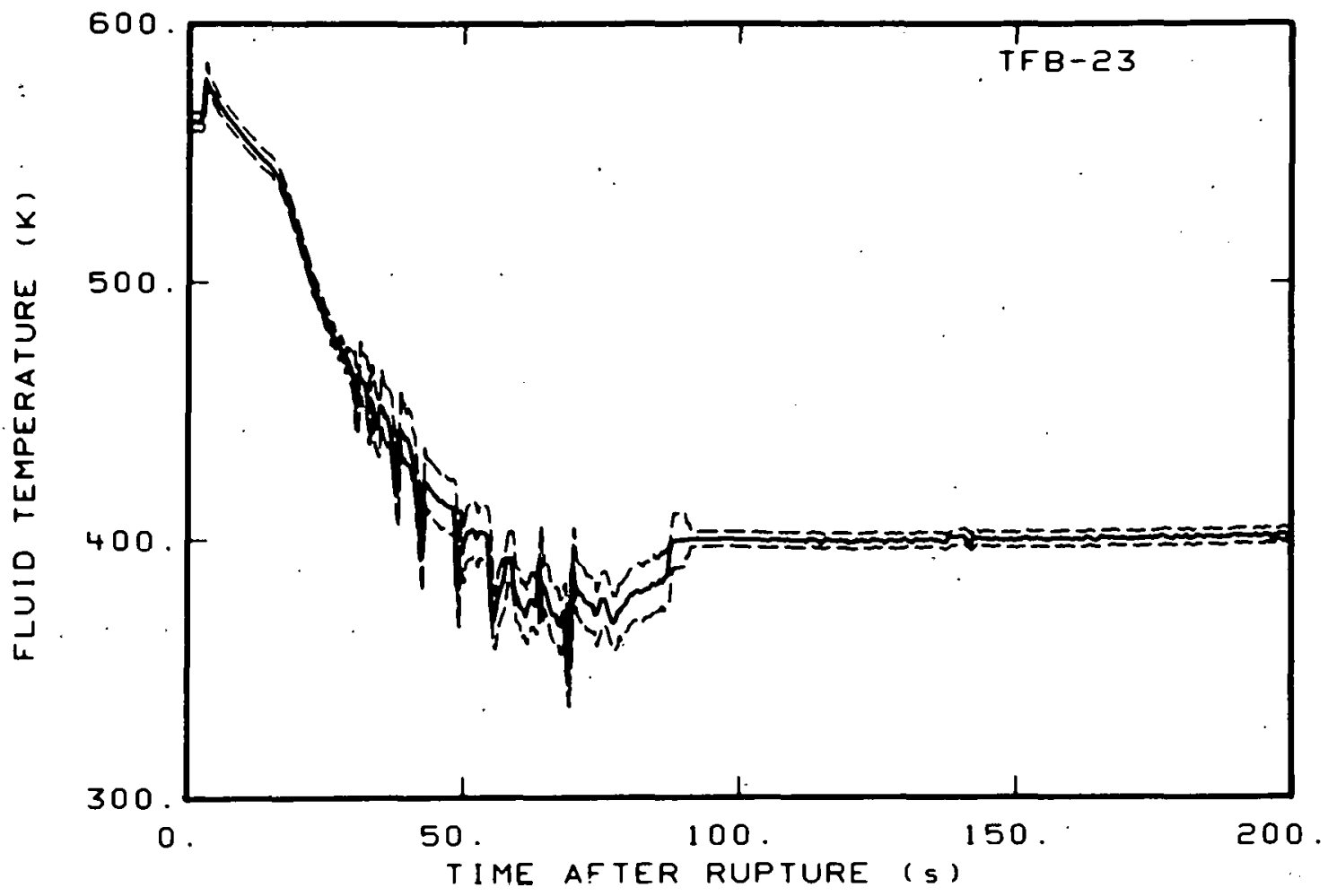

Fig. B-1 Fluid temperature in broken loop (TFB-23).

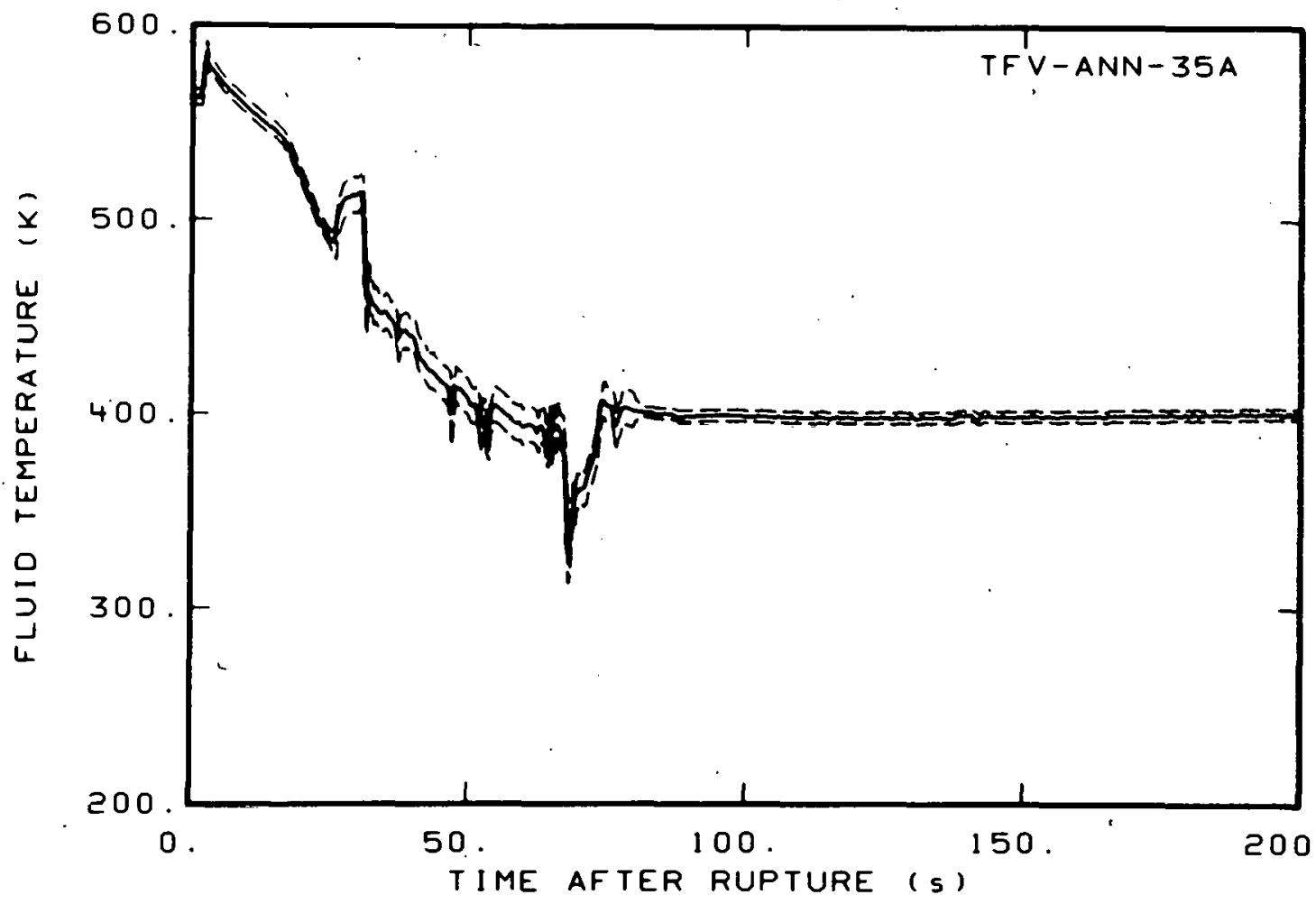

Fig. B-2 Fluid temperature in downcomer annulus (TFV-ANN-35A). 


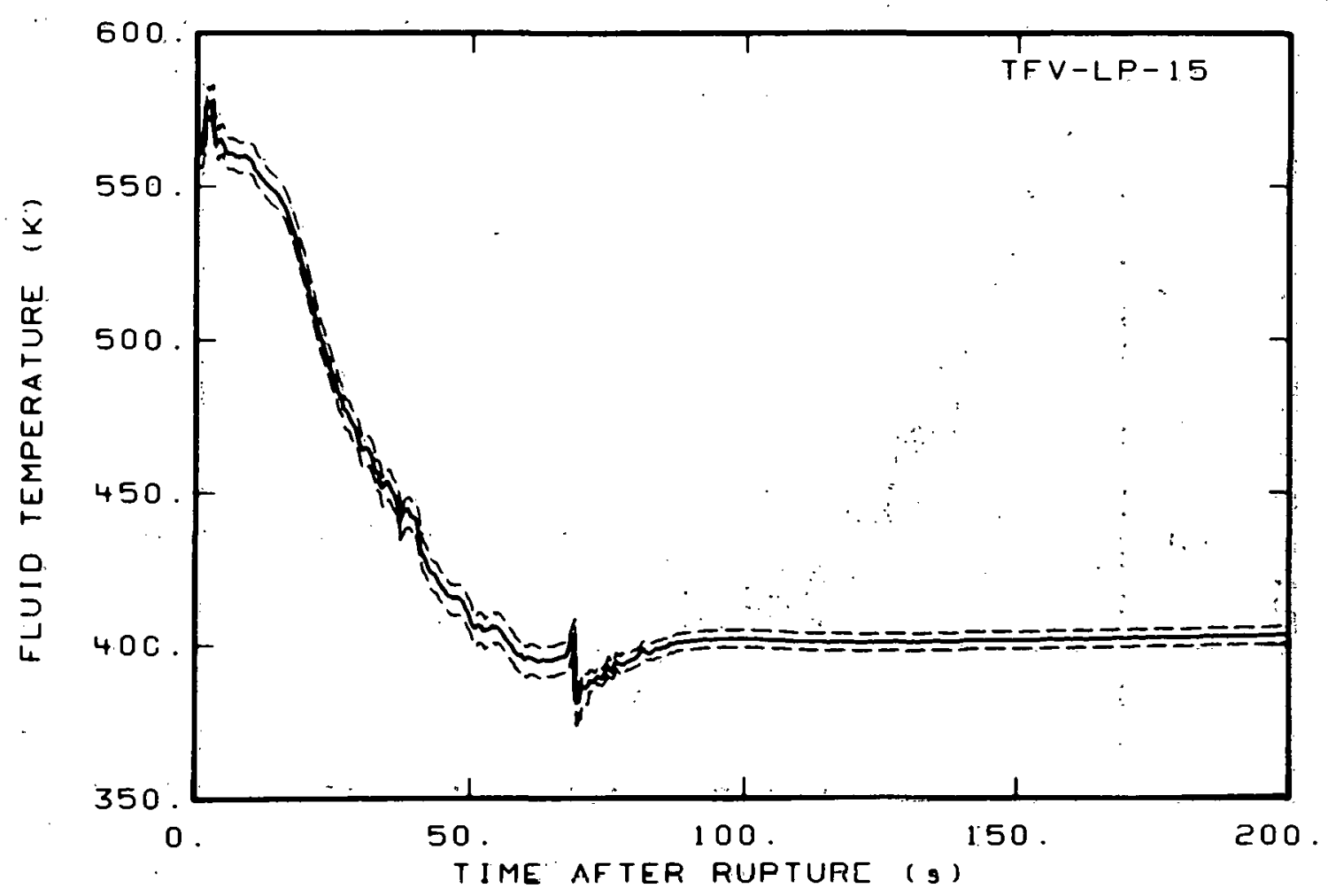

Fig. B-3 Fluid temperature in lower plenum (TFV-LP-15).

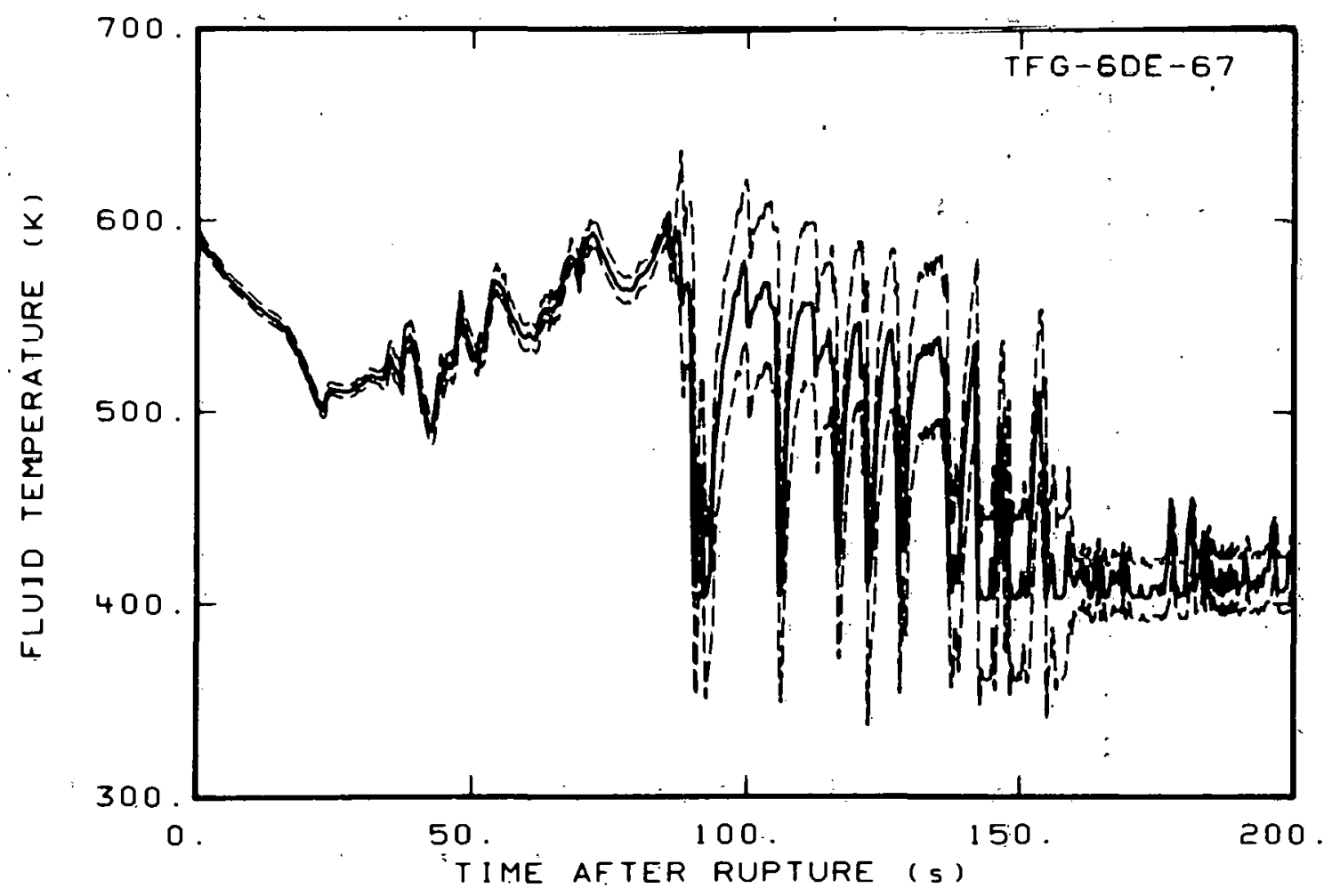

Fig. B-4 Fluid temperature in core, Grid Spacer 6 (TFG-6DE-67). 


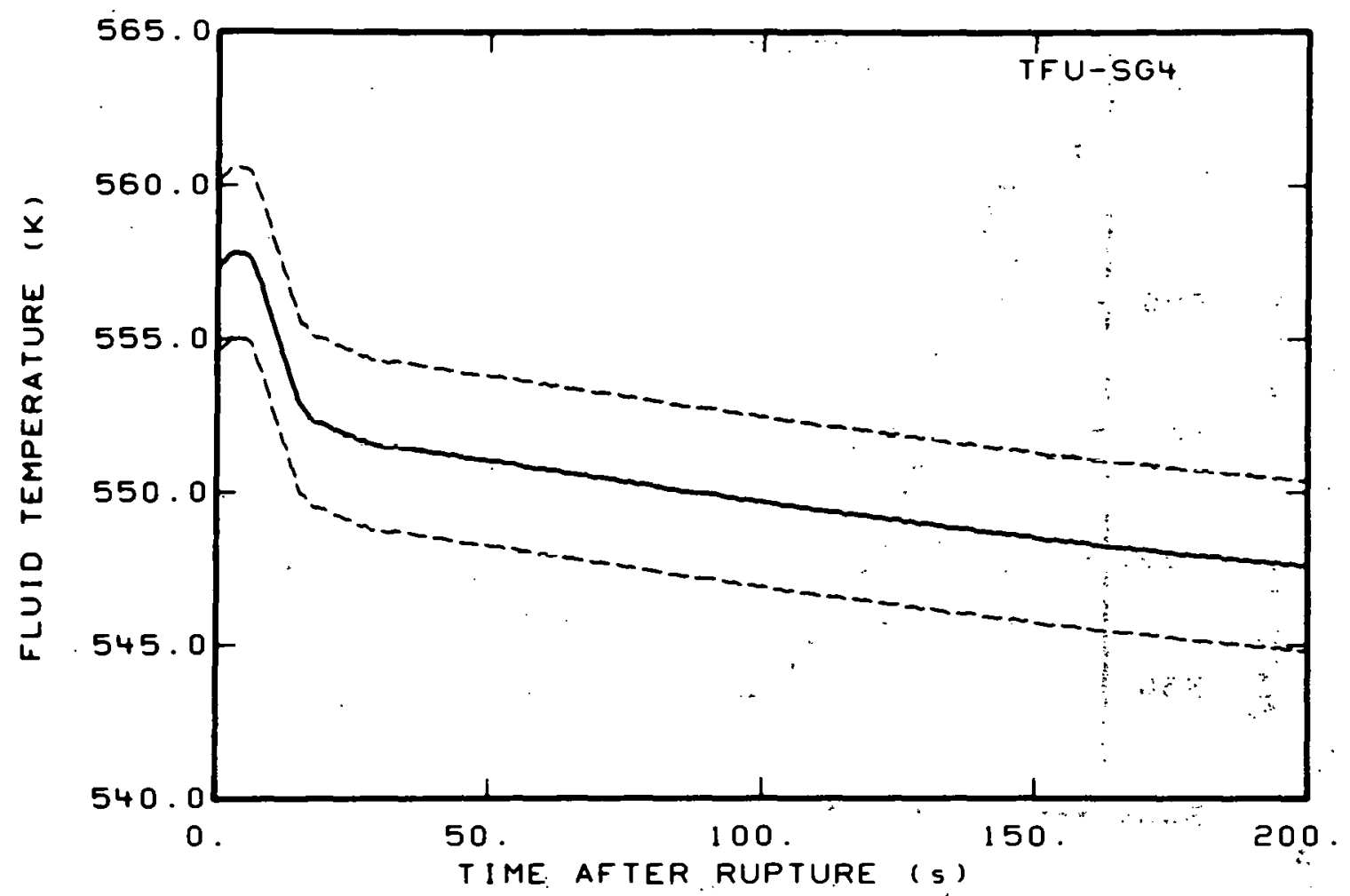

Fig. B-5 Fluid temperature in steam generator (TFU-SG4).

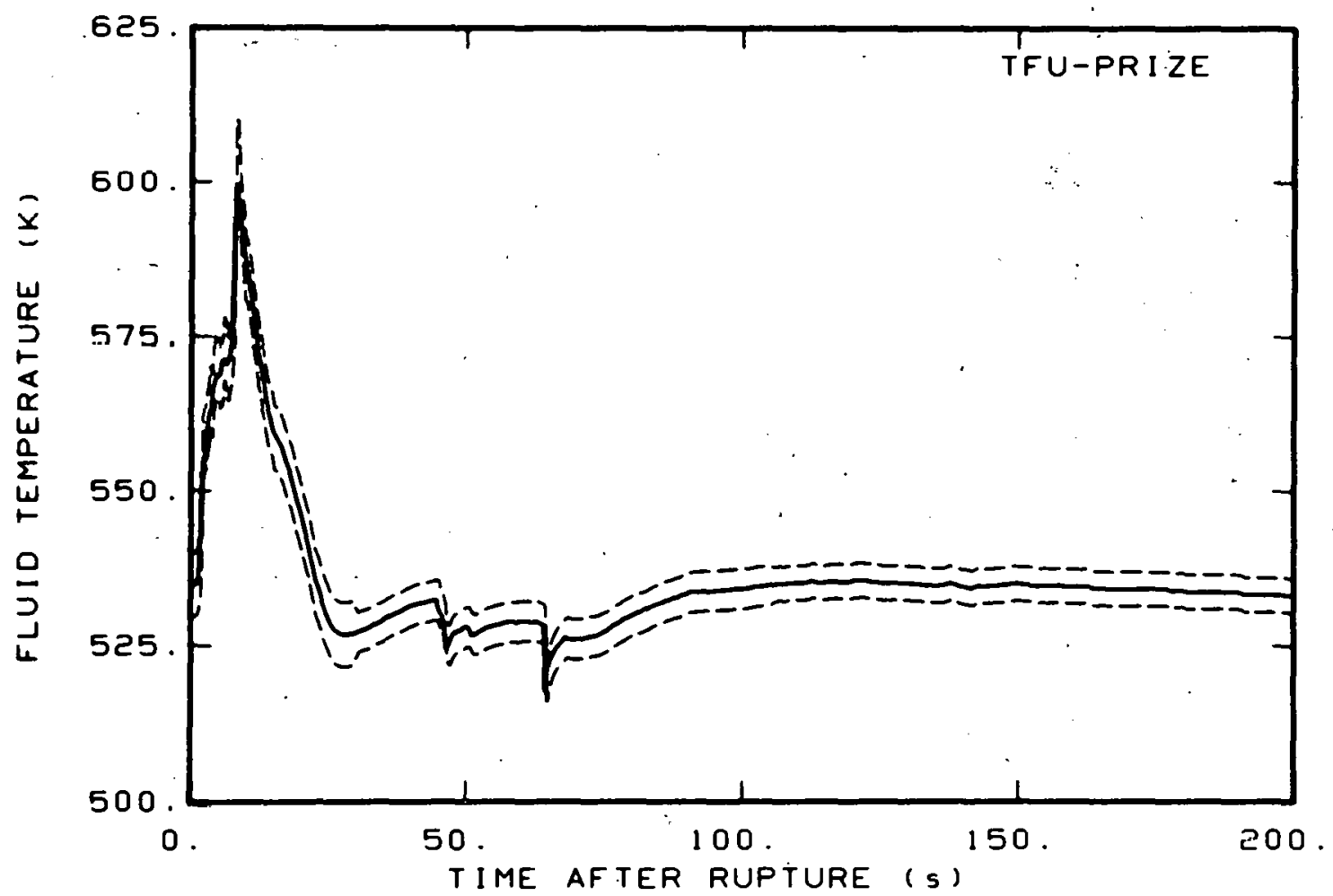

Fig. B-6 Fluid temperature in pressurizer surge line (TFU-PRIZE). 


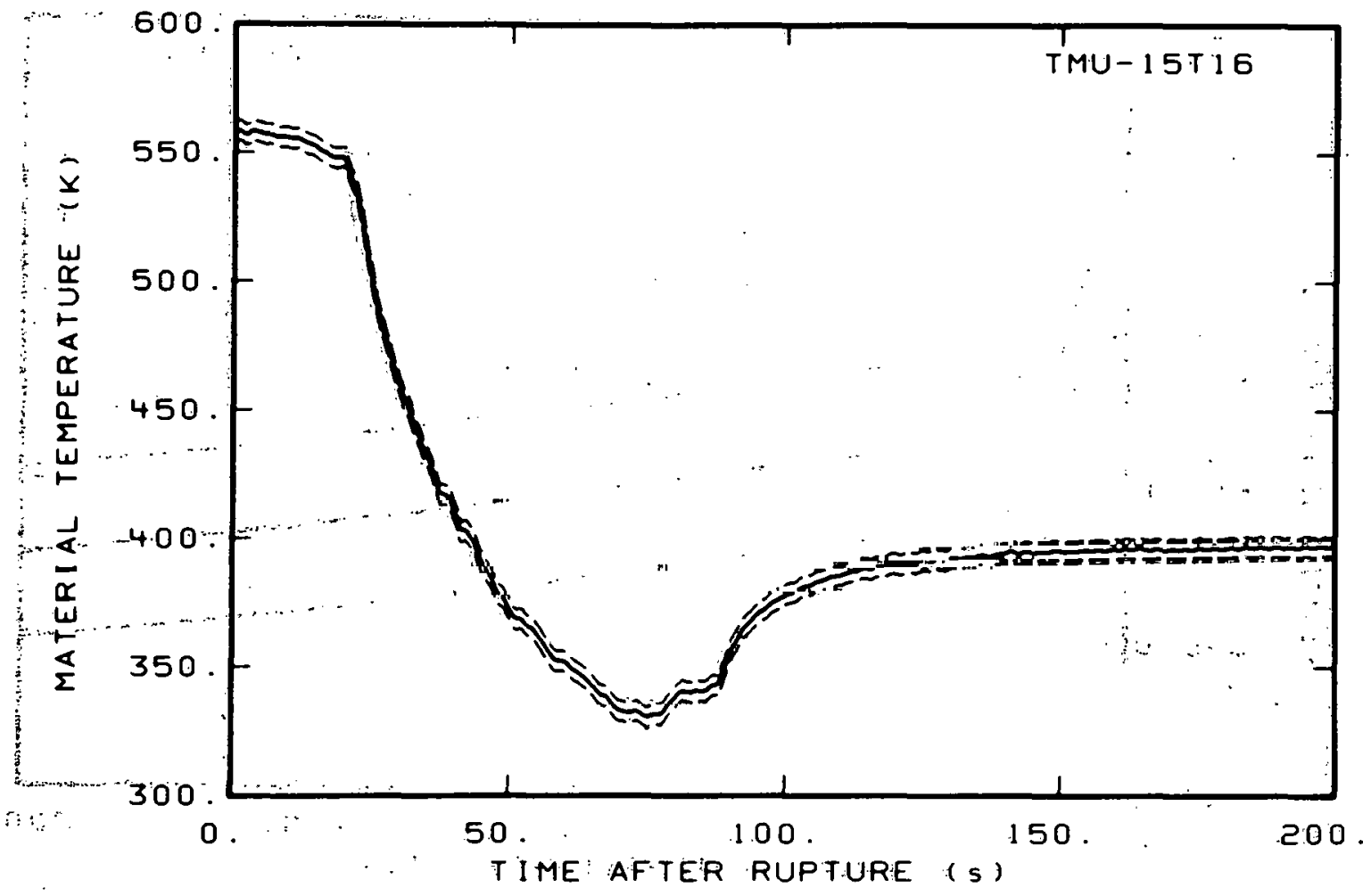

- Fig B-7 Material temperature in intact loop (TMU-15T16).

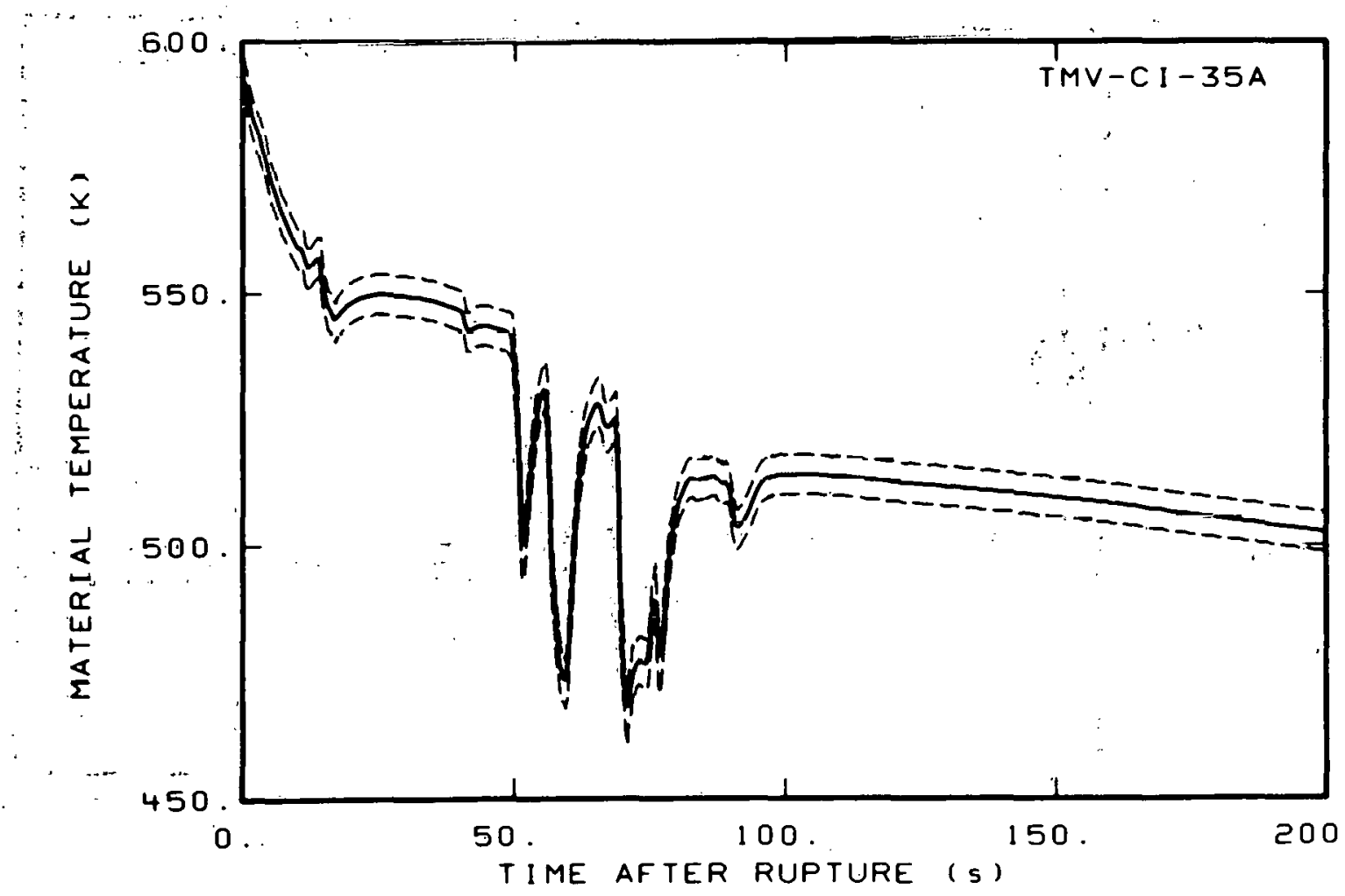

Fig. B-8 Material temperature in vessel filler (TMV-CI-35A). 


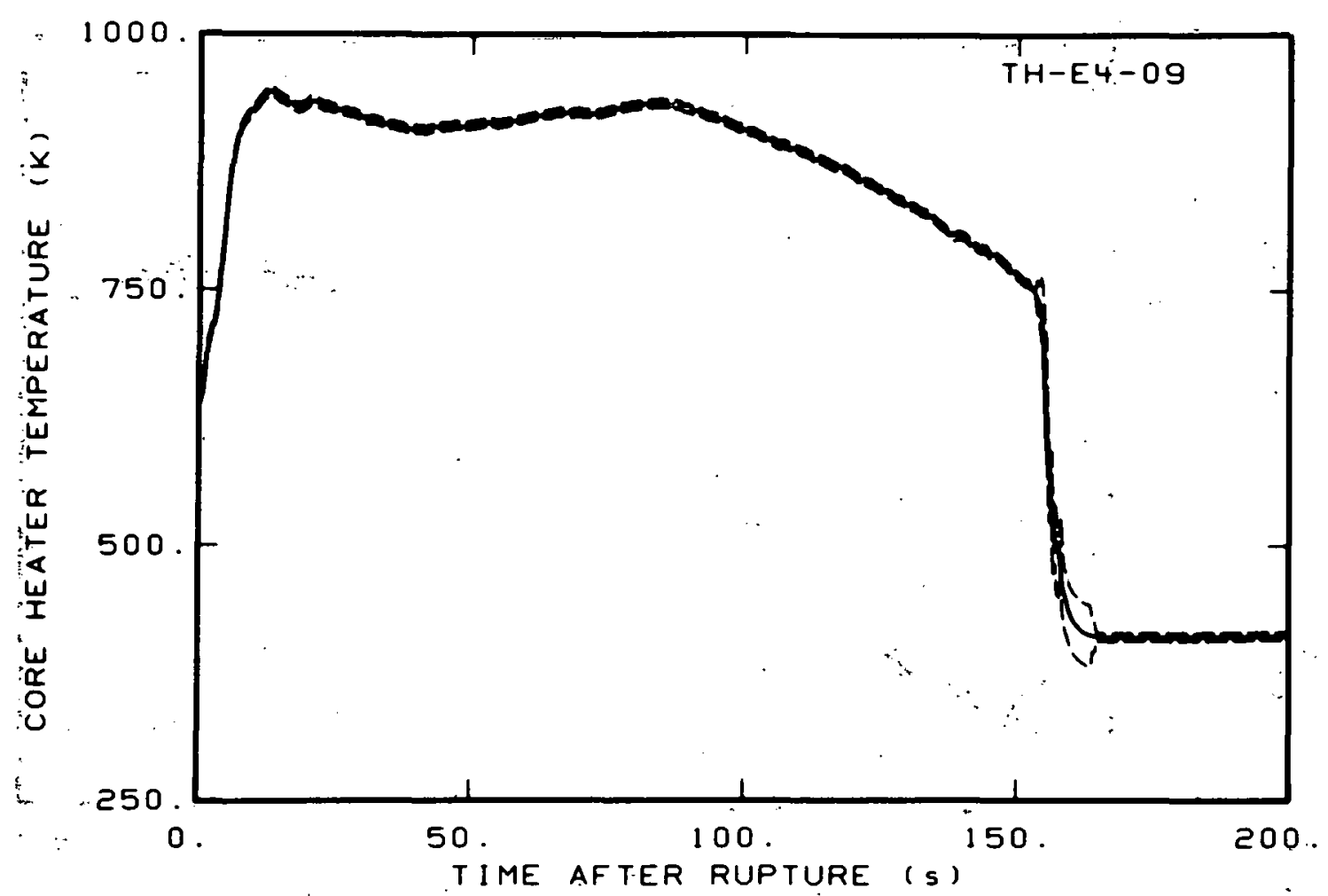

Fig. B-9 Core heater temperature, Rod E-4 (TH-E4-09).

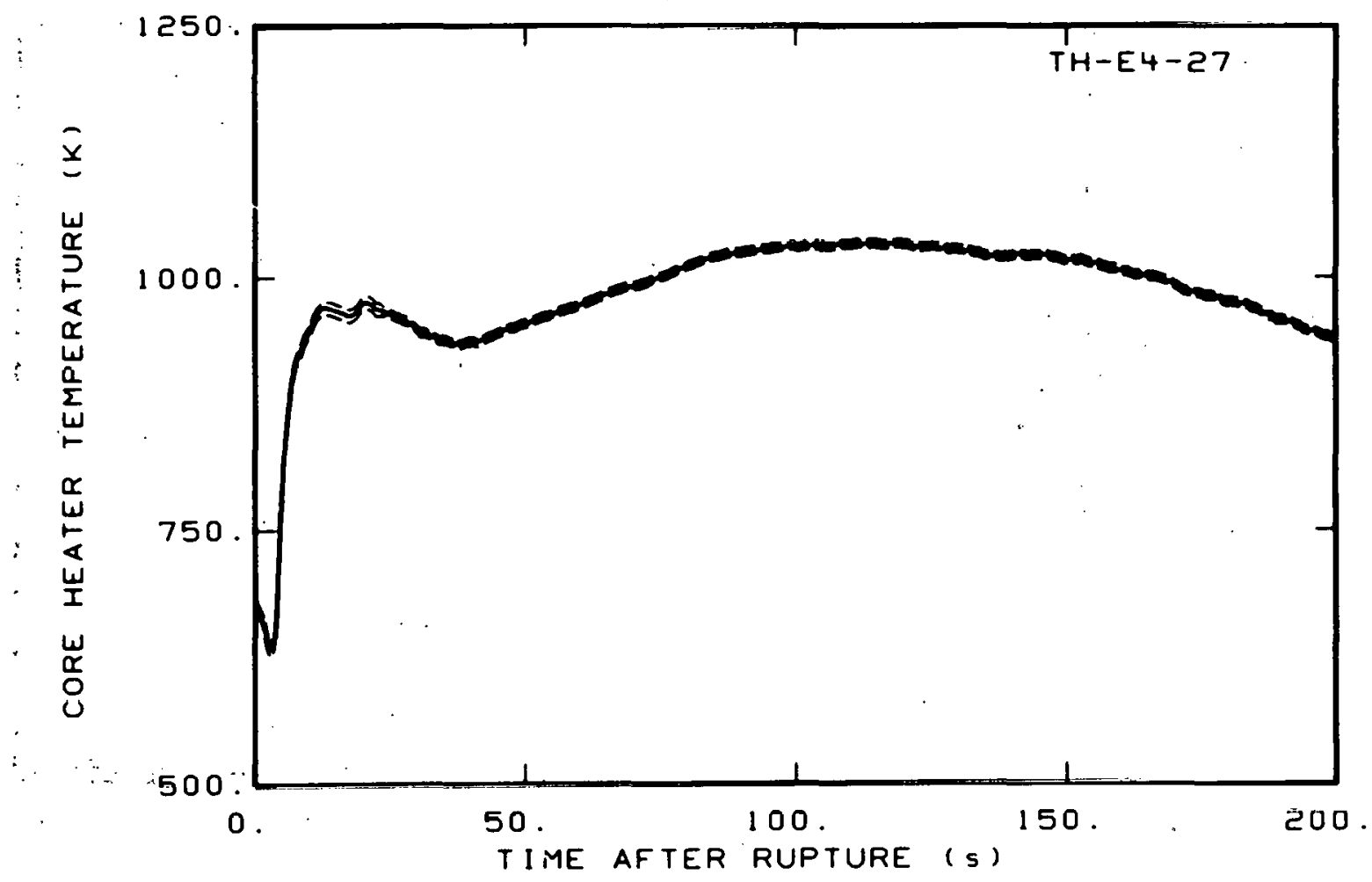

Fig. B-10 Core heater temperature, Rod E-4 (TH-E4-27). 


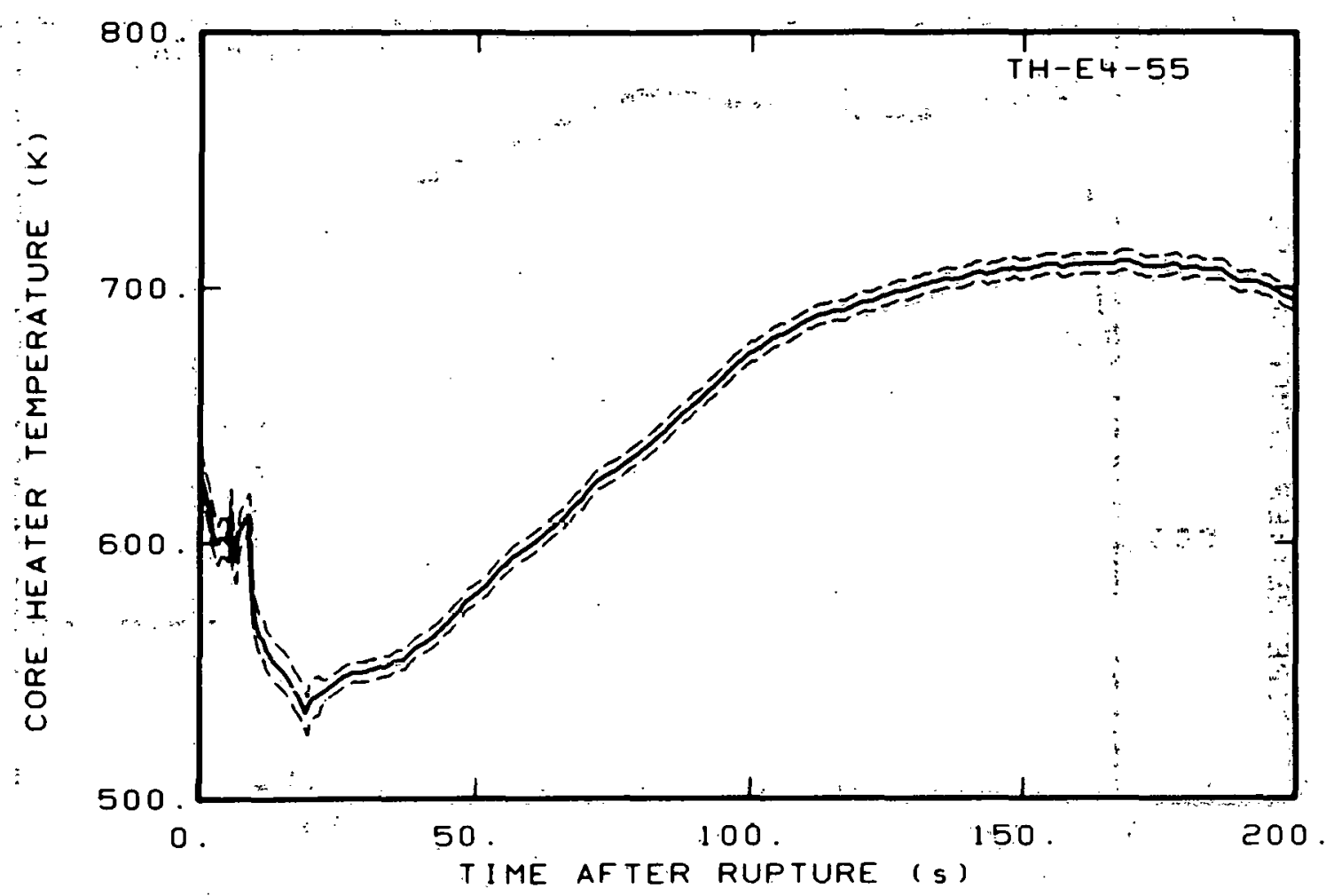

Fig. B-11 Core heater temperature, Rod E-4. (TH-E4-55).

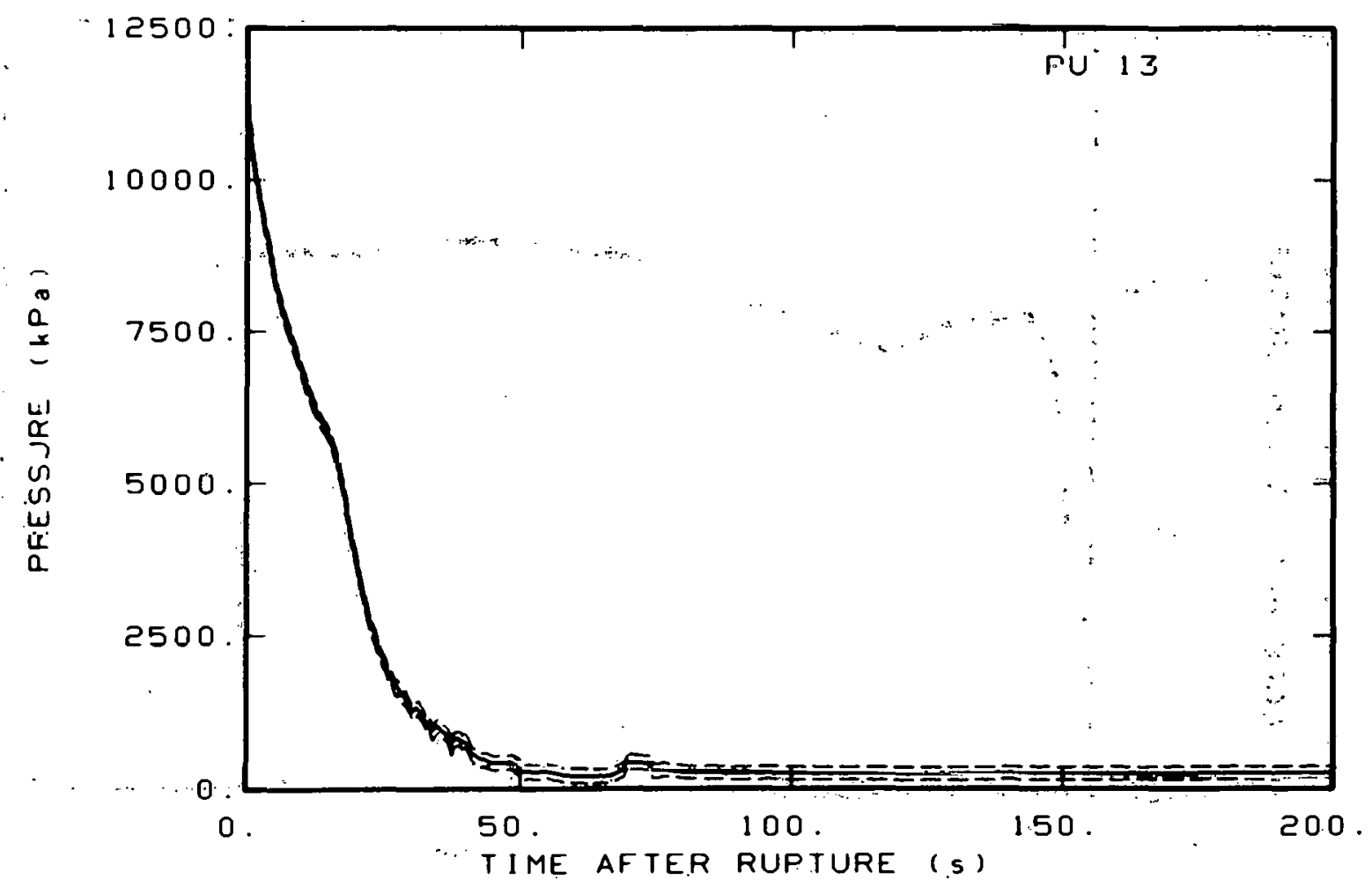

Fig. B-12 Pressure in intact 10op, Spool 13 (PU-13). 


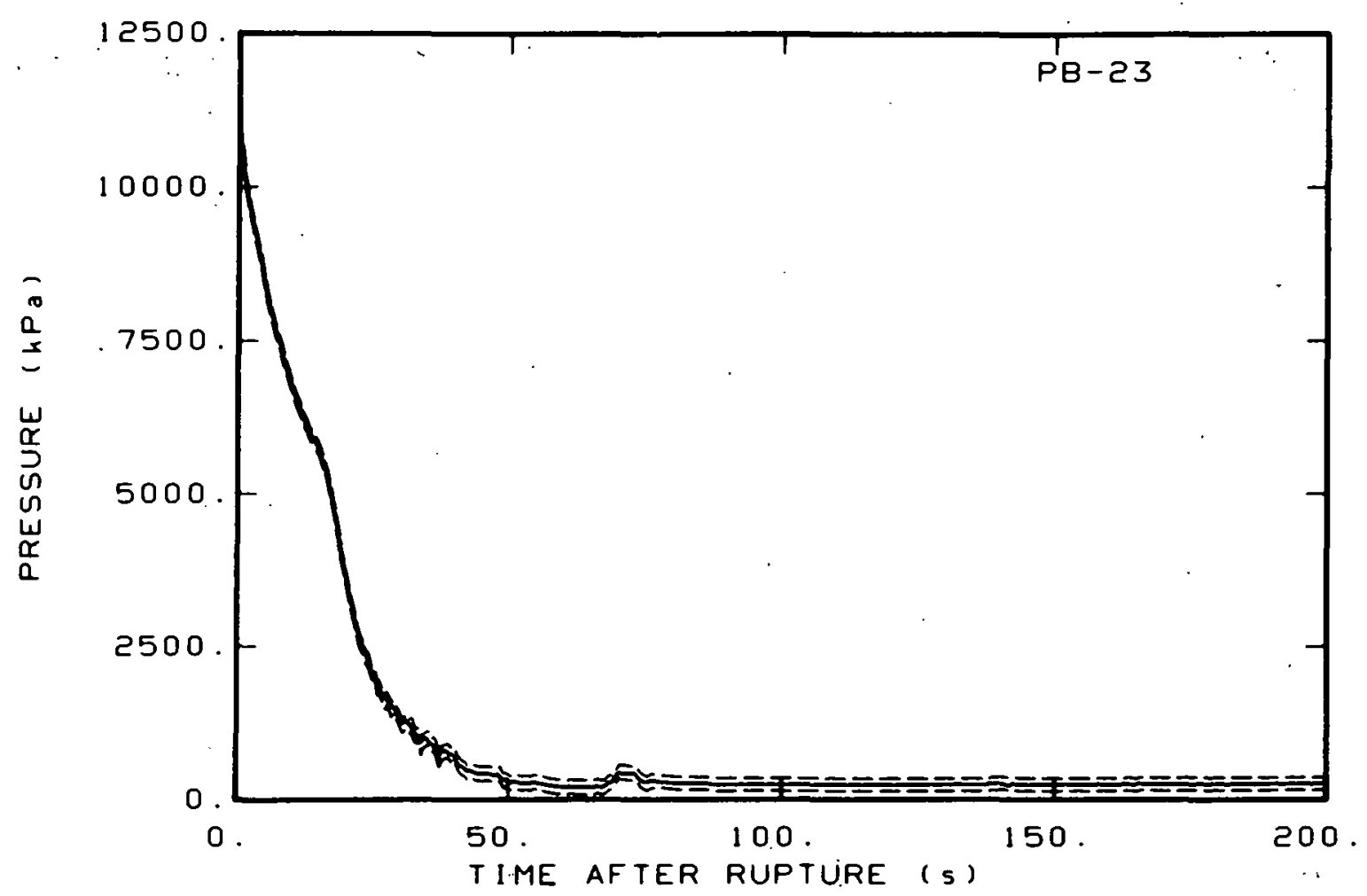

Fig. $\mathrm{B}-13$ Pressure in broken loop, Spool 23 (PB-23).

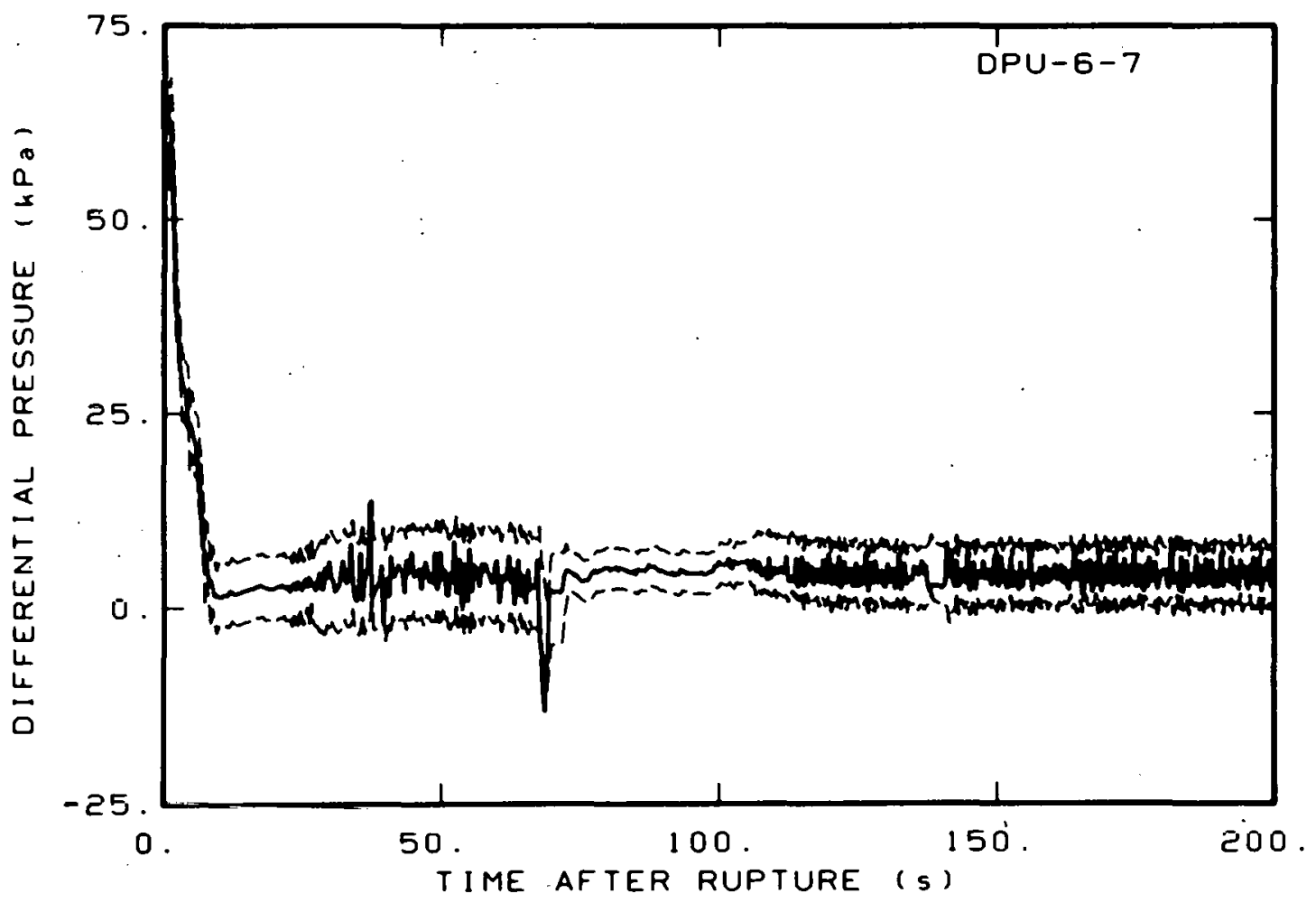

Fig. B-14 Differential pressure in intact loop (DPU-6-7). 


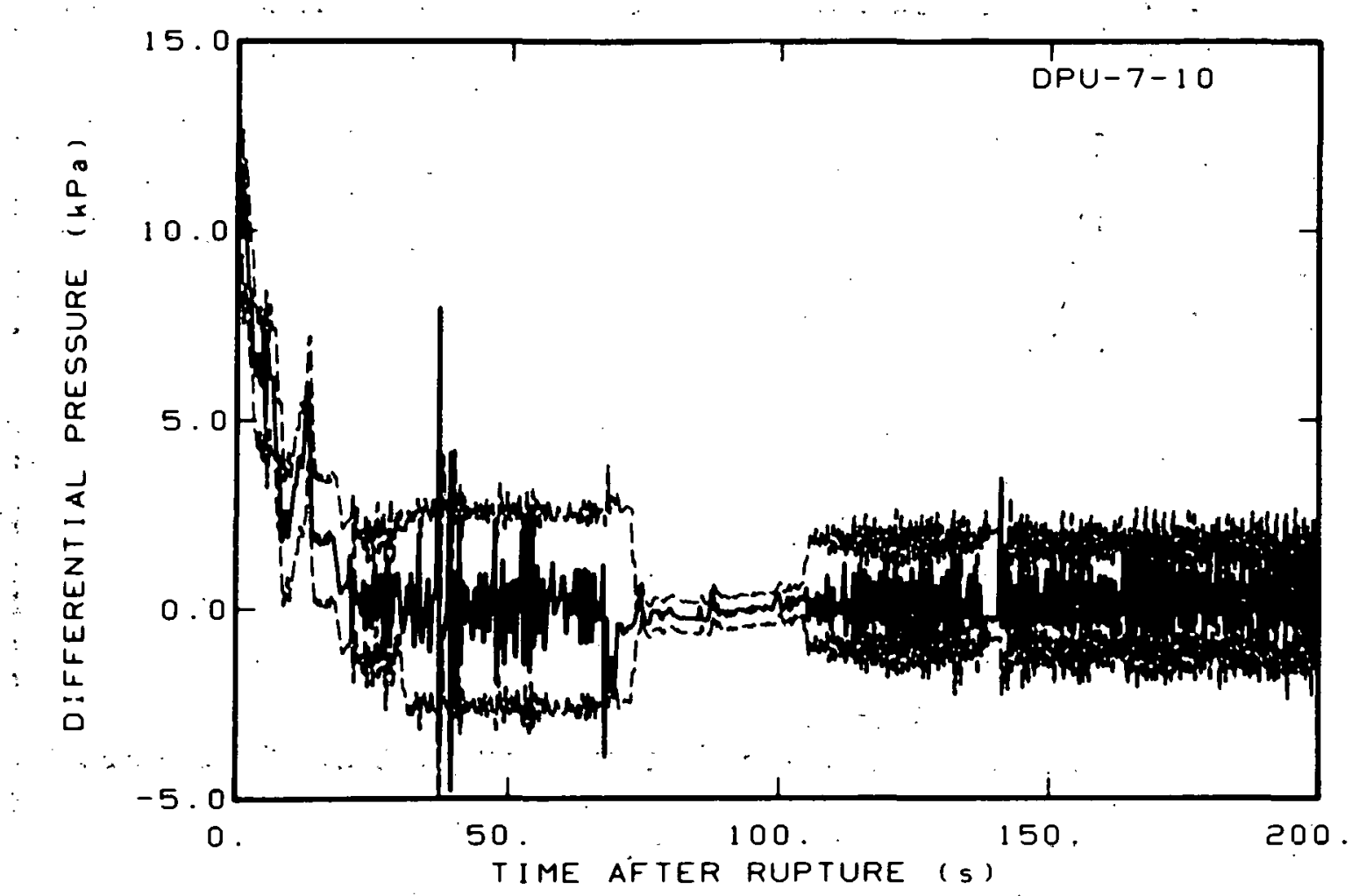

Fig. B-15 Differential pressure in intact loop (DPU-7-10).

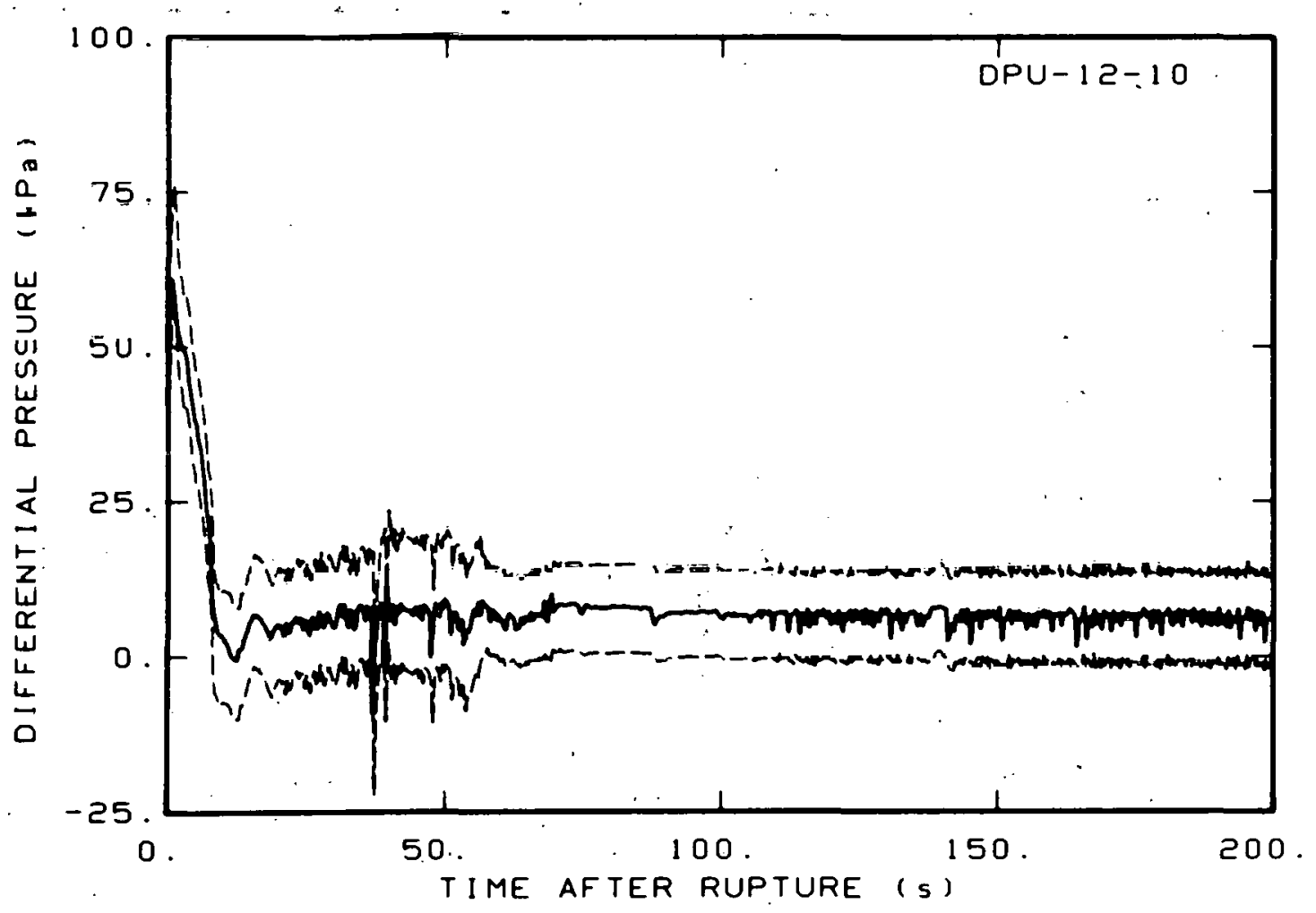

Fig. B-16 Differential pressure in intact loop (DPU-12-10). 


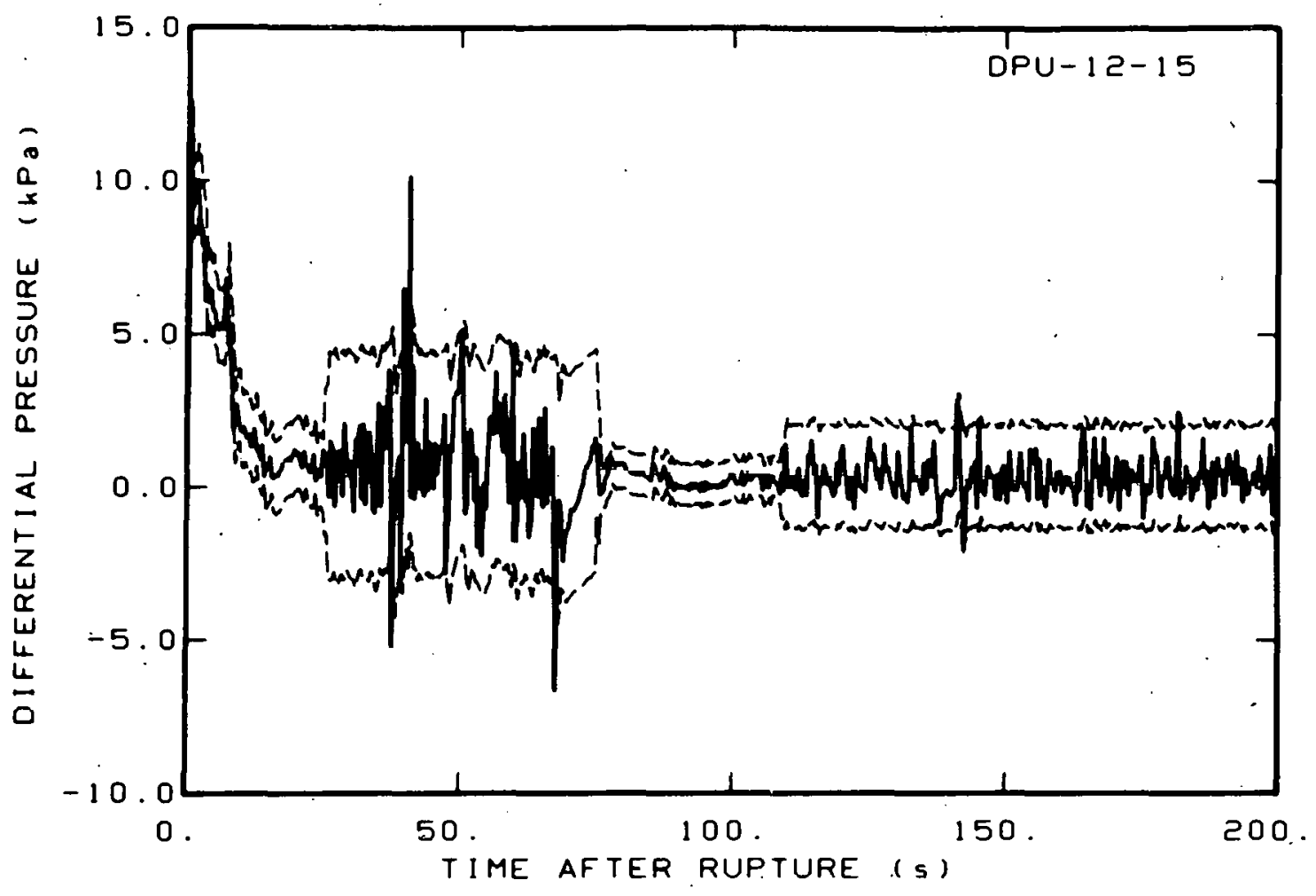

Fig. B-17 Differential pressure in intact loop (DPU-12-15).

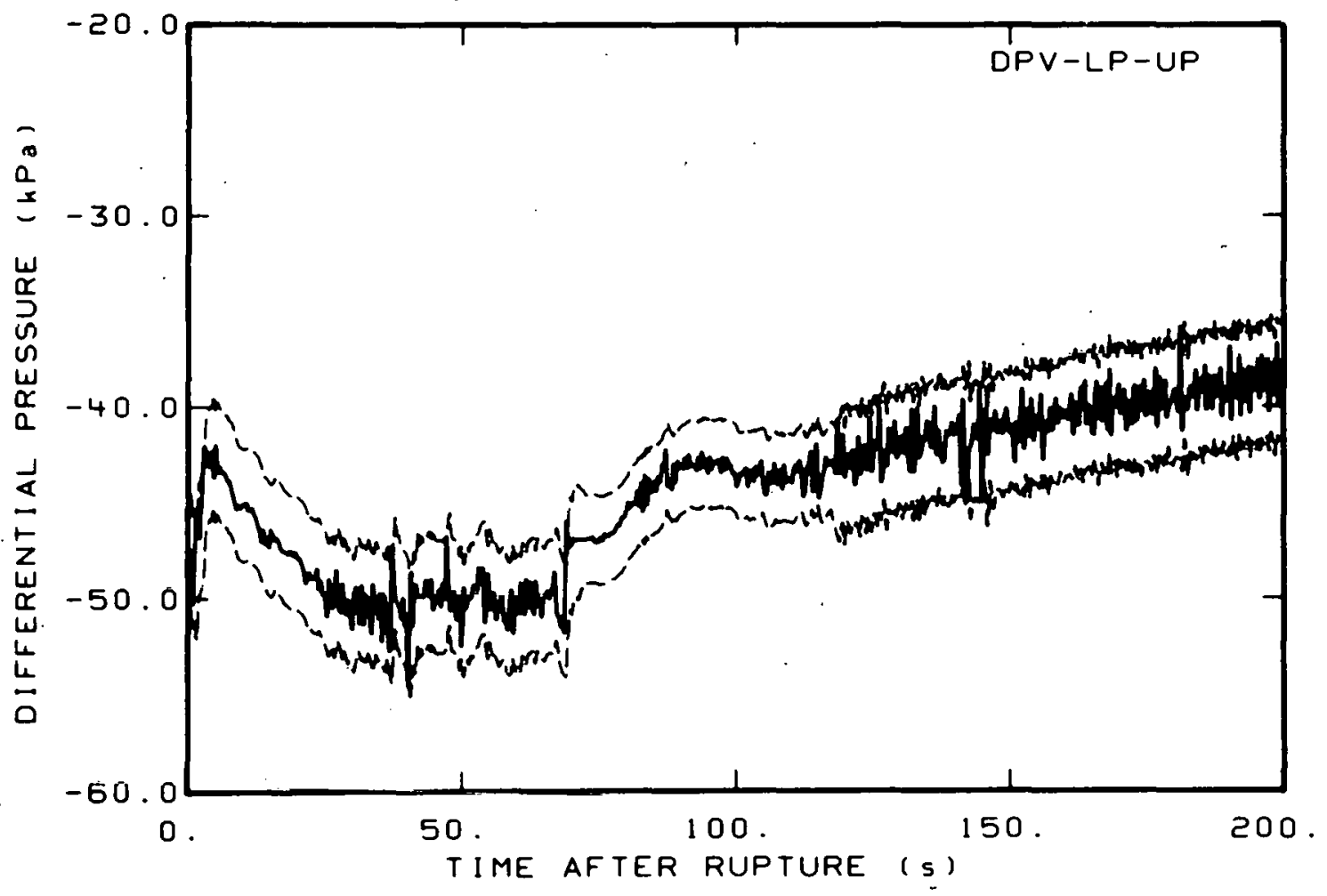

Fig. B-18 Differential pressure in vessel (DPV-LP-UP). 


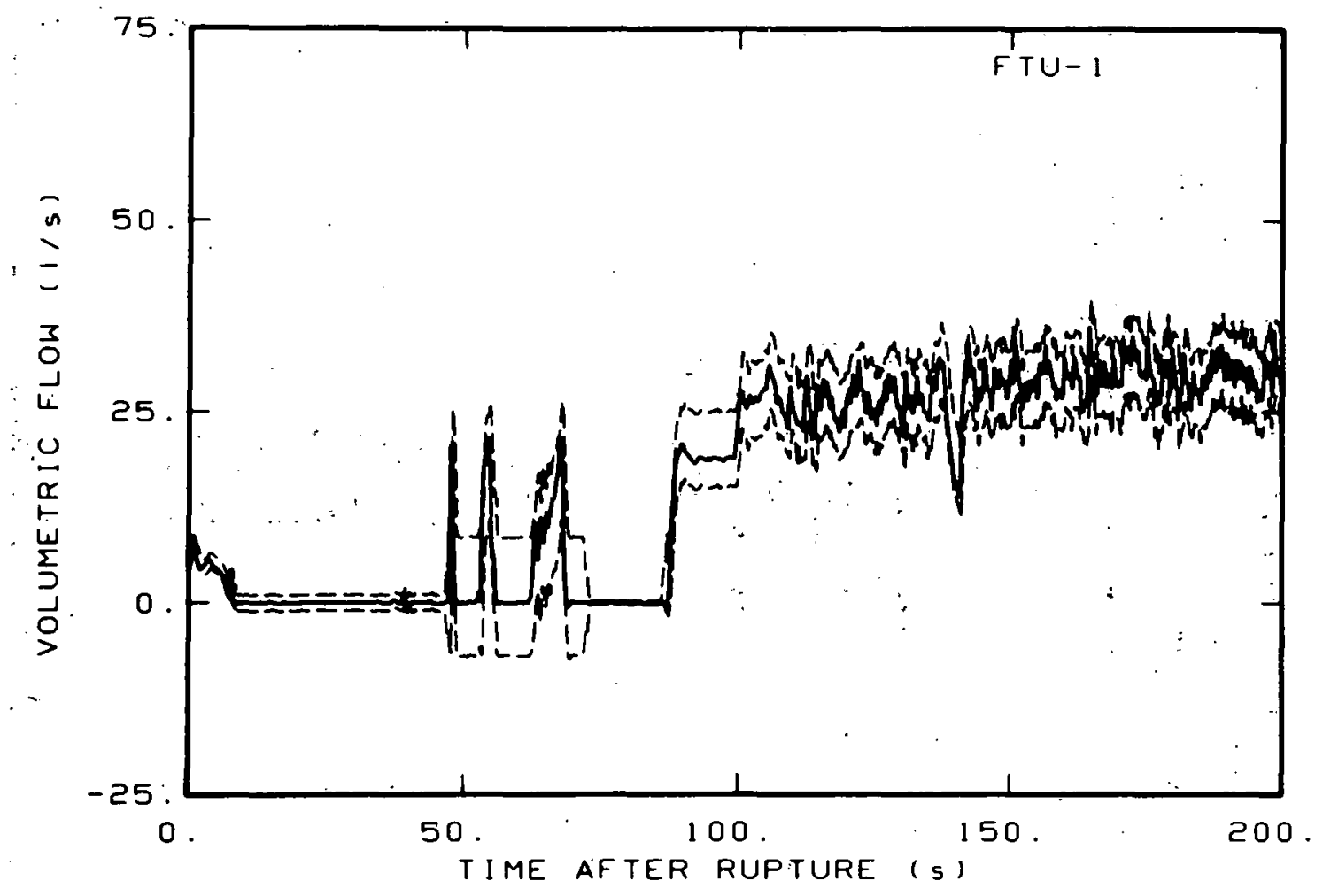

Fig. B-19 Volumetric flow in intact loop (FTU-1).

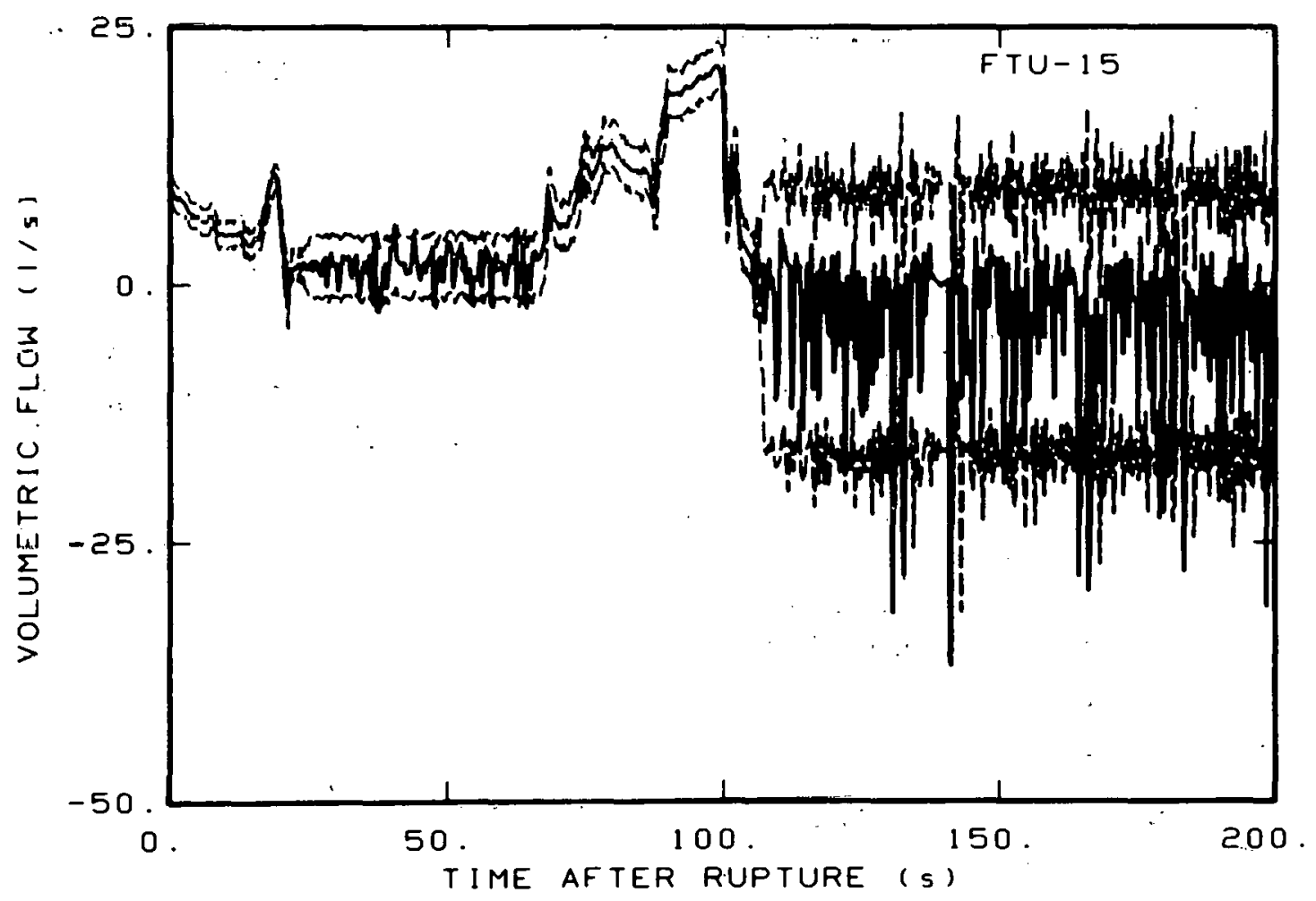

Fig. B-20 Volumetric flow in intact loop. (FTU-15). 


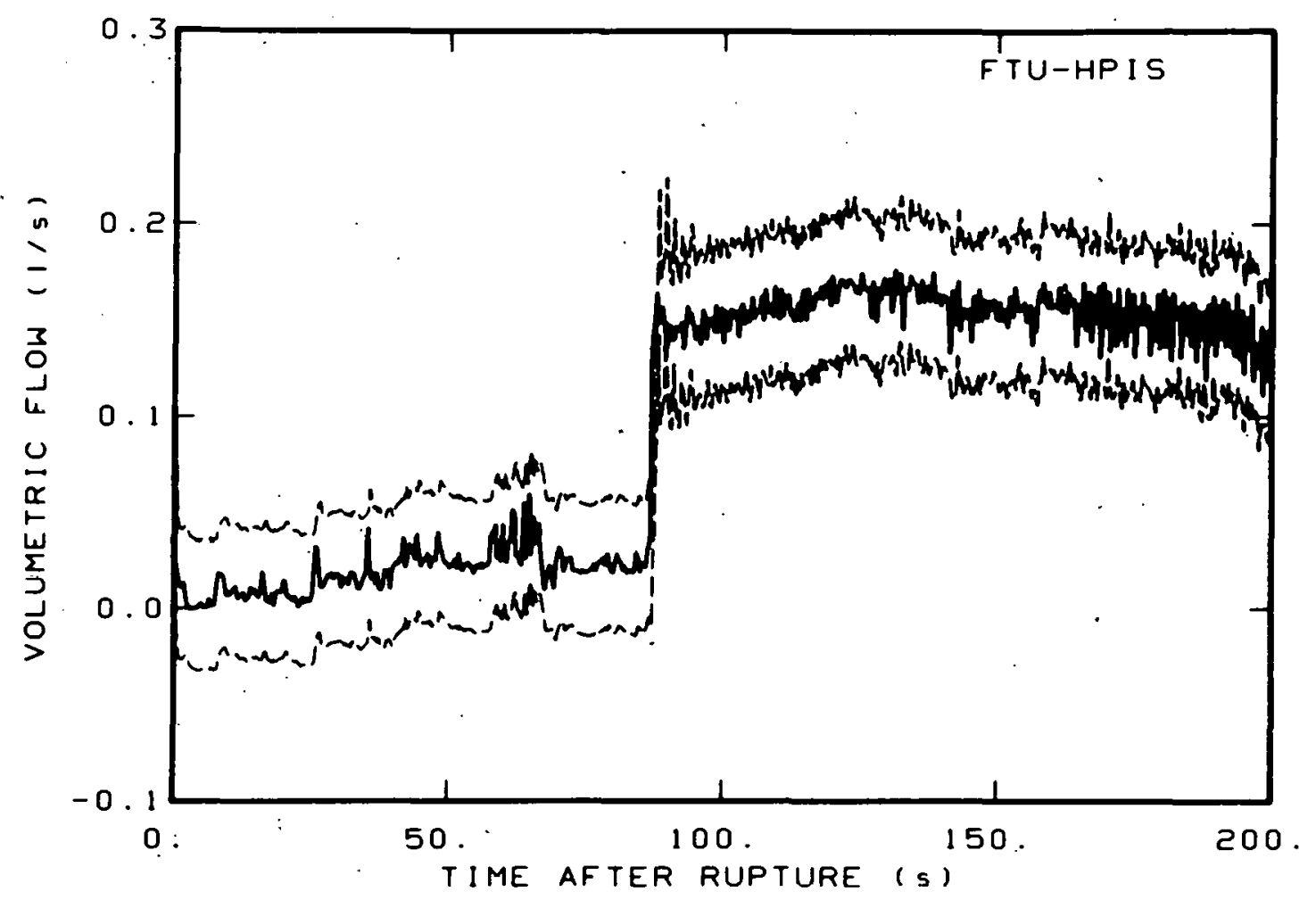

Fig. B-21 Volumetric flow in intact loop high pressure injection line: (FTU-HPIS).

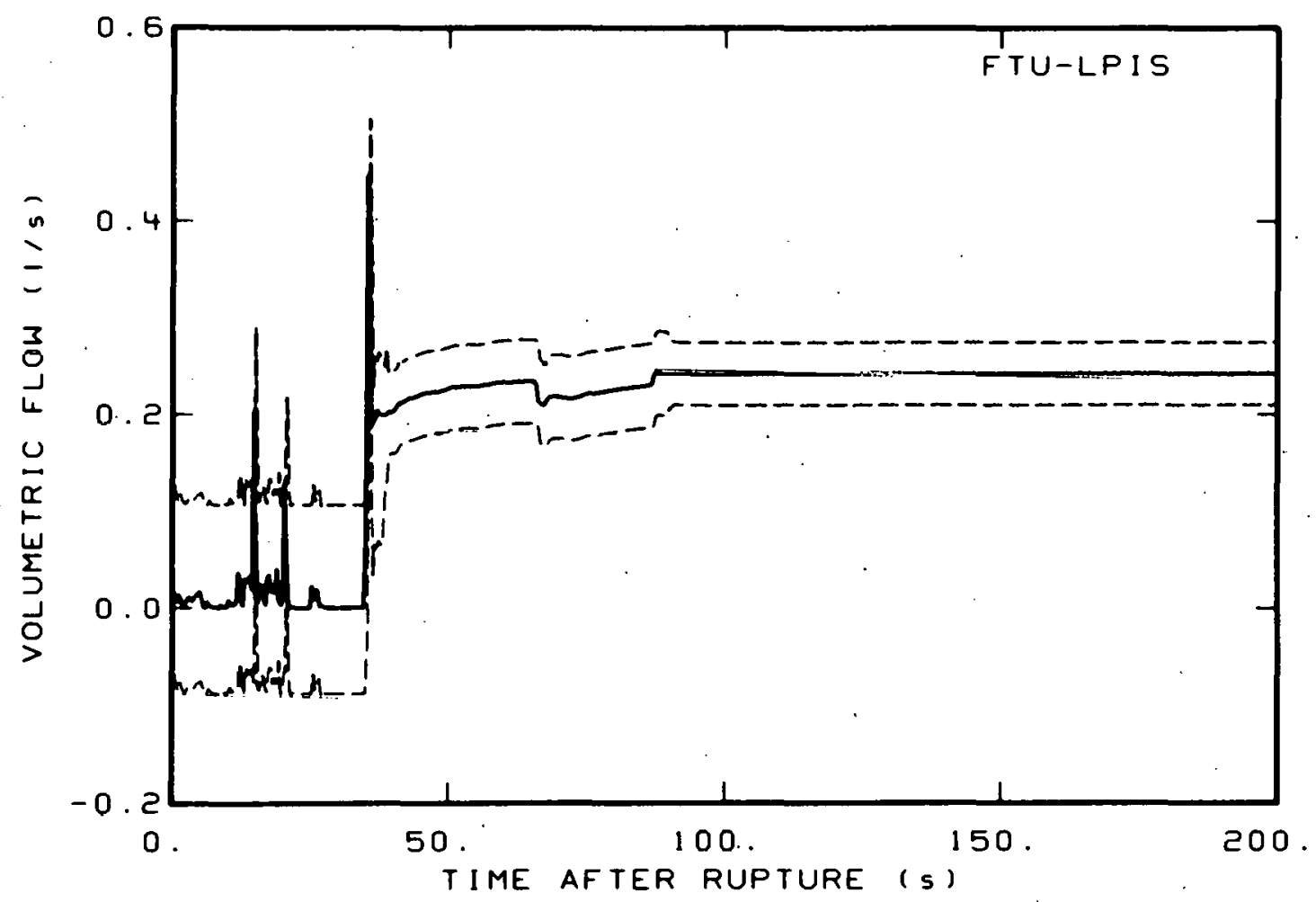

Fig. B-22 Volumetric flow in intact loop low pressure injection line (FTU-LPIS). 


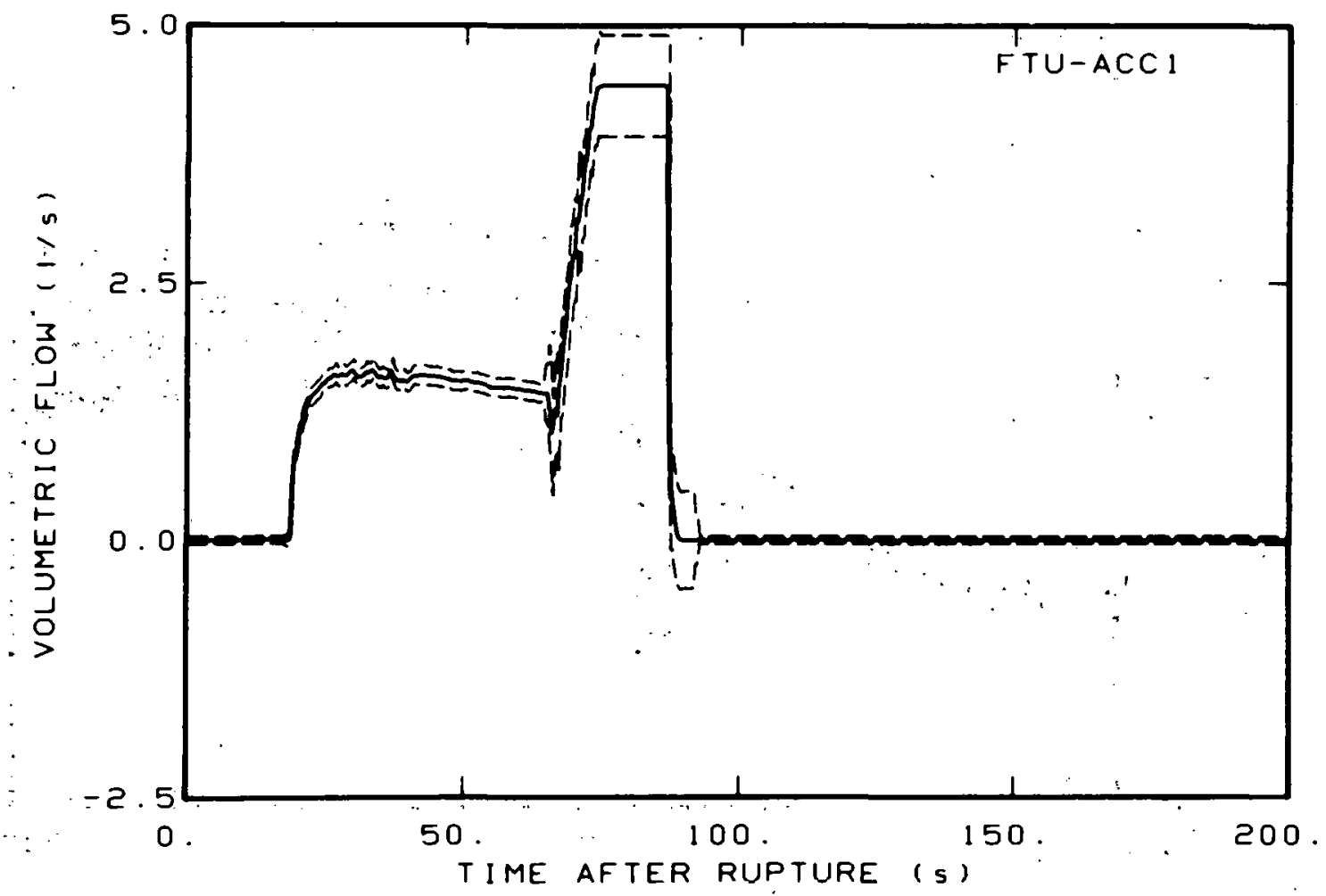

Fig. B-23 Volumetric flow in intact loop accumulator discharge line (FTU-ACC1).

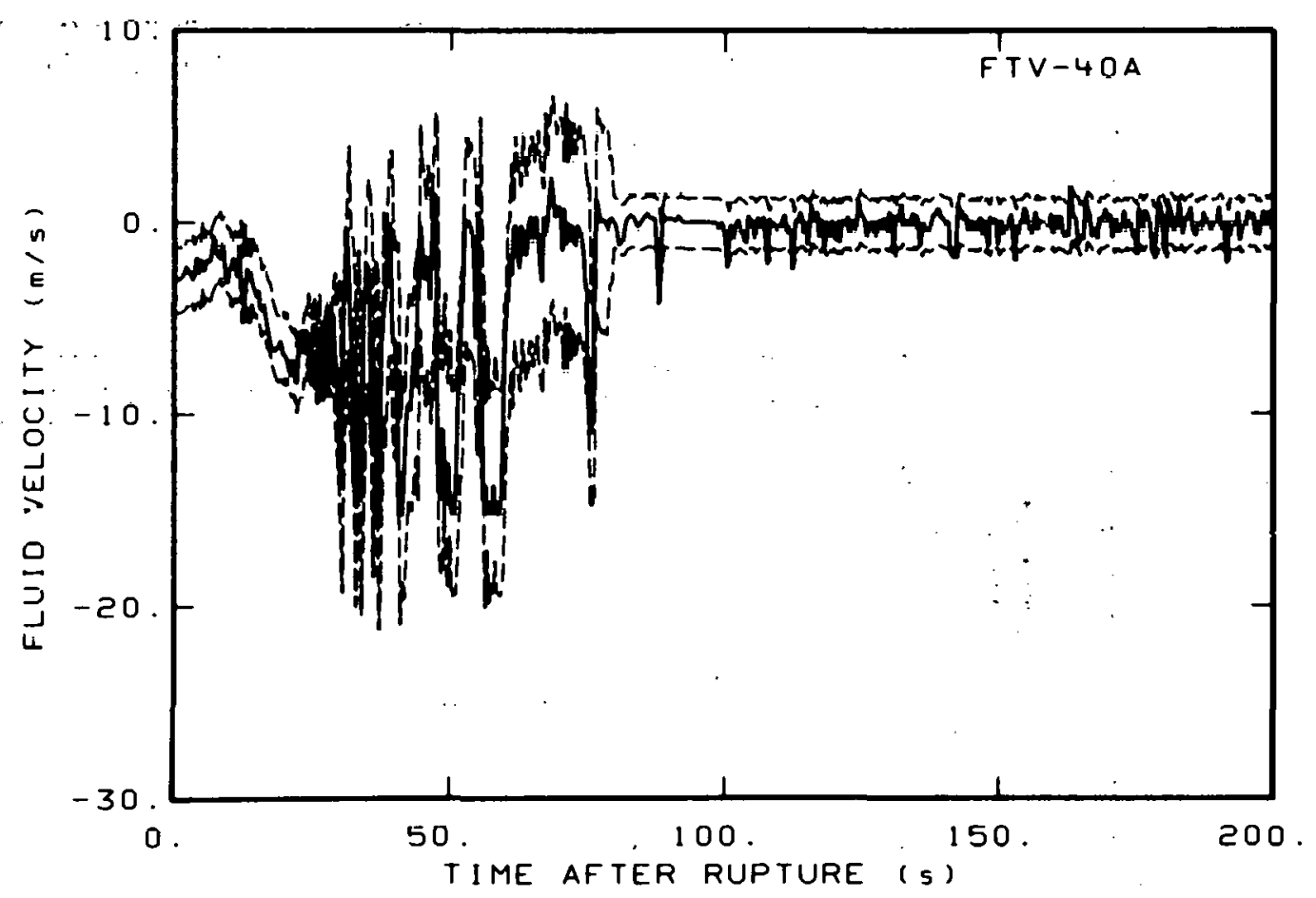

Fig. B-24 Fluid velocity in vessel (FTV-40A). 


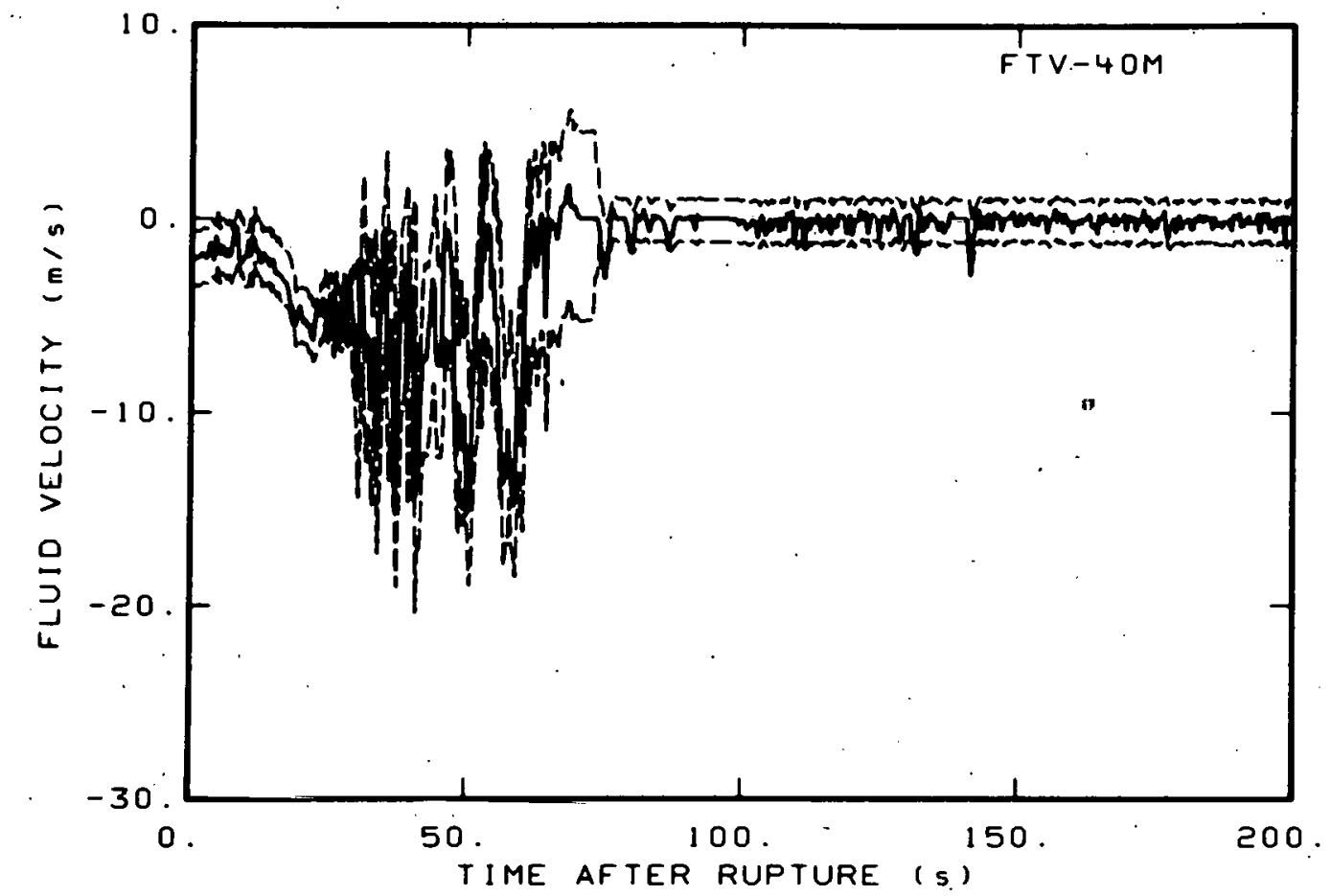

Fig. B-25 Fluid velocity in vessel (FTV-40M).

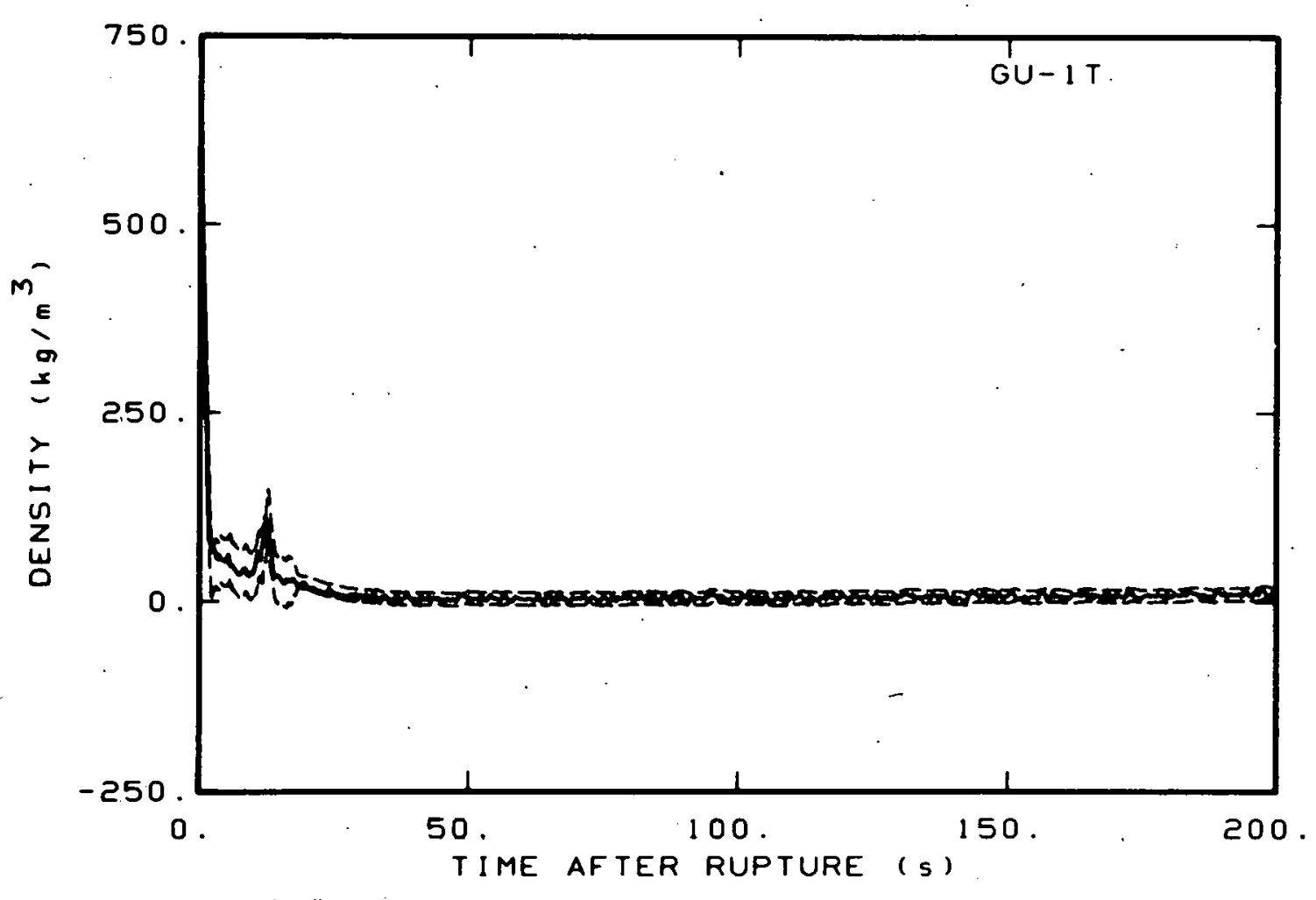

Fig. B-26 Density in intact loop (GU-1T). 


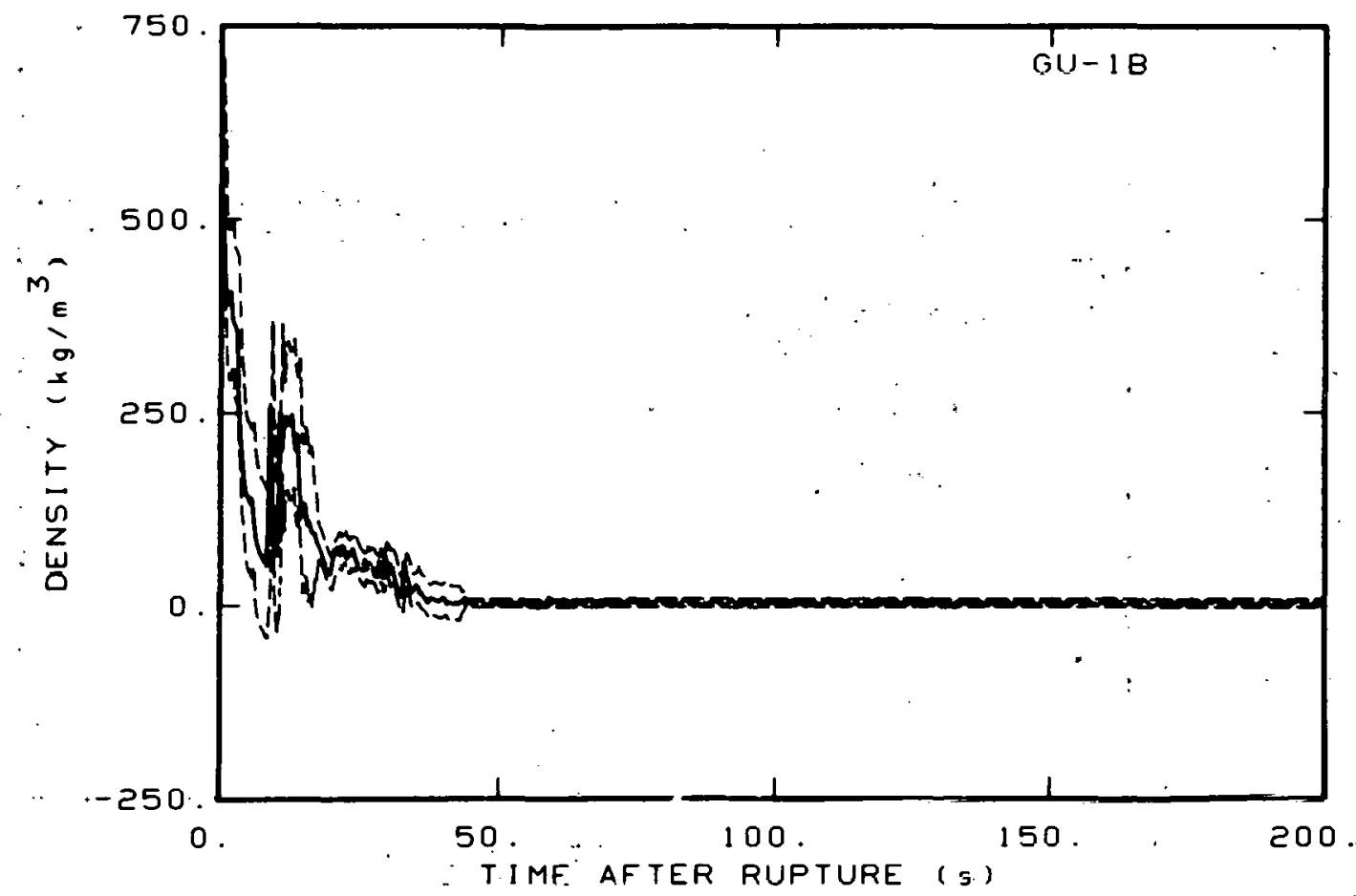

Fig. B-27 Density in intact loop (GU-1B).

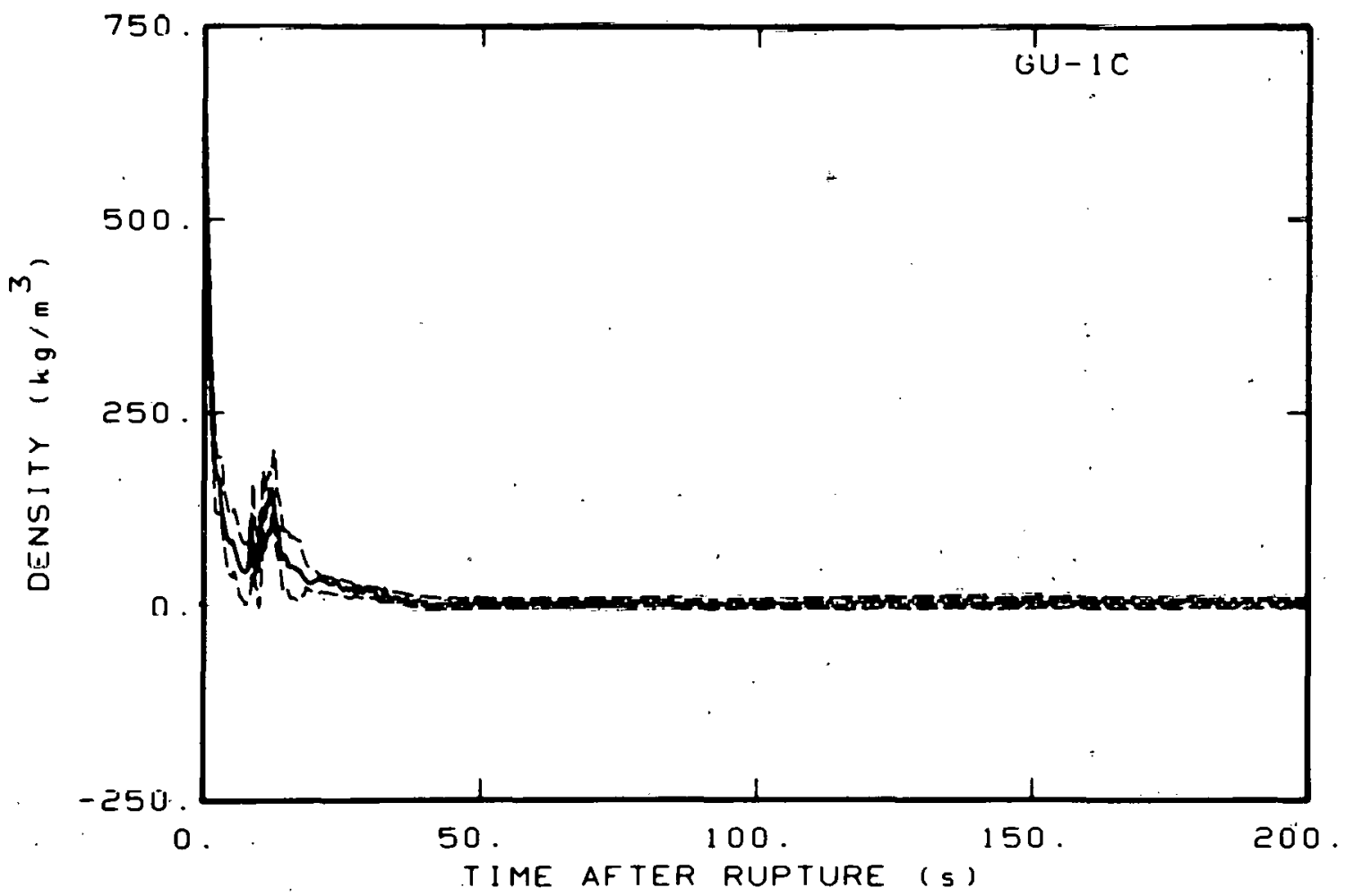

Fig. B-28 Density in intact 100p (GU-1C). 


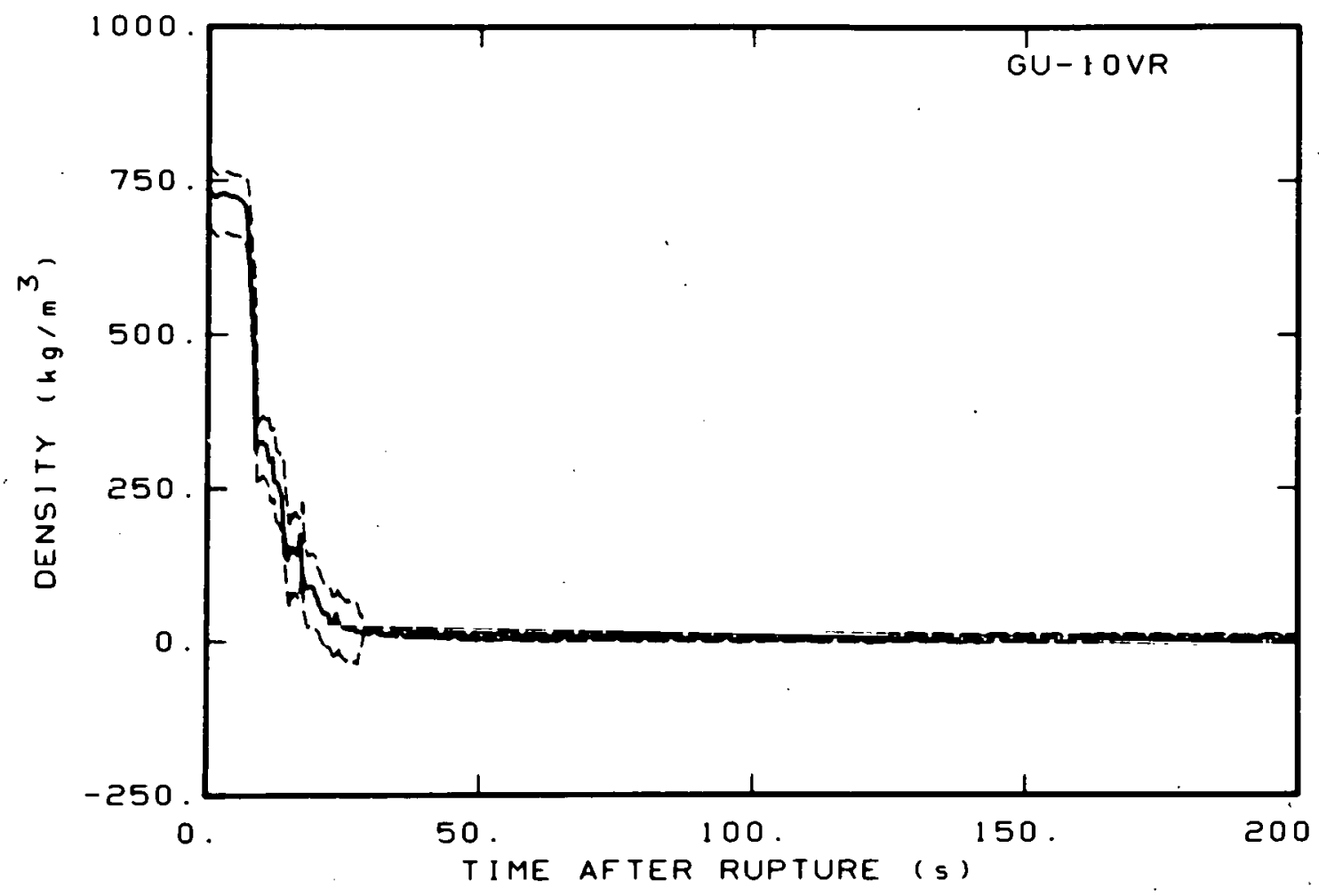

Fig. B-29 Density in intact loop (GU-10VR).

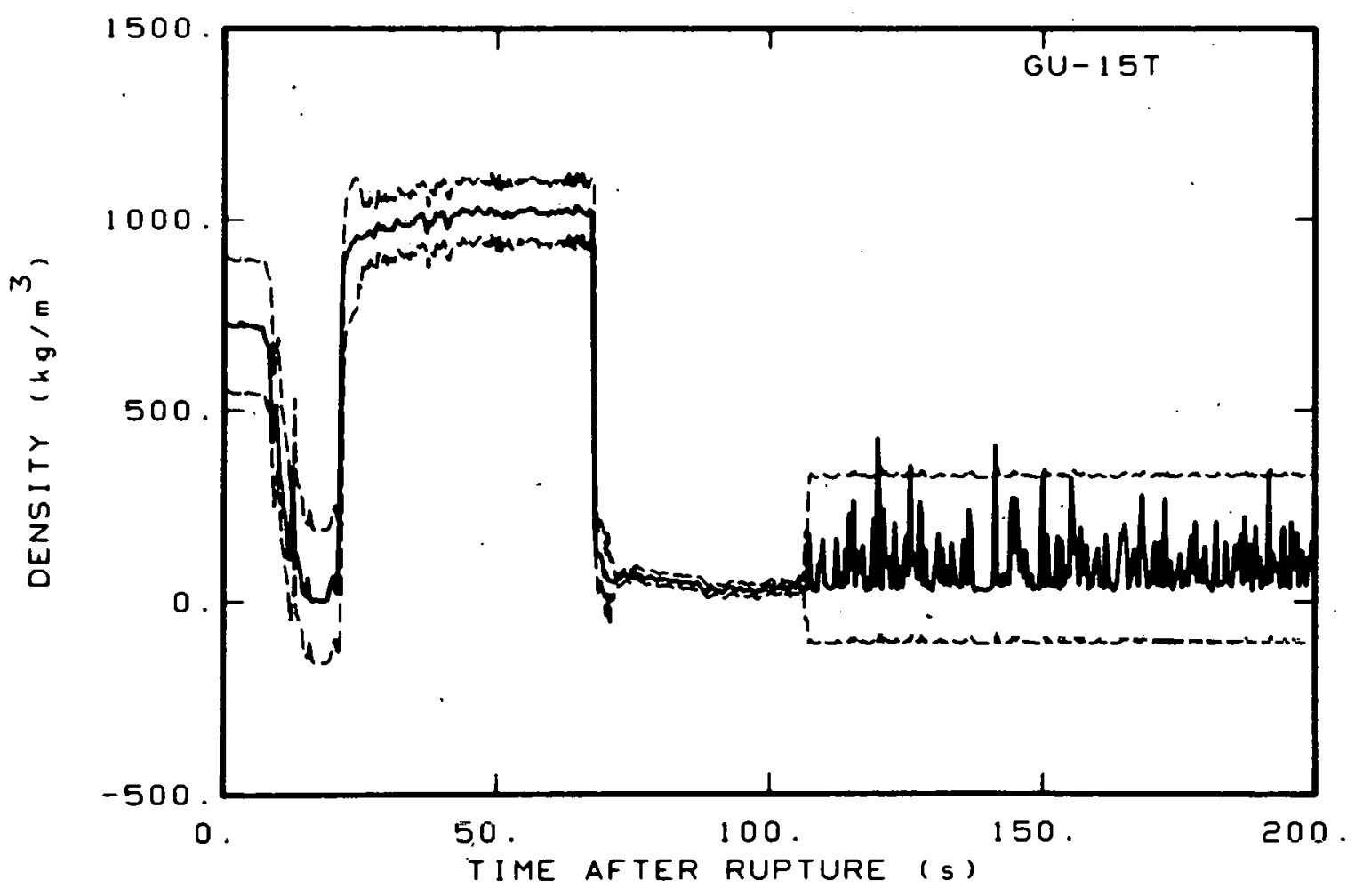

Fig. B=30 Density in intact loop (GU-15T). 


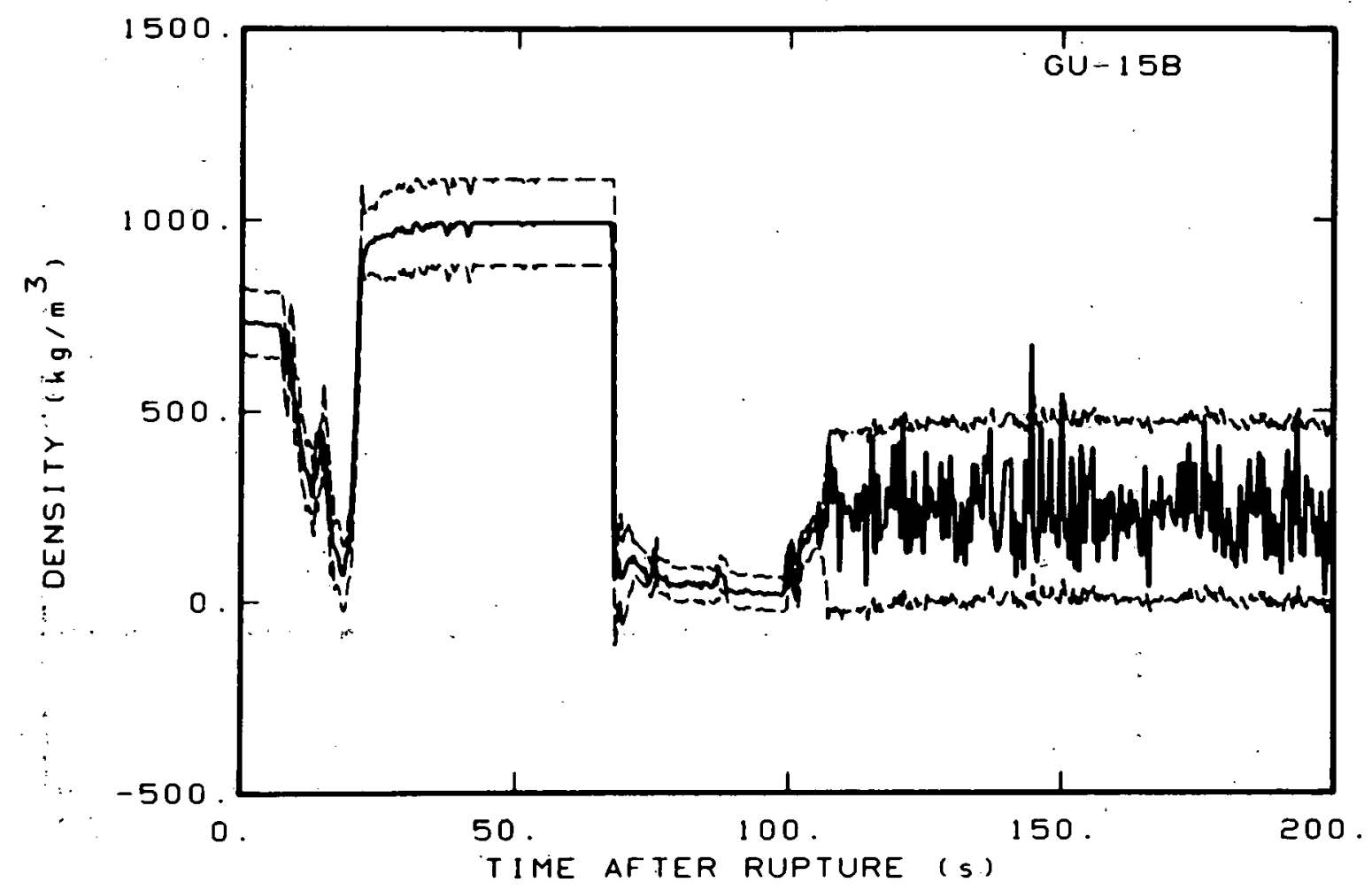

Fig. B-31 Density in intact loop (GU-15B).

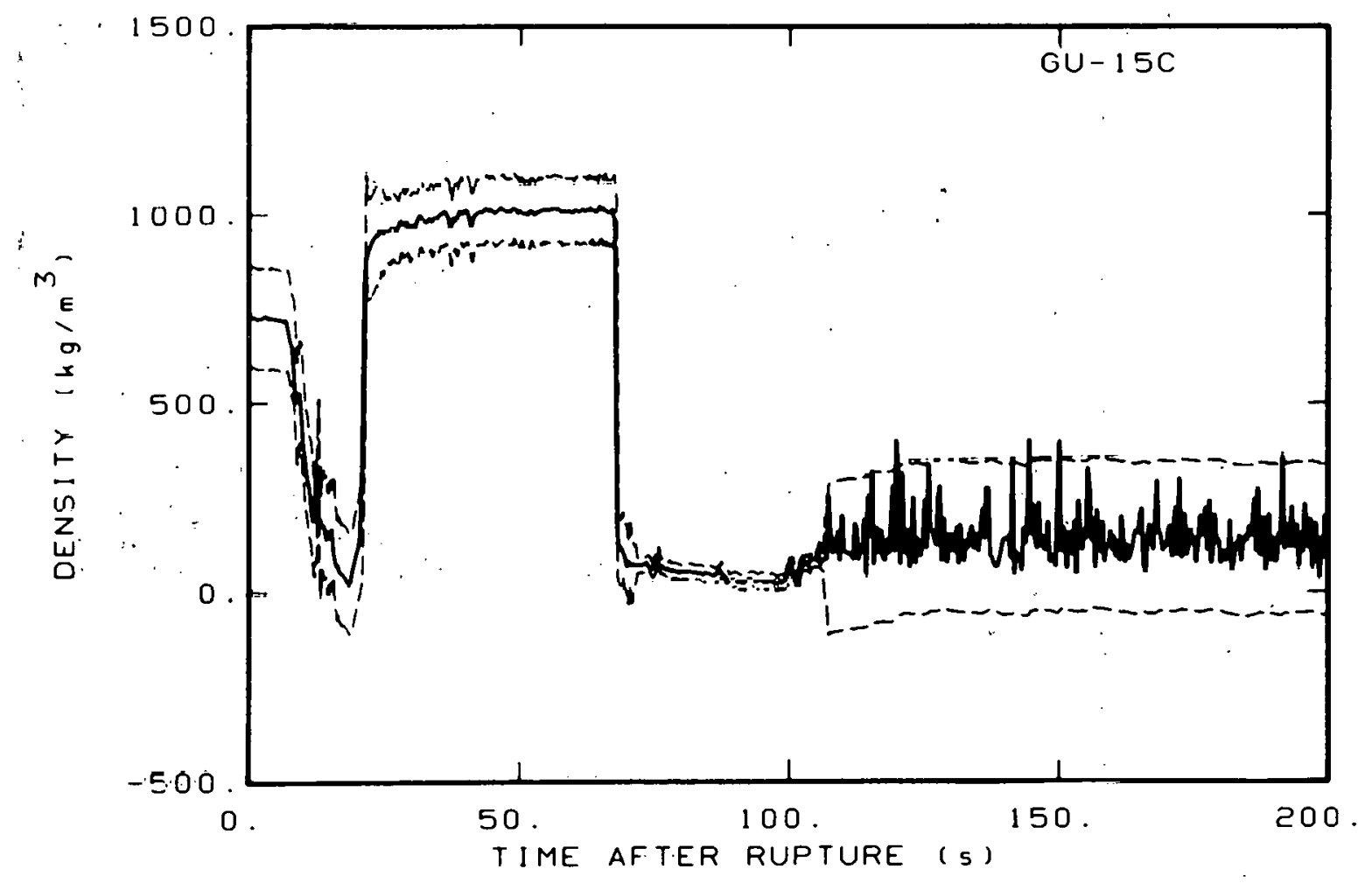

Fig. B-32 Density in intact loop (GU-15C). 


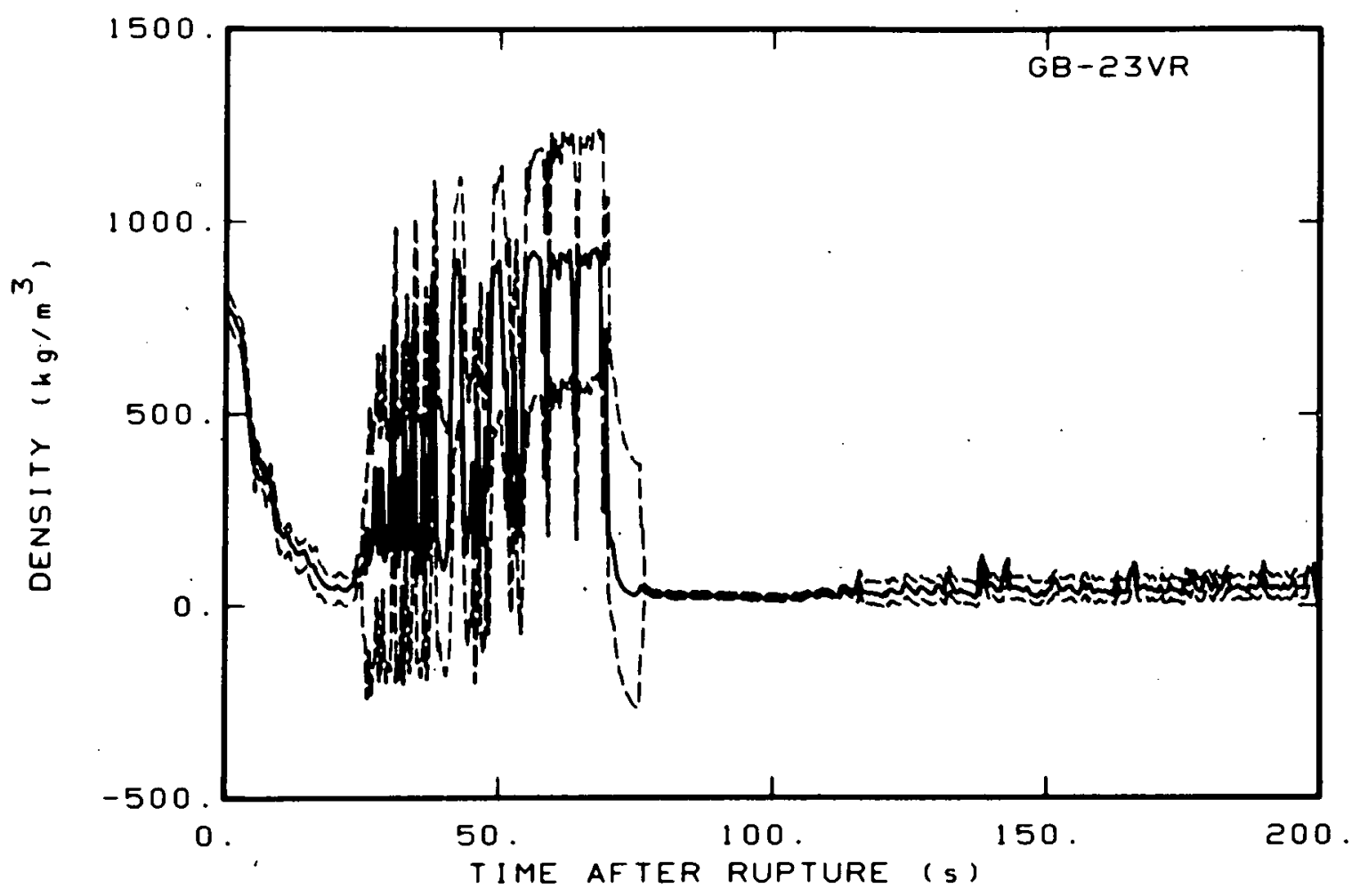

Fig. B-33 Density in broken loop (GB-23VR).

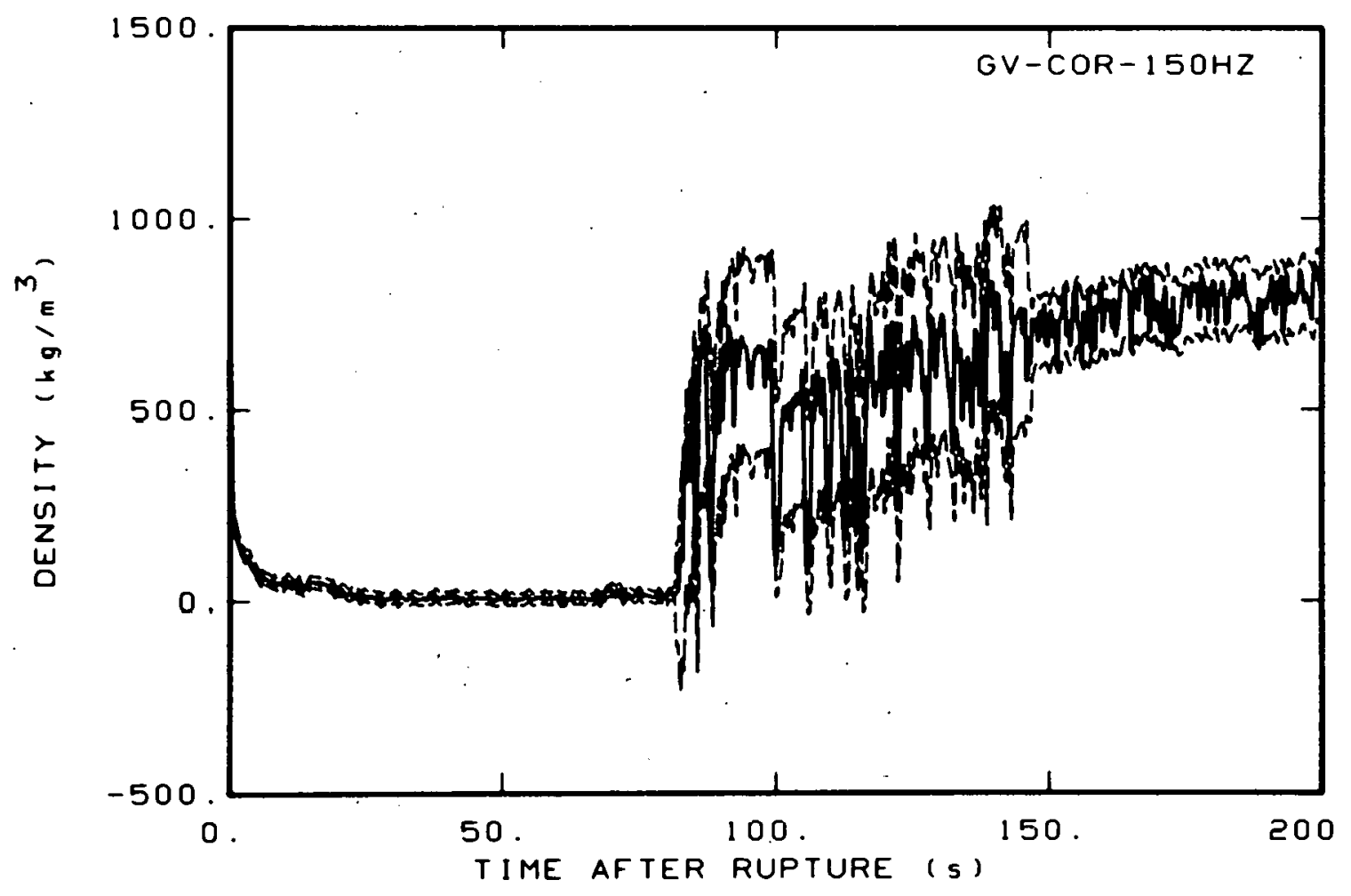

Fig. B-31 Density in vessel (GV-COR-150HZ). 


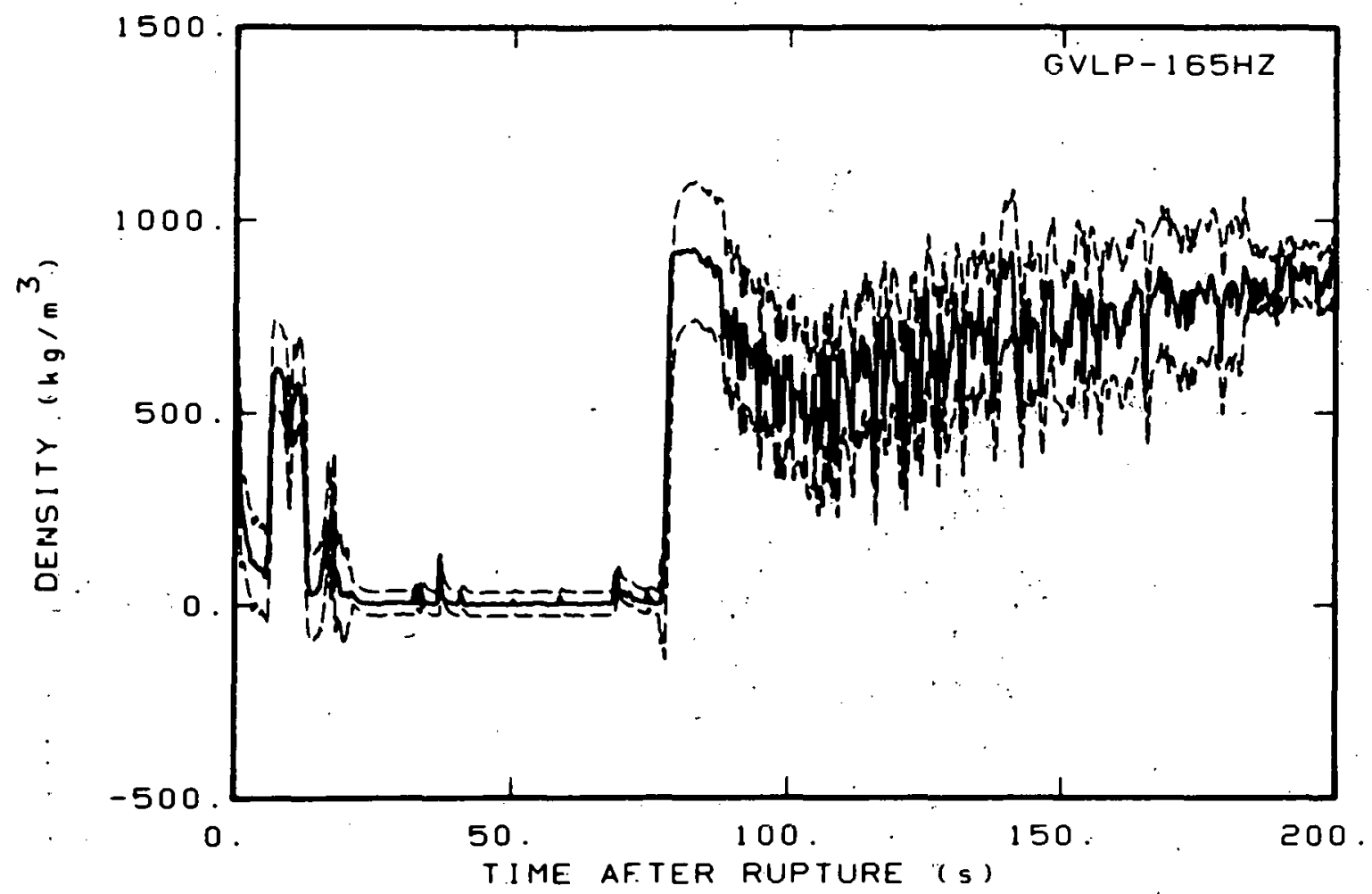

Fig. B-35 Density in vessel (GVLP-165HZ).

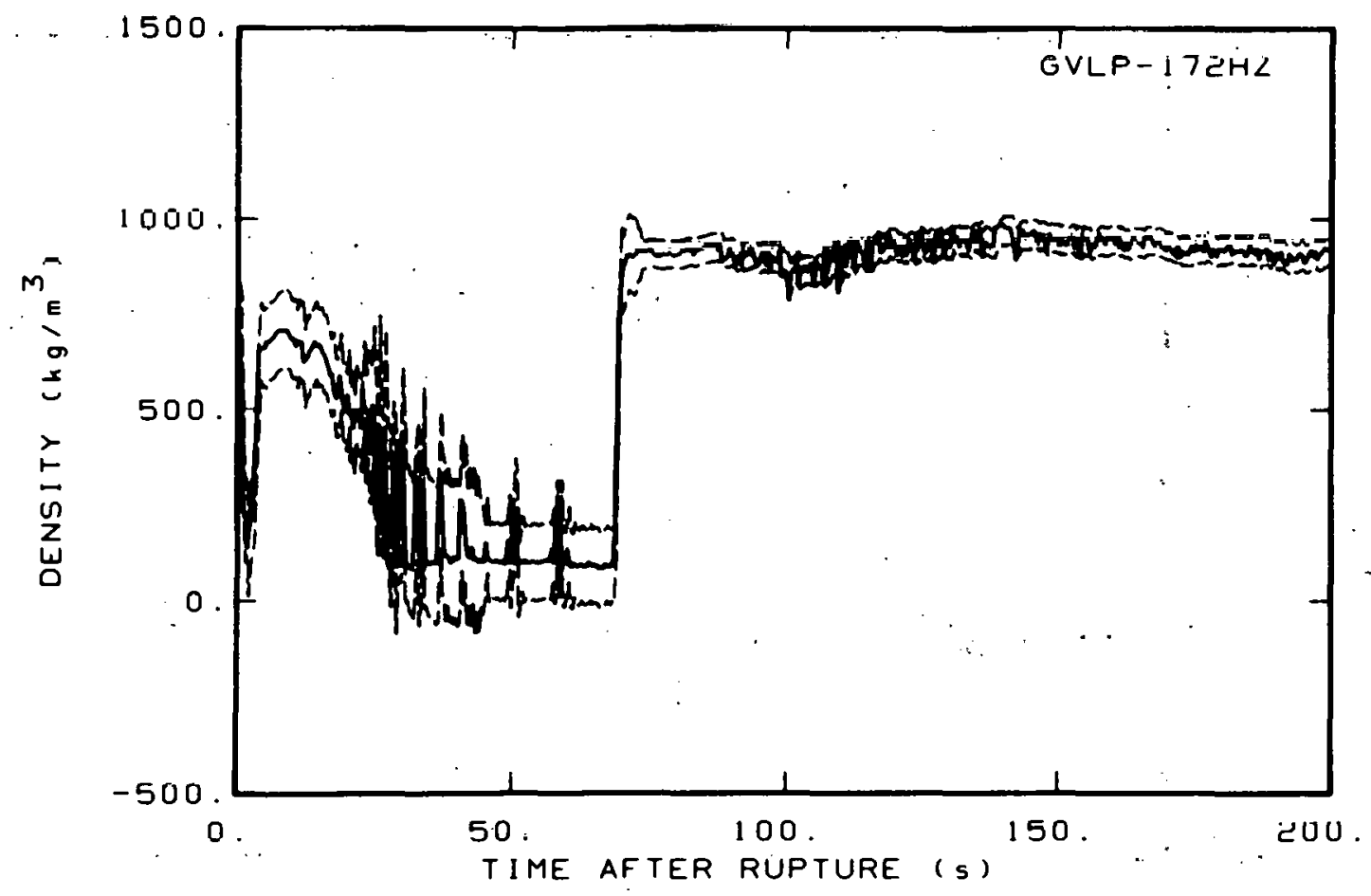

Fig. B-36 Density in vessel (GVLP-172HZ). 


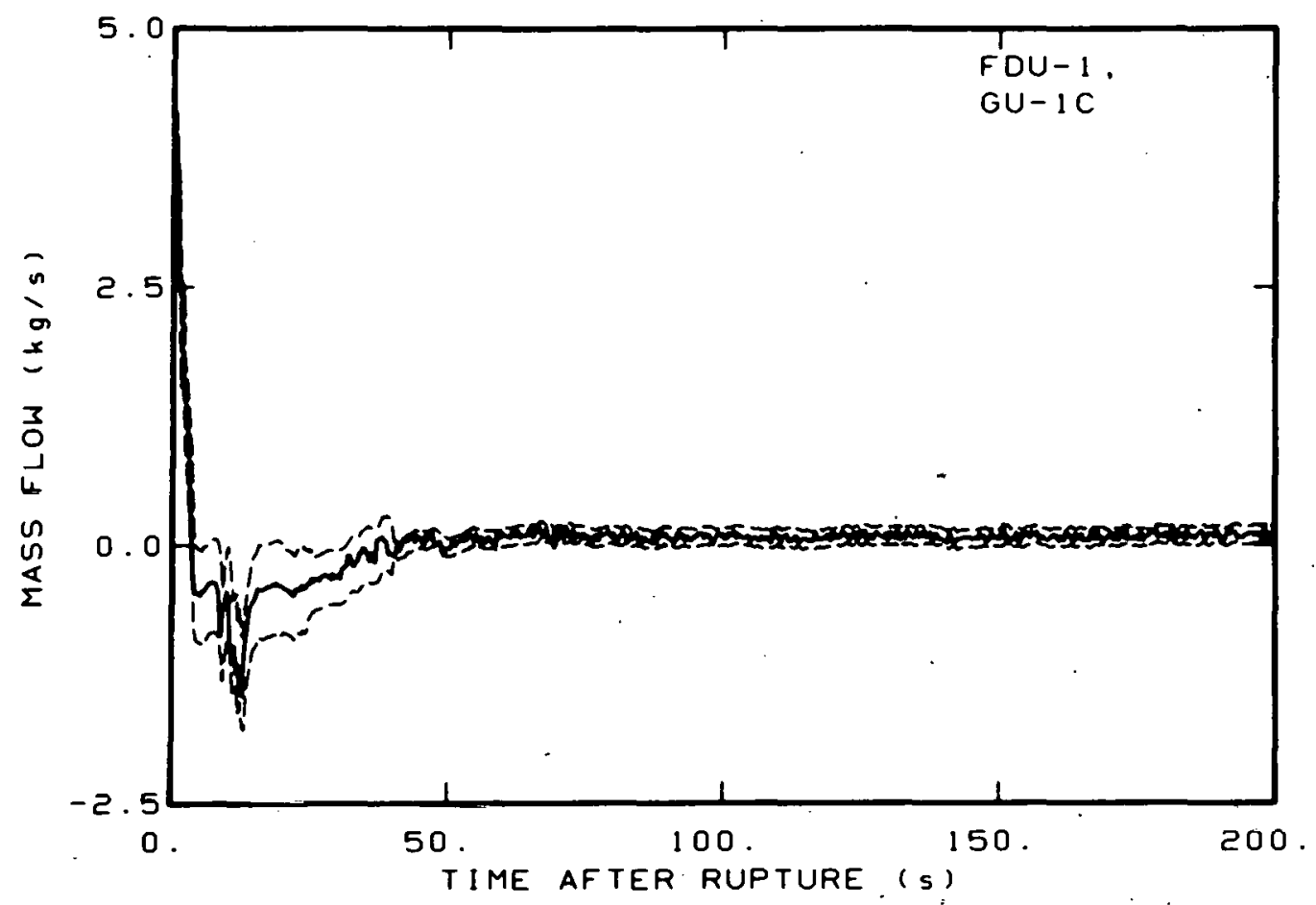

Fig. B-37 Mass flow in intact loop (FDU-1, GU-1C).

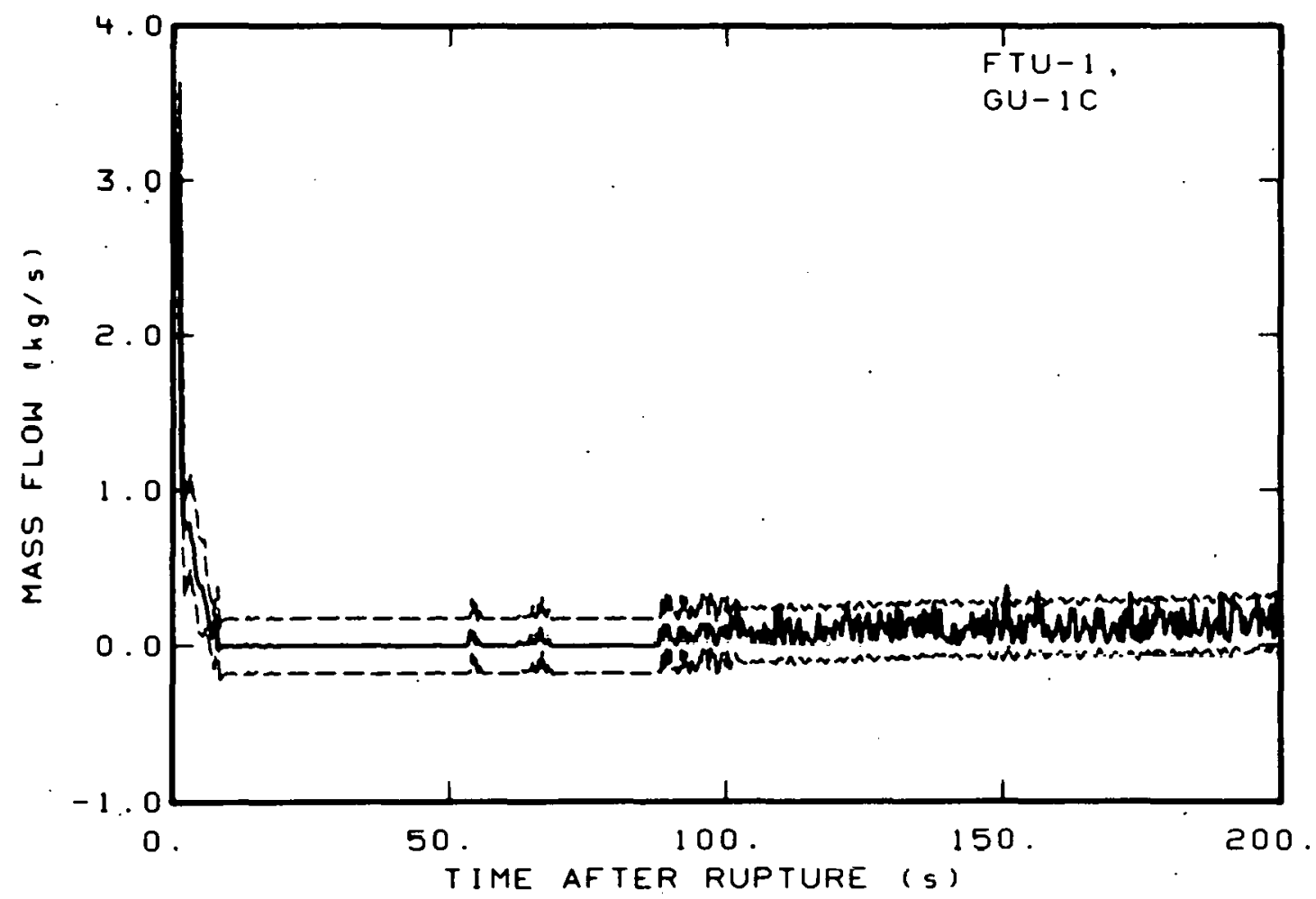

Fig. B-38 Mass flow in intact loop (FTU-1, GU-1C). 


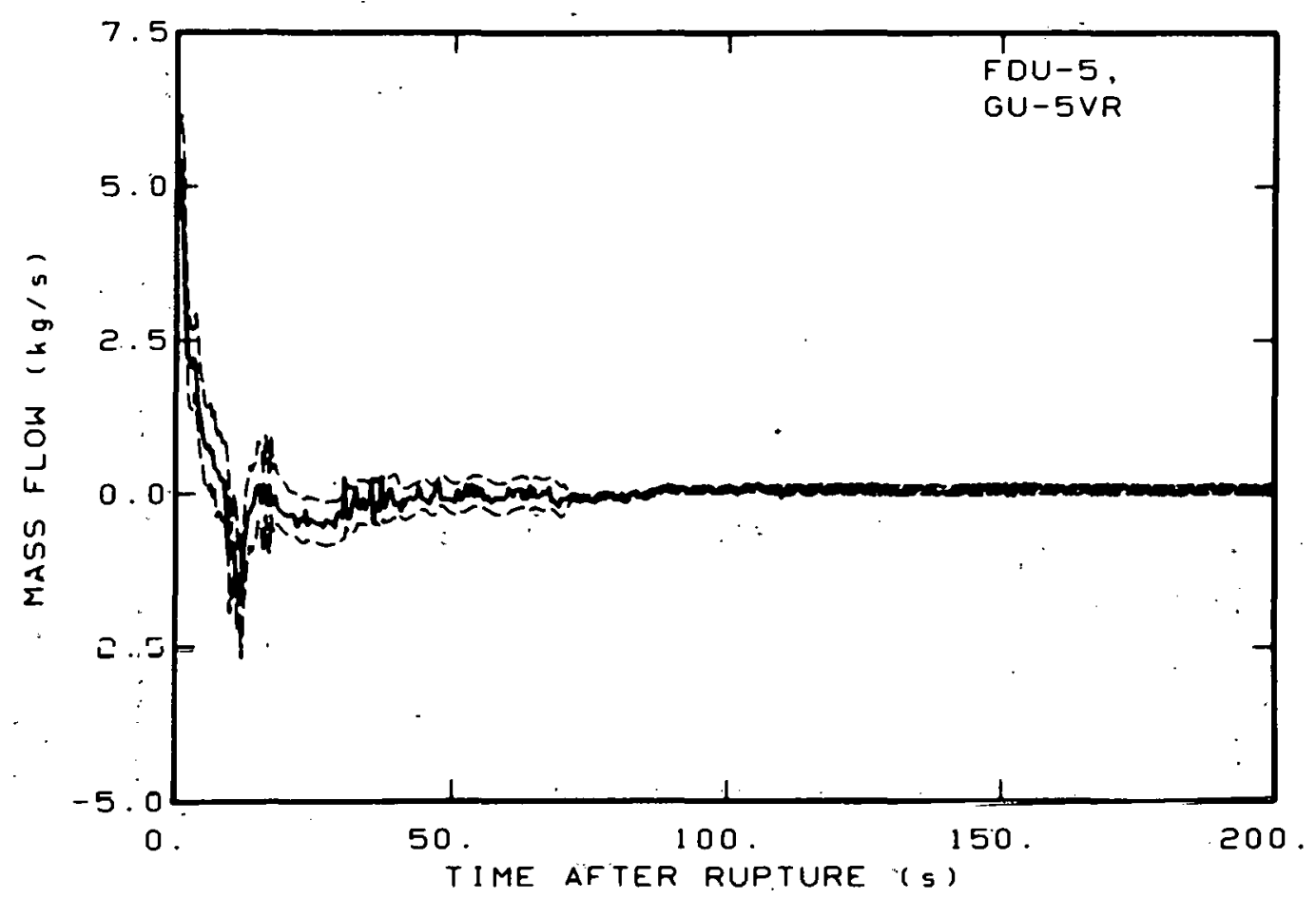

Fig. B-39 Mass flow in intact loop (FDU-5, GU-5VR).

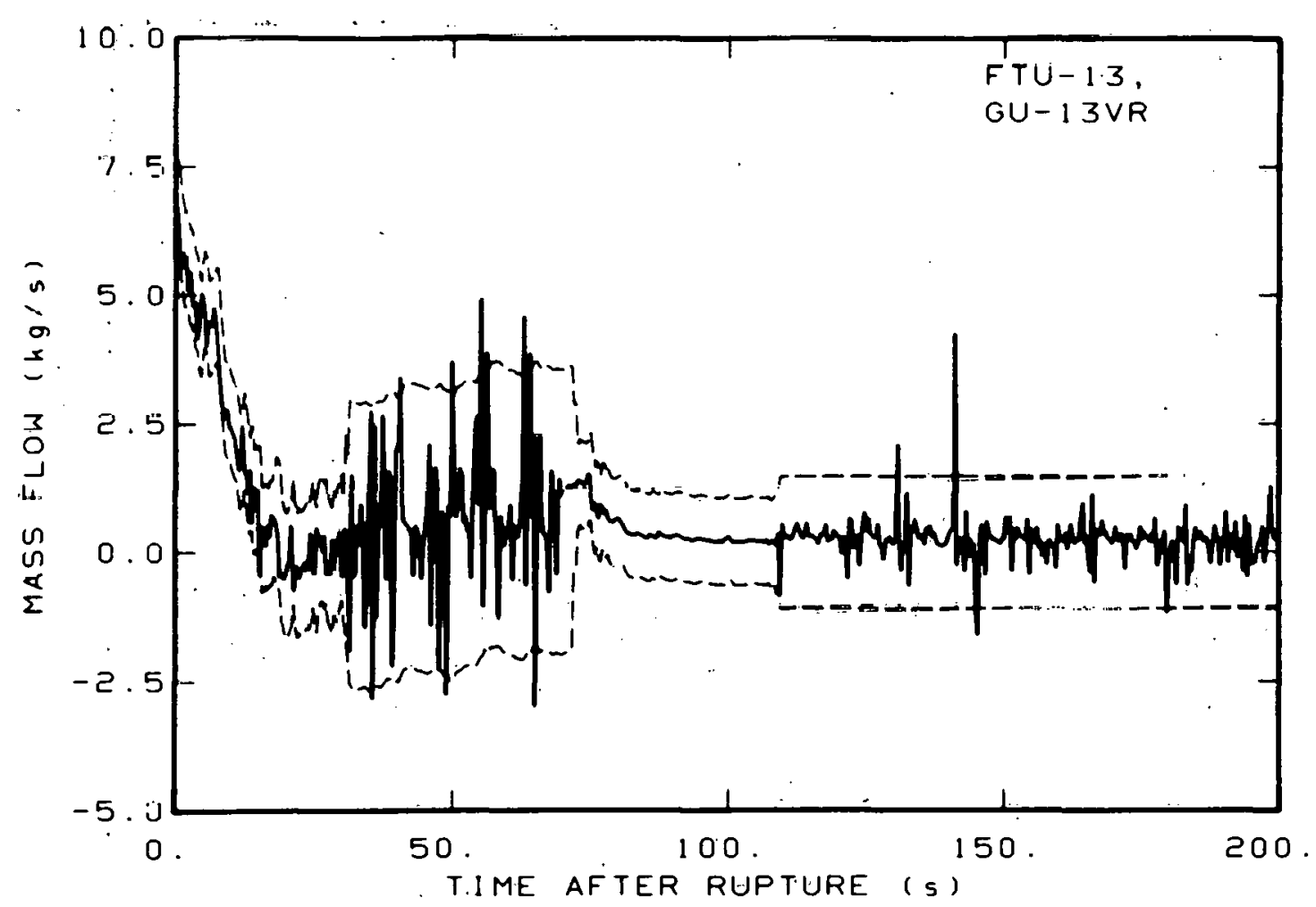

Fig. B-40 Mass flow in intact loop (FTU-13, GU-13VR). 


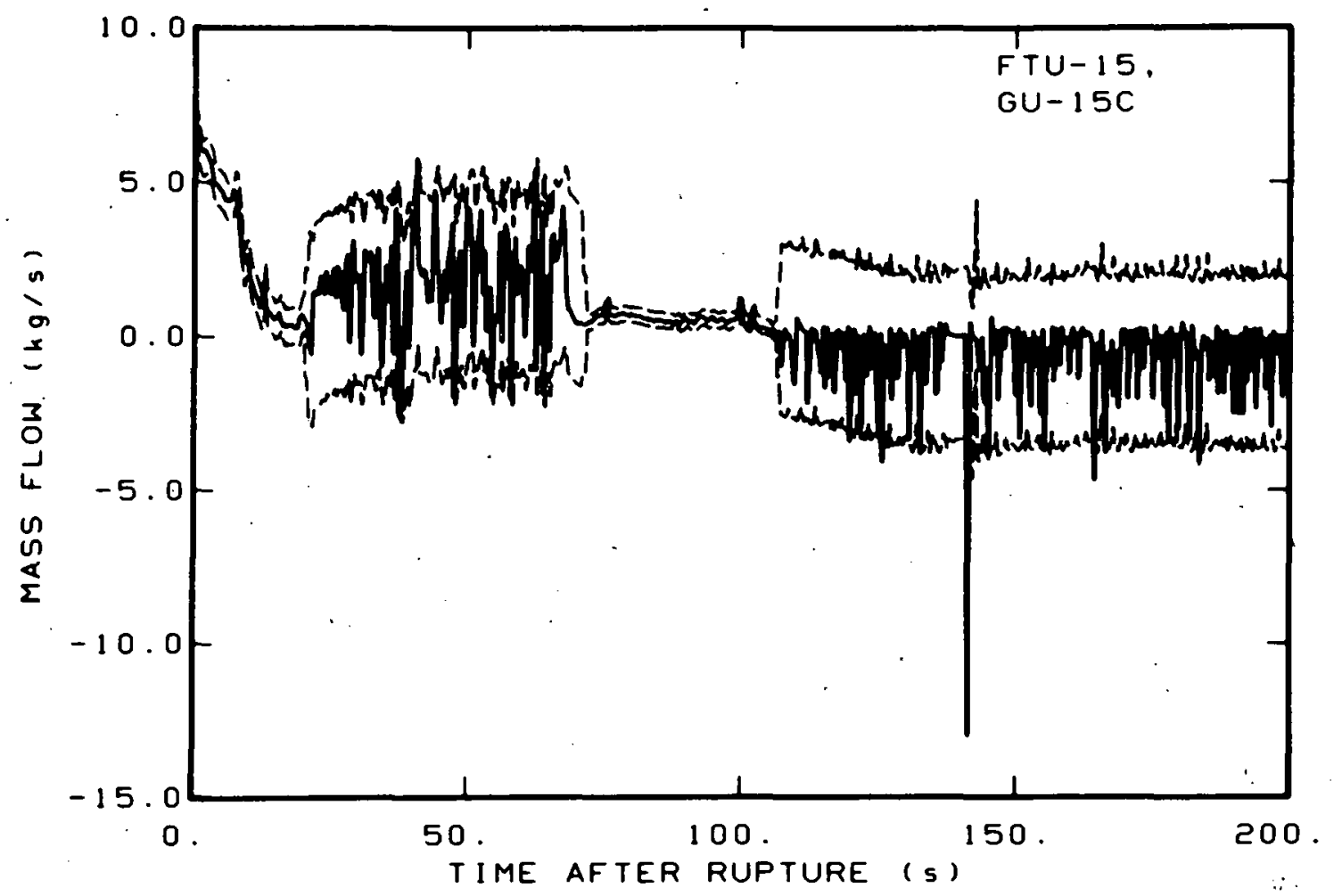

Fig. B-41 Mass flow in intact loop (FTU-15, GU-15C).

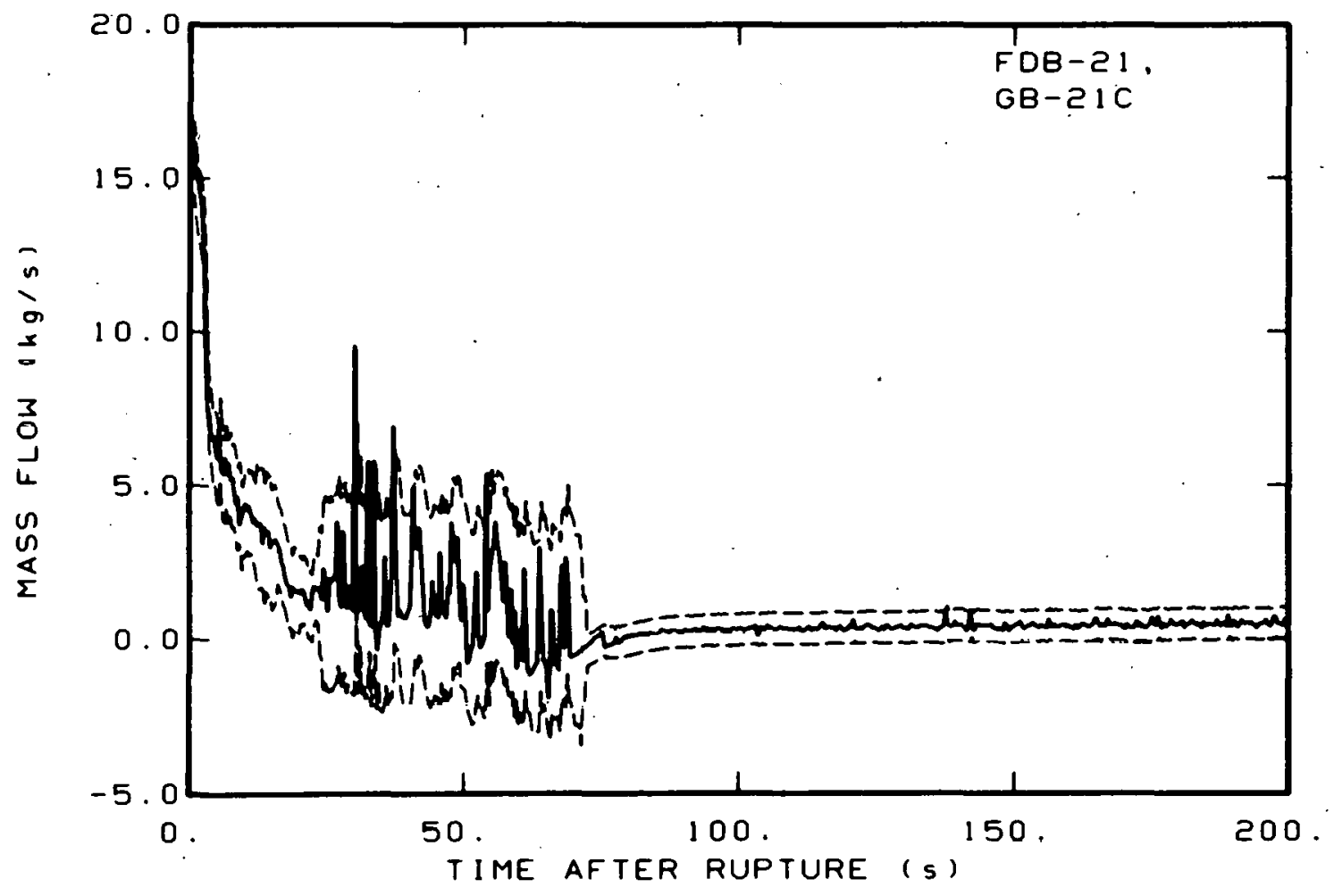

Fig. B-42 Mass flow in broken loop (FDB-21, GB-21C). 


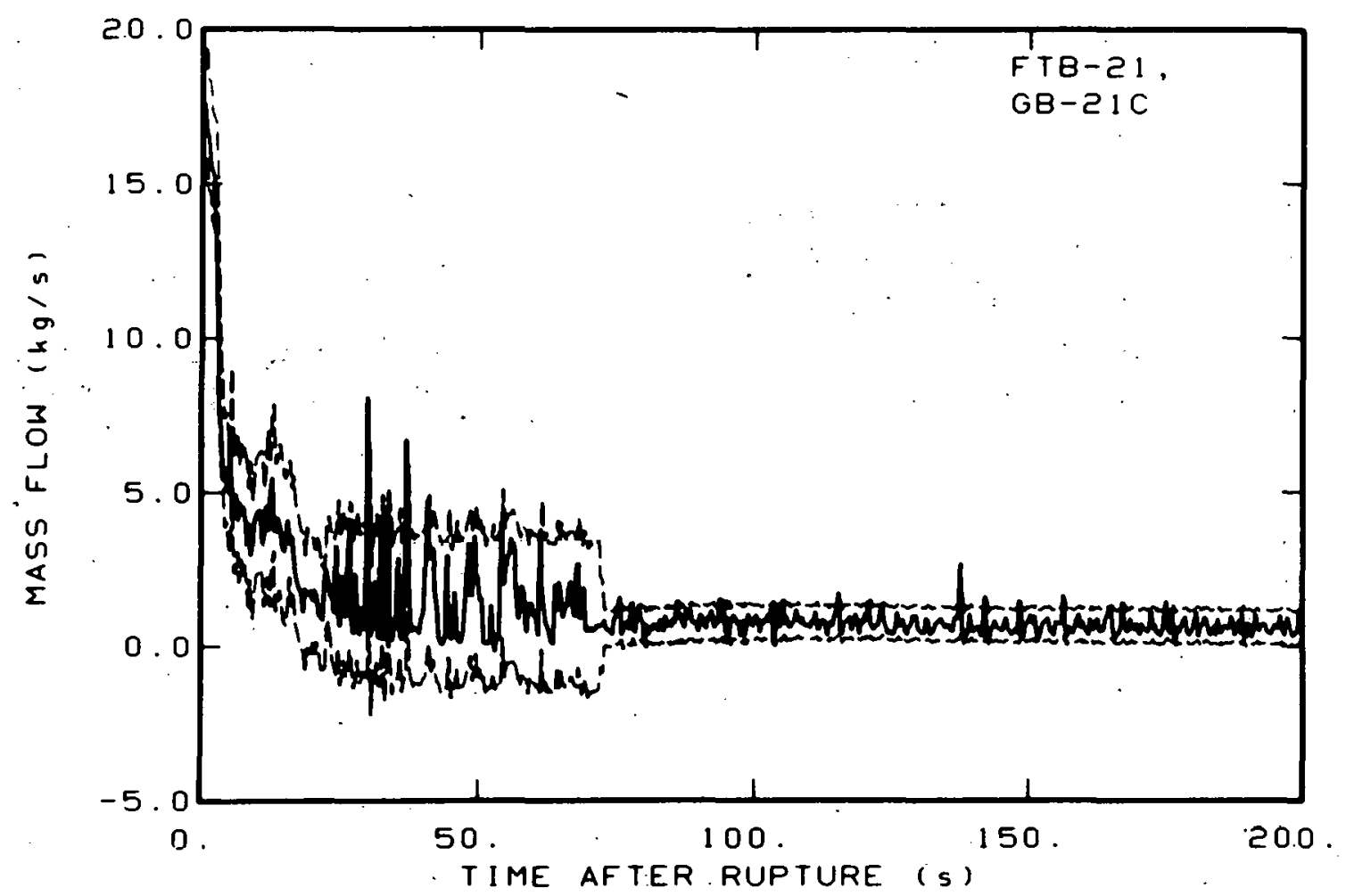

Fig. B-43 Mass flow in broken loop (FTB-21, GB-21C).

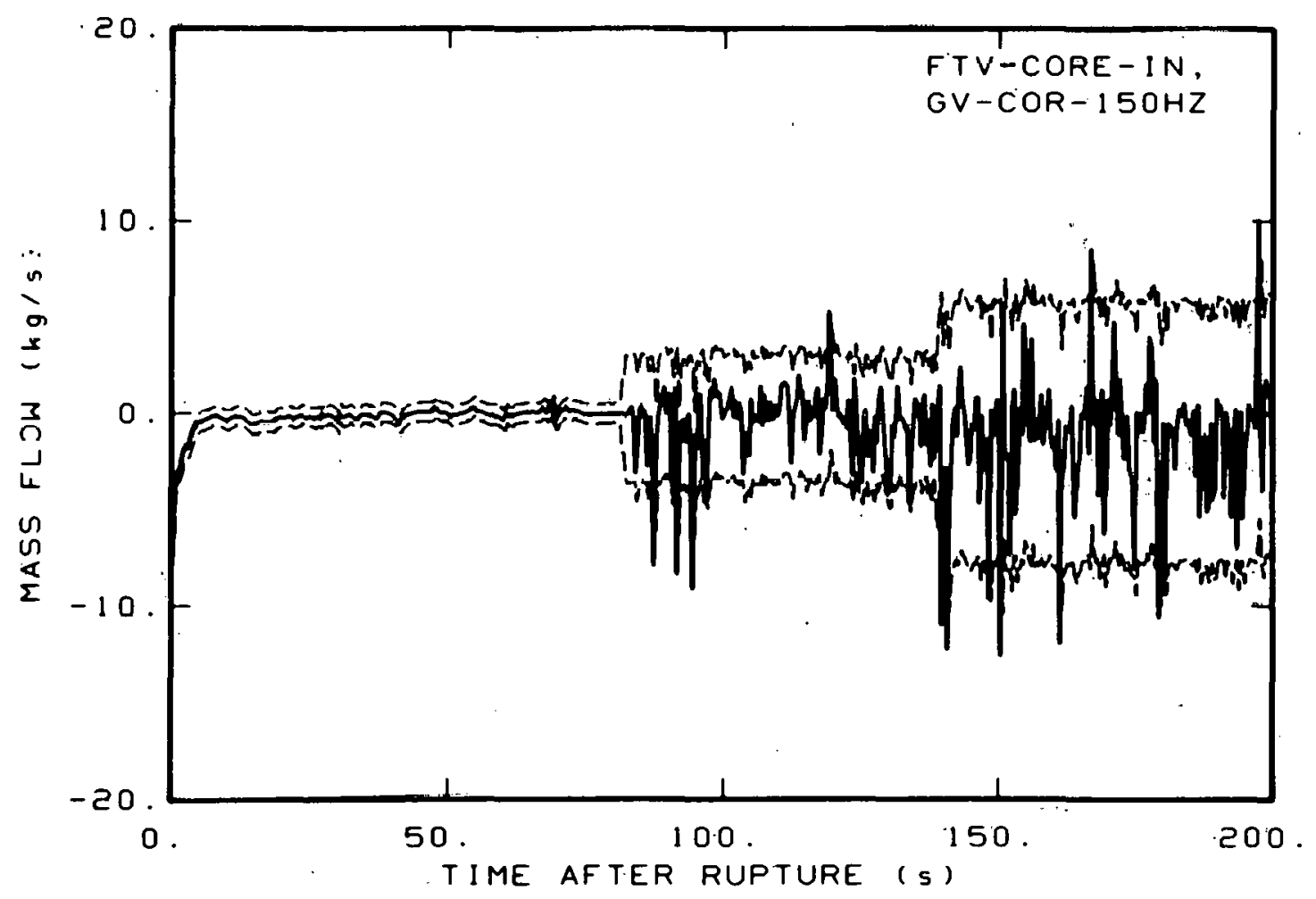

Fig. B-44 Mass flow in vessel (FTV-CORE-IN, GV-COR-150HZ). 
TABLE B-II

GENERAL MEASUREMENT ENGINEERING ERROR SOURCES AND ERROR VALUES (TEST S-06-6)

\begin{tabular}{|c|c|c|c|}
\hline $\begin{array}{c}\text { Measurement } \\
\text { Category }\end{array}$ & Error Sources & Error Value & Expected Error Value \\
\hline \multirow[t]{4}{*}{$\begin{array}{l}\text { Fluid } \\
\text { Temperature }\end{array}$} & $\begin{array}{l}\text { Changes in homogeneity of the } \\
\text { thermocouple wire due to cold } \\
\text { working }\end{array}$ & $\pm 1.11 \mathrm{~K}$ & \multirow{4}{*}{ $\pm 2.8 k^{[a]}$} \\
\hline & $\begin{array}{l}\text { Data interpretation from } \\
\text { standard reference tables }\end{array}$ & $\pm 1.11 \mathrm{~K}$ & \\
\hline & $\begin{array}{l}\text { General data acquisition } \\
\text { processing }\end{array}$ & $\pm 2.50 \mathrm{~K}$ & \\
\hline & Thermal aging of the thermocouples & $\pm 0.28 \mathrm{~K}$ & \\
\hline \multirow[t]{5}{*}{$\begin{array}{l}\text { Material } \\
\text { Temperature }\end{array}$} & $\begin{array}{l}\text { Changes in homogeneity of the } \\
\text { thermocouple wire due to cold } \\
\text { working }\end{array}$ & $\pm 1.11 \mathrm{~K}$ & \multirow{5}{*}{ $\pm 3.9 \mathrm{~K}$} \\
\hline & Thermocouple radial position & $+2.78 \mathrm{~K}$ & \\
\hline & $\begin{array}{l}\text { Data interpretation from standard } \\
\text { reference tables }\end{array}$ & $\pm 1.11 \mathrm{~K}$ & \\
\hline & $\begin{array}{l}\text { General data acquisition and } \\
\text { processing }\end{array}$ & $+2.50 \mathrm{~K}$ & \\
\hline & Thermal aging of the thermocouples & $\pm 0.28 \mathrm{~K}$ & \\
\hline
\end{tabular}


TABLE B-I I (continued)

\begin{tabular}{|c|c|c|c|}
\hline $\begin{array}{c}\text { Measurement } \\
\text { Category }\end{array}$ & Error Sources & Error Value & Expected Error Value \\
\hline \multirow[t]{4}{*}{ Pressure } & Entrance effects & $\begin{array}{l}+0.3 \% \text { of transducer } \\
\text { full scale }\end{array}$ & $\because$ \\
\hline & Calibration & $\begin{array}{l}+0.26 \% . \text { of transducer } \\
\text { full scale }\end{array}$ & \\
\hline & Tenperature sensitivity & $\begin{array}{l}+0.13 \% \text { of transducer } \\
\text { full scale }\end{array}$ & \\
\hline & $\begin{array}{l}\text { General data acquis tior and } \\
\text { processing }\end{array}$ & $\begin{array}{l}+0.1 \% \text { of system full } \\
\text { scale }\end{array}$ & \\
\hline \multirow[t]{5}{*}{$\begin{array}{l}\text { Differential } \\
\text { Pressure }\end{array}$} & Installation & $\begin{array}{l}+0.3 \% \text { of transducer } \\
\text { full scale }\end{array}$ & \\
\hline & $\begin{array}{l}\text { Ea ibration } \\
\text { Transducer ranges } \pm 4.95 \text { through } \\
\pm 199.26 \mathrm{kPa}\end{array}$ & $\begin{array}{l}+\left[(0.05)+(0.5 \mathrm{R} / \mathrm{FS})^{2}\right]^{1 / 2} \% \\
\text { of transducer ful } \\
\text { scale }\end{array}$ & \\
\hline & $\begin{array}{l}\text { Trànsducer ranges }+374.77 \\
-689.47, \pm 3447 \mathrm{kPa}^{-}\end{array}$ & $\begin{array}{c}+\left[(0.03)+(0.5 \mathrm{R} / \mathrm{FS})^{2}\right]^{i / 2} \% \\
\text { of ful scale }\end{array}$ & $+2 \%$ of $t r$ \\
\hline & $\begin{array}{l}\text {-ransducer ranges } \pm 6394 \text {, } \\
\pm 10342 \mathrm{kPa}\end{array}$ & $\begin{array}{l} \pm\left[(0.02)+(0.5 \mathrm{R} / \mathrm{FS})^{2}\right]^{1 / 2} \% \\
\text { of full scale. }\end{array}$ & full scale $e^{[c]}$ \\
\hline & , & $\begin{aligned} \dot{R}= & \text { transducer reading } \\
& (\mathrm{kPa}) \\
\mathrm{FS}= & \text { transducer rarige full } \\
& \text { scale }(\mathrm{kPa})\end{aligned}$ & \\
\hline
\end{tabular}


TABLE B-I I (continued)

\begin{tabular}{|c|c|c|c|}
\hline $\begin{array}{c}\text { Measurement } \\
\text { Category }\end{array}$ & Error Sources & Error Value & Expected Error Value \\
\hline \multirow{3}{*}{$\begin{array}{l}\text { Differential } \\
\text { Pressure } \\
\text { (continued) }\end{array}$} & Temperature sensitivity & $\begin{array}{l}+0.5 \% \text { of transducer } \\
\text { ful } 1 \text { scale }\end{array}$ & \multirow{3}{*}{$\begin{array}{l} \pm 2 \% \text { of transducer } \\
\text { full scale } e^{[c]}\end{array}$} \\
\hline & $\begin{array}{l}\text { General data acquisition and } \\
\text { processing }\end{array}$ & $\begin{array}{l}+0.1 \% \text { of system full } \\
\text { scale }\end{array}$ & \\
\hline & Air entrapmerit & $\pm 0.069 \mathrm{kPa}$ & \\
\hline \multirow{3}{*}{$\begin{array}{l}\text { Fluid Velocity } \\
\text { (point velocities } \\
\text { measured with } \\
\text { turboprobes) }\end{array}$} & Installation & $\begin{array}{l}+0.8 \% \text { of transducer } \\
\text { full scale }\end{array}$ & \multirow{3}{*}{$\begin{array}{l} \pm[0.5825+ \\
\left.(0.008 \mathrm{R})^{2}\right] 1 / 2 \mathrm{~m} / \mathrm{s}\end{array}$} \\
\hline & Calibration & $\begin{array}{l}+5 \% \text { of transducer } \\
\text { full scale }\end{array}$ & \\
\hline & $\begin{array}{l}\text { Data acquisition and processing } \\
\text { frequency conversion }\end{array}$ & $\begin{array}{l}+0.25 \% \text { of transducer } \\
\text { full scale }\end{array}$ & \\
\hline & General & $\begin{array}{l}+0.1 \% \text { of system } \\
\text { fuil scale. }\end{array}$ & \multirow[t]{2}{*}{$\begin{array}{l}\text { where } \\
\mathrm{R}=\text { transducer read- } \\
\quad \text { ing }(\mathrm{m} / \mathrm{s})\end{array}$} \\
\hline \multirow[t]{3}{*}{ Density } & Calibration & $\pm 1.0 \%$ of reading $\left(\mathrm{kg} / \mathrm{m}^{3}\right)$ & \\
\hline & Detector system error & $\pm 2.1 \mathrm{~kg} / \mathrm{m}^{3}$. & \multirow{2}{*}{ [d] } \\
\hline & $\begin{array}{l}\text { General data acquisition and } \\
\text { processing }\end{array}$ & $\pm 1.6 \mathrm{~kg} / \mathrm{m}^{3}$ & \\
\hline
\end{tabular}


TABLE B-II (continued)

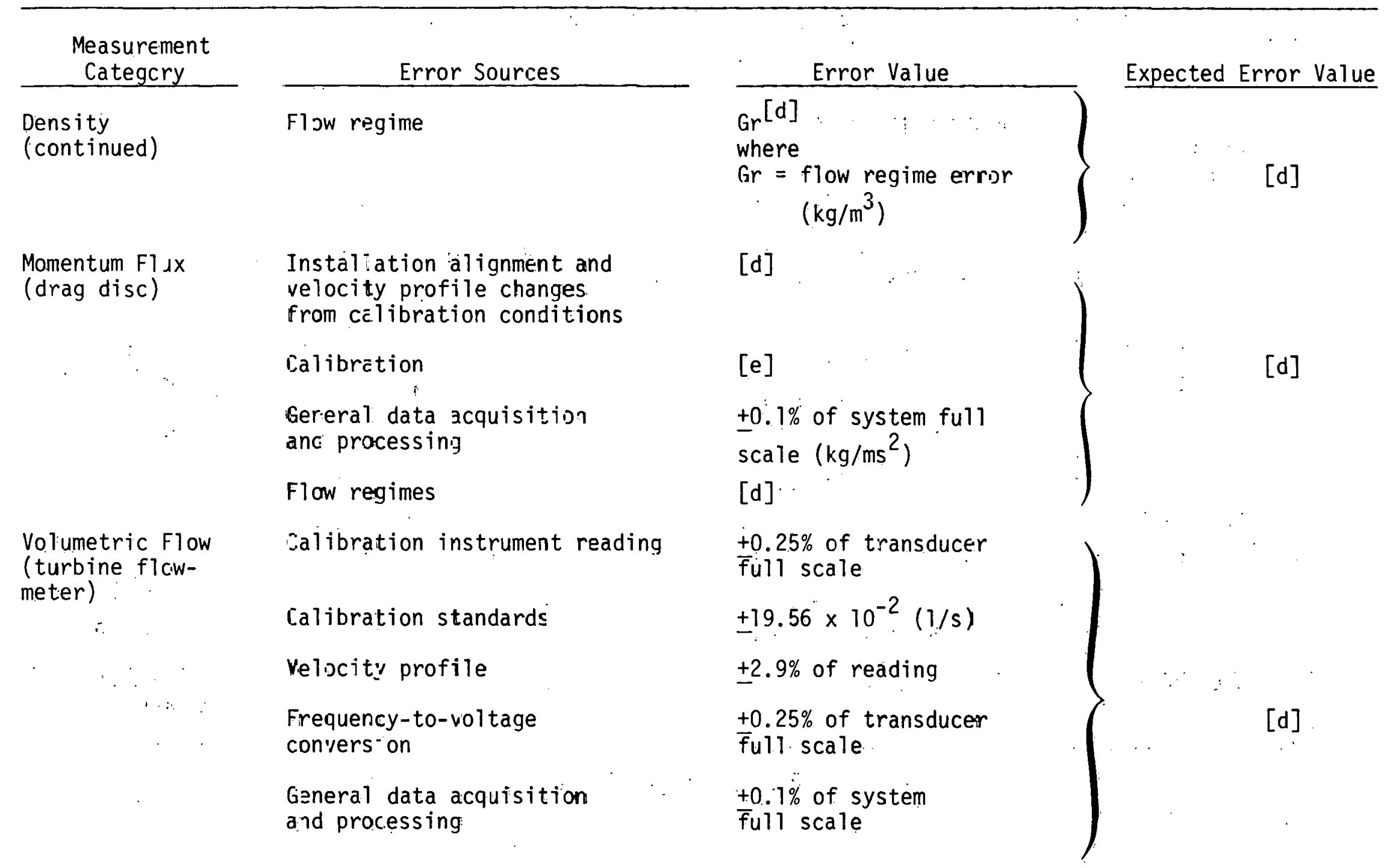


TABLE B-II (continued)

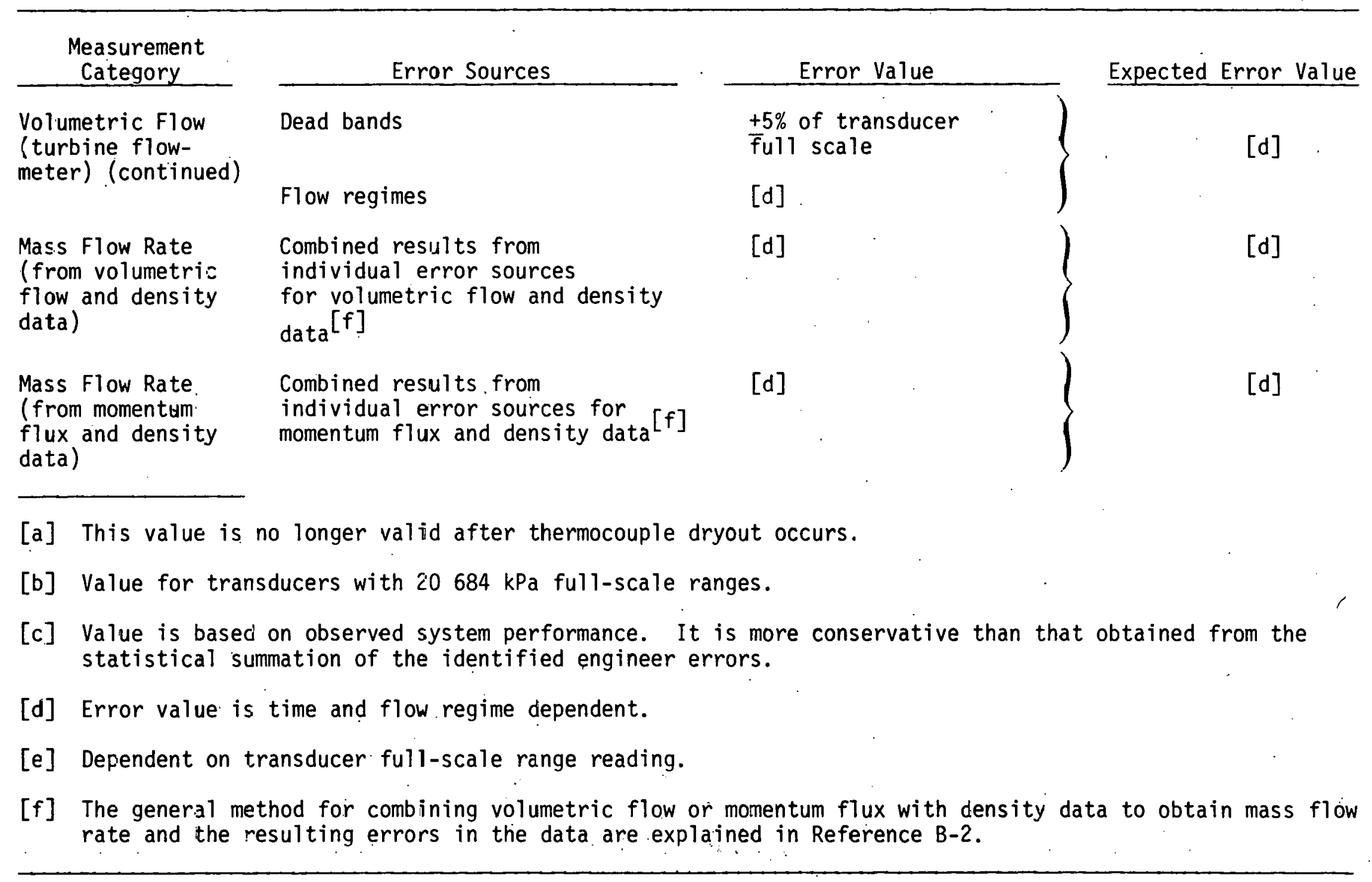


In addition to the normal hardware and installation related sources of engineering error, a significant measurement uncertainty results when the current transducer systems are subjected to separated two-phase flow regimes during the course of the blowdown transient. Accordingly, for those data affected (fluid density, momentum flux, volumetric flow; and mass flow), which are presented in this appendix, a more extensive assessment was conducted of additional engineering. error due to flow regime effects. Table B-III identifies the data analyzed and the period in the blowdown process for which flow regime errors were included as a part of the total engineering error. The time of occurrence of separated two-phase flow and the resulting effect on the uncertainty of the data were evaluated by considering, on an individual basis, each detector output with reference to indications by: other auxiliary measurements.

TABLE: B-III

TIME PERIODS WHEN FLOW REGIME ERRORS WERE APPLIED (TEST S:06 -6)

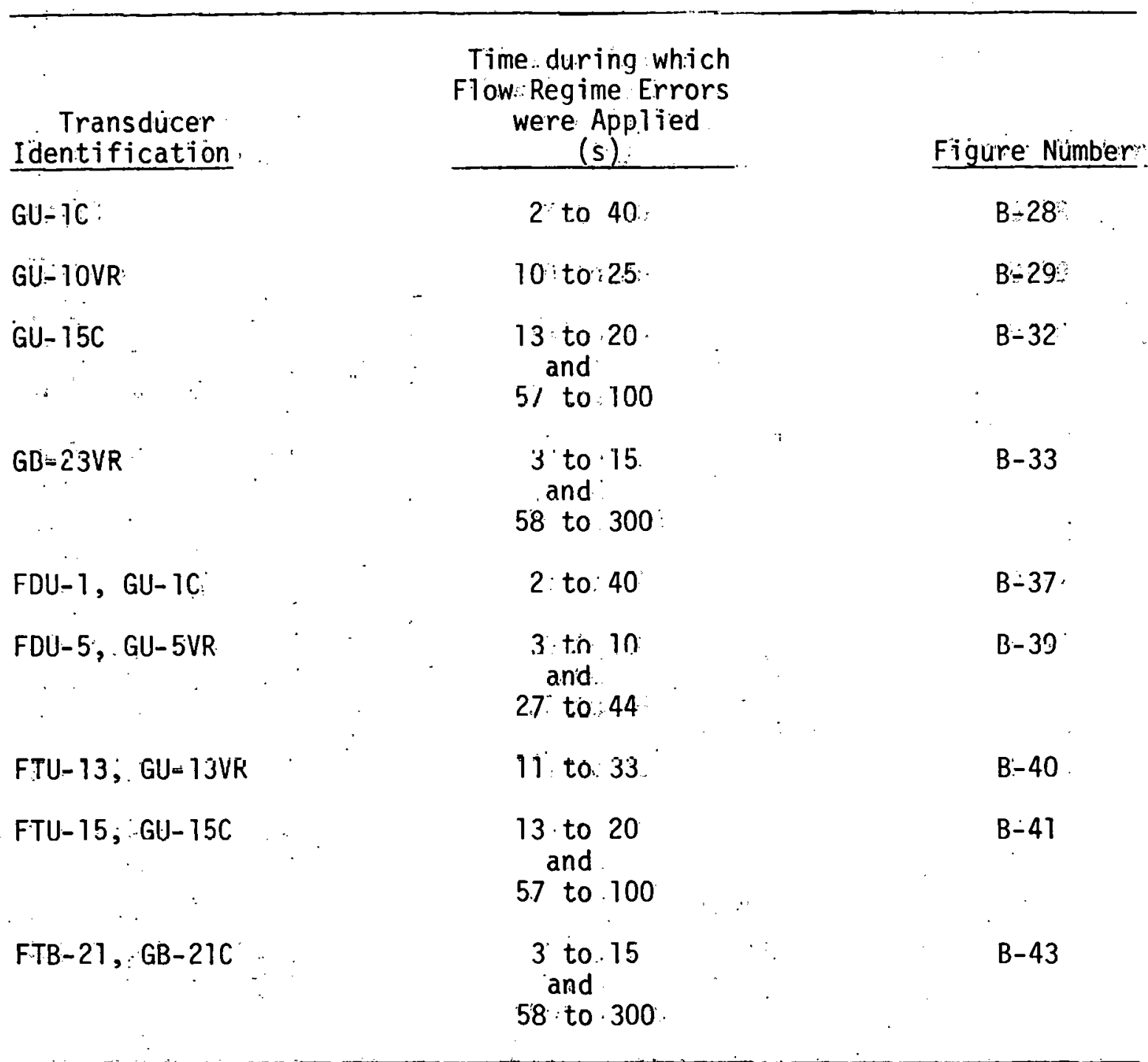


The gamma densitometer density measurement data are affected by two-phase separated flow regimes. The resulting transducer output is a measurement of the average attenuation of the gamma beam through the measured medium. The beam attenuation, in turn, is interpreted through physical relationship to be a measure of the average density along the beam path. When stratified type flow was considered present, the gamma beam attenuation was considered to be a result of a liquid layer and steam at system conditions. With this assumption and the system geometry, a void fraction was calculated and a new "effective" average density was calculated. The difference between the average density based on the assumption of homogeneous conditions and the average density for stratified conditions was considered to be the error.

Momentum flux measurement uncertainties for two-phase flow regimes present the most difficult engineering evaluation problems. The drag target and arm location, degree of flow stratification, transducer temperature sensitivity, and slip ratios all combine to produce possible flow regime errors ranging from a small fraction of the transducer output value to multiples of it. Therefore, the error values were obtained, where possible, through use of the observed discrepancies between the momentum flux and turbine flowmeter data in combination with system pressure measurements and the analysis of system fluid density measurements.

The flow regime errors of the turbine flowmeter were estimated by calculating a void fraction and the cross-sectional liquid and steam flow areas for stratified flow. This calculation was accomplished using methods similar to those used to calculate the average density for stratified flows. A simple model was used to equate the forces on the turbine with the assumption of a known void fraction, stratified flow, known component densities, and slip ratio greater than unity. This process provided phase velocities. With the phase densities, velocities, and void fraction, a volumetric flow rate could be calculated. The difference between this value and the measured value was considered to be the error.

The overall standard deviation of a data point is taken as the root mean of the sum of the random error variation and the total engineering error variance; that is,

$$
\sigma_{0}=\sigma_{R}^{2}+\sigma_{E}^{2}
$$

where

$$
\begin{aligned}
& \sigma_{\mathrm{o}}=\text { overall standard deviation of a data point } \\
& \sigma_{\mathrm{R}}=\text { random error standard deviation } \\
& \sigma_{\mathrm{E}}=\text { engineering error standard deviation. }
\end{aligned}
$$

The error bands for the data are computed about the value given by the fitted difference equation $y_{i}$ at time point, $i$; that is,

$$
\text { error band }=y_{i} \pm 1.96 \sigma_{0}
$$


With due regard to the fact that $\sigma_{\mathrm{E}}$ has been estimated subjectively, the error band may be interpreted as an approximate $95 \%$ confidence interval within which any true value of the measured variable is consistent with the data.

On certain occasions, the symmetrical error band given by -Equation (B-2) is not . appropriate. On those occasions, asymmetrical error bands were computed. (That is, with the width being greater on one side of $y_{i}$ than on the other.)

Finally; the original data trace, along with its error band from Equation (B-2); was input to a computer plot package. The resulting plot contained : the actual data trace surrounded by an error band derived both from random error and engineering error considerations. The indicated error bands after thermocouple dryout occurred for the fluid temperature measurements should be ignored. Error bands for these segments of the data wëre not obtained and bands only appear because of limitations in the plòtting package.

\section{REFERENCES:}

B-1. G. E. P: Box" and B: M. Jènkins, Time Sëries Analysis-Forecasting and Control, San Francisco: Holden-Day, 1970:

B-2.. E. M. Feldman and S. A. Naff, Error Analysis for 1:1/2:Loop Semiscale System Isothermal Test Dáta, ANCR-1188 (May:1975). 
DISTRIBUTION. RECORD FOR TREE-NUREG 1126

Internal Distribution

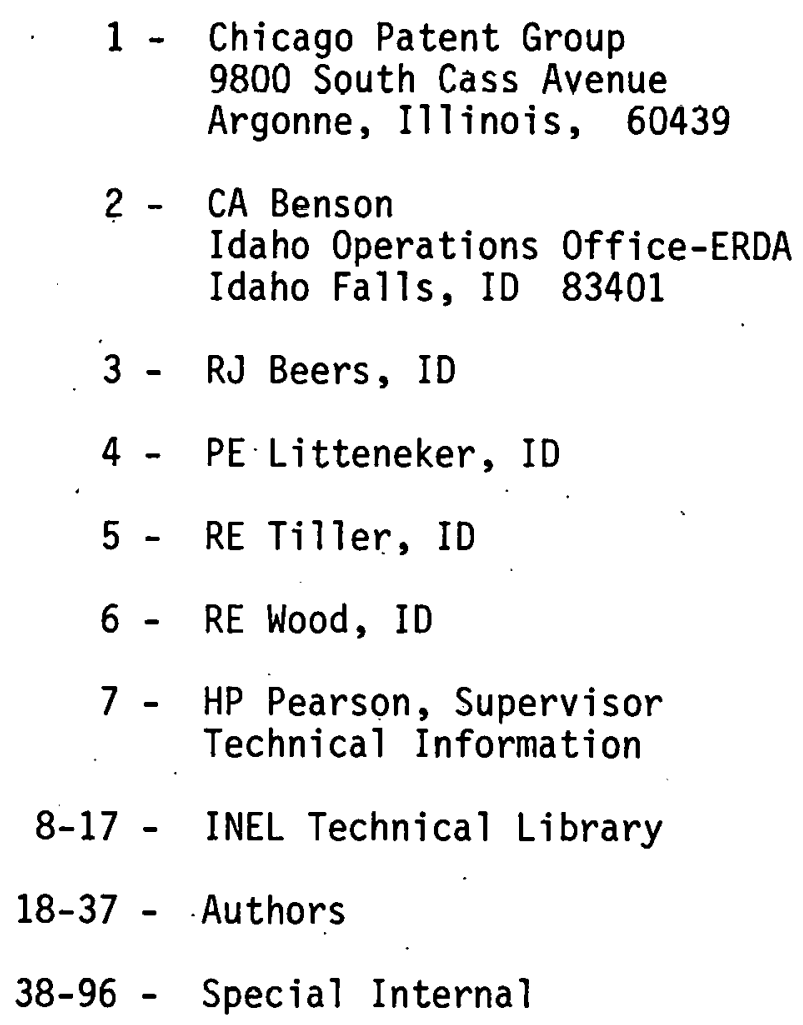

1 - Chicago Patent Group 9800 South Cass Avenue

External Distribution

97-98 - Saul Levine, Director Office of Nuclear Regulatory Research, NRC Washington, DC 20555

99-403 - Distribution under NRC-2, Water Reactor Safety Research Systems Engineering 